\title{
Hydroacoustic Evaluation of Fish Passage through Bonneville Dam in 2005
}

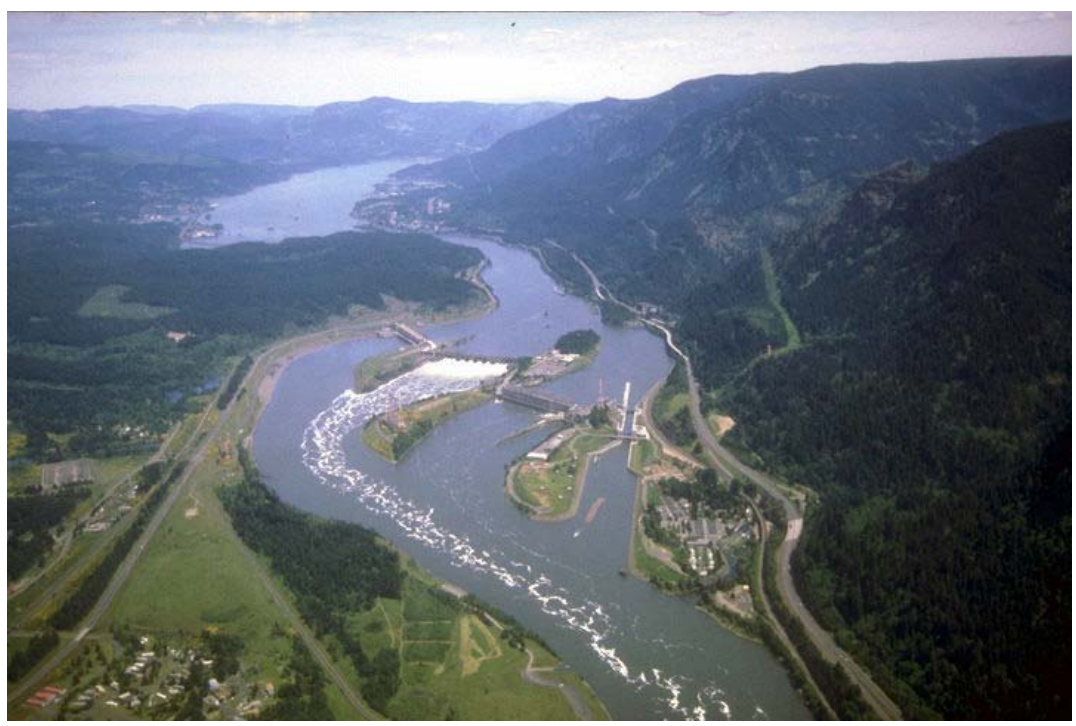

G. R. Ploskey, M. A. Weiland, S. A. Zimmerman, J. S. Hughes, K. Bouchard, E. S. Fischer

Pacific Northwest National Laboratory

C. R. Schilt, M. E. Hanks, J. Kim

BAE Systems, Analytical Solutions, Incorporated

J. R. Skalski

University of Washington

J. Hedgepeth

Tenera, Inc.

W. T. Nagy

U.S. Army Corps of Engineers, Portland District

FINAL REPORT

December 2006

Prepared for the

U.S. Army Corps of Engineers

Under a Related Services Agreement

With the U.S. Department of Energy

Contract DE-AC05-76RLO1830

\section{Pacific Northwest}

National Laboratory

Operated by Battelle for the

U.S. Department of Energy 


\title{
DISCLAIMER
}

This report was prepared as an account of work sponsored by an agency of the United States Government. Neither the United States Government nor any agency thereof, nor Battelle Memorial Institute, nor any of their employees, makes any warranty, express or implied, or assumes any legal liability or responsibility for the accuracy, completeness, or usefulness of any information, apparatus, product, or process disclosed, or represents that its use would not infringe privately owned rights. Reference herein to any specific commercial product, process, or service by trade name, trademark, manufacturer, or otherwise does not necessarily constitute or imply its endorsement, recommendation, or favoring by the United States Government or any agency thereof, or Battelle Memorial Institute. The views and opinions of authors expressed herein do not necessarily state or reflect those of the United States Government or any agency thereof.

\author{
PACIFIC NORTHWEST NATIONAL LABORATORY \\ operated by \\ BATTELLE \\ for the
}

UNITED STATES DEPARTMENT OF ENERGY

under Contract DE-AC05-76RL01830

Printed in the United States of America

Available to DOE and DOE contractors from the

Office of Scientific and Technical Information,

P.O. Box 62, Oak Ridge, TN 37831-0062;

ph: (865) 576-8401

fax: (865) 576-5728

email: reports@adonis.osti.gov

Available to the public from the National Technical Information Service,

U.S. Department of Commerce, 5285 Port Royal Rd., Springfield, VA 22161

ph: (800) 553-6847

fax: (703) 605-6900

email: orders@ntis.fedworld.gov

online ordering: http://www.ntis.gov/ordering.htm 


\title{
Hydroacoustic Evaluation of Fish Passage through Bonneville Dam in 2005
}

\author{
G. R. Ploskey \\ M. A. Weiland \\ S. A. Zimmerman \\ J. S. Hughes \\ K. Bouchard \\ E. S. Fischer \\ C. R. Schilt ${ }^{(a)}$ \\ M. E. Hanks ${ }^{\text {(a) }}$ \\ J. Kim ${ }^{\text {(a) }}$ \\ J. R. Skalski ${ }^{(b)}$ \\ J. Hedgepeth ${ }^{(\mathrm{c})}$ \\ W. T. Nagy ${ }^{(d)}$
}

FINAL REPORT

December 2006

Prepared for the U.S. Army Corps of Engineers

Portland District, Portland, Oregon

Under a Related Services Agreement

with the U.S. Department of Energy

Contract DE-AC05-76RL01830

Pacific Northwest National Laboratory

Richland, Washington 99352
(a) BAE Systems, Analytical Solutions, Incorporated
(b) University of Washington
(c) Tenera, Inc.
(d) U.S. Army Corps of Engineers, Portland District 



\section{Summary}

The Portland District of the U.S. Army Corps of Engineers requested that the Pacific Northwest National Laboratory (PNNL) conduct fish-passage studies at Bonneville Dam in 2005.

In this report, we present results of two juvenile salmonid passage studies conducted at Bonneville Dam during the spring and summer migrations between April 16 and July 15, 2005: 1) a hydroacoustic evaluation of project fish passage efficiency and other major passage metrics, and (2) a DIDSON evaluation of smolt approach and fate at the B1 Sluiceway Outlet 3C from the B1 forebay.

These studies support the Portland District's goal of maximizing fish-passage efficiency (FPE) and obtaining 95\% survival for juvenile salmon passing Bonneville Dam. Major passage routes include 10 turbines and a sluiceway at Powerhouse 1 (B1), an 18-bay spillway, and eight turbines and a sluiceway at Powerhouse 2 (B2).

\section{Fish Passage Efficiency Study}

Our primary goal was to provide project-wide estimates of fish-passage efficiency (FPE), spill efficiency, sluiceway efficiency, and spill and sluiceway effectiveness for run-of-river fish passing the Bonneville Project in 2005. Other fish-passage measures included FPE by powerhouse; fish-guidance efficiency (FGE) by turbine; and horizontal, vertical, and diel distributions of fish passage at both powerhouses and the spillway. These data complement previous studies conducted in 2000, 2001, 2002, and 2004, and provide a fifth year of estimates for the entire project and a second year of estimates with the Powerhouse 2 Corner Collector (B2CC), which was added in 2004. Sampling was conducted with $61420-\mathrm{kHz}$ hydroacoustic transducers and was nearly continuous over the April 16-July 15 study period, except for a short break each morning for downloading data. At least one split-beam transducer was used for each type of transducer deployment to provide deployment-specific data on speeds, trajectories, and target strengths of fish for detectability modeling.

Unique environmental conditions that may have affected estimates of fish passage metrics in 2005 included species composition and run timing in spring, opening three sluiceway outlets from the B1 forebay, not deploying submerged traveling screens (STSs) at B1 turbines, a B2 Powerhouse priority, the operation of the B2CC, and the absence of turbine intake extensions (TIEs) on the south half of B2. Yearling Chinook salmon dominated the spring run except during two brief periods of several days when subyearling Chinook salmon from hatcheries predominated. Except during those brief periods, juvenile coho salmon made up the second most common group migrating in spring. Project discharge was below the 10-year average from 1996 through 2005 throughout most of 2005, especially before May 10 and from about May 28 through about June 20.

As in 2004, the most outstanding metric in 2005 was the high effectiveness of surface-passage routes. In 2005, we found similar percentages of fish and flow through individual dam structures (B1, B2, or the spillway), but percent fish passage was many times higher than percent discharge for surface-passage routes. Sluiceway passage effectiveness (\% passage relative to \% flow) was 6.5 and 6.9 times higher than spillway effectiveness in spring and summer, respectively. Project FPE estimates of $73.4 \%$ in spring and $80.7 \%$ in summer 2005 were made possible primarily by the contributions of surface passage. The 
decline in mean fish-guidance efficiency (FGE) of B2 submerged traveling screens from spring (49\%) to summer (38\%) was more than offset by spring-to-summer increases in spillway passage efficiency from $41.1 \%$ in spring to $48.4 \%$ in summer and B1 FPE increases (i.e., B1 sluice efficiency relative to B1) from $46.7 \%$ to $75.9 \%$. Spill efficiency and B2 FGE estimates were about average for non-drought years for which full Project data were available. Estimates of major metrics (\%) for the spring and summer seasons are shown in Table S.1.

Table S.1. Estimates of Major Passage Metrics Based upon Hydroacoustic Sampling from 4/15 through 5/31 (Spring) and from 6/1 through 7/15 (Summer) in 2005.

\begin{tabular}{|c|c|c|}
\hline Metric & Spring & Summer \\
\hline Project Fish Passage Efficiency & $73.4 \pm 4.0 \%$ & $80.7 \pm 4.1 \%$ \\
\hline Project FPE for the B2 and Spillway only (excluding B1) & $80.4 \pm 5.0 \%$ & $81.5 \pm 5.0 \%$ \\
\hline B1 Percent of Project Passage & $16.3 \pm 1.1 \%$ & $7.2 \pm 0.5 \%$ \\
\hline B1 Percent of Project Flow & 11.6 & 3.7 \\
\hline B1 Fish Passage Efficiency & $37.37 \pm 1.64 \%$ & $70.92 \pm 2.46 \%$ \\
\hline B2 Percent of Project Passage & $44.1 \pm 3.1 \%$ & $48.6 \pm 2.9 \%$ \\
\hline B2 Percent of Project Flow & 48.2 & 44.8 \\
\hline B2 Fish Passage Efficiency & $62.8 \pm 7.8 \%$ & $64.6 \pm 7.0 \%$ \\
\hline B2 Fish Guidance Efficiency & $45.3 \pm 8.6 \%$ & $37.4 \pm 8.8 \%$ \\
\hline Spill Passage Efficiency & $39.7 \pm 2.2 \%$ & $44.2 \pm 2.6 \%$ \\
\hline Spill Percent of Project Flow & 40.3 & 51.6 \\
\hline Spill Efficiency (B2 + Spillway excluding B1) & $47.4 \pm 3.0 \%$ & $47.7 \pm 3.0 \%$ \\
\hline Sluice Passage Efficiency (B1 + B2CC as \% of Project) & $20.15 \pm 1.14 \%$ & $26.23 \pm 1.47 \%$ \\
\hline B1 Sluiceway and B2CC Percent of Flow & 3.2 & 3.5 \\
\hline B1 Sluice Efficiency (\% of Project) & $6.08 \pm 0.34 \%$ & $5.13 \pm 0.29 \%$ \\
\hline B1 Sluice Efficiency (\% of B1) = B1 FPE & $37.37 \pm 1.64 \%$ & $70.92 \pm 2.46 \%$ \\
\hline B2CC Efficiency (\% of Project) & $14.07 \pm 0.8 \%$ & $21.1 \pm 1.18 \%$ \\
\hline B2CC Efficiency (\% of B2) & $31.92 \pm 4.05 \%$ & $43.46 \pm 5.0 \%$ \\
\hline Spillway Effectiveness (\% spillway passage $\div \%$ spilled) & $0.98 \pm 0.06$ & $0.86 \pm 0.05$ \\
\hline Sluice Effectiveness (B1 + B2CC passage $\div \%$ B1 sluiceway + B2CC flow) & $6.29 \pm 0.36$ & $7.6 \pm 0.43$ \\
\hline $\begin{array}{l}\text { B1 Sluice Effectiveness relative to the Project }= \\
\text { (B1 Sluice Efficiency as } \% \text { of Project } \div \% \text { of Project flow sluiced at B1) }\end{array}$ & $10.70 \pm 0.61$ & $8.59 \pm 0.49$ \\
\hline $\begin{array}{l}\text { B1 Sluice Effectiveness relative to B1 } \\
\text { (B1 Sluice Efficiency as } \% \text { of } B 1 \div \% \text { of B1 flow sluiced) }\end{array}$ & $7.61 \pm 0.33$ & $4.33 \pm 0.15$ \\
\hline $\begin{array}{l}\text { B2CC Effectiveness relative to the Project }=(\text { B2CC Efficiency at } \% \text { of Project } \div \% \text { of } \\
\text { Project flow sluiced at the B2CC) }\end{array}$ & $5.34 \pm 0.31$ & $7.39 \pm 0.41$ \\
\hline B2CC Effectiveness (B2CC Efficiency $\div \%$ of B2 flow through the B2CC) & $5.84 \pm 0.74$ & $6.82 \pm 0.78$ \\
\hline
\end{tabular}

Adjusting 2005 spill-passage data for reduced detectability with increasing discharge through individual spill bays did not eliminate a curvilinear relation between Project FPE and percent spill. Adjusted data indicate that increases in FPE were twice as high at low percent spill as they were at high percent spill. For example, a $15 \%$ increase in spill from $25 \%$ to $40 \%$ bought a $20 \%$ increase in FPE, whereas increasing spill from $50 \%$ to $65 \%$ increased FPE by just $10 \%$. Even less was gained by $15 \%$ increases in percent spill above the 65\% level. Percent spill explained more of the variation in FPE than did spill discharge.

The report also includes many details about spatial and temporal trends in fish passage in spring and summer 2005. Spatial trends include horizontal and vertical distributions of fish passage or density, and temporal trends include seasonal and diel patterns by passage route. 


\section{Smolt Approach and Fate at B1 Sluiceway Outlet 3C}

A secondary goal was to evaluate the approach and fate of juvenile salmonids at a B1 sluiceway entrance based upon tracked fish sampled with a Dual-frequency Identification Sonar (DIDSON) acoustic camera. We successfully deployed a DIDSON in the entrance to the B1 sluiceway and acquired more than 2 million fish tracks. A Markov-chain analysis of fish movements was used to estimate fate probabilities, including the probability of a smolt entering the sluiceway as a function of its range from the forebay outlet.

The distance of the fish from the sluiceway entrance associated with 90\% entrance efficiency for B1 Sluiceway Outlet $3 \mathrm{C}$ was three times higher in the summer than it was in the spring, and reduced turbine flow in summer may be mostly responsible for observed differences. The average distance associated with the $90 \%$ entrance probability for four conditions was about $7 \mathrm{ft}$ in spring and about $21.5 \mathrm{ft}$ in summer. There were four spring conditions: "Spring Day Flow" with powerhouse flow $>7.5 \mathrm{kcfs,}$ "Spring Night Flow" with powerhouse flow $>7.5$ kcfs, "Spring Day No Flow" with powerhouse flow $<7.5$ kcfs, and "Spring Night No Flow" with powerhouse flow $<7.5$ kcfs. The four conditions in summer were "Summer Day Flow" with powerhouse flow $>7.5$ kcfs, "Summer Night Flow" with powerhouse flow $>7.5$ kcfs, "Summer Day No Flow" with powerhouse flow $<7.5$ kcfs, and "Summer Night No Flow" with powerhouse flow $<7.5 \mathrm{kcfs}$. The frequency of sampling hours with $<20,000 \mathrm{cfs}$ of B1 powerhouse flow or sluiceway-only flow was much higher in summer than it was in spring, and this would have greatly simplified the flow environment for approaching smolts in summer. Forebay circulation, including lateral flow along the face of the powerhouse on either side of the pier between Units 6 and 7 is greatly diminished when two or fewer turbines are operating because bulk flow lacks momentum.

The lack of capture velocity to entrain fish at the B1 sluiceway entrances is a shortcoming associated with the limited capacity of the existing channel. Three chain gates could only be opened down to Elevation $71.5 \mathrm{ft}$ above mean sea level (MSL) or the channel would be flooded at above-average pool elevations. If the channel had greater capacity, gates could be opened down to Elevation $68 \mathrm{ft}$ above MSL, where the existing sill is located. Hydroacoustic data showed that a noticeable percentage of the fish observed moving in an upstream direction over the chain gates at Entrances $1 \mathrm{C}$ and $3 \mathrm{C}$ also were moving downward in the water column. The chain gates at the B1 sluiceway entrances form a sharp-crested weir at elevation $71.5 \mathrm{ft}$ above MSL, and they pool a 3.5-ft-deep volume of water between the top of the weir and the concrete sill. Flow passing over the weir creates a weak hydraulic roller that fish can use as a flow refuge. From a fish-capture standpoint, it would be much better to open gates to elevation $68 \mathrm{ft}$ above MSL and eliminate any flow refuge that smolts might use to avoid entrainment. Low approach velocities may be more of a hindrance for passing yearlings in spring than for passing subyearlings in summer. Ideally, surface outlets from forebays would have capture velocities that extend at least $2 \mathrm{~m}$ upstream of the flow control structure. At the B2CC in 2004, a capture velocity extending well upstream of the sill was instrumental in taking smolts that otherwise might have initially avoided that outlet. Providing surface flow outlets with an entrainment zone extending upstream of structure could reduce entrance rejection, decrease forebay residence time and risk of predation, and increase passage of schools of smolts (Ploskey et al. 2006). Flow into the B1 sluiceway outlets was less than one-tenth of flow into the B2CC. Flow was higher at Entrance 1C near the downstream end of the channel than it was into Entrance 3C or 6C, and hydroacoustic data indicated that Entrance 1C passed the most fish and the highest densities of fish each season. 
At B1, fish could move above the controlling gate and most could still escape by diving into a flow refuge immediately upstream of the chain gate. Predators also used this flow refuge to stage attacks on approaching smolts. Providing surface passage routes without abrupt transitions to the entrainment zone would decrease forebay holding time, risk of predation, and escape from entraining flows. In spring and summer 2005, Sluiceway Outlet 1C had the highest entrance velocity, smolt passage, and passage density of the three B1 outlets.

Biologists must understand local flow, smolt, and predator dynamics on a diel basis to be able to maximize surface-collector performance for any location in a forebay. The forebay location of surface passage routes may be the primary concern to assure that smolts will encounter the outlet because they routinely travel in that area of a forebay, but it should not be the only concern. Based upon the DIDSON fish approach and entrance study in 2005, we recommend eliminating chain gates and the flow refuge they create. We also recommend installing a vortex suppression shelf upstream of the sill at sill elevation (68 ft above MSL) to prevent vortices from capturing smolts to the turbine that otherwise would pass into the outlet. (See Appendix H for movie clips of smolt movement, predators, and vortices). This horizontal shelf could be designed to hang from the top of the uppermost trash rack and therefore could be moved among intakes if desired. An alternative to vortex suppression devices would be to prioritize turbine operations so that units with open sluiceway entrances have the lowest operational priority and do not run most of the time. However, the efficiency and effectiveness of a sluiceway entrance should be evaluated with associated turbines on and off to determine which approach is best. Attraction flow by a unit and sluiceway may be more important than eliminating vortices, and testing is the only way to know for certain.

We also recommend on-and-off testing of constant lighting at sluiceway entrances at night because smolt schools held up more at night than they did during the day, and there was increased predator activity and success during the night. Predators often spooked smolts into Sluiceway Outlet 3C, which made us wonder whether a mechanical scare-fish rigged to drag back and forth at specific times of day might facilitate entry into a sluiceway outlet. Electrifying the sill area periodically might be a useful way to eliminate predators holding over a sill and upstream of chain gates. Shocked predators would be swept downstream into the sluiceway and eliminated from the forebay. Of course eliminating the low velocity water volume immediately upstream of the chain gates would eliminate the flow refuge that predators occasionally use. 


\section{Preface}

This report was prepared by the Pacific Northwest National Laboratory (PNNL), Richland, Washington, BAE Systems, the School of Aquatic and Fishery Sciences, University of Washington, Seattle, and Tenera, Incorporated. The Portland District of the U.S. Army Corps of Engineers provided funding and oversight.

\section{Acknowledgments}

Many people made valuable contributions to this study and deserve acknowledgement. Three Portland District biologists provided contract oversight and coordination between the Portland District and the Bonneville Project. Blaine Ebberts was the lead Biologist during the planning phase of the study (JuneDecember 2004), Brad Eppard assumed the lead in January 2005, and Dennis Schwartz took over after equipment was installed in late April 2005. Ben Hausman, Tim Darland, Tammy Mackey, and Jon Rerecich provided valuable coordination between study researchers and the Bonneville Dam Project and collated and transferred all dam-operations data. This study would not have been possible without the support of Randy Price, the acting structural foreman, and the teams of project riggers, who helped install and remove the hydroacoustic equipment.

Marshall Richmond's team in the PNNL Hydraulic Modeling Group made computational fluid dynamics (CFD) model runs for the sluiceway entrances at Unit 3C. The CFD runs were performed by Cindy Rakowski and John Serkowski.

BAE Systems, Inc., provided a wide range of talented staff that supported this hydroacoustic study, and three of them are authors. Deborah Patterson managed the extensive hydroacoustic databases and processed data using autotracking software developed by the PNNL and the Corps of Engineers. Peter Johnson was the on-site Manager for BAE Systems and helped with planning, installations, and the analysis of passage distribution data.

Alan Wirtz of Precision Acoustic Systems in Seattle, Washington, calibrated all hydroacoustic equipment, helped with troubleshooting, and made whatever repairs were required in a timely manner. Schlosser Machine in Hood River fabricated transducer mounts.

Our comparisons of hydroacoustic and radio telemetry estimates of fish-passage metrics would not have been possible without estimates and help provided by Michael Farley and Rachel Wardell with the U.S. Geological Survey in Cook, Washington. The radio telemetry and hydroacoustic studies overlapped but also had non-concurrent sample times that had to be eliminated before data could be compared. 
Hydroacoustic Evaluation of Fish Passage through Bonneville Dam in 2005 


\title{
Acronyms and Abbreviations
}

\author{
ADCP acoustic Doppler current profiler \\ AVI Audio Video Interleave \\ B1 Powerhouse 1 \\ B2 Powerhouse 2 \\ B2CC Powerhouse 2 Corner Collector \\ BPA Bonneville Power Administration \\ CD compact disc \\ CE Corps of Engineers \\ cfs $\quad$ cubic feet per second \\ CFD computational fluid dynamics \\ CSV portable document file \\ EBA effective beam angle \\ ERDC U.S. Army Engineer Research and Development Center \\ ESBS extended submerged bar screen \\ FEZ fish entrainment zone \\ FGE fish guidance efficiency at a turbine or intake [Guided / (Guided + Unguided)] \\ FPE fish passage efficiency [Guided / (Guided + Unguided) by Project or Powerhouse] \\ fps $\quad$ feet per second \\ $\mathrm{ft} \quad$ feet \\ h hour \\ HA hydroacoustics \\ JBS Juvenile Bypass System \\ km kilometer \\ M million \\ m meters \\ MGR minimum gap runner \\ MSL mean sea level \\ NMFS National Marine Fisheries Service \\ NOAA National Oceanic and Atmospheric Administration \\ OSPN Oregon State Plane North Zone
}




\begin{tabular}{|c|c|}
\hline PAS & Precision Acoustic Systems \\
\hline PDF & portable document file \\
\hline PNNL & Pacific Northwest National Laboratory \\
\hline PSC & Prototype Surface Collector \\
\hline RT & radio telemetry \\
\hline S & second \\
\hline SAS & Statistical Analysis System \\
\hline SLY & $\begin{array}{l}\text { Sluiceway efficiency - (Sluiceway passage / Project passage) or (Sluiceway passage / B1 } \\
\text { passage) }\end{array}$ \\
\hline SLE & $\begin{array}{l}\text { SLE divided by the proportion of total discharge going through the sluiceway. SLN may } \\
\text { be relative to the entire Project (Project SLN) or to relative to an adjacent powerhouse } \\
\text { (B1 SLN). }\end{array}$ \\
\hline SY & spill passage efficiency (spill passage / total Project passage) \\
\hline SE & $\begin{array}{l}\text { spill effectiveness is SE divided by the proportion of Project discharge going through the } \\
\text { spillway }\end{array}$ \\
\hline STS & submerged traveling screen \\
\hline TIE & turbine intake extension \\
\hline USGS & U.S. Geological Survey \\
\hline VBS & vertical barrier screen \\
\hline
\end{tabular}




\section{Contents}

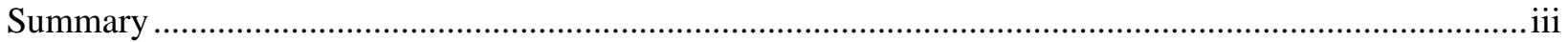

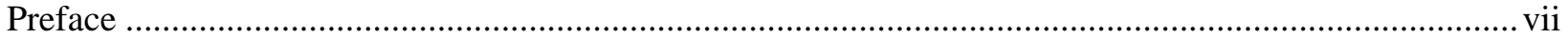

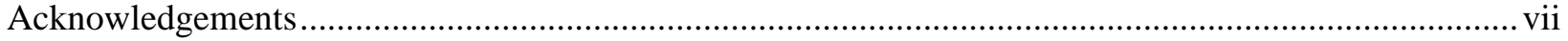

Acronyms and Abbreviations .........................................................................................................viii

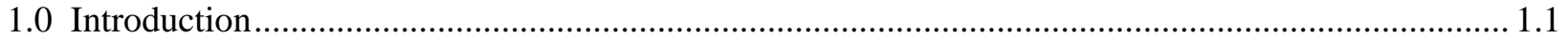

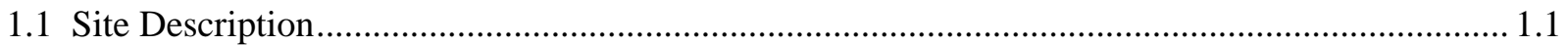

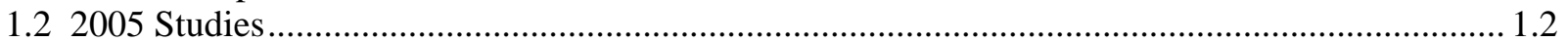

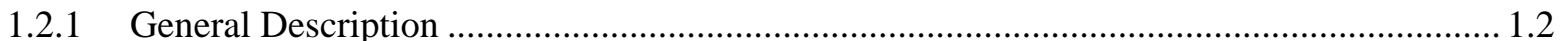

1.2.2 Objectives by Task ............................................................................................. 1.4

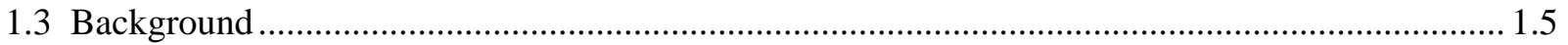

1.4 Overview of this Report......................................................................................................... 1.10

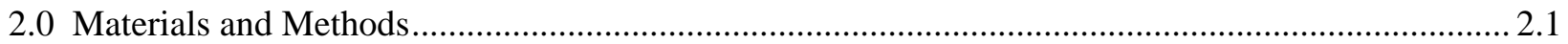

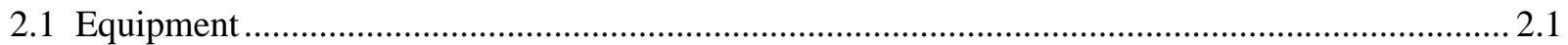

2.1.1 Fixed-Aspect Hydroacoustics ............................................................................................. 2.1

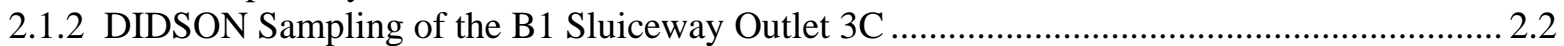

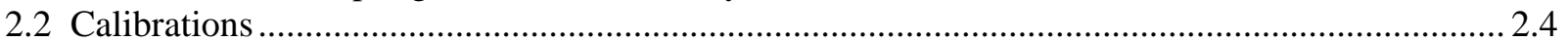

2.3 Transducer Deployments and Sampling Schemes ……………………………………………........ 2.5

2.3.1 Sampling B1 Turbines .............................................................................................. 2.5

2.3.2 Sampling B1 Sluiceway Outlets ....................................................................................... 2.7

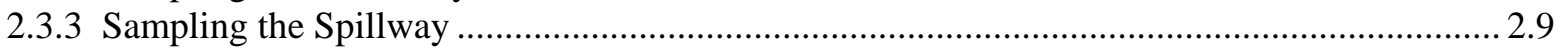

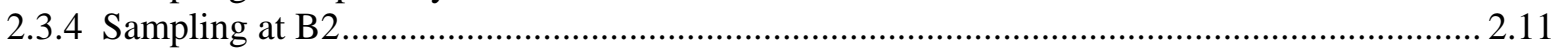

2.4 Fish Tracking and Filtering Criteria......................................................................................... 2.15

2.4.1 Fixed Aspect Hydroacoustic Sampling ................................................................................. 2.15

2.4.2 Tracking of Fish Approaching B1 Sluiceway Outlet 3C ..................................................... 2.16

2.4.3 Coordinate Systems for Fish Approach and Fate Analysis.................................................... 2.18

2.4.4 Estimating Fate Probabilities for Fish Approaching Sluiceway Outlet 3C............................. 2.2.

2.4.5 Computational Fluid Dynamics Modeling........................................................................... 2.23

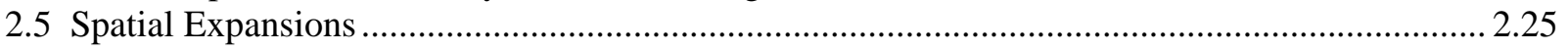

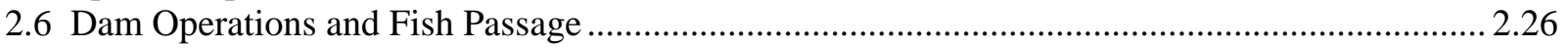

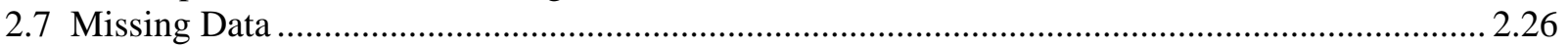

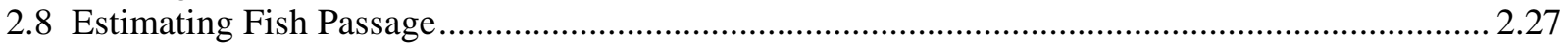

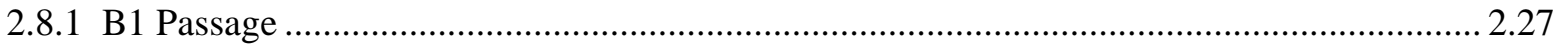

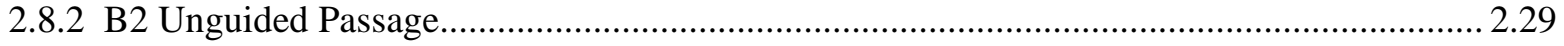

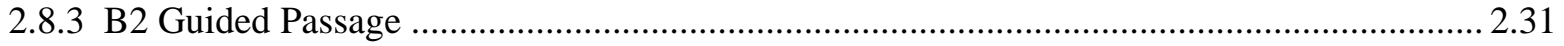

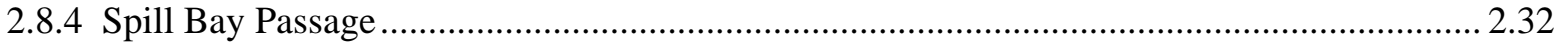

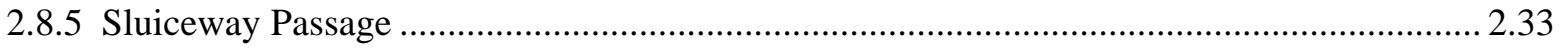

2.8.6 Corner Collector Passage ……………………………………………………………..... 2.33

2.9 Adjustment of Passage Estimates and Associated Variances ...................................................... 2.34

2.9.4 Sum of Multiple Adjusted Estimates .................................................................................. 2.35

2.9.5 Adjusting Autotracker Counts by Regression: Ratio Estimator............................................... 2.35

2.9.6 Adjusting for Direction-of-Travel Proportions ...................................................................... 2.36

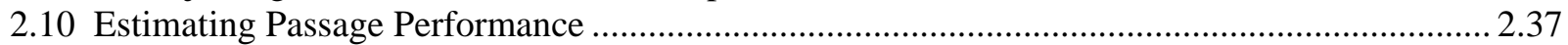

2.10.1 Project Fish Passage Efficiency (FPE) ........................................................................... 2.37

2.10.2 Project Fish Passage Efficiency - No Surface Passage.......................................................... 2.38

2.10.3 Project Fish Passage Efficiency (B2 + Spillway only) ..................................................... 2.39

2.10.4 B1 Fish Passage Efficiency (B1 FPE)............................................................................ 2.39 


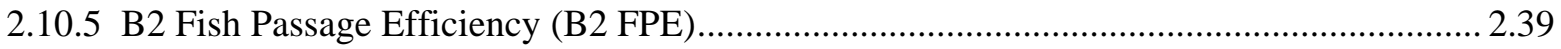

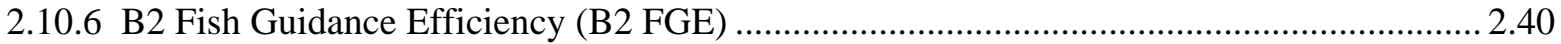

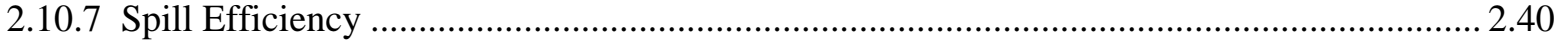

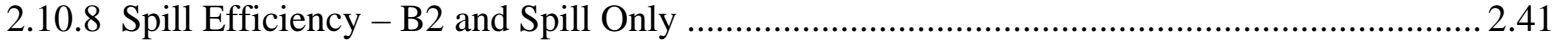

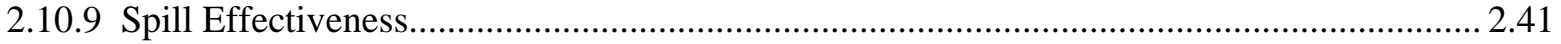

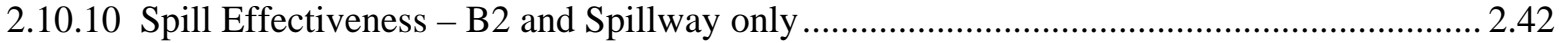

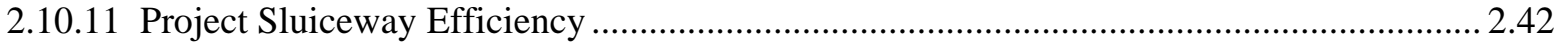

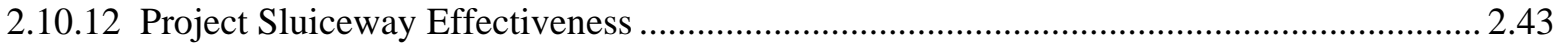

2.10.13 B1 Sluiceway Efficiency Relative to the Project Passage............................................... 2.43

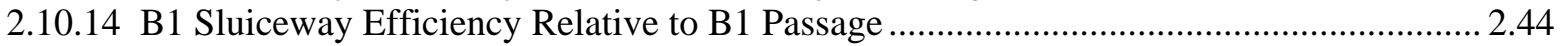

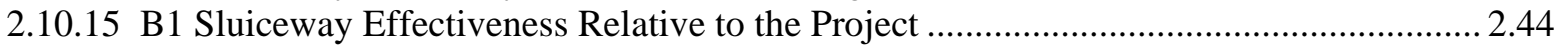

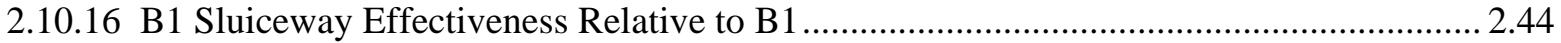

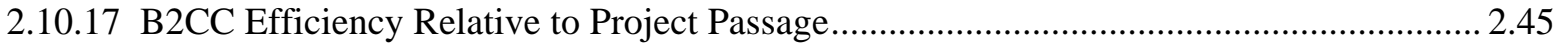

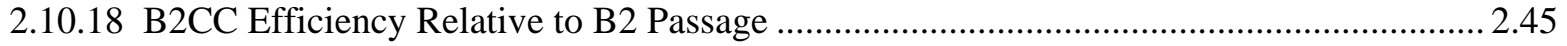

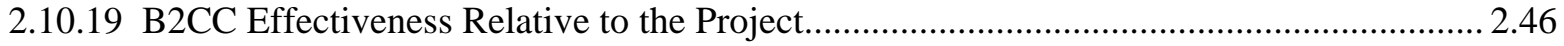

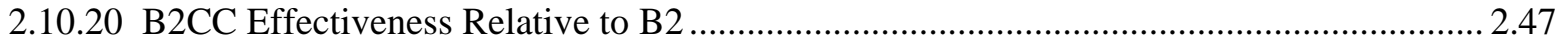

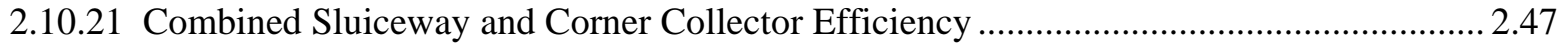

2.10.22 Combined Sluiceway and Corner Collector Effectiveness …........................................... 2.48

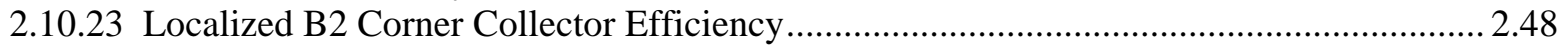

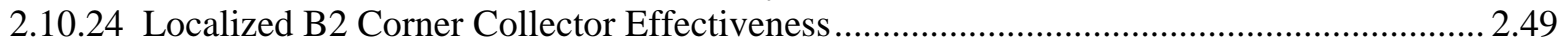

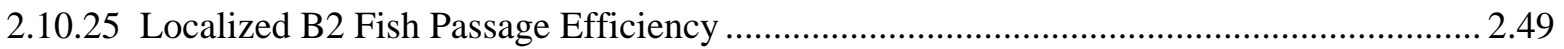

2.11 Comparing Spill-Treatment and Location Effects ............................................................... 2.50

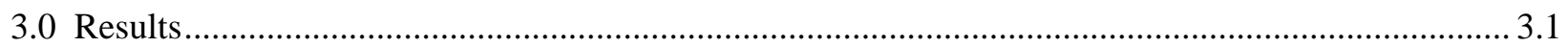

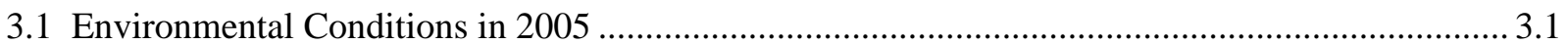

3.1.1 Run Timing and Species Composition in 2005.............................................................. 3.1

3.1.2 Project Discharge, Forebay Elevation, and Temperature.................................................... 3.3

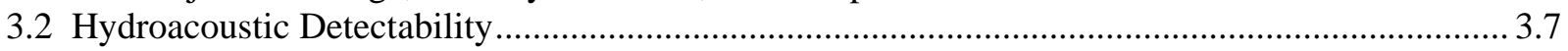

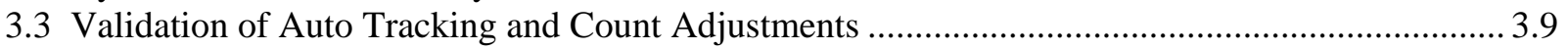

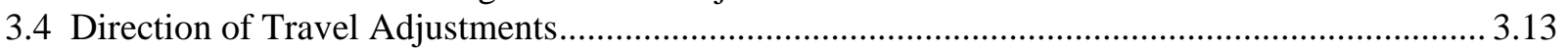

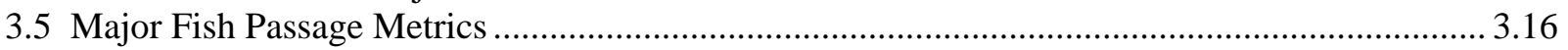

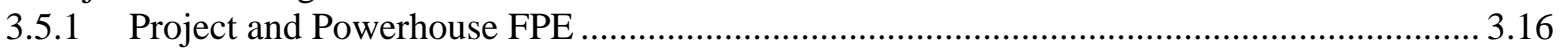

3.5.2 Spillway Efficiency and Effectiveness.......................................................................... 3.16

3.5.3 Sluiceway Efficiency and Effectiveness ........................................................................... 3.16

3.5.4 Comparison of Major Metrics from 2000 through 2005..................................................19

3.5.5 Effects of Percent Spill on Spill Efficiency and Project FPE ............................................. 3.21

3.5.6 Effects of Spill Discharge Rate on Spill Efficiency and Project FPE ................................ 3.26

3.5.7 Comparison of Hydroacoustic and Radio Telemetry Estimates .........................................2.28

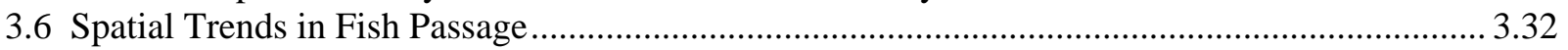

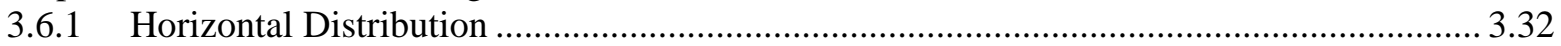

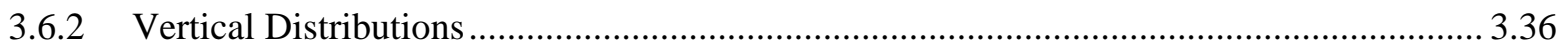

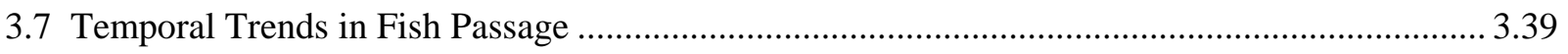

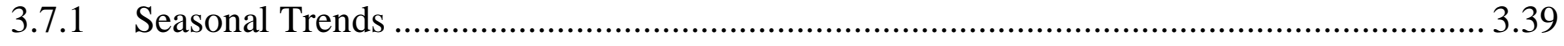

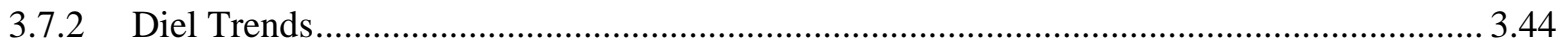

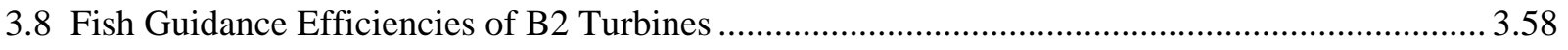

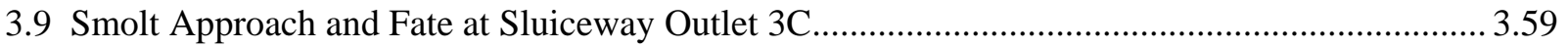

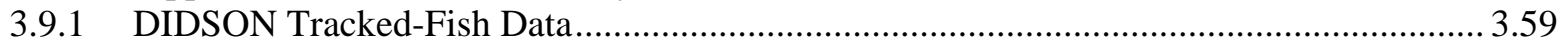

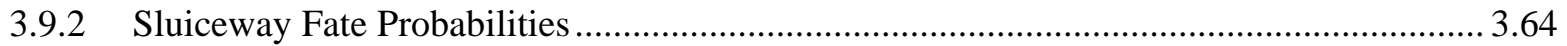

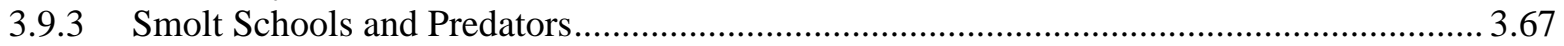




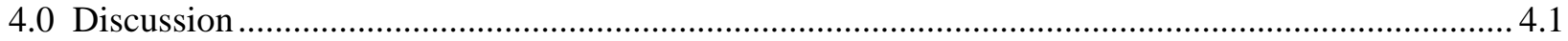

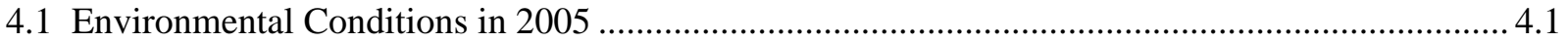

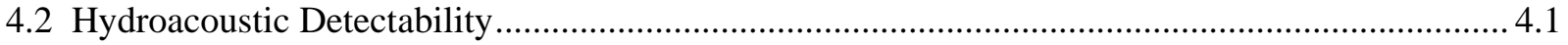

4.3 Validation of Auto Tracking and Count Adjustments .............................................................. 4.2

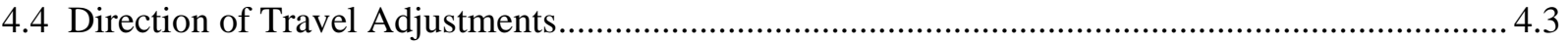

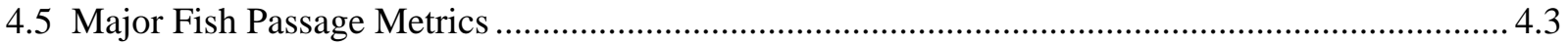

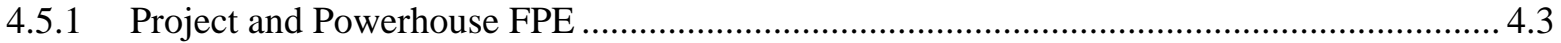

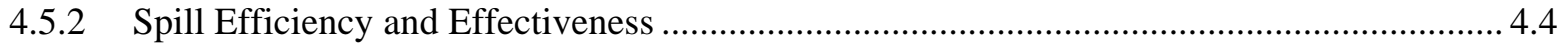

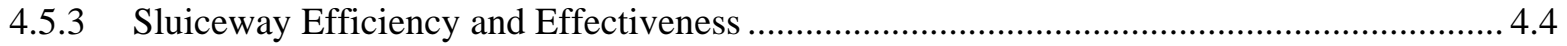

4.5.4 Effects of Percent Spill on Spill Efficiency and Project FPE ........................................... 4.5

4.5.5 Effect of Percent Spill on Percent Passage at B1 and B2 ................................................... 4.7

4.5.6 Effect of Spill on Project Sluiceway Efficiency.................................................................. 4.7

4.5.7 Effects of Spill Discharge on Spill Efficiency and Project FPE ......................................... 4.7

4.5.8 Comparison of Hydroacoustic and Radio Telemetry Estimates ......................................... 4.8

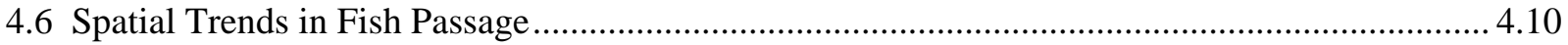

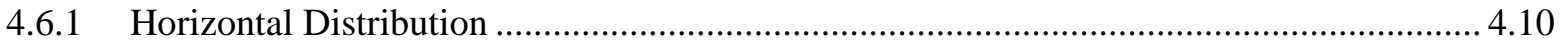

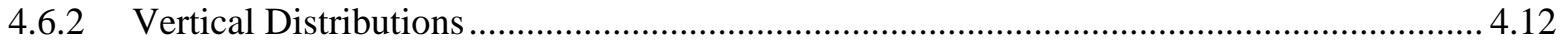

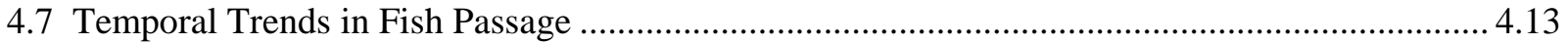

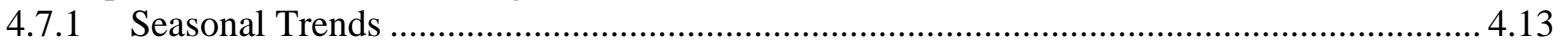

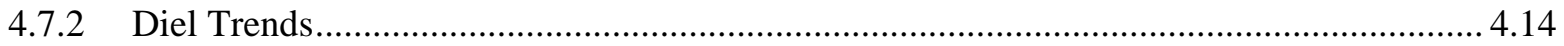

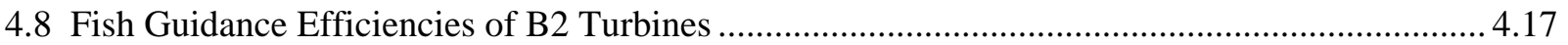

4.9 Smolt Approach and Fate at B1 Sluiceway Entrance 3C ........................................................... 4.18

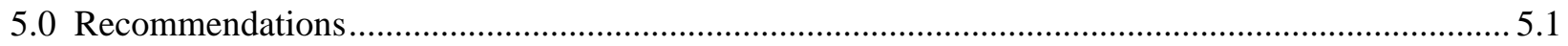

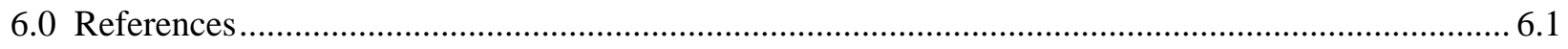

Appendix A Transducer Calibrations and Receiver Gains ............................................................ A.1

Appendix B Transducer Locations and Aiming Angles ..................................................................

Appendix C Autotracker Definitions and Parameters...........................................................................

Appendix D SAS Code for Filtering Fish Traces ........................................................................... D.1

Appendix E1. Tables of Hourly Fish Passage, Flow, and Forebay Elevation Estimates

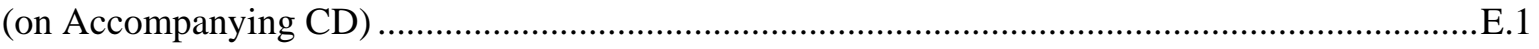

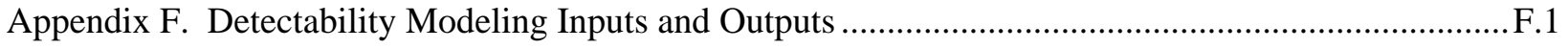

Appendix G. Analysis of Variance ANOVA on B2 Turbine Intake FGE ........................................... G.1

Appendix H. DIDSON Movie Files of Smolts Approaching Sluiceway Outlet 3C in 2005

(on Accompanying CD) 
Hydroacoustic Evaluation of Fish Passage through Bonneville Dam in 2005 


\section{Figures}

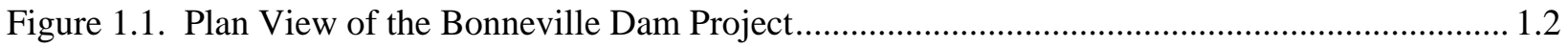

Figure 1.2. Columbia River Discharge (\% and CFS) from 1996 through 2005 during Spring and

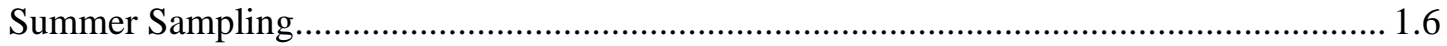

Figure 2.1. A CAD Drawing of the DIDSON Barge Deployment ….................................................... 2.2

Figure 2.2. The Pontoon Barge from which the DIDSON was Deployed in 2005 ................................. 2.2

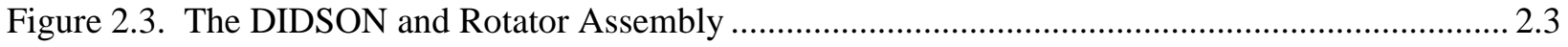

Figure 2.4. System Configuration Flowchart for DIDSON Motion Control and Data Acquisition ......... 2.4

Figure 2.5. Cross-Sectional View through a B1 Turbine Intake Showing a Single Down-Looking Transducer Beam for Sampling Fish Passage through the Intake, when No STS was Deployed

Figure 2.6. Cross-Sectional View through a B1 Turbine Intake Showing Near-Ceiling Volumes of a Single Down-Looking Transducer Beam Compared with that of an Up-Looking Transducer

Figure 2.7. The Relationship between Hourly Estimates for the Same Intake Sampled by Up-Looking and Down-Looking Transducers .....

Figure 2.8. Forebay View of a Sluiceway Outlet at Intake 1C, 3C, or 6C in 2005 Showing the Deployment of Opposing Split-Beam Transducers for Sampling Fish Passage...

Figure 2.9. Diagram Showing Six $30^{\circ}$ Wide, $12^{\circ}$ Deep Sample Volumes from a Plan View

Figure 2.10. Cross-Sectional View through a Spill Bay at Bonneville Dam .....

Figure 2.11. Diagram of a Frontal View of the B2CC Outlet Showing the Acoustic Beams from Six Split-Beam Transducers Deployed from a Barge East of the Outlet

Figure 2.12. Plan Views of the B2CC Outlet Showing Predicted Water Velocities of 5 to $10 \mathrm{fps}$ in the Area that Split-Beam Transducers Sampled Fish Passage in 2005.

Figure 2.13. Cross-Sectional View through a B2 Turbine Showing Up- and Down-Looking Transducer Beams.

Figure 2.14. One Frame from the DIDSON Autotracker Showing Fish Tracks Being Acquired

Figure 2.15. B1 Powerhouse Discharge and Forebay Elevations from Operations Data used to Separate Output Groups and Make Pan Angle Corrections to the DIDSON at the Sluiceway Outlet 3C

Figure 2.16. The Sample Volume X, Y, Z Coordinates were Aligned to the Oregon State Plane North Coordinate System....

Figure 2.17. Sample Volume Referenced to Oregon State Plane North Coordinate System. 2.20

Figure 2.18. Fates of Fish Movement Estimated when Fish Tracks were Absorbed at Cells on the Edges of the Sample Volume....

Figure 2.19. Operations at Bonneville Dam During Data Collection with the DIDSON 2.24

Figure 3.1. Smolt Monitoring Program Passage Index for April 15 - July 15, 2005, Based on Data from the B2 Juvenile Bypass System.... 
Figure 3.2. Species-Specific Distributions of Daily Passage for April 15 - July 15, 2005, Based on Data from the B2 Juvenile Bypass System

Figure 3.3. Run Composition of Juvenile Salmonids Sampled in the B2 Juvenile Bypass System

Figure 3.4. Daily Project Discharge for April 15 - July 15 in 1997, 2001, 2005, and the 10-Year Daily Average

Figure 3.5. Project and Spillway Discharge Rates for 2005 and the 10-Year Average from 1995 through 2004

Figure 3.6. Spill Discharge Rate by Date in Spring 2005 .................................................................. 3.4

Figure 3.7. Spill Discharge Rate (cfs) by Date in Summer 2005......................................................... 3.5

Figure 3.8. Mean Hourly Spill and Turbine Discharge in Spring and Summer 2005............................. 3.5

Figure 3.9. Mean Daily Forebay Elevation in 2005 and 10-Year Average ........................................... 3.6

Figure 3.10. Mean Daily Forebay Temperature in 2005 and 10-Year Average ..................................... 3.7

Figure 3.11. Plots of Effective Beam Angle as a Function of Range from Transducers

Deployed at Bonneville Dam during Spring 2005.

Figure 3.12. Plots of Effective Beam Angle as a Function of Range from Transducers Deployed at Bonneville Dam during Summer 2005.

Figure 3.13. Regressions of Mean Manual-Tracker Estimates of Hourly Fish Passage on Autotracker Estimates for Transducers at B1 Sluiceway Entrances and the B2CC

Figure 3.14. Regressions of Mean Manual-Tracker Estimates of Hourly Fish Passage on Autotracker Estimates for Transducers at B1 Turbines

Figure 3.15. Regressions of Mean Manual-Tracker Estimates of Hourly Fish Passage on Autotracker Estimates for Transducers at the Spillway....

Figure 3.16. Regressions of Mean Manual-Tracker Estimates of Hourly Fish Passage on Autotracker Estimates for Transducers at B2 Turbines

Figure 3.17. Polar Plots of Percent of Fish Traveling Different Directions across the Barrel View of Down-Looking, Split-Beam Transducers Deployed at Spill Bays in Spring and Summer 2005

Figure 3.18. Polar Plots of Percent of Fish Traveling Different Directions across the Barrel View of Side-Looking, Split-Beam Transducers at Sluice Entrances and Spill Bays in Spring 2005

Figure 3.19. Polar Plots of Percent of Fish Traveling Different Directions across the Barrel View of Side-Looking, Split-Beam Transducers at Sluice Entrances and Spill Bays in Summer 2005.

Figure 3.20. Project-Wide and Other Fish-Passage Efficiency Estimates for Spring and Summer at Bonneville Dam in 2005

Figure 3.21. Estimated Spill Efficiency and Effectiveness for the Bonneville Project and for the Spillway and B2 Only in Spring and Summer 2006

Figure 3.22. Estimated Sluiceway Efficiency for the Bonneville Project and for the Sluices Relative to the Respective Powerhouse Only for Spring and Summer 2005

Figure 3.23. Estimated Sluiceway Effectiveness for the Bonneville Project and for the Sluices Relative to the Respective Powerhouse Only for Spring and Summer 2005. 
Figure 3.24. Regression of Day and Night Estimates of Spill Passage Efficiency on Percent Spill in Spring

Figure 3.25. Regression of Hourly Estimates of Spill Passage Efficiency on Hourly Percent Spill in Spring

Figure 3.26. Regression of Day and Night Estimates of Spill Passage Efficiency on Percent Spill....... 3.22

Figure 3.27. Regression of Day and Night Estimates of Project FPE on Percent Spill in Spring .......... 3.22

Figure 3.28. Regression of Day and Night Estimates of Project FPE on Percent Spill in Summer........ 3.23

Figure 3.29. Trends in the Percent of Fish and Flow Passing B1 as a Function of Percent Spill ........... 3.23

Figure 3.30. Trends in the Percent of Fish and Flow Passing B2 as a Function of Percent Spill ........... 3.24

Figure 3.31. Effect of Percent Spill on Project Sluiceway Passage Efficiency in Spring 2006.............. 3.24

Figure 3.32. Effect of Spill Rate on Project Surface Flow Passage Efficiency in Spring 2006............. 3.25

Figure 3.33. Effect of Percent Spill on Project Sluiceway Passage Efficiency in Summer 2006........... 3.25

Figure 3.34. Regression of Day and Night Estimates of Spill Passage Efficiency on Spillway Discharge for Spring 2006...

Figure 3.35. Regression of Mean Day and Night Estimates of Spill Passage Efficiency on Spillway Discharge for Summer 2006.

Figure 3.36. Regression of Mean Day and Night Estimates of Project FPE on Spill Discharge Rate

Figure 3.37. Regressions of Mean Daily Project FPE on Spillway Discharge Rate in Summer

Figure 3.38. Percentage of Fish Passage and Discharge at Each Major Passage Structure in Spring 2005.

Figure 3.39. Percentage of Fish Passage and Discharge at Each Major Passage Structure in Summer 2005.

Figure 3.40. Fish Passage by Route in Spring 2005 ........................................................................3.33

Figure 3.41. Fish Passage by Route in Summer 2005.......................................................................3.33

Figure 3.42. Fish Passage Density by Route in Spring and Summer 2005 ......................................... 3.34

Figure 3.43. Distributions of Fish Passage across Three B1 Sluiceway Outlets in Spring.................... 3.34

Figure 3.44. Distributions of Fish Passage across Three B1 Sluiceway Outlets in Summer.................. 3.35

Figure 3.45. Horizontal Distribution of Fish Passage at the B2CC ................................................... 3.35

Figure 3.46. Vertical Distributions of Fish within Turbine Intakes at B1 .......................................... 3.36

Figure 3.47. Average Vertical Distributions of Fish Passage within B1 Turbine Intakes in Spring and Summer 2005, after Adjusting for Reducing Maximum to Pre-2004 Sampling Levels

Figure 3.48. Average Vertical Distributions of Fish Passage within B1 Turbine Intakes in Spring and Summer 2002

Figure 3.49. Vertical Distributions of Fish at Spillway ...................................................................... 3.38

Figure 3.50. Vertical Distributions of Fish at the B2CC Entrance .................................................... 3.38

Figure 3.51. Vertical Distributions of Fish within B2 Turbine Intakes in Spring 2005........................ 3.39 
Figure 3.52. Vertical Distributions of Fish within B2 Turbine Intakes in Summer 2005

Figure 3.53. Patterns of Run Timing Estimated by Hydroacoustics and by the B2 SMF Smolt Index at Bonneville Dam in 2005

Figure 3.54. Patterns of Adult American Shad and Juvenile Salmonid Run Timing According to Fish Passage Center Counts and Hydroacoustic Counts, Respectively

Figure 3.55. Time Histories of Estimated Route-Specific Passage in Summer.

Figure 3.56. Time History of Project FPE Estimates for Bonneville Dam in 2005

Figure 3.57. Time History of Estimated Spill Efficiency

Figure 3.58. Time History of Daily Estimates of Project Spillway Effectiveness...

Figure 3.59. Time History of Estimated Project Sluiceway Efficiency

Figure 3.60. Time History of Estimated Project Sluiceway Effectiveness

Figure 3.61. Seasonal Trends in the B2 FGE of Submerged Traveling Screens

Figure 3.62. Diel Trends in Project FPE in Spring and Summer 2005.

Figure 3.63. Diel Trends in Project Spill Efficiency in Spring and Summer 2005. 3.45

Figure 3.64. Estimated Hourly Spillway Passage Efficiency and Discharge at Bonneville Dam during Six Days in Spring 2005.

Figure 3.65. Diel Trends in Project Sluiceway Passage Efficiency in Spring and Summer 2005. 3.46

Figure 3.66. Diel Trends in B1 Sluiceway Passage Efficiency Relative to the Entire Project in Spring and Summer 2005

Figure 3.67. Diel Trends in B2CC Passage Efficiency Relative to the Entire Project in Spring and Summer 2005

Figure 3.68. Diel Patterns of B2CC Passage Efficiency Relative to B2 in 2005. 3.48

Figure 3.69. Diel Trends in B1 FPE in Spring and Summer 2005. 3.48

Figure 3.70. Diel Patterns of B2 FPE in Spring and Summer 2005. 3.49

Figure 3.71. Diel Patterns of Project Spill Effectiveness in Spring and Summer 2005. 3.49

Figure 3.72. Diel Patterns of Project Sluiceway Effectiveness in Spring and Summer 2005. 3.50

Figure 3.73. Diel Patterns of B1 Sluice Effectiveness Relative to the Project in 2005 .... 3.50

Figure 3.74. Diel Patterns of B2CC Effectiveness Relative to the Project in 2005 3.51

Figure 3.75. Diel Patterns of B1 Sluice Effectiveness Relative to B1 and B2CC Effectiveness Relative to B2 in 2005. 3.51

Figure 3.76. Estimated Hourly B1 Total Passage, B1 Turbine Passage, and B1 Sluiceway Passage and Associated Discharge in Spring of 2005.

Figure 3.77. Estimated Sum of Hourly Fish Passage at B1, B1 Turbines, and the B1 Sluiceway, and Associated Discharge in Summer 2005

Figure 3.78. Estimated Hourly Spillway Passage and Discharge at Bonneville Dam in Spring and Summer of 2005.

Figure 3.79. Estimated Hourly B2 Total Passage, B2 Turbine Passage, and B2CC Passage and Associated Discharge in Spring 2005. 
Figure 3.80. Estimated Hourly B2 Total, B2 Turbine, and B2CC Passage and Associated Discharge in Summer 2005

Figure 3.81. Estimated Hourly B2 Guided and Unguided Turbine Passage and Discharge in Spring and Summer of 2005

Figure 3.82. Fish Guidance Efficiency Estimates for B2 in Spring and Summer

Figure 3.83. Fish Guidance Efficiency Estimates for B2 Turbines in Spring and Summer

Figure 3.84. Tracked Fish Upstream and Approaching the 3C Sluiceway Outlet at Bonneville Dam Based Upon the DIDSON Acoustic Camera Sampling in Spring 2005.

Figure 3.85. Tracked Fish Upstream and Approaching the 3C Sluiceway Outlet at Bonneville Dam Based Upon the DIDSON Acoustic Camera Sampling in Summer 2005

Figure 3.86. Composite View of Fish Tracks Approaching the 3C Sluiceway Outlet in Spring 2005

Figure 3.87. Composite View of Fish Tracks Approaching the 3C Sluiceway Outlet in Summer 2005.

Figure 3.88. Contours of Fish Passage Probabilities at the B1 3C Sluiceway in Spring 2005.

Figure 3.89. Contours of Fish Passage Probabilities at the B1 3C Sluiceway in Summer 2005

Figure 3.90. Mean and Maximum Entrance Probabilities at a Function of Range for Bonneville Dam Sluiceway Outlet 3C in 2005

Figure 3.91. Two Sets of Three-Frame Series of Movements of Two Predators Feeding on Juvenile Salmonids Upstream of Sluiceway Outlet 3C at Night

Figure 3.92. Series of DIDSON Images Show Schools of Juvenile Salmonids Upstream of Sluiceway Outlet 3C

Figure 4.1. Box-and-Whisker Plots Describing Slope Statistics by Deployment Type.

Figure 4.2. Revised Regression of Day and Night Estimates of Spill-Passage Efficiency on Percent Spill in Spring 2005

Figure 4.3. Regression of Day and Night Estimates of Spill-Passage Efficiency on Percent Spill in 2000 


\section{Tables}

Table 2.1. Units and Intake Slots that were Offline or Randomly Selected for Sampling in 2005 .......... 2.5

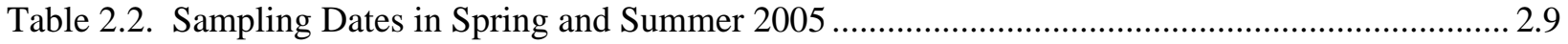

Table 2.3. Statistical Analysis System (SAS) Code Used to Spatially Expand Detected Fish ............... 2.12

Table 2.4. Intake Slots Randomly Selected for Sampling at B2 during the 2005 Study ....................... 2.13

Table 2.5. Scenario Runs of the CFD Model Based Forebay Elevation and Discharge (Q) through the B1 Turbines and Sluiceway ......................................................................... 2.24

Table 3.1. Estimates of Major Passage Metrics Based upon Hydroacoustic Sampling from 4/15 through 5/31 (Spring) and from 6/1 through 7/15 (Summer) in 2005 ...

Table 3.2. Estimates of Major Passage Metrics Based upon Hydroacoustic Sampling in 2000, 2001, 2002, 2004, and 2005

Table 3.3. Comparison of Passage Performance Metrics for the Run-at-Large, as Measured by Hydroacoustics, and for Yearling Chinook Salmon and Steelhead Combined, as Measured by Radio Telemetry; estimates are for concurrent periods of sampling from May 1 through May 31, 2005

Table 3.4. Comparison of Passage Performance Metrics for the Run-at-Large, as Measured by Hydroacoustics, and for Yearling Chinook Salmon and Steelhead Combined, as Measured by Radio Telemetry; estimates are for concurrent periods of sampling from June 15 through July 15, 2005

Table 3.5. Estimates of Fish Guidance Efficiency, by Turbine Unit, at B2 for the Run-at-Large as Measured by Hydroacoustics and for Yearling Chinook Salmon and Steelhead Combined, as Measured by Radio Telemetry, from May 1-May 31, 2005

Table 3.6. Estimates of FGE, by Turbine Unit, at B2 for the Run-at-Large as Measured by Hydroacoustics and for Yearling Chinook Salmon and Steelhead Combined, as Measured by Radio Telemetry, from June 15 through July 15, 2005

Table 3.7. Characteristics of Tracked Fish as They Approached the B1 3C Sluiceway Outlet at Bonneville Dam, 2005.

Table 3.8. Characteristics of Data Used in Markov Chain Models of Fish Movement 3.62

Table 3.9. Fates, Expressed as Probabilities of Passage, Averaged from a Semi-Circular Area Near the 3C Sluiceway Outlet at Bonneville Dam in 2005 Based on Eight Markov Chain Analyses.

Table 4.1. Percentage by Species of Total Fish Radio-Tagged and of the Run-at Large as Sampled by the Juvenile Bypass System in Spring, 2005 .

Table 4.2. Proportion of Fish Passed and Water Discharged by Structure and Season for each Non-Drought Year with Full Project Passage Assessment.

Table 4.3. Unit 11 FGE Estimates in Years when the B2 Sluiceway Entrances were Closed and Opened. 


\subsection{Introduction}

The Portland District of the U.S. Army Corps of Engineers requested that the Pacific Northwest National Laboratory (PNNL) conduct fish-passage studies at Bonneville Dam in 2005. In this report, we present results of two juvenile salmonid passage studies conducted at Bonneville Dam during the spring and summer migrations between April 16 and July 15, 2005: 1) a hydroacoustic evaluation of fish passage efficiency and other major passage metrics, and 2) a DIDSON evaluation of smolt approach and fate at B1 Sluiceway Outlet 3C from the B1 forebay.

These studies support the Portland District's goal of maximizing fish-passage efficiency (FPE) and obtaining 95\% survival for juvenile salmon passing Bonneville Dam. Major passage routes include 10 turbines and a sluiceway at Powerhouse 1 (B1), an 18-bay spillway, and eight turbines and a sluiceway at Powerhouse 2 (B2).

\subsection{Site Description}

Bonneville Lock and Dam consist of several dam structures that together impound the Columbia River between Oregon and Washington at River Mile 146.1, about 40 miles east of Portland, Oregon. From the Oregon shore north toward Washington, the Project currently is composed of a navigation lock, a 10turbine-unit Powerhouse 1 (B1), Bradford Island, an 18-gate spillway, Cascades Island, and an 8-turbineunit Powerhouse 2 (B2), as shown in Figure 1.1. The turbine units are numbered from 1 to 10 north to south at B1 and from 11 to 18 at B2 and each unit has three intakes A, B, and C. The B1 sluiceway has chain gates above every turbine intake, but only outlets 1C, 3C, and 6C were open in 2005.

Bonneville Dam was formally authorized by Congress in the Rivers and Harbor Act of August 30, 1935. This act also provided the authority for the construction of additional hydroelectric generation facilities when requested by the Administrator of the Bonneville Power Administration (BPA). The spillway and B1 were constructed between 1933 and 1937 without specific regard for protecting juvenile salmonids migrating downstream. Public Law 329, passed by the 75th Congress on August 20, 1937, provided authority for the completion, maintenance, and operations of Bonneville Dam. Administrative letters of BPA dated January 21, 1965, and February 2, 1965, stated the need for the construction of B2.

Construction of turbine units 11 through 18 and two fish units at B2 began in 1974 and was completed in 1982.

Principal passage routes for juvenile salmonids include the spillway and two powerhouses, but within each powerhouse, fish passage can be through ice and trash sluiceways, turbines, or the juvenile bypass system (JBS). Smolts enter the JBS after they encounter screens in the upper part of turbine intakes and are diverted to gatewell slots and orifices opening to a bypass channel. In spring of 2004, the B2 Corner Collector (B2CC) became fully operational (Figure 1.1). It was converted from the old B2 Sluice Chute in the fall and winter of 2003-2004. The B2CC outlet provides a passage route for high concentrations of smolts at the south end of B2 on the north side of Cascades Island. The B2CC channel transports fish from the B2 forebay to the downstream tip of Cascades Island between the spillway and B2 tailwaters. 


\subsection{Studies}

\subsubsection{General Description}

Bonneville Dam is the most downstream of all of the hydropower dams in the Columbia-Snake-River hydropower system. Therefore, more downstream-migrating juvenile salmonids must pass Bonneville Dam than any other dam in the system. The U.S. Army Corps of Engineers, Portland District, has made a concerted effort to improve passage conditions for downstream migrants, because the turbines at Bonneville Dam have consistently low fish-guidance efficiency (FGE; Krcma et al. 1982; Gessel et al. 1988 and 1991; Magne 1987; Magne et al. 1986 and 1989; Stansell et al. 1990; Evans et al. 2001a-d and 2003a, 2003b; and Ploskey et al. 1998, 2001a, 2002a-c, and 2003, 2005). Gessel et al. (1991) discussed the history of the development of submerged traveling screens (STSs) and estimates of FGE at B2. Other improvements to fish guidance, collection, and passage are part of ongoing research and engineering activities. The 2005 work reported here is a part of that continuing effort.

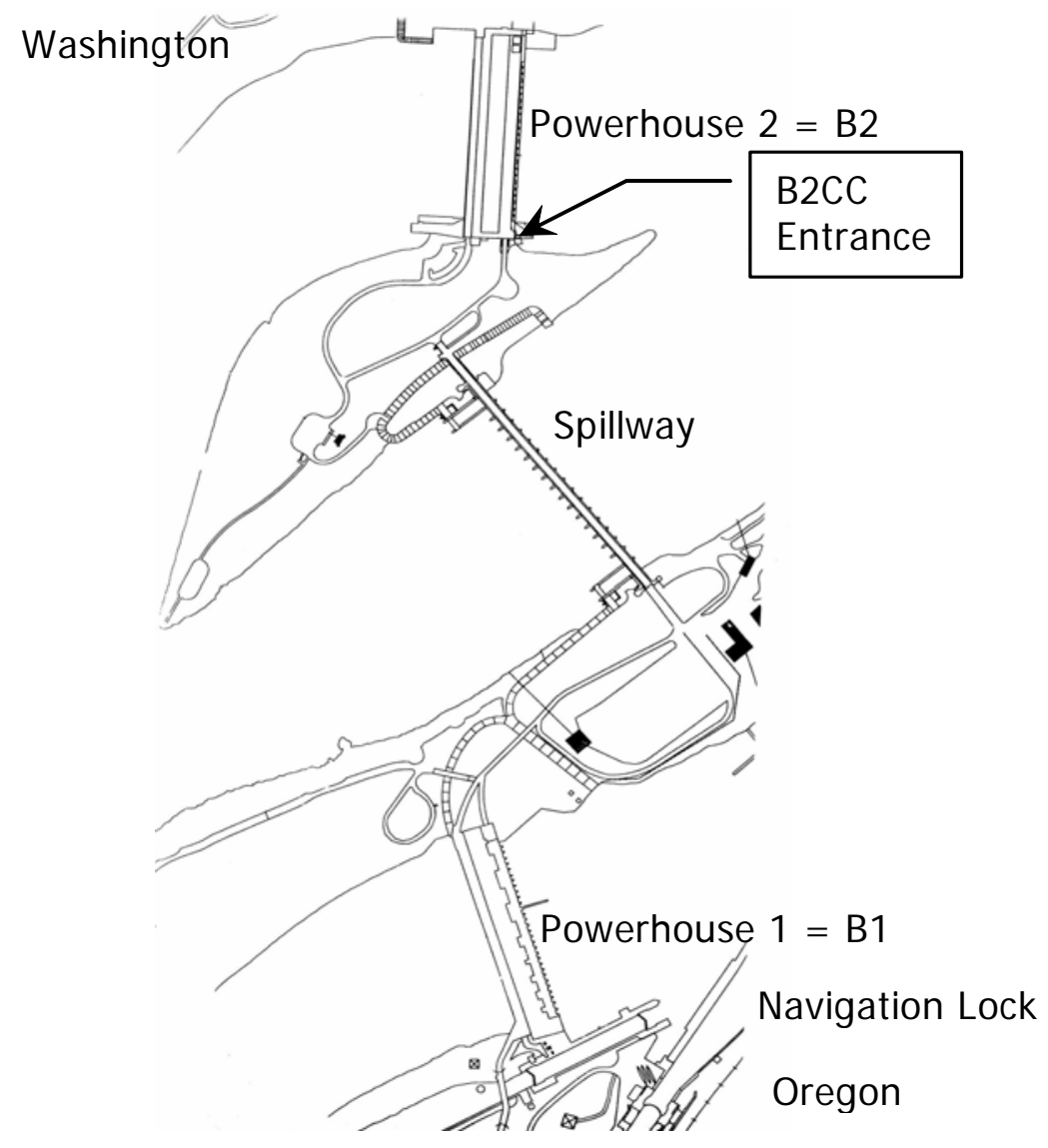

Figure 1.1. Plan View of the Bonneville Dam Project

As in prior years of study, the 2005 hydroacoustic research involved the estimation of fish-passage metrics for the entire Project as well as spatial and temporal variation in those estimates. The 2005 study also included a fish approach and fate evaluation based upon DIDSON tracking of juvenile fish 
movements upstream of Outlet 3C to the B1 sluiceway. This outlet efficiency study was similar to one conducted in 2004 at the B2 Corner Collector.

In this report, we present results of the fifth year in which enough of the Project's many passage routes (18 turbines, including guided and unguided fractions at B2, 18 spill bays, three sluiceway outlets at B1, and the B2CC) were sampled to permit estimation of project-wide fish-passage metrics. The other years with adequate fish-passage sampling were 2000, 2001, 2002, and 2004. These years and 2005 had concurrent and extensive juvenile-passage studies on radio tagged fish by the U.S. Geological Survey (USGS), so there were many independent estimates of metrics available for comparison. Each of these years had environmental and operational factors that made it unique. These factors included testing of new passage routes and structural modifications, powerhouse priority, turbine outages, project generation demand, and water availability.

During hydroacoustic sampling from April 16 through July 15, 2005, no submerged traveling screens were installed at B1; three B1 sluiceway outlets from the forebay were opened; B2 was the priority powerhouse for generation; no turbine intake extensions (TIES) was installed upstream of B2 turbines 11 through 14; and the B2CC was passing water and fish. The 2005 configuration of passage routes and operations was similar to that evaluated in 2004, but river discharge was $10 \%$ lower in 2005 . It was $75 \%$ of the 10-year average from 1996-2005. It was $85 \%$ of the 10 -year average in 2004 . In study years before 2004, TIES were installed in every other B2 intake from 11A through 18B. Removal of TIES from intakes at units 11-14 in 2004 and 2005 facilitated southerly flow along the powerhouse toward the B2CC. Two of the three B1 sluiceway outlets sampled in 2005 were located about $60 \mathrm{ft}$ to the south of the outlets sampled in 2004. Outlets 2C, 4C, and 6C were opened and were sampled in 2004, and Outlets 1C, 3C, and 6C were opened and sampled in 2005. Besides the B2CC, the 2004 and 2005 passage years were unique in that no in-turbine screens were deployed in the $30 \mathrm{~B} 1$ turbine intakes, where there are three intakes per turbine. Before 2004, submerged traveling screens (STS) were deployed in most B1 intakes. The exception was that extended length submersible bar screens were installed in all intakes of Unit 8 and tested in 2001 and 2002. Regional fish managers decided not to have screens deployed at B1 in 2004 and 2005, after they examined recent survival estimates for fish passing B1 turbines and noted that survival was higher for fish passing through minimum gap runner (MGR) turbines than it was for fish passing through the juvenile bypass system.

At B2, there were two units with modified gatewell slots (Units 15 and 17), as there were in the 2002 and 2004 study years. In an attempt to improve fish guidance at B2, several modifications were made and tested in the gatewells of Unit 15 in 2001; gatewells of Unit 17 were modified for the 2002 study year (Ploskey et al. 2003). These modifications were devised after physical modeling of B2 intakes in 2000 raised concerns that fish guidance efficiency was limited by insufficient flow moving above the STS and into gatewells. There also was concern that a high proportion of flow, and potentially of fish, was moving through the gap between the top of the STS and the intake ceiling back into the turbine intake. The modifications consisted of removing part of a concrete beam, greatly expanding the surface area of the vertical barrier screen (VBS), and adding a turning vane and gap closure device to direct more water up the slot and away from the gap between the top of the STS and the intake ceiling. The VBSs in the gatewells of Unit 17 were modified prior to the 2004 season. Concrete was removed from the downstream side of the gatewell and sturdier VBSs were installed to handle higher flows into the gatewell and greater debris loading. 


\subsubsection{Objectives by Task}

\subsubsection{Task 1: Bonneville Review and Synthesis}

We reviewed, summarized, and integrated 2004 research reports about juvenile fish-passage and survival at Bonneville Dam with information in a draft synthesis report produced in 2004. The 2004 draft report covered research through 2003. Information of interest included direct and indirect survival studies, fishpassage studies based upon hydroacoustics, telemetry (radio and acoustic), and netting, as well as outfall egress, fish-guidance efficiency, and predation studies. After errors in spill discharge estimates for 20002004 were identified by the Portland District in fall 2004, it was clear that spill corrections would have to be made and data reanalyzed before the synthesis report could be completed in 2006 . The reanalysis is scheduled for 2006. No interim product was produced for 2005.

\subsubsection{Task 2: Project FPE Evaluation}

This task continues fish-passage estimation studies conducted in 2000-2002 and 2004. We used fixedaspect hydroacoustic methods to sample route-specific passage of smolt-sized fish by hour, day, and season. We also estimated fish-passage statistics such as the efficiency of fish passage (Project, B1, B2, spill, and sluiceway) and the effectiveness of fish passage for the spillway and sluiceway. Efficiency is the percent of fish or water passage by various routes and effectiveness is the ratio of fish-passage efficiency to water-passage efficiency. We compare the 2005 results with concurrent estimates by radiotelemetry, as in previous years, and compare 2005 hydroacoustic estimates with flow-independent estimates of previous hydroacoustic studies to identify effects of structural and operational changes through time. In fall 2004, the Hydraulics Branch, Portland District, discovered that spill discharge estimates for 2000-2004 were inaccurate, particularly at low spill rates. Therefore corrections will have to be made to hourly spill-discharge estimates for the years 2000, 2001, 2002, and 2004 before flowdependent metrics such as fish-passage effectiveness can be compared reliably. This retrospective analysis is planned for 2006 .

Our specific objectives for 2005 were as follows:

1. Estimate numbers of smolt-sized fish that pass downstream through the Bonneville Dam Project by all major routes including above and below in-turbine screens at each powerhouse, through the spillway, B1 sluiceway, and the B2CC.

2. Estimate route-specific passage percentages, including Project and powerhouse-specific FPE, the efficiency and effectiveness of the spillway, the B1 sluiceway, and the B2CC (relative to the powerhouse or Project, as appropriate) by hour, day, and season. Estimate fish-guidance efficiency (FGE) by turbine unit at B2 to compare efficiency among units relative to treatment conditions such as modified versus unmodified gatewells or the presence or absence of TIES. No screens were deployed inside B1 turbines in 2004 or 2005, and therefore there was no guided-fish percentage from which to estimate FGE for B1 turbines.

3. Describe vertical and horizontal distributions of smolt-sized fish passing B1 turbine intakes, B2 turbine intakes (guided and unguided), and the B2CC. Describe horizontal distributions of passage at B1 sluiceway outlets and the spillway.

4. Analyze temporal and spatial variations in fish passage, FGE, and major passage metrics. Examples of temporal trends include average diel (hourly) trends in fish-passage rates within days and daily trends within seasons. Spatial trends include lateral distributions at B1, the spillway, 
and B2; lateral and vertical distributions at the B2CC; and lateral distributions across B1 sluiceway outlets above Intakes 1C, 3C, and 6C.

5. Compare results with those of previous hydroacoustic studies to identify effects of structural and operational changes through time and compare results of concurrent studies with other methods such as radio telemetry or fyke netting.

\subsubsection{Task 3: Smolt Approach Evaluation at B1 Sluiceway Outlet 3C}

The objectives were to:

1. Sample with a DIDSON mounted on a dual-axis rotator to acquire data on the swim paths of smolts approaching the B1 Sluiceway Outlet 3C during three consecutive 24-h periods in early, mid, and late spring and summer.

2. Process and analyze the data to qualitatively describe fish behavior, distributions, and the probability that smolts in various forebay locations will pass into the outlet (i.e., outlet efficiency as a function of smolt range upstream from the outlet). We compare the zone of influence and differences in the outlet efficiency of the B1 sluiceway sampled in 2005 with that of the B2CC sampled in 2004.

\subsection{Background}

The U.S. Army Corps of Engineers - Portland District is striving to meet the goal, set in the 2000 Biological Opinion on the Federal Columbia River Power System (NMFS 2000), of maximizing juvenile salmonid fish passage efficiency (FPE, the proportion of all fish passing the Project by non-turbine routes) and obtaining 95\% survival for juvenile salmon (Oncorhynchus spp.) passing Bonneville Dam.

Project FPE is the estimated proportion of all juvenile salmon passing the Project by non-turbine routes, but FPE also can be calculated for individual powerhouses (B1 and B2) or for either powerhouse plus the spillway. In all cases, FPE is estimated non-turbine passage divided by the total passage at the Project for a passage season. Non-turbine passage consists of the sum of passage through B1 sluiceway outlets, the spillway, the B2CC, and the B2 Juvenile Bypass System (JBS). The proportions of juvenile salmon that pass through all major passage routes must be estimated to calculate Project FPE, and that had been done at Bonneville Dam for the years 2000-2002 and 2004 by both fixed-aspect hydroacoustics (Ploskey et al. 2002b, 2002c, 2003, 2005) and radio telemetry (e.g., Evans et al. 2001 a-d and 2003 a and b). This document reports the results of the 2005 spring and summer hydroacoustic efforts.

In a typical water year, the goal of maximizing FPE largely determines the operation of the Project. Managers presume that large volumes of spill are necessary to compensate for the low fish guidance efficiency (FGE) of in-turbine screens, particularly in summer. In a typical year, spill volumes are limited to between 50,000 and $75,000 \mathrm{ft}^{3} / \mathrm{s}$ during the day and up to $120 \%$ of the "gas cap" at night. The gas cap was established to control total dissolved gas supersaturation, which is harmful to fish (NMFS 2000).

Within general guidelines, however, there is a great deal of variability among passage years. The two most obvious determinants of dam operations are water availability in the reservoir and the demand for hydropower generation. The drought of 2001 was an extreme case wherein discharge was only $48 \%$ of the ten-year average annual discharge from 1996-2005 (Figure 1.2), which, combined with very high generation demand, led to unusually low spill volumes over a curtailed spill season (Ploskey et al. 2002c). 
In 2001, the project spilled $16 \%$ of the total discharge in spring and $11 \%$ in summer, down from $31 \%$ and $50 \%$, respectively, in 2000 . Total spill volume was less than a quarter (23\%) in spring and less than an eighth (12\%) in summer of what it was in 2000, a much more normal water and generation year.

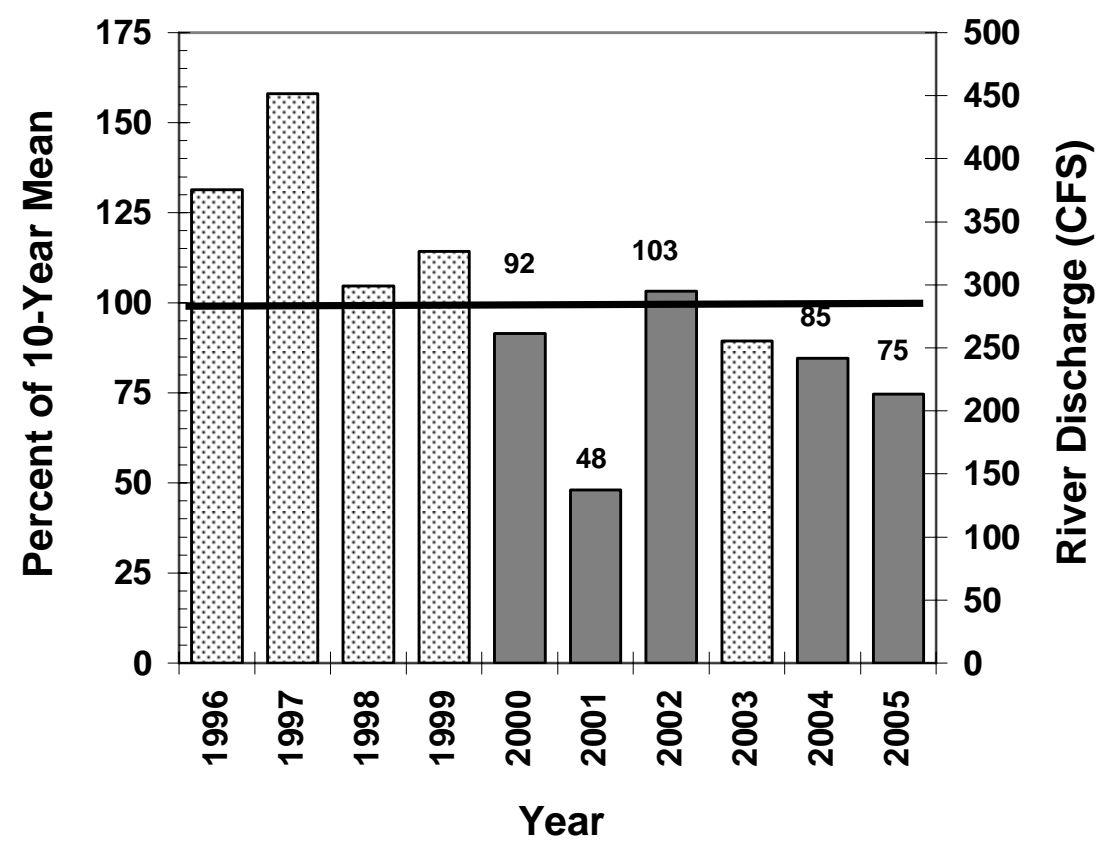

Figure 1.2. Columbia River Discharge (\% and CFS) from 1996 through 2005 during Spring and Summer Sampling with Fixed-Aspect Hydroacoustic Methods. Data are from the Dart Website (http://www.cbr.washington.edu/dart/). Gray bars with percent labels highlight years with enough sampling data to estimate fish-passage efficiency for the Project. The heavy black line at 100 percent indicates the 10-year-average.

Even without the complications of unusual water years and generation demand, conducting dam operations to enhance fish passage and survival is a complex affair. Spill under 50,000 $\mathrm{ft}^{3} / \mathrm{s}$ creates eddies and slack water areas in the spillway tailrace. High risk of predation is assumed in the tailrace when currents do not carry juvenile fish downstream quickly. Spill levels above 75,000 $\mathrm{ft}^{3} / \mathrm{s}$ during the day can lead to high numbers of adult salmon falling back through the spillway, as adults exit the Bradford Island fish ladder and follow the shoreline around to the spillway forebay. Adult salmon do not pass through the ladder at night, and therefore spill can be increased in an attempt to maximize FPE for a 24-hour period. However, spill above $120,000 \mathrm{ft}^{3} / \mathrm{s}$ typically causes total dissolved gas (TDG) levels to exceed $120 \%$ of saturation, which is the allowable maximum set by state water-quality standard waivers. Levels of TDG above this may increase fish mortality downstream of the dam.

In the 1980s and early 1990s, hydroacoustics was used on limited spatial and temporal scales to evaluate sampling potential or relative passage among a few routes. Thorne and Kuehl (1989) evaluated the effects of noise on hydroacoustic assessment of passage within several turbines at B1. Results showed that acoustic sampling is feasible at the units they tested. Magne et al. (1986, 1989), Magne (1987) and Stansell et al. (1990) made hydroacoustic estimates of FGE for turbine Units 11 and 17 and found that estimates were closer to netting estimates by the National Marine Fisheries Service when they sampled 
longer than just a few hours with hydroacoustic gear. These findings were later confirmed by Ploskey and Carlson (1999).

The Portland District's Fishery Field Unit attempted hydroacoustic sampling of juvenile salmon passing through several spillway gates in the mid 1980s. Transducers were mounted on the bottom of gates and aimed upward and upstream of vertical. Apparently, noise generated by sound echoing off vortices at some gates masked echoes from juvenile salmon and prevented equalized sampling efforts among gates. BioSonics tested several methods for sampling spillway passage in 1997 (BioSonics Incorporated 1998). Their best approach was to mount their transducers on piers and aim them down toward the ogee just upstream of the gates. BioSonics also designed a mount to deploy transducers and estimate passage through the B2 sluice chute. Transducers were placed at the bottom center of the upstream bulkhead slot and aimed upward vertically and slightly upstream of vertical.

The Portland District first acquired mobile hydroacoustic data on fish distributions in both powerhouse forebays in 1996 (Ploskey et al. 1998) and 1997 (BioSonics Incorporated 1998). For B1, these data indicated that high average fish densities occurred upstream of Units 4 through 6 in spring and upstream of Units 4 through 6 and 8 and 9 in summer. For B2, average fish densities were highest upstream of Units 11 through 13 (adjacent to the south eddy and sluice chute) in spring and in summer. Fish densities also were high upstream of Unit 18 in 1996 but not in 1997. Vertical distribution data usually showed that over $80 \%$ of the fish were in the upper $49 \mathrm{ft}$ of the water column. The low fish-guidance efficiency of many submerged traveling screens at the Project would not be expected from an examination of the vertical distribution data collected within $33 \mathrm{ft}$ of the dam. If fish did not alter their vertical distribution from what was observed in forebay areas, data from 1996 and 1997 would suggest that fish guidance efficiency usually would exceed $80 \%$. Data acquired from in-turbine sampling and using fixed uplooking transducers deployed on the bottom of the B2 forebay in 2000 indicated that FGE estimates were much lower than expected from vertical distributions in the forebay (Ploskey et al. 2002b).

Diel (24-hour) patterns of smolt passage are not uniform in either sluiceways (Uremovich et al. 1980; Willis and Uremovich 1981) or the JBS (Hawkes et al. 1991; Wood et al. 1994). Diel passage through the JBS often has a bimodal distribution with a major peak occurring just after dark and a minor peak after sunrise. In contrast, passage through sluiceways and other surface passage routes usually is higher during the day than at night (Willis and Uremovich 1981; Ploskey et al. 2001a; Ploskey et al. 2002a; Ploskey et al. 2003; Ploskey et al. 2005). However, patterns apparently are influenced by the operation of sluice gates (Uremovich et al. 1980), flow, unit outages, and species composition (Willis and Uremovich 1981). Netting required to estimate FGE is intensive but, because netting is limited to a few hours per day, it does not provide diel passage information. Diel patterns of fish passage above and below screens were estimated by hydroacoustics in spring and summer 1996 for randomly selected intakes of every turbine at B2 and every intake of Units 3 and 5 at B1 (Ploskey et al. 1998). Estimates also were made in the spring and summer of 1998, 2000, 2001, 2002, and 2004. These indicate that fish passage through turbines usually is higher at night than it is during the day (Ploskey et al. 2001a; Ploskey et al. 2002a; Ploskey et al. 2003; Ploskey et al. 2005), which is consistent with historical findings at Bonneville Dam and other projects in the Northwest (Thorne and Johnson 1993).

Available data indicate that the horizontal distribution of smolt passage among turbine intakes is not uniform. Much of the early FGE data collected at B2 with in-turbine hydroacoustics (e.g., Magne et al. 1989; Stansell et al. 1990) and netting (Gessel et al. 1988; Muir et al. 1989) are of limited value for 
evaluating the horizontal distribution of passage because they typically focused on one or two units at a time. However, project-wide FPE studies show wide variation in horizontal distributions whether sampling was by hydroacoustics (Ploskey et al. 2001a; Ploskey et al. 2002a; Ploskey et al. 2003; Ploskey et al. 2005) or radio telemetry (Evans et al. 2001a-d and 2003a, 2003b). Gatewell sampling has indicated that the number and location of operating units and sluice gates as well as the species of smolt determine lateral distributions of juvenile salmon at B1 (Willis and Uremovich 1981). Interactions among factors may account for a lack of consistency in measures of horizontal patterns by Uremovich et al. (1980), who found fish concentrated at Units 6, 7, and 10; Willis and Uremovich (1981), who found variable patterns depending on operations; and Krcma et al. (1982), who observed most fish passage at Units 4 through 6.

A new corner collector, at the south end of B2, was completed in time for operation in the 2004 passage seasons. It is on the site of and replaces the old B2 ice-and-trash sluiceway and its development as a surface-passage route has occurred over several years. Hydroacoustic sampling in 1996 (Ploskey et al. 1998), using both fixed and mobile hydroacoustics, found that Unit 11 had the highest passage of any intake sampled in that year. Ploskey et al. (1998) and BioSonics (1998) found high densities of fish upstream of Units 11-13 when they sampled with mobile hydroacoustics. Like the Fisheries Field Unit in previous years, BioSonics reported that large numbers of fish passed through the sluice chute when that route was available. However, it is not known what contribution the sluice chute or a corner collector could make to guidance at B2 or to project-wide FPE. Data from Ploskey et al. (1998) indicated that the combined FGE of Units 11, 12, and 13 was only 35\%. However, operation of the chute increased the combined FGE to $87 \%$ after sluice passage was added to the guided fish terms. This finding could be significant because 1996 mobile hydroacoustic sampling indicated that there was a 2:1 skew in the distribution of fish toward the south end of B2. In 2004, a fully functional B2CC, passed $13.4 \%$ of the Project fish in just $2.53 \%$ of the water in spring and $20.0 \%$ of the Project fish in just $2.44 \%$ of the water in summer. Effectiveness of the B2CC relative to the Project therefore was 5.3 in spring and 8.2 in summer. This means that the proportion of fish passed by the B2CC was 5.3 and 8.2 times higher than the proportion of water that it passed. Relative to fish passage at B2 alone, the B2CC passed 31.4\% of the fish in just $5.41 \%$ of the water in spring and $39.6 \%$ of the fish in $5.14 \%$ of the water in summer. Effectiveness of the B2CC relative to B2 was 5.8 in spring and 7.7 in summer. These levels of effectiveness are very high relative to spillway-passage effectiveness, which usually is near 1:1 each season.

An important factor contributing to successful fish passage in 1998 and 2004 was removal of one half of the TIEs at Units 11-14, which increased lateral flow toward the sluice chute. When in place, TIEs reduce lateral flows along the face of the powerhouse. In 2001, with B2 generation priority and TIEs in place, estimated fish passage was again skewed to the south and highest at Unit 11 in both spring and summer (Ploskey et al. 2002c), and similar trends were observed in 2002 (Ploskey et al. 2003). In the 2004 and 2005 passage seasons the TIEs were in place on intakes 15A and C, 16B, 17A and C, and 18B (alternating intakes of Units 15-18 starting with 15A), and there were no TIEs on any of the intakes of Units 11-14, comprising the south half of the powerhouse.

From 1998 through 2000, the Portland District evaluated two distinct smolt bypass approaches for B1, surface flow bypass and extended-length submersible bar screens. The year 2001 was scheduled for a decision on which complement of smolt passage devices to emphasize for long-term smolt protection 
at B1. The Corps prepared a special document, called the decision document, to analyze the relative merits of surface bypass and screens at B1.

Johnson and Carlson (2000) reviewed the research conducted on surface flow bypass from 1998 through 2000 in the Columbia-Snake River System. The goal of the surface flow bypass program was to develop and evaluate surface bypass and collection prototype concepts that would lead, if justified by prototype test results, to permanent systems for improving survival of juvenile salmon. In 1998, a prototype surface collector (PSC) was installed at Units 3-6 and was extensively studied (see Johnson and Giorgi 1999 for a review). In 1999, limited research occurred to prepare for tests in 2000. In 2000, the PSC was extended from Units 3-6 to also cover Units 1-2, because a noticeable number of radio tagged smolts were observed in 1998 to move obliquely from north to south along the face of the PSC (Hansel et al. 1999). A thorough evaluation of the PSC was conducted in 2000 as part of the Anadromous Fish Evaluation Program. The 2000 PSC evaluation emphasized forebay fish behavior as well as PSC performance, i.e., fish passage efficiency and effectiveness.

Of the five years of project-wide sampling, results for 2004 and 2005 should be the most comparable because of the consistency of sampling methods, river discharge, and dam operations in those years. After the first project-wide hydroacoustic FPE study in 2000 (Ploskey et al. 2002b), there were additional project FPE studies conducted in 2001, 2002, and 2004 (Ploskey et al. 2002c; Ploskey et al. 2003; Ploskey et al. 2005). Each study year had some unique characteristics. In 2000, the PSC was tested and B1 was prioritized for generation to support that study. In contrast, B1 had a lower priority for generation than B2 in all subsequent years. Hydroacoustic sampling for shallow B1 sluiceway entrances were not developed until 2002, so some of the differences in passage metrics before and after 2002 result from changes in sampling methods. The 2001 study occurred during a drought year in which spill was limited in duration and amount each season. While the drought provided unique opportunities to examine effect of very low spill and no spill, it also made difficult comparisons of metrics between 2001 and other years. Studies in 2002 and 2004 were conducted under closer-to-average water conditions and with comparable methods, but 2004 had an operational B2CC and 2002 did not. There was no hydroacoustics study at Bonneville Dam in 2003.

This hydroacoustic evaluation was conducted to complement a radio telemetry study because hydroacoustics samples the run at large, whereas telemetry only provides data on individuals of species and age classes that are chosen for study. Estimates of FPE can be made by radio telemetry, but only for tagged fish and under the assumption that tagged fish behave like untagged fish. Radio telemetry provides species-specific information, reservoir passage routes and rates, forebay delay times, and other insights that hydroacoustics cannot. However, radio telemetry cannot provide the robust horizontal and vertical distribution information for assessing changes in fish passage or for suggesting improvements in fish interception and passage structures or operations. Telemetry sample sizes sometimes may be too small when divided among 36 or more passage routes at a project. Hydroacoustic sampling not only provides overall measures of Project performance, but also can indicate where improvements can be made and what kind and how much of a change might be required. For example, continuous hydroacoustic sampling allows for regression of performance measures (such as spill efficiency) on continuous operations data such as spill volume. These types of regressions can suggest Project operations to optimize juvenile fish passage at a project. Provision of continuous fish-passage data on run-of-river fish is a unique strength of hydroacoustic sampling. 


\subsection{Overview of this Report}

Chapter 2 is a description of materials and methods. Chapter 3 provides results. Chapter 4 is discussion. Chapter 5 is recommendations. Chapter 6 is references. Appendix A describes transducer calibrations and receiver gains. Appendix B provides transducer locations and aiming angles. Appendix $\mathrm{C}$ is autotracker definitions and parameters. Appendix D is SAS code for filtering fish traces. Appendix $\mathrm{E}$ is sums and variances of fish passage in spring and summer and forebay elevations and route-specific discharges in spring and summer. These are provided as six large comma-separated-variable (.CSV) files on the compact disk (CD) that accompanies this final report. Appendix F is detectability modeling inputs and outputs. Appendix G is analysis of variance ANOVA on B2 Turbine Intake FGE. Appendix H is Audio Video Interleave (AVI) files of DIDSON-movie clips of the area upstream of B1 Sluiceway Outlet 3C (Appendix H). Those video clips show smolts approaching the outlet, predators feeding on smolts, and vortices that sometimes entrained approaching smolts into turbines. The CD also includes Adobe Acrobat Portable Document Files (PDF) of the entire report and appendices. 


\subsection{Materials and Methods}

\subsection{Equipment}

\subsubsection{Fixed-Aspect Hydroacoustics}

We deployed 62 fixed-aspect hydroacoustic transducers as part of 16 systems, each consisting of an echosounder, cables, transducers, an oscilloscope, and a computer to sample fish passage at 16 of $30 \mathrm{~B} 1$ turbine intakes, all three open B1 sluiceway outlets, all 18 spill bays, the B2CC outlet, and 8 of 24 B2 turbine intakes. Echosounders and computers were plugged into uninterruptible power supplies. An echosounder generates electric signals of specific frequency and amplitude and at the required pulse durations and repetition rates. Cables conduct those transmit signals from the echosounder to transducers and return data signals from the transducers to the echosounder. Transducers convert voltages into sound on transmission and sound into voltages after echoes return to the transducer. The oscilloscopes are used to display echo voltages and calibration tones as a function of time, and the computer system controls echosounder activity and records data to a hard disk. All 420-kHz, circular, single- or split-beam transducers were controlled by Precision Acoustic Systems (PAS) echosounders and Hydroacoustic Assessments' HARP180 software running on Pentium-class computers. All transducers were manufactured by PAS, except for the $420-\mathrm{kHz}$ circular single beams deployed at the spillway, which were made by BioSonics, Incorporated.

Eight of the 16 systems deployed in 2005 were made up of split-beam echosounders and transducers that provide $\mathrm{x}$ and $\mathrm{y}$ phase data from which we could estimate the location of echoes in the plane perpendicular to range from a transducer. With estimates of target location within the beam we could also estimate fish size, speed, and trajectory, all of which are important for detectability modeling to obtain deployment-specific expansion factors. At least one split-beam transducer was deployed in the same way as the many single-beam transducers deployed in the B1 and B2 turbines and at the spill bays. Singlebeam passage estimates for spill bays were multiplied by the estimated proportion of fish moving downstream through split-beams to adjust for the inability of single-beam systems to account for direction of travel. Details about these adjustments and associated variance adjustments are described below under Section 2.9.

Split-beam systems also were used to sample B1 sluiceway outlets $1 \mathrm{C}, 3 \mathrm{C}$, and $6 \mathrm{C}$ and the $\mathrm{B} 2 \mathrm{CC}$. Echosounders used to sample sluiceway outlets were modified to optimize the detectability of closely spaced fish by increasing bandwidth from 20 to $100 \mathrm{kHz}$ and transmitting shorter pulse widths (80 instead of $200 \mu \mathrm{s}$ ) to reduce the target resolution distance from 6 inches to about 2.36 inches. The direction of travel information was critical for adjusting estimates of fish passage into the B1 sluiceway outlets to exclude fish that were not moving into the outlet when they were detected. Visual observations at all three B1 sluiceway outlets indicated that smolts were not entrained until they passed over the downstream edge of the chain gates controlling flow. 


\subsubsection{DIDSON Sampling of the B1 Sluiceway Outlet 3C}

A DIDSON (Belcher et al. 1999) was used to record and later track movements of juvenile salmonids approaching the B1 Sluiceway Outlet 3C in spring and summer. We deployed a DIDSON from a barge upstream of the pier between Sluiceway Outlets 3B and 3C (Figure 2.1 and 2.2). The DIDSON was mounted on a rotator and aimed laterally so it could view the Sluiceway Outlet $3 \mathrm{C}$ and rotate to sample the approach of fish upstream of the outlet. In spring 2005, a DIDSON was leased from BAE Systems, Inc. while the Corps of Engineers' (CE) DIDSON was upgraded from a 12-volt system to a 24-volt system. The BAE DIDSON was replaced with the CE DIDSON for the summer season.

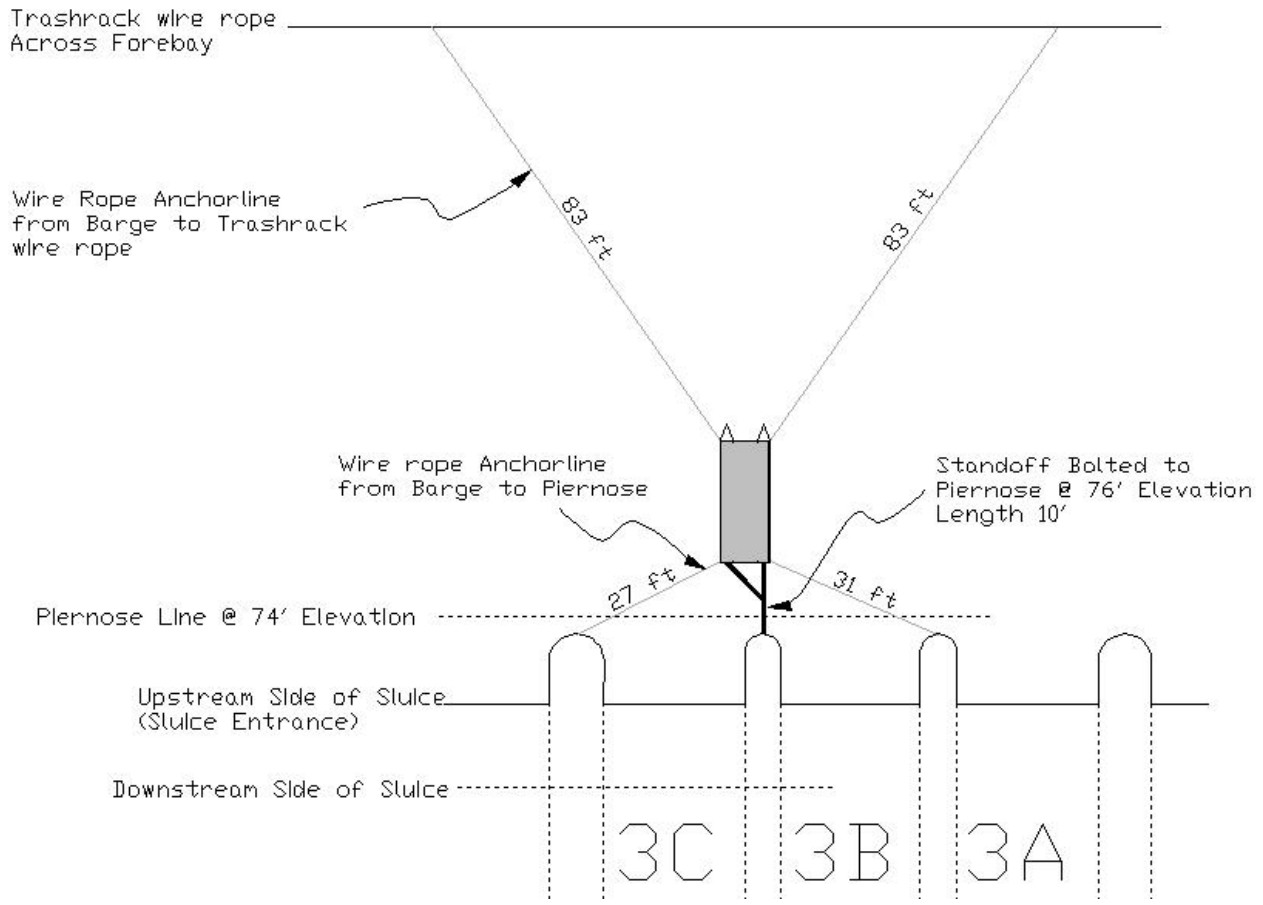

Figure 2.1. A CAD Drawing of the DIDSON Barge Deployment. This figure shows the location of the barge upstream of the pier and all attachment points for securing the barge in place.

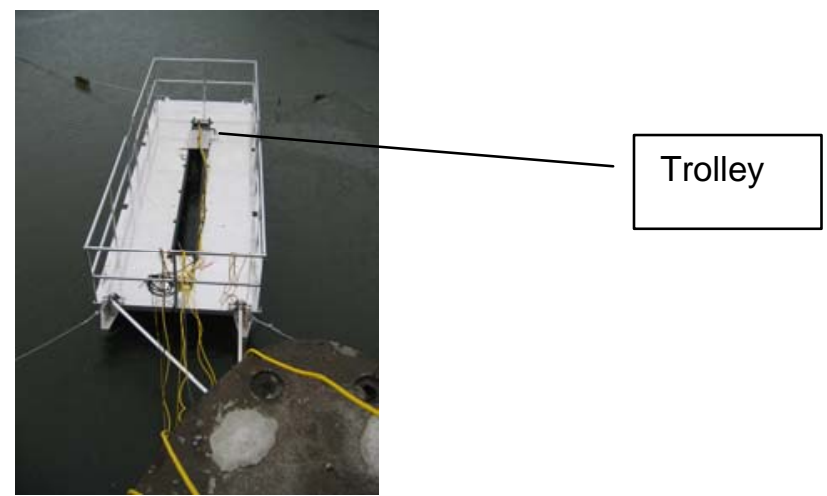

Figure 2.2. The Pontoon Barge from which the DIDSON was Deployed in 2005. The DIDSON was located about $5 \mathrm{ft}$ below the trolley labeled in the photograph. The cabling, suspended over the water connected the rotator to the controls in a waterproof deck box and connected the DIDSON to the computer in a trailer. 
The DIDSON was suspended on a rotator below a 8' x 25' aluminum pontoon barge. The barge included a trolley and rail system that was used to adjust the upstream/downstream position of the DIDSON at the time of installation. This was crucial for viewing the upstream edge of the sluiceway using high resolution DIDSON capture. The barge was anchored to the pier between slots 3B and 3C using a yshaped standoff (Figure 2.1). The standoff had pivot points at both ends so the DIDSON would remain at the same depth during the entire study period. The standoff also acted as the primary stabilizer to cancel large side-to-side and rotational movements. Additionally, the barge was anchored using $1 / 2$ " wire rope as a safety precaution and as a secondary stabilizer.

We used a two-piece device to pan and tilt the DIDSON, and it provided us with $360^{\circ}$ of pan and $90^{\circ}$ of tilt. The pan device was a 200RT series Rotary Table and the tilt device was an ET series linear actuator. Both were driven by SM series Brushless Servo Motors powered by Gemini GV Servo Drives and controlled by a 6K4 Motion Controller. All of these parts were built by Parker and supplied by Olympic Controls. The motion controller was connected to a computer by Ethernet cable, and we used Parker's Motion Controller software to build a sampling control program which was downloaded to the motion controller. We also used a 2-axis joystick built by Olympic Controls to provide manual control of the vertical and horizontal aim of the DIDSON. The joystick was connected directly to the motion controller using a serial cable. Olympic Controls supplied technical support on a variety of issues involving hardware and software. The rotator was attached to the underside of the trolley on the barge (Figure 2.3). We attached a disk with a 2" diameter, 3' long aluminum pipe welded off center to the rotary table. The DIDSON bracket was attached to the bottom end of the pipe with a bolt as a pivot. The actuator was attached to the disk also using a pin at the top as a pivot. A 1.5 foot long rod was attached to the bottom of the actuator and the top of the DIDSON bracket to provide tilt. The servo motor cables were run into a box on the deck of the powerhouse where they connected to the servo drives. The main power supply, servo drives, and the 6K4 Motion Controller were in the instrument box on the deck. Cables were then run from the motion controller to a trailer where they were hooked to the joystick and two computers.

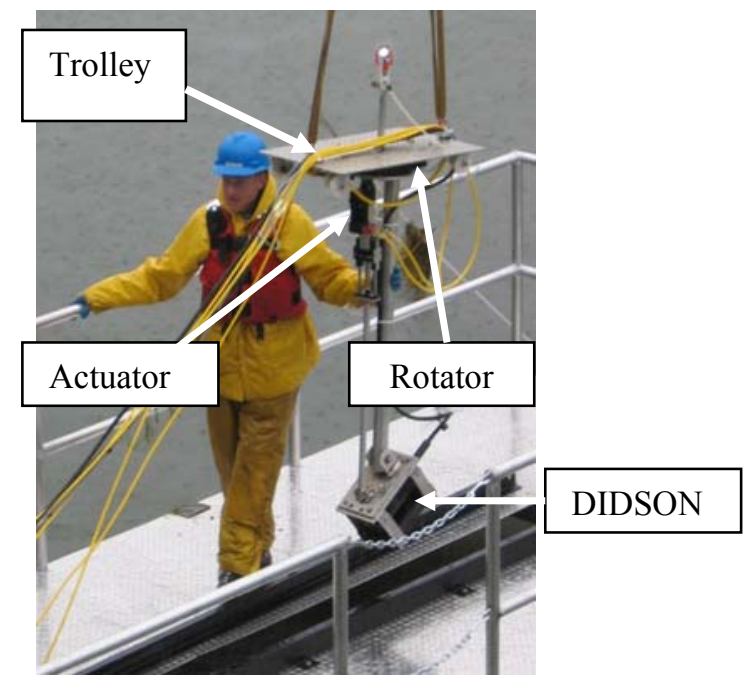

Figure 2.3. The DIDSON and Rotator Assembly. In this picture the assembly is attached to the trolley and is suspended from a crane as it is being lowered into place on the barge. 
Computer 1 ran the DIDSON software, which controlled the DIDSON and also recorded DIDSON data to a large hard drive. Computer 1 also was connected through a serial port to the $6 \mathrm{~K} 4$ Motion Controller. This line provided the position feed from the rotator and actuator. The motion controller sent an output to the DIDSON software every $\sec ^{-1000}$ in the form of a degree position. This was recorded with the DIDSON output files for positional processing of the fish tracks. Computer 2 ran the Motion Controller software, which was used to verify the rotator position data being fed into the DIDSON data stream on Computer 1. The flowchart in Figure 2.4 shows the system configuration.

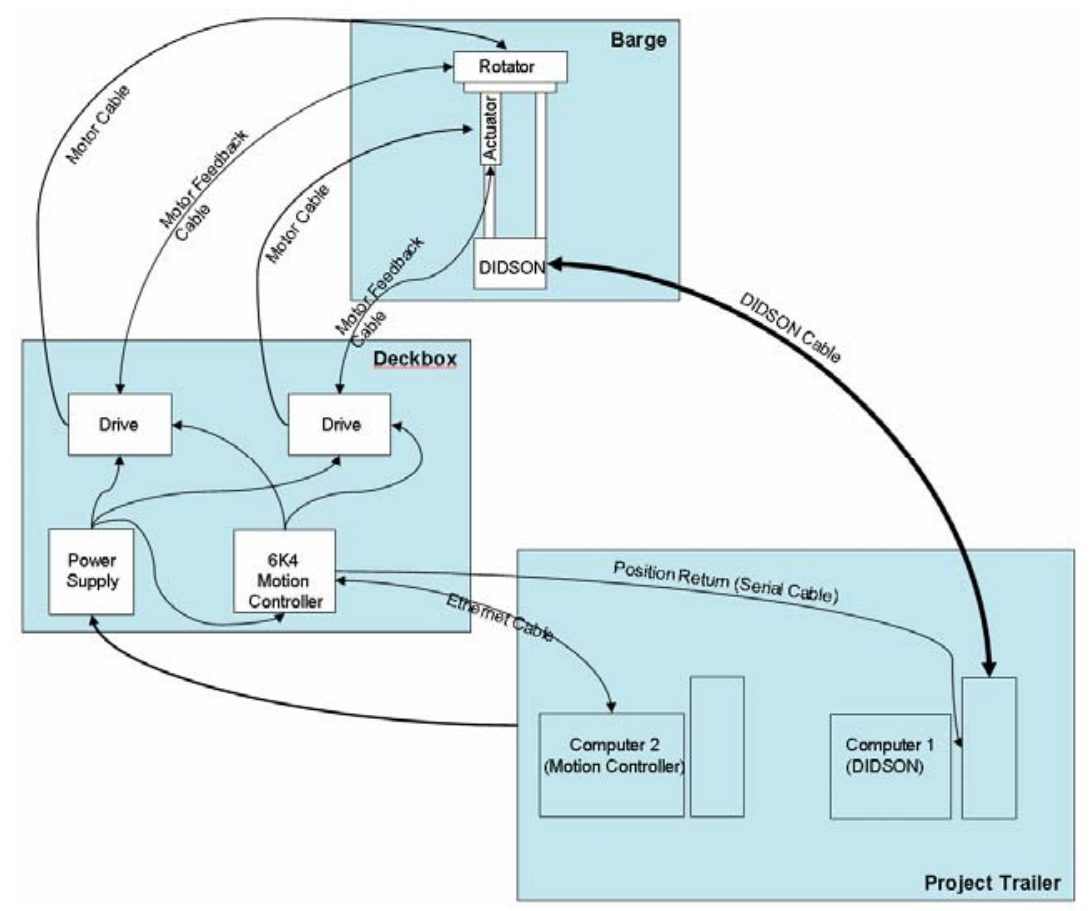

Figure 2.4. System Configuration Flowchart for DIDSON Motion Control and Data Acquisition

\subsection{Calibrations}

Before deployment, all single and split-beam hydroacoustic equipment was transported to Seattle, Washington, where PAS electronically checked and calibrated the echosounders and transducers using a standard transducer. After calibration, we calculated receiver gains to equalize the output voltages among transducers for on-axis targets ranging in hydroacoustic size from -56 to $-35 \mathrm{~dB} \| 4 \pi \mathrm{m}^{2}$ (Appendix A). Lengths of fish corresponding to that acoustic size range would be about 1.3 to 12 inches, respectively, for fish insonified within $21^{\circ}$ of dorsal aspect (Love 1977). Inputs for receiver-gain calculations included calibration data (i.e., echosounder source levels and $40 \mathrm{log}$ [range] receiver sensitivities for specific transducers and cable lengths) and acquisition equipment data and settings (installed cable lengths, maximum output voltage, and on-axis target strengths of the smallest and largest fish of interest). In most instances, calibrated and installed cable lengths were identical. When installed cable lengths differed from calibrated cable lengths because we had insufficient cable for a deployment, we used an empirically derived correction factor to compensate for cable-length effects on source levels, receiver sensitivity, and receiver gain settings. 


\subsection{Transducer Deployments and Sampling Schemes}

This section describes hydroacoustic and DIDSON deployments and sampling schemes. Technical details about transducer locations and aiming angles are presented in Appendix B. In 2005, all equipment was deployed in March and early April. The spring sampling season was from April 16 through May 31, 2005, and summer sampling was from June 1 through July 15, 2005.

\subsubsection{Sampling B1 Turbines}

In 2005, as in 2004, no in-turbine screens were deployed at B1, so we modified our B1 turbine deployments and sampling scheme from what was used in 2000, 2001, and 2002 when screens were present. From one to three intake slots per turbine unit were selected for monitoring, and spatial strata were assigned to estimate within-unit, among-intake variances in passage estimates (Table 2.1), as described under Section 2.8 (Estimating Fish Passage) below. We used most of the same sampling locations and mounting brackets that were used in 2004 to reduce the amount of welding required in 2005. Powerhouse 1 is composed of ten turbine units numbered 1-10, but Units 2 and 10 were offline throughout this study. Each turbine unit has three intake slots. Unit-hours were considered as temporal strata, with systematic sampling within each intake-hour. Split-beam transducers were installed in Unit 6, but the remaining locations used single-beam transducers. Hydroacoustic sampling was continuous, 24 hours per day, throughout the course of the study, except for 10 to 15 minutes per day when data were downloaded.

At each selected intake, a single downward-looking transducer was deployed to monitor fish passage. Transducers were mounted near the top on the downstream side of Trash Rack 1 and aimed downward to sample juvenile salmon passing down into the intake (Figure 2.5). In a preliminary study in fall of 2003, we determined that passage estimates for the near-ceiling volume of a single down-looking transducer and for another up-looking transducer (Figure 2.6) were correlated $\left(\mathrm{r}^{2}=0.79\right.$, see Figure 2.7). The correlation indicated to us that a single down-looking transducer would be adequate to estimate fish passage when an STS is not deployed at B1. The lateral location of each down-looking transducer within an intake was randomized among the north, center, and south sides. Every transducer at B1 transmitted at $25 \mathrm{pings} / \mathrm{s}$ to maximize detectability. One single-beam transceiver and computer was used to control seven transducers, so two transceivers were required to sample 14 intakes at the powerhouse.

Table 2.1. Units and Intake Slots that Were Offline or Randomly Selected for Sampling in 2005

\begin{tabular}{|c|c|c|}
\hline Unit & \multicolumn{1}{|c|}{ Intake Slots Sampled } & Spatial Strata \\
\hline \hline 1 & A, B & 1 \\
\hline 2 & Off-line & \\
\hline 3 & A, B, C & 2 \\
\hline 4 & A, B & 3 \\
\hline 5 & A, B & 4 \\
\hline 6 & A, B & 5 \\
\hline 7 & A, C & 6 \\
\hline 8 & C & 7 \\
\hline 9 & B & \\
\hline 10 & Off-line \\
\hline
\end{tabular}




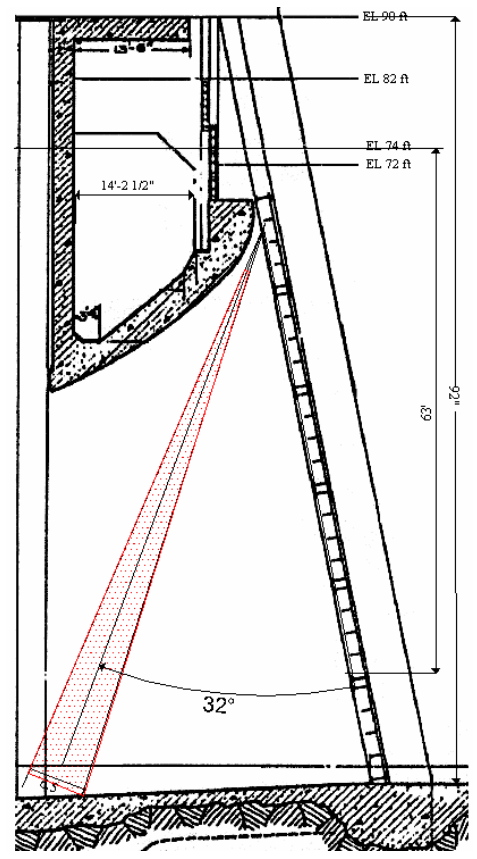

Figure 2.5. Cross-Sectional View through a B1 Turbine Intake Showing a Single Down-Looking Transducer Beam for Sampling Fish Passage through the Intake, when No STS Was Deployed. Flow into the intake is from right to left. Minimum and maximum ranges for tracking fish were 1 and about $22 \mathrm{~m}$, respectively.

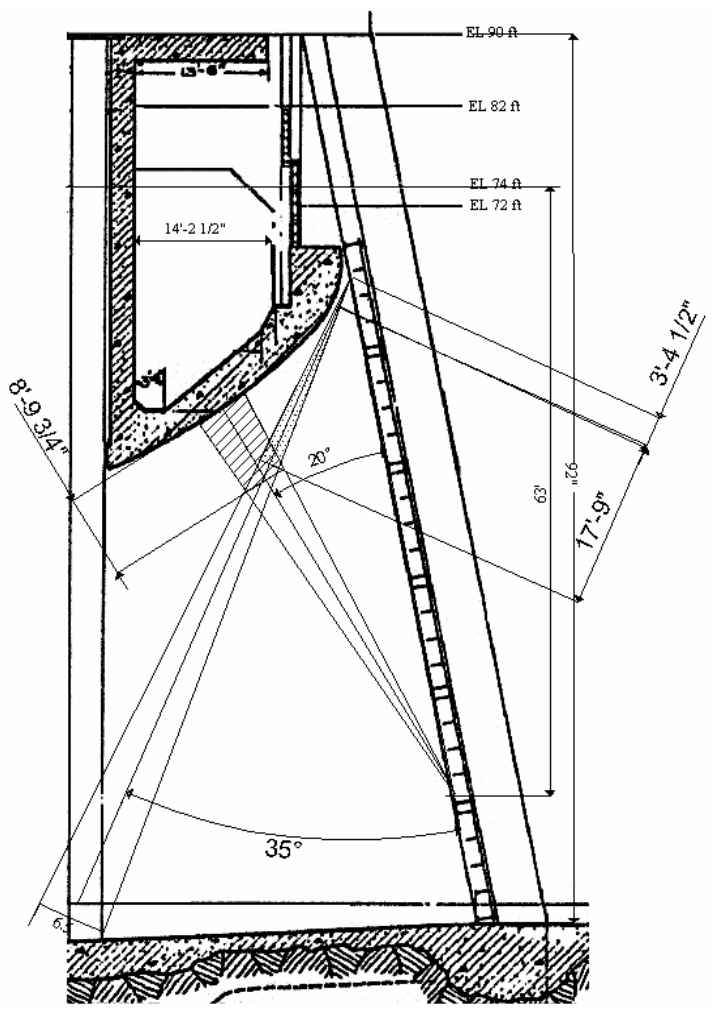

Figure 2.6. Cross-Sectional View through a B1 Turbine Intake Showing Near-Ceiling Volumes of a Single Down-Looking Transducer Beam Compared with that of an Up-Looking Transducer, from Preliminary Fall 2003 Study. Flow into the intake is from right to left. 


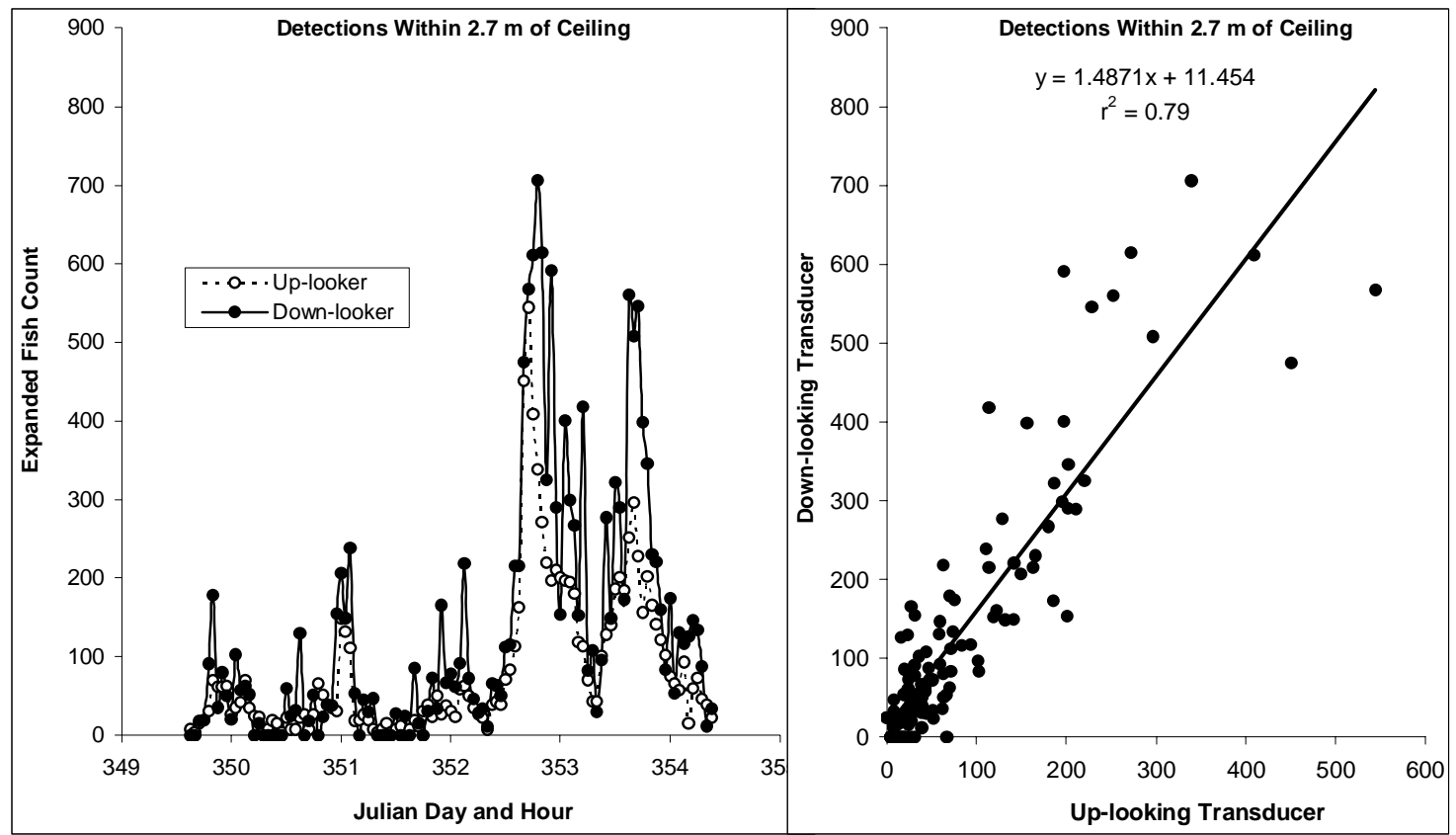

Figure 2.7. The Relationship between Hourly Estimates for the Same Intake Sampled by Up-Looking and Down-Looking Transducers. The left plot shows a time-history of expanded fish counts by Julian day and hour for the same near-ceiling volume sampled by up-looking and downlooking transducers, and the right plot shows a regression of down-looking transducer counts on up-looking transducer counts.

Acoustic counts for each intake sampled were expanded spatially using Equation 1 (see "Data Processing" below). These spatially expanded numbers of fish and within-hour variances for each of 81 minute periods per single-beam-transducer hour, or 20 1-minute periods per split-beam-transducer hour, were expanded to a full hour. Hourly passage per intake also was expanded to estimate passage for entire turbine units, as described below (see "Data Processing"). Hourly passage estimates and variances were summed to obtain daily and seasonal estimates.

\subsubsection{Sampling B1 Sluiceway Outlets}

\subsubsection{Fixed-Aspect Hydroacoustics}

At each sluiceway outlet above turbine intakes $1 \mathrm{C}, 3 \mathrm{C}$, and $6 \mathrm{C}$, two opposing 6-degree split-beam transducers were aimed across the outlet and sampled throughout spring and summer sampling seasons. One transducer was aimed toward the south and the other transducer was aimed toward the north (Figure 2.8), and only the distal half of each beam was used to count fish passing through one half of the outlet. The split-beams provided data on fish speed, trajectory, direction of movement, and target strength. Transducers were fast-multiplexed at 50 pings per second ( 25 pings / s each) and each outlet was sampled for 201 -minute intervals every hour. Echo traces from fish detected at ranges $>9.8 \mathrm{ft}$ from transducers were counted as passing if they met discharge-dependent slope criteria, were not eliminated by other filters described in Appendix D, and were moving downstream toward the outlet. Acoustic counts were expanded spatially using Equation 1 below, but opening height (water depth over the weir) was substituted for opening width so that expansion factors were based upon the ratio of the height of water passing over the chain gate to the diameter of the beam at the range of detection. Spatially 
expanded numbers in each of the 20 1-minute periods per transducer hour were expanded to a full hour, as was the within-hour variance. Hourly passage estimates and variances were summed to obtain daily and seasonal estimates. All fish passing into the sluice outlets were classified as guided fish for estimating B1 and Project FPE, and sluice-passage efficiency was equivalent to B1 FPE because inturbine screens were not deployed in 2005, and sluice passage was the only guided-fish fraction.

\subsubsection{DIDSON Sampling of B1 Sluiceway Outlet 3C}

The DIDSON and rotator device was adjusted in the upstream/downstream direction by moving the trolley on the barge so that the 12-m sample range would extend just past the chain gate in the sluiceway. The chain gate sat on a sill located approximately $6 \mathrm{ft}$ under the water's surface at normal pool elevation. We fixed the vertical axis so the DIDSON could see over the sill with the maximum beam volume and still not pick up too much surface noise produced by wind or rain. This resulted in a vertical axis return of $0^{\circ}$ during the entire sampling period. Due to the shallow configuration of the sluice outlet, we only needed to cover the top 2-3 $\mathrm{m}$ of water, and this was accomplished by sampling only one vertical zone.

The fan of 960.3 degree beams was oriented horizontally to successively sample each of six $30^{\circ}$-wide, $12^{\circ}$-deep volumes of water immediately below the water's surface for 10 minutes apiece (Figure 2.9). Sampling covered a $180^{\circ}$ arc from the pier nose between slot $3 \mathrm{~B}$ and $3 \mathrm{C}$, rotating to the north, and ending almost directly upstream of slot 3C. The sampled area covered all flow approaching Outlet 3C.

We sampled using the high-frequency mode at seven frames per second to increase resolution of smolt images entering the sluiceway outlet. We wanted to sample a minimum of three 3-day blocks each season. Equipment problems in spring precluded sampling before May 20, so we were forced to acquire all three sample blocks during one 10-day period near the end the spring season (Table 2.2). Sampling blocks were more evenly distributed in summer, and each block contained closer to 5 days of sampling instead of the proposed 3-day minimum (Table 2.2). The sampling routine was controlled by a program run through the $6 \mathrm{~K} 4$ Motion Controller. The program was set to sample each $30^{\circ}$ block for 10 minutes and then rotate to the next $30^{\circ}$ position. A complete sample pattern took 1 hour to complete.

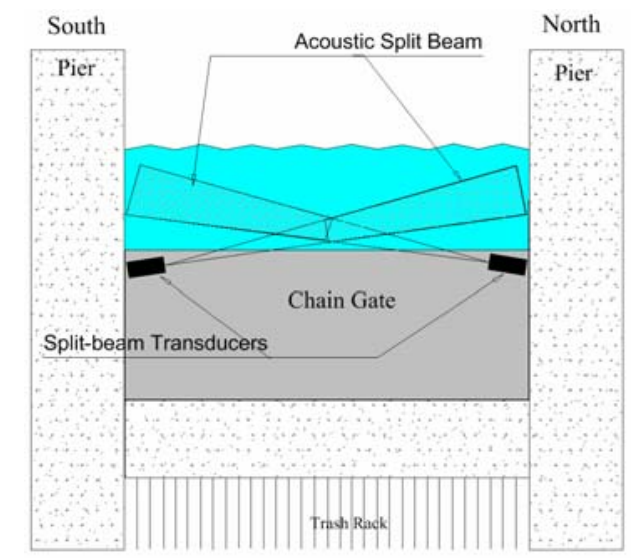

Figure 2.8. Forebay View of a Sluiceway Outlet at Intake 1C, 3C, or 6C in 2005 Showing the Deployment of Opposing Split-Beam Transducers for Sampling Fish Passage. The transducers were mounted $1 \mathrm{ft}$ below the top of the chain gate. The minimum range for sampling fish in each of the acoustic beams was about $3 \mathrm{~m}$ and the maximum range was the distance to the opposite pier (about $6 \mathrm{~m}$ ). Flow into the outlet is from the reader's location toward the page. 


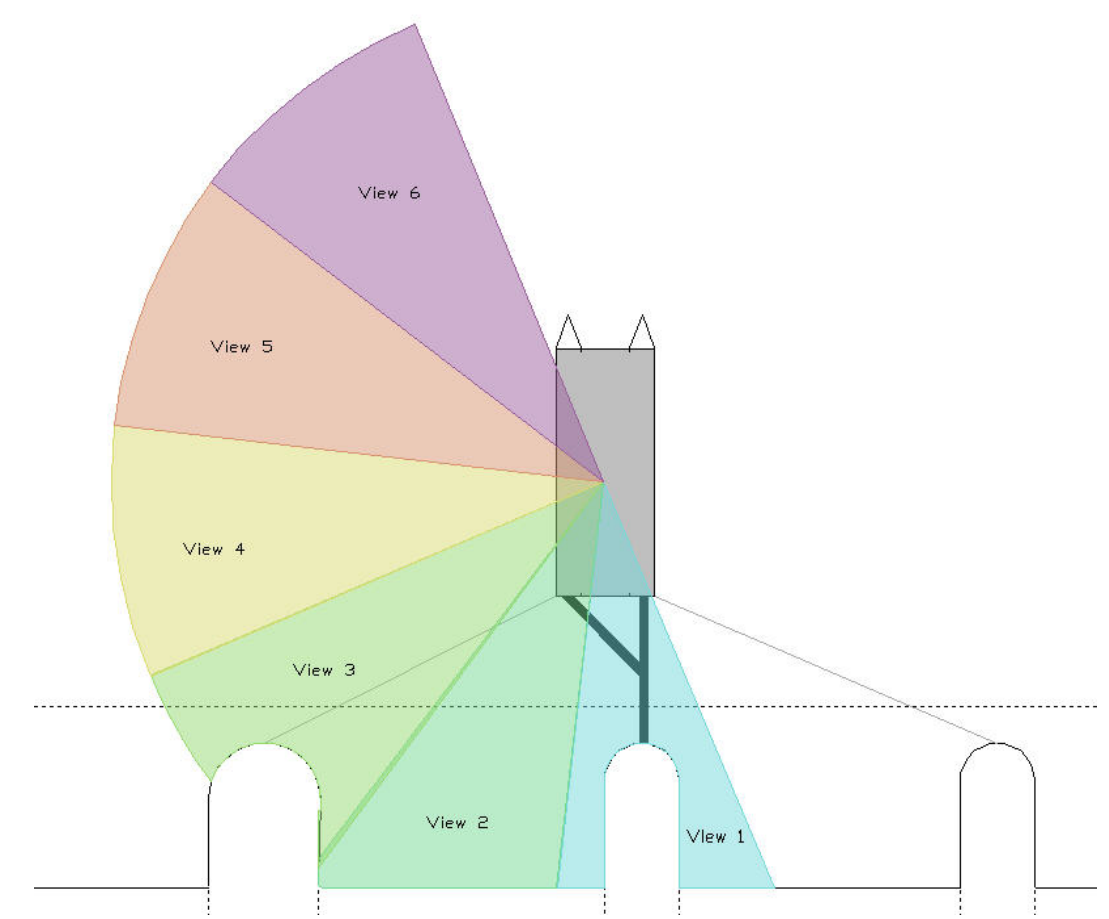

Figure 2.9. Diagram Showing Six $30^{\circ}$ Wide, $12^{\circ}$ Deep DIDSON Sample Volumes from a Plan View. Successive sample volumes were sampled sequentially for 10 minutes each.

Table 2.2. DIDSON Sampling Dates in Spring and Summer 2005

\begin{tabular}{||cccc||}
\hline Start Date & Start Time & End Date & End Time \\
\hline \hline \multicolumn{4}{c}{ Spring } \\
20-May & 1455 & 1-Jun & 0230 \\
10-Jun & 1812 & 15-Jun & 2240 \\
23-Jun & 0819 & 28-Jun & 0600 \\
5-Jul & 0919 & 10-Jul & 1820 \\
\hline
\end{tabular}

\subsubsection{Sampling the Spillway}

Each of the 18 spill bays was sampled with one transducer, and the lateral location of each transducer within a bay was randomly selected to be on the north, center, or south one-third of the bay so that some of the lateral variation in passage within bays would be captured in the variance estimate for the entire spillway. All transducers had a pulse repetition rate of 25 pings per second. Most transducers were $10^{\circ}$ single-beams, except for three $10^{\circ}$ split-beams on spill bays 5,7, and 17 . The split-beams provided data on fish speed, trajectory, direction of movement, and target strength. Transducers were mounted on spill 
gates and angled $9^{\circ}$ upstream from vertical so that the downstream edges of the beams were within about $4^{\circ}$ of spill gates (Figure 2.10). Transducers were at elevation (EL) $56.5 \mathrm{ft}$ when the gate was closed and at EL $69 \mathrm{ft}$ when the gate was opened $12.5 \mathrm{ft}$. Maximum ranges from the transducer to the ogee were about $32.8 \mathrm{ft}$ (nominal beam diameter $=5.8 \mathrm{ft}$ ) when a gate was closed and $45.6 \mathrm{ft}$ (nominal beam diameter $=8 \mathrm{ft}$ ) if a gate was raised up $12.5 \mathrm{ft}$ above the ogee. Echo traces from fish detected at ranges $>$ $16 \mathrm{ft}$ from the transducer were counted as passing if they met discharge-dependent slope criteria and were not eliminated by other filters described in Appendix D.

Hydroacoustic sampling was continuous, 24 hours per day, throughout the study, except for 10-15 minutes per day when data were downloaded. Spill bays 5, 7, and 17 with split-beam transducers were sampled for 20 1-minute periods dispersed throughout each hour, and the remaining spill bays with single-beam transducers were sampled for 1 minute at 5-minute intervals for 121 -minute periods per hour. Acoustic counts for each intake sampled were expanded spatially using Equation 1 (see Data Processing below), and spatially expanded numbers of fish and within-hour variances for each of 121 minute periods per single-beam-transducer hour or 201 -minute periods per split-beam-transducer hour were expanded to a full hour. Hourly passage estimates and variances were summed to obtain daily and seasonal estimates. The maximum discharge in 2005 was about 10,400 cfs.

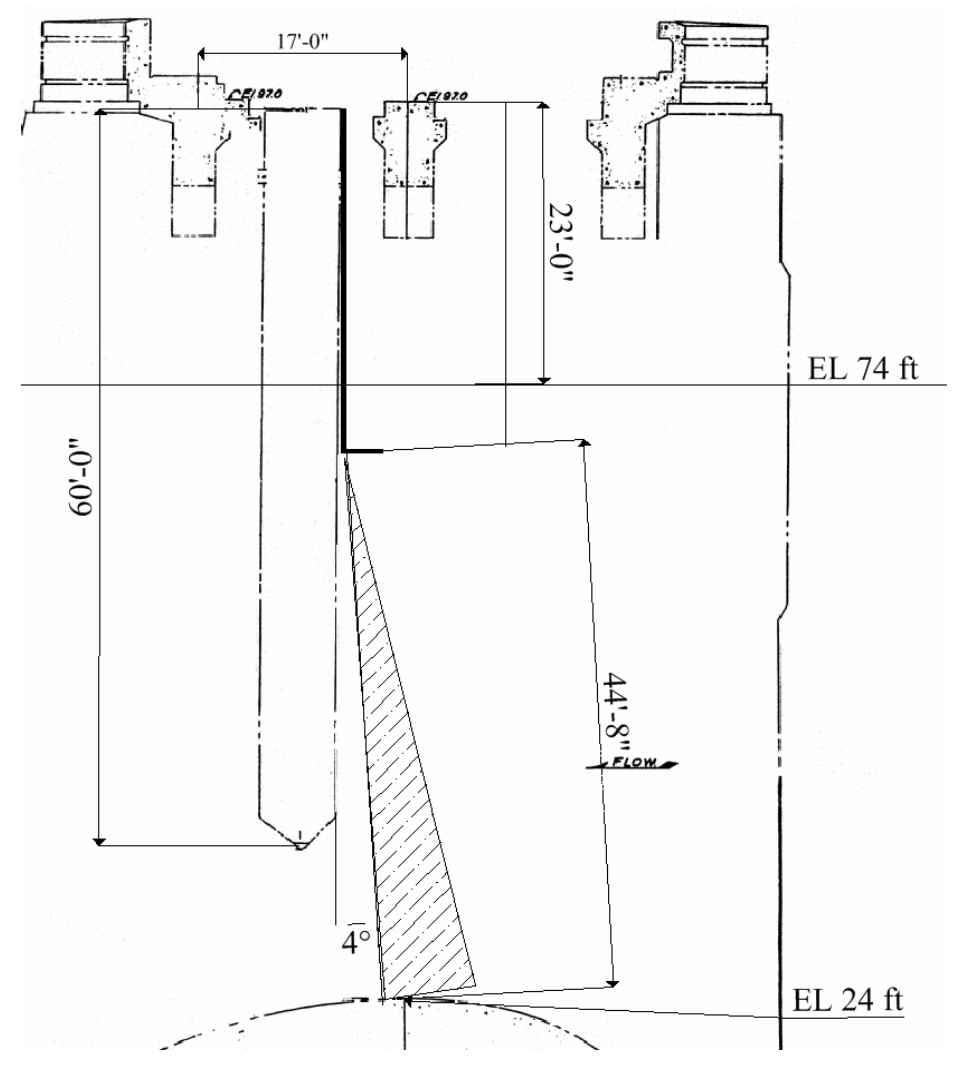

Figure 2.10. Cross-Sectional View through a Spill Bay at Bonneville Dam. The diagram shows a transducer mount on the upstream side of a spill gate and the orientation of the hydroacoustic beam upstream of the spill gate. The minimum range for sampling fish regardless of slope criteria was $5 \mathrm{~m}$ from the transducer, and the maximum range was at the concrete ogee. Flow under the gate is from right to left. 


\subsubsection{Sampling at B2}

\subsubsection{Hydroacoustic Sampling of Fish Passage}

We sampled smolt passage into the B2CC outlet and through all turbines at B2 in 2005.

\section{B2CC Sampling}

The B2CC outlet leads to a new sluice channel that was extensively modified in 2003 to transport water and fish down an ogee and out to the downstream tip of Cascades Island, as opposed to a 50-ft free fall onto a concrete surface, as was the case before modifications. The B2CC was operated 24-h per day throughout the spring and summer out-migration seasons in 2005.

We located six split-beam transducers on a vertical pipe about $15 \mathrm{ft}$ to the east of the B2CC outlet and acoustic beams were aimed across the outlet (Figure 2.11). Fish were detected mostly in side aspect, thereby maximizing signal-to-noise ratios and fish detection. The pipe supporting the vertical array of six transducers was rotated to aim acoustic beams about 12 to $15 \mathrm{ft}$ upstream of the immediate outlet where flows were sufficient to capture smolts ( 5 to $10 \mathrm{ft} / \mathrm{s}$ ) but low enough to allow adequate detectability (Figure 2.12). With a pulse repetition rate of 33 pings / s, a fish moving $8 \mathrm{ft} / \mathrm{s}$ through the center of an acoustic beam would provide about 7 echoes if it passed into the outlet on the south side and 13 echoes if it passed on the north side. Four echoes were the minimum required to classify an echo trace as a fish. The upper two split-beams had nominal 3-degree acoustic beams to minimize volume reverberation, which was worst near the surface. The lower four transducers had nominal 6-degree acoustic beams. Counts of detected fish were expanded by the ratio of the vertical dimension of a truncated trapezoidal area sampled by each acoustic beam to the diameter of the beam at the range of detection (Table 2.3).

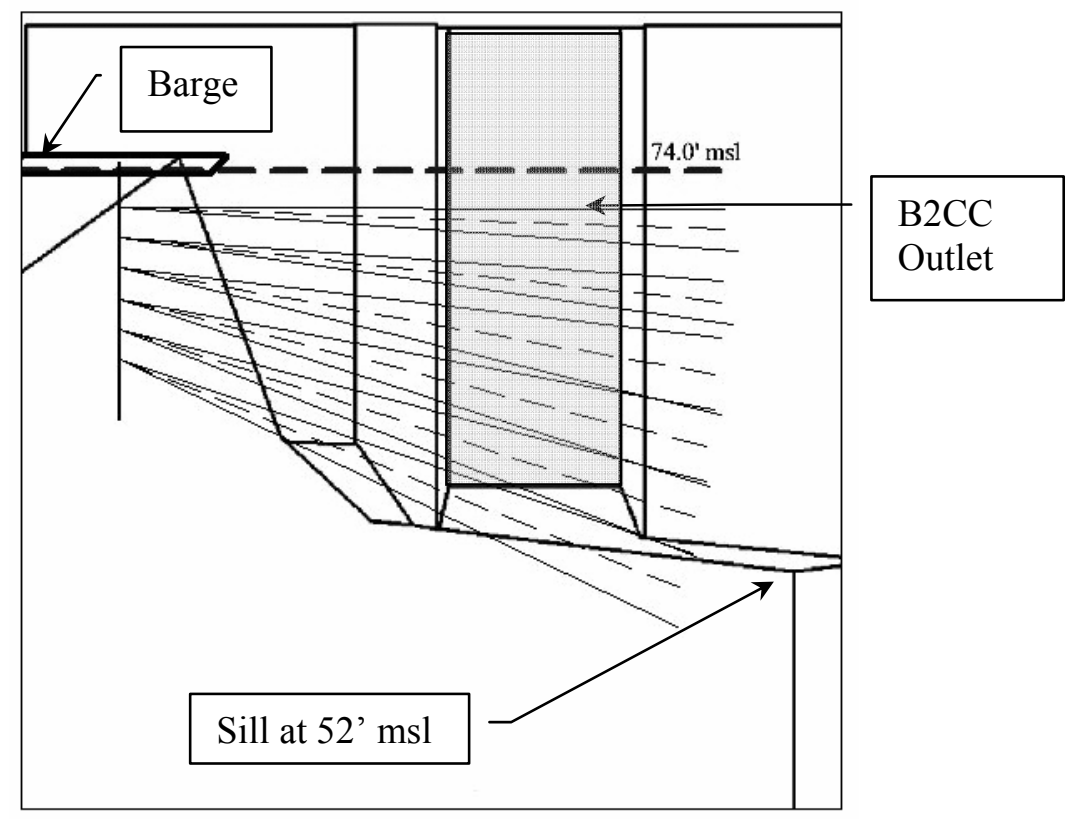

Figure 2.11. Diagram of a Frontal View of the B2CC Outlet Showing the Acoustic Beams from Six Split-Beam Transducers Deployed from a Barge East of the Outlet. Minimum and maximum ranges for tracking fish were 4.6 and about 9-12 ft (depending upon the beam), respectively. 

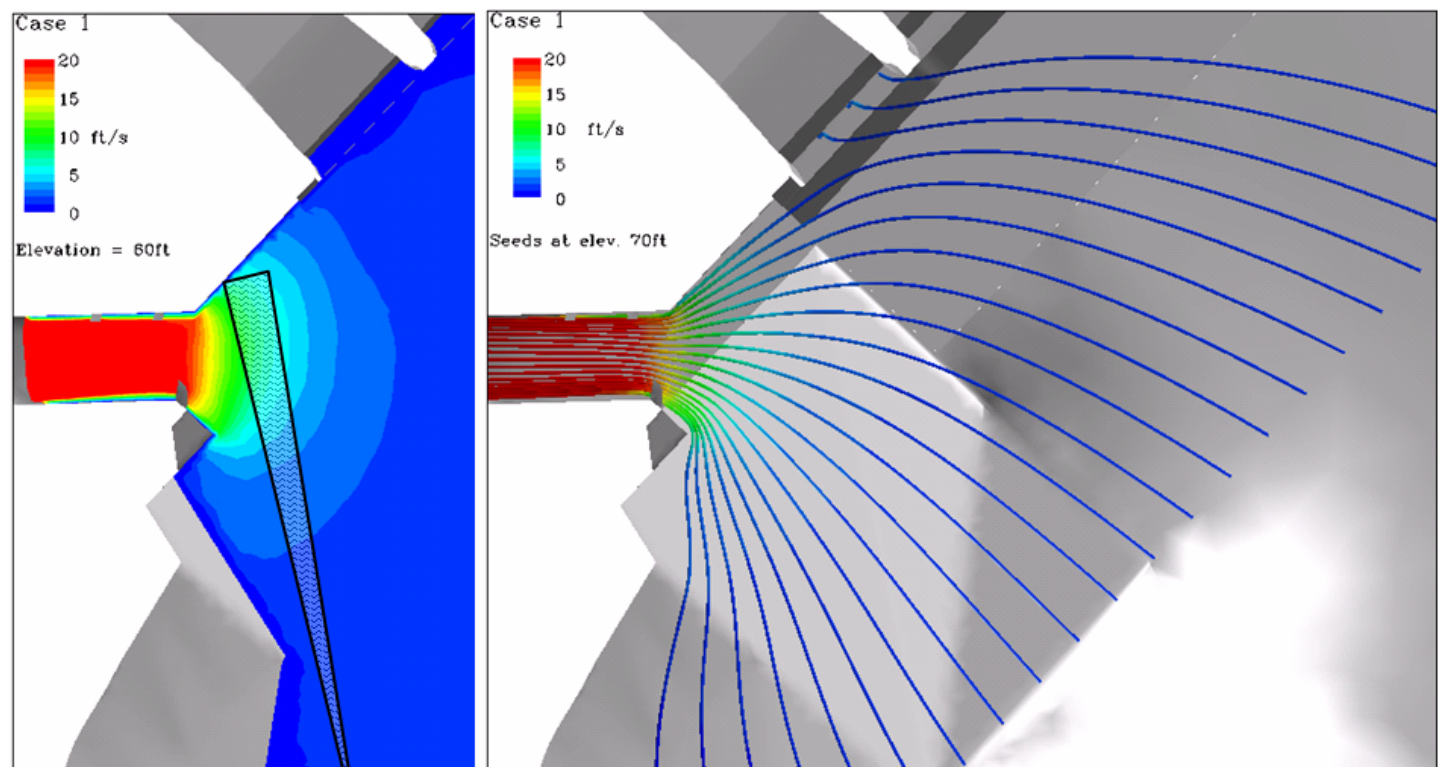

Figure 2.12. Plan Views of the B2CC Outlet Showing Predicted Water Velocities of 5 to $10 \mathrm{fps}$ in the Area that Split-Beam Transducers Sampled Fish Passage in 2005. The transducers were aimed across the outlet as indicated by the triangle in the left diagram. The left figure indicates velocity magnitudes and the right figure shows both magnitude and direction. The CFD runs were made by Cindy Rakowski and the figures were created by John Serkowski, both of PNNL.

Table 2.3. Statistical Analysis System (SAS) Code Used to Spatially Expand Detected Fish Based upon the Ratio of the Height of the Truncated Trapezoid Sampled to the Diameter of the Acoustic Beam at the Range of Detection. System U, V, and W refer to the echosounder and transducer combinations where $\mathrm{W}$ included $3^{\circ}$ transducers 1 and $2, \mathrm{~V}$ included $6^{\circ}$ transducers 3 and 4 , and $U$ included $6^{\circ}$ transducers 5 and 6 . Sample region height (SRH) was calculated from regression equations and expanded numbers of fish (EXP_FISH) were calculated from SRH divided by the tangent (TAN) of one half of the effective beam angle (ANGLE) times the mid-range (MID_RANGE) times two. All units are in m.

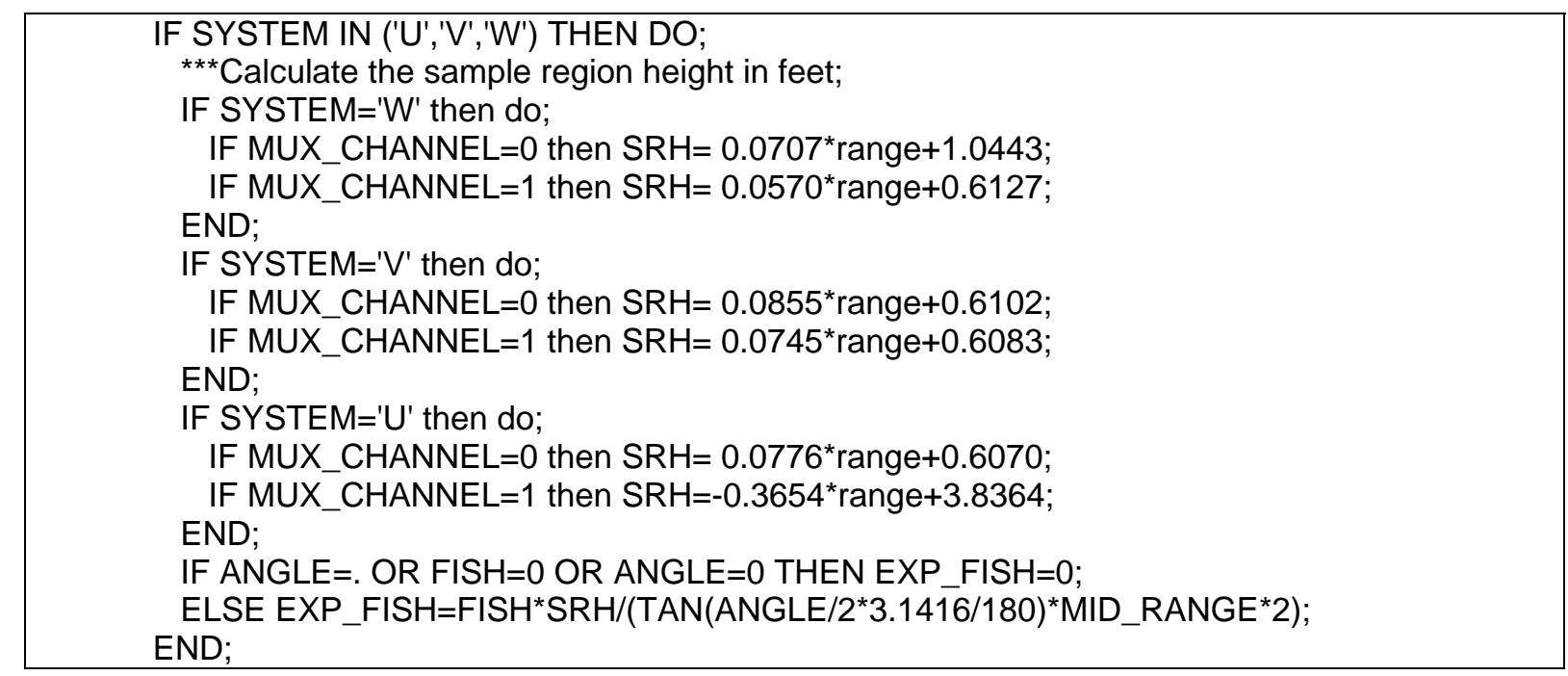


Each of the six transducers was sampled for 1 minute, 30 times per hour, and spatially expanded counts were temporally expanded to the whole hour $(\times 2)$. Hydroacoustic sampling was continuous, 24 hours per day, except for a 15-minute period each day when data were downloaded. Each transceiver interrogated only one of its two transducers at a time to maximize the pulse repetition rate at 33.3 pings / s. Transmissions from one transducer and transceiver from each of three transceivers were synchronized. Numbered from the top down, transducers 1,3, and 5 sampled simultaneously during odd numbered minutes, and transducers 2, 4, and 6 sampled simultaneously during even numbered minutes. Hence, arrays 1-3-5 and 2-4-6 each sampled approximately half of the corner collector outlet. We summed passage estimates from each of the areas sampled to obtain a total for the outlet, and hourly estimates were summed to estimate passage by day and season.

A problem with sampling sluiceway outlets is that fish densities can sometimes be so high that typical hydroacoustic gear with pulse widths of $200 \mu$ s cannot resolve all individual fish unless they are $\geq 6$ inches apart. We encountered this problem at a B1 sluiceway outlet in summer 2002 (Ploskey et al. 2003). Therefore, the split-beam transceivers used to sample the B2CC in 2004 and 2005 had their bandwidth increased from 20 to $100 \mathrm{kHz}$ and pulse widths shortened from 200 to $80 \mu$ s to reduce the target resolution distance from about 6 inches to about 2.36 inches, where resolution distance is the minimum range between resolvable targets.

\section{B2 Turbine Sampling}

One out of three intakes at every turbine unit was randomly selected for sampling, and spatial strata were assigned to estimate within-unit, among-intake variances in passage estimates (Table 2.4) as described under Estimating Fish Passage below. At every sampled intake, a pair of transducers was mounted on the downstream sides of trash racks 1 and 4 (Figure 2.13). One transducer of each pair was mounted at the bottom of the uppermost trash rack (Trash Rack 1) and aimed downward to sample unguided fish passing below the tip of the traveling screen. The second transducer of each pair was mounted at the middle of the fourth trash rack (Trash Rack 4) from the top and aimed upward to sample guided fish passing above the tip of the screen. The location of transducers within intakes also was randomized among the north, center, and south. A pair of split-beam transducers was deployed in Intake 16 to obtain fish velocity, trajectory, and target strength data for modeling detectability.

Table 2.4. Intake Slots Randomly Selected for Sampling at B2 during the 2005 Study

\begin{tabular}{|c|c|c|}
\hline Unit & \multicolumn{1}{|c|}{ Intake Slots Sampled } & Spatial Strata \\
\hline 11 & A & \multirow{2}{*}{1} \\
\hline 12 & C & \multirow{2}{*}{2} \\
\hline 13 & B & \multirow{2}{*}{3} \\
\hline 14 & B & \\
\hline 15 & B & \multirow{2}{*}{4} \\
\hline 16 & B \\
\hline 17 & A & \\
\hline 18 & B \\
\hline
\end{tabular}




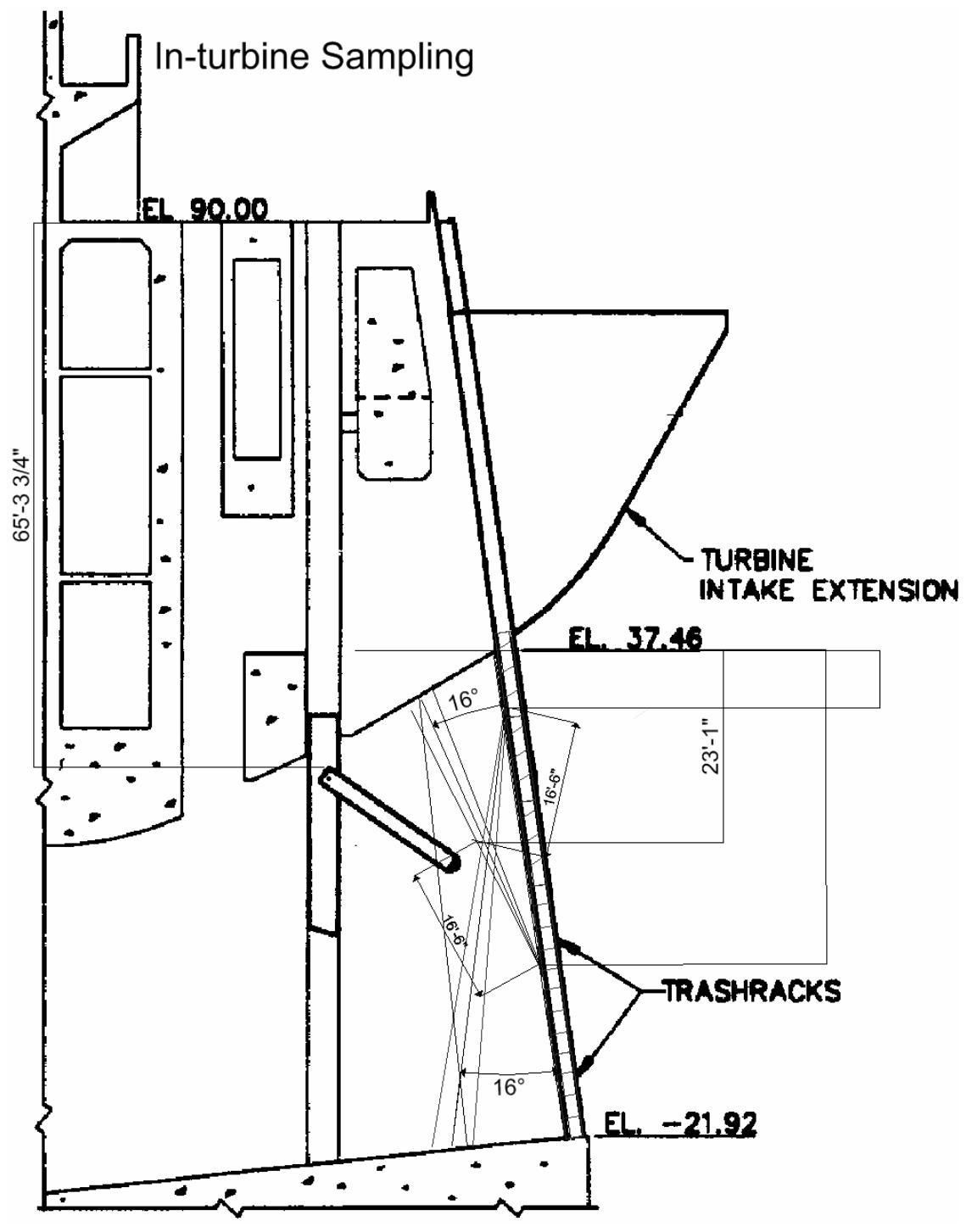

Figure 2.13. Cross-Sectional View through a B2 Turbine Showing Up- and Down-Looking Transducer Beams. The minimum range for sampling guided and unguided fish was $5 \mathrm{~m}$ in both cases. Flow into the intake is from right to left.

Throughout the study, hydroacoustic sampling was continuous for 24 hours per day, except for a 10-15 minute period per system to download data. Single-beam transducers were sampled for 15 1-minute intervals per hour depending upon the number of transducers on the system. The split-beam transducer was sampled for 201 -minute intervals per hour. Transducers on each system were sampled sequentially for 1 minute each to allow a high transmit rate of 23 pings / second. Therefore, up-looking and downlooking transducers sampled different minutes within the hour. For each sampled intake, counts of echo traces deemed to represent fish were expanded spatially using Equation 1 (see Data Processing below). Spatially expanded numbers of fish and within-hour variances for each of the 10 or 151 -minute periods per single-beam-transducer hour or 201 -minute periods per split-beam-transducer hour were expanded to a full hour. Hourly passage estimates and variances were summed to obtain daily and seasonal estimates. 


\subsection{Fish Tracking and Filtering Criteria}

\subsubsection{Fixed Aspect Hydroacoustic Sampling}

We used autotracking software developed from 1998 through 2002 by the Corps of Engineers and PNNL to process raw data into tracked-fish observations. As in prior years, the hydroacoustic sampling effort for Bonneville Dam in 2005 was so extensive that it was not practical or cost-effective to manually process all of the data required to make reliable fish-passage estimates.

The autotracker software tells the processing computer to:

1. Identify and remove echoes whenever more than $7.5 \%$ of pings detect structure at a constant range.

2. Find seed echoes for candidate tracks.

Go to every echo.

Define a 10-ping by 1-m window centered on that echo.

Place all echoes in the window into 5-degree angle bins.

If any bin-count is $>3$, flag the center echo as a candidate seed.

3. Re-examine candidate seed echoes.

Go to every seed-echo window.

Count echoes in all possible line features (Hough transform).

If no echoes in the window are part of a strong line feature then drop the seed echo (to distinguish between dense noise and dense fish tracks).

4. Initiate alpha-beta tracking.

Track forward, starting at each seed echo.

Track backward from the same seed echo after forward tracking has ended.

Check the track segment against criteria (echo density; minimum and maximum gap).

5. Link collinear track segments into single tracks. This involves projecting the first track segment forward and the second segment backward and linking them into one track if the ping gap $\leq 20$ pings and the two segments line up and meet a track link criteria.

6. Write out track statistics (echo statistics optional).

We describe and present autotracker parameters and the settings used to process the 2005 data in Appendix C. During most of spring and early summer, we reviewed samples of the autotracker's performance for every deployment on a fish-by-fish basis to evaluate and fine-tune the autotracker and to develop post-processing filters for eliminating false traces from the autotracker's output. We released the autotracker to process data for a given deployment only after we determined that it was missing few of the echo patterns that we would have tracked manually.

In Appendix D, we describe filter criteria and present the SAS code used to reject non-fish traces that the autotracker selected. In another part of the processing program, we eliminated fish detected at ranges less than $1 \mathrm{~m}$ for B1 turbines (Figure 2.5), $3 \mathrm{~m}$ for B1 sluiceway outlets (Figure 2.8), $5 \mathrm{~m}$ for spill bays (Figure 2.10), $4.57 \mathrm{~m}$ for the B2CC outlet (Figure 2.11), and $5 \mathrm{~m}$ for B2 turbines, both guided and unguided (Figure 2.13). Filtering non-fish traces based upon variables like range, slope, and noise level is a critical part of using autotracking software, because the autotracker is more likely to track an 
intermittent series of structural echoes or noise than are technicians. Filters were designed to eliminate echo traces that had a high probability of being from structure, noise, or large non-target fish based upon their track statistics.

Although the autotracker was a very efficient tool, we evaluated its performance and post-processing filters in both seasons by comparing counts of fish by the software and by trained technicians. We did extensive training and testing on raw hydroacoustic data from previous years and from early 2005 data before the 2005 tracking season began. In previous years (Ploskey et al. 2001a-c and 2002a-c), we found that there are important and consistent differences that occur among different human trackers of hydroacoustic data and that these differences, if not carefully controlled, can seriously bias counts used either for passage estimates or for quality control and assurance of automatic tracking. For that reason, we always compare our automatically tracked estimates with the average estimate from more than one human tracker. We selected from five to about 50 samples (mean $\approx 10$ ) from each of 62 transducers for manual tracking based upon percentile estimates of numbers of tracked fish per sample in spring 2005 autotracking results. This approach usually provided a wide and an even spread of points from near zero to the maximum observed. Raw echogram data were tracked by humans and the autotracker, and the resulting data were filtered and expanded identically. Each tracker's output, whether from a human or from the autotracker, was processed with a channel-specific software "filter" that automatically rejects traces that do not meet specific criteria. Output files from each human or automatic tracker were post processed identically. Post-processing included deployment-specific "filtering" for trace length, trace slope, echo or target strength, structure, and other regular noise, and other characteristics described in Appendix D. The resulting filtered fish counts on each day were then summed separately to produce the hourly passage estimates for the appropriate passage route.

We used linear regression to compare human and autotracked counts for each of the transducer channels. A transducer-channel-level analysis is essential because there are important differences in passage characteristics, ranges of interest, trace slopes and lengths, and noise conditions for each transducer's site and aiming angle. Comparing at the system level, which involves several transducer channels with different deployments, could mask error by pooling and thereby obscuring offsetting errors for different channels within a system (Ploskey et al. 2002c). Up-looking transducer channels sampling guided fish have very different noise regimes from those of down-looking-transducer channels and the slopes of regression lines fitted to autotracker and mean human counts often differ too. They can even vary in opposite directions, so that up-looking-transducer channels have higher autotracked counts and downlooking transducer channels have higher human-tracked counts. In those cases, comparing at the system level would mask some of the disagreement between the humans and the autotracker. Even with the same aiming (such as all of the down-looking channels at a powerhouse), different channels have different noise, clutter, and range of interest characteristics.

\subsubsection{Tracking of Fish Approaching B1 Sluiceway Outlet 3C}

Autotracking software developed by William Nagy of the Fisheries Field Unit, Portland District, was used to extract fish tracks and rotator pan and tilt data from raw DIDSON files so that successive fish positions could be placed in 3D real-world coordinates and overlaid on a computational fluid dynamics (CFD) grid. In the 2004 approach-and-fate study at the B2CC (Ploskey et al. 2005), we used manual processing software to track fish in DIDSON images. This process was very slow and tedious. With manual tracking, a technician used a mouse to draw a box around fish images in successive frames to spatially and temporally define a fish track. Some fish were tracked for over 100 frames, so repeated 
mouse selection of images in frames was time consuming. In addition, technicians had to reprocess frames to track multiple individual fish in a series because only one fish per frame could be tracked at a time. When schools of fish were encountered, the entire school was tracked as a single entity and the number of fish in the school was estimated. It took at least 30 minutes to manually track a 10-minute DIDSON file. In contrast, the automated tracking software processed a 10-minute DIDSON file in about 10 minutes. All fish within a DIDSON image could be tracked simultaneously, and schools were separated into individual fish. The autotracker also eliminated biases associated with having many different technicians manually process the data.

The autotracking program was designed to batch process groups of DIDSON files. The program extracted fish tracks using standard image processing algorithms and an alpha-beta tracking method. Fish track data was output as a text file containing descriptive information about each fish track including DIDSON orientation (pan and tilt angles), position in the DIDSON image (range and beam), size of target (number of pixels), and amplitude of the target. A second autotracking program was developed that also output the DIDSON data file as a video showing the fish tracks as they were being processed (Figure 2.14). These videos were used to verify that the autotracking program was performing well and also as an aid in developing filters to remove non-smolt targets that were tracked. Filters were developed to remove false tracks created when the rotator was panning to move the DIDSON to a different orientation. The data was also filtered to remove structure that was tracked as a fish. Targets with high mean amplitude or many pixels were removed to eliminate targets that were too large to be smolts.

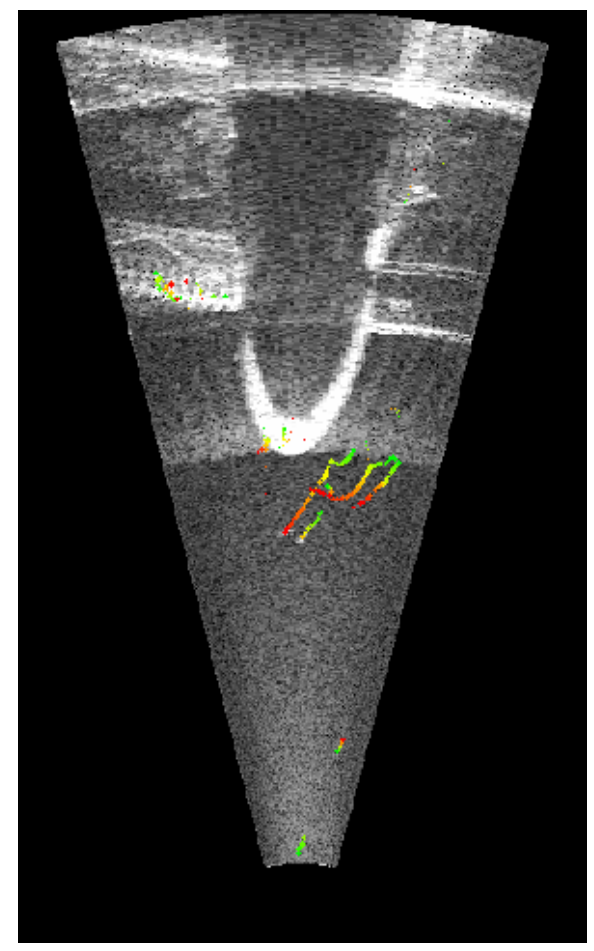

Figure 2.14. One Frame from the DIDSON Autotracker Showing Fish Tracks Being Acquired. The frame shows tracks that met the tracking criteria of the alpha-beta tracker. The color of the track shows the direction of travel of the fish from first detection (green) to last detection (red). 


\subsubsection{Coordinate Systems for Fish Approach and Fate Analysis}

The DIDSON tracking system data collected in front of the Sluiceway Outlet $3 \mathrm{C}$ at B1 were divided in two groups, "Spring" and "Summer," based on a date division of June 1 at 0230 hours for the end of Spring. Sunrise and sunset were used to differentiate day from night. SAS was used to filter tracks considered to be false from these text files using feedback from Amtec Engineering's Tecplot software viewer. The autotracker file format was slightly modified in this process but contained essentially the same information. Four text datasets of filtered fish tracks for 2005 were output, one each for "Spring Day," "Spring Night," "Summer Day," and "Summer Night."

Several steps were made after obtaining the tracked fish files and prior to Markov chain analysis. These included conversion to fixed coordinate systems, fish track visualization, separation into season and daynight datasets, and selection of the volumes to analyze. The process of aligning the relative tracked fish data to fixed coordinates consisted of applying pan angle corrections, river elevation corrections, and rotations and translations to the coordinate system. "Oregon State Plane North Zone" (OSPN) was used for three-dimensional visualization and Markov chain analysis. The OSPN coordinate system was approximately $66.6^{\circ}$ rotated from the $\mathrm{B} 1$ orientation. The DIDSON was located at different elevations based on forebay elevation and was located $3 \mathrm{ft}$ below river water elevation. The DIDSON $x$ - and $y$ position was assumed constant with Easting 1630362.599 and Northing 722686.1252 OSPN feet. River elevations were entered in a computer file "BONN2005elevation.txt" for input to the program converting tracked fish coordinates.

Sunrise and sunset were used to differentiate day from night and input as "NBsunset.txt". Times were based on a table found at the website http://aa.usno.navy.mil/data/ of the Astronomical Applications

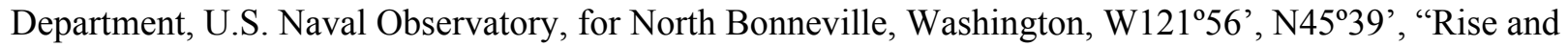
Set for the Sun for 2005."

B1 powerhouse flows varied over the course of the study. Further conditions of "Flow" and No Flow" were delineated at a powerhouse flow of $7.5 \mathrm{ft}^{3} / \mathrm{s}$, from data collected in five-minute intervals and averaged for each hour during the study at B1 (Figure 2.15). Flow of $7.5 \mathrm{ft}^{3} / \mathrm{s}$ was used to separate "Flow" from "No Flow" because at this discharge only one of the ten turbine units at B1 could be operating, and at a discharge below $7.5 \mathrm{ft}^{3} / \mathrm{s}$ that one unit would be shutting down.

Output files were named "*.SPL" for Oregon State Plane North coordinates and "*.DAT" for Tecplot visualization in OSPN coordinates.

The position of a detected fish $(X, Y)$, its range $(R)$, and the tilt angle $\theta=6^{\circ}$ down from horizontal, relative to the DIDSON, was calculated for each detection where a single $X, Y, Z$ tracked fish position was computed as

$$
(X, Y \cos (\theta), R \sin (\theta))
$$

This position was corrected by applying river elevation and pan angle corrections, and rotation and translation into positions in the OSPN coordinate system. Rotations of $8^{\circ}$ and $66.6^{\circ}$ were used for orientation of the DIDSON and the dam with respect to OSPN (Figure 2.16). 


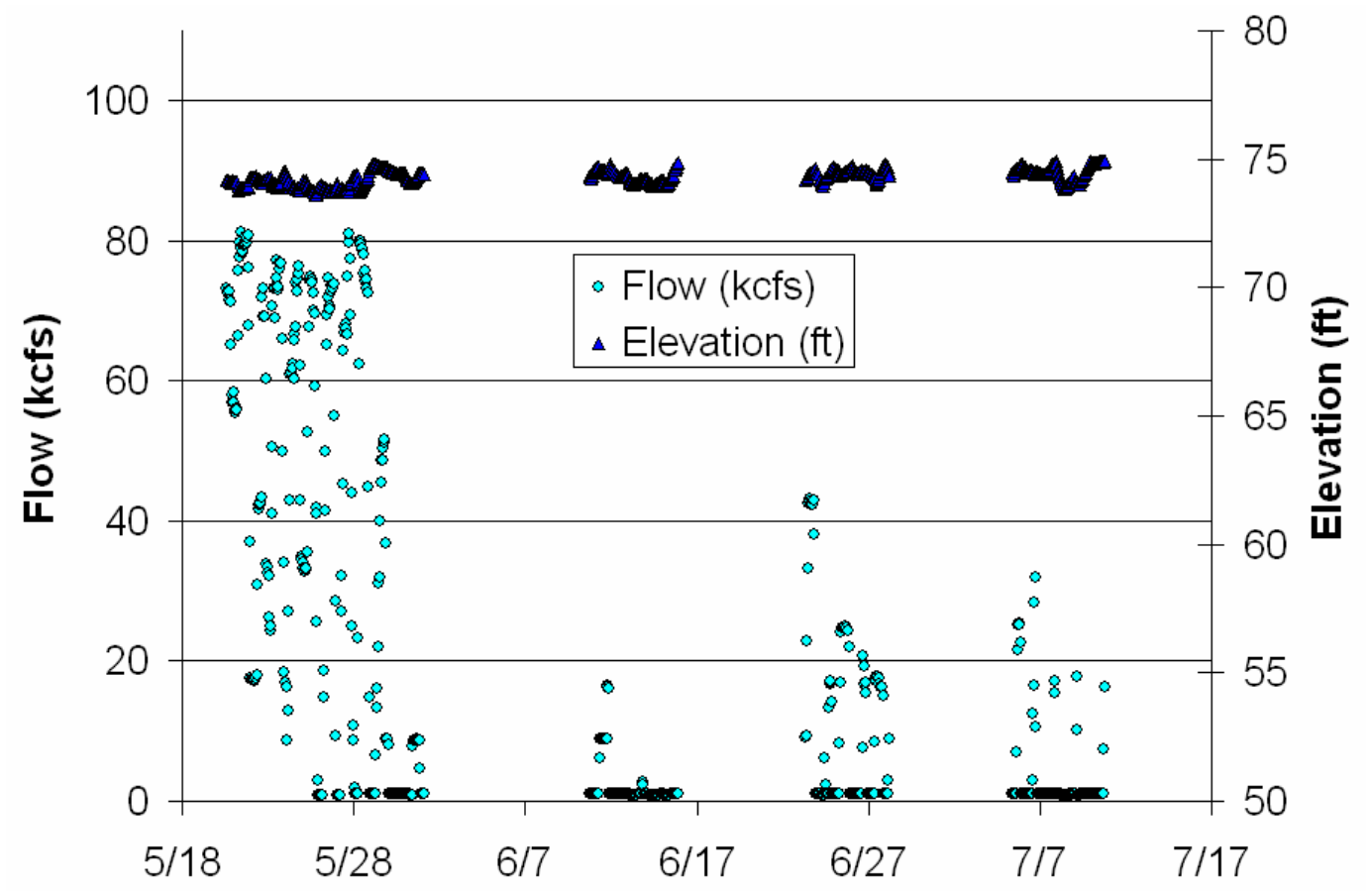

Figure 2.15. B1 Powerhouse Discharge and Forebay Elevations from Operations Data used to Separate Output Groups and make Pan Angle Corrections to the DIDSON at the Sluiceway Outlet 3C.

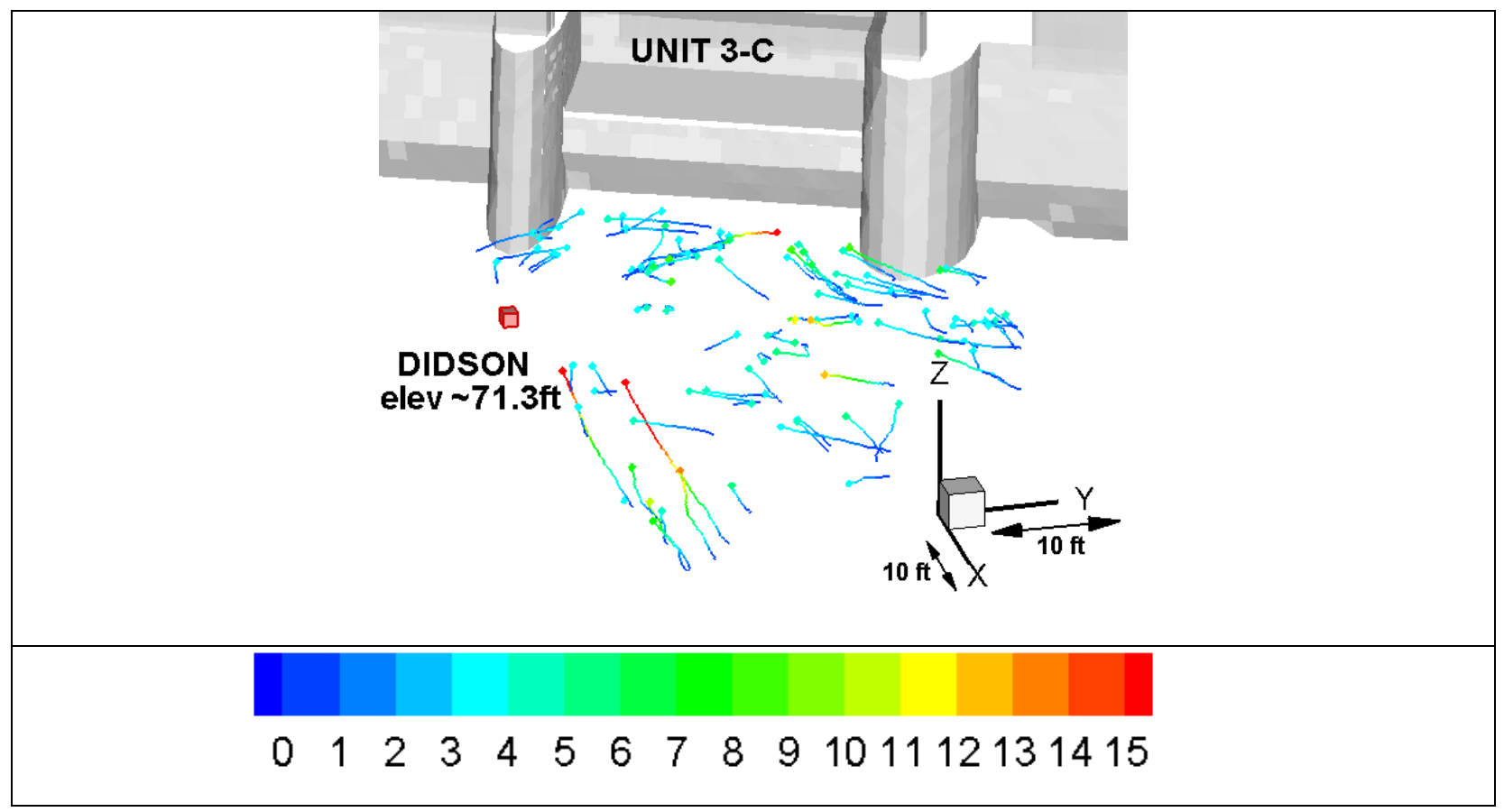

Figure 2.16. The Sample Volume X, Y, Z Coordinates were Aligned to the Oregon State Plane North Coordinate System. 100 fish tracks appear in the figure colorized by time in track (red oldest) sampled from "Summer Night Flow." Colored "heads" symbolize ends of fish tracks. 


\subsubsection{Estimating Fate Probabilities for Fish Approaching Sluiceway Outlet 3C}

\subsubsection{Overview}

We applied a Markov Chain analysis to estimate probabilities of fish approaching and entering Sluiceway Outlet 3C. The Markov Chain analysis is described below.

\subsubsection{Markov Chain Volume}

The Markov-Chain methods used to analyze fish movement were similar to those used at Bonneville Dam (Ploskey et al. 2005) and at The Dalles Dam (Johnson et al. 2004, Johnson et al. 2005). An absorbing Markov chain (Kemeny and Snell 1960) was used to capture fish movement to a particular location where fish were entrained. A Markov chain can model transition movement probabilities based upon continuous movement in a continuous volume when discrete time steps are chosen and volumetric cells of a sample volume are delineated. We used a Markov chain to analyze data on fish movements (Figure 2.17) collected with the DIDSON. The resulting Markov chain model allowed us to estimate fish movement probabilities from a given cell within the sample volume to each absorbing cell.

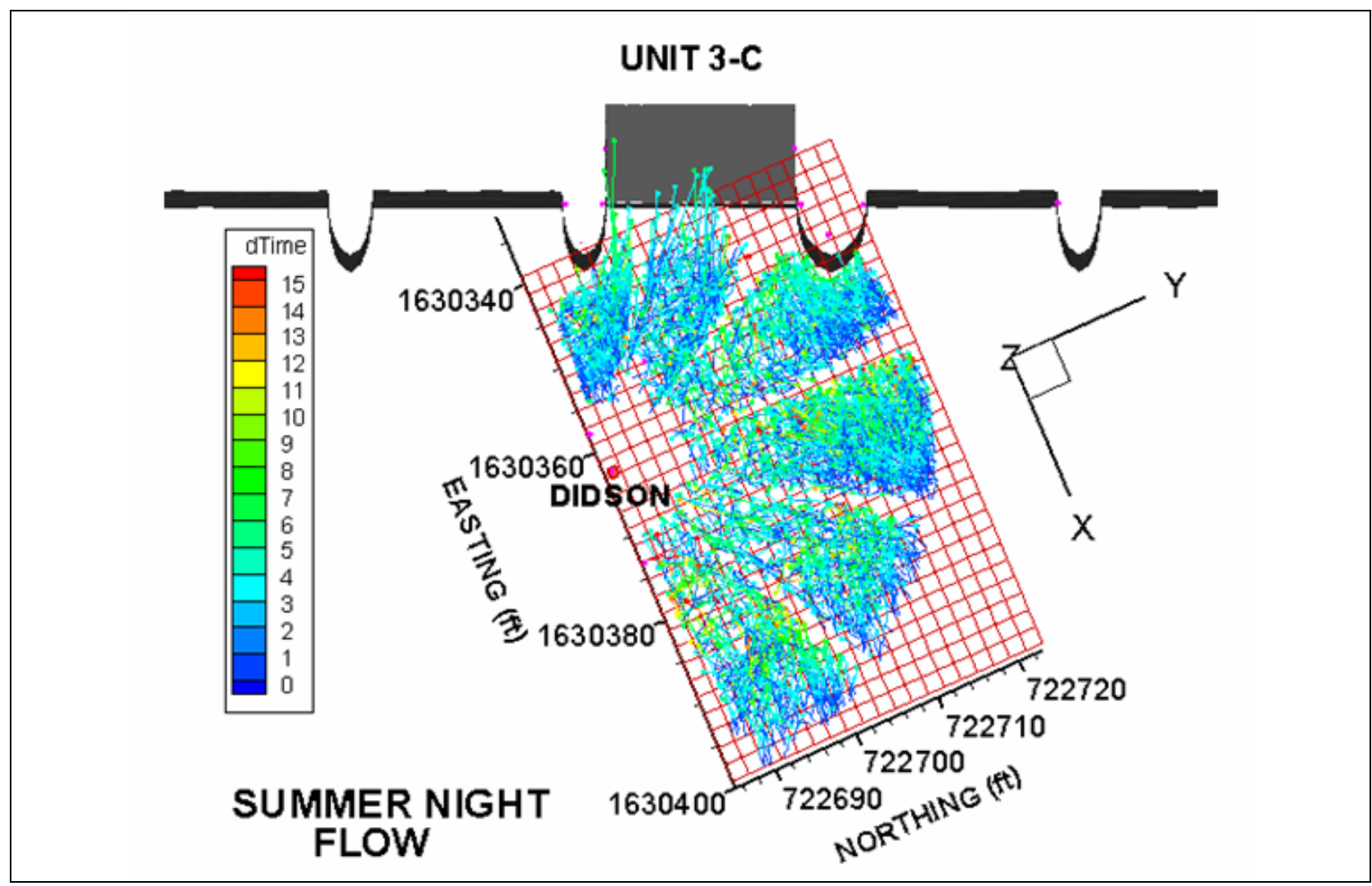

Figure 2.17. Sample Volume Referenced to Oregon State Plane North Coordinate System. Fish tracks collected in Summer Night 2005 with powerhouse flow $>7.5 \mathrm{kcfs}$. The $\mathrm{x}$ - (Easting) and y(Northing) scales are in feet. "dTime" is the time from the start of each fish track in seconds. Colored "heads" symbolize ends of fish tracks. Filled rectangle at top indicates dam sluiceway opening. 
The sample volume coordinate system (Figure 2.17) was defined as follows:

The $x$-dimension was rotated $66.6^{\circ}$ from the long-axis of the dam and parallel to the east-west direction with east movement in the positive $x$-dimension; $y$-dimension was parallel to the north-south direction with north movement in the positive $y$-dimension; $z$-dimension was vertically in the water column with movement upward in the positive $z$-dimension.

The sample area was rectangular (Figure 2.18), and $66 \mathrm{ft}(20.1 \mathrm{~m})$ across in the x-direction by $38 \mathrm{ft}(11.6$ $\mathrm{m})$ in the y-direction. Depth was ignored but would have ranged from near the water's surface to about 8 $\mathrm{ft}$ deep at maximum range. The model's sample volume included the entire volume sampled by the DIDSON. It was partitioned into 6272 -ft square cells so that the entire volume was 33 cells in the $x$ dimension, 19 cells in the $y$-dimension, and 1 cell deep in the $z$-dimension (627 total cells and states, including absorption states). We formed states (Kemeny and Snell 1960) for the Markov chain that corresponded to the location of each volumetric cell (Figure 2.18).

Markov absorbing states (Kemeny and Snell 1960), called "Fates" here, were assigned on edges of the volume. In addition, movement was not allowed through the surface or bottom. Fates were calculated as probabilities of absorption into cells at a particular portion or combination of edges of the sample volume as either moving into the B1 3C sluiceway outlet (Sluiceway) or moving away from the sluiceway (Other -- Figure 2.18). Movements to a boundary were observed; otherwise the fate would be called "Stagnation." Movement fates to the faces of the sample volume are simply probabilities for movements to a face from a position within the sample volume. Absorption cells further than one layer away from the absorption cell first encountered were not needed by the Markov chain process but are included for pragmatic purposes in the $\mathrm{C}$-language program used to calculate fates. The first layer of absorption cells surrounding the non-absorbing cells was placed to include fish movement termination. The placement of this layer differed between Spring, Summer, Night and Day due to operational considerations (e.g., DIDSON start range in Spring was $3.0 \mathrm{~m}$ and in Summer was $2.25 \mathrm{~m}$ ). There were 321 non-absorbing cells in Spring Day and Summer Day, 294 non-absorbing cells in Spring Night, and 297 non-absorbing cells in Summer Night. Although the number of functional absorption cells differed between conditions (for example in Summer Night there were 96 functional absorption cells) there were consistently 18 that were associated with the Sluiceway fate.

\subsubsection{Markov Chain Analysis}

To determine fate probabilities, we applied a Markov chain analysis (Karlin 1968), which described smolt movement as a stochastic process. A stochastic model does not imply that the fish movements are a random process of to and fro motions. Where a deterministic model describes movements as a function of covariates such as flow variables that are believed to govern fish behaviors, the movements are certain and without deviation. Instead, the Markov model describes the fish movements as a function of empirically observed transition probabilities. Taylor and Karlin (1998) noted that a Markov process is stochastic, and they pointed out that transition probabilities are functions not only of the initial and final states, but also of the time of transition as well. When the one-step transition probabilities are independent of the time variable, then the Markov chain has stationary probabilities (Karlin 1968). The time of transition was set at $0.5 \mathrm{~s}$ and is constrained in our application by the nature of the data, specifically the size of the cells in the sample volume and the frame interval. That is, we chose a transition time small enough to characterize a fish track and (for efficiency in subsequent data 
manipulations) larger than the frame interval so that the probability of remaining in a cell was not large. The choice of volumetric cell size ( $2 \mathrm{ft}$ on $\mathrm{x}$ - and $\mathrm{y}$-sides) was based on having as many cells as possible with fish movement data given the number of samples and the velocity of fish movements.

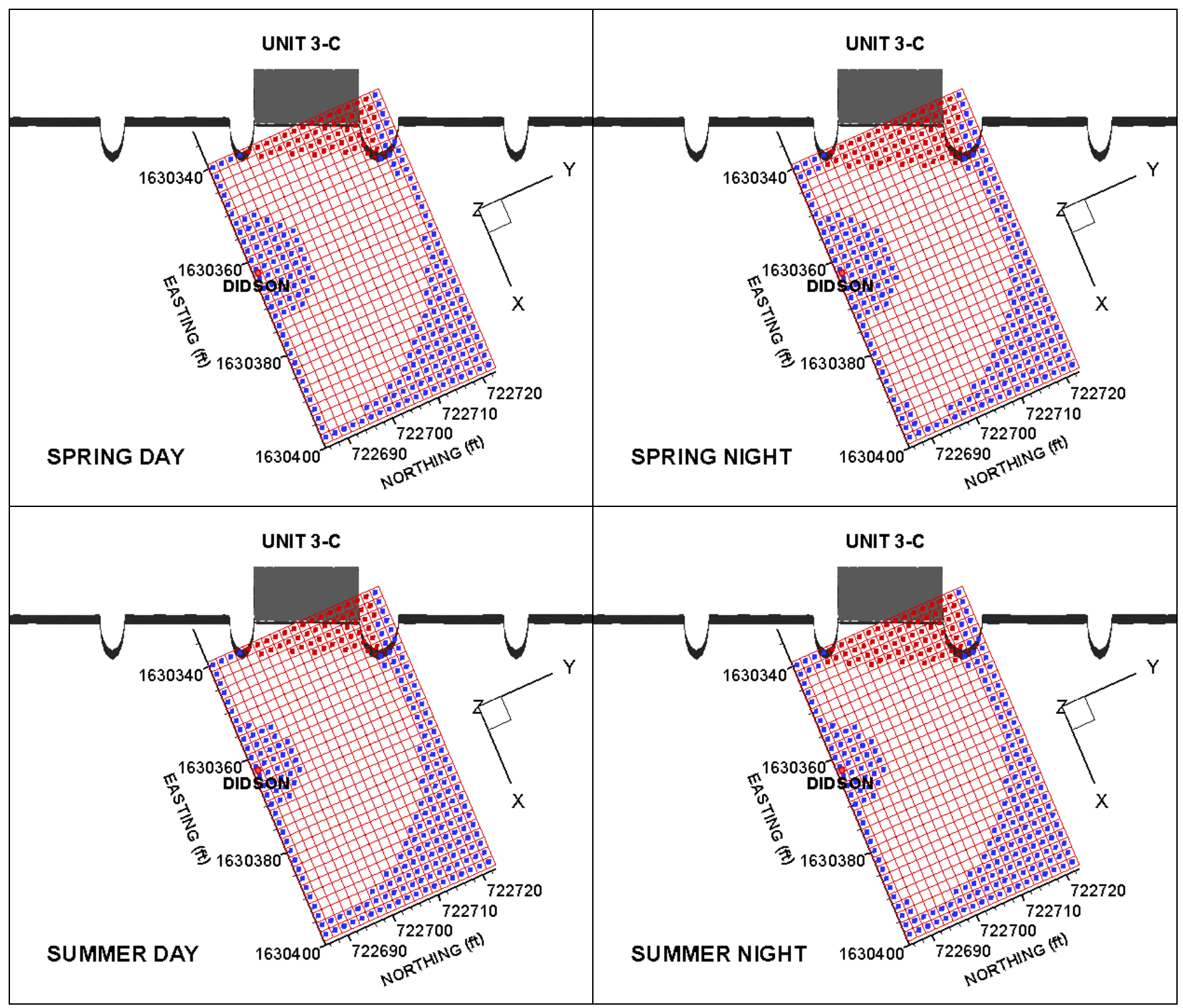

Figure 2.18. Fates of Fish Movement Estimated when Fish Tracks were Absorbed at Cells on the Edges of the Sample Volume. Sluiceway fates are indicated by cells with red marks, and other fates are indicated by cells with blue marks. Units for axes scales are in feet.

Several assumptions were made and verified regarding connectivity in the sample volume for the Markov model: (1) There were no absorbing non-boundary cells, i.e., no interior cell's probability was equal to one. (2) Exterior cells' probabilities were set to one as described above. (3) No interior connectivity was forced, but they relied upon empirical measurements. (4) Where no movement observation from a cell was measured using the DIDSON camera, then the closest movement was interpolated to that cell using inverse distance squared weights. Gaps between DIDSON sectors were filled using sector broadening. 
A C-language program was used to construct a transition matrix and apply the Markov chain analysis. The Markov transition matrix was a square matrix the size of $k \mathrm{x} k$, where $k$ was the number of distinct cells being modeled (i.e., $k=627$ ). The $i j^{\text {th }}$ element in the $i^{\text {th }}$ row of the $j^{\text {th }}$ column of the transition matrix was the estimated probability $\left(p_{i j}\right)$ of moving from cell $i$ to cell $j$ in the next time step. These probabilities were estimated by

$$
\hat{p}_{i j}=\frac{n_{i j}}{n_{i}}
$$

where,

$n_{i}=$ number of observations of smolts in the $i$ th cell;

$n_{i j}=$ number of observations where a smolt in cell $i$ moved to cell $j$ in the next time step.

The transition probabilities for cells $(2 \mathrm{ft} \times 2 \mathrm{ft})$ that bordered the edges of the sample volume (e.g. Sluiceway) were set to unity to absorb any movement that reached our defined fates. The transition matrix $T$ was constructed using a time step of $0.5 \mathrm{~s}$, using average position (i.e., $\bar{x}, \bar{y}, \bar{z}$ ) during each 0.5 $\mathrm{s}$ interval a fish was tracked. This process required that a fish be tracked for at least $1.0 \mathrm{~s}$ before the transition matrix was amended to obtain location $i$ from the first interval and location $j$ from the next, and so on.

After the transition matrix was formed, it was examined to find cells that were not sampled by the DIDSON acoustic camera. In these instances of no observation, nearby cells in Cartesian space with movement data were found and the movement patterns through those cells were interpolated to the cell with no observations using inverse distance squared weights. We limited the search radius to three cells away in order to use local data for interpolation. Of the eight Markov chain analyses (Spring and Summer; Day and Night; powerhouse flow above and below $7.5 \mathrm{kcfs}$ ) there were only two cells in Spring Day No Flow and two cells in Summer Night Flow that required this interpolation.

The transition matrix $T$ for one time step was used to estimate the transition probabilities for two or more time steps as $T^{t}$ where $t=$ the number of time steps. Matrix $T^{t}$ is the transition matrix for $t$ time steps and the transition probabilities $p_{i j}{ }^{(t)}$ express the probability of moving from cell $i$ to cell $j$ in $t$ time steps. The size of $t$ was sufficiently large so that the tracked fish revealed an absorption state or became stagnant. The $t$-step transition probabilities to absorbing cells were visualized using Amtec Engineering's Tecplot software by contouring the sums of each state's (each representing an $x, y, z$ cell) probabilities over the absorbing surfaces previously described.

\subsubsection{Computational Fluid Dynamics Modeling}

A computational fluid dynamics (CFD) model of the full Bonneville Dam forebay was used to provide hydrodynamics information to complement the smolt approach and fate study at B1 Sluiceway Outlet 3C. The CFD code used in this study was STAR-CD (www.cd-adapco.com), which had been used in previous studies at the Bonneville project (Rakowski et al. 2001a, 2001b). Two operational conditions had the most obvious impact on hydrodynamic conditions at Sluiceway Outlet 3C; these were "Unit 3 on" or "Unit 3 off." Therefore, two conditions were simulated using the CFD model: (1) eight unit operation at B1, which always included the "Unit 3 on" condition and which predominated during most of spring sampling (Figure 2.19), and (2) Unit 3 off, which was equivalent to all B1 units off. The latter condition 
occurred briefly near the end of spring sampling and during the first and last sampling period in summer (Figure 2.19). The project operations for the two scenarios are summarized in Table 2.5.

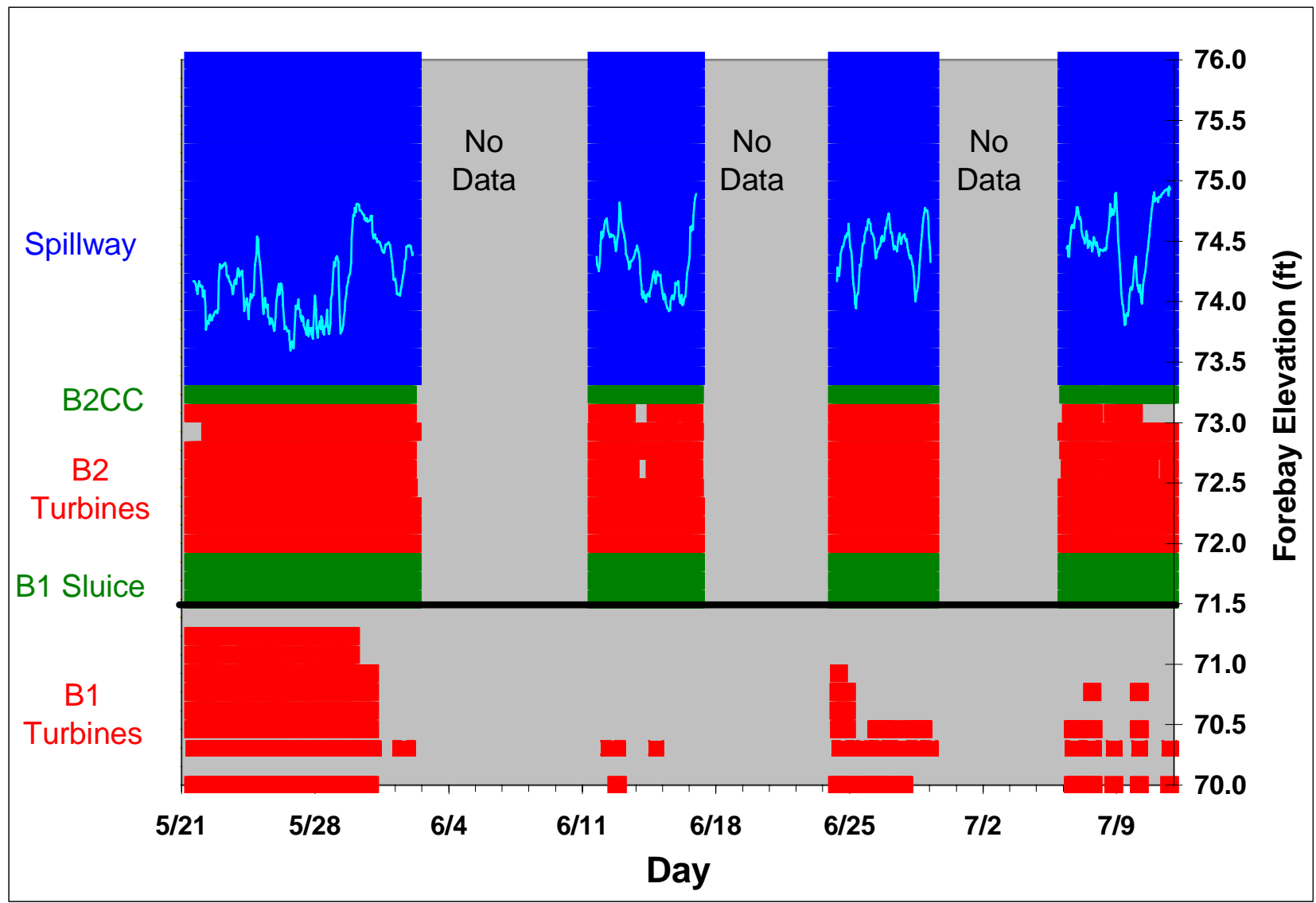

Figure 2.19. Operations at Bonneville Dam During Data Collection with the DIDSON. Colored blue, green, and red squares indicate discharge by a route, and the line represents forebay elevation. There is one row for every turbine, sluiceway outlet, and spill bay.

Table 2.5. Scenario Runs of the CFD Model Based Forebay Elevation, and Discharge (Q) through the B1 Turbines and Sluiceway.

\begin{tabular}{|cccc|}
\hline CFD Run & Forebay & $\begin{array}{c}\text { B1 } \\
\text { Discharge }\end{array}$ & $\begin{array}{c}\text { B1 Sluiceway } \\
\text { Discharge }\end{array}$ \\
\hline \hline 1 & 74.5 & 2.1 & 1.1 \\
2 & 74.5 & 67.5 & 1.1 \\
\hline
\end{tabular}

The domain of the numerical model included B1, B2, the spillway, and about one mile of the Columbia River upstream from the Project. The computational mesh contained about 1.9 million cells and was based on multiple data sources. The forebay bathymetry was developed from multiple detailed field surveys. The data for the engineered structures were based on as-built drawings provided by USACE CENWP. The numerical model included the three intake bays for each turbine unit at B1 and B2, individual spill bays, fish units, station service flows, and sluiceway outflows at B1 and the B2CC. 
The CFD model was validated in the Bonneville forebay to the best available field-measured acoustic Doppler current profiler (ADCP) velocity data (Rakowski et al. 2001b). For a complete description of the mesh development and model validation see Rakowski et al. (2001a) and Rakowski et al. (2001b).

\subsection{Spatial Expansions}

Detectability modeling and spatial expansions are very important for FPE studies that estimate proportions of fish passing a dam by all major routes or even FGE estimation for a single turbine because estimates assume equal detectability among routes. Differences in hydroacoustic deployments make it very unlikely that equal detectability will occur, and therefore some adjustment is required to improve the assumption of equal detectability. For hydroacoustic sampling, we adjust for differences in detectability as a function of range from every transducer by expanding every fish count by the ratio of the width (vertical beams) or depth (horizontal beams) of a passage route to the diameter of the hydroacoustic beam at the range that a fish is detected. Calculating the diameter of the beam at the range of detection requires modeling of the effective-beam angle, which is a measure of hydroacoustic detectability.

Effective beam angle (EBA) depends upon the detectability of fish of different sizes in the acoustic beam and is a function of nominal beam width, ping rate, trace criteria, and fish size, aspect, trajectory, velocity, and range. We modeled detectability for every transducer deployment to determine EBA as a function of range from each transducer, and we also modeled the detectability of spillway deployments for 10 levels of discharge through individual bays. The speed of flow and targets moving through hydroacoustic beams increases with discharge and range, so detectability declines as spill-bay discharge increases. Discharge-specific expansions of counts for individual spill bays attempt to compensate for the reduced detectability associated with increased discharge and fish speed. Data that influence detectability (see Appendix F.1 through F.4) were entered in a stochastic detectability model developed by William Nagy (Portland District). Model output consisted of EBA as a function of range from a transducer.

Polynomials fitted to those EBA estimates (Appendix F.5) were substituted for EBA in the equation below to correct for differences in detectability among transducers, range of detection, and for spill-bay discharge for spillway deployments. Those polynomials also were used to plot the detectability curves over the range in which fish traces were counted. Minimum ranges for modeling detectability (Appendix F.1) usually were less than minimum ranges for counting fish (as described in legends of Figures 2.5, 2.8, $2.10,2.11$, and 2.13) to improve curve fitting. Filtered ranges of detection truncated the polynomial curves to appropriate ranges so that only the portion of the curves where fish were counted were used for deriving spatial expansion factors.

The count of each fish detected in a hydroacoustic beam was spatially expanded based upon the ratio of the opening width (vertically oriented beams) or depth (horizontal beams) to beam diameter at the range of detection. For nearly horizontal beams, we substituted forebay elevation minus weir elevation (B1 sluiceway outlets) or sample region height (B2CC - see Table 2.3) for $\mathrm{OW}$ in the spatial expansion equation: 


$$
E X P_{-} N U M=\frac{O W}{\left[M I D_{-} R \times T A N\left(\frac{E B A}{2}\right) \times 2\right]}
$$

where OW is opening width (or depth), MID_R is the mid-point range of a trace in $\mathrm{m}$, TAN is the tangent, and EBA is the effective beam angle in degrees.

\subsection{Dam Operations and Fish Passage}

Operations data, including discharge by spill bay and turbine unit at 5-minute time intervals, were provided by Bonneville Dam operators from an automated data acquisition system. Dam-operations data were integrated with fish passage data, and fish passage was set to zero when passage routes were closed. All spill bays happened to be opened and discharging water throughout the spring and summer sampling seasons so closure adjustments were unnecessary, but most turbines were on and off several times a day. This was important because transducers sampled continuously regardless of operations, and samples from closed turbine units or spill bays will include many traces that may be tracked as passed fish, often multiple times, even when a turbine unit is off or a spill bay is closed. Fortunately, operations data were recorded in five-minute intervals so we knew within 2.5 minutes when every turbine was started and shut down each day. Therefore, we were able to set the 1-minute samples of fish passage to zero whenever a turbine was off. Polynomial regression equations were used to estimate flow into sluiceways outlets at intakes 1C, 3C, and 6C from average hourly forebay elevations, which were obtained from Project operations data. The equations were

$$
\begin{aligned}
& \text { CFS_1C }=-2.643357(\text { FB_EL })^{3}+585.571096\left(F B \_E L\right)^{2}-43107.896270\left(F B \_E L\right)+1054895.728672 \\
& \text { CFS_3C }=0.205128(\text { FB_EL })^{3}-58.860140\left(F B \_E L\right)^{2}+5415.896270\left(F B \_E L\right)-161243.174825 \\
& \text { CFS_6C }=-1.617716\left(F B \_E L\right)^{3}+346.682984\left(F B \_E L\right)^{2}-24662.386946\left(F B \_E L\right)+582357.579021 \text {, }
\end{aligned}
$$

where CFS is sluiceway outlet flow and suffixes $1 \mathrm{C}, 3 \mathrm{C}$, and $6 \mathrm{C}$ refer to outlet locations. These equations were the same as those used to estimate discharge into Sluiceways $2 \mathrm{C}, 4 \mathrm{C}$, and $6 \mathrm{C}$ in 2004 (Ploskey et al. 2005).

Hourly rates and variances in fish passage and hourly rates of water discharge through various routes at Bonneville Dam are presented in Appendix E on the accompanying compact disk. Tables 1 and 2 of Appendix E describe the variables in the comma-separated variable files.

\subsection{Missing Data}

We made a special effort to make certain that missing samples were accounted for in the spring and summer data sets. First, we created a data set consisting of all possible sample locations and times each season and set an expanded fish variable to missing in every observation. Second, we merged the missing data set with the acquired data set so that counts of expanded fish, if present in the acquired data, overwrote missing counts. When a sample was not acquired for whatever reason, there was nothing in the acquired data set to overwrite the missing value for expanded fish. Therefore, the observation was appropriately designated as missing, as opposed to an actual zero count, and could be interpolated before data were analyzed. 
Missing hourly sums and variances that resulted from equipment outages $>45$ minutes were estimated by temporal linear interpolation for periods $<6$ hours and by spatial interpolation or linear regression for periods $>6$ hours. Occasionally the ratio of guided to unguided numbers at adjacent turbines with similar screens was useful for interpolating estimates of guided or unguided numbers. Regression equations relating hourly variances with hourly sums were sometimes used to estimate missing variance estimates. Whole system failures resulting from computer lock ups were very rare and usually were fixed within an hour, but a number of cables to B2 turbine transducers failed each season and had to be replaced. These failures resulted in missing data for those deployments and the missing sum and variance estimates had to be interpolated from data from adjacent deployments or by linear regression. Short-term equipment failures lasting up to 45 minutes were not a problem because fish counts and associated variances could still be estimated from the remaining within-hour samples.

\subsection{Estimating Fish Passage}

This section describes methods of estimating fish passage at B1, B2, and the spillway at Bonneville Dam in 2005. Estimates of passage from these methods are used to calculate subsequent measures of fish passage performance (Section 2.10 below). Within every hour, we sampled 7 to 30 minutes systematically depending upon location, and we assumed that these systematic samples would behave as if they were simple random samples. This approach will be unbiased when the passage is random and variance estimates will be upwardly biased when there is linear trend, positive autocorrelation, or stratification effect. Negatively biased variance estimates would only occur in unusual situations. We also estimated more than just the temporal variation in passage within intakes by post-stratifying adjacent turbine units and estimating the variation in passage between intakes of multi-unit strata. This approach usually would include more between-intake variation than we would expect from sampling two or more intakes of individual units because variation among units usually exceeds the variation among intakes within a unit.

Ninety-five percent confidence intervals for individual intakes or spill bays were calculated as 1.96 times the square root of the temporal variance estimate for the time frame of interest (day, week, or season). The following sub-sections describe procedures for estimating temporal variances in fish passage through individual intakes and spill bays as first steps for estimating the variance for strata of intakes or bays or for each powerhouse and the spillway.

\subsubsection{B1 Passage}

The sampling at B1 can be viewed as a two-stage sampling scheme. The first stage is the sampling of intake slots within a stratum composed of single turbine units or neighboring turbine units that were operating simultaneously. In 2005, two intakes were sampled at most active turbines so stratification of adjacent turbine units was only required for Units 8 and 9, where only one intake was sample per unit (see Table 2.1). The resulting variance estimates for the stratum including Units 8 and 9 can generally be considered conservative for they often include more between-intake variance than expected under the original sampling design. 
The fish passage at B1 $(T)$ is estimated by the quantity

$$
\hat{T}=\sum_{i=1}^{D} \sum_{j=1}^{23} \sum_{k=1}^{K_{i j}}\left[\frac{A_{i j k}}{a_{i j k}}\left[\sum_{l=1}^{a_{i j k}} \hat{T}_{i j k l}\right]\right],
$$

where

$\hat{T}_{i j k l}=$ estimated fish passage in the $l$ th intake slot $\left(l=1, \ldots, a_{i j k}\right)$ within the $k$ th turbine stratum $\left(k=1, \ldots K_{i j}\right)$ during the $j$ th hour $(j=1, \ldots, 24)$ on the $i$ th day $(i=1, \ldots, D)$;

$a_{i j k}=$ number of intake slots actually sampled in the $k$ th turbine stratum $\left(k=1, \ldots K_{i j}\right)$ during the $j$ th hour $(j=1, \ldots, 24)$ on the $i$ th day $(i=1, \ldots, D)$;

$A_{i j k}=$ total number of intake slots within the $k$ th turbine stratum $\left(k=1, \ldots K_{i j}\right)$ during the $j$ th hour $(j=1, \ldots, 24)$ on the $i$ th day $(i=1, \ldots, D)$;

$K_{i j}=$ number of turbine strata created during the $j$ th hour $(j=1, \ldots, 24)$ on the $i$ th day $(i=1, \ldots, D)$.

Because of the varying power loads over time, the number of spatial strata (i.e., $K_{i j}$ ) formed by poststratification of adjacent turbine units may vary between hours $(j=1, \ldots, 24)$ and days $(i=1, \ldots, D)$. The estimate of $\hat{T}_{i j k l}$ is based on the assumption of simple random sampling within a slot-hour, in which case

$$
\hat{T}_{i j k l}=\frac{B_{i j k l}}{b_{i j k l}} \sum_{g=1}^{b_{i j k l}} z_{i j k l g} .
$$

Combining Equations (1) and (2), the overall estimate of fish passage at B1 during $D$ days can be expressed as

$$
\hat{T}=\sum_{i=1}^{D} \sum_{j=1}^{23} \sum_{k=1}^{K_{i j}}\left[\frac{A_{i j k}}{a_{i j k}}\left[\frac{B_{i j k l}}{b_{i j k l}} \sum_{g=1}^{b_{i j k l}} z_{i j k l g}\right]\right],
$$

where

$Z_{i j k l g}=$ expanded fish count in the $g$ th sampling unit $\left(g=1, \ldots, b_{i j k l}\right)$ in the lth intake slot

$\left(l=1, \ldots, a_{i j k}\right)$ within the $k$ th turbine stratum $\left(k=1, \ldots K_{i j}\right)$ during the $j$ th hour

$(j=1, \ldots, 23)$ on the $i$ th day $(i=1, \ldots, D)$;

$b_{i j k l}=$ number of sampling units actually observed in the $l$ th intake slot $\left(l=1, \ldots, a_{i j k}\right)$ within the $k$ th turbine stratum $\left(k=1, \ldots K_{i j}\right)$ during the $j$ th hour $(j=1, \ldots, 23)$ on the $i$ th day $(i=1, \ldots, D)$;

$B_{i j k l}=$ total number of sampling units within the $l$ th intake slot $\left(l=1, \ldots, a_{i j k}\right)$ within the $k$ th turbine stratum $\left(k=1, \ldots K_{i j}\right)$ during the $j$ th hour $(j=1, \ldots, 23)$ on the $i$ th day $(i=1, \ldots, D)$.

Nominally, $B_{i j k l}=60$ and $b_{i j k l}=20 \forall i j k l$. Based on the assumption of simple random sampling 


$$
\widehat{\operatorname{Var}}\left(\hat{T}_{i j k l}\right)=\frac{B_{i j k l}^{2}\left(1-\frac{b_{i j k l}}{B_{i j k l}}\right) s_{z_{i j k l}^{2}}^{2}}{b_{i j k l}}
$$

where

$$
s_{z_{i j k l}}^{2}=\frac{\sum_{g=1}^{b_{i j k l}}\left(z_{i j k l g}-\overline{z_{i j k l}}\right)^{2}}{\left(b_{i j k l}-1\right)}
$$

and where

$$
\overline{Z_{i j k l}}=\frac{1}{b_{i j k l}} \sum_{g=1}^{b_{i j k l}} Z_{i j k l g} .
$$

The variance of $\hat{T}$ can then be estimated by the formula

$$
\widehat{\operatorname{Var}}(\hat{T})=\sum_{i=1}^{D} \sum_{j=1}^{24} \sum_{k=1}^{K_{i j}}\left[\frac{A_{i j k}^{2}\left(1-\frac{a_{i j k}}{A_{i j k}}\right) s_{\widehat{T U}}^{2}}{a_{i j k}}+\frac{A_{i j k l} \sum_{l=1}^{a_{i j k}} \widehat{\operatorname{Var}}\left(\widehat{T}_{i j k l}\right)}{a_{i j k}}\right],
$$

where

$$
\begin{aligned}
& s_{\hat{T}_{i j k}}^{2}=\frac{\sum_{l=1}^{a_{i j k}}\left(\hat{T}_{i j k l}-\hat{\bar{T}}_{i j k}\right)^{2}}{\left(a_{i j k}-1\right)}, \\
& \hat{\bar{T}}_{i j k}=\frac{1}{a_{i j k}} \sum_{l=1}^{a_{i j k}} \hat{T}_{i j k l} .
\end{aligned}
$$

\subsubsection{B2 Unguided Passage}

The same two-stage sampling scheme used to estimate fish passage at B1 was used to estimate fish passage at B2, Units 11-18. Two consecutive turbine units (e.g., 11-12, 13-14, ...) were combined to form a stratum with two or more intake slots selected for monitoring (Table 2.4). On rare occasions, unit shutdowns because of load demands required further post-stratification to assure within-stratum replication of turbine slots. Under these circumstances, the turbine units at B2 were grouped into four or fewer strata. To accommodate all circumstances, the estimators and variances will be expressed generically. Using the fish counts from the down-looking transducers, total unguided fish passage at B2 was estimated by the quantity

$$
\widehat{H U}=\sum_{i=1}^{D} \sum_{j=1}^{23} \sum_{k=1}^{K_{i j}}\left[\frac{C_{i j k}}{C_{i j k}}\left[\frac{D_{i j k l}}{d_{i j k l}} \sum_{g=1}^{d_{i j k l}} x_{i j k l g}\right]\right],
$$


where

$X_{i j k l g}=$ expanded fish passage in the $g$ th sampling unit $\left(g=1, \ldots, b_{i j k l}\right)$ in the lth intake slot $\left(l=1, \ldots, a_{i j k}\right)$ within the $k$ th turbine stratum $\left(k=1, \ldots K_{i j}\right)$ during the $j$ th hour $(j=1, \ldots, 23)$ on the $i$ th day $(i=1, \ldots, D)$;

$d_{i j k l}=$ number of sampling units actually observed in the $l$ th intake slot $\left(l=1, \ldots, a_{i j k}\right)$ within the $k$ th turbine stratum $\left(k=1, \ldots K_{i j}\right)$ during the $j$ th hour $(j=1, \ldots, 23)$ on the $i$ th day $(i=1, \ldots, D)$;

$D_{i j k l}=$ total number of sampling units within the $l$ th intake slot $\left(l=1, \ldots, a_{i j k}\right)$ within the $k$ th turbine stratum $\left(k=1, \ldots K_{i j}\right)$ during the $j$ th hour $(j=1, \ldots, 23)$ on the $i$ th day $(i=1, \ldots, D)$;

$c_{i j k}=$ number of intake slots actually sampled in the $k$ th turbine stratum $\left(k=1, \ldots K_{i j}\right)$ during the $j$ th hour $(j=1, \ldots, 23)$ on the $i$ th day $(i=1, \ldots, D)$;

$C_{i j k}=$ total number of intake slots within the $k$ th turbine stratum $\left(k=1, \ldots K_{i j}\right)$ during the $j$ th hour $(j=1, \ldots, 23)$ on the ith day $(i=1, \ldots, D)$;

$K_{i j}=$ number of turbine strata created during the $j$ th hour $(j=1, \ldots, 23)$ on the $i$ th day $(i=1, \ldots, D)$.

Nominally, $D_{i j k l}=60 \forall i j k l$ and $d_{i j k l}=7,10$, or 20 depending on location.

The variance of $\widehat{H U}$ can then be estimated by the formula

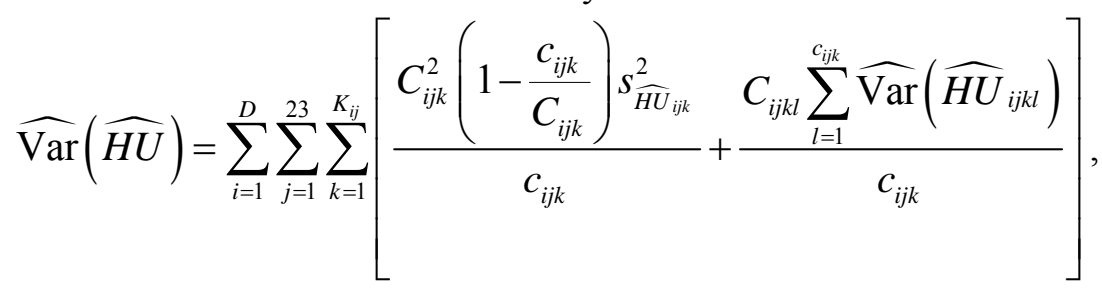

where

$$
\begin{aligned}
\widehat{\operatorname{Var}}\left(\widehat{H U}_{i j k l}\right) & =\frac{D_{i j k l}^{2}\left(1-\frac{d_{i j k l}}{D_{i j k l}}\right) s_{x_{i j k l}^{2}}}{d_{i j k l}}, \\
s_{x_{i j k l}^{2}}^{2} & =\frac{\sum_{g=1}^{d_{i j k l}}\left(x_{i j k l g}-\bar{x}_{i j k l}\right)^{2}}{\left(d_{i j k l}-1\right)}, \\
\bar{x}_{i j k l} & =\frac{1}{d_{i j k l}} \sum_{g=1}^{d_{i j k l}} x_{i j k l g},
\end{aligned}
$$


and where

$$
\begin{aligned}
& S_{\widehat{H U}_{i j k}^{2}}^{2}=\frac{\sum_{l=1}^{a_{i j k}}\left(\widehat{H U}_{i j k l}-\widehat{H U}_{i j k}\right)^{2}}{\left(a_{i j k}-1\right)}, \\
& \widehat{H U}_{i j k}=\frac{1}{a_{i j k}} \sum_{l=1}^{a_{i k}} \widehat{H U}_{i j k l} .
\end{aligned}
$$

\subsubsection{B2 Guided Passage}

The same two-stage sampling scheme used to estimate unguided passage (HU) at B2 was used to sample guided passage (HG) at B2. Hence, the estimator for guided fish passage at B2 can be written as

$$
\widehat{H G}=\sum_{i=1}^{D} \sum_{j=1}^{23} \sum_{k=1}^{K_{i j}}\left[\frac{C_{i j k}}{C_{i j k}}\left[\frac{D_{i j k l}}{d_{i j k l}} \sum_{g=1}^{d_{i j k l}} w_{i j k l g}\right]\right],
$$

where

$$
\begin{aligned}
w_{i j k l g}= & \text { expanded fish passage in the } g \text { th sampling unit }\left(g=1, \ldots, b_{i j k l}\right) \text { in the } l \text { th intake slot } \\
& \left(l=1, \ldots, a_{i j k}\right) \text { within the } k \text { th turbine stratum }\left(k=1, \ldots K_{i j}\right) \text { during the } j \text { th hour } \\
& (j=1, \ldots, 23) \text { on the } i \text { th day }(i=1, \ldots, D)
\end{aligned}
$$

The estimated variance of $\widehat{H G}$ can then be expressed as

$$
\widehat{\operatorname{Var}}(\widehat{H G})=\sum_{i=1}^{D} \sum_{j=1}^{23} \sum_{k=1}^{K_{i j}}\left[\frac{C_{i j k}^{2}\left(1-\frac{C_{i j k}}{C_{i j k}}\right) S_{\widehat{H G}}^{2}}{C_{i j k}}+\frac{C_{i j k l} \sum_{l=1}^{c_{i j k}} \widehat{\operatorname{Var}}\left(\widehat{H G}_{i j k l}\right)}{C_{i j k}}\right]
$$

where

$$
\begin{gathered}
\widehat{\operatorname{Var}}\left(\widehat{H G}_{i j k l}\right)=\frac{D_{i j k l}^{2}\left(1-\frac{d_{i j k l}}{D_{i j k l}}\right) s_{w_{i j k l}^{2}}}{d_{i j k l}}, \\
s_{w_{i j k l}^{2}}^{2}=\frac{\sum_{g=1}^{d_{i j k l}}\left(w_{i j k l g}-\bar{w}_{i j k l}\right)^{2}}{\left(d_{i j k l}-1\right)}, \\
\bar{w}_{i j k l}=\frac{1}{d_{i j k l}} \sum_{g=1}^{i_{i j l}} w_{i j k l g},
\end{gathered}
$$

and where 


$$
\begin{aligned}
& s_{\widehat{H G}_{i j k}^{2}}=\frac{\sum_{l=1}^{c_{i j k}}\left(\widehat{H G}_{i j k l}-\widehat{H G}_{i j k}\right)^{2}}{\left(c_{i j k}-1\right)}, \\
& \widehat{H G}_{i j k}=\frac{1}{c_{i j k}} \sum_{l=1}^{c_{i j k}} \widehat{H G}_{i j k l} .
\end{aligned}
$$

\subsubsection{Spill Bay Passage}

During spring 2005, hydroacoustic transducers were placed in each of the operational spill bays, one transducer per spill bay. Sampling was envisioned as systematic sampling within individual spill bay-hrs. The estimate of total spillway passage was estimated by the formula

$$
\hat{S}=\sum_{i=1}^{H} \sum_{j=1}^{D} \sum_{k=1}^{23} \frac{T_{i j k}}{t_{i j k}} \sum_{l=1}^{t_{i j k}} p_{i j k l},
$$

where

$p_{i j k l}=$ expanded fish passage in the $l$ th sampling interval $\left(l=1, \ldots, t_{i j k}\right)$ during the $k$ th hour $(k=1, \ldots, 23)$ in the $j$ th day $(j=1, \ldots, D)$ at the ith spill bay $(i=1, \ldots, 17)$;

$T_{i j k}=$ total number of possible sampling units the $k$ th hour $(k=1, \ldots, 23)$ in the $j$ th day $(j=1, \ldots, D)$ at the $i$ th spill bay $(i=1, \ldots, 17)$;

$t_{i j k}=$ actual number of sampling units drawn within the $k$ th hour $(k=1, \ldots, 23)$ in the $j$ th day $(j=1, \ldots, D)$ at the $i$ th spill bay $(i=1, \ldots, 17)$.

Assuming the systematic sampling within an hour can be approximated by a random sampling formula, the estimated variance of $\hat{S}$ can be written as

$$
\widehat{\operatorname{Var}}(\hat{S})=\sum_{i=1}^{H} \sum_{j=1}^{D} \sum_{k=1}^{23}\left[\frac{T_{i j k}^{2}\left(1-\frac{t_{i j k}}{T_{i j k}}\right) s_{p_{i j k}}^{2}}{t_{i j k}}\right],
$$

where

$$
\begin{aligned}
s_{p_{i j k}}^{2} & =\frac{\sum_{l=1}^{t_{i j k}}\left(p_{i j k l}-\bar{p}_{i j k}\right)^{2}}{\left(t_{i j k}-1\right)}, \\
\bar{p}_{i j k}= & \frac{\sum_{l=1}^{t_{i j k}} p_{i j k l}}{t_{i j k}} .
\end{aligned}
$$

Nominally, $T_{i j k}=60 \forall i j k$ and $t_{i j k}=12$ or 20 depending on location. 


\subsubsection{Sluiceway Passage}

For the sluiceways above turbine intakes $1 \mathrm{C}, 3 \mathrm{C}$, and $6 \mathrm{C}$ at $\mathrm{B} 1$, the estimation of smolt passage is based on stratified sampling. Each half of one of the sluiceways was considered a spatial stratum, in which case, total sluiceway passage can be estimated by the quantity

$$
\widehat{S L}=\sum_{g=1}^{3} \sum_{h=1}^{2} \sum_{i=1}^{D} \sum_{j=1}^{23} \frac{E}{e} \sum_{k=1}^{e} v_{g h i j k},
$$

where

$$
\begin{aligned}
& v_{\text {ghijk }}=\text { expanded fish counts in the } k \text { th sample interval }(k=1, \ldots, e) \text { in the } j \text { th hour } \\
& (j=1, \ldots, 23) \text { of the } i \text { th day }(i=1, \ldots, D) \text { at the } h \text { th half-section }(h=1,2) \text { of the } g \text { th } \\
& \text { sluiceway }(g=1,3) ; \\
& \qquad \begin{array}{l}
E=\text { total number of possible sampling intervals within an hour; } \\
e=\text { actual number of sampling intervals drawn within an hour. }
\end{array}
\end{aligned}
$$

Nominally, $E=60$ and $e=20 \forall$ ghij.

The variance of $\widehat{S L}$, based on simple random sampling within an hour, is then

$$
\widehat{\operatorname{Var}}(\widehat{S L})=\sum_{g=1}^{3} \sum_{h=1}^{2} \sum_{i=1}^{D} \sum_{j=1}^{23}\left[\frac{E^{2}\left(1-\frac{e}{E}\right) s_{v_{g h i j}}^{2}}{e}\right],
$$

where

$$
\begin{aligned}
s_{v_{g h i j}}^{2} & =\frac{\sum_{k=1}^{e}\left(v_{g h i j k}-\bar{v}_{g h i j}\right)^{2}}{(e-1)}, \\
\bar{v}_{g h i j} & =\frac{\sum_{k=1}^{e} v_{g h i j k}}{e} .
\end{aligned}
$$

\subsubsection{Corner Collector Passage}

Sampling at the corner collector can be visualized as stratified random sampling. The collector opening has been spatially stratified by transducers 1-3-5 and transducers 2-4-6. Within these spatial strata, sampling within an hour is assumed to be random sampling. Define the following variables:

$y_{h i j k}=$ expanded fish count in the $k$ th sampling interval $(k=1, \ldots, f)$ in the $j$ th hour

$(j=1, \ldots, 23)$ at the $i$ th half-section $(i=1,2)$ on the $h$ th day $(h=1, \ldots, D)$;

$F=$ total number of possible sampling intervals within an hour;

$f=$ actual number of sampling intervals drawn within an hour.

The estimate of total corner collector passage is then calculated as

$$
\widehat{B 2 C C}=\sum_{h=1}^{D} \sum_{i=1}^{2} \sum_{j=1}^{23} \frac{F}{f} \sum_{k=1}^{f} y_{h i j k} .
$$

Nominally, $F=60$ and $f=30 \forall h i j$. 
The variance of $\widehat{B 2 C C}$ is based on simple random sampling within an hour, where

$$
\widehat{\operatorname{Var}}(\widehat{B 2 C C})=\sum_{h=1}^{D} \sum_{i=1}^{2} \sum_{j=1}^{23}\left[\frac{F^{2}\left(1-\frac{f}{F}\right) s_{y_{h i j}^{2}}}{f}\right] \text {, }
$$

where

$$
\begin{aligned}
s_{y_{h i j}}^{2} & =\frac{\sum_{k=1}^{f}\left(y_{h i j k}-\bar{y}_{h i j}\right)^{2}}{(f-1)}, \\
\bar{y}_{h i j} & =\frac{\sum_{k=1}^{f} y_{h i j k}}{f} .
\end{aligned}
$$

\subsection{Adjustment of Passage Estimates and Associated Variances}

We adjusted autotracker counts and variances in two ways according to the general methods described in subsequent paragraphs of this section.

First, we regressed mean hourly fish counts by three technicians on autotracker counts for each transducer hour and used slopes of regression lines with intercepts forced through zero to convert autotracker counts into mean technician counts and thereby remove systematic bias in autotracker counts among deployments. Regressions provided a measure of agreement between the two methods in the form of the coefficient of determination (r2) and a slope with which to assess the degree of under counting or over counting that the autotracker does relative to the human trackers. Plots of the regressions of mean technician counts on autotracker counts for every deployment are presented in the Results section of this report. Manually analyzing the hydroacoustic tracks is generally considered the most reliable and accurate method of processing raw hydroacoustic data. However, because of the sheer magnitude of the data collected, automated tracking algorithms programmed for pattern recognition are often employed to process the raw hydroacoustic data. The pattern recognition abilities of people are generally considered superior to computer algorithms which can only identify patterns that have been pre-specified. To account for errors in pattern recognition, the regression analyses described below were performed.

Second, we examined the azimuth direction of travel of fish through all routes and found that the proportion of fish detected moving downstream through routes was less than $100 \%$ for the sluiceway outlets at B1 and for the three spill bays sampled with split-beam transducers (single-beam data lack the phase information that enables direction-of-travel estimates). We reduced counts at sluiceway and spillway routes by multiplying passage estimates by the average hourly proportion of fish detected moving downstream toward the openings. Direction of travel was based upon a line fitted to all echoes in a fish trace.

Let $\hat{X}$ be an estimate of smolt passage and $\hat{B}$ be an estimate of a "calibration" adjustment. The calibration adjustments could include:

1. Adjustment of autotracker counts for manual counts

2. Adjustment of passage numbers for proportion of fish detected that enter a passage route. 
The adjusted estimate was written as

$$
\tilde{X}=\hat{B} \hat{X}
$$

with the associated variance estimator

$$
\widehat{\operatorname{Var}}(\tilde{X})=\widehat{\operatorname{Var}}(\hat{X}) \hat{B}^{2}+\widehat{\operatorname{Var}}(\hat{B}) \hat{X}^{2}-\widehat{\operatorname{Var}}(\hat{X}) \cdot \widehat{\operatorname{Var}}(\hat{B})
$$

when $\hat{X}$ and $\hat{B}$ are estimated independently. The variance can alternatively be expressed as

$$
\begin{aligned}
\widehat{\operatorname{Var}}(\tilde{X}) & =(\hat{B} \hat{X})^{2}\left[\frac{\widehat{\operatorname{Var}}(\hat{X})}{\hat{X}^{2}}+\frac{\widehat{\operatorname{Var}}(\hat{B})}{\hat{B}^{2}}-\frac{\widehat{\operatorname{Var}}(\hat{X}) \cdot \widehat{\operatorname{Var}}(\hat{B})}{\hat{X}^{2} \hat{B}^{2}}\right] . \\
& =(\hat{B} \tilde{X})^{2}\left[C V(\hat{X})^{2}+C V(\hat{B})^{2}-C V(\hat{X})^{2} \cdot C V(\hat{B})^{2}\right] .
\end{aligned}
$$

\subsubsection{Sum of Multiple Adjusted Estimates}

Assume there are multiple passage estimates, each with their own calibration adjustment that need to be summed such that

$$
\tilde{X}=\sum_{i=1}^{n} \tilde{X}_{i}=\sum_{i=1}^{n} \hat{B}_{i} \hat{X}_{i}
$$

Then the variance of $\tilde{X}$ was estimated by

$$
\begin{gathered}
\widehat{\operatorname{Var}}(\tilde{X})=\operatorname{Var}\left(\sum_{i=1}^{n} \tilde{X}_{i}\right) \\
\widehat{\operatorname{Var}}(\tilde{X})=\operatorname{Var}\left(\sum_{i=1}^{n} \hat{B}_{i} \hat{X}_{i}\right) \\
=\sum_{i=1}^{n}\left[\widehat{\operatorname{Var}}\left(\hat{X}_{i}\right) \hat{B}_{i}^{2}+\widehat{\operatorname{Var}}\left(\hat{B}_{i}\right) \hat{X}_{i}^{2}-\widehat{\operatorname{Var}}\left(\hat{X}_{i}\right) \cdot \widehat{\operatorname{Var}}\left(\hat{B}_{i}\right)\right] .
\end{gathered}
$$

\subsubsection{Adjusting Autotracker Counts by Regression: Ratio Estimator}

Consider the case of autotracking versus manual counts. Let $\hat{X}$ be the passage estimate based on autotracking and let $\tilde{X}$ be the estimate of passage for manual counts where

$$
\tilde{X}=\hat{B} \cdot \hat{X} \text {. }
$$

The estimator $\hat{B}$ was obtained from the straight-line regression through the origin where

and where

$$
y_{i}=B x_{i}
$$

$y_{i}=$ manual count for the $i$ th observation,

$x_{i}=$ autotracker count for the ith observation.

The regression was plotted as follows:

The estimator of the slope was

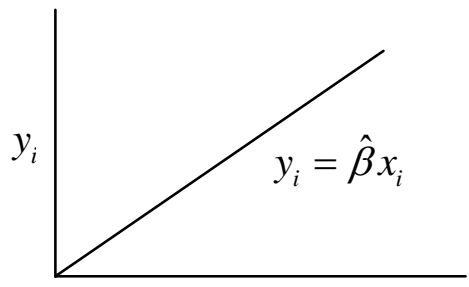




$$
\hat{\beta}=\frac{\sum_{i=1}^{n} y_{i}}{\sum_{i=1}^{n} x_{i}}
$$

The values of ${ }^{X_{i}}$ and ${ }^{y_{i}}$ used in the estimation of $\hat{B}$ were hourly counts, as was the estimate of $\tilde{X}$. The variance of $\hat{B}$ was estimated by the expression

$$
\widehat{\operatorname{Var}}(\hat{B})=\frac{\sum_{i=1}^{n}\left(y_{i}-\hat{\beta} x_{i}\right)^{2}}{n(n-1) \bar{x}^{2}}
$$

or equivalently,

$$
\widehat{\operatorname{Var}}(\hat{B})=\frac{\sum_{i=1}^{n} y_{i}^{2}-2 \hat{B} \sum_{i=1}^{n} y_{i} x_{i}+\hat{B}^{2} \sum_{i=1}^{n} x_{i}^{2}}{n(n-1) \bar{x}^{2}}
$$

and where

$$
\bar{x}=\frac{\sum_{i=1}^{n} x_{i}}{n}
$$

\subsubsection{Adjusting for Direction-of-Travel Proportions}

Consider the case where the calibration adjustment is the proportion of observed smolts moving downstream through a passage route. The estimate of the adjustment was

$$
\hat{B}=\frac{\hat{V}}{\hat{V}+\hat{W}}
$$

Where

$\hat{V}=$ estimated number of smolts that entered the passage route in the $i$ th observation,

$\hat{W}=$ estimated number of smolts that did not enter the passage route in the $i$ th observation.

The variance of $\hat{B}$ in this case was estimated as follows:

$$
\widehat{\operatorname{Var}}(\hat{B})=\frac{\hat{B}(1-\hat{B})}{(\hat{V}+\hat{W})}+\hat{B}^{2}(1-\hat{B})^{2}\left[\frac{\widehat{\operatorname{Var}}(\hat{V})}{\hat{V}^{2}}+\frac{\widehat{\operatorname{Var}}(\hat{W})}{\hat{W}^{2}}-\frac{2 \widehat{\operatorname{Cov}}(\hat{V}, \hat{W})}{\hat{V} \hat{W}}\right] .
$$

The variance of $\hat{V}$ and $\hat{W}$ depends on how the total passage was estimated from multiple locations over time, so

$$
\hat{V}=\sum_{i=1}^{L} \sum_{j=1}^{D} \sum_{k=1}^{24}\left[\frac{N}{n} \sum_{l=1}^{n} v_{i j k l}\right]
$$

where

$$
v_{i j k l}=\text { expanded fish count for the } i \text { th sampling interval }(l=1, \ldots, n) \text { in the } k \text { th hour }
$$$$
(k=1, \ldots, 24) \text { for the } j \text { th day }(j=1, \ldots, D) \text { at the } i \text { th location }(i=1, \ldots, L) \text {; }
$$ 
$n=$ number of intervals sampled per hour;

$N=$ number of possible sampling intervals within an hour.

where

$$
\widehat{\operatorname{Var}}(\hat{V})=\sum_{i=1}^{L} \sum_{j=1}^{D} \sum_{k=1}^{24}\left[\frac{N^{2}\left(1-\frac{n}{N}\right)}{n} s_{v_{i j k}}^{2}\right]
$$

$$
s_{v_{i j k}}^{2}=\frac{\sum_{l=1}^{n}\left(v_{i j k l}-\bar{v}_{i j k l}\right)^{2}}{(n-1)},
$$

$$
\bar{v}_{i j k}=\frac{\sum_{l=1}^{n} v_{i j k l}}{n} \text {. }
$$

The variance of $\hat{W}$ was computed analogously.

The covariance of $\hat{V}$ and $\hat{W}$ was estimated as follows:

$$
\widehat{\operatorname{Cov}}(\hat{V}, \hat{W})=\sum_{i=1}^{L} \sum_{j=1}^{D} \sum_{k=1}^{24}\left[\frac{N^{2}\left(1-\frac{n}{N}\right)}{n} \operatorname{cov}\left(v_{i j k}, w_{i j k}\right)\right]
$$

where $\operatorname{cov}\left(v_{i j k}, w_{i j k}\right)=\frac{\sum_{l=1}^{n}\left(v_{i j k l}-\bar{v}_{i j k}\right)\left(w_{i j k l}-\bar{w}_{i j k}\right)}{(n-1)}$.

\subsection{Estimating Passage Performance}

Estimates of fish passage through the powerhouses, sluiceways, the corner collector, and the spillway will be used to estimate measures of passage performance. This section presents the estimators and associated variance estimators.

\subsubsection{Project Fish Passage Efficiency (FPE)}

The project-wide FPE was estimated by the quotient

$$
\widehat{F P E}=\frac{[\hat{S}+\widehat{H G}+\widehat{S L}+\widehat{C C}]}{[\widehat{H U}+\widehat{H G}+\widehat{T}+\widehat{S L}+\widehat{C C}+\hat{S}]},
$$

where the numerator is the estimated spillway, B2 bypass guided, sluiceway, and B2CC passage, respectively, and the denominator is the total project passage composed of $\mathrm{B} 2$ unguided, $\mathrm{B} 2$ guided, $\mathrm{B} 1$ turbine, B1 sluiceway, B2CC, and spillway passage, respectively. Project FPE can be alternatively expressed as

$$
\widehat{F P E}=\frac{\hat{G}}{\hat{G}+\hat{U}},
$$

where 


$$
\begin{aligned}
& \hat{G}=\hat{S}+\widehat{H G}+\widehat{S L}+\widehat{C C}, \\
& \hat{U}=\widehat{H U}+\hat{T} .
\end{aligned}
$$

The variance of $\widehat{F P E}$ was estimated by

$$
\widehat{\operatorname{Var}}(\widehat{F P E})=\widehat{F P E}^{2}(1-\widehat{F P E})^{2}\left[\frac{\widehat{\operatorname{Var}}(\hat{G})}{\hat{G}^{2}}+\frac{\widehat{\operatorname{Var}}(\hat{U})}{\hat{U}^{2}}\right],
$$

where

$$
\begin{aligned}
& \widehat{\operatorname{Var}}(\hat{G})=\widehat{\operatorname{Var}}(\hat{S})+\widehat{\operatorname{Var}}(\widehat{H G})+\widehat{\operatorname{Var}}(\widehat{S L})+\widehat{\operatorname{Var}}(\widehat{C C}), \\
& \widehat{\operatorname{Var}}(\hat{U})=\widehat{\operatorname{Var}}(\widehat{H U})+\widehat{\operatorname{Var}}(\hat{T}) .
\end{aligned}
$$

\subsubsection{Project Fish Passage Efficiency - No Surface Passage}

The project-wide FPE with no surface bypass was estimated by the quotient

$$
\widehat{F P E}_{N S}=\frac{[\hat{S}+\widehat{H G}]}{[\widehat{H U}+\widehat{H G}+\widehat{T}+\hat{S}]}
$$

where the numerator is the estimated spillway and B2 bypass guided passage, respectively, and the denominator is the total project passage composed of B2 unguided, B2 guided, B1 turbine, and spillway passage, respectively. Sluiceway and B2CC passage were ignored. Project FPE can be alternatively expressed as

$$
\widehat{F P E}_{N S}=\frac{\hat{G}}{\hat{G}+\hat{U}},
$$

where

$$
\begin{aligned}
& \hat{G}=\hat{S}+\widehat{H G}, \\
& \hat{U}=\widehat{H U}+\hat{T} .
\end{aligned}
$$

The variance of $\widehat{F P E}$ can then be estimated by

$$
\widehat{\operatorname{Var}}\left(\widehat{F P E_{N S}}\right)=\widehat{F P E}_{N S}^{2}\left(1-\widehat{F P E}_{N S}\right)^{2}\left[\frac{\widehat{\operatorname{Var}}(\hat{G})}{\hat{G}^{2}}+\frac{\widehat{\operatorname{Var}}(\hat{U})}{\hat{U}^{2}}\right] \text {, }
$$

where

$$
\begin{aligned}
& \widehat{\operatorname{Var}}(\hat{G})=\widehat{\operatorname{Var}}(\hat{S})+\widehat{\operatorname{Var}}(\widehat{H G}), \\
& \widehat{\operatorname{Var}}(\hat{U})=\widehat{\operatorname{Var}}(\widehat{H U})+\widehat{\operatorname{Var}}(\hat{T}) .
\end{aligned}
$$




\subsubsection{Project Fish Passage Efficiency (B2 + Spillway only)}

The project-wide FPE ignoring B1 passage was estimated by the quotient

$$
\widehat{F P E_{B 2+\text { Spill }}}=\frac{[\hat{S}+\widehat{H G}+\widehat{C C}]}{[\widehat{H U}+\widehat{H G}+\widehat{C C}+\hat{S}]},
$$

where the numerator is the estimated spillway, B2 bypass guided, and B2CC passage, respectively, and the denominator is the total project passage ignoring B1 passage and is composed of B2 unguided, B2 guided, B1 turbine, B2CC, and spillway passage, respectively. Project FPE for B2 and the spillway only can be alternatively expressed as

where

$$
\widehat{F P E_{B 2+\text { Spill }}}=\frac{\hat{G}}{\hat{G}+\hat{U}}
$$

$$
\begin{aligned}
& \hat{G}=\hat{S}+\widehat{H G}+\widehat{C C}, \\
& \hat{U}=\widehat{H U} .
\end{aligned}
$$

The variance of $\widehat{F P E}_{B 2+\text { Spill }}$ was estimated by

$$
\widehat{\operatorname{Var}}\left(\widehat{F P E_{B 2+\text { Spill }}}\right)={\widehat{F P E_{B 2+\text { Spill }}}}^{2}\left(1-{\widehat{F P E_{B 2+\text { Spill }}}}^{2}\left[\frac{\widehat{\operatorname{Var}}(\hat{G})}{\hat{G}^{2}}+\frac{\widehat{\operatorname{Var}}(\hat{U})}{\hat{U}^{2}}\right]\right. \text {, }
$$

where

$$
\begin{aligned}
& \widehat{\operatorname{Var}}(\hat{G})=\widehat{\operatorname{Var}}(\hat{S})+\widehat{\operatorname{Var}}(\widehat{H G})+\widehat{\operatorname{Var}}(\widehat{C C}), \\
& \widehat{\operatorname{Var}}(\hat{U})=\widehat{\operatorname{Var}}(\widehat{H U})
\end{aligned}
$$

\subsubsection{B1 Fish Passage Efficiency (B1 FPE)}

For B1, FPE is estimated by the quantity

$$
\widehat{F P E}_{B 1}=\frac{\widehat{S L}}{\hat{T}+\widehat{S L}},
$$

with the associated variance estimator

$$
\widehat{\operatorname{Var}}\left(\widehat{F P E}_{B 1}\right)=\widehat{F P E}_{B 1}^{2}\left(1-\widehat{F P E}_{B 1}\right)^{2}\left[\frac{\widehat{\operatorname{Var}}(\widehat{S L})}{\widehat{S L}^{2}}+\frac{\widehat{\operatorname{Var}}(\hat{T})}{\hat{T}^{2}}\right] \text {. }
$$

\subsubsection{B2 Fish Passage Efficiency (B2 FPE)}

For B2, FPE is estimated by the quantity 


$$
\widehat{F P E}_{B 2}=\frac{\widehat{H G}+\widehat{C C}}{\widehat{H U}+\widehat{H G}+\widehat{C C}}
$$

with associated variance estimator

where

$$
\widehat{\operatorname{Var}}\left(\widehat{F P E}_{B 2}\right)=\widehat{F P E}_{B 2}^{2}\left(1-\widehat{F P E}_{B 2}\right)^{2}\left[\frac{\widehat{\operatorname{Var}}(\widehat{H U})}{\widehat{H U}^{2}}+\frac{\widehat{\operatorname{Var}}\left(\hat{G}_{2}\right)}{\hat{G}_{2}^{2}}\right] \text {, }
$$

$$
\begin{aligned}
\hat{G}_{2} & =\widehat{H G}+\widehat{C C} \\
\widehat{\operatorname{Var}}\left(\hat{G}_{2}\right) & =\widehat{\operatorname{Var}}(\widehat{H G})+\widehat{\operatorname{Var}}(\widehat{C C}) .
\end{aligned}
$$

\subsubsection{B2 Fish Guidance Efficiency (B2 FGE)}

For B2, FGE is estimated by the quantity

$$
\widehat{F G E}_{B 2}=\frac{\widehat{H G}}{\widehat{H U}+\widehat{H G}}
$$

where the numerator is the sum of guided fish in all B2 turbines and the denominator is the sum of unguided fish and guided fish in B2 turbines. Surface collection at the B2CC is ignored. The associated variance estimator is

$$
\widehat{\operatorname{Var}}\left(\widehat{F G E_{B 2}}\right)=\widehat{F G E}_{B 2}^{2}\left(1-\widehat{F G E_{B 2}}\right)^{2}\left[\frac{\widehat{\operatorname{Var}}(\widehat{H U})}{\widehat{H U}^{2}}+\frac{\widehat{\operatorname{Var}}(H \hat{G})}{H \hat{G}^{2}}\right]
$$

\subsubsection{Spill Efficiency}

The spill efficiency at the Bonneville project is estimated by the quotient

$$
\widehat{S Y}=\frac{\hat{S}}{[\widehat{H U}+\widehat{H G}+\widehat{T}+\widehat{S L}+\widehat{C C}+\hat{S}]},
$$

where the numerator is the estimated spillway passage and the denominator is total project passage composed of B2 unguided, B2 guided, B1 turbine, B1 sluiceway, B2CC, and spillway passage, respectively. The variance of $\widehat{S Y}$ is estimated by the expression

$$
\widehat{\operatorname{Var}}(\widehat{S Y})=\widehat{S Y}^{2}(1-\widehat{S Y})^{2}\left[\frac{\widehat{\operatorname{Var}}(\hat{S})}{\hat{S}^{2}}+\frac{\widehat{\operatorname{Var}}(\widehat{N S})}{\widehat{N S}^{2}}\right],
$$

where

$$
\widehat{N S}=\widehat{H U}+\widehat{H G}+\widehat{T}+\widehat{S L}+\widehat{C C}
$$


and where

$$
\widehat{\operatorname{Var}}(\widehat{N S})=\widehat{\operatorname{Var}}(\widehat{H U})+\widehat{\operatorname{Var}}(\widehat{H G})+\widehat{\operatorname{Var}}(\hat{T})+\widehat{\operatorname{Var}}(\widehat{S L})+\widehat{\operatorname{Var}}(\widehat{C C})
$$

\subsubsection{Spill Efficiency - B2 and Spill Only}

The spill efficiency at the Bonneville project when B1 passage is ignored is estimated by the quotient

$$
\widehat{S Y_{\text {B2+Spill }}}=\frac{\hat{S}}{[\widehat{H U}+\widehat{H G}+\widehat{C C}+\hat{S}]},
$$

where the numerator is the estimated spillway passage and the denominator is total project passage composed of B2 unguided, B2 guided, B1 turbine, B1 sluiceway, B2CC, and spillway passage, respectively. The variance of $\widehat{S Y}$ is estimated by the expression

$$
\widehat{\operatorname{Var}}\left(\widehat{S Y_{B 2+\text { Spill }}}\right)={\widehat{S Y_{B 2+\text { Spill }}}}^{2}\left(1-\widehat{S Y}_{B 2+\text { Spill }}\right)^{2}\left[\frac{\widehat{\operatorname{Var}}(\hat{S})}{\hat{S}^{2}}+\frac{\widehat{\operatorname{Var}}(\widehat{N S})}{\widehat{N S}^{2}}\right]
$$

where

$$
\widehat{N S}=\widehat{H U}+\widehat{H G}+\widehat{C C},
$$

and where

$$
\widehat{\operatorname{Var}}(\widehat{N S})=\widehat{\operatorname{Var}}(\widehat{H U})+\widehat{\operatorname{Var}}(\widehat{H G})+\widehat{\operatorname{Var}}(\widehat{C C})
$$

\subsubsection{Spill Effectiveness}

The spill effectiveness at the Bonneville project is estimated by the quantity

$$
\widehat{S E}=\frac{\left(\frac{\hat{S}}{V_{S}}\right)}{\frac{(\widehat{N S}+\hat{S})}{V_{T}}}=\widehat{S Y} \cdot \frac{V_{T}}{V_{S}},
$$

where

$$
\begin{aligned}
& \hat{S}=\text { spill passage, } \\
& V_{S}=\text { volume of water spilled, } \\
& \widehat{N S}=\widehat{H U}+\widehat{H G}+\widehat{T}+\widehat{S L}+\widehat{C C}, \\
& V_{T}=\text { total volume of water passing the dam during the period of inference, and } \\
& \widehat{S Y}=\text { spill efficiency. }
\end{aligned}
$$

The variance of $\widehat{S E}$ can be estimated by 


$$
\widehat{\operatorname{Var}}(\widehat{S E})=\left(\frac{V_{T}}{V_{S}}\right)^{2} \cdot \widehat{\operatorname{Var}}(\widehat{S Y})
$$

\subsubsection{Spill Effectiveness - B2 and Spillway Only}

The spill effectiveness at the Bonneville project ignoring B1 passage is estimated by the quantity

$$
\widehat{S E_{B 2+\text { Spill }}}=\frac{\left(\frac{\hat{S}}{V_{S}}\right)}{\frac{(\widehat{N S}+\hat{S})}{V_{T}}}=\widehat{S Y}{ }_{B 2+\text { Spill }} \cdot \frac{V_{T}}{V_{S}},
$$

where

$\hat{S}=$ spill passage,

$V_{S}=$ volume of water spilled,

$\widehat{N S}=\widehat{H U}+\widehat{H G}+\widehat{C C}$,

$V_{T}=$ total volume of water passing the dam during the period of inference, and

$\widehat{S Y_{B 2+S p i l l}}=$ spill efficiency.

The variance of $\widehat{S E}$ can be estimated by

$$
\widehat{\operatorname{Var}}\left(\widehat{S E_{B 2+\text { Spill }}}\right)=\left(\frac{V_{T}}{V_{S}}\right)^{2} \cdot \widehat{\operatorname{Var}}\left(\widehat{S Y_{B 2+\text { Spill }}}\right) .
$$

\subsubsection{Project Sluiceway Efficiency}

Across the entire project, sluiceway efficiency is estimated by the quantity

$$
\widehat{S L Y}=\frac{\widehat{S L+\widehat{C C}}}{\widehat{H U}+\widehat{H G}+\hat{T}+\widehat{C C}+\widehat{S}+\widehat{S L}},
$$

where the numerator is the estimated $\mathrm{B} 1$ sluiceway passage and $\mathrm{B} 2 \mathrm{CC}$ passage and the denominator is the total project passage composed of B2 unguided, B2 guided, B1 turbine, B2CC, spillway, and B1 sluiceway passage, respectively. The variance of $\widehat{S L Y}$ is estimated by the quantity

$$
\widehat{\operatorname{Var}}(\widehat{S L Y})=\widehat{S L Y}^{2}(1-\widehat{S L Y})^{2}\left[\frac{\widehat{\operatorname{Var}}(\widehat{S L+C C})}{\widehat{S L+C C}^{2}}+\frac{\widehat{\operatorname{Var}}(\widehat{N S L})}{\widehat{N S L}^{2}}\right],
$$

where

$$
\widehat{N S L}=\widehat{H U}+\widehat{H G}+\widehat{T}+\hat{S}
$$

and where

$$
\widehat{\operatorname{Var}}(\widehat{N S L})=\widehat{\operatorname{Var}}(\widehat{H U})+\widehat{\operatorname{Var}}(\widehat{H G})+\widehat{\operatorname{Var}}(\hat{T})+\widehat{\operatorname{Var}}(\hat{S})
$$




\subsubsection{Project Sluiceway Effectiveness}

Project-wide sluiceway effectiveness was estimated by the quantity

$$
\begin{aligned}
& \widehat{S L E}=\frac{\left(\frac{\widehat{S L+C C}}{V_{S L}+V_{C C}}\right)}{\left(\frac{\widehat{H U}+\widehat{H G}+\widehat{T}+\widehat{C C}+\hat{S}+\widehat{S L}}{V_{T}}\right)} \\
& =\widehat{S L Y}\left(\frac{V_{T}}{V_{S L}+V_{C C}}\right)
\end{aligned}
$$

with associated variance estimator

$$
\widehat{\operatorname{Var}}(\widehat{S L E})=\left(\frac{V_{T}}{V_{S L}+V_{C C}}\right)^{2} \cdot \widehat{\operatorname{Var}}(\widehat{S L Y})
$$

where

$V_{T}=$ total volume of water passing through the project,

$V_{S L}=$ volume of water passing through the sluiceways at B1,

$V_{C C}=$ volume of water passing through the $\mathrm{B} 2 \mathrm{CC}$; other variables are as defined previously.

\subsubsection{B1 Sluiceway Efficiency Relative to the Project Passage}

Across the entire project, B1 sluiceway efficiency is estimated by the quantity

$$
\widehat{S L Y_{B 1: P}}=\frac{\widehat{S L}}{\widehat{H U}+\widehat{H G}+\widehat{T}+\widehat{C C}+\widehat{S}+\widehat{S L}},
$$

where the numerator is the estimated sluiceway passage through B1 only and the denominator is the total project passage composed of B2 unguided, B2 guided, B1 turbine, B2CC, spillway, and B1 sluiceway passage, respectively. The variance of $\widehat{S L Y}_{B 1}$ is estimated by the quantity

$$
\widehat{\operatorname{Var}}\left(\widehat{S L Y_{B 1: P}}\right)={\widehat{S L Y_{B 1: P}}}^{2}\left(1-\widehat{S L Y_{B 1: P}}\right)^{2}\left[\frac{\widehat{\operatorname{Var}}(\widehat{S L})}{\widehat{S L}^{2}}+\frac{\widehat{\operatorname{Var}}(\widehat{N S L})}{\widehat{N S L}^{2}}\right],
$$

where

$$
\widehat{N S L}=\widehat{H U}+\widehat{H G}+\widehat{T}+\hat{S}
$$

and where

$$
\widehat{\operatorname{Var}}(\widehat{N S L})=\widehat{\operatorname{Var}}(\widehat{H U})+\widehat{\operatorname{Var}}(\widehat{H G})+\widehat{\operatorname{Var}}(\hat{T})+\widehat{\operatorname{Var}}(\hat{S})
$$




\subsubsection{B1 Sluiceway Efficiency Relative to B1 Passage}

Relative to B1 passage, B1 sluiceway efficiency is estimated by the quantity

$$
\widehat{S L Y_{B 1: B 1}}=\frac{\widehat{S L}}{\widehat{T}+\widehat{S L}}
$$

where the numerator is the estimated sluiceway passage through $\mathrm{B} 1$ only and the denominator is the total project passage composed of $\mathrm{B} 2$ unguided, $\mathrm{B} 2$ guided, $\mathrm{B} 1$ turbine, $\mathrm{B} 2 \mathrm{CC}$, spillway, and $\mathrm{B} 1$ sluiceway passage, respectively. The variance of $\widehat{S L Y}_{B 1}$ is estimated by the quantity

$$
\widehat{\operatorname{Var}}\left(\widehat{S L Y_{B 1: B 1}}\right)={\widehat{S L Y_{B 1: B 1}}}^{2}\left(1-\widehat{S L Y_{B 1: B 1}}\right)^{2}\left[\frac{\widehat{\operatorname{Var}}(\widehat{S L})}{\widehat{S L}^{2}}+\frac{\widehat{\operatorname{Var}}(\hat{T})}{\widehat{T}^{2}}\right] \text {, }
$$

where

$$
\widehat{T}=\mathrm{B} 1 \text { turbine passage }
$$

\subsubsection{B1 Sluiceway Effectiveness Relative to the Project}

B1 sluiceway effectiveness relative to the Project was estimated by the quantity

$$
\begin{aligned}
\widehat{S L E_{B 1: P}} & =\frac{\left(\frac{\widehat{S L}}{V_{S L}}\right)}{\left(\frac{\widehat{H U}+\widehat{H G}+\widehat{T}+\widehat{C C}+\hat{S}+\widehat{S L}}{V_{T}}\right)} \\
& =\widehat{S L Y_{B 1: P}}\left(\frac{V_{T}}{V_{S L}}\right)
\end{aligned}
$$

with associated variance estimator

$$
\widehat{\operatorname{Var}}\left(\widehat{S L E_{B 1: P}}\right)=\left(\frac{V_{T}}{V_{S L}}\right)^{2} \cdot \widehat{\operatorname{Var}}\left(\widehat{S L Y_{B 1: P}}\right),
$$

where

$$
\begin{aligned}
& V_{T}=\text { total volume of water passing through the project, } \\
& V_{S L}=\text { volume of water passing through the sluiceways at B1. }
\end{aligned}
$$

\subsubsection{B1 Sluiceway Effectiveness Relative to B1}

B1 sluiceway effectiveness relative to B1 was estimated by the quantity 


$$
\begin{aligned}
\widehat{S L E_{B 1: B 1}} & =\frac{\left(\frac{\widehat{S L}}{V_{S L}}\right)}{\left(\frac{\widehat{H U}+\widehat{H G}+\widehat{T}+\widehat{C C}+\hat{S}+\widehat{S L}}{V_{B 1}}\right)} \\
& =\widehat{S L Y_{B 1: B 1}}\left(\frac{V_{B 1}}{V_{S L}}\right)
\end{aligned}
$$

with associated variance estimator

$$
\widehat{\operatorname{Var}}\left(\widehat{S L E_{B 1: B 1}}\right)=\left(\frac{V_{B 1}}{V_{S L}}\right)^{2} \cdot \widehat{\operatorname{Var}}\left(\widehat{S L Y_{B 1: B 1}}\right),
$$

where

$$
\begin{aligned}
& V_{B 1}=\text { total volume of water passing through } \mathrm{B} 1, \\
& V_{S L}=\text { volume of water passing through the sluiceways at B1. }
\end{aligned}
$$

\subsubsection{B2CC Efficiency Relative to Project Passage}

The B2CC efficiency relative to the Project is estimated by the quotient

$$
\widehat{C C Y}=\frac{\widehat{C C}}{\widehat{H U}+\widehat{H G}+\widehat{T}+\hat{S}+\widehat{S L}+\widehat{C C}},
$$

where the numerator is the estimate of corner collector passage and the denominator is the total project passage composed of B2 unguided, B2 guided, B1 turbine, spillway, B1 sluiceway, and B2CC passage, respectively. The variance of $\widehat{C C E}$ is estimated by the quantity

$$
\widehat{\operatorname{Var}}(\widehat{C C Y})=\widehat{C C Y}^{2}(1-\widehat{C C Y})^{2}\left[\frac{\widehat{\operatorname{Var}}(\widehat{C C})}{\widehat{C C}^{2}}+\frac{\widehat{\operatorname{Var}}(\widehat{N C C})}{\widehat{N C C}^{2}}\right],
$$

where

$$
\widehat{N C C}=\widehat{H U}+\widehat{H G}+\widehat{T}+\hat{S}+\widehat{S L}
$$

and where

$$
\widehat{\operatorname{Var}}(\widehat{N C C})=\widehat{\operatorname{Var}}(\widehat{H U})+\widehat{\operatorname{Var}}(\widehat{H G})+\widehat{\operatorname{Var}}(\hat{T})+\widehat{\operatorname{Var}}(\hat{S})+\widehat{\operatorname{Var}}(\widehat{S L})
$$

\subsubsection{B2CC Efficiency Relative to B2 Passage}

The $\mathrm{B} 2 \mathrm{CC}$ efficiency relative to $\mathrm{B} 2$ passage is estimated by the quotient

$$
\widehat{C C Y_{B 2}}=\frac{\widehat{C C}}{\widehat{H U}+\widehat{H G}+\widehat{C C}}
$$


where the numerator is the estimate of corner collector passage and the denominator is B2 passage composed of $\mathrm{B} 2$ unguided, $\mathrm{B} 2$ guided, and $\mathrm{B} 2 \mathrm{CC}$ passage, respectively. The variance of $\widehat{C C Y}_{B 2}$ is estimated by the quantity

$$
\widehat{\operatorname{Var}}\left(\widehat{C C Y_{B 2}}\right)={\widehat{C C Y_{B 2}}}^{2}\left(1-{\widehat{C C Y_{B 2}}}^{2}\right)^{2}\left[\frac{\widehat{\operatorname{Var}}(\widehat{C C})}{\widehat{C C}^{2}}+\frac{\widehat{\operatorname{Var}}\left(\widehat{N C C_{B 2}}\right)}{\widehat{N C C}_{B 2}^{2}}\right],
$$

where

$$
\widehat{N C C_{B 2}}=\widehat{H U}+\widehat{H G}
$$

and where

$$
\widehat{\operatorname{Var}}\left(\widehat{N C C_{B 2}}\right)=\widehat{\operatorname{Var}}(\widehat{H U})+\widehat{\operatorname{Var}}(\widehat{H G})
$$

\subsubsection{B2CC Effectiveness Relative to the Project}

Project-wide corner collector effectiveness is estimated by the quantity

$$
\begin{aligned}
\widehat{C C E} & =\frac{\left(\frac{\widehat{C C}}{V_{C C}}\right)}{\left(\frac{\widehat{H U}+\widehat{H G}+\widehat{T}+\hat{S}+\widehat{S L}+\widehat{C C}}{V_{T}}\right)} \\
& =C C Y\left(\frac{V_{T}}{V_{C C}}\right),
\end{aligned}
$$

with an associated variance estimator

$$
\widehat{\operatorname{Var}}(\widehat{C C E})=\left(\frac{V_{T}}{V_{C C}}\right)^{2} \cdot \widehat{\operatorname{Var}}(\widehat{C C Y})
$$

where

$V_{T}=$ total volume of water passing through the project, and $V_{C C}=$ volume of water passing through the corner collector. 


\subsubsection{B2CC Effectiveness Relative to B2}

Project-wide corner collector effectiveness relative to $\mathrm{B} 2$ is estimated by the quantity

$$
\begin{aligned}
\widehat{C C E_{B 2}} & =\frac{\left(\frac{\widehat{C C}}{V_{C C}}\right)}{\left(\frac{\widehat{H U}+\widehat{H G}+\widehat{T}+\hat{S}+\widehat{S L}+\widehat{C C}}{V_{B 2}}\right)} \\
& =C C Y_{B 2}\left(\frac{V_{B 2}}{V_{C C}}\right),
\end{aligned}
$$

with an associated variance estimator

$$
\widehat{\operatorname{Var}}\left(\widehat{C C E_{B 2}}\right)=\left(\frac{V_{B 2}}{V_{C C}}\right)^{2} \cdot \widehat{\operatorname{Var}}\left(\widehat{C C Y_{B 2}}\right)
$$

where

$$
\begin{aligned}
& V_{C C}=\text { volume of water passing through the corner collector, and } \\
& V_{B 2}=\text { volume of water passing through B2. }
\end{aligned}
$$

\subsubsection{Combined Sluiceway and Corner Collector Efficiency}

The estimate of the combined sluiceway and corner collector efficiency is calculated by the quantity

$$
\widehat{C S L C C E}=\frac{\widehat{S L}+\widehat{C C}}{\widehat{H U}+\widehat{H G}+\widehat{T}+\hat{S}+\widehat{S L}+\widehat{C C}}
$$

where the numerator estimates smolt passage through the sluiceway and corner collector, and the denominator is the total project passage. The variance of CSLCCE is estimated by the quantity

$$
\widehat{\operatorname{Var}}(\widehat{C S L C C E})=\widehat{C S L C C E}^{2}(1-\widehat{C S L C C E})^{2}\left[\frac{\widehat{\operatorname{Var}}(\hat{A})}{\hat{A}^{2}}+\frac{\widehat{\operatorname{Var}}(\hat{B})}{\hat{B}^{2}}\right],
$$

where

$$
\begin{aligned}
\hat{A} & =\widehat{S L}+\widehat{C C}, \\
\widehat{\operatorname{Var}}(\hat{A}) & =\widehat{\operatorname{Var}}(\widehat{S L})+\widehat{\operatorname{Var}}(\widehat{C C}), \\
\hat{B} & =\widehat{H U}+\widehat{H G}+\hat{T}+\hat{S}, \\
\widehat{\operatorname{Var}}(\hat{B}) & =\widehat{\operatorname{Var}}(\widehat{H U})+\widehat{\operatorname{Var}}(\widehat{H G})+\widehat{\operatorname{Var}}(\widehat{T})+\widehat{\operatorname{Var}}(\hat{S}) .
\end{aligned}
$$




\subsubsection{Combined Sluiceway and Corner Collector Effectiveness}

Project-wide sluiceway and corner collector effectiveness is estimated by the quantity

$$
\begin{aligned}
\widehat{C S L C C N} & =\frac{\left(\frac{\widehat{S L}+\widehat{C C}}{V_{S L}+V_{C C}}\right)}{\left(\frac{\widehat{H U}+\widehat{H G}+\widehat{T}+\hat{S}+\widehat{S L}+\widehat{C C}}{V_{T}}\right)} \\
& =C S L C C E \cdot\left(\frac{V_{T}}{V_{S L}+V_{C C}}\right)
\end{aligned}
$$

with an associated variance estimator

$$
\widehat{\operatorname{Var}}(\widehat{C S L C C N})=\left(\frac{V_{T}}{V_{S L}+V_{C C}}\right)^{2} \cdot \widehat{\operatorname{Var}}(\widehat{C S L C C E}) .
$$

\subsubsection{Localized B2 Corner Collector Efficiency}

The localized efficiency of the corner collector in the vicinity of turbine Units 11-18 is estimated by the quantity

$$
\widehat{L C C E}=\frac{\widehat{C C}}{\widehat{H U}_{11-18}+\widehat{H G}_{11-18}+\widehat{C C}}
$$

where

$$
\begin{aligned}
& \widehat{H U}_{11-18}=\text { estimated unguided fish passage through Units 11-18, B2; } \\
& \widehat{H G}_{11-18}=\text { estimated guided fish passage through Units 11-18, B2. }
\end{aligned}
$$

The variance of $\widehat{L C C E}$ is estimated by the quantity

$$
\widehat{\operatorname{Var}}(\widehat{L C C E})=\widehat{L C C E}^{2}(1-\widehat{L C C E})^{2}\left[\frac{\widehat{\operatorname{Var}}(\widehat{C C})}{\widehat{C C}^{2}}+\frac{\widehat{\operatorname{Var}}(\hat{L})}{\hat{L}^{2}}\right],
$$

where

$$
\begin{aligned}
\hat{L} & =\widehat{H U}_{11-18}+\widehat{H G}_{11-18} \\
\widehat{\operatorname{Var}}(\hat{L}) & =\widehat{\operatorname{Var}}\left(\widehat{H U}_{11-18}\right)+\widehat{\operatorname{Var}}\left(\widehat{H G}_{11-18}\right)
\end{aligned}
$$




\subsubsection{Localized B2 Corner Collector Effectiveness}

The localized effectiveness of the corner collector in the vicinity of turbine Units 11-18 is estimated by the quantity

$$
\begin{aligned}
\widehat{L C C N} & =\frac{\left(\frac{\widehat{C C}}{V_{C C}}\right)}{\left(\frac{\widehat{H U}_{11-18}+\widehat{H G}_{11-18}+\widehat{C C}}{V_{L}}\right)} \\
& =\left(\frac{V_{L}}{V_{C C}}\right) \widehat{L C C E},
\end{aligned}
$$

with associated variance estimator

$$
\widehat{\operatorname{Var}}(\widehat{L C C N})=\left(\frac{V_{L}}{V_{C C}}\right)^{2} \cdot \widehat{\operatorname{Var}}(\widehat{L C C E})
$$

where

$$
V_{L}=\text { volume of water through the corner collector and turbine Units 11-18, B2. }
$$

\subsubsection{Localized B2 Fish Passage Efficiency}

The localized fish passage efficiency in the vicinity of turbine Units 11-18, B2, is estimated by the quantity

$$
\widehat{L F P E}_{2}=\frac{\widehat{H G}_{11-18}+\widehat{C C}}{\widehat{H U}_{11-18}+\widehat{H G}_{11-18}+\widehat{C C}}
$$

The variance of $\widehat{L F P E}_{2}$ is estimated by the quantity

$$
\widehat{\operatorname{Var}}\left(\widehat{L F P E}_{2}\right)=\widehat{L F P E}_{2}^{2}\left(1-\widehat{L F P E}_{2}\right)^{2}\left[\frac{\widehat{\operatorname{Var}}\left(\widehat{H U}_{11-18}\right)}{\widehat{H U}_{11-18}^{2}}+\frac{\widehat{\operatorname{Var}}(\widehat{L G})}{\widehat{L G}^{2}}\right]
$$

where

$$
\begin{aligned}
& \widehat{L G}=\widehat{H G}_{11-18}+\widehat{C C} \\
& \widehat{\operatorname{Var}}(\widehat{L G})=\widehat{\operatorname{Var}}\left(\widehat{H G}_{11-18}\right)+\widehat{\operatorname{Var}}(\widehat{C C})
\end{aligned}
$$




\subsection{Comparing Spill-Treatment and Location Effects}

We used weighted ANOVA on daily estimates of FGE to evaluate effects of intake on FGE at B2. We used Proc Mixed (SAS) to do the analysis of variance and included repeating Julian day in an AR(1) design to account for autocorrelation among data within location conditions. We tested for differences among all pairs of least-square means using the LSMEAN statement with Tukey-Kramer adjustment for the unbalanced design each season. 


\subsection{Results}

\subsection{Environmental Conditions in $\mathbf{2 0 0 5}$}

This section contains a brief description of the environmental conditions that occurred during the hydroacoustic study in 2005. These conditions include the species composition of the smolt run, Project and spillway discharge, water temperature, and forebay elevation.

\subsubsection{Run Timing and Species Composition in 2005}

The daily composition of the run was estimated from fish-count data collected at the B2 smolt monitoring facility by the Fish Passage Center. Our study, which ran from mid-April until mid-July (April 16 through July 15), encompassed most of the downstream migration period for yearling Chinook salmon (Oncorhynchus tshawytscha), coho salmon (O. kisutch), sockeye salmon (O. nerka), steelhead (O. mykiss), and subyearling Chinook salmon (Figure 3.1). Based on these data, subyearling Chinook salmon passed Bonneville Dam throughout the study period with two substantial peaks in early spring and, after the first week of summer, made up most of the B2 JBS samples. In summer, there was a large peak in the occurrence of subyearling Chinook salmon beginning on June 20 and generally declining until the end of the study. The other salmonid species were most abundant in the samples in spring with yearling Chinook salmon, coho salmon, and steelhead present throughout spring until about June 10. Sockeye salmon were present in samples only in late May and only in relatively low numbers.

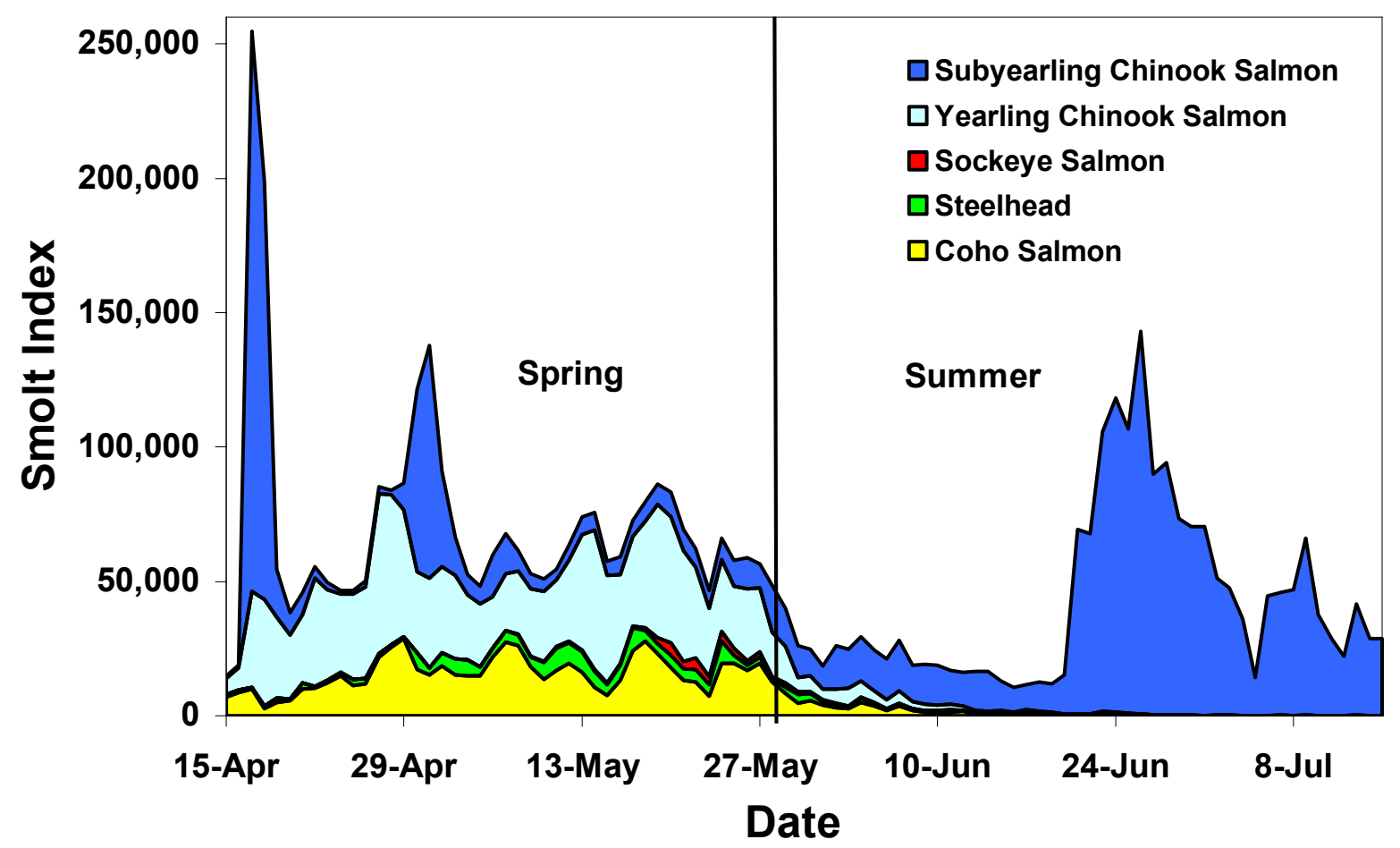

Figure 3.1. Smolt Monitoring Program (SMP) Passage Index for April 15 - July 15, 2005, Based on Data from the B2 Juvenile Bypass System. Data were obtained from the DART website (http://www.cqs.washington.edu/dart/pass_com.html). 
The run timing expressed as a daily percentage by species (Figure 3.2) and a seasonal percentage by species (Figure 3.3) indicate that the spring run was dominated by yearling Chinook salmon (45\%), followed by sub-yearling Chinook salmon (27\%), and then by coho (22\%). Most of the spring contribution by sub-yearling Chinook salmon was in two peaks on April 19 and May 1, with sub-yearling hatchery fish making up $80 \%$ and $60 \%$ of the run on those days. Daily data indicate that yearling Chinook salmon and coho each contributed at least $10 \%$ to the summer run before mid June (Figure 3.2), but sub-yearling Chinook salmon made up $94 \%$ of the entire summer run sampled between June 1 and July 15 (Figure 3.3).

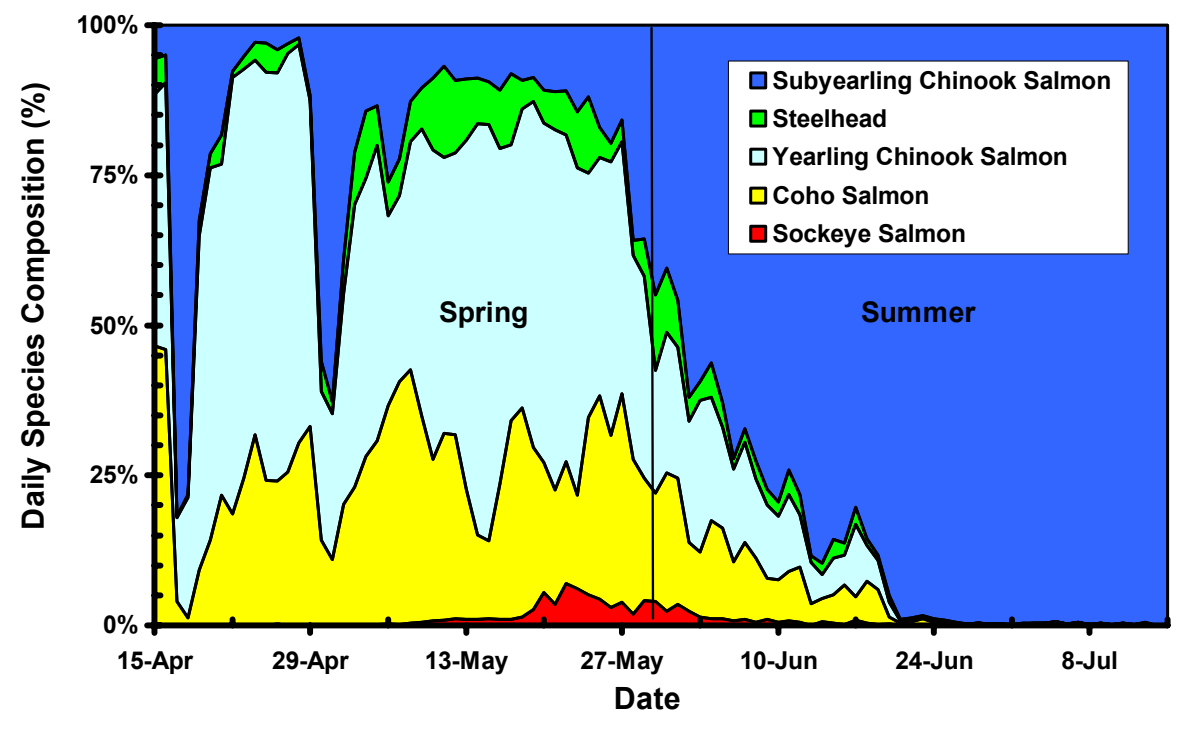

Figure 3.2. Species-Specific Distributions of Daily Passage for April 15 - July 15, 2005, Based on Data from the B2 Juvenile Bypass System. Data were obtained from the DART website (http://www.cqs.washington.edu/dart/pass_com.html).

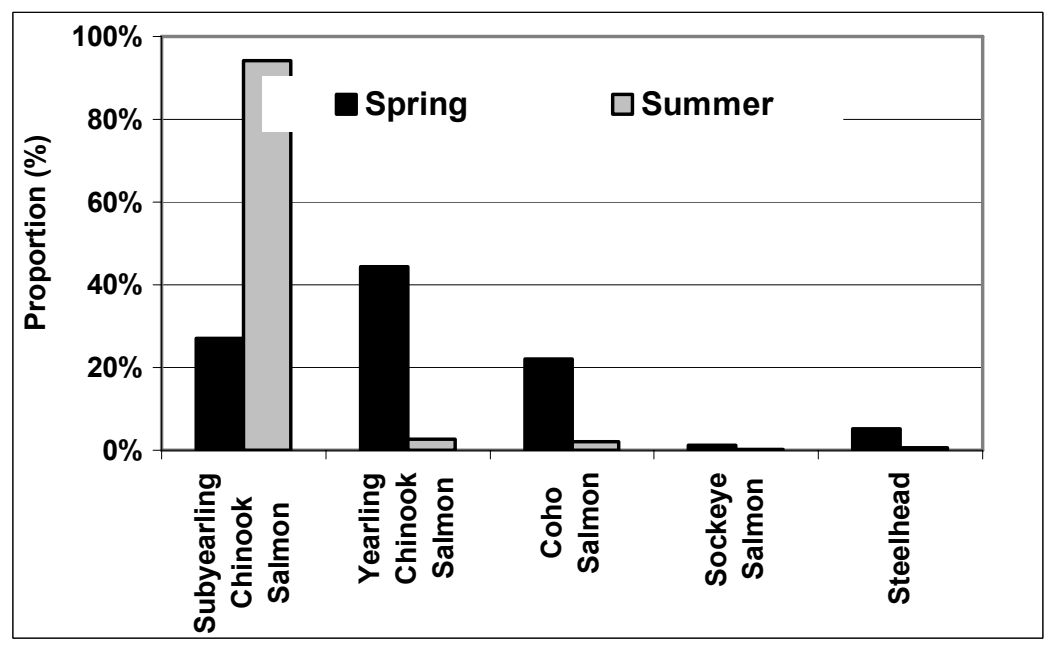

Figure 3.3. Run Composition of Juvenile Salmonids Sampled in the B2 Juvenile Bypass System. Data were obtained from the DART website http://www.cqs.washington.edu/dart/pass_com.html. 


\subsubsection{Project Discharge, Forebay Elevation, and Temperature}

Figure 3.4 depicts the daily Project discharge for 2005 (white dots) along with three other time histories for context. In 2005, there was a period of moderately high Project discharge in late May, but for most of the study period discharge was well below the 10-year average discharge (black dots with 95\% confidence limit bars). Project discharge in 2005 was substantially higher than that in the 2001 drought year (light gray dots) and much lower that that in the flood year of 1997 (dark gray dots). The Project discharge peak was in mid-May, about three weeks earlier than the ten-year average.

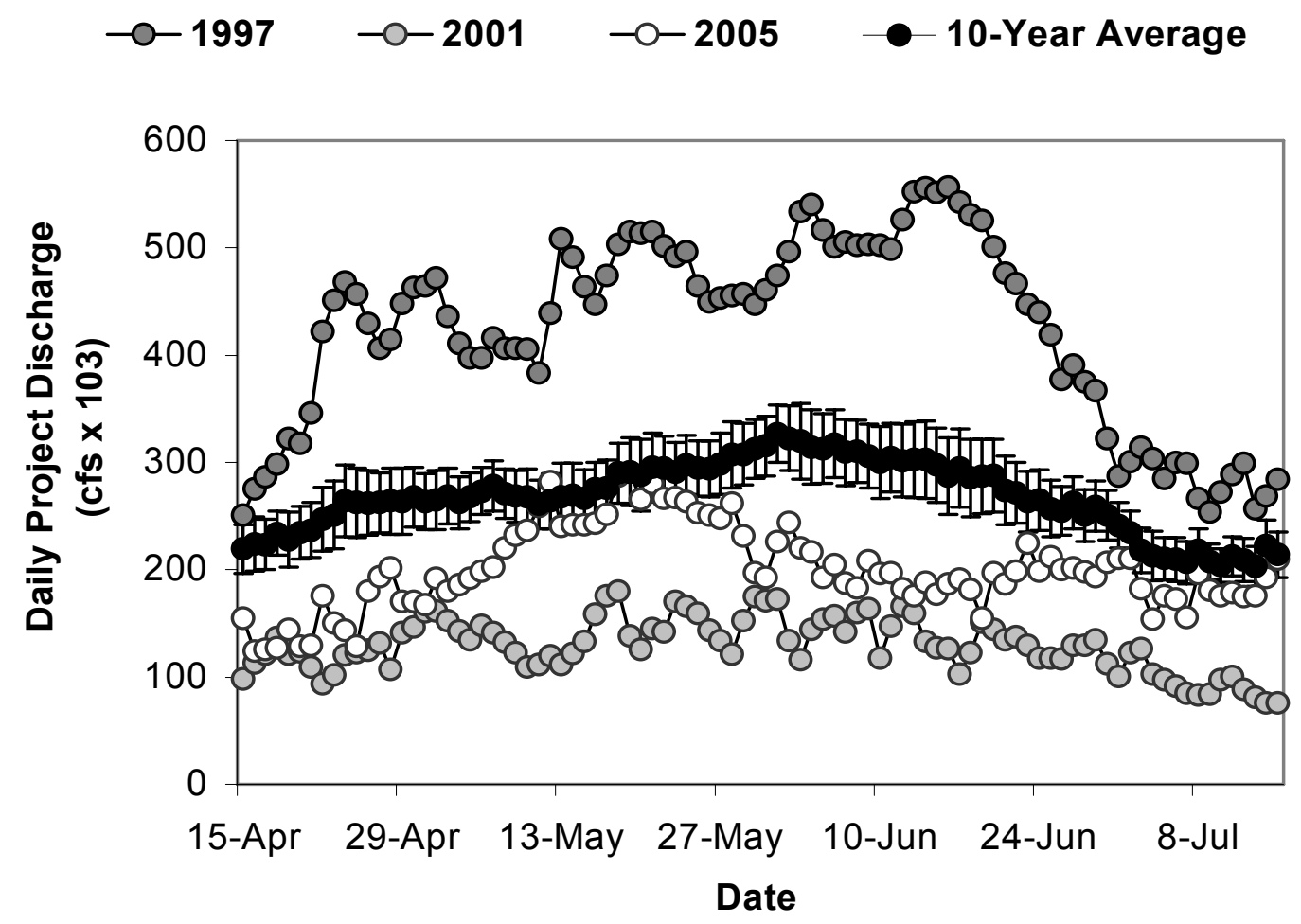

Figure 3.4. Daily Project Discharge for April 15 - July 15 in 1997 (a Flood Year, Dark Gray), 2001 (a Drought Year, Light Gray), 2005 (the Year Under Study, White), and the 10-Year (19952004) Daily Average (Black with $95 \%$ Confidence Limits). Data were obtained from the DART website (http://www.cqs.washington.edu/dart/pass_com.html).

Spillway discharge and the proportion of Project discharge spilled can have a profound effect on the passage and survival of downstream migrating fish. Although the time history of daily Project discharge varied considerably, spillway discharge, which largely is determined by the NMFS Biological Opinion, (NMFS 2000) was much more regular. In Figure 3.5, the 10-Year Average Project Discharge curve (black dots in Figure 3.5) and the 10-Year Average spillway discharge curve are approximately parallel. In 2005, when Project discharge was highest (white dots), the concurrent spillway discharge (white triangles) remained relatively low so that the proportion of total Project discharge spilled actually was lower than during the rest of the study period.

The typical diel pattern of spill observed during most of May (Figure 3.6) and all of summer (Figure 3.7) had strong nighttime peaks associated with spill to the gas cap and daytime valleys of about 75,000 cfs. 
In spring, there were six days (4-19 through 4-25) during which spill was held constant at about 72,000 cfs during day and night (Figure 3.6).

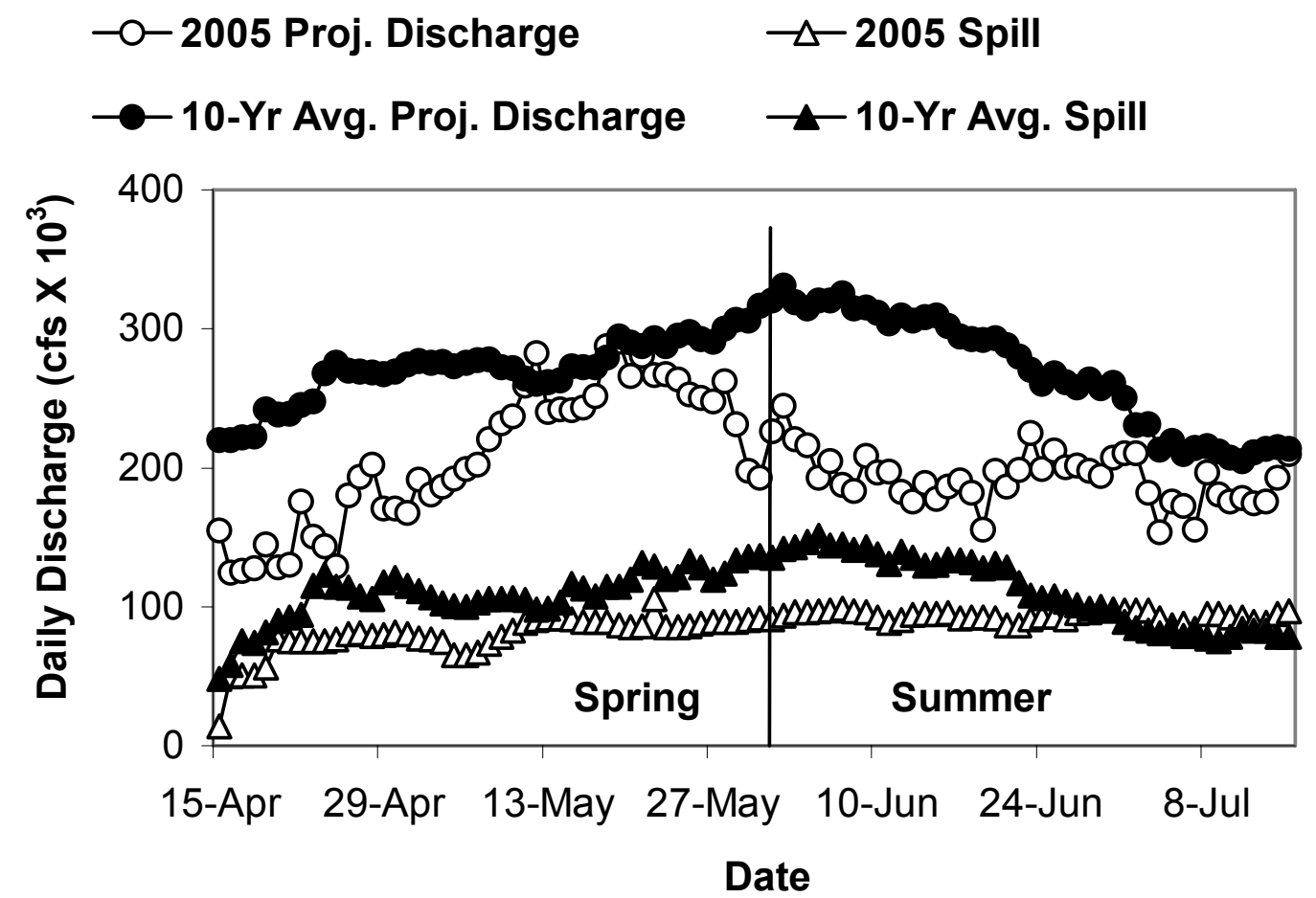

Figure 3.5. Project and Spillway Discharge Rates for 2005 and the 10-year Average from 1995 through 2004. Black dots represent the 10-Year average Project discharge and black triangles represent the 10-year average daily spillway discharge. White dots and white triangles represent the same respective data for 2005. Data were obtained from the DART website (http://www.cqs.washington.edu/dart/river.html).

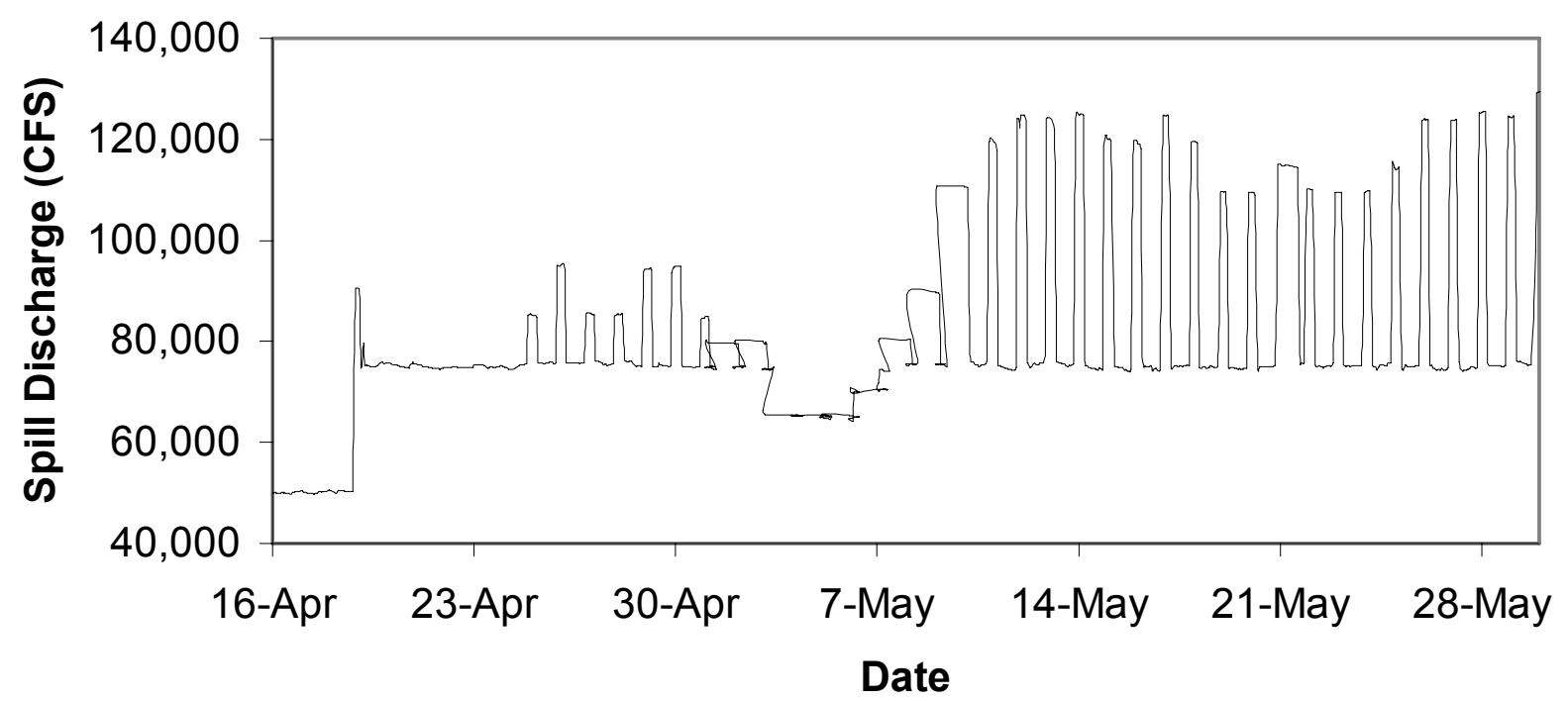

Figure 3.6. Spill Discharge Rate by Date in Spring 2005. Peaks were associated with night spill and the valleys at about 75,000 cfs occurred during the daytime. 
In spring and summer, turbine discharge generally was greater than or equal to spill discharge during the day and less than or equal to spill discharge at night. Operators had to reduce turbine discharge at night to accommodate spill to the gas cap, especially in summer (Figure 3.8), and they did so by shutting down turbines.

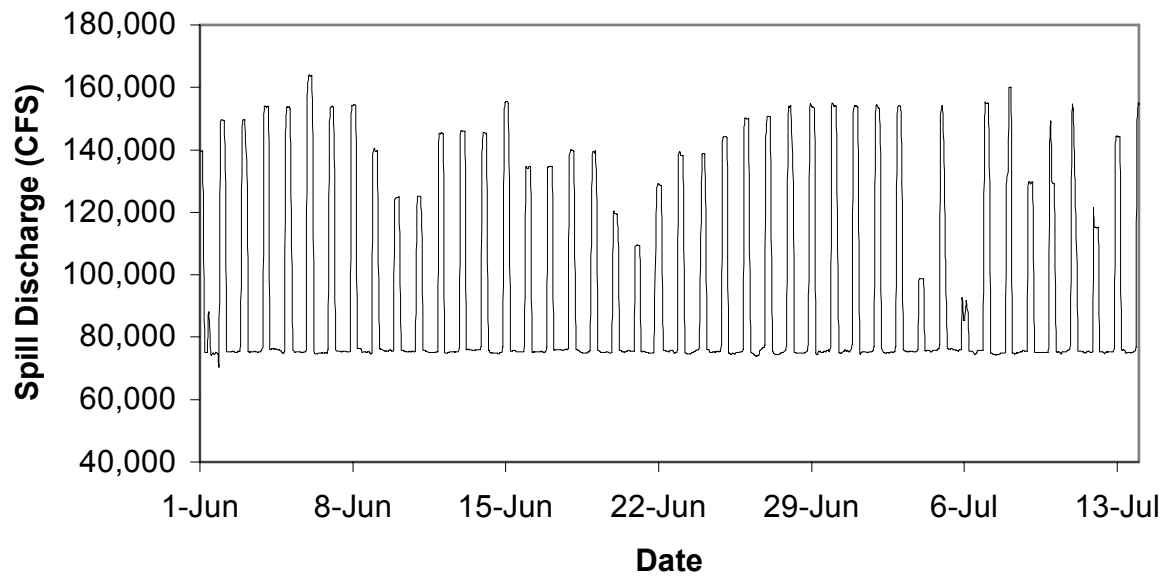

Figure 3.7. Spill Discharge Rate (cfs) by Date in Summer 2005. Peaks were associated with night spill to the gas cap, and valleys at about 75,000 cfs occurred during the day.
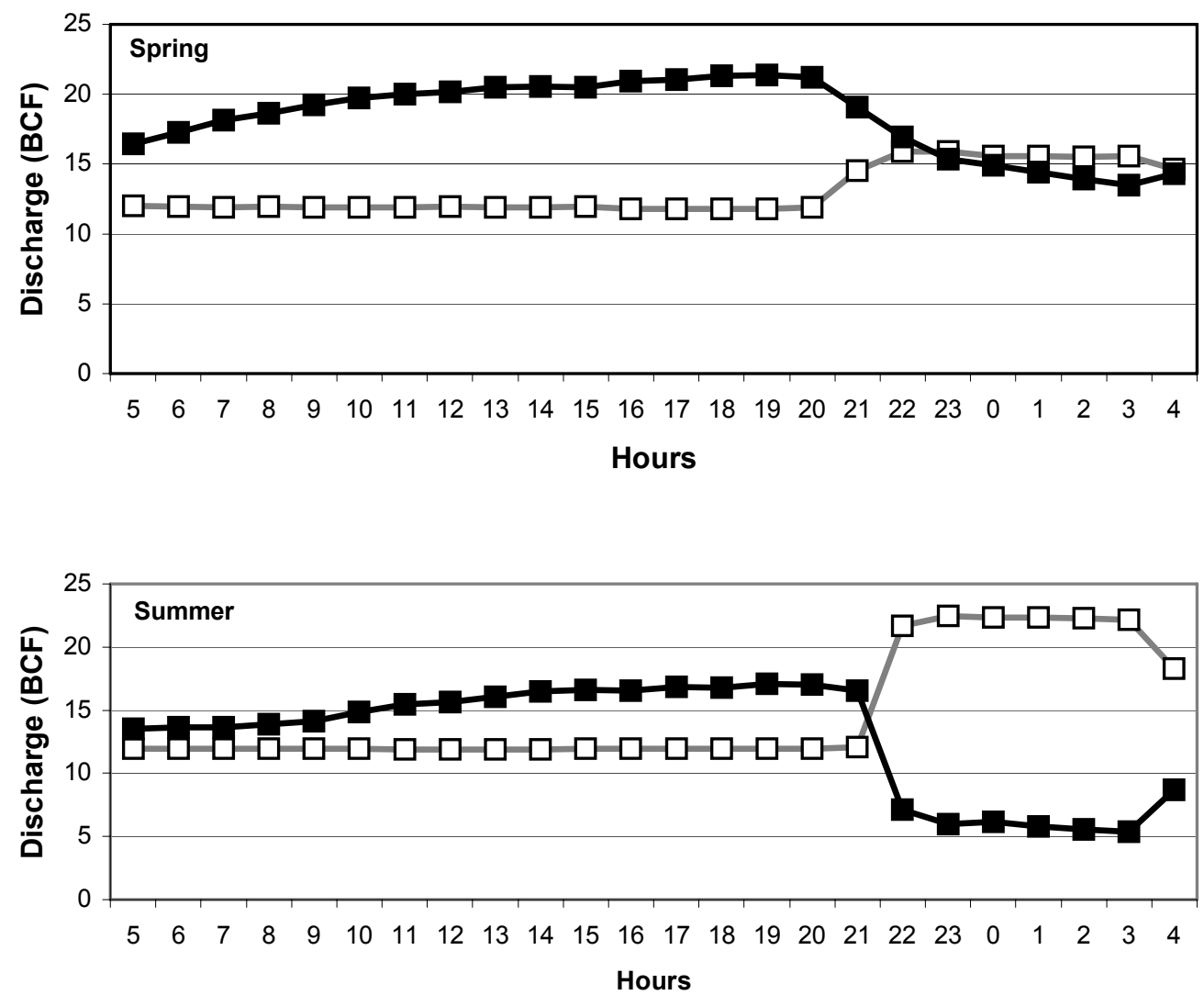

Figure 3.8. Mean Hourly Spill (White Squares) and Turbine Discharge (Black Squares) in Spring and Summer 2005. 
In spring, forebay surface elevation, which determines the rate of discharge through surface-passage routes (B2CC and B1 sluiceway outlets) usually was between 74.5 and $76.5 \mathrm{ft}$ above MSL (Figure 3.9). The spring average was $75.4 \mathrm{ft}$ above MSL. Exceptions included a brief drop to $73.5 \mathrm{ft}$ above MSL on April 22nd and a more dramatic drop, down to $71.7 \mathrm{ft}$ above MSL on April 28th. In summer, forebay surface elevations oscillated about a foot above and below $75 \mathrm{ft}$ above MSL, and the average was $75 \mathrm{ft}$ above MSL (Figure 3.9). There were several large decreases in elevation in summer. On June 22 and 29 and July 7, forebay elevation dropped to about 73, 72.5, and $71.6 \mathrm{ft}$ above MSL, respectively. After July 10 and before the end of July 13, surface elevation was mostly below $73 \mathrm{ft}$ above MSL.

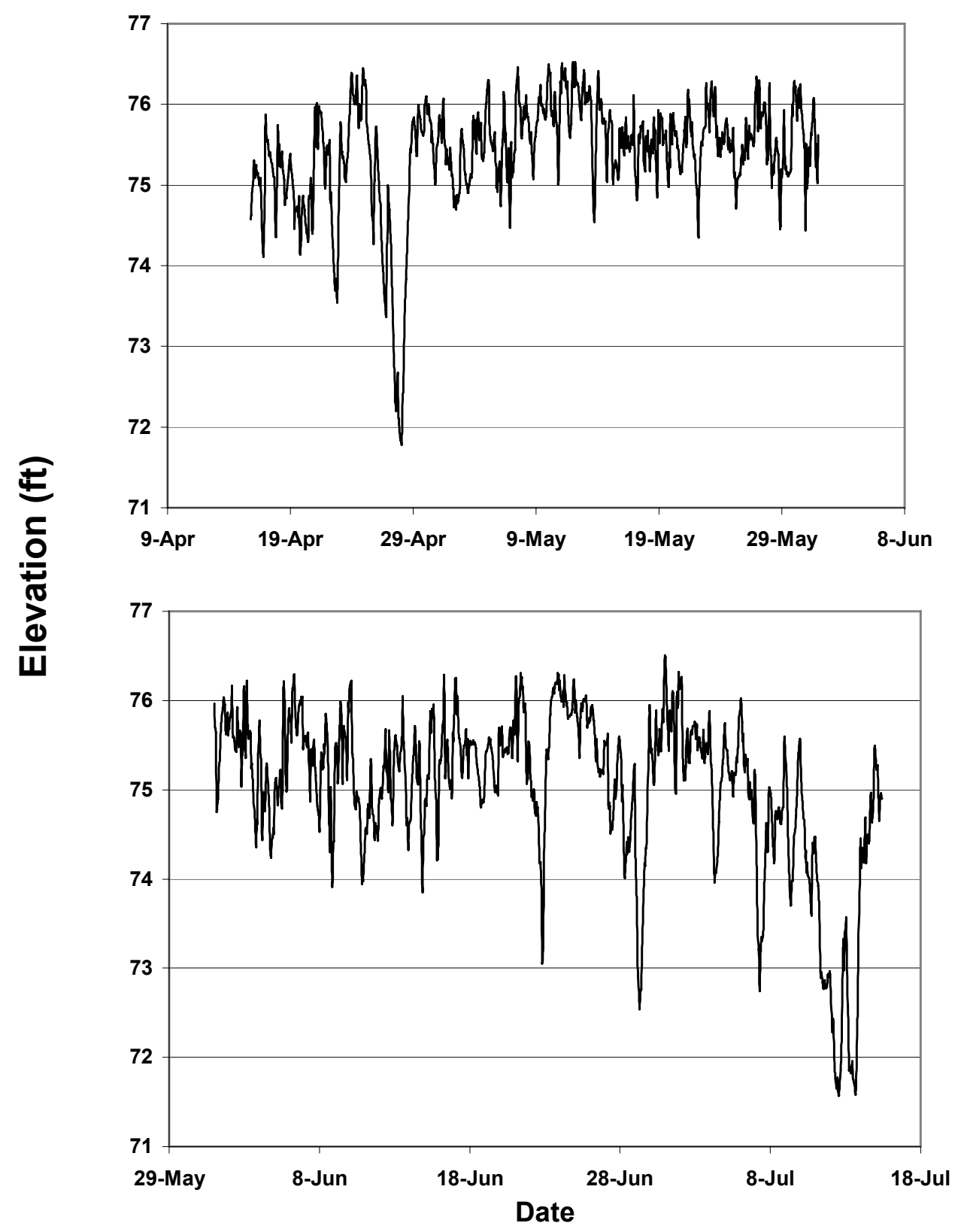

Figure 3.9. Mean Daily Forebay Elevation in 2005 (white) and 10-Year (1995-2004) Average (Black). Data from DART website (http://www.cqs.washington.edu/dart/dart.html). 
In 2005 , the daily water temperatures at the project steadily increased throughout the study period, from $9^{\circ} \mathrm{C}$ to almost $20^{\circ} \mathrm{C}$ in a pattern similar to that of the mean daily temperature for the previous ten years (1995-2004), see Figure 3.10.

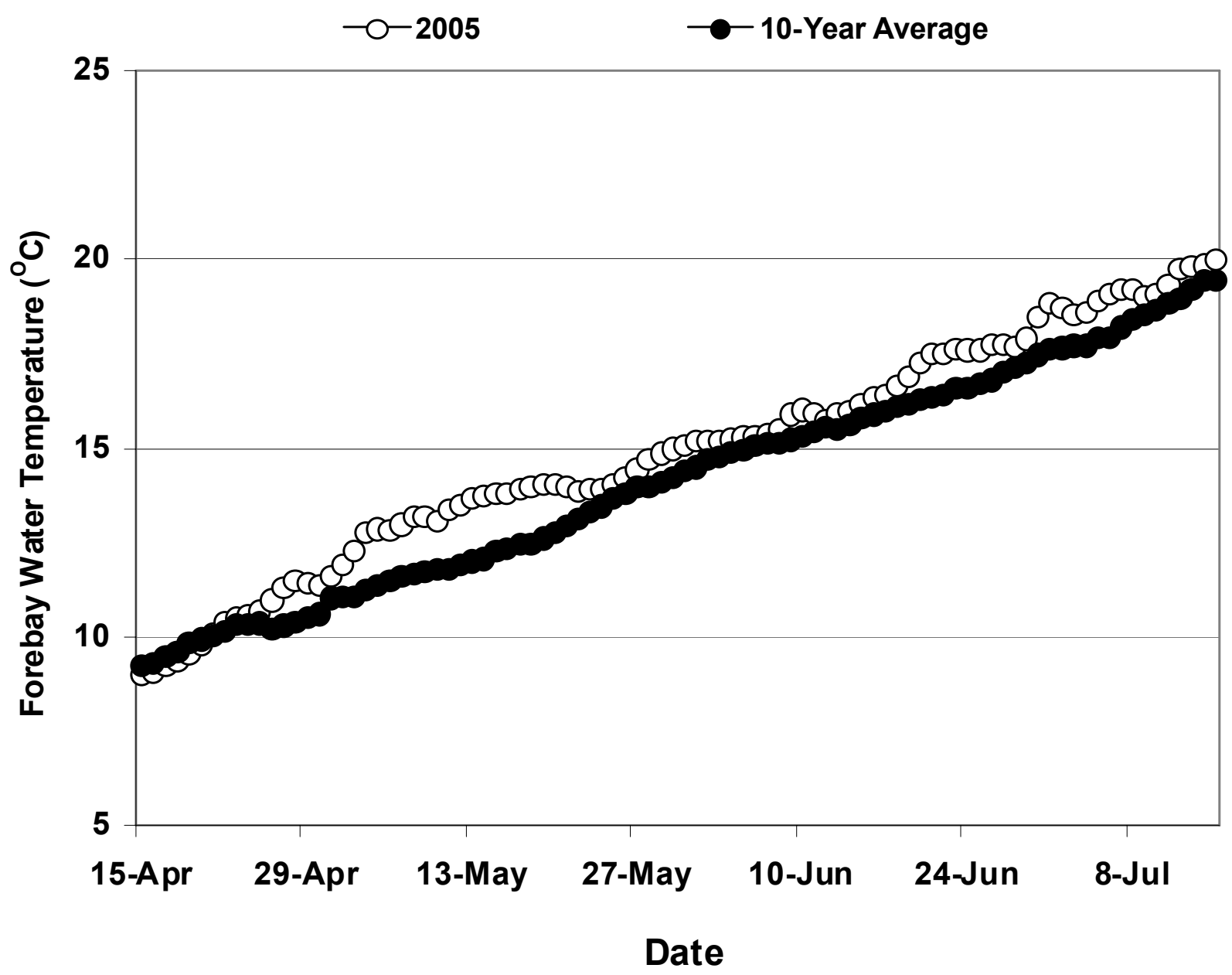

Figure 3.10. Mean Daily Forebay Temperature in 2005 (white) and 10-Year (1995-2004) Average (Black). Monitoring data from DART website (http://www.cqs.washington.edu/dart/dart.html).

\subsection{Hydroacoustic Detectability}

Except for Transducers 1 and 2 at the B2CC and B2 turbine deployments, detectability curves were above the nominal beam angles over most ranges in spring (Figure 3.11). The high EBA was most obvious for the three B1 sluiceway entrances. The EBA for B2 transducers was pretty close to the nominal beam angle over most of the range. At the B1 sluiceway, detectability was slightly higher at Entrance $6 \mathrm{C}$ than it was at Entrance 1C. At the spillway, detectability declined with increasing discharge, although the effective beam angle was above nominal even at the highest discharge level for an individual bay. 

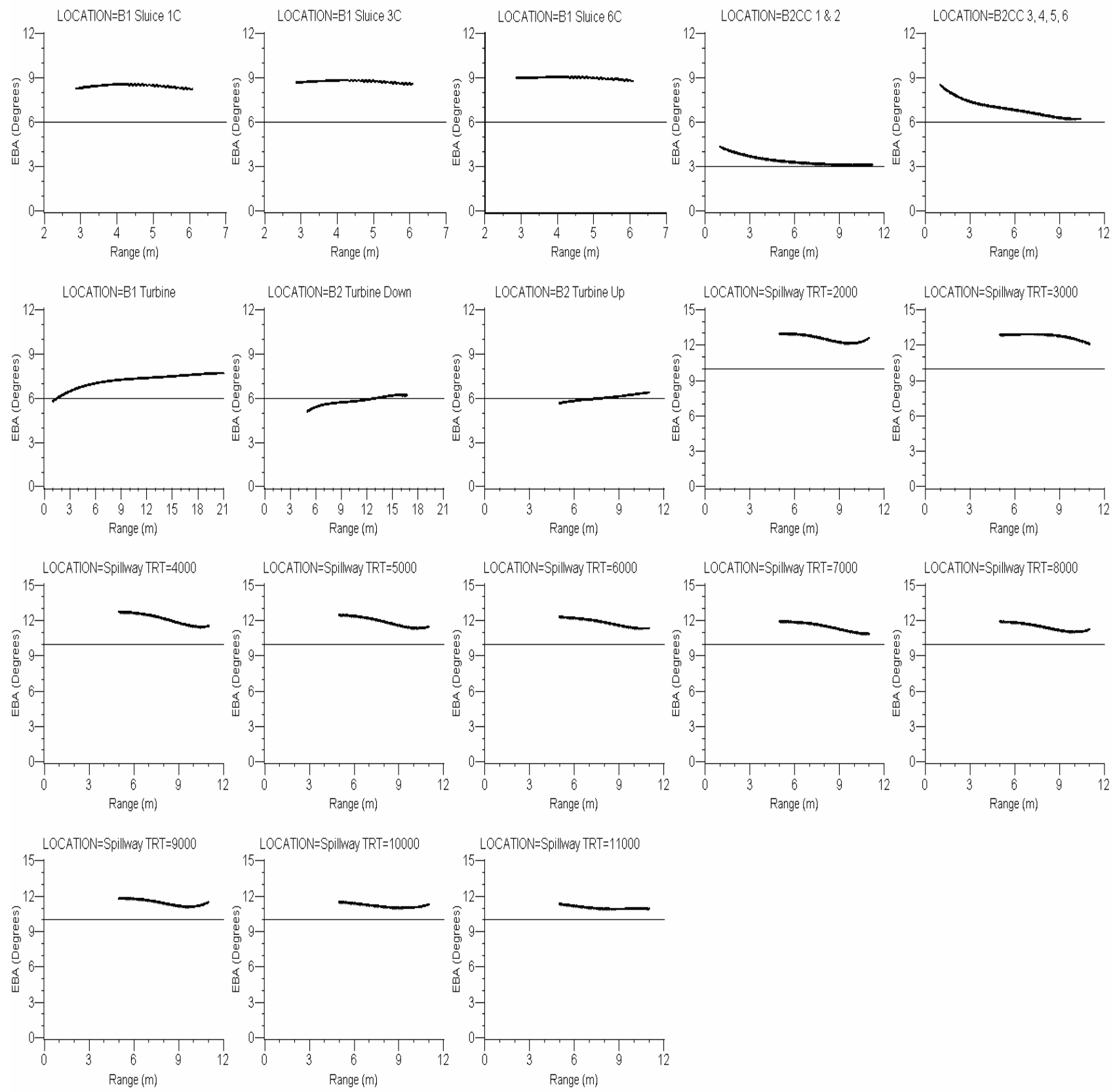

Figure 3.11. Plots of Effective Beam Angle as a Function of Range from Transducers Deployed at Bonneville Dam during Spring 2005. Horizontal lines denote nominal beam angles of transducers. Scales vary among plots.

In summer 2005, the EBA curves were near nominal beam angles or slightly less than the nominal angle at the B2CC, inside turbines, or at spill bays with high discharge (Figure 3.12). At most locations, detectability was lower in summer than it was in spring. As in spring, detectability was slightly higher at Entrance 6C than it was at Entrance 1C for the B1 sluiceway deployments, and detectability at the spillway declined gradually as spill-bay discharge increased (Figure 3.12). 

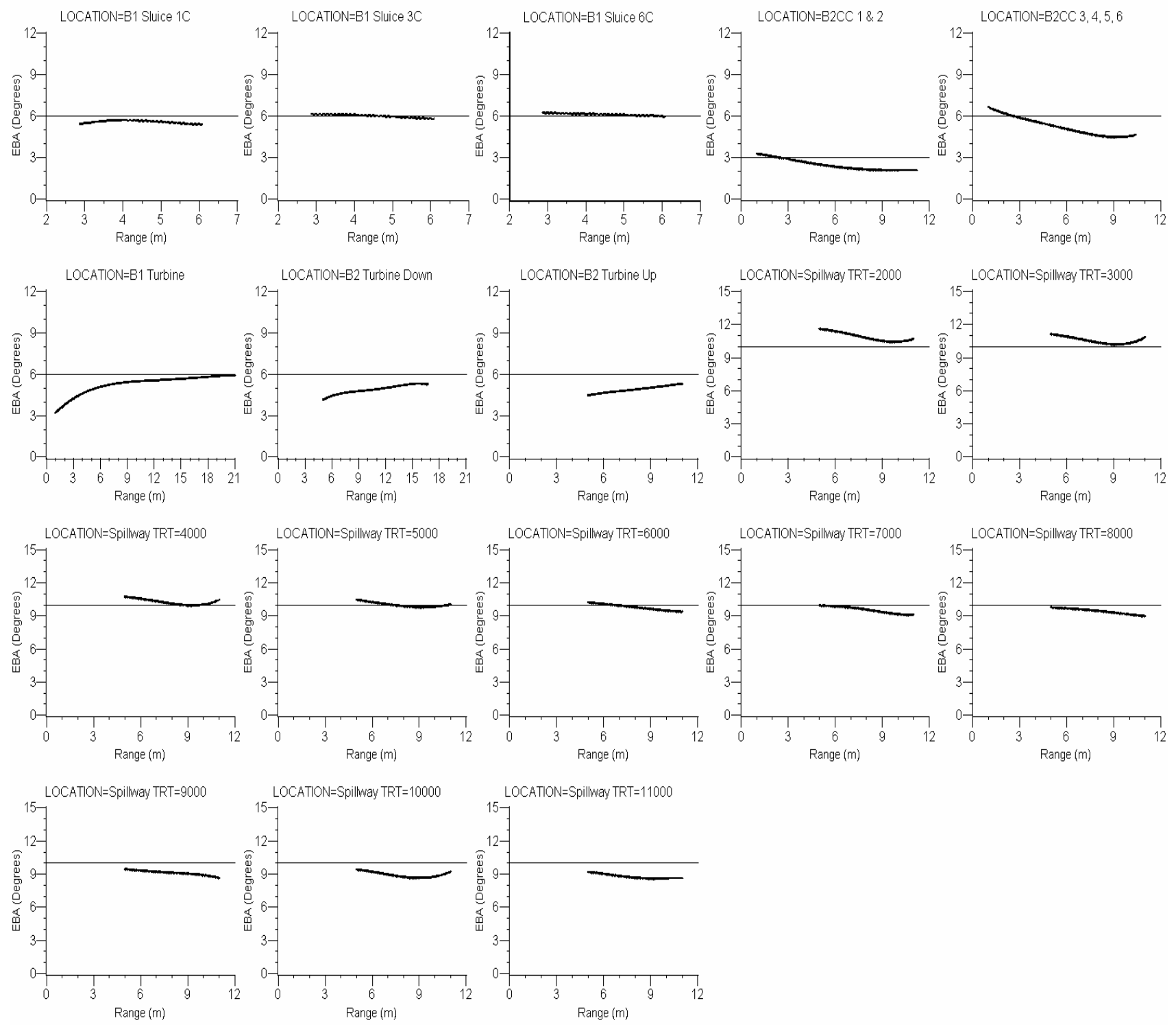

Figure 3.12. Plots of Effective Beam Angle as a Function of Range from Transducers Deployed at Bonneville Dam during Summer 2005. Horizontal lines denote nominal beam angles of transducers. Scales vary among plots.

\subsection{Validation of Auto Tracking and Count Adjustments}

We found reasonably good correspondence between technician counts of fish and autotracker counts for every deployment (Figures 3.13, 3.14, 3.15, and 3.16), but there were deployment-specific differences in fits of regression lines and slopes, so we used slopes to convert autotracker counts into mean technician counts. 

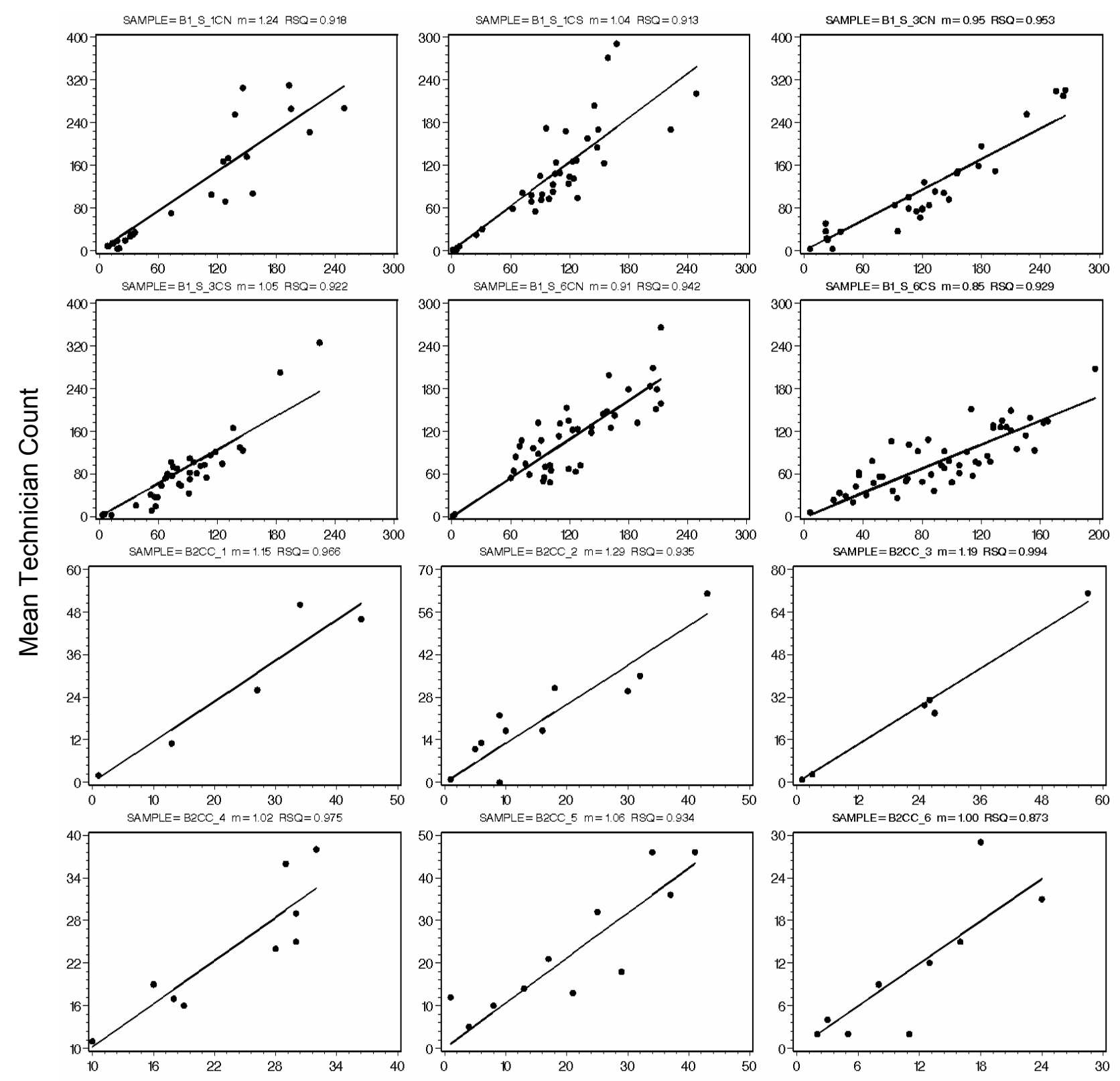

\section{Autotracker Count}

Figure 3.13. Regressions of Mean Manual-Tracker Estimates of Hourly Fish Passage on Autotracker Estimates for Transducers at B1 Sluiceway Entrances and the B2CC. Sample names consist of a concatenation of location indicator $\left(B 1 \_S=B 1\right.$ Sluiceway Entrance; B2CC = B2

Corner Collector), an underscore, and a transducer indicator $(1 \mathrm{CN}=1 \mathrm{C}$ north; $1 \mathrm{CS}=1 \mathrm{C}$ south; $3 \mathrm{CN}=3 \mathrm{C}$ north; $3 \mathrm{CS}=3 \mathrm{C}$ south; $6 \mathrm{CN}=6 \mathrm{C}$ north and $6 \mathrm{CS}=6 \mathrm{C}$ south; and numbers 1 to 6 for the B2CC transducers. The " $\mathrm{m}$ " and "RSQ" abbreviations refer to the slope of the regression line forced through zero and the coefficient of determination $\left(\mathrm{r}^{2}\right.$ value), respectively. 

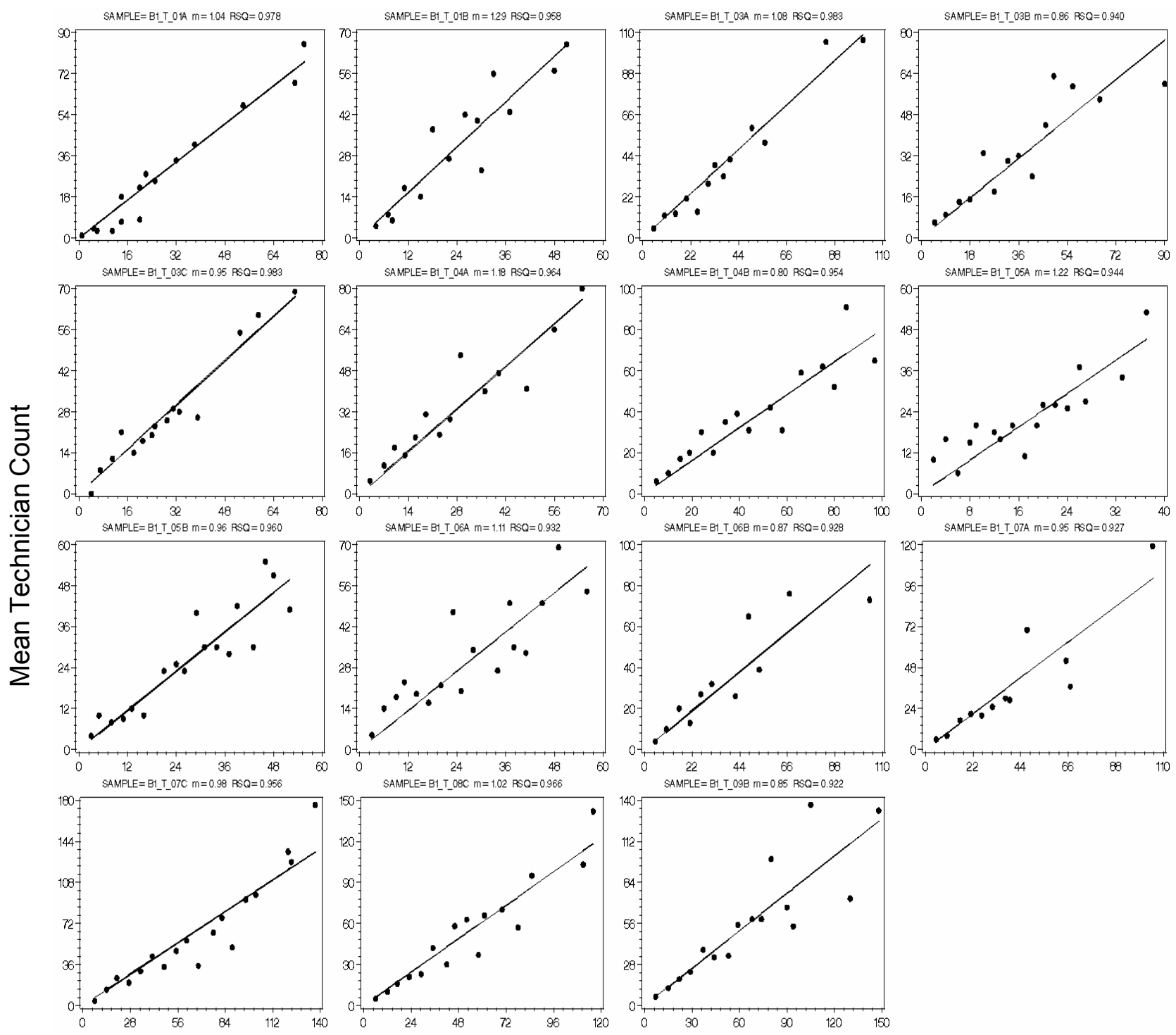

Autotracker Count

Figure 3.14. Regressions of Mean Manual-Tracker Estimates of Hourly Fish Passage on Autotracker Estimates for Transducers at B1 Turbines. Sample names consist of a concatenation of location indicator (B1_T=B1 Turbine), an underscore, and an intake location consisting of two digits and a letter. The " $\mathrm{m}$ " and "RSQ" abbreviations refer to the slope of the regression line forced through zero and the coefficient of determination ( $r^{2}$ value), respectively. 

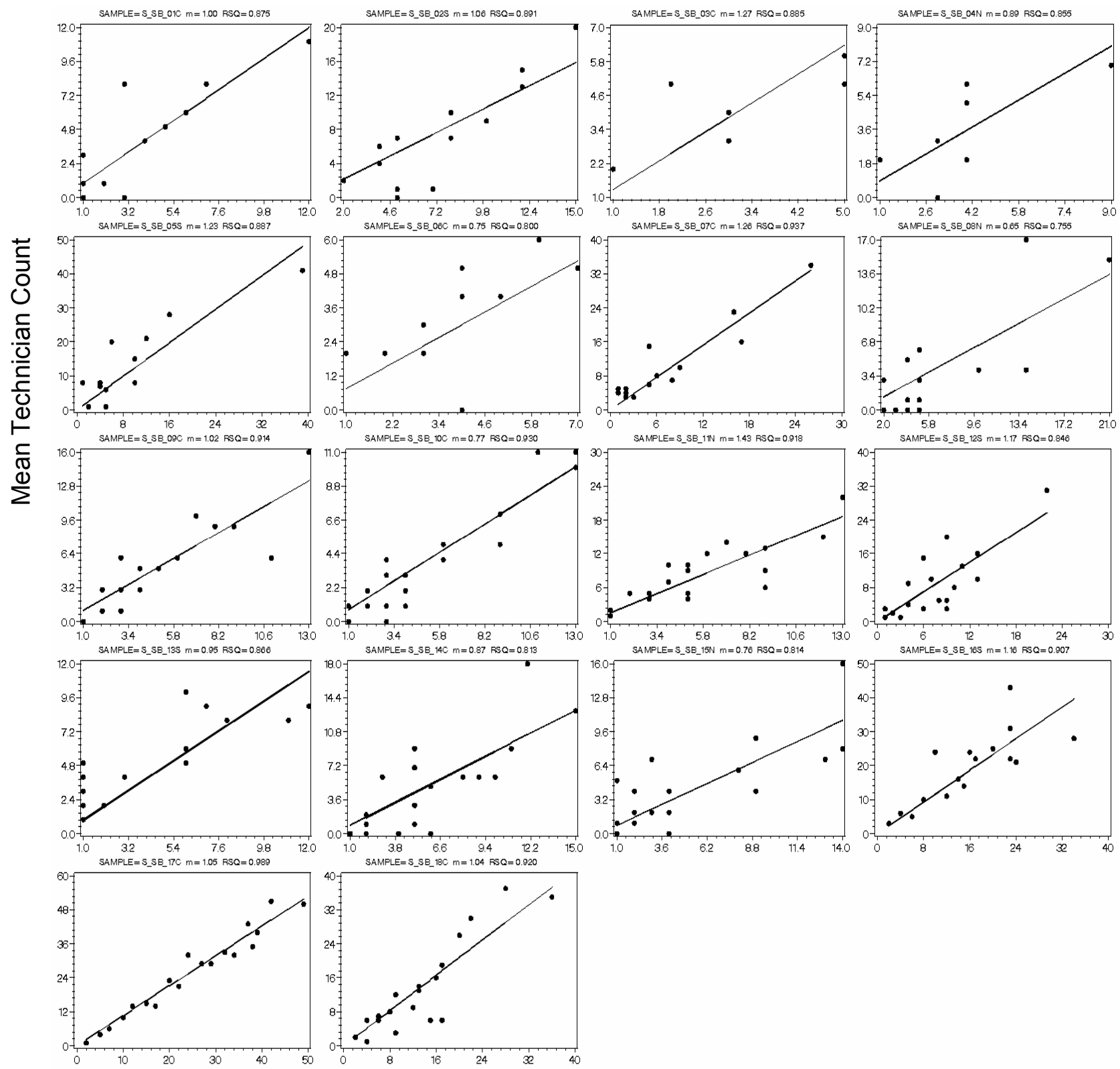

\section{Autotracker Count}

Figure 3.15. Regressions of Mean Manual-Tracker Estimates of Hourly Fish Passage on Autotracker Estimates for Transducers at the Spillway. Sample names consist of a concatenation of a location indicator $\left(\mathrm{S}_{-}=\right.$Spillway), an underscore, a spill bay indicator (SB_01 through SB_18), and a letter indicating the lateral position of the transducer $(\mathrm{N}=$ north, $\mathrm{C}=$ center, and $\mathrm{S}=$ south). The " $\mathrm{m}$ " and "RSQ" abbreviations refer to the slope of the regression line forced through zero and the coefficient of determination $\left(r^{2}\right.$ value $)$, respectively. 

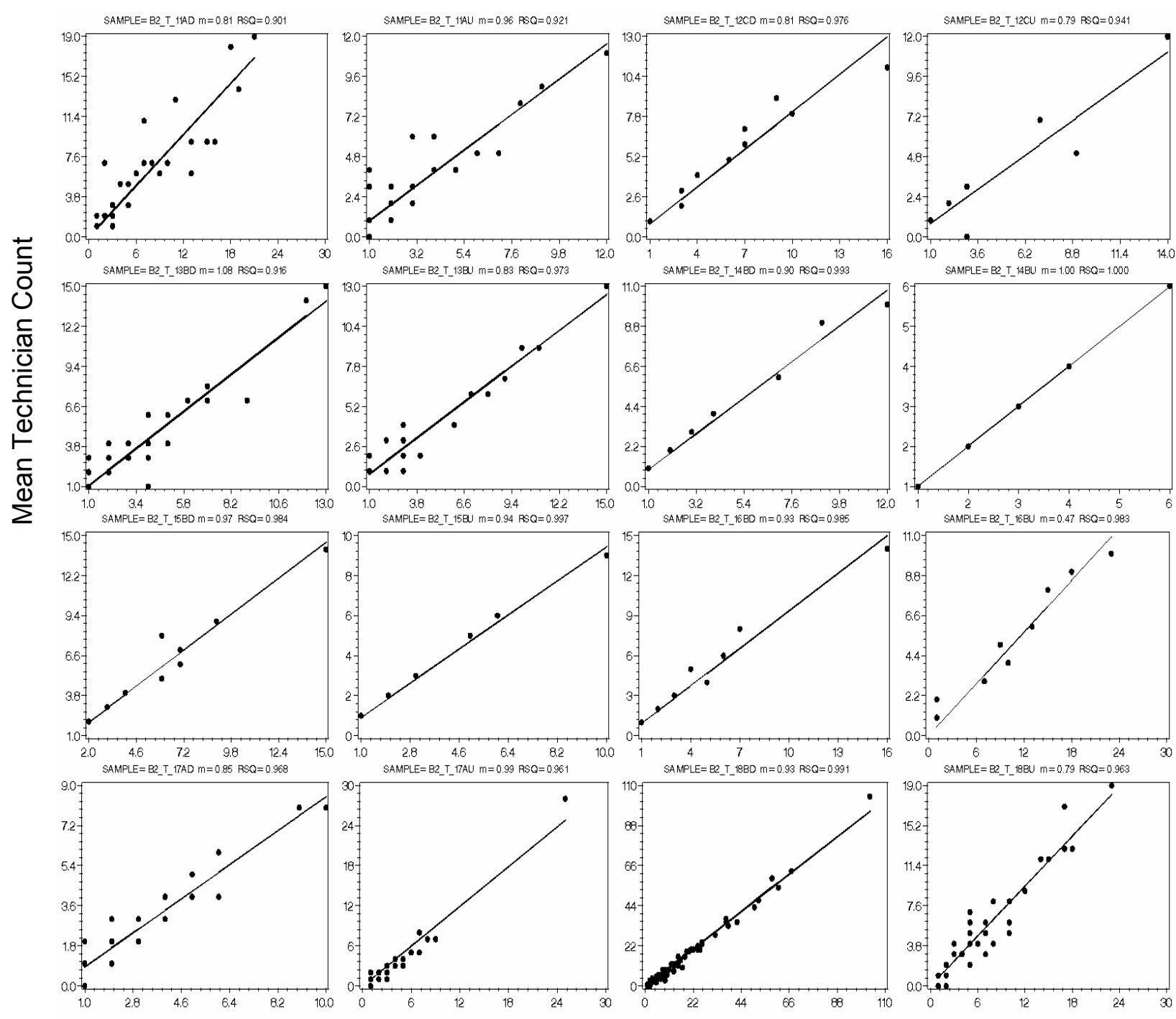

Autotracker Count

Figure 3.16. Regressions of Mean Manual-Tracker Estimates of Hourly Fish Passage on Autotracker Estimates for Transducers at B2 Turbines. Sample names consist of a concatenation of a location indicator (B2_T=B2 Turbine), an underscore, and an intake location consisting of two digits, a letter, and a "D" or " $U$ " indicating that the aiming angle was down or up, respectively. The " $\mathrm{m}$ " and "RSQ" abbreviations refer to the slope of the regression line forced through zero and the coefficient of determination $\left(r^{2}\right.$ value), respectively.

\subsection{Direction of Travel Adjustments}

The mean hourly percent of fish moving downstream at three spill bays was the same in both seasons, i.e., $87 \pm 7.9$ (standard error $=\mathrm{SE}$ ) in spring and $87 \pm 8.2(\mathrm{SE})$ in summer (Figure 3.17). Estimates of the hourly mean and variance of the percent of fish moving downstream were used to adjust single-beam passage estimates for direction of travel. 


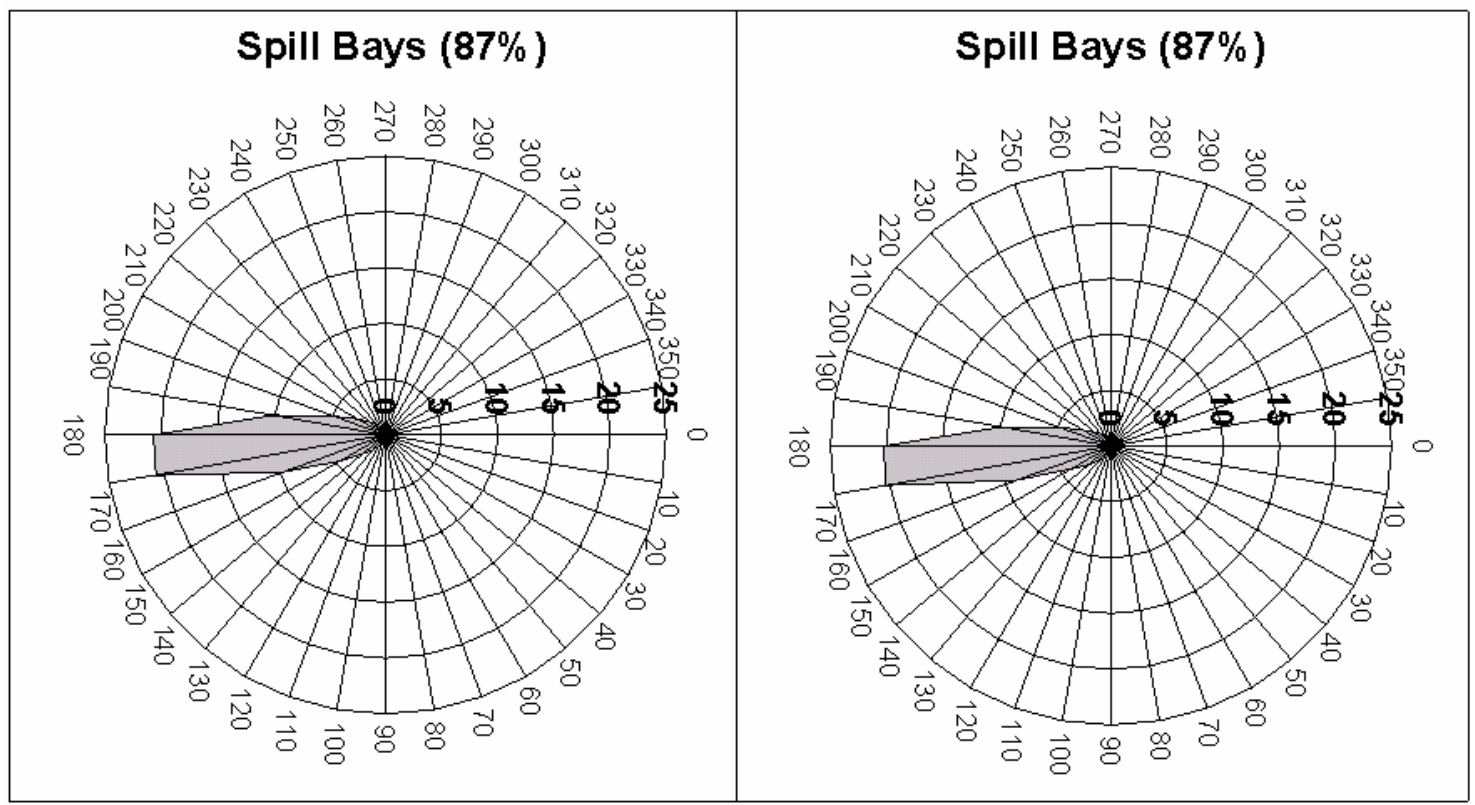

Figure 3.17. Polar Plots of Percent of Fish Traveling Different Directions across the Barrel View of Down-Looking, Split-Beam Transducers Deployed at Spill Bays in Spring (left) and Summer (right) 2005. Flow was from the right to left across the beam, and angles $>90^{\circ}$ and $\angle 270^{\circ}$ indicate movement in a downstream direction across the upstream / downstream plane.

The percent of fish moving in a downstream direction was nearly 100 at the $\mathrm{B} 2 \mathrm{CC}$, but it was much lower for the B1 sluiceway entrances. The percent of fish moving downstream at B1 sluiceway entrances generally was similar in spring (55\% to $63 \%$ ) and summer (45 to 67\%), and was lowest at Entrance 1C in both seasons (Figure 3.18 and 3.19). Mean discharge through the B2CC was 5,258 \pm 361 (SE) cfs in spring, and 5,165 $\pm 311.4 \mathrm{cfs}$ in summer. Flow into the B1 sluiceway entrances was less than one-tenth of flow into the $\mathrm{B} 2 \mathrm{CC}$. It was higher at Entrance $1 \mathrm{C}$ near the downstream end of the channel (spring = $459.9 \pm 80.6 \mathrm{cfs}$; summer $=429.4 \pm 69.3 \mathrm{cfs})$ than it was into Entrance $3 \mathrm{C}$ (spring $=388.9 \pm 34.8 \mathrm{cfs}$; summer $=376.7 \pm 30.4 \mathrm{cfs}$ ) or $6 \mathrm{C}($ spring $=285.0 \pm 30.1 \mathrm{cfs}$; summer $=274.9 \pm 26.7 \mathrm{cfs})$. Of fish moving in an upstream direction, a noticeable percentage at Entrances $1 \mathrm{C}$ and $3 \mathrm{C}$ were moving downward in the water column. The chain gates at the B1 sluiceway entrances form a sharp crested weir. When the top of the chain gates are located at elevation $71.5 \mathrm{ft}$ above MSL, as they were in 2005, the gates pool a 3.5-ft-deep volume of water between the top of the weir and the concrete sill at elevation 68 $\mathrm{ft}$ above MSL. Flow passing over the weir may cause a weak hydraulic roller to form immediately upstream of the chain gate. 


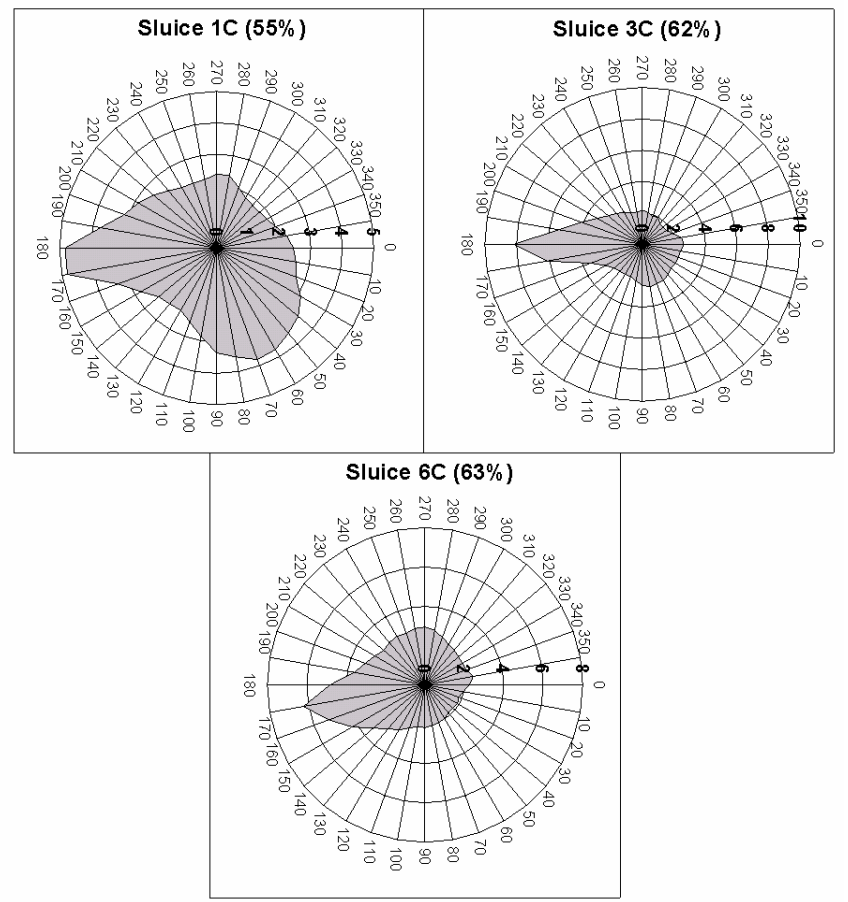

Figure 3.18. Polar Plots of Percent of Fish Traveling Different Directions across the Barrel View of Side-Looking, Split-Beam Transducers at B1 Sluice Entrances in Spring 2005. Flow was from the right to left across the beam, and angles $>90^{\circ}$ and $<270^{\circ}$ indicate movement in a downstream direction across the upstream / downstream plane.

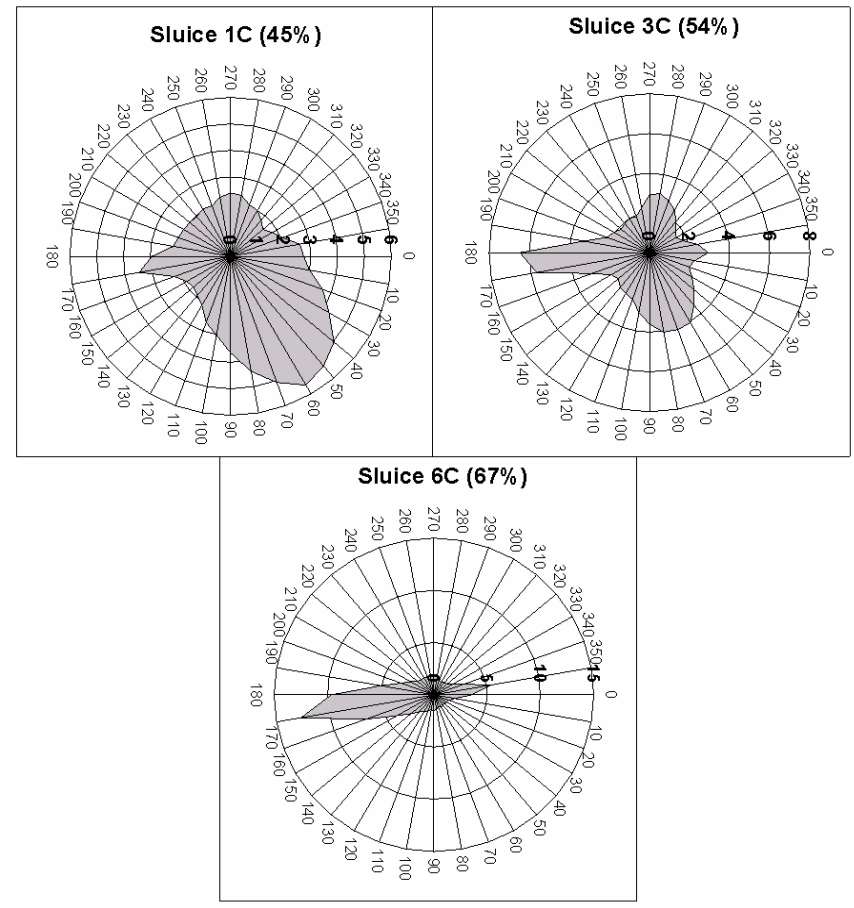

Figure 3.19. Polar Plots of Percent of Fish Traveling Different Directions across the Barrel View of Side-Looking, Split-Beam Transducers at B1 Sluice Entrances in Summer 2005. Flow was from the right to left across the beam, and angles $>90^{\circ}$ and $<270^{\circ}$ indicate movement in a downstream direction across the upstream / downstream plane. 


\subsection{Major Fish Passage Metrics}

In 2005, we found a similarity between the percent of discharge through an entire dam structure (B1, B2, or the spillway) and the estimated proportion of fish passing that structure. This was especially the case with the spillway where an estimated $39.67 \%$ of the fish passed in $40.3 \%$ of the discharge in spring and an estimated $44.2 \%$ of fish passed in $51.6 \%$ of discharge in summer. That result computes to spill effectiveness of 0.98 in spring and 0.86 in summer. At B1, we estimated that $16.3 \%$ of the fish passed in $11.6 \%$ of the flow in spring, and $7.2 \%$ of the fish passed in only $4.6 \%$ of the flow in summer. At B2, $44.1 \%$ of fish passed in $48.1 \%$ of the flow in spring, and $48.6 \%$ of fish passed in $44.8 \%$ of Project flow in summer.

Estimates of major passage metrics for the whole Bonneville Project and its structures for spring and summer of 2005 are presented in Table 3.1. "Efficiency" is percentage of whole-project or partial Project total passage to pass by non-turbine routes. "Effectiveness" is the appropriate "Efficiency" divided by the proportion of total Project or partial-Project discharge through the non-turbine route or routes in question.

\subsubsection{Project and Powerhouse FPE}

Project-wide FPE estimates are presented in Figure 3.20, as are FPE estimates calculated for various portions of the project. We calculated FPE for the entire Project, B1 only, B2 only, and for just B2 and the spillway (without B1), since B2 has been the priority powerhouse since 2001 and most water passes through B2 and the spillway. Estimated Project-wide FPE was estimated at $73.4 \%$ in spring and $80.7 \%$ in summer. The B1 FPE estimate, which was equal to B1 sluiceway passage since no screens were deployed in 2005 , was $37.37 \%$ in spring and $70.92 \%$ in summer. The FPE for B2, the numerator of which included fish passage at the B2CC and above in-turbine screens was $63 \%$ in spring and $65 \%$ in summer. For only B2 and the spillway (excluding B1), estimated FPE was $80.41 \%$ in spring and $81.49 \%$ in summer, or over $5 \%$ higher in spring and $0.8 \%$ higher in summer than were the corresponding estimates for the entire project.

Subsequent sections present details and graphical representations of estimates of major fish passage metrics for spring and summer.

\subsubsection{Spillway Efficiency and Effectiveness}

Spill passage efficiency for the entire Bonneville Project was $39.7 \%$ in spring and $44.2 \%$ in summer (Figure 3.21). For only B2 and the spillway (excluding B1), estimated spill efficiency was considerably higher, $47.4 \%$ in spring and $47.7 \%$ in summer. We estimated spill effectiveness for the entire project at 0.98 in spring and 0.86 in summer. For just B2 and the spillway, spill effectiveness was estimated to be 1.04 in spring and 0.89 in summer.

\subsubsection{Sluiceway Efficiency and Effectiveness}

Estimates of sluiceway efficiency appear in Figure 3.22. The estimated sluiceway efficiency for the entire Project (the B2CC is a sluiceway) was $20.15 \%$ for spring and $26.23 \%$ for summer. The sluiceway efficiency of each powerhouse's sluice (the proportion of the entire Project's passage to go through each) was $6.08 \%$ in spring and $5.13 \%$ in summer for the B1 sluiceway and $14.07 \%$ in spring and $21.1 \%$ in 
summer for the B2CC. Within each powerhouse the sluiceway efficiency at B1 was $37.37 \%$ in spring and $70.92 \%$ in summer and at B2 it was $31.92 \%$ in spring and $43.46 \%$ in summer.

Table 3.1. Estimates of Major Passage Metrics Based upon Hydroacoustic Sampling from 4/15 through 5/31 (Spring) and from 6/1 through 7/15 (Summer) in 2005

\begin{tabular}{|c|c|c|}
\hline Metric & Spring & Summer \\
\hline Project Fish Passage Efficiency & $73.4 \pm 4.0 \%$ & $80.7 \pm 4.1 \%$ \\
\hline Project FPE for the B2 and Spillway only (excluding B1) & $80.4 \pm 5.0 \%$ & $81.5 \pm 5.0 \%$ \\
\hline B1 Percent of Project Passage & $16.3 \pm 1.1 \%$ & $7.2 \pm 0.5 \%$ \\
\hline B1 Percent of Project Flow & 11.6 & 3.7 \\
\hline B1 Fish Passage Efficiency & $37.37 \pm 1.64 \%$ & $70.92 \pm 2.46 \%$ \\
\hline B2 Percent of Project Passage & $44.1 \pm 3.1 \%$ & $48.6 \pm 2.9 \%$ \\
\hline B2 Percent of Project Flow & 48.2 & 44.8 \\
\hline B2 Fish Passage Efficiency & $62.8 \pm 7.8 \%$ & $64.6 \pm 7.0 \%$ \\
\hline B2 Fish Guidance Efficiency & $45.3 \pm 8.6 \%$ & $37.4 \pm 8.8 \%$ \\
\hline Spill Passage Efficiency & $39.7 \pm 2.2 \%$ & $44.2 \pm 2.6 \%$ \\
\hline Spill Percent of Project Flow & 40.3 & 51.6 \\
\hline Spill Efficiency (B2 + Spillway excluding B1) & $47.4 \pm 3.0 \%$ & $47.7 \pm 3.0 \%$ \\
\hline Sluice Passage Efficiency (B1 + B2CC as \% of Project) & $20.15 \pm 1.14 \%$ & $26.23 \pm 1.47 \%$ \\
\hline B1 Sluiceway and B2CC Percent of Flow & 3.2 & 3.5 \\
\hline B1 Sluice Efficiency (\% of Project) & $6.08 \pm 0.34 \%$ & $5.13 \pm 0.29 \%$ \\
\hline B1 Sluice Efficiency (\% of B1) = B1 FPE & $37.37 \pm 1.64 \%$ & $70.92 \pm 2.46 \%$ \\
\hline B2CC Efficiency (\% of Project) & $14.07 \pm 0.8 \%$ & $21.1 \pm 1.18 \%$ \\
\hline B2CC Efficiency (\% of B2) & $31.92 \pm 4.05 \%$ & $43.46 \pm 5.0 \%$ \\
\hline Spillway Effectiveness (\% spillway passage $\div \%$ spilled) & $0.98 \pm 0.06$ & $0.86 \pm 0.05$ \\
\hline $\begin{array}{l}\text { Sluice Effectiveness (B1 }+B 2 C C \text { passage } \div \% \text { B1 sluiceway }+B 2 C C \text { flow) } \\
\text { B1 Sluice Effectiveness relative to the Project }=\end{array}$ & $6.29 \pm 0.36$ & $7.6 \pm 0.43$ \\
\hline $\begin{array}{l}\text { (B1 Sluice Efficiency as } \% \text { of Project } \div \% \text { of Project flow sluiced at B1) } \\
\text { B1 Sluice Effectiveness relative to B1 }=\end{array}$ & $10.70 \pm 0.61$ & $8.59 \pm 0.49$ \\
\hline (B1 Sluice Efficiency as $\%$ of B1 $\div \%$ of B1 flow sluiced) & $7.61 \pm 0.33$ & $4.33 \pm 0.15$ \\
\hline $\begin{array}{l}\text { B2CC Effectiveness relative to the Project }= \\
\text { (B2CC Efficiency at } \% \text { of Project } \div \% \text { of Project flow sluiced at the B2CC) }\end{array}$ & $5.34 \pm 0.31$ & $7.39 \pm 0.41$ \\
\hline B2CC Effectiveness (B2CC Efficiency $\div \%$ of B2 flow through the B2CC) & $5.84 \pm 0.74$ & $6.82 \pm 0.78$ \\
\hline
\end{tabular}

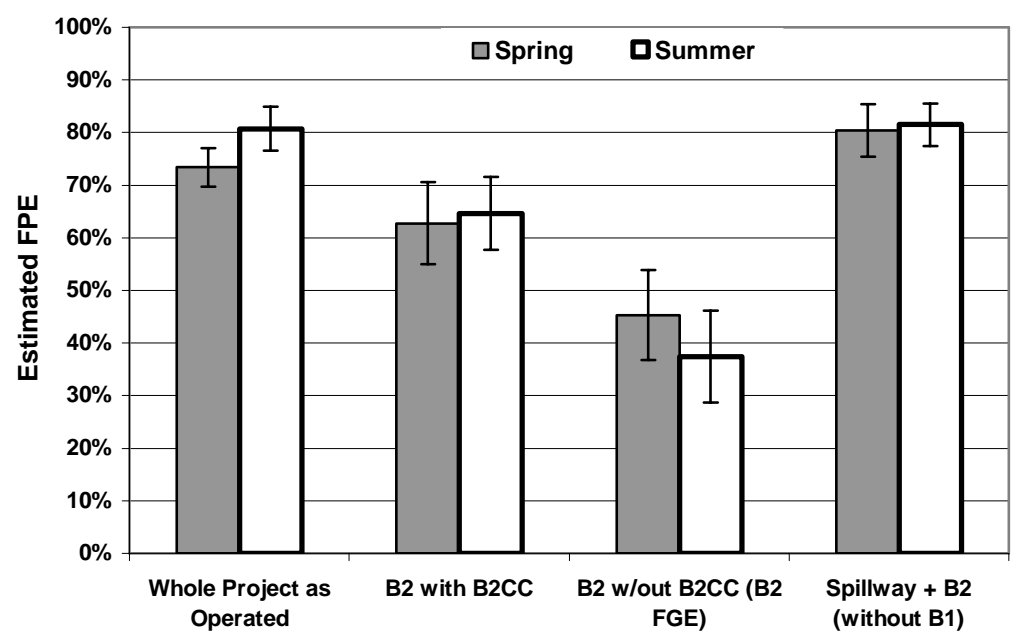

Figure 3.20. Project-Wide and Other Fish Passage Efficiency Estimates for Spring and Summer at Bonneville Dam in 2005. Vertical bars are 95\% confidence intervals. 


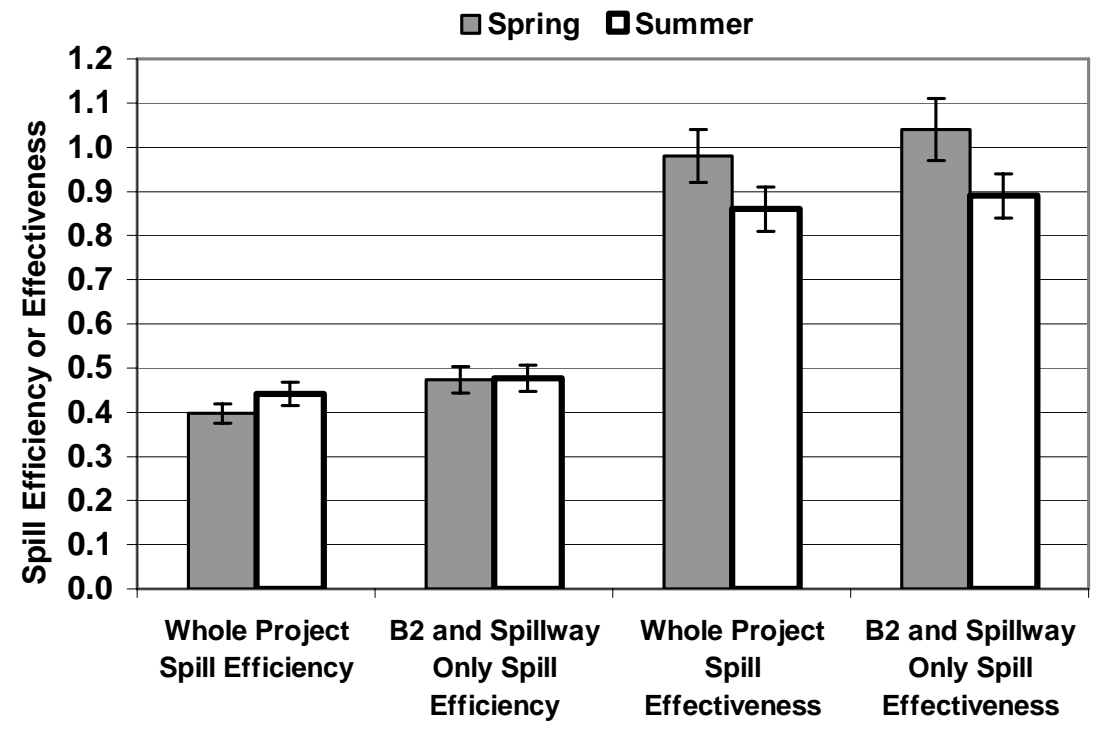

Figure 3.21. Estimated Spill Efficiency and Effectiveness for the Bonneville Project and for the Spillway and B2 Only in Spring and Summer 2006. Vertical bars are 95\% confidence intervals.

In 2005, we estimated Project-wide sluiceway effectiveness (B1 entrances and the B2CC) to be 6.3 in spring and 7.6 in summer (Figure 3.23). For clarity, that means that the proportion of fish passage through surface routes was 6.3 and 7.6 times higher than the proportion of water passed by the same routes each season. The B1 sluiceway effectiveness relative to the Project was 10.7 in spring and 8.6 in summer, whereas B2CC effectiveness relative to the Project was lower at 5.3 in spring and 7.4 in summer. Relative to B1 alone, B1 sluiceway effectiveness was 7.6 in spring and 4.3 in summer. Relative to B2, the effectiveness of the B2CC was 5.8 in spring and 6.8 in summer.

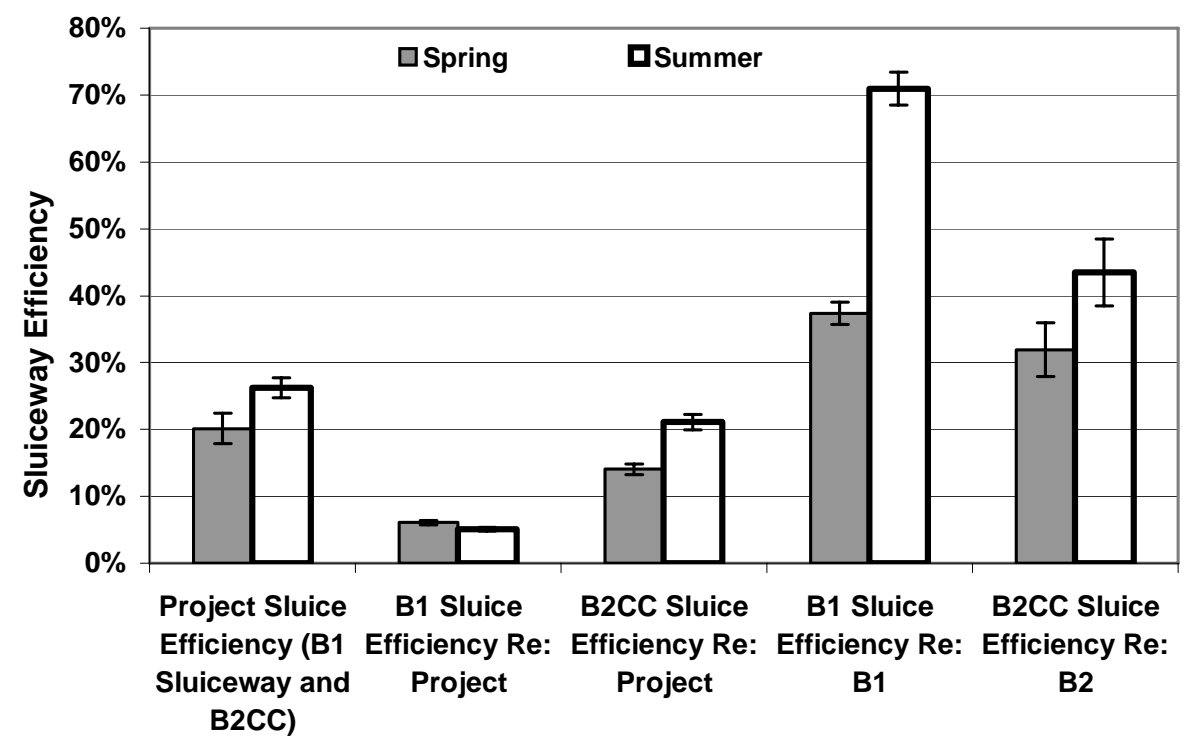

Figure 3.22. Estimated Sluiceway Efficiency for the Bonneville Project and for the Sluices (including the B2CC) Relative to the Respective Powerhouse Only for Spring and Summer 2005. Vertical bars are $95 \%$ confidence intervals. 


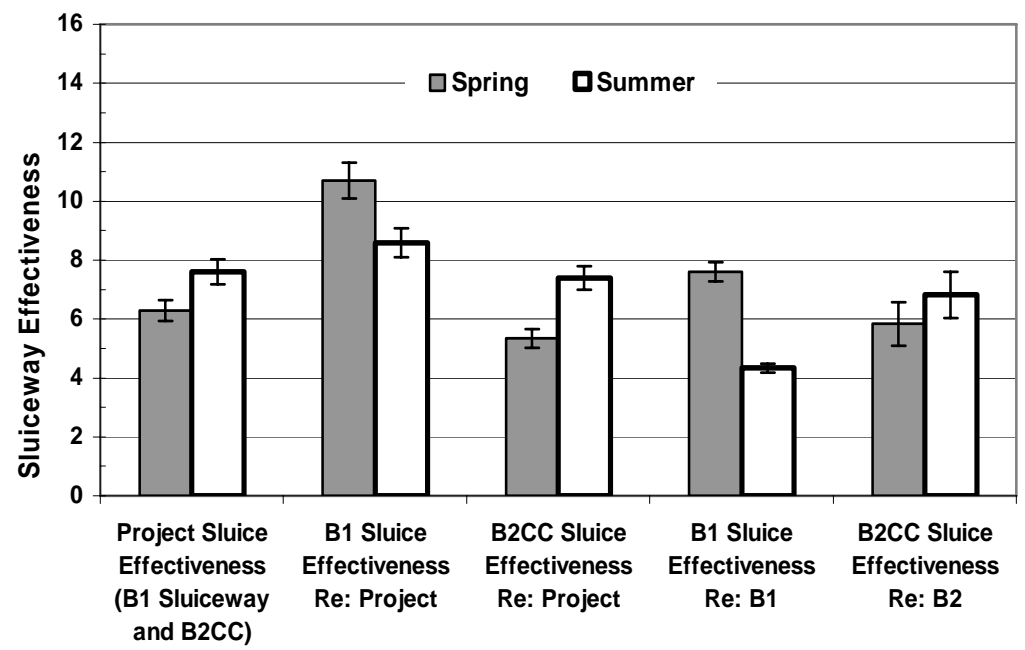

Figure 3.23. Estimated Sluiceway Effectiveness for the Bonneville Project and for the Sluices (including the B2CC) Relative to the Respective Powerhouse Only for Spring and Summer 2005. Vertical bars are $95 \%$ confidence intervals.

\subsubsection{Comparison of Major Metrics from 2000 through 2005}

This is the fifth year of full-Project hydroacoustic studies at Bonneville Dam. Taken together, the five studies constitute an extensive baseline data set for evaluating future management improvements. In each spring and summer since 2000, except in 2003, we have sampled major downstream passage routes during the spring and summer migrations of juvenile salmon. Sampled routes never included adult fish ladders or the navigation lock, which together accounted for $<1 \%$ of Project passage of radio-tagged juvenile salmonids in 2001 (Evans et al. 2001a, b) and 2002 (Evans et al. 2003a, b). Most of the individual studies were designed to evaluate specific things, e.g., prototype routes like the PSC (in 2000) and B2CC (in 2004 and 2005), powerhouse priority, spill proportions or rates, or the fish-guidance efficiency of in-turbine screens. We estimated the guidance efficiency of B1 screens at Units 7 through 10 in 2000 (the PSC was at Units 1-6), Units 1-18 in 2001 and 2002, and Units 11 through 18 in 2004 and 2005.

Major flow and fish passage metrics for each of the five years are presented in Table 3.2. Important characteristics of each year, in terms of the dam configuration, operation, and river discharge are presented in table headings. Most years had important environmental or operational factors that set them apart from other years. The year 2000 was the only one with B1 generation priority and in that year there was also a PSC over all 18 intakes of turbine Units 1 through 6 . In 2001, there was a severe drought as well as higher than typical power demand, and we had not yet determined an effective way to sample surface-passage routes. In 2002, we sampled the B1 sluiceway with horizontally aimed beams for the first time, and in 2004 and 2005, the B2CC was added and sampled along with B1 sluiceway outlets. At B1, different sluiceway outlets were open in different years. Opened B1 sluiceway outlets were above Intake 10C (a very small entrance at the extreme north end of B1) and Intake 7A on the south side of a forebay wall in 2002. Opened sluiceway outlet intakes at B1 included 2C, 4C, and 6C in 2004 and 1C, 3C, and 6C in 2005. In 2004 and 2005, in-turbine screens at B1 were not installed so that all fish passing B1 other than by the sluiceway entrances were turbine-passed, whereas in the earlier years all B1 turbine intakes had screens. Most were STSs, except for Unit 8, which had an ESBS in 2001 and 2002. Our comparison of metrics among all years is limited to FPE, spill efficiency, spill effectiveness, and B2 FGE 
because of differences in sluiceway sampling, B1 screen deployments, and the operation of the B2 sluiceway among years.

For spring, Project FPE was highest in 2000 and 2002 (79\%) and this was about 6\% higher than it was in 2004 and 2005 (73\%) and 16\% higher than it was in 2001. Spill efficiency was highest in spring of 2002, intermediate and similar in 2000, 2004, and 2005, and lowest in 2001 (Table 3.2).

Spill effectiveness was highest in spring of 2000 (1.36) and relatively similar and closer to 1:1 in spring of 2001, 2002, 2004, and 2005. Estimates of B2 FGE were remarkably consistent among the five springs sampled, ranging from 45 to 57 (mean $=51.4)$.

For summer, Project FPE was highest in 2000, 2002, and 2005, as were estimates of spill efficiency (Table 3.2). The lowest Project FPE and spill efficiency were recorded in summer 2001, but spill effectiveness was highest in summer 2001 (1.83). Spill effectiveness was closer to 1:1 in the summer of other years and, for those other summers, ranged from 0.83 in summer 2004 to 1.03 in summer of 2000 . Estimates of B2 FGE in summer ranged from 35\% to $46 \%$ and averaged $39.2 \%$.

Table 3.2. Estimates of Major Passage Metrics Based upon Hydroacoustic Sampling in 2000, 2001, 2002, 2004, and 2005. Headings list some important differences in conditions or sampling among the years.

\begin{tabular}{|c|c|c|c|c|c|}
\hline Major Passage Metric & $\begin{array}{c}2000 \\
\text { PSC } \\
\text { (Units 1-6) } \\
\text { B1 Priority } \\
\text { No } \\
\text { Sluiceway } \\
\text { Sampled } \\
\text { No STS in } \\
\text { PSC } \\
\end{array}$ & $\begin{array}{c}2001 \\
\text { Severe } \\
\text { Drought; B2 } \\
\text { Priority; No } \\
\text { Sluiceway } \\
\text { Sampled }\end{array}$ & $\begin{array}{c}2002 \\
\text { B2 Priority } \\
\text { B1 Sluiceway } \\
\text { Sampled } \\
\& \\
\text { B1 Screens } \\
\text { Installed }\end{array}$ & $\begin{array}{c}2004 \\
\text { B2 Priority } \\
\text { B1 Sluiceway } \\
\& \\
\text { B2CC } \\
\text { Sampled } \\
\text { No B1 } \\
\text { Screens }\end{array}$ & $\begin{array}{c}2005 \\
\text { B2 Priority } \\
\text { B1 Sluiceway \& } \\
\text { B2CC Sampled } \\
\text { No B1 } \\
\text { Screens }\end{array}$ \\
\hline \multicolumn{6}{|c|}{ Spring } \\
\hline Project FPE & $79 \pm 0.2 \%$ & $63 \pm 0.3 \%$ & $79 \pm 0 . \%$ & $73 \pm 2.3 \%$ & $73.4 \pm 4.01 \%$ \\
\hline B1 FPE (without Sluiceway) & $67 \pm 0.4 \%$ & $49 \pm 2.3 \%$ & N/A & $N / A$ & $N / A$ \\
\hline B1 FPE (with Sluiceway) & N/A & N/A & $58 \pm 0.4 \%$ & $33.3 \pm 3.9 \%$ & $37.4 \pm 1.6 \%$ \\
\hline B2 FGE & $54 \pm 0.8 \%$ & $57 \pm 0.3 \%$ & $53 \pm 0.3 \%$ & $48 \pm 6.6 \%$ & $45 \pm 8.6 \%$ \\
\hline B2 FPE (with B2CC) & N/A & N/A & N/A & $64.0 \pm 4.24 \%$ & $62.8 \pm 7.8 \%$ \\
\hline B2 + Spillway FPE & $\mathrm{N} / \mathrm{A}$ & $64 \pm 0.3 \%$ & $83 \pm 0.4 \%$ & $81.5 \pm 0.02 \%$ & $80.4 \pm 0.05 \%$ \\
\hline Spill Efficiency & $44 \pm 0.4 \%$ & $14 \pm 0.2 \%$ & $52 \pm 0.5 \%$ & $40.3 \pm 1.7 \%$ & $39.7 \pm 2.2 \%$ \\
\hline Spill Effectiveness & $1.36 \pm 0.01$ & $0.84 \pm 0.00$ & $1.08 \pm 0.01$ & $1.0 \pm 0.04$ & $0.98 \pm 0.06$ \\
\hline Project Sluiceway Efficiency & N/A & $\mathrm{N} / \mathrm{A}$ & $6.0 \pm 0.1 \%$ & $19.1 \pm 0.8 \%$ & $20.15 \pm 1.14 \%$ \\
\hline $\begin{array}{l}\text { Project Sluiceway } \\
\text { Effectiveness }\end{array}$ & $\mathrm{N} / \mathrm{A}$ & N/A & $21.9 \pm 0.01$ & $6.3 \pm 0.27$ & $6.29 \pm 0.36 \%$ \\
\hline \multicolumn{6}{|c|}{ Summer } \\
\hline Project FPE & $79 \pm 0.2 \%$ & $53 \pm 0.4 \%$ & $74 \pm 0.2 \%$ & $70.0 \pm 2.3 \%$ & $80.72 \pm 4.12 \%$ \\
\hline B1 FPE (without Sluiceway) & $61 \pm 0.2 \%$ & $40 \pm 1.8 \%$ & N/A & N/A & NA \\
\hline B1 FPE (with Sluiceway) & N/A & N/A & $61 \pm 1.2 \%$ & $37.6 \pm 2.85 \%$ & $70.92 \pm 2.46 \%$ \\
\hline B2 FGE & $35 \pm 2.2 \%$ & $42 \pm 0.4 \%$ & $46 \pm 0.7 \%$ & $36 \pm 6.0 \%$ & $37 \pm 8.8 \%$ \\
\hline B2 FPE (with B2CC) & N/A & N/A & N/A & $61 \pm 3.92 \%$ & $64.63 \pm 6.96 \%$ \\
\hline B2 + Spillway FPE & $\mathrm{N} / \mathrm{A}$ & $54 \pm 0.4 \%$ & $82 \pm 0.5 \%$ & $76 \pm 0.03 \%$ & $82 \pm 0.04 \%$ \\
\hline Spill Efficiency & $49 \pm 0.4 \%$ & $20 \pm 0.3 \%$ & $42 \pm 0.5 \%$ & $32.7 \pm 1.3 \%$ & $44.2 \pm 2.5 \%$ \\
\hline Spill Effectiveness & $1.03 \pm 0.01$ & $1.83 \pm 0.01$ & $0.96 \pm 0.01$ & $0.83 \pm 0.03$ & $0.86 \pm 0.05 \%$ \\
\hline Project Sluiceway Efficiency & $\mathrm{N} / \mathrm{A}$ & $\mathrm{N} / \mathrm{A}$ & $11.0 \pm 0.1 \%$ & $26.4 \pm 1.0 \%$ & $26.23 \pm 1.47 \%$ \\
\hline $\begin{array}{l}\text { Project Sluiceway } \\
\text { Effectiveness }\end{array}$ & N/A & N/A & $47.9 \pm 0.03$ & $8.82 \pm 0.35$ & $7.60 \pm 0.43 \%$ \\
\hline
\end{tabular}




\subsubsection{Effects of Percent Spill on Spill Efficiency and Project FPE}

\subsubsection{Effects of Percent Spill on Spill Efficiency}

Spring percent in spill ranged from about $25 \%$ to $67 \%$ of Project discharge, and explained about 34\% of the variation in spill passage efficiency in spring (Figure 3.24). A curvilinear fit for spring explained about $9 \%$ more variation than a linear fit. Hourly estimates showed a similar trend although there was a lot more variability in estimates (Figure 3.25).

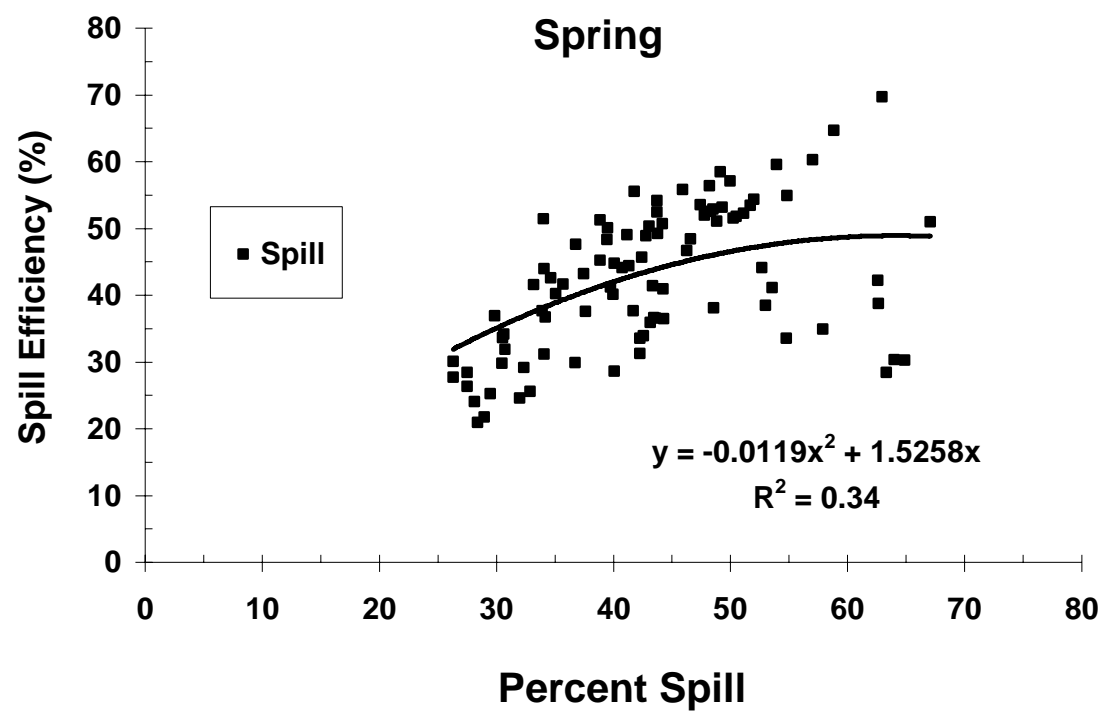

Figure 3.24. Regression of Day and Night Estimates of Spill Passage Efficiency on Percent Spill in Spring

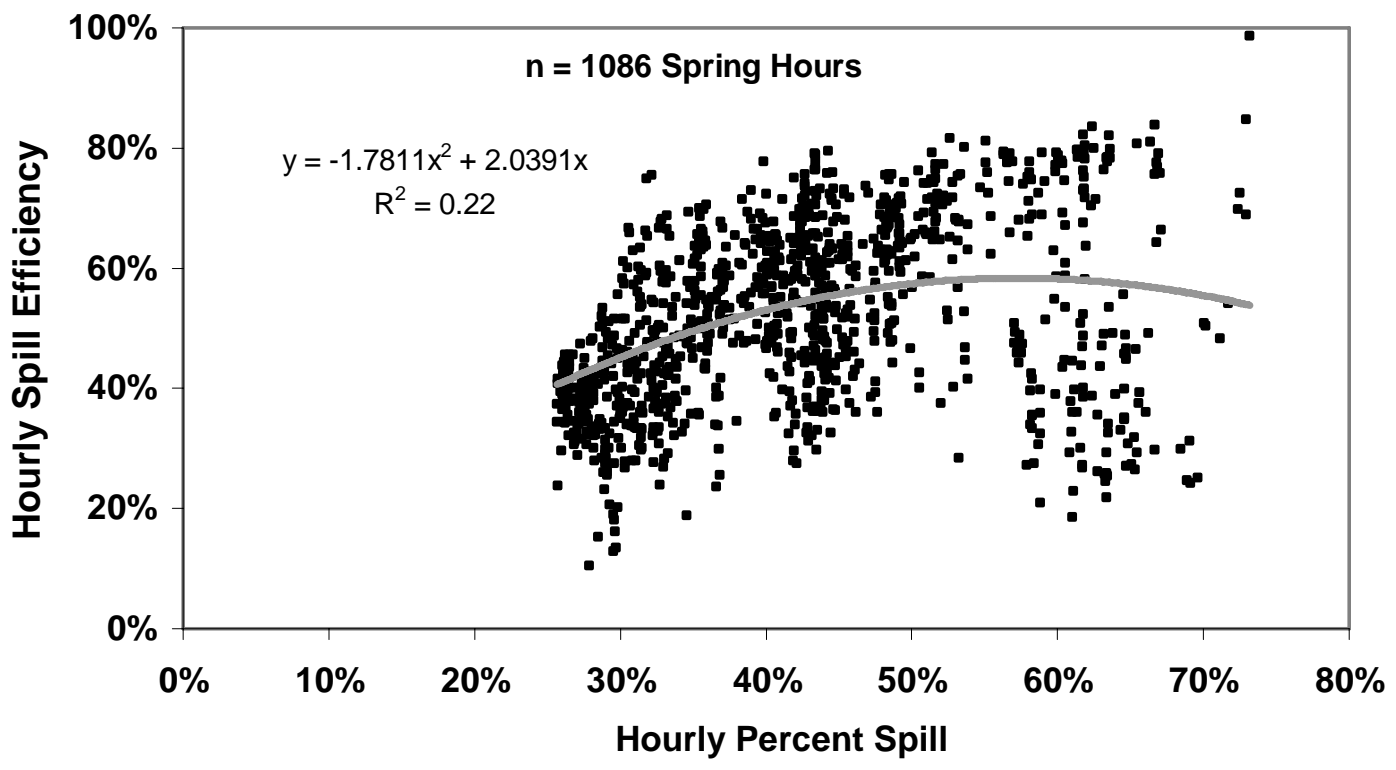

Figure 3.25. Regression of Hourly Estimates of Spill Passage Efficiency on Hourly Percent Spill in Spring 
In summer, percent spill explained about $72 \%$ of the variation in spill passage efficiency, and a linear fit was as good as higher order polynomial fits (Figure 3.26). The range in percent spill was from about 30\% to $78 \%$ in summer, and the upper end was higher in summer than it was in spring.

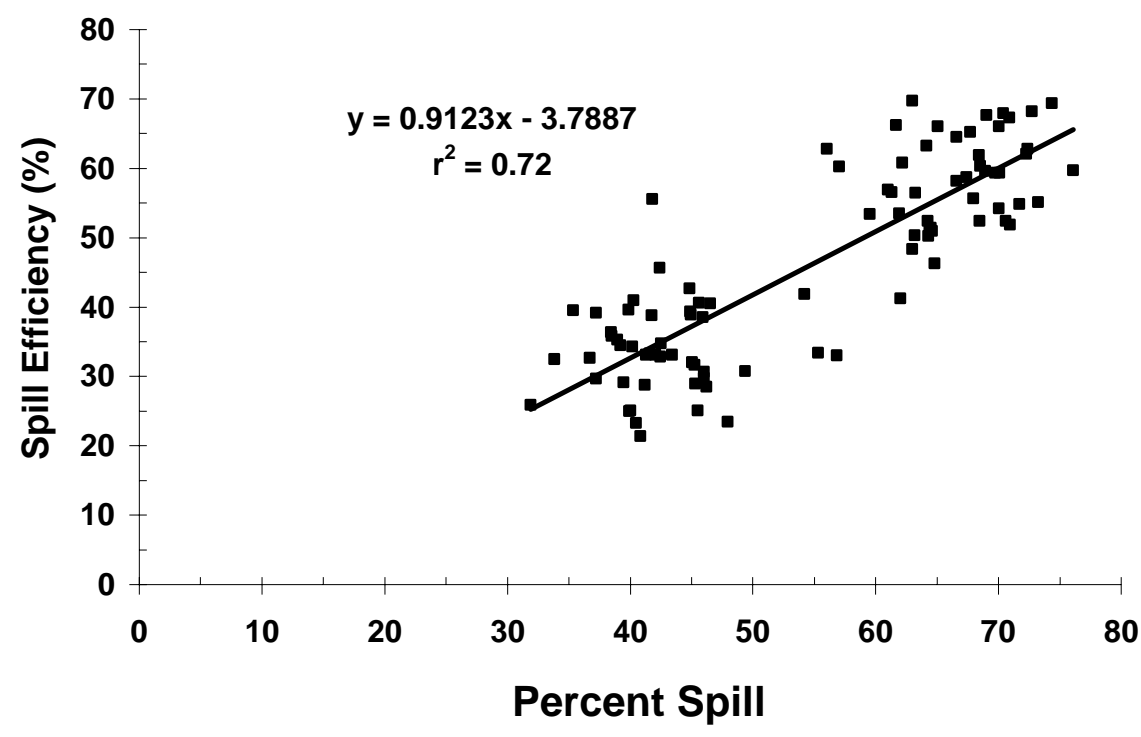

Figure 3.26. Regression of Day and Night Estimates of Spill Passage Efficiency on Percent Spill

\subsubsection{Effects of Percent Spill on Project FPE}

Percent spill explained about 72\% of the variation in Project FPE in spring (Figure 3.27) and about 69\% in summer (Figure 3.28). The quadratic fit increased the $r^{2}$ by about $5 \%$ over a linear fit each season.

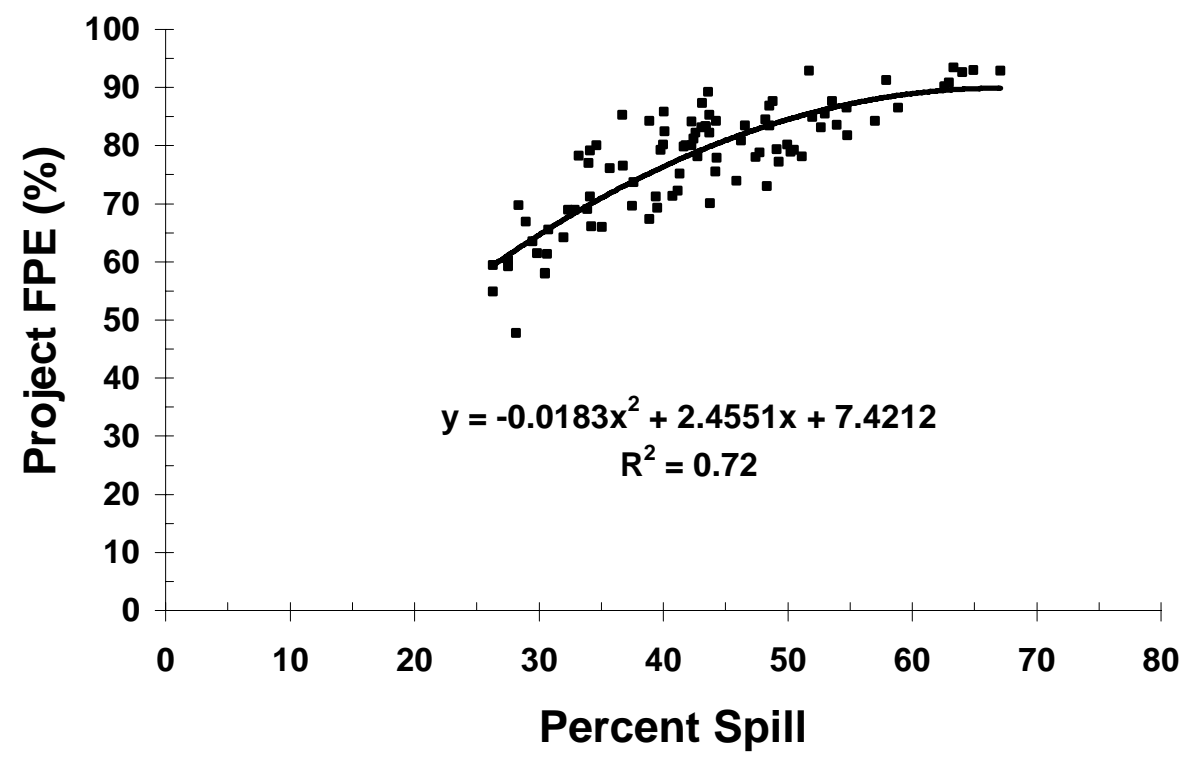

Figure 3.27. Regression of Day and Night Estimates of Project FPE on Percent Spill in Spring 


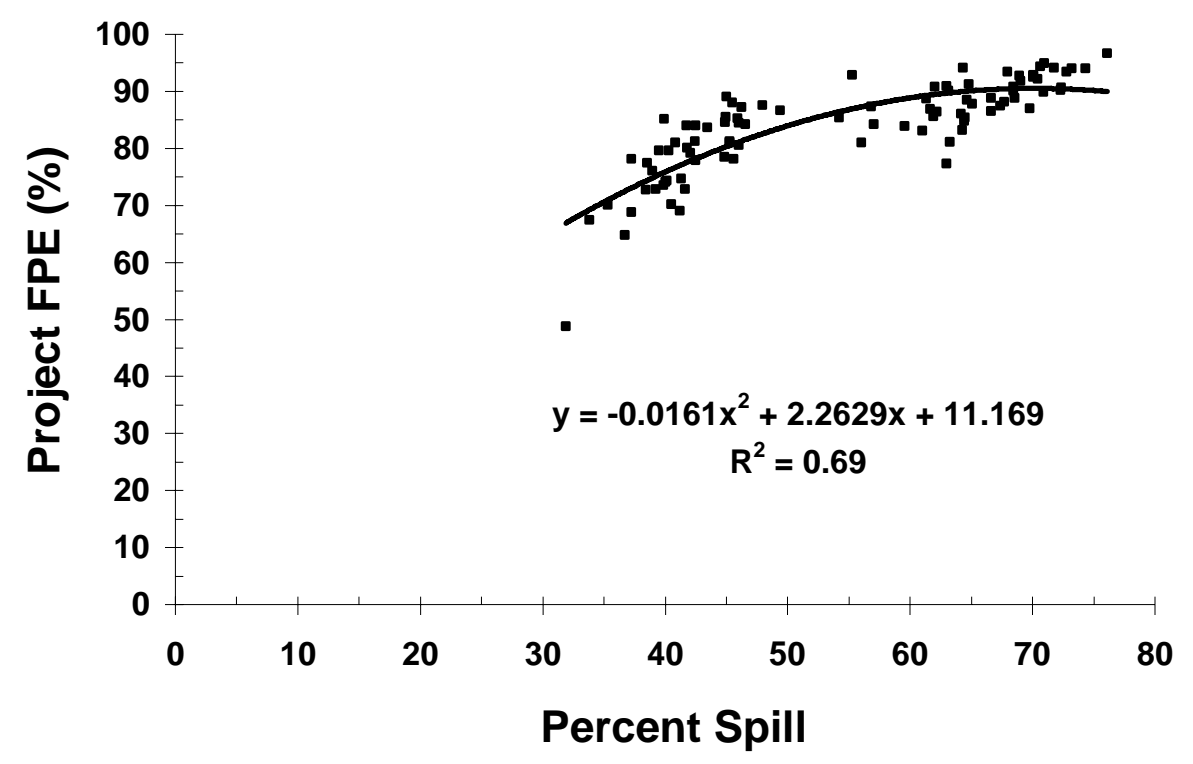

Figure 3.28. Regression of Day and Night Estimates of Project FPE on Percent Spill in Summer

\subsubsection{Effects of Percent Spill on B1 and B2 Passage}

The percentage of fish and flow passing the Project through B1 declined precipitously as the percent spill increased from about $25 \%$ to $40 \%$, but changed little at $>40 \%$ spill (Figure 3.29 ).

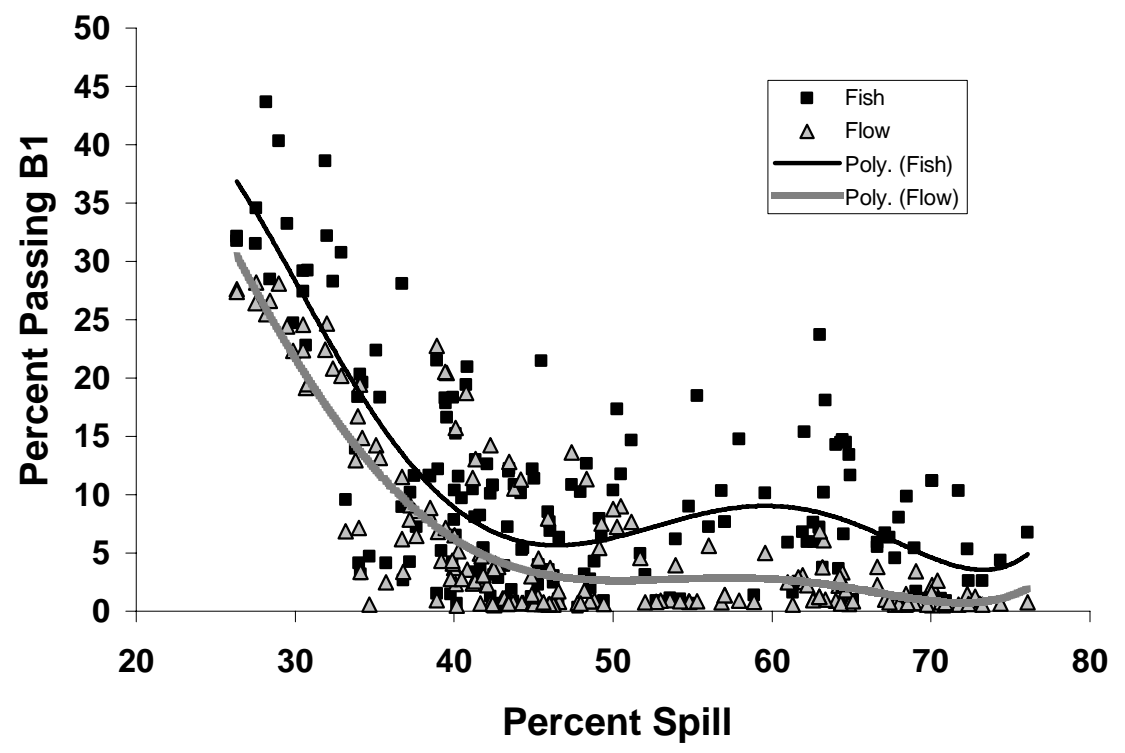

Figure 3.29. Trends in the Percent of Fish and Flow Passing B1 as a Function of Percent Spill. Points include all day and night estimates from both passage seasons.

The percentage of fish and flow passing the Project through B2 increased with increasing percent spill from about 25 to $40 \%$, but then declined about $20 \%$ as percent spill increased from about $40 \%$ to $77 \%$ (Figure 3.30). 


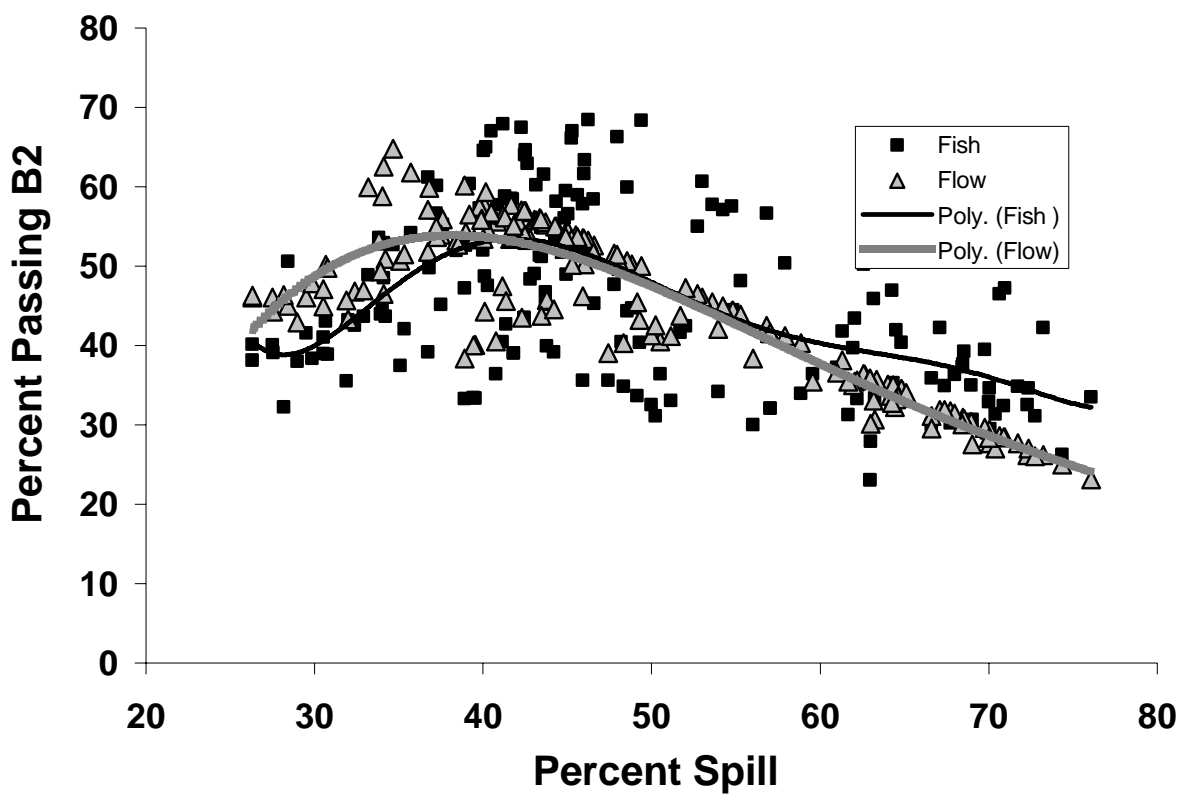

Figure 3.30. Trends in the Percent of Fish and Flow Passing B2 as a Function of Percent Spill. Points include all day and night estimates from both passage seasons.

\subsubsection{Effects of Spill on Project Sluiceway Efficiency}

Over the entire range, percent spill explained just $28 \%$ of the variation in Project sluiceway efficiency in spring 2006 (Figure 3.31). The day and night estimates of Project sluiceway passage efficiency (B1 and the B2CC combined) were highly variable and apparently unrelated to percent spill when spill ranged from $25 \%$ to about $50 \%$. Based upon seven point estimates, sluiceway efficiency appeared to increase with increasing percent spill from about $50 \%$ to $70 \%$.

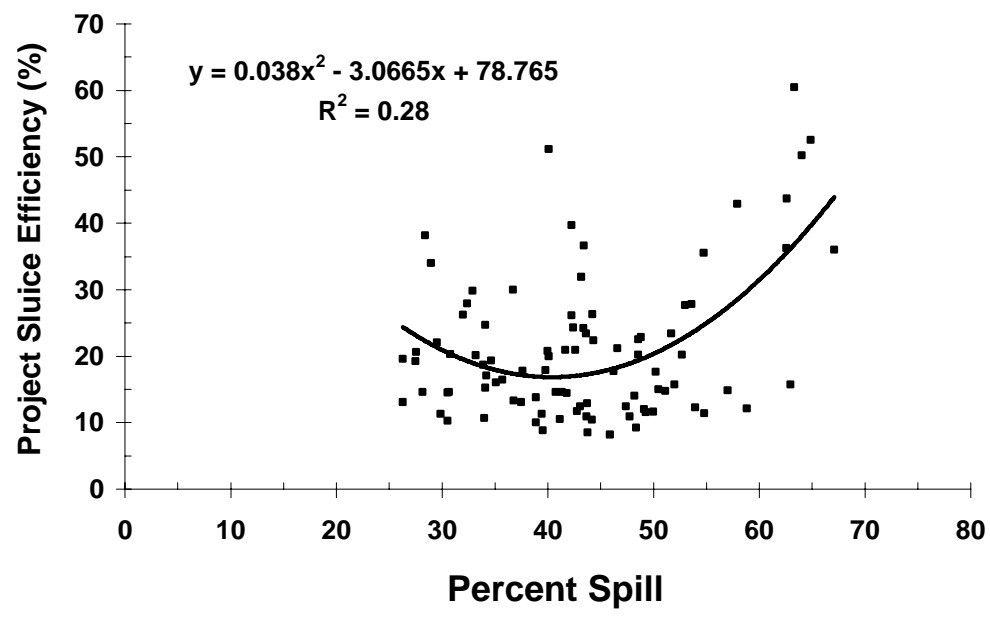

Figure 3.31. Effect of Percent Spill on Project Sluiceway Passage Efficiency (B1 + B2CC) in Spring 2006 
Hourly estimates of spillway discharge in spring 2006 explained about 5\% of the variation in Project sluiceway passage efficiency, and the fitted line suggests that average Project sluiceway efficiency declined by about $18 \%$ as the spill rate increased from 35,000 to 125,000 cfs (Figure 3.32).

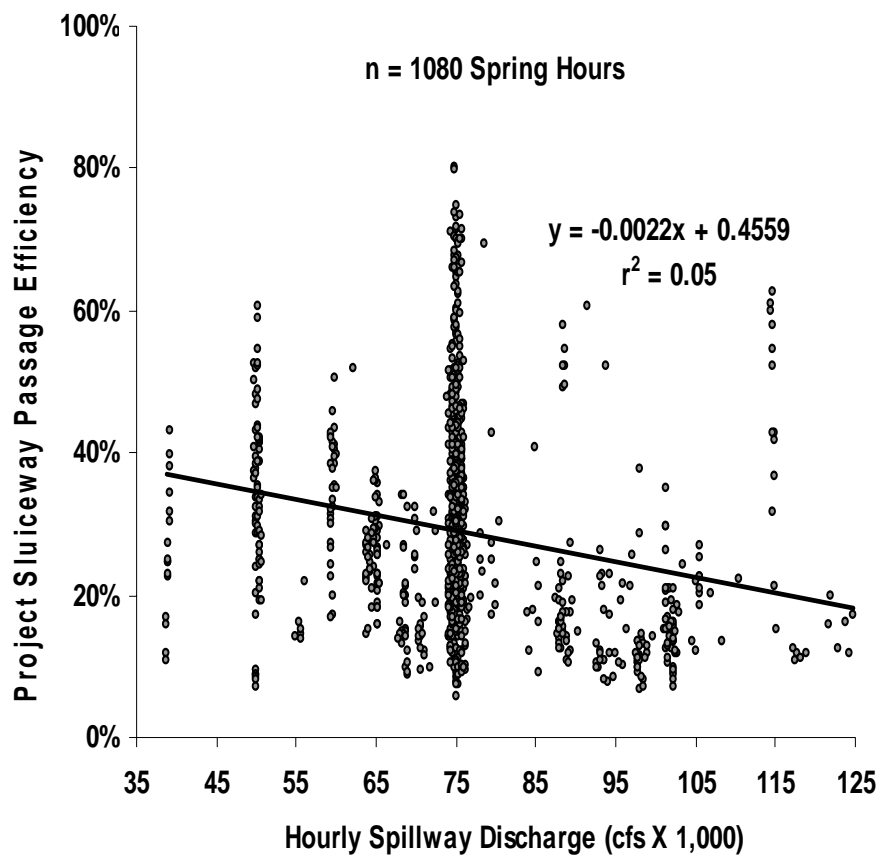

Figure 3.32. Effect of Spill Rate on Project Surface Flow Passage Efficiency (B1 + B2CC) in Spring 2006

In summer, day and night estimates of percent spill explained just $4 \%$ of the variation in Project sluiceway efficiency (B1 and B2CC combined) and mean efficiency declined about 10\% over the entire range of percent spill (Figure 3.33).

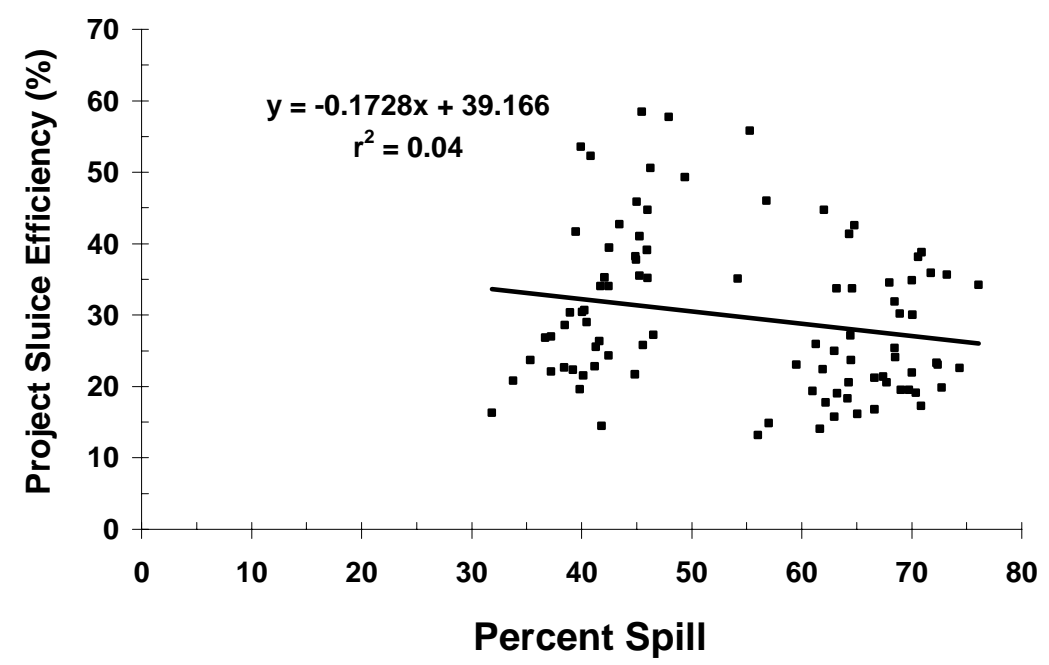

Figure 3.33. Effect of Percent Spill on Project Sluiceway Passage Efficiency (B1 + B2CC) in Summer 2006 


\subsubsection{Effects of Spill Discharge Rate on Spill Efficiency and Project FPE}

This section presents regression data relating the spillway discharge rate, in thousands of cubic $\mathrm{ft}$ per sec (cfs $x 10^{3}$ ) to estimates of spill efficiency and Project FPE.

\subsubsection{Effects of Spillway Discharge Rate on Spill Efficiency}

In spring, average Project spill rates estimated for day and night periods ranged from about 50,000 to 120,000 cfs (Figure 3.34), and spill discharge explained about 16\% of the variation in spill passage efficiency (Figure 3.34). Over the range of discharge, average efficiency increased about 20\% from about $30 \%$ to $50 \%$.

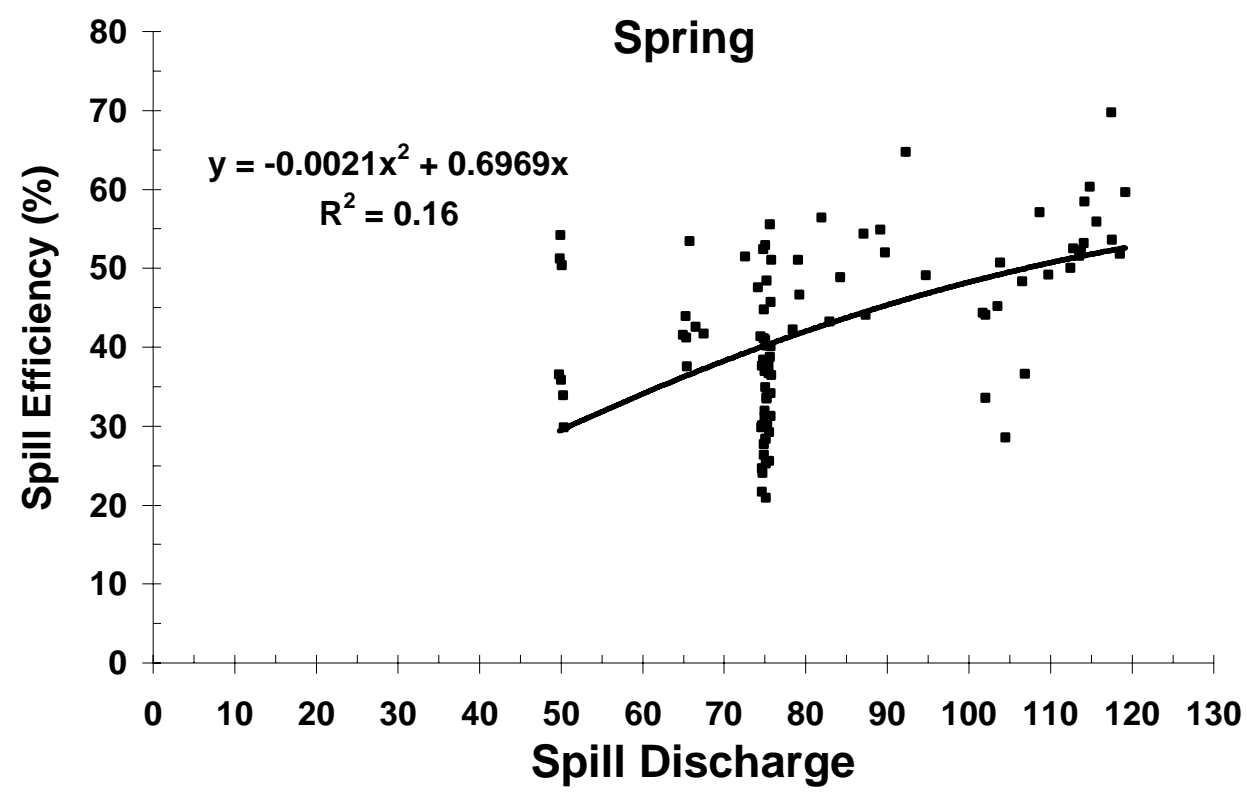

Figure 3.34. Regression of Day and Night Estimates of Spill Passage Efficiency on Spillway Discharge for Spring 2006

In summer, mean discharge during day and night periods explained $77 \%$ of the variability in Project spill passage efficiency, and average efficiency increased $30 \%$ from about $35 \%$ at 75,000 cfs to about $65 \%$ at 135,000 cfs (Figure 3.35). 


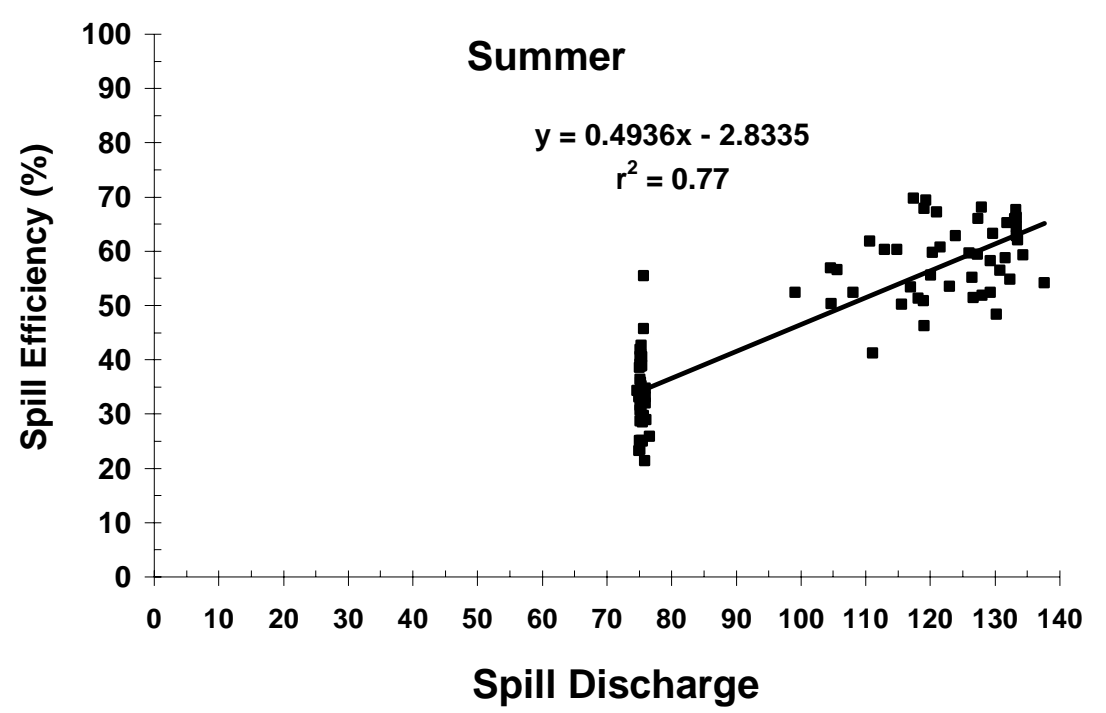

Figure 3.35. Regression of Mean Day and Night Estimates of Spill Passage Efficiency on Spillway Discharge for Summer 2006

\subsubsection{Effects of Spillway Discharge Rate on Project FPE}

In spring, estimates of Project FPE for day and night periods were not correlated with spill discharge rate, although the range in spill rate was wide (Figure 3.36), and although they were strongly correlated with percent spill (Figure 3.27).

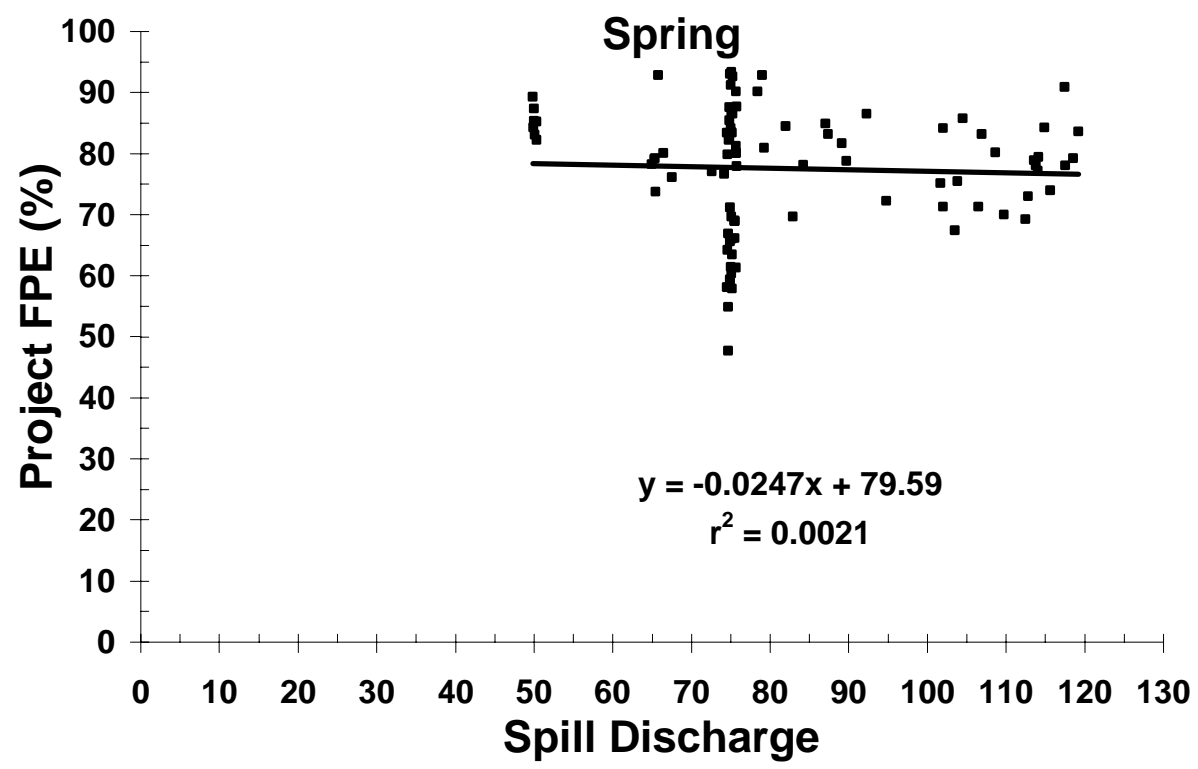

Figure 3.36. Regression of Mean Day and Night Estimates of Project FPE on Spill Discharge Rate (cfs x $1,000)$

In summer, average day and night estimates of spill discharge rate explained about $40 \%$ of the variation in Project FPE, but Project FPE only increased about 10\% (from about 80\% to 90\%) over the entire range of spill discharge estimates (Figure 3.37). The percent of explained variation was $29 \%$ lower than the percent explained by percent spill (Figure 3.28). 


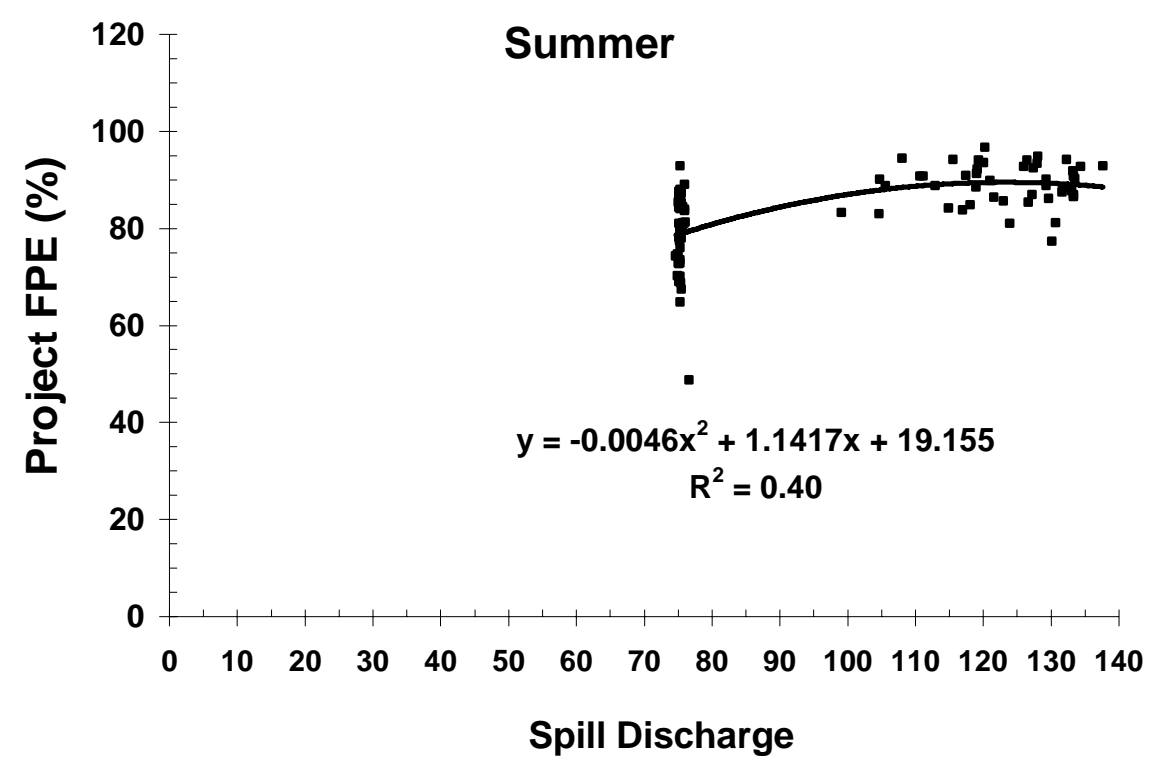

Figure 3.37. Regressions of Mean Daily Project FPE on Spillway Discharge Rate in Summer

\subsubsection{Comparison of Hydroacoustic and Radio Telemetry Estimates}

In spring, hydroacoustic and USGS radio-telemetry estimates of major fish-passage metrics were very similar, except for B1 sluiceway effectiveness relative to the Project (Table 3.3). All hydroacoustic efficiency estimates were within about $7 \%$ of radio telemetry estimates; $89 \%$ were within $5 \%$; and $50 \%$ were within $2 \%$ (Table 3.3). Three of five estimates of effectiveness were within $5 \%$ of each other. However, the hydroacoustic estimate of B2CC effectiveness relative to the Project was 21\% lower than the respective radio telemetry estimate. The hydroacoustic estimate of B1 sluiceway effectiveness relative to the Project was 2.8 times higher than the radio-telemetry estimate.

For summer, we observed greater differences between estimates of most major passage metrics by hydroacoustics and radio telemetry methods than were observed in spring (compare Table 3.3 with Table 3.4). In summer, all hydroacoustic efficiency estimates were within about $20.5 \%$ of radio-telemetry estimates; $89 \%$ were within $14.1 \%$; $78 \%$ were within $10.5 \%$; and $56 \%$ were within $4 \%$ (Table 3.4 ). The smallest differences were for the B2CC (0.5-1.3\%), the B1 sluiceway relative to the Project (3.9\%), Project FPE (4\%), and Project spill efficiency (4.3\%). The radio telemetry estimates of B1 FPE and B1 sluiceway efficiency were identical by hydroacoustic methods since the sluiceway was the only nonturbine passage route but differed by $10 \%$ for radio telemetry estimates. Summer effectiveness measures differed even more than efficiency measures, and the greatest differences were for the B1 sluiceway relative to the Project and relative to B1 (Table 3.4). Estimates of the effectiveness of the spillway and of the B2CC by both methods were reasonably similar. 
Table 3.3. Comparison of Passage Performance Metrics for the Run-at-Large, as Measured by Hydroacoustics (HA), and for Yearling Chinook Salmon and Steelhead Combined, as Measured by Radio Telemetry (RT). Estimates are for concurrent periods of sampling from May 1 through May 31, 2005. Radio telemetry estimates are weighted by the proportion of run size for each species based on the equation: $\mathrm{RT}$ estimate $=(\mathrm{RT}$ estimateCH1 $\mathrm{x}$ proportion of runCH1) + (RT estimateSTH x proportion of runSTH).

\begin{tabular}{|c|c|c|c|}
\hline Passage metric & HA estimate & RT estimate & Difference \\
\hline \multicolumn{4}{|l|}{ Efficiency } \\
\hline FPE $_{\text {Project }}$ & $70.9 \%$ & $71 \%$ & $-0.1 \%$ \\
\hline $\mathrm{FPE}_{\mathrm{B} 1}$ & $34.4 \%$ & $33 \%$ & $1.4 \%$ \\
\hline $\mathrm{FPE}_{\mathrm{B} 2}$ & $60.8 \%$ & $56 \%$ & $4.8 \%$ \\
\hline $\mathrm{FGE}_{\mathrm{B} 2}$ & $43.4 \%$ & $36 \%$ & $7.4 \%$ \\
\hline Spillway passage efficiency & $38.6 \%$ & $39 \%$ & $-0.4 \%$ \\
\hline B2CC efficiency в2 & $30.7 \%$ & $31 \%$ & $-0.3 \%$ \\
\hline B2CC efficiency Project & $13.0 \%$ & $17 \%$ & $-4.0 \%$ \\
\hline B1 Sluiceway efficiency в1 & $34.4 \%$ & $31 \%$ & $3.4 \%$ \\
\hline B1 Sluiceway efficiency Project & $6.5 \%$ & $2 \%$ & $4.5 \%$ \\
\hline \multicolumn{4}{|l|}{ Effectiveness } \\
\hline Corner collector effectiveness $\mathrm{B}_{\mathrm{B} 2}$ & 6.5 & 6.5 & 0.0 \\
\hline Corner collector effectiveness Project & 5.7 & 7.2 & -1.5 \\
\hline Spillway effectiveness & 1.03 & 1.03 & 0.0 \\
\hline B1 Sluiceway effectiveness ${ }_{B 1}$ & 10.4 & 9.9 & 0.5 \\
\hline B1 Sluiceway effectiveness Project & 13.6 & 4.8 & 8.8 \\
\hline
\end{tabular}


Table 3.4. Comparison of Passage Performance Metrics for the Run-at-large, as Measured by Hydroacoustics (HA), and for Yearling Chinook Salmon and Steelhead Combined, as Measured by Radio Telemetry (RT). Estimates are for concurrent periods of sampling from June 15 through July 15, 2005. Radio telemetry estimates are weighted by the proportion of run size for each species based on the equation: $\mathrm{RT}$ estimate $=(\mathrm{RT}$ estimateCH1 $\mathrm{x}$ proportion of runCH1) + (RT estimateSTH x proportion of runSTH).

\begin{tabular}{|c|c|c|c|}
\hline Passage metric & HA estimate & RT estimate & Difference \\
\hline \multicolumn{4}{|l|}{ Efficiency } \\
\hline FPE $_{\text {Project }}$ & $81.0 \%$ & $77 \%$ & $4 \%$ \\
\hline $\mathrm{FPE}_{\mathrm{B} 1}$ & $82.5 \%$ & $72 \%$ & $10.5 \%$ \\
\hline $\mathrm{FPE}_{\mathrm{B} 2}$ & $63.7 \%$ & $54 \%$ & $9.7 \%$ \\
\hline $\mathrm{FGE}_{\mathrm{B} 2}$ & $38.1 \%$ & $24 \%$ & $14.1 \%$ \\
\hline Spillway passage efficiency & $44.7 \%$ & $49 \%$ & $-4.3 \%$ \\
\hline B2CC Efficiency $_{\mathrm{B} 2}$ & $41.3 \%$ & $40 \%$ & $1.3 \%$ \\
\hline B2CC Efficiency Project & $20.5 \%$ & $20 \%$ & $0.5 \%$ \\
\hline B1 Sluiceway efficiency $y_{B 1}$ & $82.5 \%$ & $62 \%$ & $20.5 \%$ \\
\hline B1 Sluiceway efficiency Project & $4.7 \%$ & $0.8 \%$ & $3.9 \%$ \\
\hline \multicolumn{4}{|l|}{ Effectiveness } \\
\hline Spillway effectiveness & 0.9 & 1.2 & -0.3 \\
\hline Corner collector effectiveness $\mathrm{B}_{\mathrm{B} 2}$ & 6.3 & 7.2 & -0.9 \\
\hline Corner collector effectiveness Project & 7.0 & 6.8 & 0.2 \\
\hline B1 Sluiceway effectiveness ${ }_{B 1}$ & 4.2 & 7.8 & -3.6 \\
\hline B1 Sluiceway effectivenesS Project $_{1}$ & 7.7 & 1.4 & 6.3 \\
\hline
\end{tabular}

In spring, all estimates of FGE for B2 units by hydroacoustic and radio-telemetry methods were within $16 \%$ of each other; $88 \%$ were within $13 \%$; $62 \%$ were within $11 \%$; and $38 \%$ were within $4.4 \%$ (Table 3.5 ). The average FGE estimate in spring was $46 \%$ by hydroacoustic methods and $38 \%$ by radio-telemetry methods. Hydroacoustic estimates of FGE were higher than radio-telemetry estimates at six of eight units. Hydroacoustic estimates and radio-telemetry estimates were within $4.4 \%$ of each other at three units on the south end of the powerhouse (Units 11-13). Estimates by hydroacoustics were from $10.1 \%$ to $15.9 \%$ higher than radio-telemetry estimates at Units 14-18.

In summer, all estimates of FGE for B2 units were within 24\% of each other; $75 \%$ were within 16\%; $62 \%$ were within $11 \%$; and only $25 \%$ were within $7.2 \%$. There was worse correspondence between estimates in summer than there was in spring. Hydroacoustic estimates in summer exceeded radio telemetry estimates by $7.2 \%$ to $23.5 \%$ at Units 11 through 16 , and radio telemetry estimates exceeded hydroacoustic estimates by $4.7 \%$ and $11.7 \%$ at Units 17 and 18 on the north end of the powerhouse. The average FGE estimate for B2 turbines was $39 \%$ by hydroacoustics and $31 \%$ by radio telemetry. 
Table 3.5. Estimates of Fish Guidance Efficiency (FGE), by Turbine Unit, at B2 for the Run-at-Large as Measured by Hydroacoustics (HA) and for Yearling Chinook Salmon and Steelhead Combined, as Measured by Radio Telemetry (RT), from May 1-May 31, 2005. Radio telemetry estimates are weighted by the proportion of run size for each species based on the equation: RT FGE $=($ RT FGECH1 $x$ proportion of runCH1 $)+($ RT FGESTH $x$ proportion of runSTH).

\begin{tabular}{||cccc|}
\hline Location & HA FGE (\%) & RT FGE (\%) & Difference \\
\hline Unit 11 & 42.2 & 43 & -0.8 \\
Unit 12 & 42.4 & 38 & 4.4 \\
Unit 13 & 37.9 & 40 & -2.1 \\
Unit 14 & 47.5 & 35 & 12.5 \\
Unit 15 & 55.9 & 40 & 15.9 \\
Unit 16 & 50.1 & 40 & 10.1 \\
Unit 17 & 53.9 & 41 & 12.9 \\
Unit 18 & 34.7 & 24 & 10.7 \\
\hline \hline
\end{tabular}

Table 3.6. Estimates of FGE, by Turbine Unit, at B2 for the Run-at-Large as Measured by Hydroacoustics (HA) and for Yearling Chinook Salmon and Steelhead Combined, as Measured by Radio Telemetry (RT), from June 15 through July 15, 2005. Radio telemetry estimates are weighted by the proportion of run size for each species based on the equation: RT FGE = $($ RT FGECH1 $x$ proportion of runCH1 $)+($ RT FGESTH $x$ proportion of run STH $)$.

\begin{tabular}{||cccc||}
\hline Location & HA FGE (\%) & RT FGE (\%) & Difference \\
\hline \hline Unit 11 & 53.5 & 33 & 20.5 \\
Unit 12 & 39.6 & 24 & 15.6 \\
Unit 13 & 37.5 & 27 & 10.5 \\
Unit 14 & 33.2 & 26 & 7.2 \\
Unit 15 & 45.7 & 36 & 9.7 \\
Unit 16 & 43.5 & 20 & 23.5 \\
Unit 17 & 48.3 & 53 & -4.7 \\
Unit 18 & 13.3 & 25 & -11.7 \\
\hline
\end{tabular}




\subsection{Spatial Trends in Fish Passage}

\subsubsection{Horizontal Distribution}

\subsubsection{Among Dam Structures}

We examined the horizontal distribution of fish passage across the entire project as well as the horizontal and the vertical distributions of passage at surface collection routes, each powerhouse, and the spillway. During both sampling seasons, the percentage of the total fish that passed each major structure (Powerhouse 1, Spillway, and Powerhouse 2) was similar to the percentage of discharge through each structure (Figures 3.38 and 3.39). Within each structure, however, and particularly at the powerhouses, the horizontal distribution of fish passage was less related to discharge.

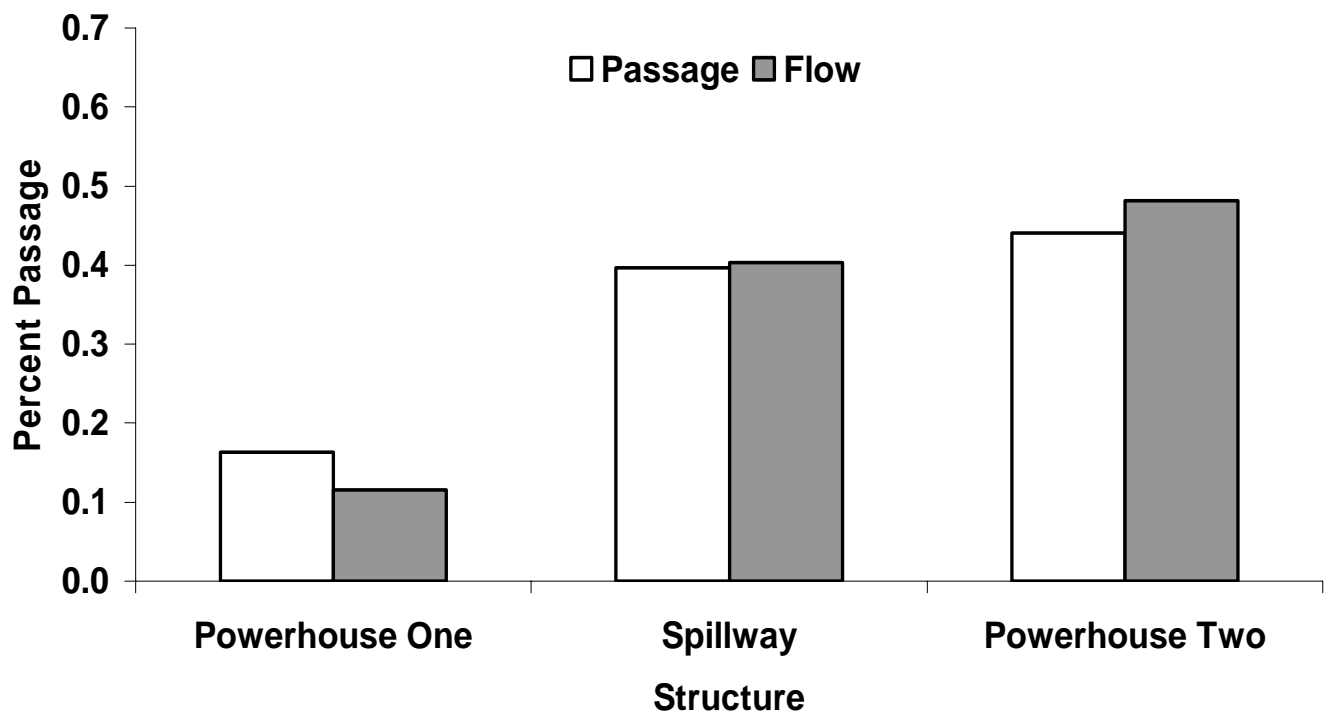

Figure 3.38. Percentage of Fish Passage and Discharge at Each Major Passage Structure in Spring 2005

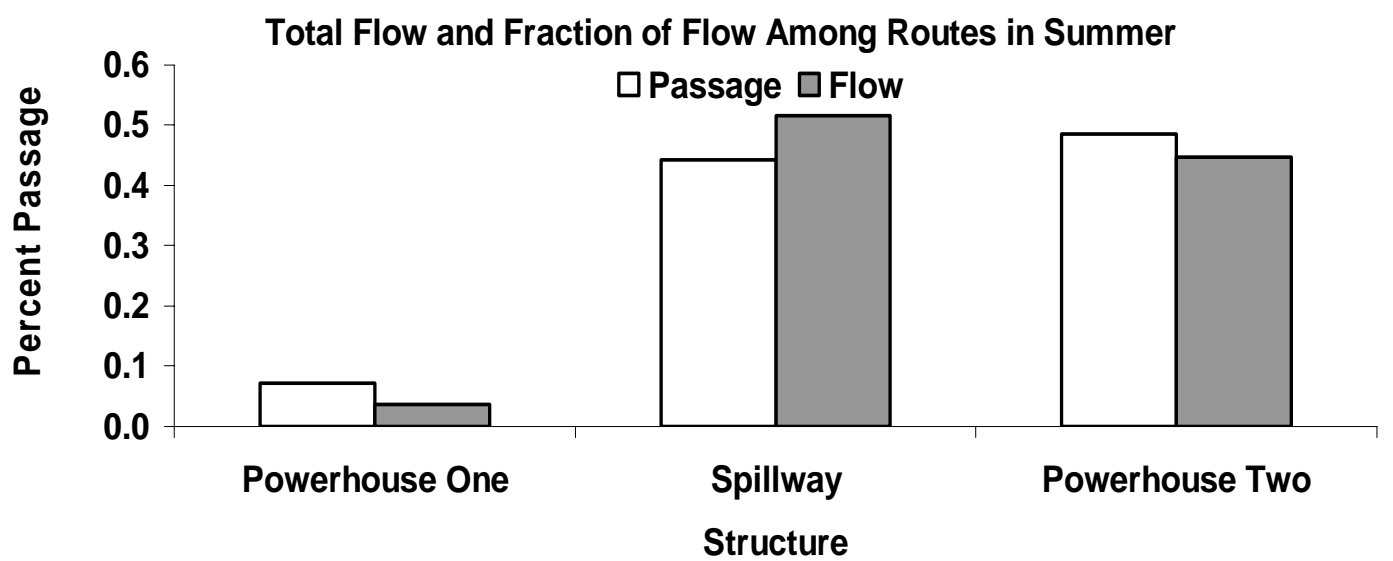

Figure 3.39. Percentage of Fish Passage and Discharge at Each Major Passage Structure in Summer 2005 


\subsubsection{Among Routes}

In spring and summer, most fish passed at the B2CC, at B2 Units 11-13 and 18, the south end of the spillway (Bays 16-18), and at B1 Sluiceway Outlet 1C and, except for passage at surface flow outlets, usually paralleled route-specific discharge (Figures 3.40 and 3.41). The proportion of flow and fish passage at B1 was lower in summer than it was in spring as more flow was routed from B1 to the spillway in summer (compare Figures 3.40 and 3.41).

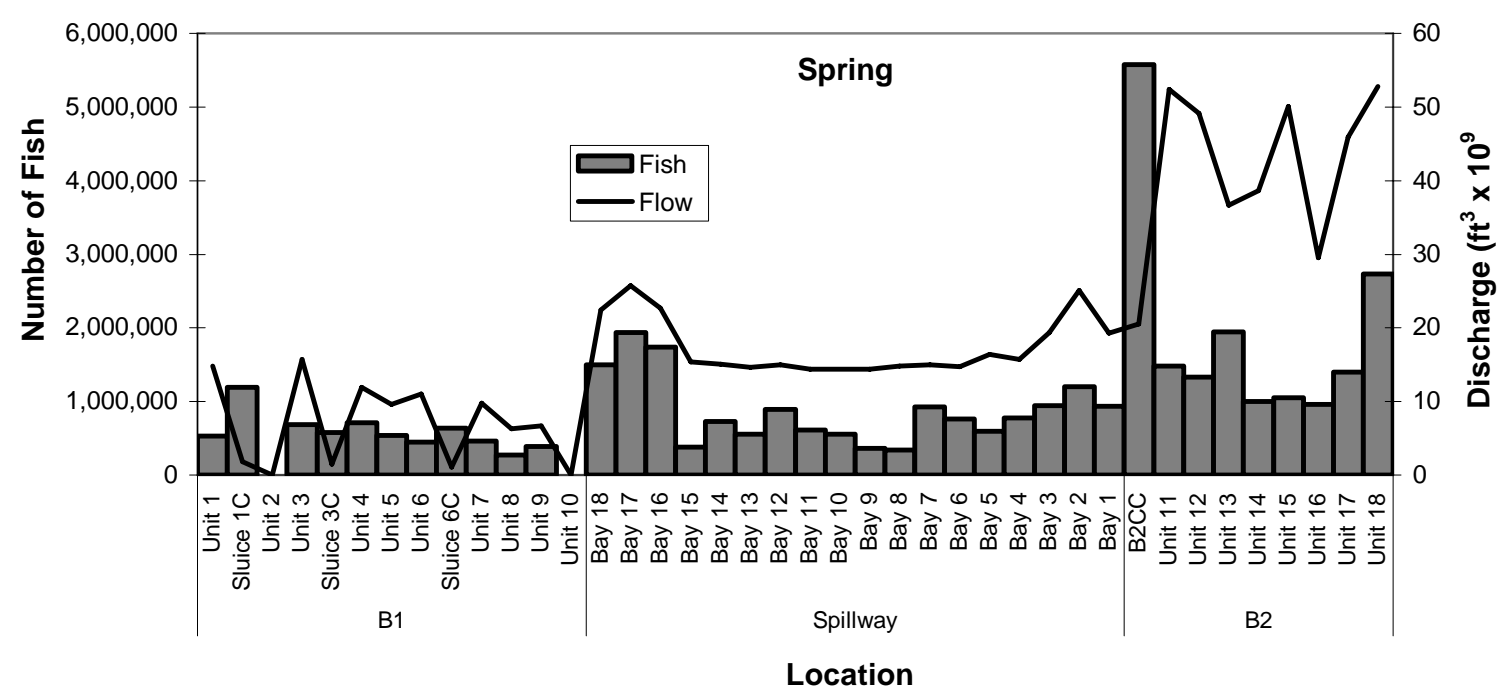

Figure 3.40. Fish Passage by Route in Spring 2005

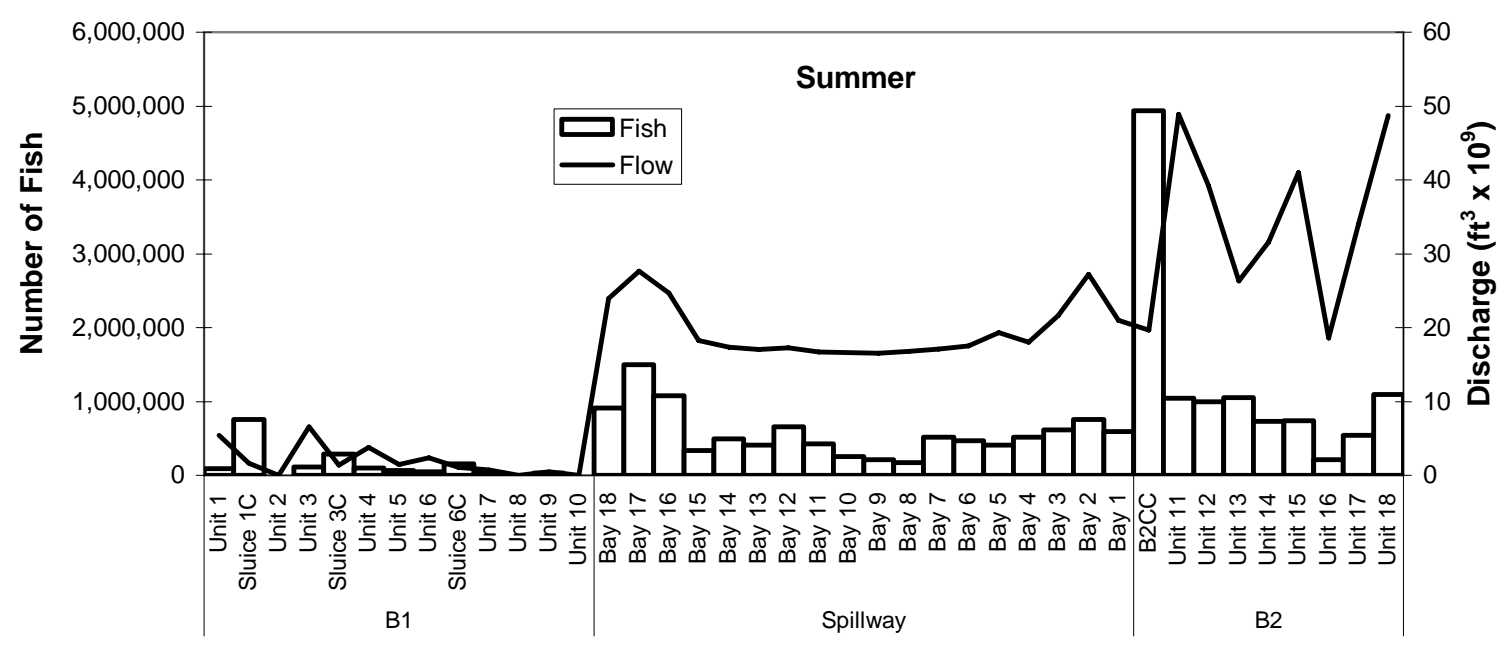

Location

Figure 3.41. Fish Passage by Route in Summer 2005 
The surface flow outlets passed many more fish relative to the flow than other passage routes, as clearly indicated by the horizontal distribution of fish-passage density (Figure 3.42). The horizontal distribution of fish passage at B1 (Units 1-10 and Sluice Outlets 1C, 3C, and 6C) was dominated by sluiceway passage in both seasons. Passage density through Sluiceway Outlet $1 \mathrm{C}$ was higher than any other route in both seasons.

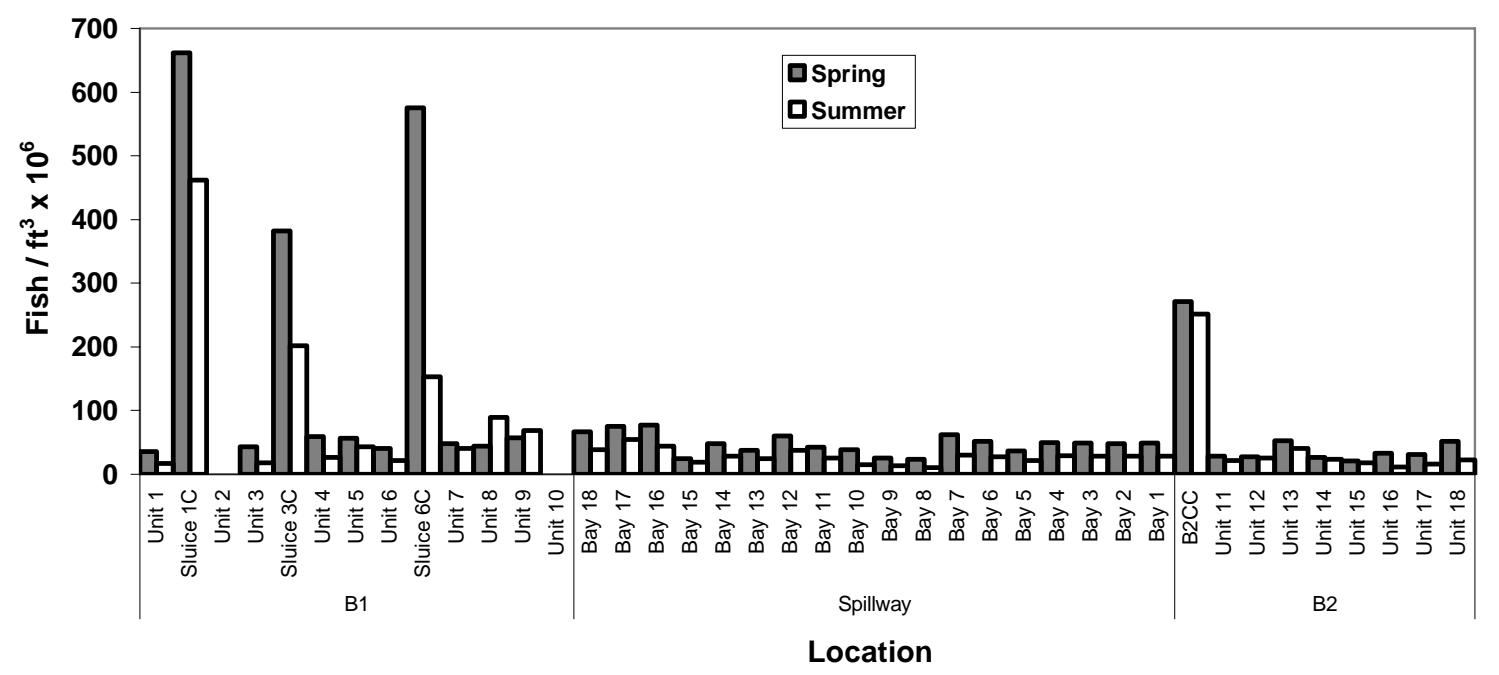

Figure 3.42. Fish Passage Density by Route in Spring and Summer 2005

\subsubsection{Across Surface Outlets}

The distributions of fish passage across the $20 \mathrm{ft}$ width of each sluiceway outlet's entrance at B1 varied a lot among seasons and among locations within the spring season (Figure 3.43) but were more consistent in summer (Figures 3.44). During spring, fish passage was fairly uniform across the Sluiceway Outlets 3C and 6C, but it was skewed towards the piers at Outlet 1C (Figure 3.43). In summer passage was highest near the piers at all sluiceway outlets (Figure 3.44).

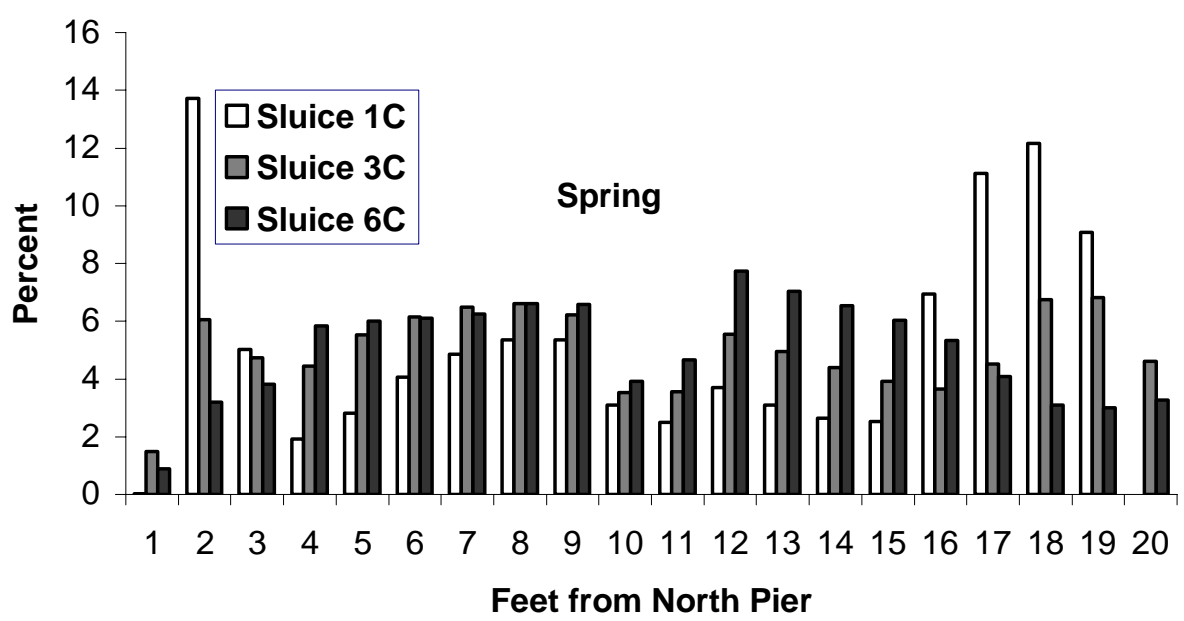

Figure 3.43. Distributions of Fish Passage across Three B1 Sluiceway Outlets in Spring 


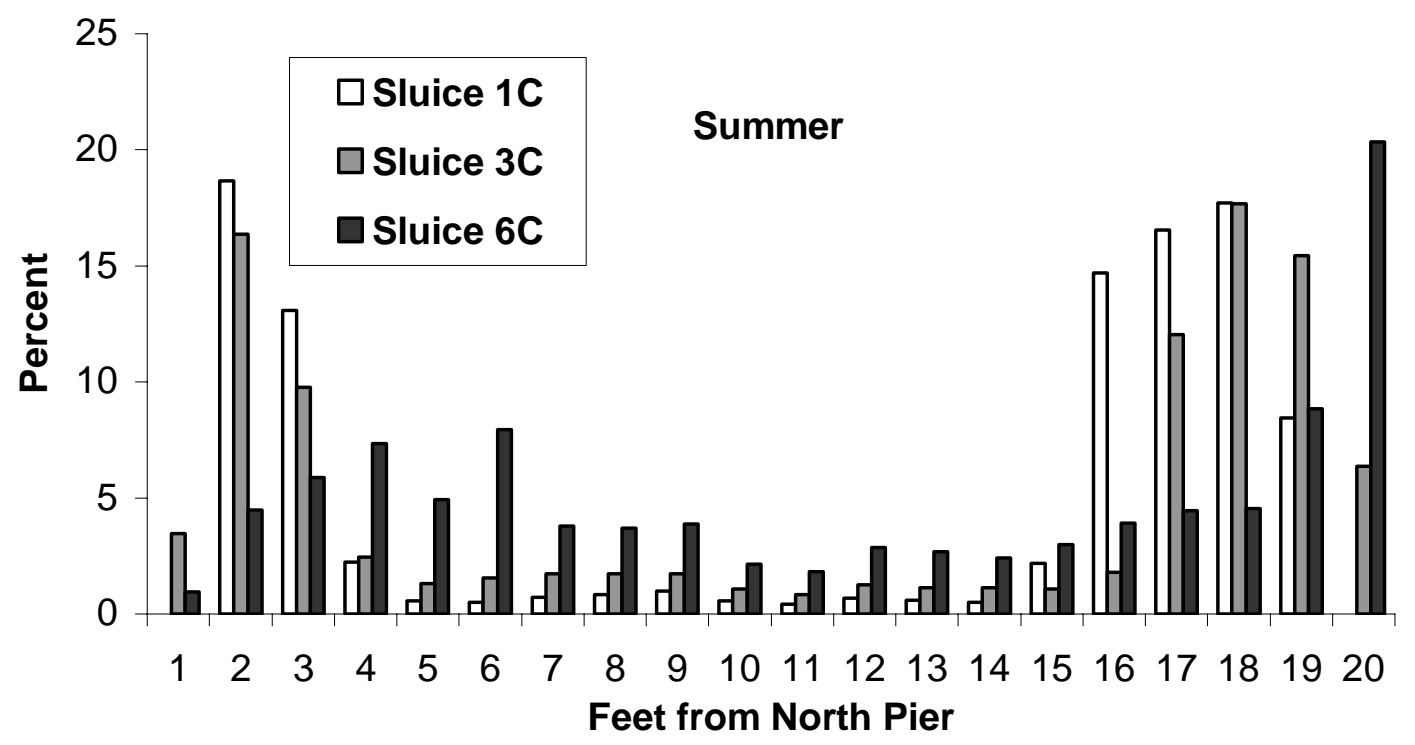

Figure 3.44. Distributions of Fish Passage across Three B1 Sluiceway Outlets in Summer

The horizontal distribution of fish passage across the entrance to the B2CC was highest in the center of the entrance during spring and was slightly skewed toward the south during summer (Figure 3.45).

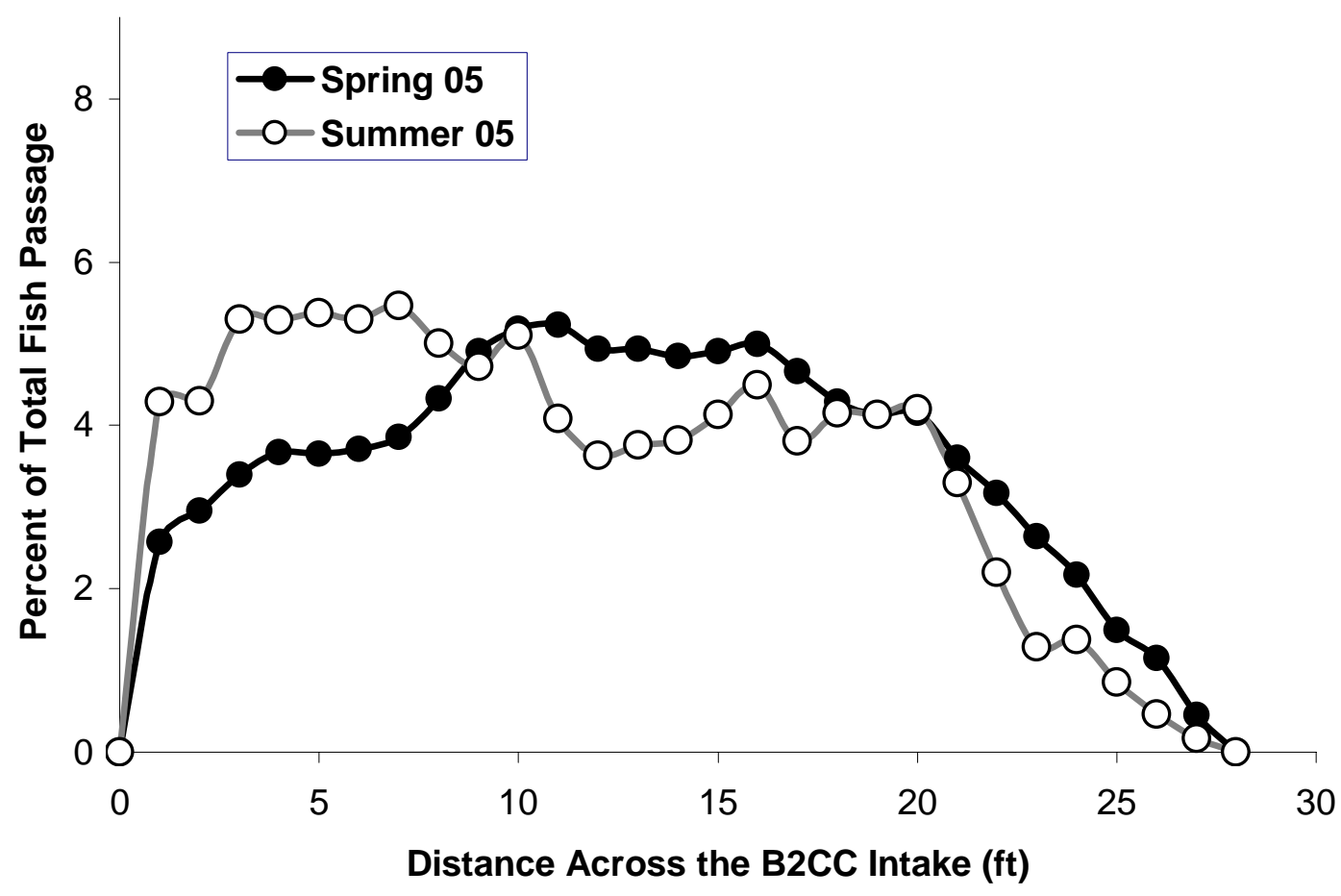

Figure 3.45. Horizontal Distribution of Fish Passage at the B2CC 


\subsubsection{Vertical Distributions}

\subsubsection{B1 Turbines}

The estimated vertical distributions of fish within turbine intakes at B1 were multi-modal, with peaks in fish-passage percentages near the top of the intakes (about elevation $60 \mathrm{ft}$.), at about the middle of the intakes (elevation $36 \mathrm{ft}$.), and near the bottom of the intakes (Figure 3.46). The largest peak was near the bottom of the intake each season. A similar pattern was observed in 2004, with a prominent peak near the bottom of intakes that rivaled the peak near the ceiling in spring and exceeded the ceiling peak in summer.

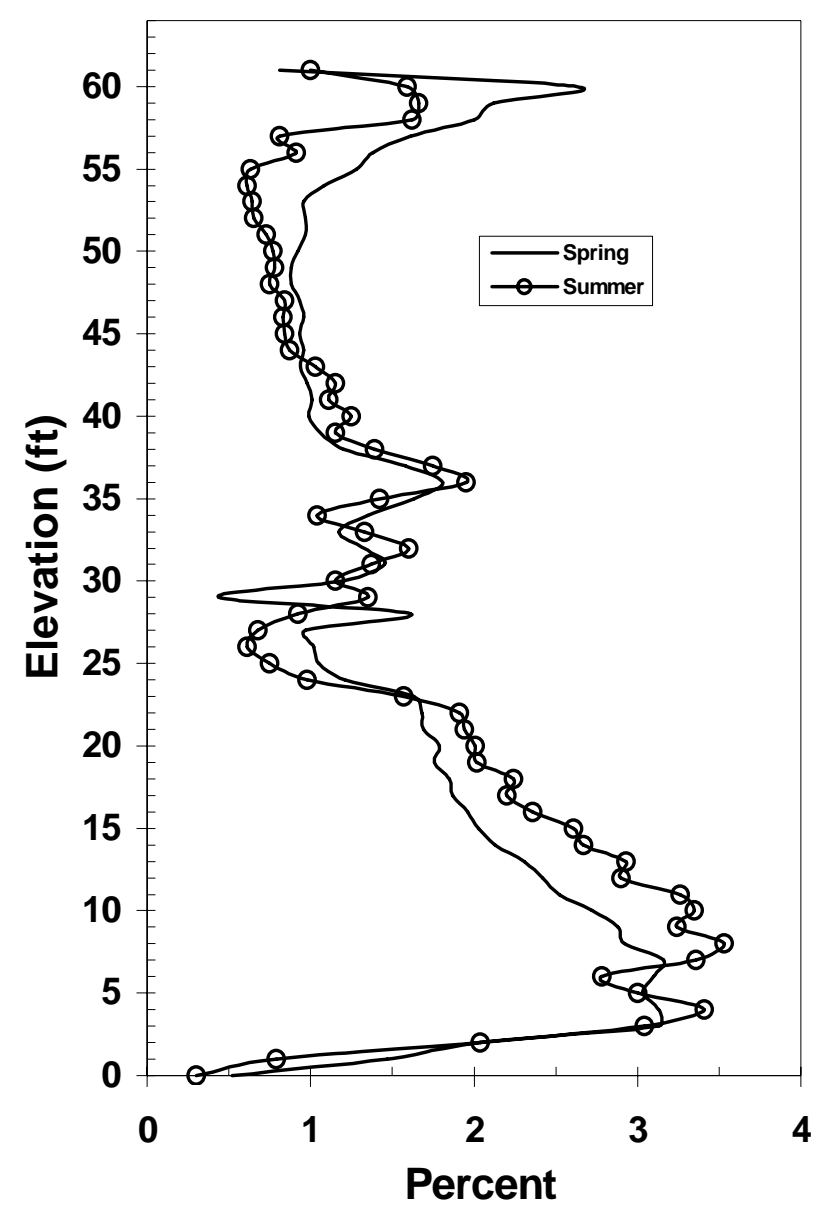

Figure 3.46. Vertical Distributions of Fish within Turbine Intakes at B1

We adjusted the average B1 vertical distributions in 2005 (Figure 3.46) by moving fish detected above Elevation $47 \mathrm{ft}$ down into the uppermost strata sampled in 2002 and earlier years (EL 41-47). This standardization of maximum elevations to those sampled in 2001 and 2002, restored the predominance of fish passage in the upper water column for the 2005 data (Figure 3.47), although a substantial percent of fish passed deep through B1 turbines. Data from 2002 (Figure 3.48) also show sizeable percentages of fish passing deep, as do data from 2001 (Ploskey et al. 2002c). 


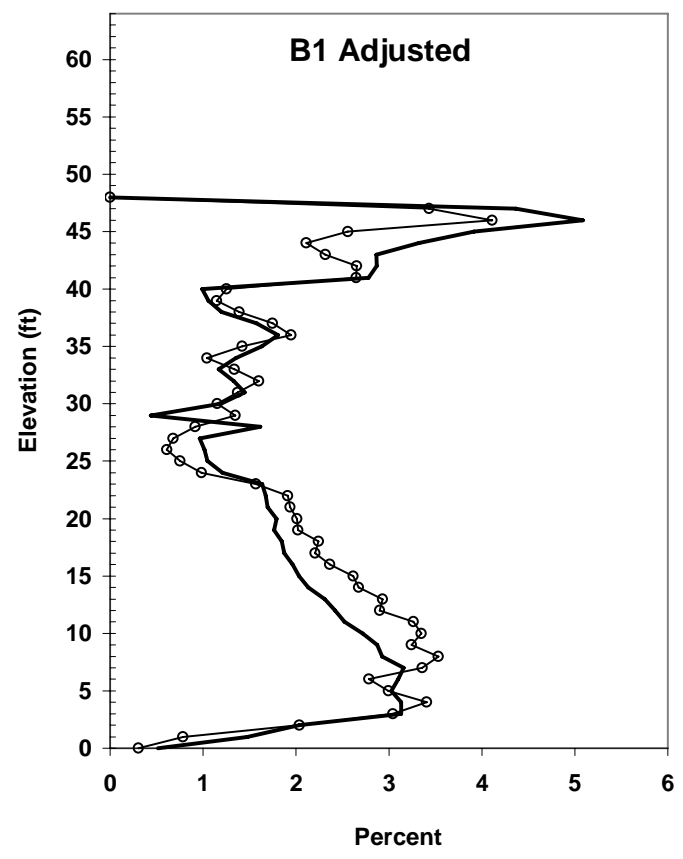

Figure 3.47. Average Vertical Distributions of Fish Passage within B1 Turbine Intakes in Spring and Summer 2005, after Adjusting for Reducing Maximum to Pre-2004 Sampling Levels. Percentages above elevation $31 \mathrm{ft}$ were estimated from samples of up-looking hydroacoustic beams and those at or below elevation $31 \mathrm{ft}$ were estimated from down-looking hydroacoustic beams.

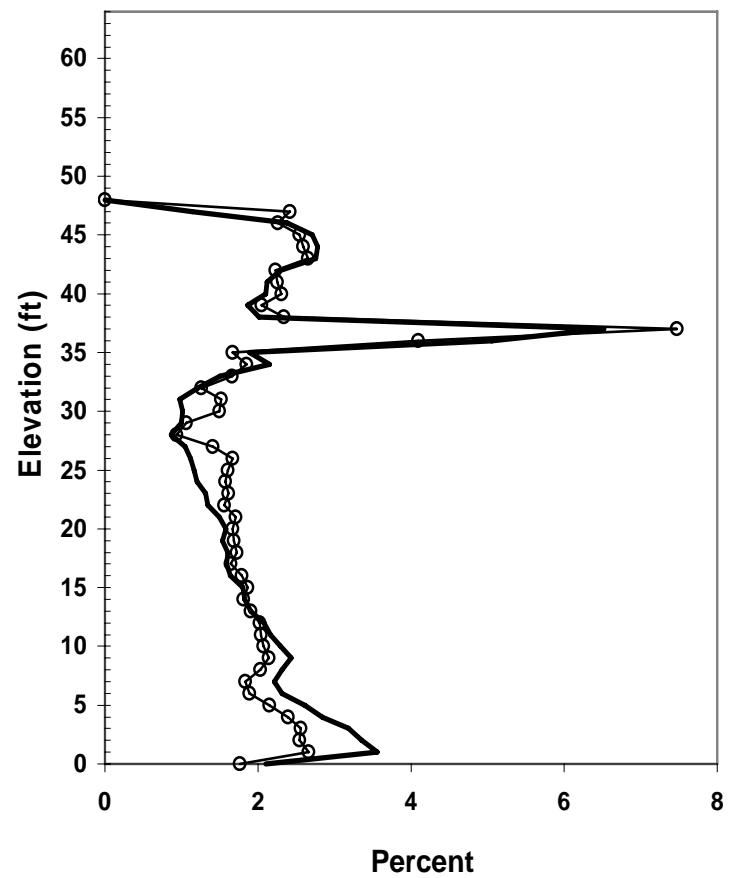

Figure 3.48. Average Vertical Distributions of Fish Passage within B1 Turbine Intakes in Spring and Summer 2002. Percentages above elevation $31 \mathrm{ft}$ were estimated from samples of uplooking hydroacoustic beams and those at or below elevation $31 \mathrm{ft}$ were estimated from down-looking hydroacoustic beams. 


\subsubsection{Spillway}

The vertical distribution of fish passing the spillway in spring and summer were similar (Figure 3.49), with peak passage occurring at very near the ogee, which is at Elevation $24 \mathrm{ft} \mathrm{MSL}$. A similar pattern was observed in 2004 (Ploskey et al. 2005).

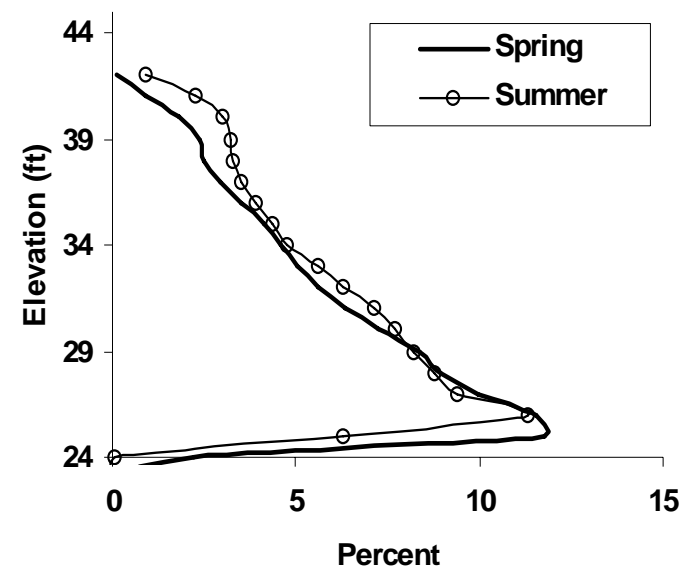

Figure 3.49. Vertical Distributions of Fish at Spillway

\subsubsection{B2CC}

Fish entering the B2CC were surface oriented in both seasons but were somewhat lower in the water column in summer than they were in spring (Figure 3.50). About 70\% were detected in the top half of the opening (about $11 \mathrm{ft}$ of depth) in spring, while only $60 \%$ were in the top half of the opening in summer.

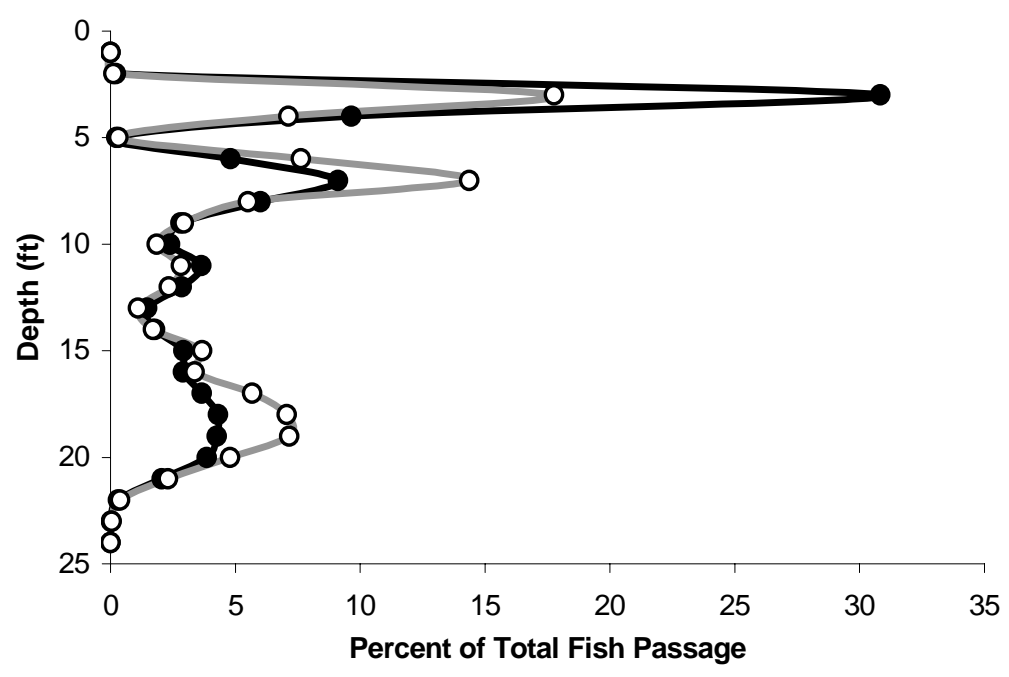

Figure 3.50. Vertical Distributions of Fish at the B2CC Entrance. The line with black dots is spring and the line with circles is the average of summer data. 


\subsubsection{B2 Turbines}

The percent of fish passage varied just $1 \%$ to $2 \%$ among 1-ft depth strata in B2 turbines and exhibited only a slight decline with decreasing elevation in spring and summer 2005. In spring, the percent passage within 1-ft strata between the bottom and the ceiling of the intakes ranged from 1.0 to 3.5\% (Figure 3.51). Except for a single peak of 5.4\% at Elevation $21 \mathrm{ft}$ in summer, the same relatively narrow range in percent passage also was observed for all strata in summer (Figure 3.52).

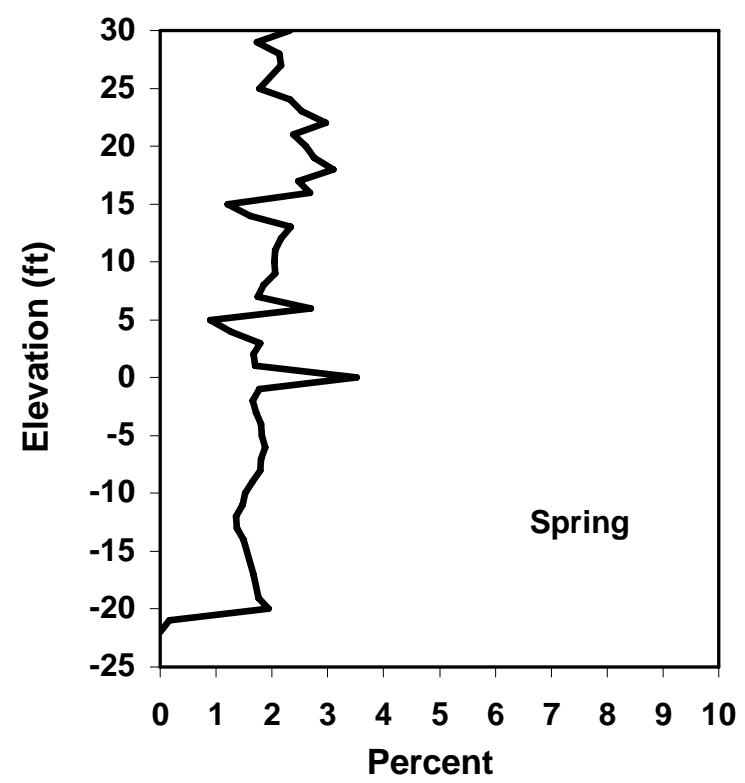

Figure 3.51. Vertical Distributions of Fish within B2 Turbine Intakes in Spring 2005

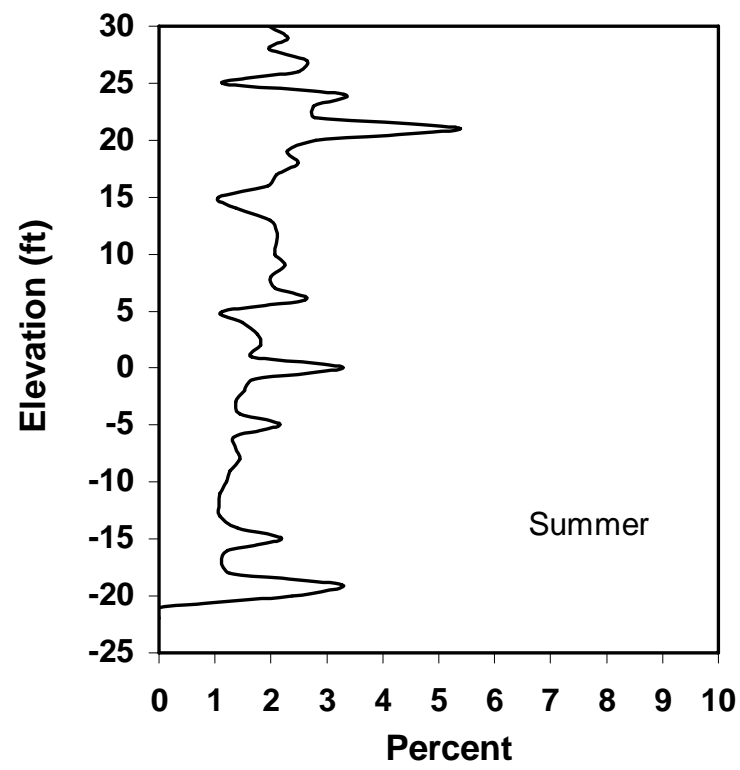

Figure 3.52. Vertical Distributions of Fish within B2 Turbine Intakes in Summer 2005 


\subsection{Temporal Trends in Fish Passage}

\subsubsection{Seasonal Trends}

\subsubsection{Smolt Run Timing}

Percent passage of juvenile salmonids based on the Smolt Monitoring Facility (SMF) index and daily fullproject hydroacoustic sampling generally had similar timing of peaks in passage during spring and summer, although magnitudes of the two measures differed by 2 to 3\% on some days (Figure 3.53).

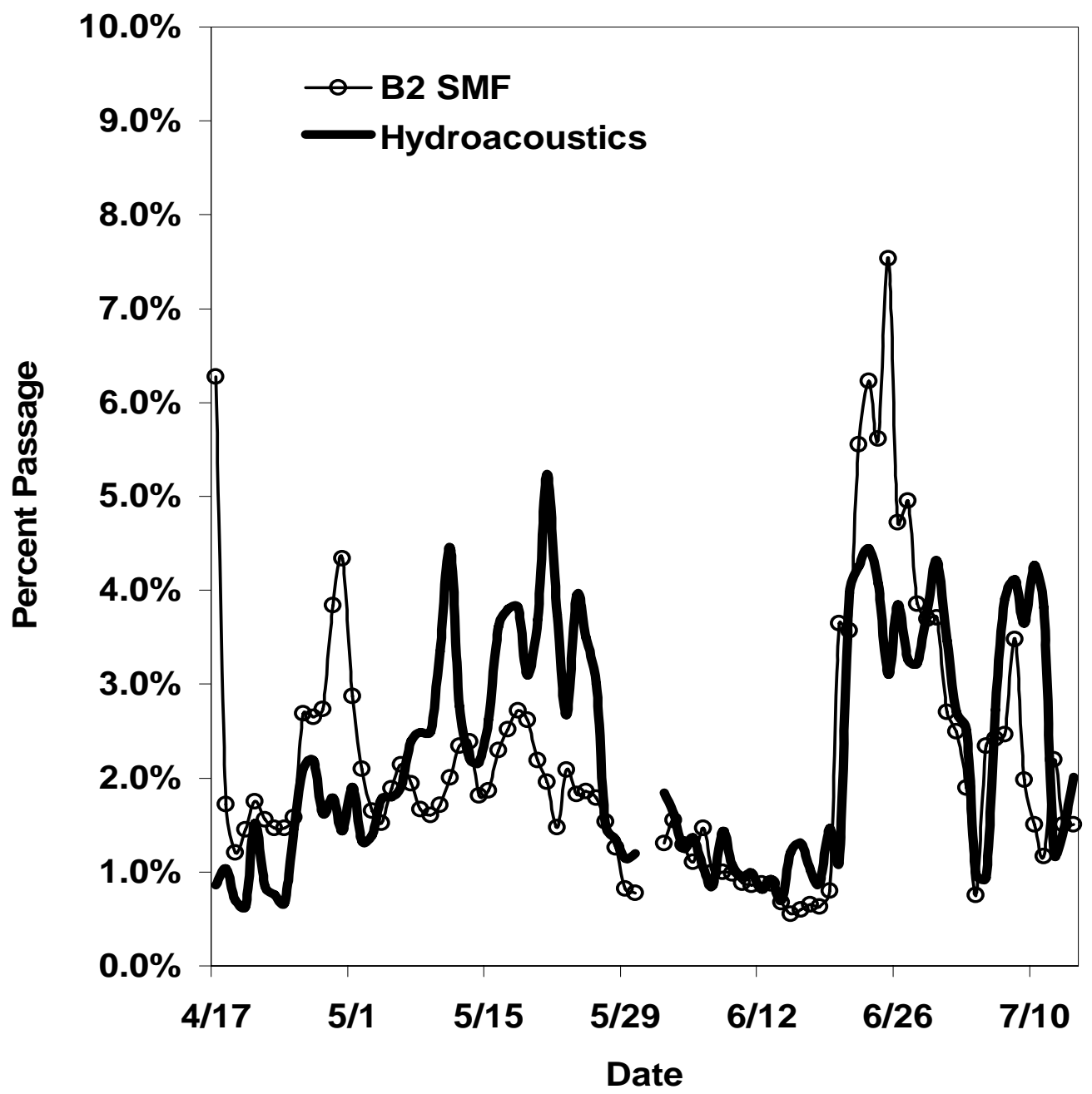

Figure 3.53. Patterns of Run Timing Estimated by Hydroacoustics (heavy line) and by the B2 SMF Smolt Index (thin line) at Bonneville Dam in 2005. The SMP data were obtained from http://www.cqs.washington.edu/dart/pass com.html.

\subsubsection{Adult American Shad Run Timing Effects in Summer}

The peak of the upstream migration of adult American shad occurred between the spring and summer peaks in juvenile salmonid out-migrations (Figure 3.54). The out migration of spent American shad (Alosa sapidissima) could cause false detections by hydroacoustic sampling, typically in July, but the first 
and second summer peaks in hydroacoustic estimates were clearly associated with passage of subyearling Chinook salmon (Figure 3.54). Also, all routes of passage contributed hydroacoustic detections during the summer peaks in juvenile fish passage (Figure 3.55), and the distribution among routes was not highly skewed toward surface-passage routes that would be dominated by Amercian shad.

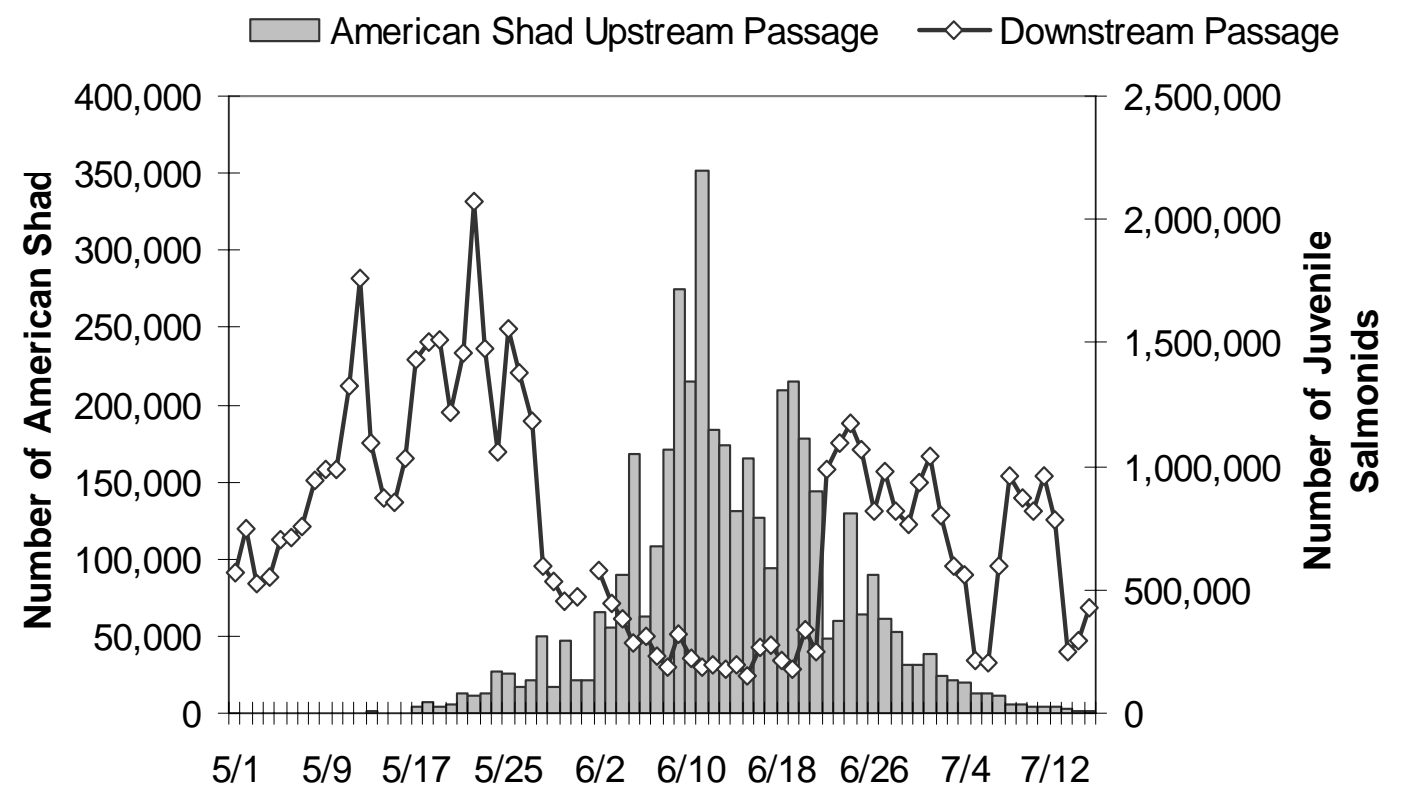

Date

Figure 3.54. Patterns of Adult American Shad and Juvenile Salmonid Run Timing According to Fish Passage Center Counts and Hydroacoustic Counts, Respectively. Shad data were obtained from http://www.cqs.washington.edu/dart/adult.html.

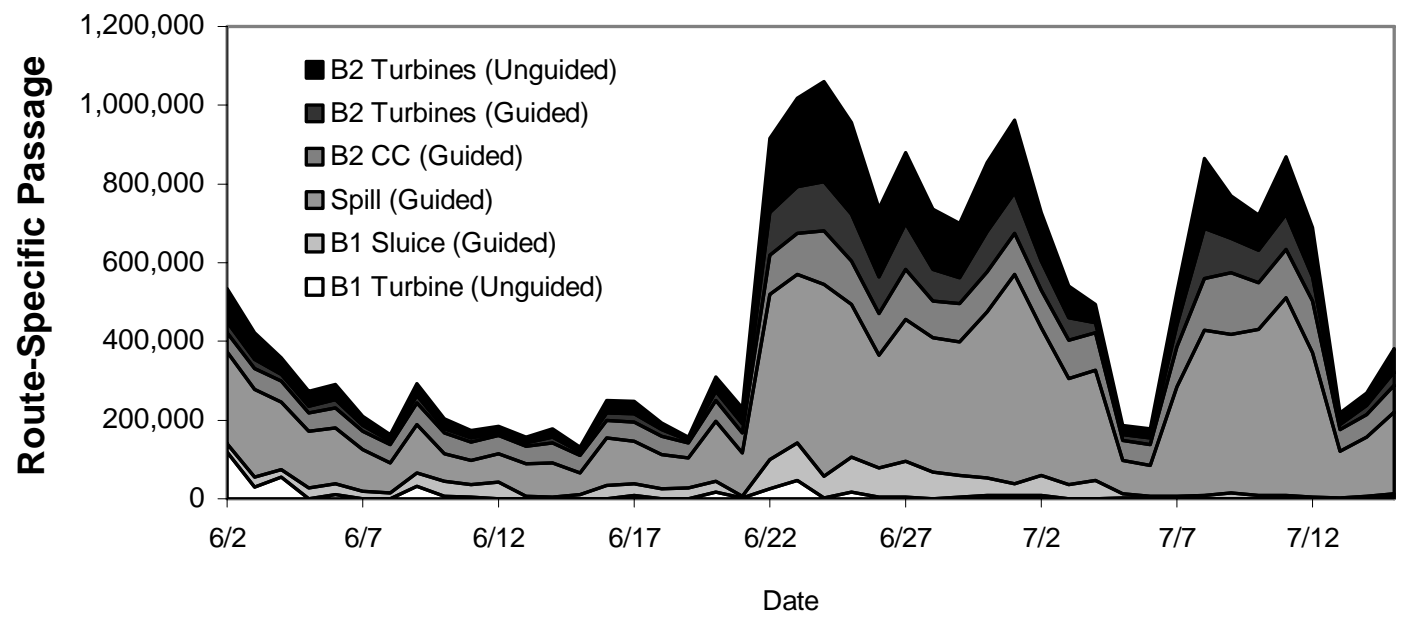

Figure 3.55. Time Histories of Estimated Route-Specific Passage in Summer 


\subsubsection{Major Fish Passage Metrics}

Estimated Project FPE exhibited trends lasting several days at a time, sometimes with 2 to 3 days of higher efficiency followed by 2 to 3 days of lower efficiency (Figure 3.56). There is also a gradual decline in FPE during spring with values starting at $92.7 \%$ on $4 / 19$ and ending with a low of $57.3 \%$ on 5/27. Daily Project FPE estimates for spring averaged 76.6\%. Summer FPE increased at the beginning of the season with a sharp drop during the middle from $94.4 \%$ on $6 / 18$ to a mid-summer low of $72.6 \%$ on 6/22. From the middle to the end of summer, there was a gradual increase in FPE but day-to-day fluctuations were low. Daily Project FPE for summer averaged of $83.0 \%$ with a high of $94.5 \%$ on $6 / 18$ and a low of $60.4 \%$ on $6 / 1$. There was a $7.0 \%$ increase in Project FPE from spring to summer.

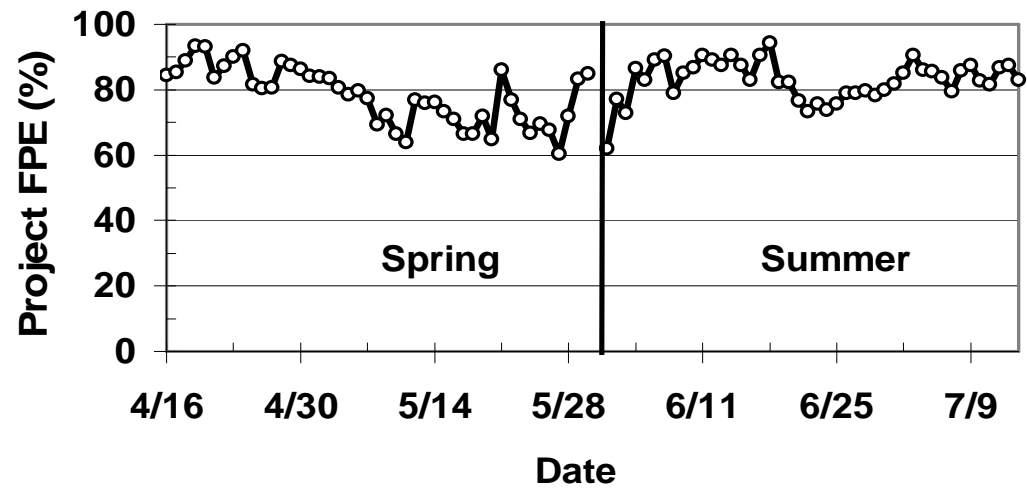

Figure 3.56. Time History of Project FPE Estimates for Bonneville Dam in 2005

Daily spill efficiency estimates, presented in Figure 3.57, also had high day-to-day variability. The beginning of spring showed a general trend of the average of $40.9 \%$ with a peak of $54.4 \%$ on $4 / 29$ occurring towards the middle of the spring season. Spring estimates had a low of $26.1 \%$ on $5 / 22$ occurring three-quarters of the way through its season and increasing to a high of $61.1 \%$ on $5 / 30$. Variable daily estimates continued through summer. The average daily spill efficiency estimate for summer was $43.5 \%$ with a high of $53.2 \%$ on $7 / 9$ and a low of $31.2 \%$ on $6 / 9$.

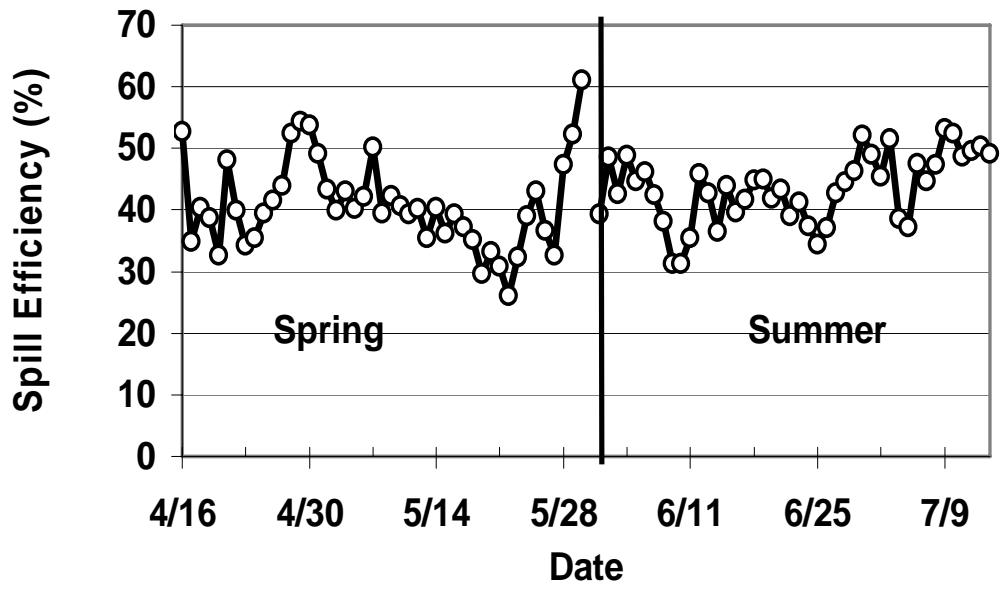

Figure 3.57. Time History of Estimated Spill Efficiency 
Daily estimated Project spill effectiveness varied from a high of 1.43 on 5/8 to a low of 0.52 on $4 / 2$ in spring with an average effectiveness of 1.0, and it varied from a high of 1.07 on $7 / 1$ to a low of 0.63 on 7/10 in summer with an average effectiveness of 0.8 (Figure 3.58). Spill effectiveness, like spill efficiency, had high day-to-day and weekly variability, but on average was lower in summer than it was in spring.

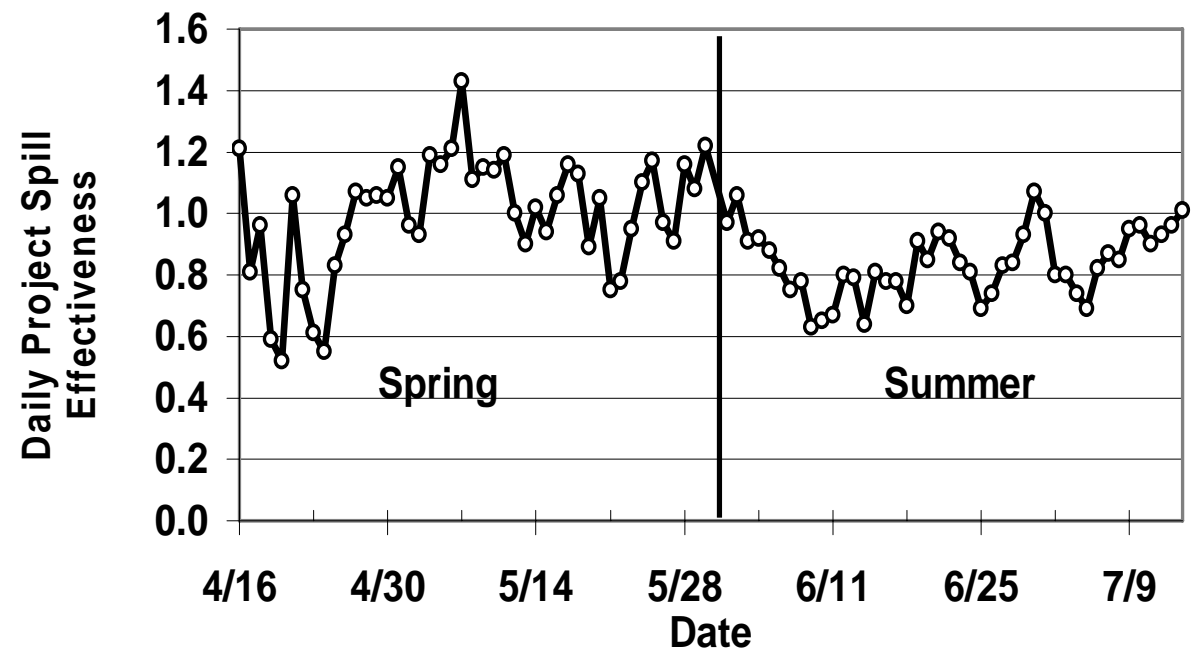

Figure 3.58. Time History of Daily Estimates of Project Spillway Effectiveness

Daily estimates of Project sluiceway efficiency (B1 and the B2CC) varied more than any other metric, especially in spring where estimates vary as much as 31.7\% from one day to the next (Figure 3.59). Although there were several peaks in the $30 \%$ to 55\% range in mid April and late May, the overall average sluiceway efficiency for spring was only $21.4 \%$. In summer, efficiency estimates tracked total project passage patterns with a gradual increase peaking at $51.4 \%$ on $6 / 12$, followed by a brief rapid decline in late June. Another, smaller increase and peak at $40.0 \%$ on $7 / 5$ coincides with the pulse of subyearling Chinook passage in early July. The overall average for summer sluice passage efficiency was $30.8 \%$, about $9.4 \%$ higher than the spring average.

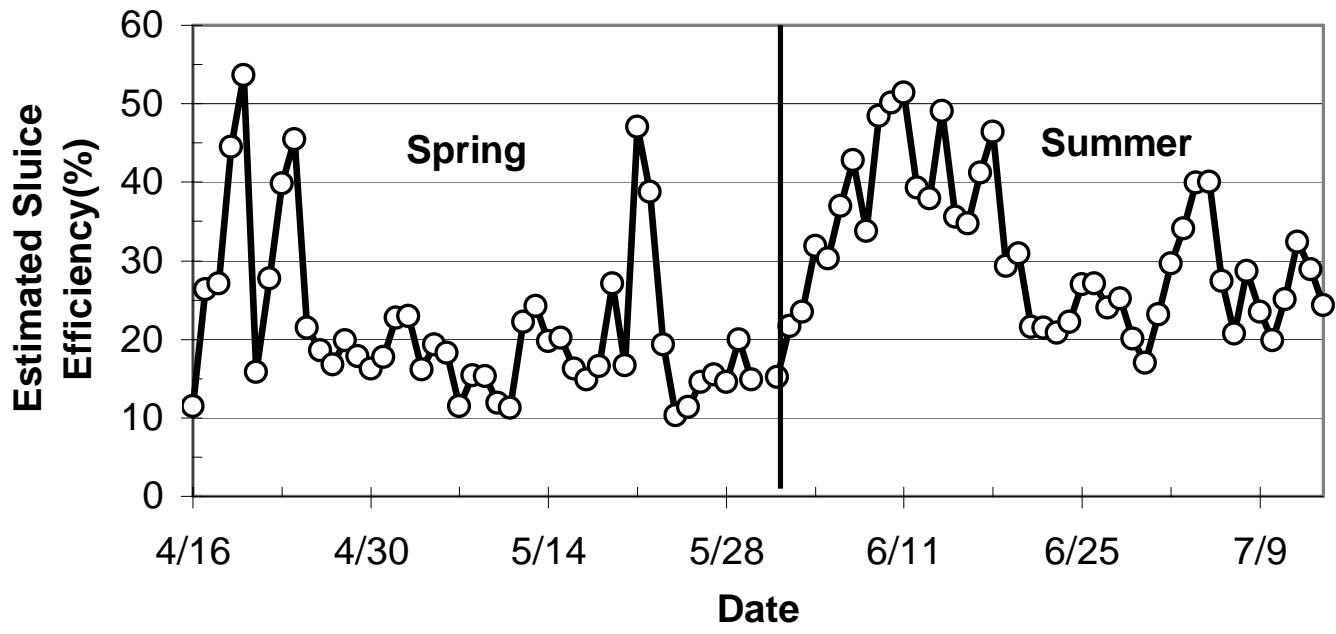

Figure 3.59. Time History of Estimated Project Sluiceway Efficiency (B1 and the B2CC) 
The seasonal trend in Project Sluiceway effectiveness generally paralleled that of Project sluiceway efficiency, although the relative size of peaks were sometimes different (compare Figure 3.60 with Figure 3.59). The average effectiveness estimates for spring (6.5) and for summer (8.8) indicate the number of times that fish proportions exceeded flow proportions passing at all Project surface-passage routes.

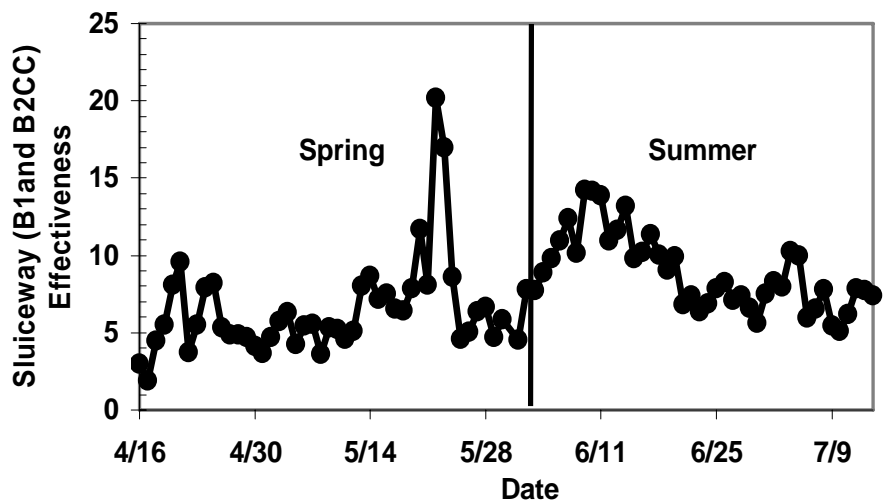

Figure 3.60. Time History of Estimated Project Sluiceway (B1 Sluiceway and the B2CC) Effectiveness There was a significant decline in the average FGE of B2 submerged traveling screens from early spring (about 60\%) through early summer (about 38\%), but FGE was similar at the beginning and end of summer (Figure 3.61).

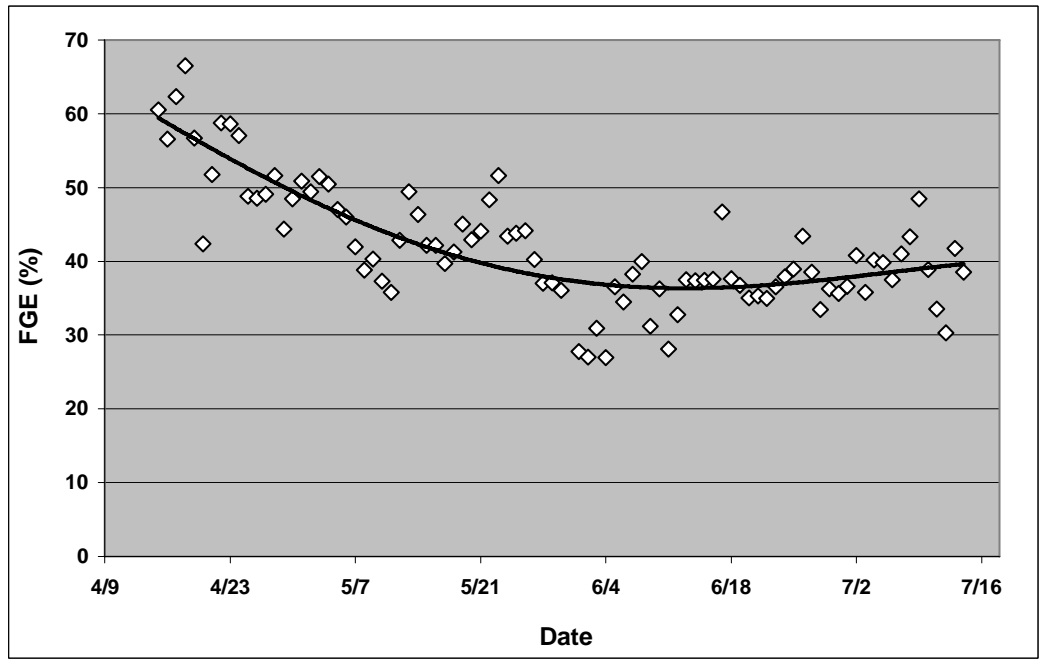

Figure 3.61. Seasonal Trends in the B2 FGE of Submerged Traveling Screens

\subsubsection{Diel Trends}

\subsubsection{Passage Efficiency and Effectiveness Estimates}

Project FPE showed diel patterns that were similar in character across both sampling seasons (Figure 3.62). Spring FPE ranged from $70 \%$ to $80 \%$ for morning hours, remained constant at $70 \%$ for afternoon and evening hours and increased to around $80 \%$ for nighttime. Summer FPE showed a range from $75 \%-80 \%$, held constant at $75 \%$ and increased to $90 \%-95 \%$ respectively. 


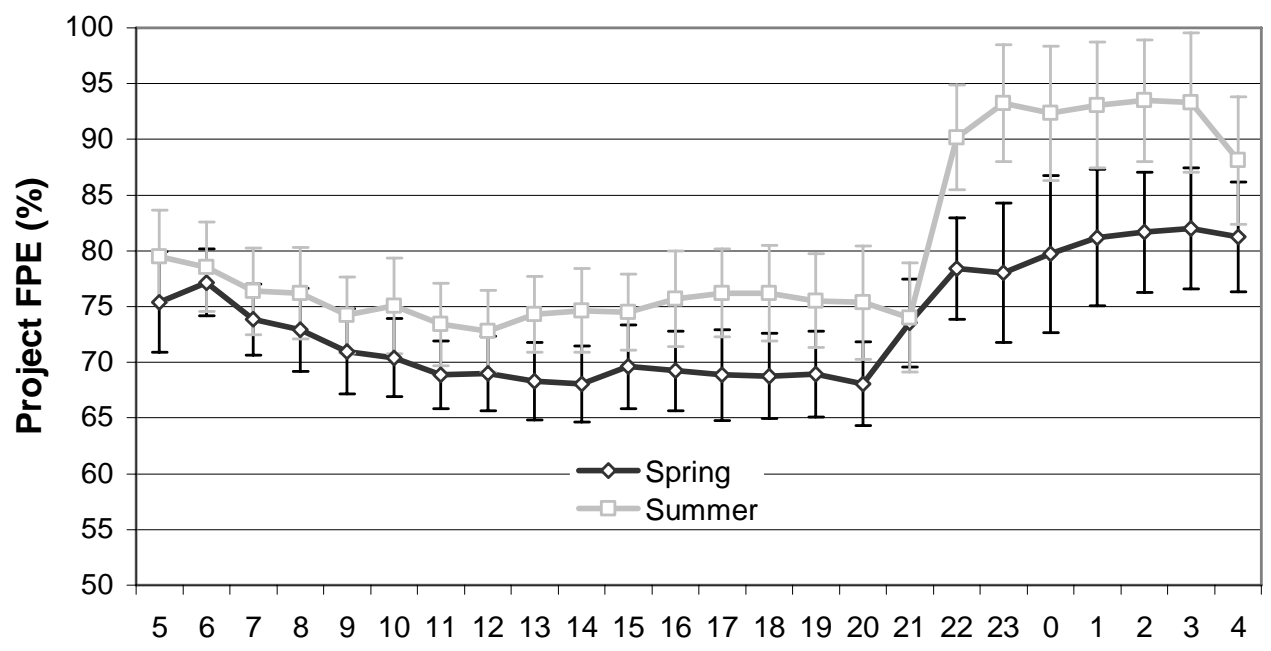

Figure 3.62. Diel Trends in Project FPE in Spring and Summer 2005. Error bars represent 95\% confidence limits for hydroacoustic estimates.

The diel pattern in spill efficiency closely resembled that for Project FPE, with relatively uniform, gradually declining estimates during daylight hours before a pronounced increase at nightfall and higher spill efficiency throughout the nighttime (Figure 3.63). Efficiency was similar for both spring and summer throughout the day and ranged from $30 \%$ to $40 \%$. At night, trends for both spring and summer were also similar but summer efficiency estimates were generally $15 \%$-20\% higher than were spring estimates.

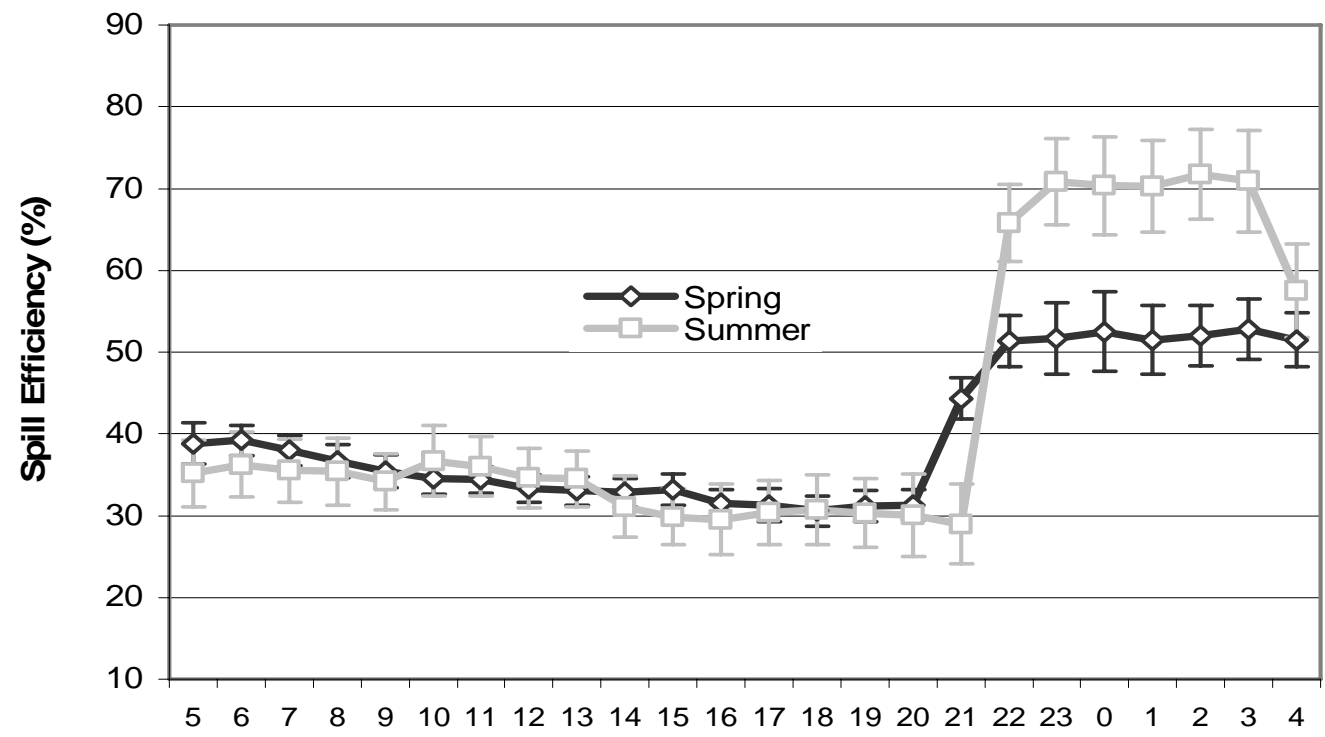

Figure 3.63. Diel Trends in Project Spill Efficiency in Spring and Summer 2005. Error bars represent 95\% confidence limits for hydroacoustic estimates.

During a six-day period in spring, the spillway discharge was held constant for 24 hours. This allowed us to examine diel patterns of spill passage efficiency independent of discharge (Figure 3.64). Like diel 
results from constant discharge during the drought of 2001 (Ploskey et al. 2002c) and for six days in summer 2004 (Ploskey et al. 2005), the data clearly indicates that the diel pattern observed in Figure 3.64 is not entirely due to increased discharge at night.

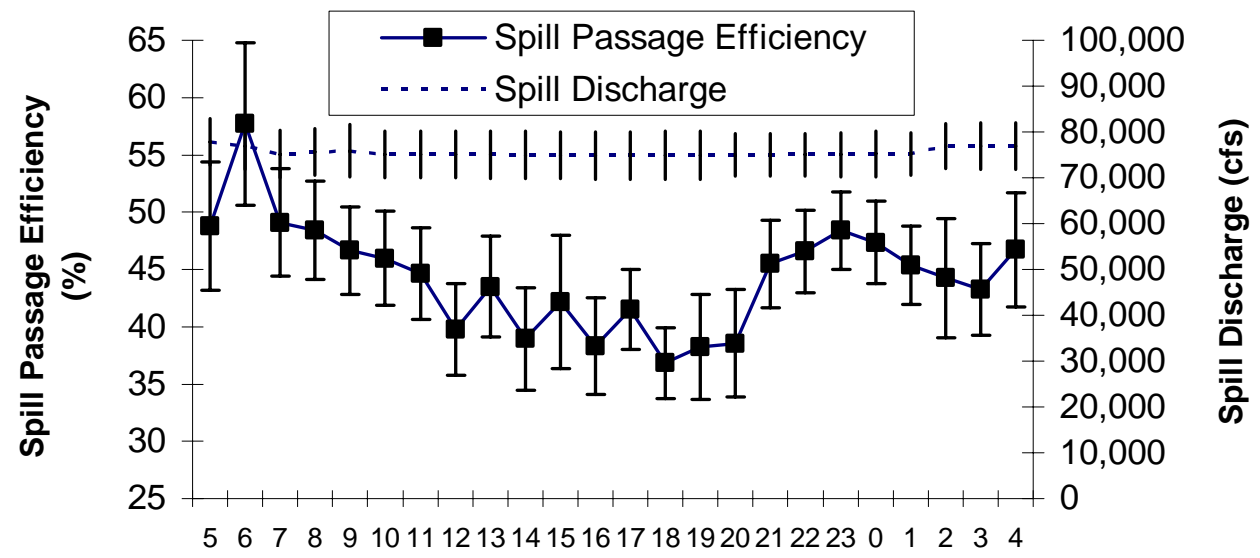

Hour of the Day

Figure 3.64. Estimated Hourly Spillway Passage Efficiency and Discharge at Bonneville Dam during Six Days in Spring 2005

Hourly total sluice passage efficiency trends (including both the B1 sluice and the B2CC - Figure 3.65) were similar across seasons, but the patterns were distinctly different from those for Project FPE (Figure 3.62) and spill efficiency (Figure 3.63). Total sluice passage efficiency was at its lowest of 15\% to $20 \%$ during nighttime hours and peaked at 30\% to 35\% during midday hours (1400 to $1900 \mathrm{~h}$ ). Sluiceway efficiency was $5 \%$ higher during the summer than it was in spring during night and morning hours and 10\% higher during afternoon hours (Figure 3.65).

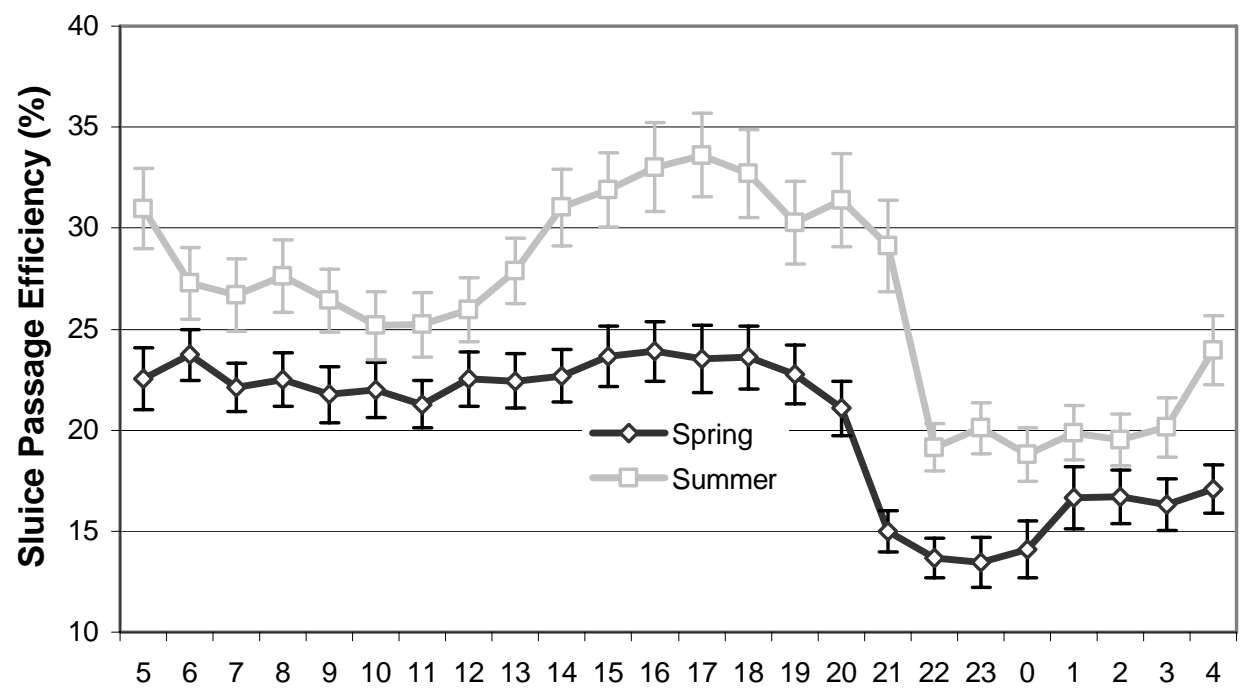

Figure 3.65. Diel Trends in Project Sluiceway Passage Efficiency in Spring and Summer 2005. Error bars represent $95 \%$ confidence limits for hydroacoustic estimates. 
Hourly patterns of B1 sluiceway efficiency relative to the Project (Figure 3.66) were similar to those observed for total Project sluice passage efficiency (B1 Sluiceway + B2CC). Morning and midday peak estimates were higher in the spring than they were in summer, but nighttime estimates were higher in summer than they were in spring (Figure 3.66). Estimates of B1 sluiceway efficiency relative to B1 are identical to B1 FPE (see below) because the B1 sluiceway was the only non-turbine route at B1 in 2005.

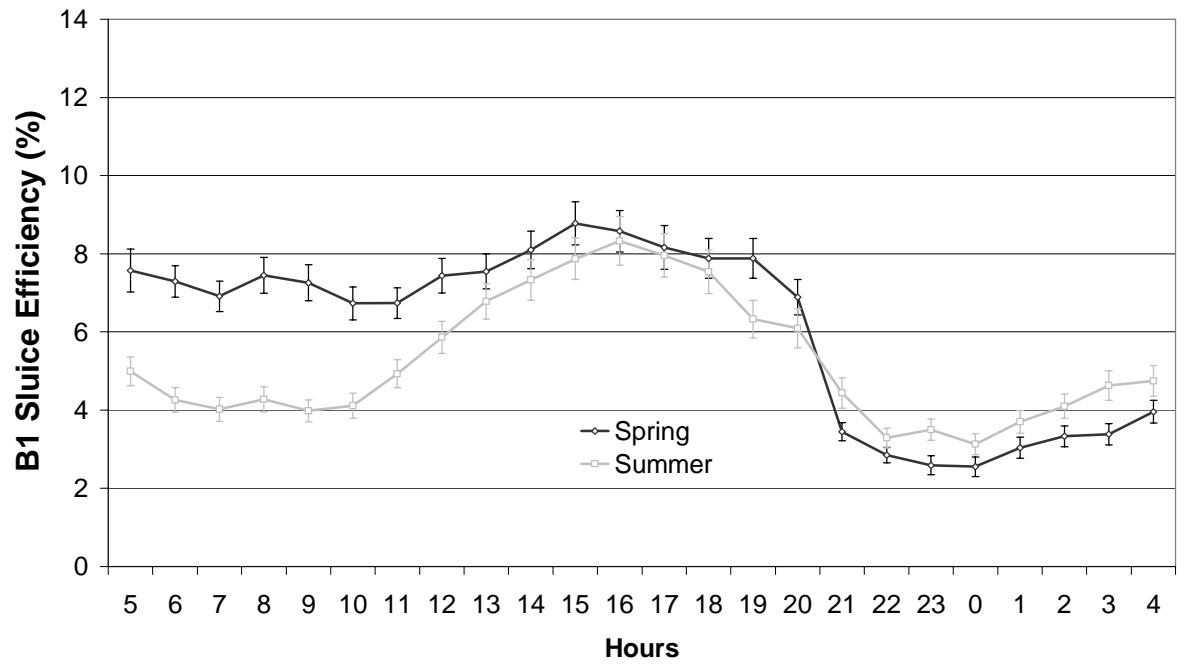

Figure 3.66. Diel Trends in B1 Sluiceway Passage Efficiency Relative to the Entire Project in Spring and Summer 2005. Error bars represent 95\% confidence limits.

The B2CC performed more efficiently relative to the Project in the summer than in spring, and differences between day and nighttime hourly estimates were more pronounced in summer than they were in spring (Figure 3.67). Except for a slight dip in efficiency during nighttime hours, the B2CC showed little diel variation in spring. In summer, the B2CC was about 5\% more efficient in mid-morning hours than it was at night, but during afternoon hours, the B2CC was 10\% more efficient than it was at night.

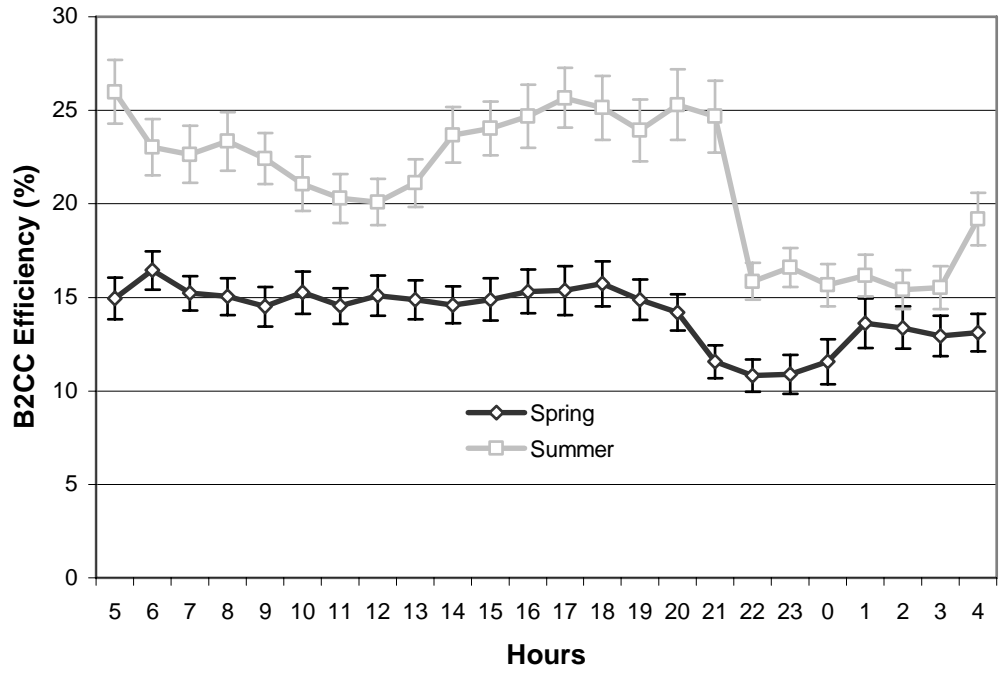

Figure 3.67. Diel Trends in B2CC Passage Efficiency Relative to the Entire Project in Spring and Summer 2005. Error bars represent 95\% confidence limits. 
Hourly patterns of B2CC efficiency relative to B2 passage for spring were similar to the patterns of B2CC efficiency relative to the entire Project in spring but not in summer (compare Figure 3.67 to Figure 3.68). In summer, Project B2CC efficiency decreased at night, but B2CC efficiency relative to B2 increased at night.

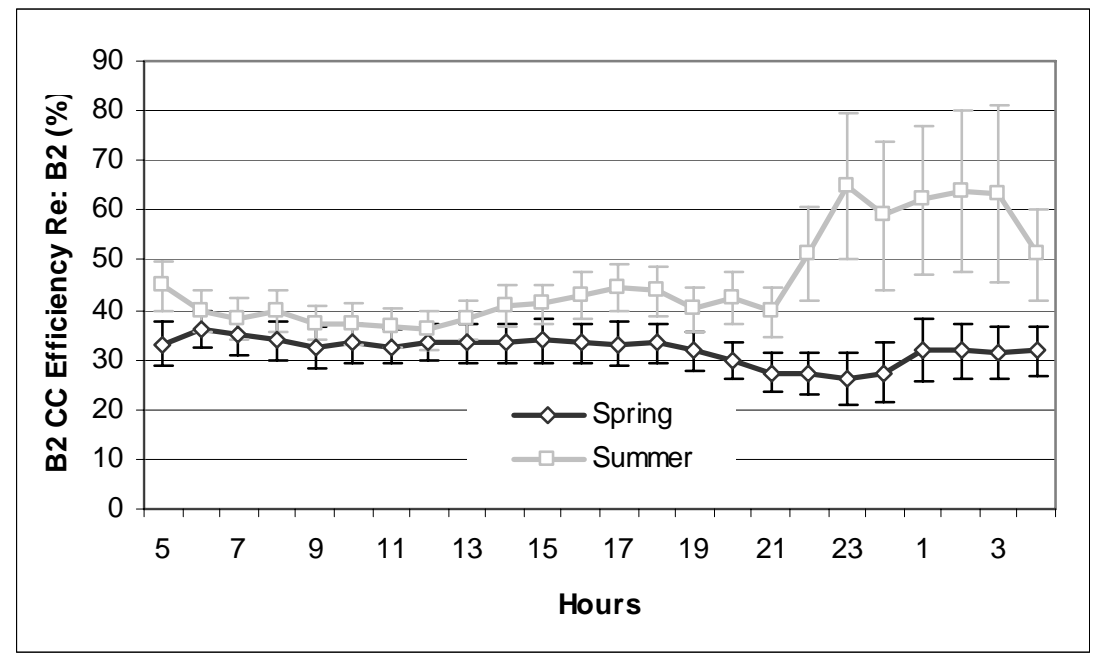

Figure 3.68. Diel Patterns of B2CC Passage Efficiency Relative to B2 in 2005. Error bars represent 95\% confidence limits for hydroacoustic estimates.

The hourly pattern of FPE at B1 (i.e., B1 sluiceway efficiency relative to B1) was generally similar in both seasons, although estimates were consistently higher in summer than they were in spring (Figure 3.69). Summer estimates of B1 FPE were about 30\% higher than spring estimates from 0500 through 2100 hours, 50-70\% higher from 2200 through midnight, and about 50\% higher from 0100 through 0400 hours. The pattern in both seasons involved a gradual decline in efficiency from 0500 through 2100 hour and higher efficiency at night than during the day.

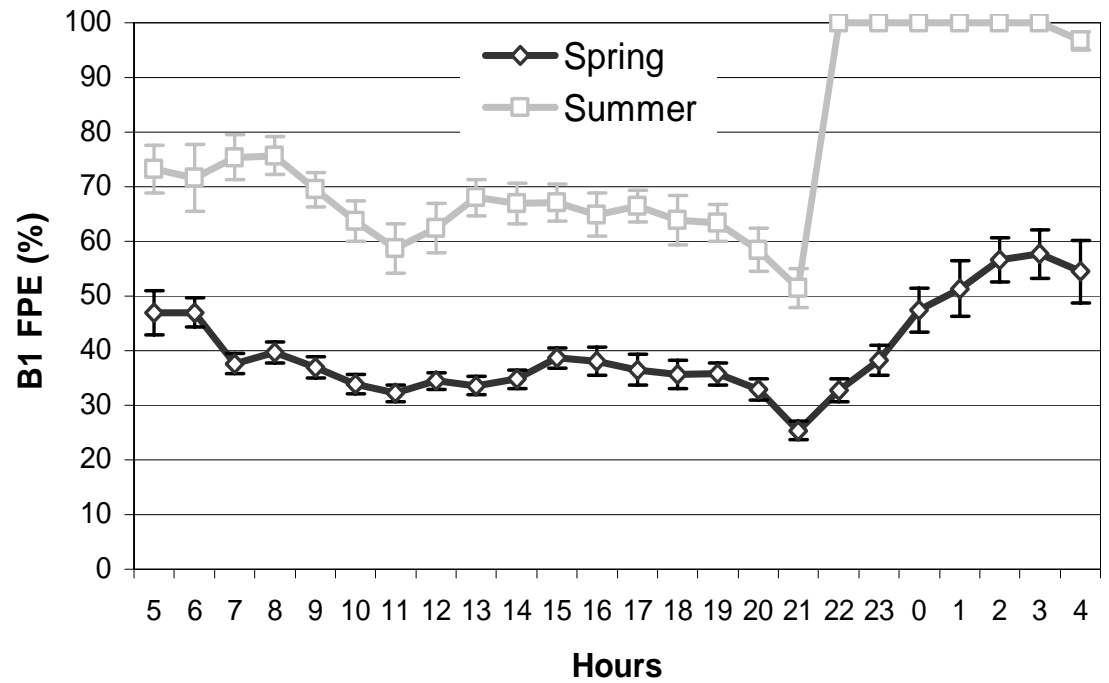

Figure 3.69. Diel Trends in B1 FPE in Spring and Summer 2005. Error bars represent 95\% confidence limits for hydroacoustic estimates. 
The diel trends in B2 FPE were weak in both seasons (Figure 3.70) and similar in pattern to those for the B2CC relative to $\mathrm{B} 2$ (Figure 3.68).

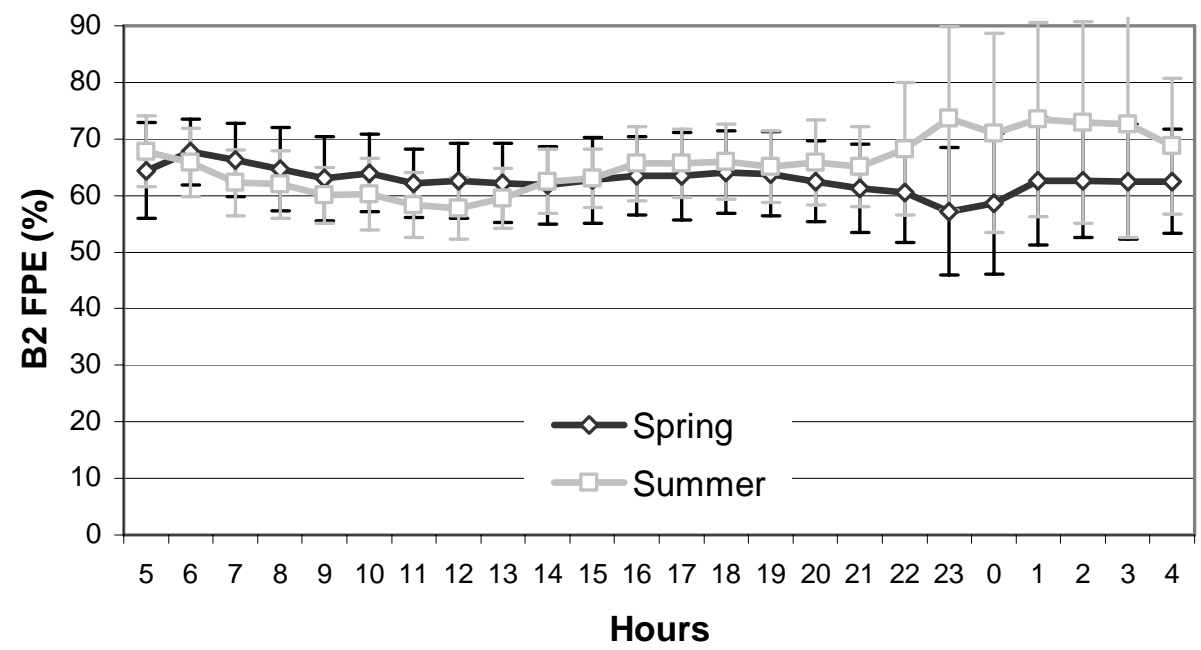

Figure 3.70. Diel Patterns of B2 FPE in Spring and Summer 2005. Error bars represent 95\% confidence limits for hydroacoustic estimates.

Diel patterns in spill effectiveness were similar in both seasons, and spill was more effective for passing fish at night than during the day, although day and night differences were very small (Figure 3.71). The average hourly spill effectiveness was 0.97 in spring and 0.82 in summer.

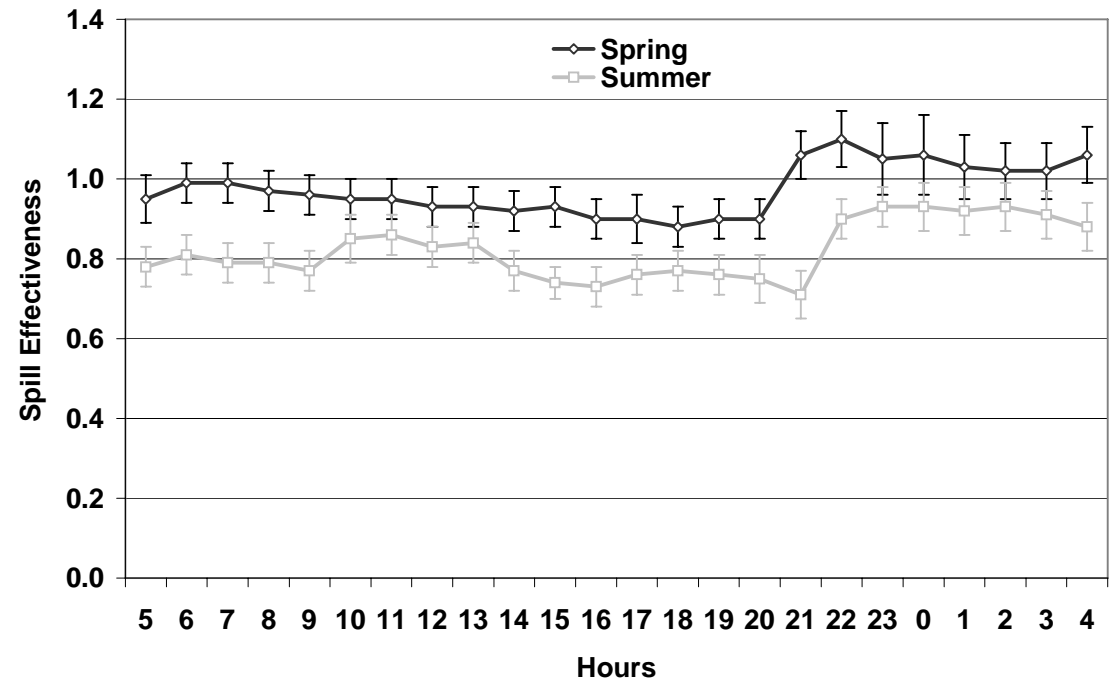

Figure 3.71. Diel Patterns of Project Spill Effectiveness in Spring and Summer 2005. Error bars represent 95\% confidence limits.

The diel patterns of total sluice effectiveness (B1 sluice and B2CC) were similar in spring and summer, and the sluiceways were more effective during the day, particularly in the afternoon and evening, than they were at night (Figure 3.72). Sluiceway effectiveness was 6 to 8 times higher than spill effectiveness during the day and 4 to 5 times higher than spill effectiveness at night (compare Figure 3.72 with Figure 3.71). 


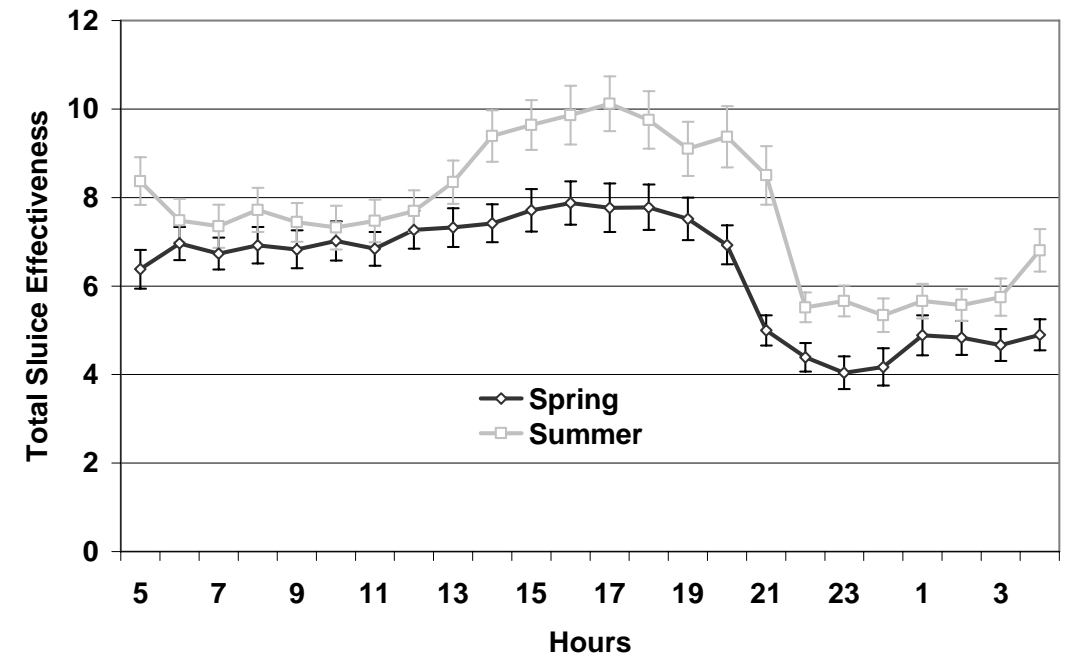

Figure 3.72. Diel Patterns of Project Sluiceway Effectiveness (B1 and B2CC) in Spring and Summer 2005. Error bars represent $95 \%$ confidence limits.

The sluice at B1 relative to the Project also was most effective in the afternoon and evening hours and least effective at night in both seasons and during the morning in summer (Figure 3.73).

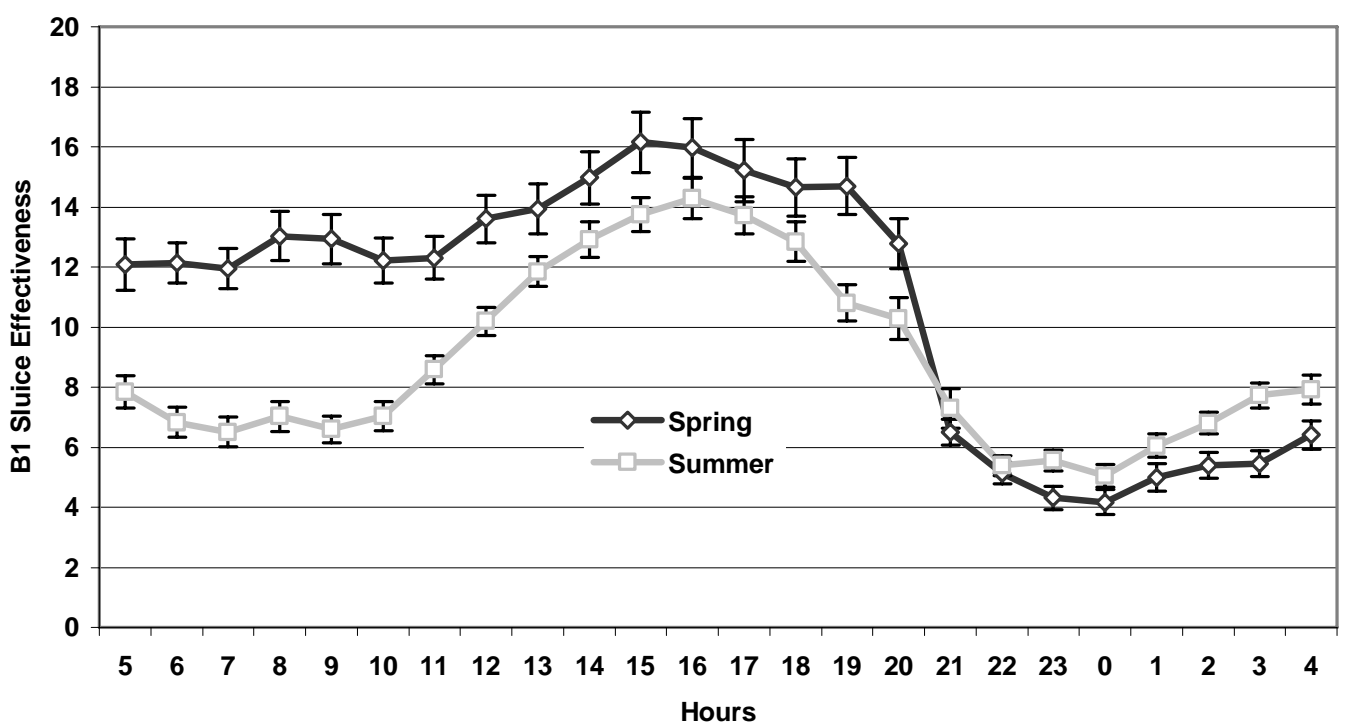

Figure 3.73. Diel Patterns of B1 Sluice Effectiveness Relative to the Project in 2005. Error bars represent 95\% confidence limits.

The B2CC had two levels of effectiveness in spring and three levels in summer, and the difference between the levels was about 1.8 to 2.0 (Figure 3.74). In spring, effectiveness was higher during daylight than at night. In summer, effectiveness was lowest at night, intermediate from 0600 through 1300 hours, and highest from about 1400 through 2100 hours. 


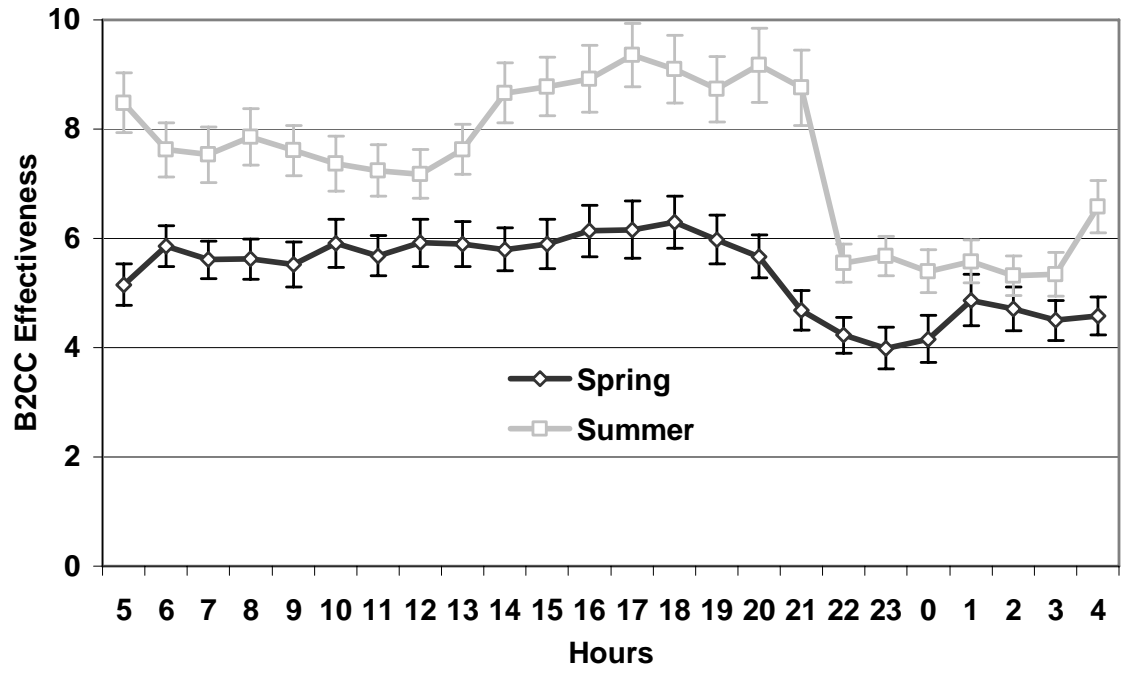

Figure 3.74. Diel Patterns of B2CC Effectiveness Relative to the Project in 2005. Error bars represent 95\% confidence limits.

Hourly patterns of B1 sluice effectiveness relative to B1 and B2CC effectiveness relative to B2 were similar in spring and summer, with higher effectiveness during the day than at night, although trends were more pronounced for the B1 sluiceway than for the B2CC (Figure 3.75).
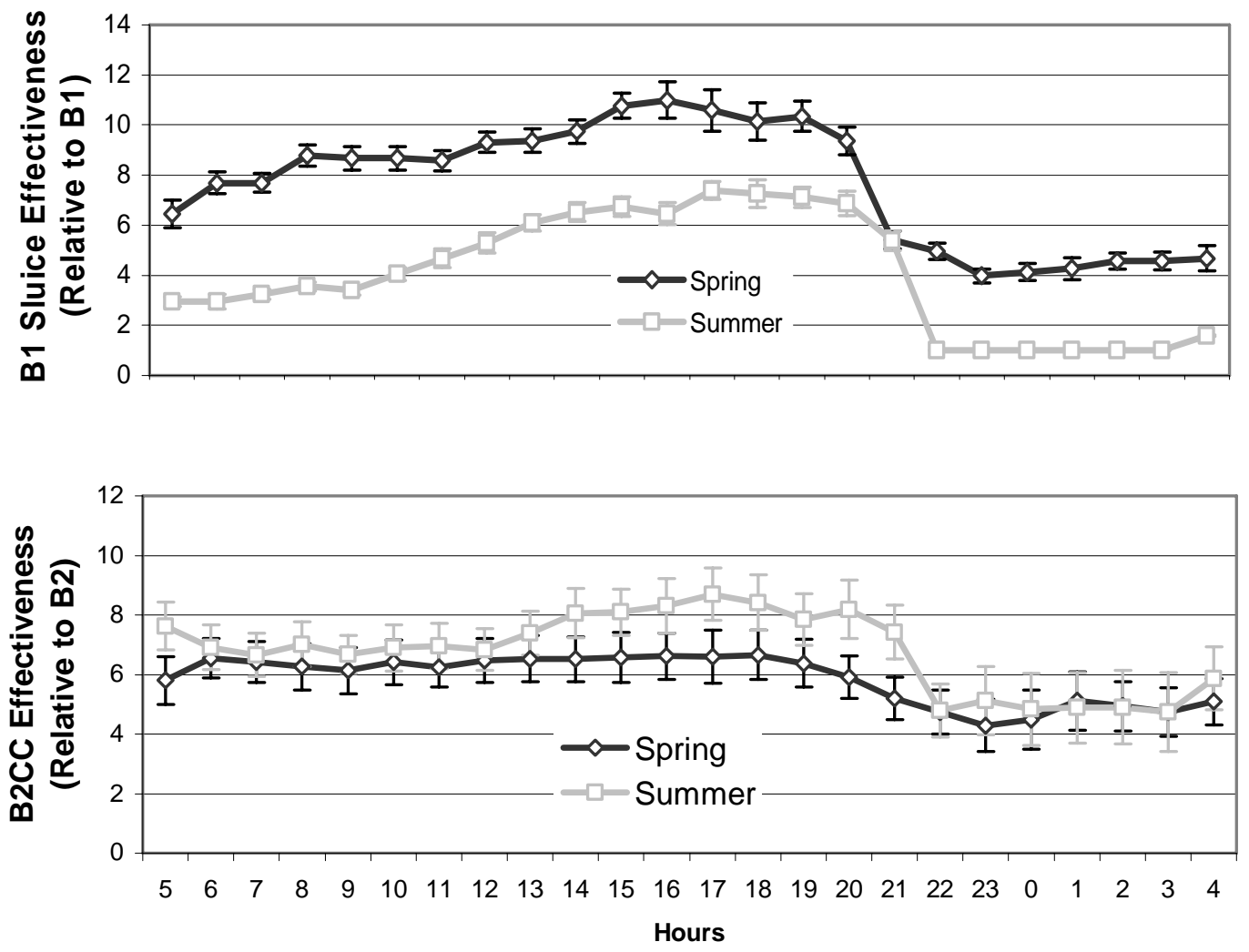

Figure 3.75. Diel Patterns of B1 Sluice Effectiveness Relative to B1 and B2CC Effectiveness Relative to B2 in 2005. Error bars represent 95\% confidence limits. 


\subsubsection{Passage Estimates and Guidance Efficiency}

\subsection{Powerhouse 1}

Diel patterns of estimated fish passage through B1 and B1 turbines closely followed the patterns of hourly discharge in both spring and summer, but passage into the B1 sluiceway did not correlate with sluiceway discharge (Figures 3.76 and 3.77). Both total and turbine passage estimates increased throughout the day as discharge increased and then declined over night, as discharge decreased in both seasons. The hourly pattern of B1 sluice passage indicated higher passage during the day when discharge was low, than at night when discharge through the sluiceway was highest in both spring (Figure 3.76) and summer (Figure 3.77).
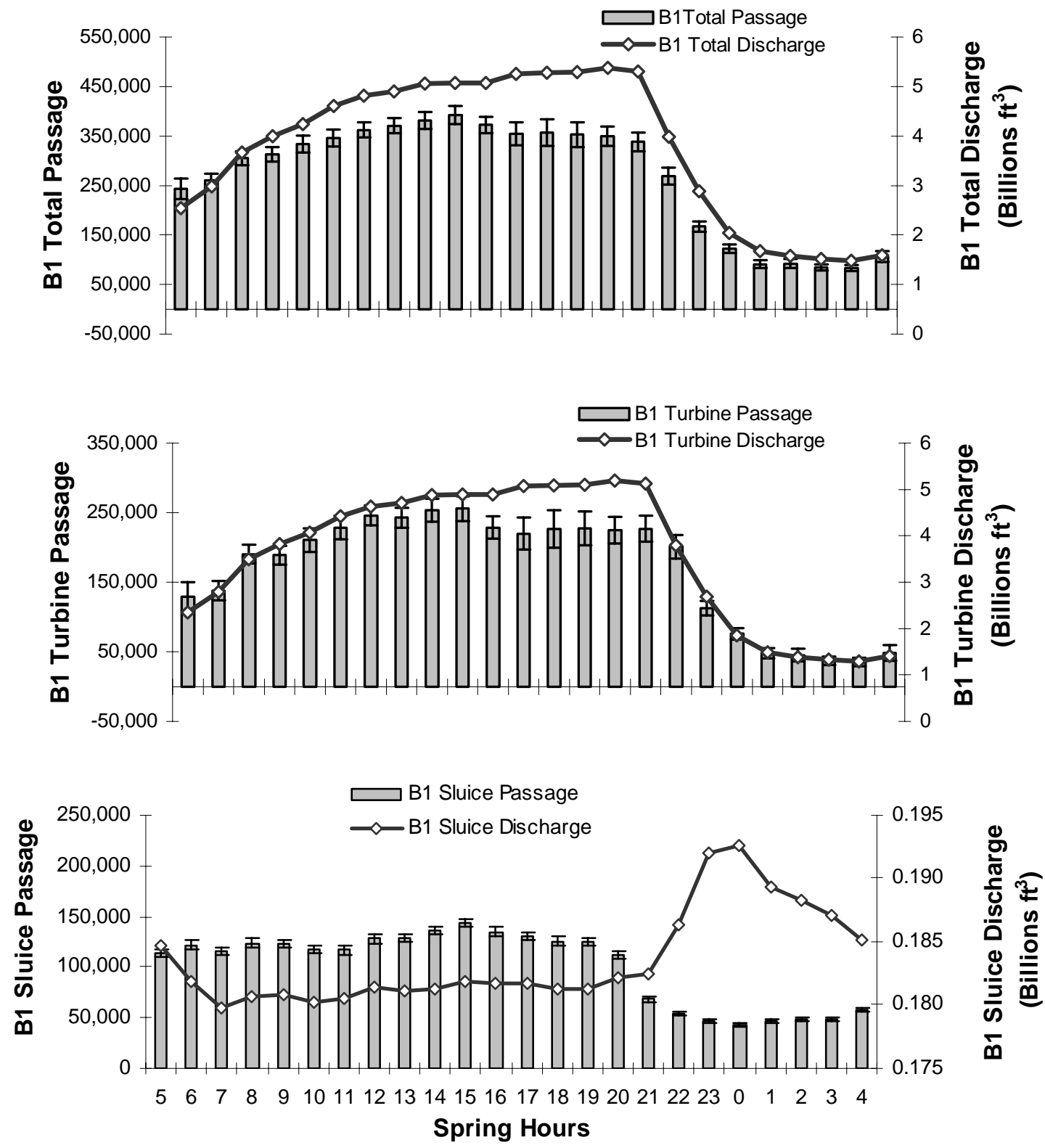

Figure 3.76. Estimated Hourly B1 Total Passage, B1 Turbine Passage, and B1 Sluiceway Passage and Associated Discharge in Spring of 2005. Error bars represent 95\% confidence limits on fish passage estimates. 

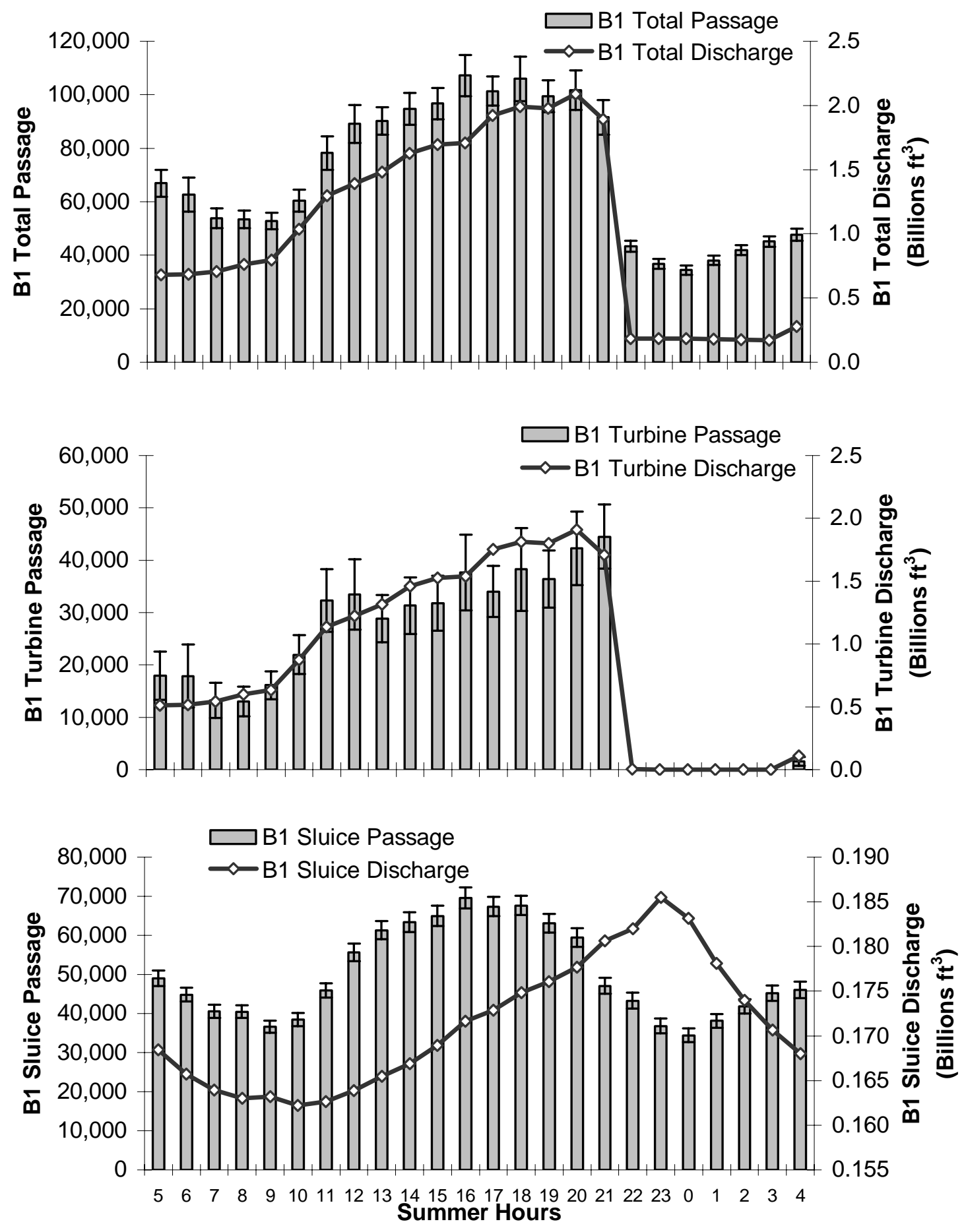

Figure 3.77. Estimated Sum of Hourly Fish Passage at B1, B1 Turbines, and the B1 Sluiceway, and Associated Discharge in Summer 2005. Error bars represent 95\% confidence limits on fish passage estimates. 


\subsection{Spill Passage}

The diel distribution of spillway passage showed the greatest fish passage at night when discharge also was the greatest. Throughout the day, discharge remained constant while fish passage declined slightly (Figure 3.78). Peaks in spill passage occurred at $2200 \mathrm{~h}$ in the spring and summer, and lowest hourly passage occurred at $2000 \mathrm{~h}$ and $1500 \mathrm{~h}$ respectively.
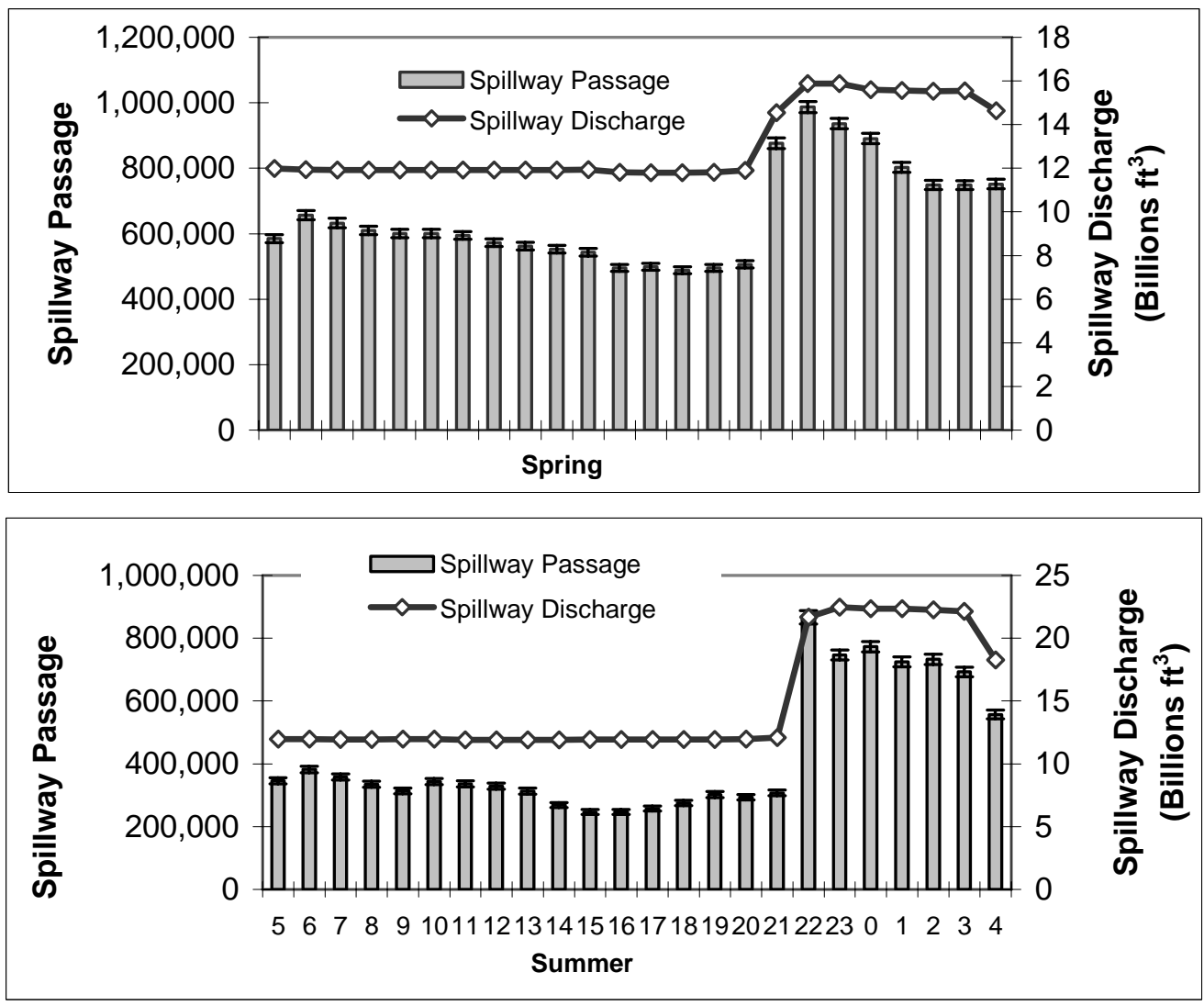

Figure 3.78. Estimated Hourly Spillway Passage and Discharge at Bonneville Dam in Spring and Summer of 2005. Error bars represent 95\% confidence limits on fish passage estimates.

\subsection{Powerhouse 2}

Hourly passage estimates for total and turbine passage at B2 in the spring follow the hourly discharge pattern, but passage at B2CC did not track its discharge pattern (Figure 3.79). In spring, B2 total and turbine passage increased through the morning hours until $1000 \mathrm{~h}$ when there is a small decline in passage until $1500 \mathrm{~h}$. Passage again increases until it reaches its maximum passage at $2100 \mathrm{~h}$ then once more the passage declines through the night (Figure 3.79). At the B2CC, passage was higher during the day than it was at night and the discharge pattern was the opposite.

In summer, as in spring, B2 total, turbine passage, and B2CC passage were higher during the day than they were at night, with the total and turbine passage generally following discharge and B2CC passage the inverse of discharge by that route (Figure 3.80).

In spring and summer, diel passage patterns through the B2CC followed discharge patterns throughout the day, but did not follow discharge through the B2CC at night (Figures 3.79 and 3.80); highest discharge occurred at night when B2CC passage estimates were lowest relative to other time periods. 

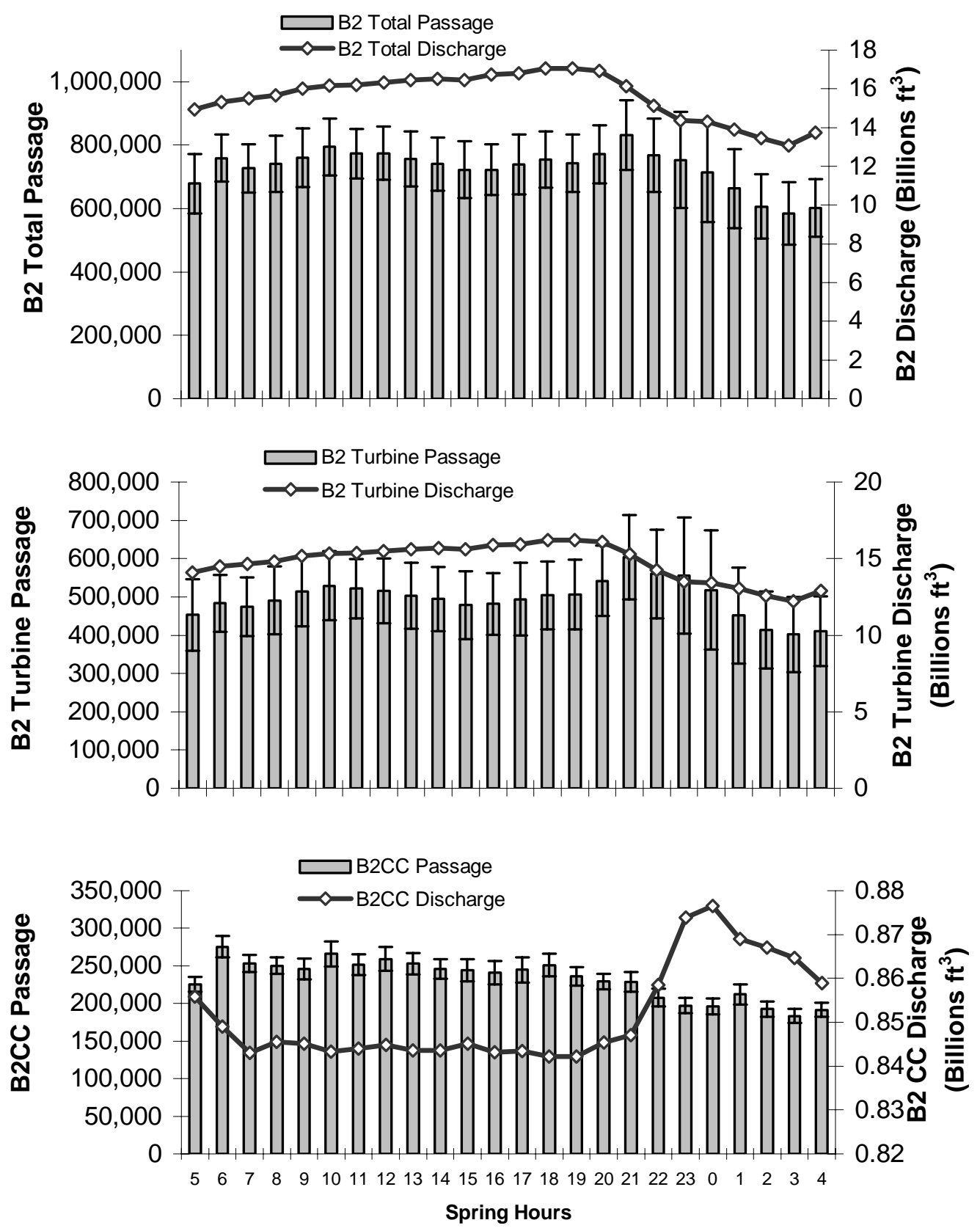

Figure 3.79. Estimated Hourly B2 Total Passage, B2 Turbine Passage (Both Guided and Unguided), and B2CC Passage and Associated Discharge in Spring 2005. Error bars represent 95\% confidence limits. 

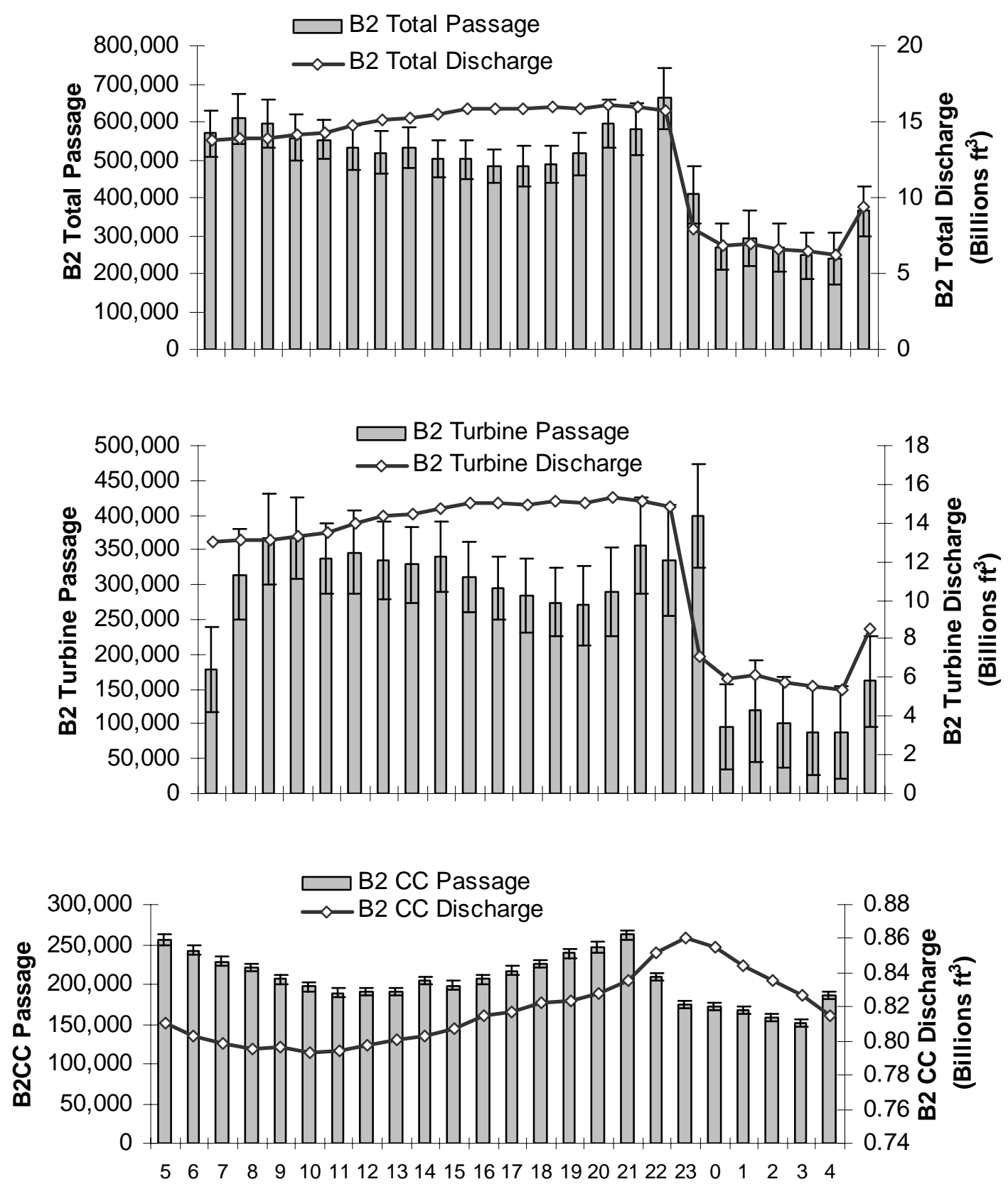

Summer Hours

Figure 3.80. Estimated Hourly B2 Total, B2 Turbine, and B2CC Passage and Associated Discharge in Summer 2005. Error bars represent 95\% confidence limits.

\subsection{B2 Guided and Unguided Passage and FGE}

Guided and unguided fish passage at B2 turbines generally exhibited a crepuscular peak after sunset in both seasons, and estimates generally were higher during the day than they were at night, as was turbine discharge (Figure 3.81). Unguided turbine passage estimates exceeded those of guided passage for all hours in the summer. 

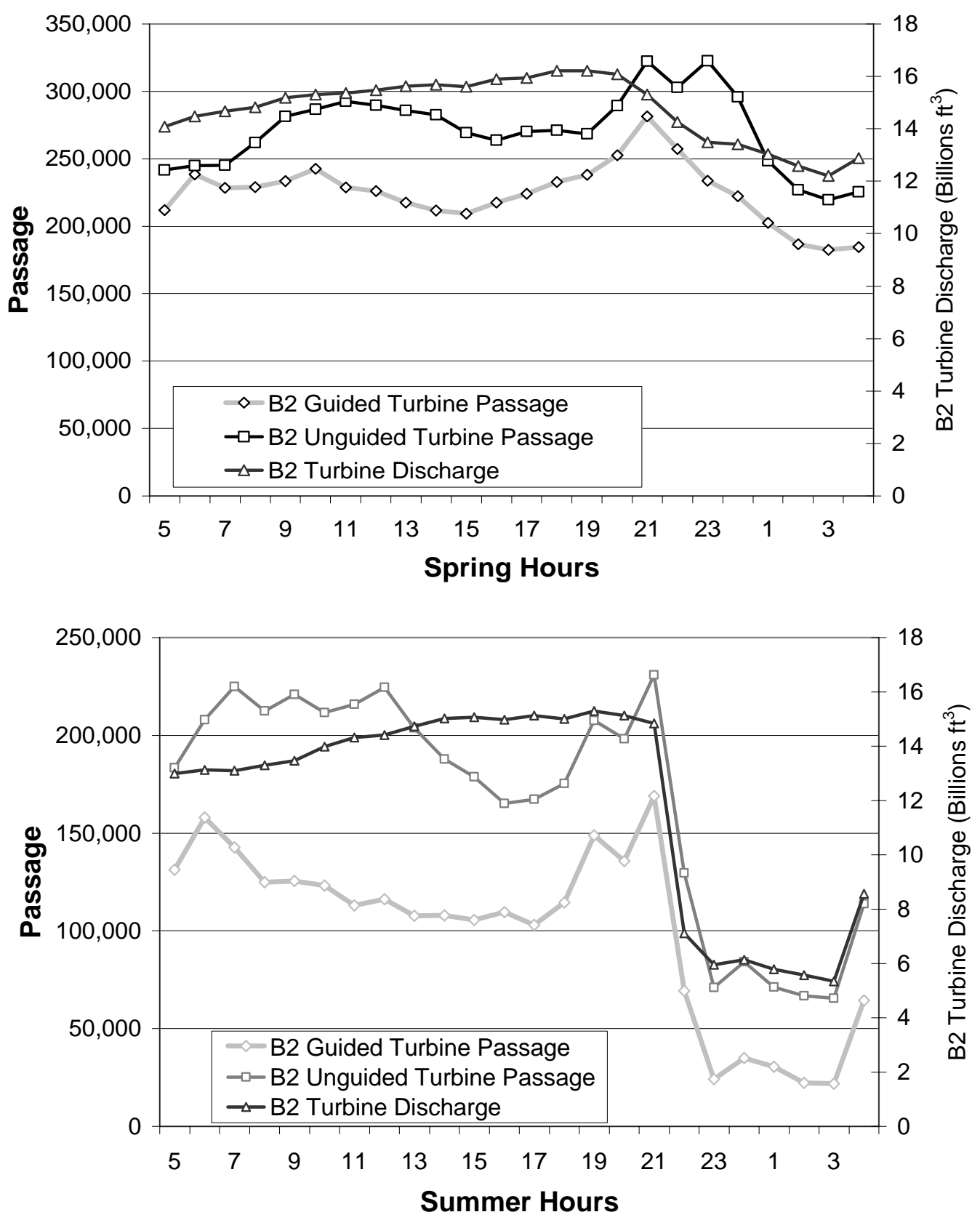

Figure 3.81. Estimated Hourly B2 Guided and Unguided Turbine Passage and Discharge in Spring and Summer of 2005. Error bars represent 95\% confidence limits on passage estimates.

Diel patterns of FGE at B2 turbines were very weak in both seasons; there was more of a diel trend in summer with lower guidance during more nighttime hours, but estimates were highly variable (Figure 3.82). The FGE in spring was higher than that in summer during most hours of the day and particularly during most night hours. 


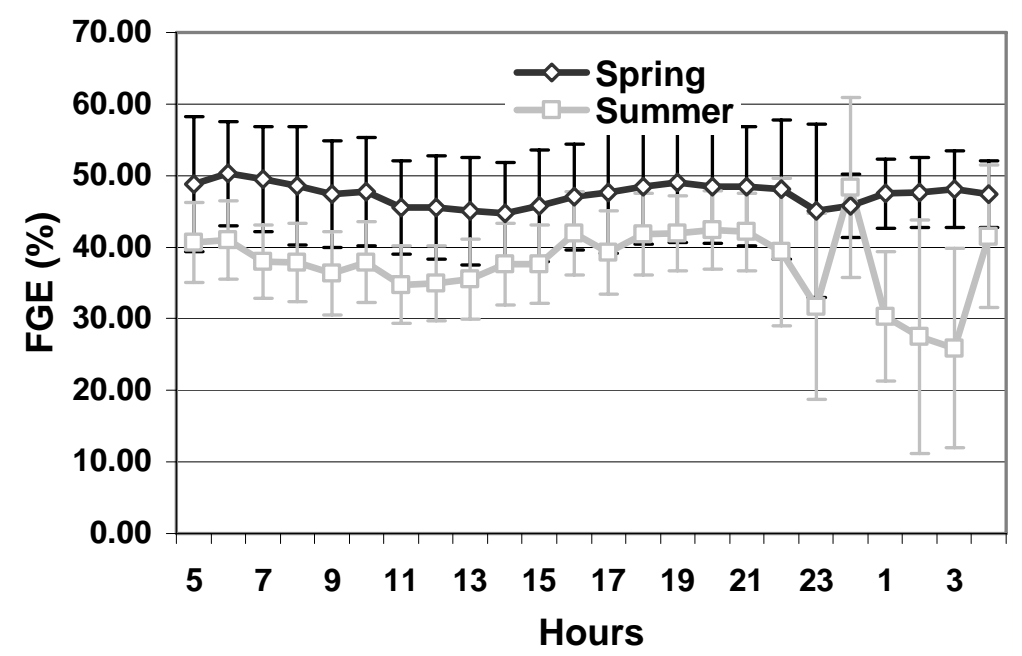

Figure 3.82. Fish Guidance Efficiency (FGE) Estimates for B2 in Spring and Summer. Error bars represent $95 \%$ confidence limits.

\subsection{Fish Guidance Efficiencies of B2 Turbines}

Median estimates of FGE by season and intake are plotted in Figure 3.83, and the highest FGE estimates in spring were provided by modified Unit 15 (55.8\%) and modified Unit 17 (58.3\%), according to an analysis of variance (Appendix G). In summer, the FGE of modified Unit 17 was comparable to the estimate for unmodified Unit 11 adjacent to the B2CC, and the Unit 11 estimate exceeded the estimate for modified Unit 15 by 5.2\%. The FGE at Unit 11 adjacent to the B2CC was surprisingly high in spring (48.1\%) and summer (49.2\%). The single intake between two TIEs (modified Intake 15B) had the second highest FGE at B2 in spring (55.8\%) and the third highest in summer (43.96\%). The average FGE at B2 in spring was $47.4 \%$, and in summer it was $38.2 \%$ (9.2\% lower than the spring estimate). Unit 18 had the lowest FGE in both seasons.

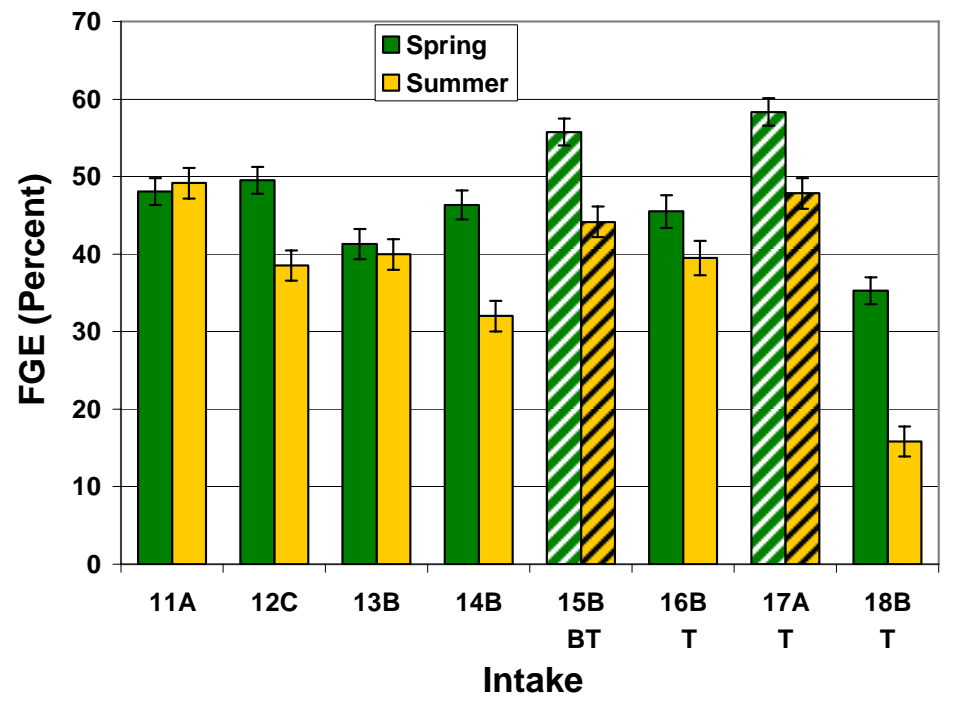

Figure 3.83. Fish Guidance Efficiency (FGE) Estimates for B2 Turbines in Spring and Summer. Error bars represent 95\% confidence limits on hydroacoustic estimates. 


\subsection{Smolt Approach and Fate at Sluiceway Outlet 3C}

\subsubsection{DIDSON Tracked-Fish Data}

Over 46,000,000 DIDSON fish images were tracked during processing of the DIDSON data from the B1 3C sluiceway fish approach and fate study. These individual frames made up 2,078,132 tracks (i.e., swim paths) of fish. The majority of these, 2,009,022 were tracked during spring data collection, 1,033,566 during the day and 975,456 at night. In summer, 69,110 fish were tracked, 43,964 during the day and 25,146 at night. Table 3.7 shows the numbers of tracked fish, fish speed, track length statistics, and the time separation between successive fish images with powerhouse flow above and below $7.5 \mathrm{kcfs}$.

The DIDSON was located about $25 \mathrm{ft}$ to the east of the entrance. A composite of swim paths of smolts approaching the 3C Sluiceway Outlet in spring and summer, by day and night with powerhouse flow above and below $7.5 \mathrm{kcfs}$ helps to visualize the area sampled (Figures 3.84 and 3.85). The maximum range of detection from the DIDSON was about $40 \mathrm{ft}$ using the high-resolution sampling mode.

Table 3.7. Characteristics of Tracked Fish as They Approached the B1 3C Sluiceway Outlet at Bonneville Dam, 2005.

\begin{tabular}{|c|c|c|c|c|c|c|c|c|c|}
\hline $\begin{array}{c}\text { Period and } \\
\text { Powerhouse Flow }\end{array}$ & Dates & $\begin{array}{l}\text { Fish } \\
\text { Tracks } \\
\text { (N) }\end{array}$ & $\begin{array}{l}\text { Fish Image } \\
\text { Detection (N) }\end{array}$ & $\begin{array}{l}\text { Mean } \\
\text { Speed } \\
\text { (ft/s) }\end{array}$ & $\begin{array}{c}\text { Max } \\
\text { Speed } \\
\text { (ft/s) }\end{array}$ & $\begin{array}{c}\text { Mean } \\
\text { Track } \\
\text { Length } \\
\text { (ft) }\end{array}$ & $\begin{array}{c}\text { Max } \\
\text { Track } \\
\text { Length } \\
\text { (ft) }\end{array}$ & $\begin{array}{c}\text { Mean } \\
\text { Images } \\
\text { Per } \\
\text { Track }\end{array}$ & $\begin{array}{l}\text { Mean } \\
\text { Image } \\
\text { Interval } \\
\text { (s) }\end{array}$ \\
\hline Spring Day $>7.5 \mathrm{kcfs}$ & $5 / 21$ to $5 / 31$ & $1,016,287$ & $23,587,431$ & 0.76 & 6.06 & 3.26 & 87.43 & 23.2 & 0.25 \\
\hline Spring Night $>7.5 \mathrm{kcfs}$ & $5 / 20$ to $5 / 30$ & 872,747 & $18,592,889$ & 0.65 & 7.28 & 2.53 & 27.81 & 21.3 & 0.26 \\
\hline Spring Day $<7.5 \mathrm{kcfs}$ & $5 / 26$ to $5 / 31$ & 17,279 & 320,282 & 1.09 & 5.09 & 3.92 & 21.51 & 18.5 & 0.32 \\
\hline Spring Night $<7.5 \mathrm{kcfs}$ & $5 / 25$ to $6 / 01$ & 102,709 & $2,671,750$ & 0.58 & 5.84 & 2.54 & 29.20 & 26.0 & 0.25 \\
\hline Summer Day > 7.5kcfs & $6 / 11$ to $7 / 09$ & 16,088 & 355,307 & 1.06 & 5.24 & 4.16 & 24.23 & 22.1 & 0.28 \\
\hline Summer Night $>7.5 \mathrm{kcfs}$ & $6 / 11$ to $7 / 09$ & 2,198 & 55,330 & 1.09 & 4.34 & 4.64 & 23.12 & 25.2 & 0.25 \\
\hline Summer Day < 7.5kcfs & $6 / 10$ to $7 / 10$ & 27,876 & 560,169 & 0.73 & 5.09 & 2.73 & 21.74 & 20.1 & 0.31 \\
\hline Summer Night $<7.5 \mathrm{kcfs}$ & $6 / 10$ to $7 / 10$ & 22,948 & 606,578 & 0.73 & 4.80 & 3.31 & 30.14 & 26.4 & 0.27 \\
\hline
\end{tabular}

Fish were tracked during 13 days in spring and 18 days in summer. Eight Markov-chain models were enumerated. There were four spring conditions: "Spring Day Flow" with powerhouse flow $>7.5 \mathrm{kcfs}$, "Spring Night Flow" with powerhouse flow $>7.5$ kcfs, "Spring Day No Flow" with powerhouse flow $<7.5$ kcfs, "Spring Night No Flow" with powerhouse flow $<7.5$ kcfs. The four conditions in summer were: "Summer Day Flow" with powerhouse flow $>7.5$ kcfs, "Summer Night Flow" with powerhouse flow $>7.5$ kcfs, "Summer Day No Flow" with powerhouse flow $<7.5$ kcfs, and "Summer Night No Flow" with powerhouse flow $<7.5 \mathrm{kcfs}$. The number of $0.5 \mathrm{~s}$ movements used for the Markov chain analyses 
was generally greater in spring than in summer and reflected the number of fish tracked during each period (Table 3.8). The spring period with fewest movements $(105,341)$ was the condition "Spring Day flow $<7.5$ kcfs." The summer period with the fewest movements was the condition "Summer Night flow $>7.5$ kcfs" with 16,493.

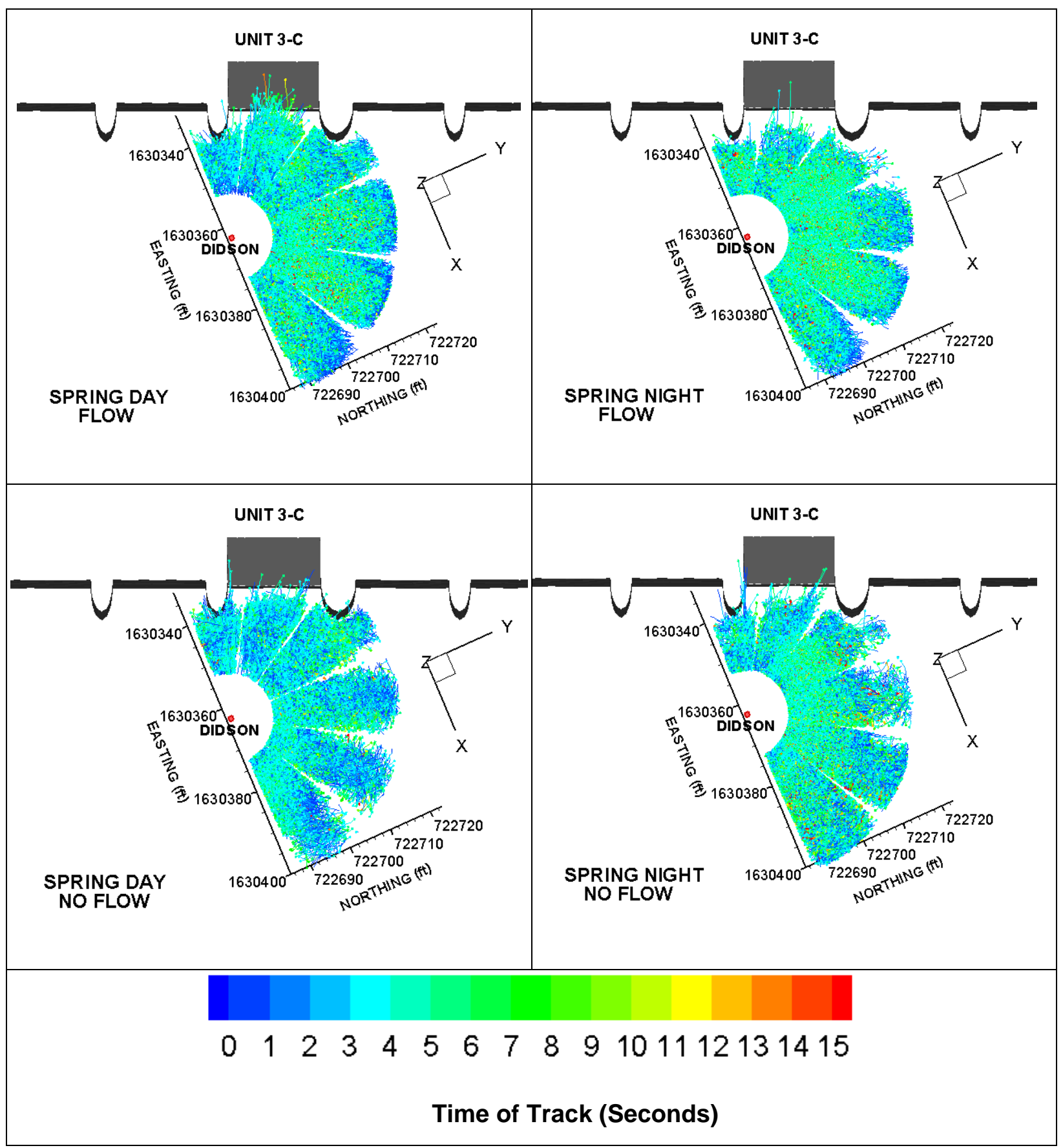

Figure 3.84. Tracked Fish Upstream and Approaching the 3C Sluiceway Outlet at Bonneville Dam Based Upon the DIDSON Acoustic Camera Sampling in Spring 2005. Track portions are color-coded by the seconds from start of each fish track. 


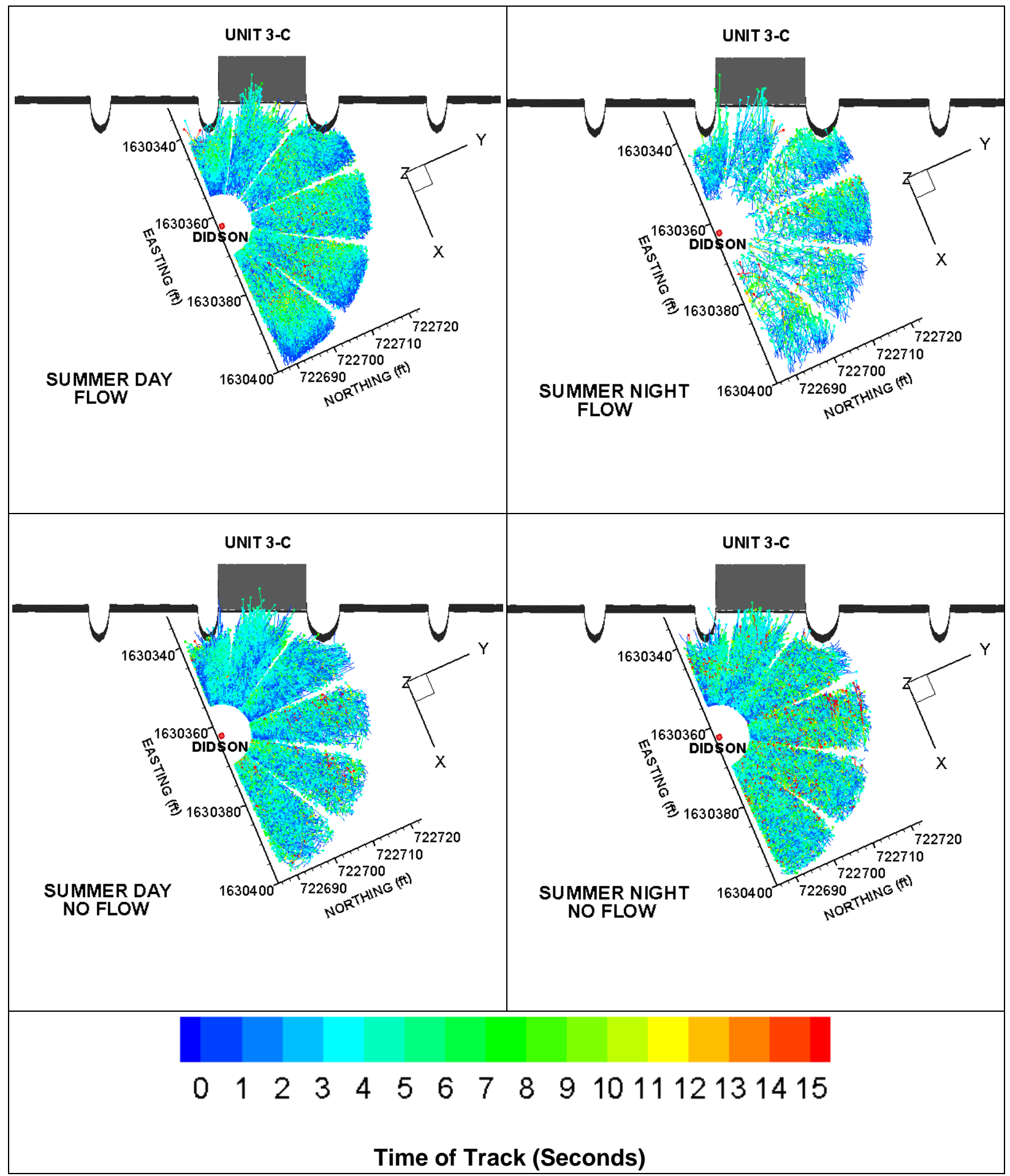

Figure 3.85. Tracked Fish Upstream and Approaching the 3C Sluiceway Outlet at Bonneville Dam Based Upon the DIDSON Acoustic Camera Sampling in Summer 2005. Track portions are color-coded by the seconds from start of each fish track. 
Fish tracks were slightly modified to connect sectors of the roughly half-circular sample volume. Fish movement was sampled using the DIDSON acoustic camera and moving 30 degrees between six zones. Each zone subtended somewhat less than 30 degrees and as a result there was little or no overlap so that infilling was needed to provide connectedness in the Markov chain analysis. Infilling gaps was accomplished by widening sector data $6.7 \%$ in spring and 16.7\% in summer (Figures 3.86 and 3.87).

Of the eight Markov chain analyses there were only two cells in "Spring Day No Flow," one cell in "Spring Night No Flow," and two cells in "Summer Night Flow" that held no data and required interpolation from surrounding cells.

Table 3.8. Characteristics of Data Used in Markov Chain Models of Fish Movement

\begin{tabular}{|c|c|c|c|c|c|c|}
\hline $\begin{array}{c}\text { Period and } \\
\text { Powerhouse Flow }\end{array}$ & Dates & $\begin{array}{c}\text { Total } \\
\text { Fish } \\
\text { Tracks (N) }\end{array}$ & $\begin{array}{c}\text { Used } \\
\text { Fish } \\
\text { Tracks (N) }\end{array}$ & $\begin{array}{c}\text { Total } \\
0.5 \text { s Moves } \\
\text { (N) }\end{array}$ & $\begin{array}{c}\text { Used } \\
0.5 \mathrm{~s} \\
\text { Moves (N) }\end{array}$ & $\begin{array}{l}\text { Average } \\
\text { Measures } \\
\text { Per Track }\end{array}$ \\
\hline Spring Day $>7.5 \mathrm{kcfs}$ & $5 / 21$ to $5 / 31$ & $1,016,287$ & $1,005,391$ & $7,196,727$ & $6,104,169$ & 6.07 \\
\hline Spring Night $>7.5 \mathrm{kcfs}$ & $5 / 20$ to $5 / 30$ & 872,747 & 872,391 & $6,036,386$ & $5,159,068$ & 5.91 \\
\hline Spring Day $<7.5 \mathrm{kcfs}$ & $5 / 26$ to $5 / 31$ & 17,279 & 17,257 & 105,341 & 87,717 & 5.08 \\
\hline Spring Night $<7.5 \mathrm{kcfs}$ & $5 / 25$ to $6 / 01$ & 102,709 & 102,341 & 802,922 & 696,992 & 6.81 \\
\hline Summer Day $>7.5 \mathrm{kcfs}$ & $6 / 11$ to $7 / 09$ & 16,088 & 16,086 & 111,789 & 95,649 & 5.95 \\
\hline Summer Night $>7.5 \mathrm{kcfs}$ & $6 / 11$ to $7 / 09$ & 2,198 & 2,198 & 16,493 & 14,276 & 6.49 \\
\hline Summer Day $<7.5 \mathrm{kcfs}$ & $6 / 10$ to $7 / 10$ & 27,876 & 27,876 & 183,675 & 155,775 & 5.59 \\
\hline Summer Night $<7.5 \mathrm{kcfs}$ & $6 / 10$ to $7 / 10$ & 22,948 & 22,948 & 183,222 & 160,244 & 6.98 \\
\hline
\end{tabular}




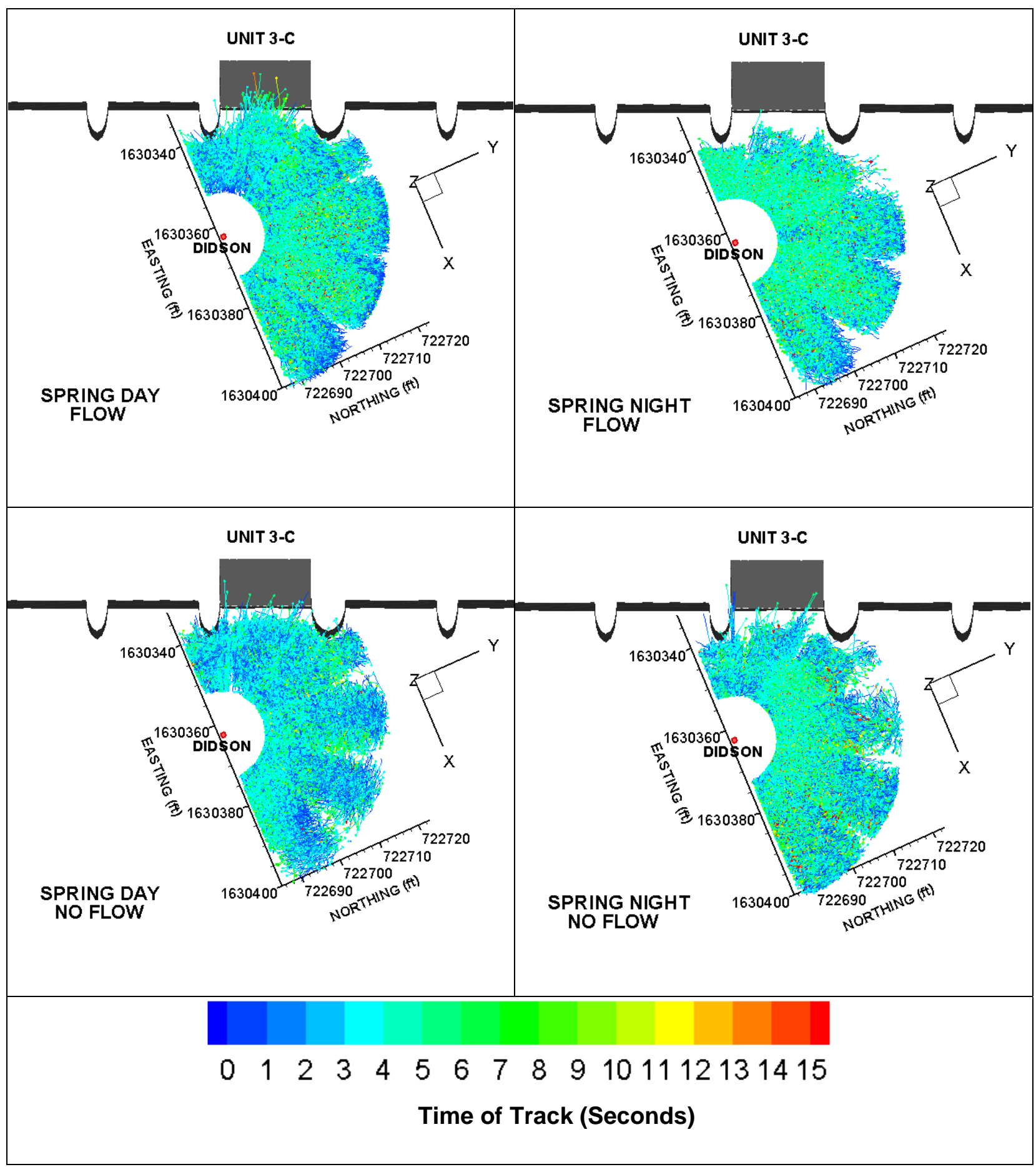

Figure 3.86. Composite View of Fish Tracks Approaching the 3C Sluiceway Outlet in Spring 2005. Tracks were moved slightly by widening $29^{\circ}$ sectors by $6.7 \%$ for insuring connectivity in Markov chains. Track portions are color-coded by the seconds from start of each fish track. 


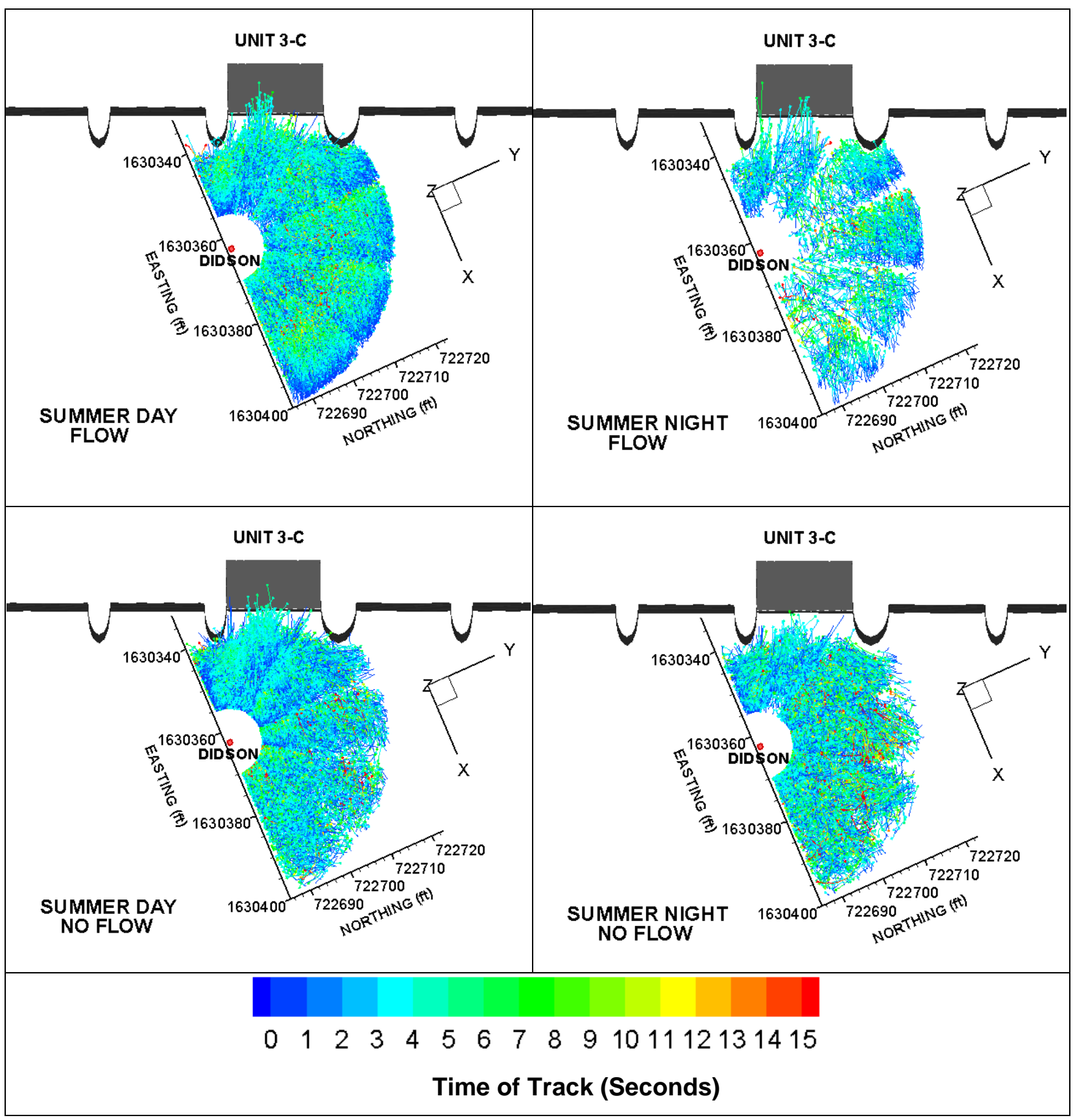

Figure 3.87. Composite View of Fish Tracks Approaching the 3C Sluiceway Outlet in Summer 2005. Tracks were moved slightly by widening $29^{\circ}$ sectors by $16.7 \%$ for insuring connectivity in Markov chains. Track portions are color-coded by the seconds from start of each fish track.

\subsubsection{Sluiceway Fate Probabilities}

Figures 3.88 and 3.89 show contours of each spatial cell's sluiceway fate (probabilities of state values going to sluiceway states) after $n=214$ steps (i.e., 214 multiplications of the transition matrices). No stagnation occurred because all fish moved to edges of the volume analyzed. The sums of the fate 
probabilities are shown in Table 3.9 for the eight Markov chain analyses. A two-tailed t-test showed that the summer average sluiceway passage was significantly higher $(\mathrm{P}=0.0255)$ than spring average sluiceway passage (0.48 vs. 0.19$)$.

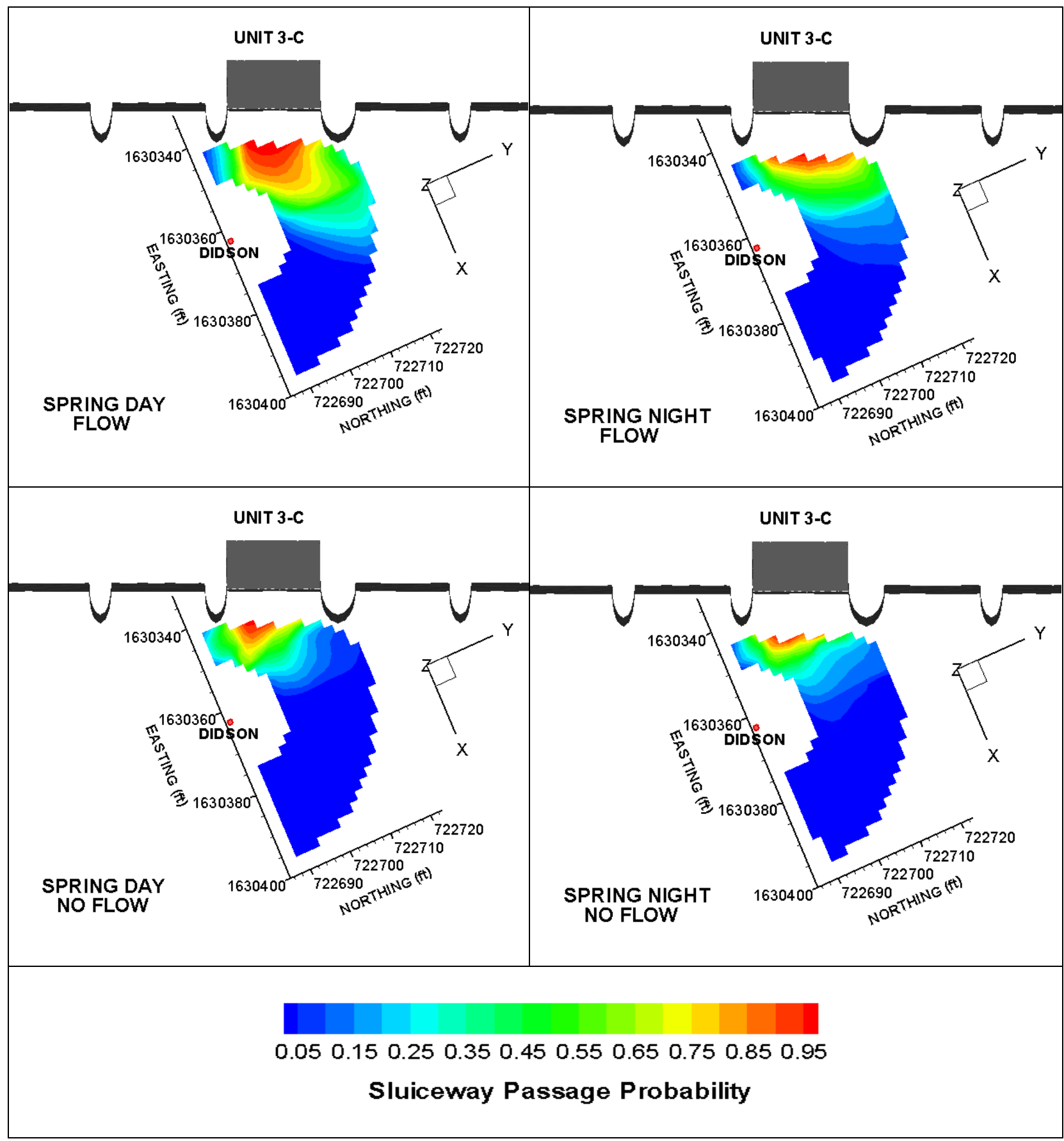

Figure 3.88. Contours of Fish Passage Probabilities at the B1 3C Sluiceway in Spring 2005. Probabilities above are shown for the day (left panels) and night (right panels), and powerhouse flow $>7.5$ kcfs (upper panels) and $<7.5$ kcfs (lower panels). Sluiceway passage fates. X- and Y-scales are in feet. 


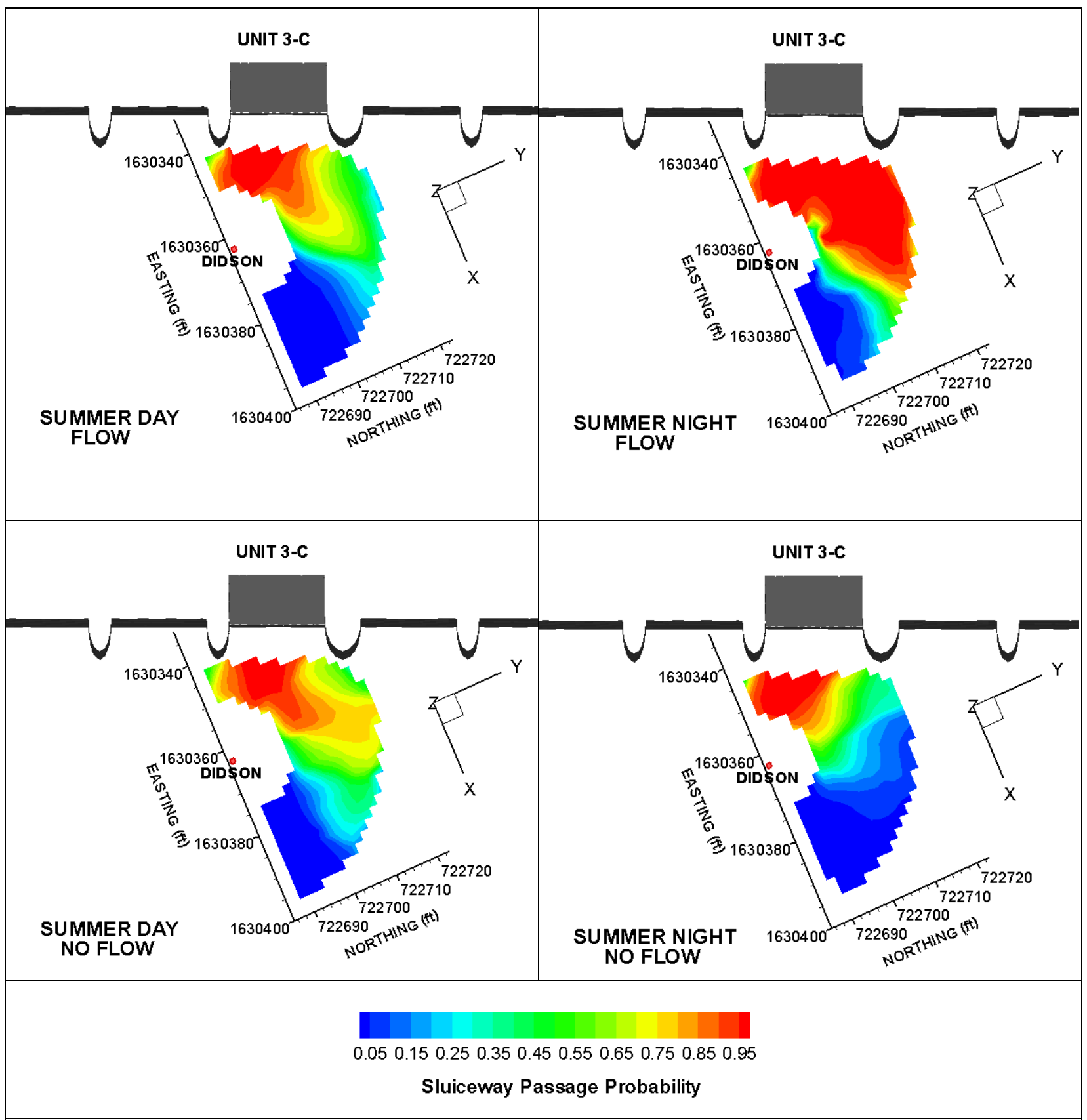

Figure 3.89. Contours of Fish Passage Probabilities at the B1 3C Sluiceway in Summer 2005. Probabilities above are shown for the day (left panels) and night (right panels), and powerhouse flow $>7.5 \mathrm{kcfs}$ (upper panels) and $<7.5 \mathrm{kcfs}$ (lower panels). Sluiceway passage fates. $\mathrm{X}$ - and $\mathrm{Y}$-scales are in feet.

The fish entrainment zone (FEZ), defined as the contour where $90 \%$ of fish would pass into the outlet, varied greatly between seasons and in distance upstream from a line between piers at elevation $90 \mathrm{ft}$ MSL (e.g., Figure 3.88 and 3.89). Therefore, we estimated the average and maximum distances of points along the $90 \%$ contour upstream from a line across the opening at pier elevation $90 \mathrm{ft}$ (Figure 3.90). The mean 
of maximum FEZ distances for four spring treatments was $7.25 \mathrm{ft}$, and maximum distances in spring were less than $10 \mathrm{ft}$. The average summer FEZ was $21.5 \mathrm{ft}$, and the largest FEZ of about $30 \mathrm{ft}$ occurred in summer at night (Figure 3.90). The largest FEZ in summer was based upon the fewest tracks per treatment condition $(16,493)$. The difference between the maximum and mean distance of the $90 \%$ contour upstream of the outlet is an indication of contour uniformity. When the mean and maximum distances are nearly equal, the contour distance upstream would be most uniform across the outlet. When maximum greatly exceeds the mean, the contour is much further upstream of the piers at one lateral position than at others.

Table 3.9. Fates, Expressed as Probabilities of Passage, Averaged from a Semi-Circular Area Near the 3C Sluiceway Outlet at Bonneville Dam in 2005 Based on Eight Markov Chain Analyses. A two-tailed t-test showed that the average probability of sluiceway passage was significantly different among the seasons $(\mathrm{P}=0.0255)$.

\begin{tabular}{|ccccc||}
\hline Period & $\begin{array}{c}\text { Day or } \\
\text { Night }\end{array}$ & $\begin{array}{c}\text { Powerhouse } \\
\text { Flow }\end{array}$ & $\begin{array}{c}\text { Sluiceway } \\
\text { Passage }\end{array}$ & Other Passage \\
\hline \hline Spring & Day & $>7.5 \mathrm{kcfs}$ & 0.2868 & 0.7132 \\
Spring & Night & $>7.5 \mathrm{kcfs}$ & 0.2055 & 0.7945 \\
Spring & Day & $<7.5 \mathrm{kcfs}$ & 0.1296 & 0.8704 \\
Spring & Night & $<7.5 \mathrm{kcfs}$ & 0.1224 & 0.8776 \\
Spring Average & & & $\mathbf{0 . 1 8 6 1}$ & $\mathbf{0 . 8 1 3 9}$ \\
Summer & Day & $>7.5 \mathrm{kcfs}$ & 0.4301 & 0.5699 \\
Summer & Night & $>7.5 \mathrm{kcfs}$ & 0.6528 & 0.3472 \\
Summer & Day & $<7.5 \mathrm{kcfs}$ & 0.4912 & 0.5088 \\
Summer & Night & $<7.5 \mathrm{kcfs}$ & 0.3278 & 0.6722 \\
Summer Average & & 0.65394 & $\mathbf{0 . 4 7 5 5}$ & $\mathbf{0 . 5 2 4 5}$ \\
\hline
\end{tabular}

\subsubsection{Smolt Schools and Predators}

Large schools of smolts were observed at Sluiceway Outlet 3C from the B1 forebay in spring and summer, and large schools were more likely to be observed $>5 \mathrm{~m}$ upstream and holding at night (Figure 3.91 and Figure 3.92 - Frame 1), but schools were more likely to be moving toward and into the outlet during the daytime (Figure 3.92 Frames 2-7). The chain gate provided a flow refuge below the top of the gate for smolts and predators, and predators were more often observed at dawn, dusk, and night than they were during the day. Smolts usually stayed $1 \mathrm{~m}$ from large fish during day and night except when an 
attack closed that distance. Vortices upstream sometimes took smolts that otherwise would have entered the sluiceway. Some movie clips of predators hunting and a vortex are in Appendix $\mathrm{H}$ on the accompanying compact disk.

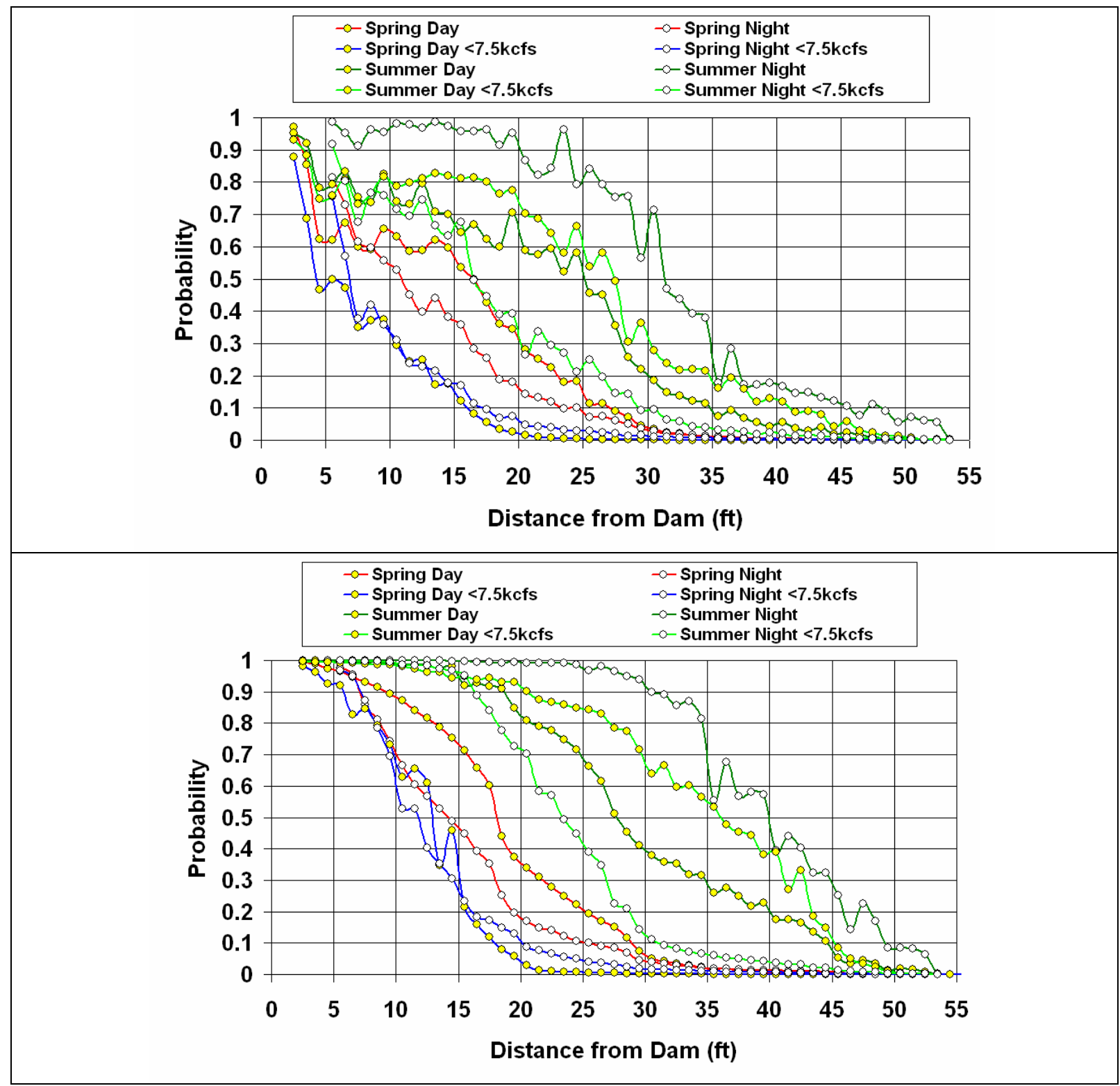

Figure 3.90. Mean (Top) and Maximum (Bottom) Entrance Probabilities at a Function of Range for Bonneville Dam Sluiceway Outlet 3C in 2005. Probabilities are expressed as the mean (top) and maximum (bottom) distances upstream of a line across the entrance between two piers 


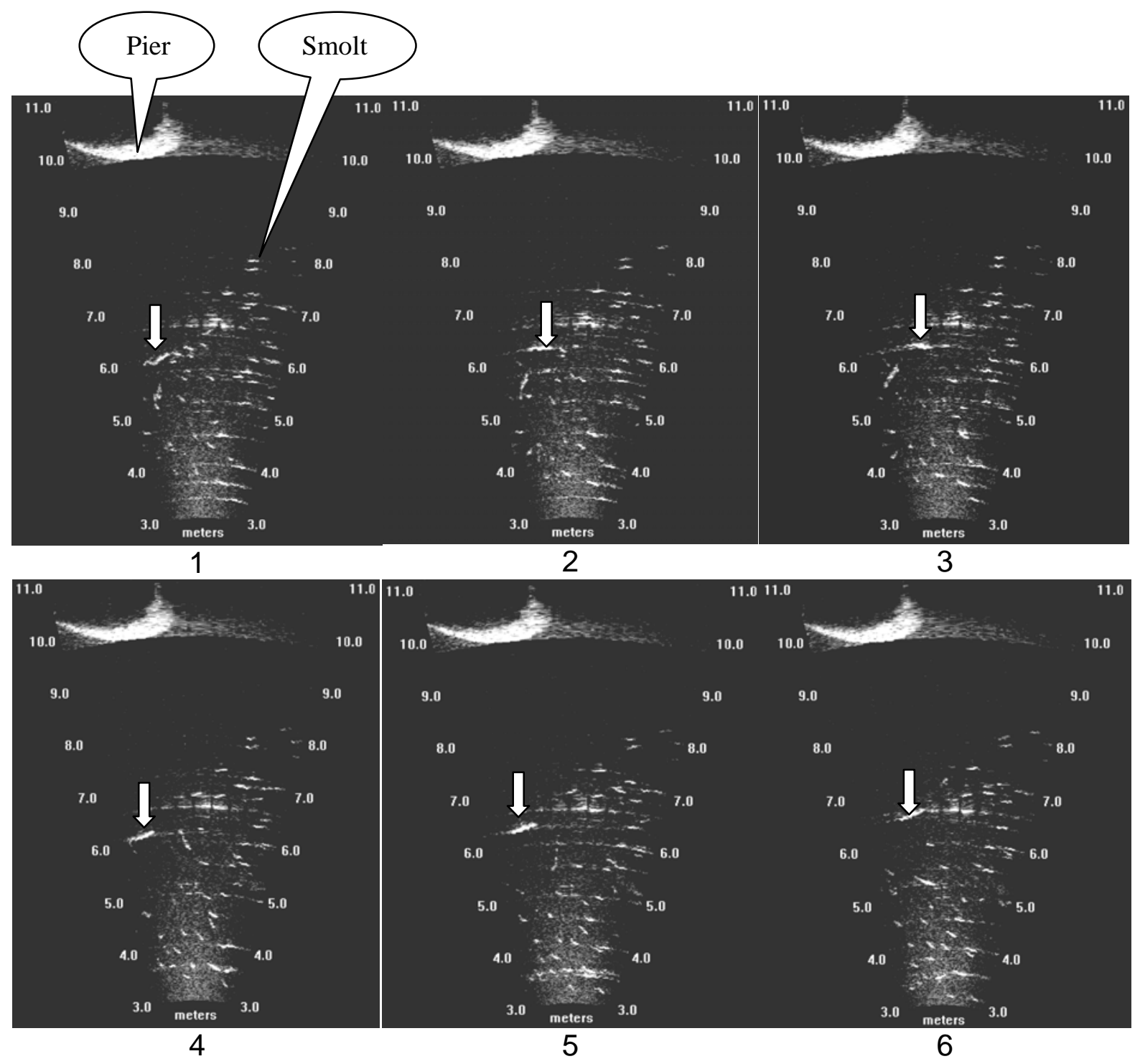

Figure 3.91. Two Sets of Three-Frame Series of Movements of Two Predators (Frames 1-3 and 4-6) Feeding on Juvenile Salmonids Upstream of Sluiceway Outlet 3C at Night. The pier between Intakes $3 \mathrm{~B}$ and $3 \mathrm{C}$ is in the upper left of each frame. Smolts show as small white marks, and predator positions are indicated by white arrows in each frame. 

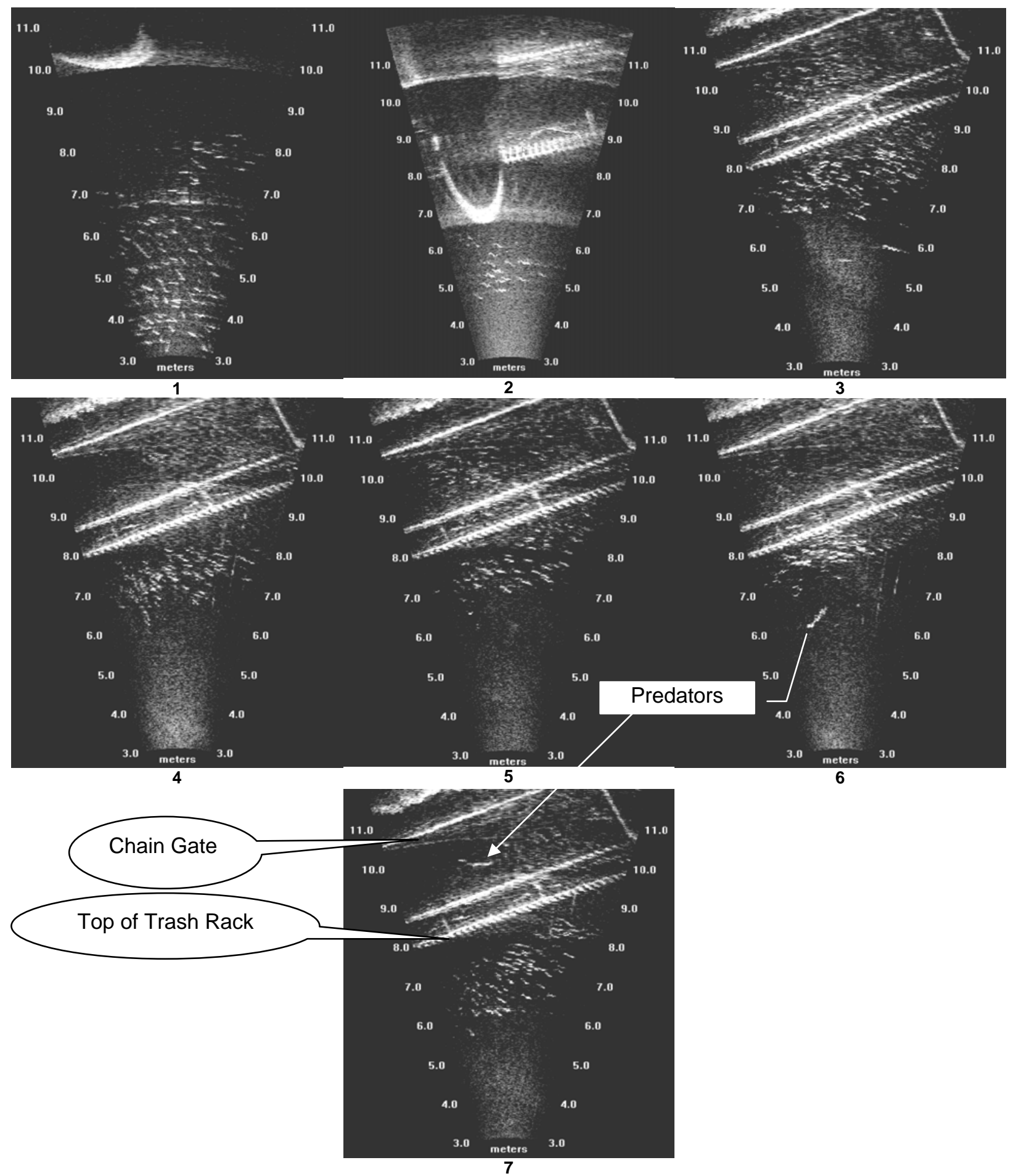

Figure 3.92. Series of DIDSON Images Show Schools of Juvenile Salmonids Upstream of Sluiceway Outlet 3C. Frames show the following: (1) a dense school upstream of the pier from 3.0 to $8.3 \mathrm{~m}$ at night, (2) a small school upstream of pier with top of Trash rack 1 visible to right at about $9 \mathrm{~m}$ and chain gate at about 11 m, (3) large school over sill, Trash Rack 1, and upstream, (4 and 5) sequence of school passing over trash rack and sill, (6) predator spooking a school into the sluiceway outlet, and (7) predator over the sill between the chain gate at $10.5 \mathrm{~m}$ and the trash rack top from 10 to $11 \mathrm{~m}$ keeping a school of smolts upstream of the trash rack. Frame 1 was at night and Frames 2-7 were imaged during the day. 


\subsection{Discussion}

\subsection{Environmental Conditions in 2005}

Unique environmental conditions that may have affected estimates of fish passage metrics in 2005 included species composition and run timing in spring, opening three sluiceway outlets from the B1 forebay, not deploying STSs at B1 turbines, a B2 Powerhouse priority, the operation of the B2CC, and the absence of TIEs on the south half of B2. Yearling Chinook salmon dominated the spring run except during two brief periods of several days when subyearling Chinook salmon from hatcheries predominated. Except during those brief periods, juvenile coho salmon made up the second most common group migrating in spring. The detection of all species of migrating fish by hydroacoustics would result in composite metric estimates that may or may not match those of radio-tagged fish. Project discharge was below the 10-year average throughout most of 2005, especially before May 10 and from about May 28 through about June 20. The B1 sluiceways and B2CC passed only about 5\% of project flow but were much more effective at passing fish than was the spillway. Adequate river flow allowed operators to provide prescribed spill levels for day and night periods each season. Generation was curtailed to provide for increased spill at night and most of this water was obtained by reducing B1 turbine discharge. The B1 turbines ran little during the day or night in summer which left the B1 sluiceway as the only major passage route at B1.

\subsection{Hydroacoustic Detectability}

The motivation for efforts to improve detectability modeling is the desire to provide hydroacoustic estimates that are quantitative as well as relative indices to fish passage. Ratio estimators such as fish guidance efficiency only require that the hydroacoustic beams sampling guided and unguided fish have equal detectability so that the ratios of counts, not necessarily the counts themselves, are accurate. Combining counts from different locations such as powerhouses and a spillway also requires equal detectability so that counts from different locations are comparable, although the counts themselves may not be accurate. Nevertheless, accurate counts estimated by proper expansion of detected fish have the potential to provide estimates with inherent quantitative value as well as providing acceptable relative estimates.

We feel that detectability was adequate at all deployments in 2005 because most effective beam angles were above the nominal beam angle in spring and within 1 to 2 degrees of the nominal beam angle at fishcounting ranges in summer. The only exception was from 1 to $2 \mathrm{~m}$ of range from the down-looking transducers inside B1 turbine intakes. Nevertheless, spatial expansions incorporated effective beam angle, so there was appropriate compensation for lower detectability even at short range.

Our pulse repetition rate of 25 pings per second at the spillway was adequate to detect passing fish even at the highest spill discharge observed in 2005, although there was a slight decrease in detectability with increasing discharge through individual spill bays (Figures 3.12 and 3.13). Lower detectability results from increased fish speed through the hydroacoustic beams at higher discharge. Higher speed provides fewer echo detections at any cross section of the beam, and at the edge of the beam, the minimum of four echoes may not be obtained; this loss of a fish detection causes a narrowing of the effective beam angle. Our modeling of detectability at ten levels of spill-bay discharge (Appendix F) provided spatial expansion factors to compensate for declining detectability. This effort was important because the loss of 
detectability with increased spill-bay discharge could result in the misinterpretation of relations between spill efficiency or effectiveness and spill discharge. Therefore, we recommend that comparable discharge-dependent expansion factors be applied to data collected in 2000, 2001, 2002, and 2004 when spilled passage relations are re-examined in 2006.

\subsection{Validation of Auto Tracking and Count Adjustments}

We were reassured about autotracker performance and filtering after observing reasonably good correspondence between technician and autotracker counts for every deployment (Figures 3.14, 3.15, 3.16, and 3.17). Deployment-specific differences in slopes of correlation lines likely result from differences in noise regimes among deployments. Median slopes of correlation lines for each deployment type were within about 10\% of 1:1 (Figure 4.1). Median slopes for B1 sluiceways, B1 turbines, and the spillway were closest to 1:1, and the variance in slopes was highest for the spillway and for B2 turbine up-lookers, which had an outlier in B2 Intake 16B (0.47). The use of channel-specific correlation slopes to adjust autotracker counts to estimate manual tracker counts was reasonable given the variability in slopes and systematic deviation from a 1:1 slope for B2 turbines and the B2CC (Figure 4.1). This method of evaluation and correction is an adequate method of quality control and assurance for autotracker estimates. This approach is not only more economical but qualitatively superior to manual tracking by people. Due to the magnitude of the data sets involved in Project-wide sampling and the established individual variation in human trackers (Ploskey et al. 2001b and c; 2002a-c; 2003), manual tracking is neither feasible nor desirable.

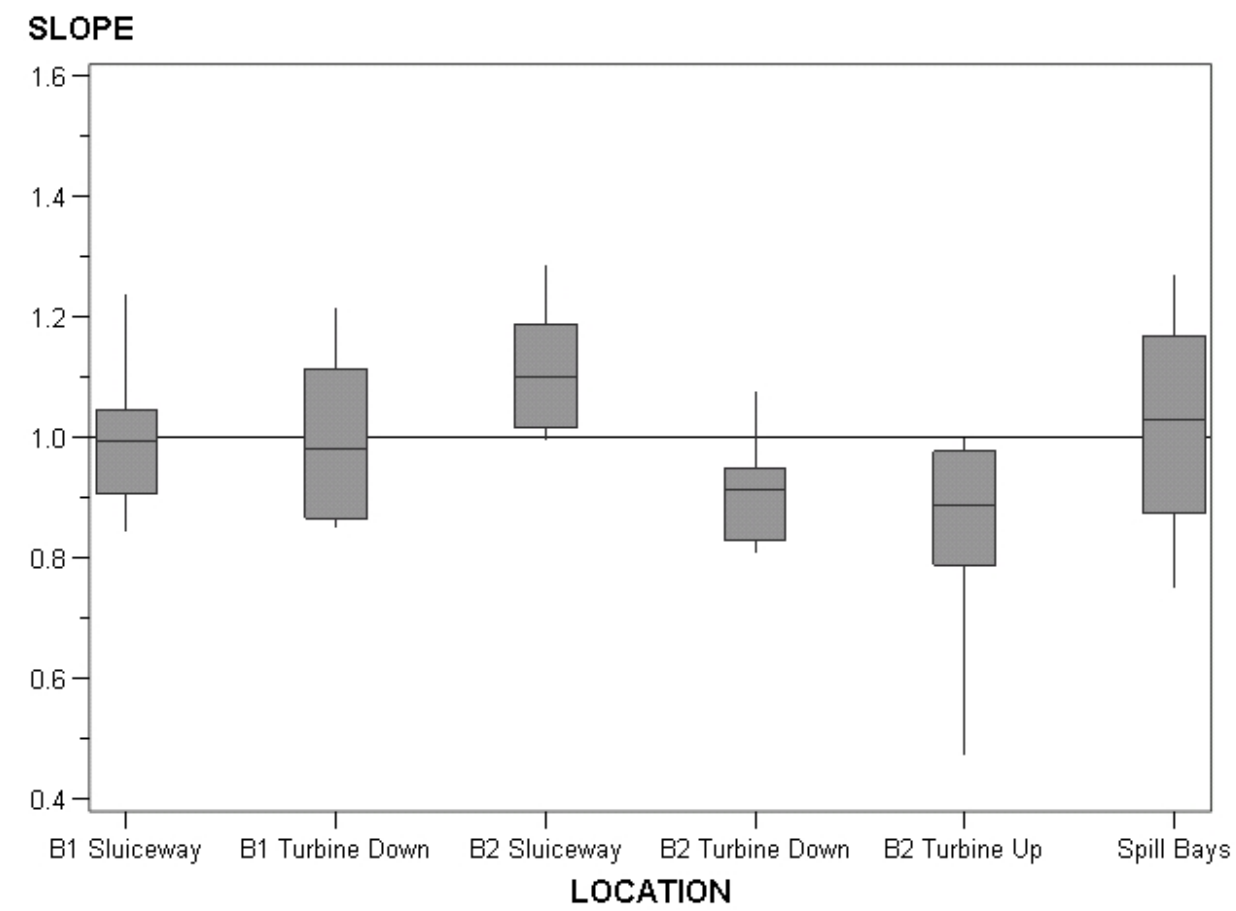

Figure 4.1. Box-and-Whisker Plots Describing Slope Statistics by Deployment Type. The horizontal line through each box is the median and the top and bottom edges of the box are located at the sample 25th and 75th percentiles. Whiskers are drawn from the box to extreme points. 


\subsection{Direction of Travel Adjustments}

The $87 \%$ downstream movement at spill bays in spring and summer suggests that most fish were entrained by the time they were detected, except perhaps at the lowest spill discharge rates through individual bays. The 12\% not moving downstream at the spillway tended to be detected from 5 to $8 \mathrm{~m}$ from the transducer where water velocities were lower than velocities from 7 to $11 \mathrm{~m}$ from the transducer and near the ogee.

If the B1 sluiceway channel is modified in the future to accept greater flow, we recommend that sluiceway entrances also be modified to replace the sharp crested weir created by a chain gate with a broad crested weir. A broad crested weir would eliminate the flow refuge immediately upstream of the chain gate, which, in 2005, facilitated smolt escape from higher velocity flow over the gate and provided a convenient refuge for predators. Of upstream moving smolts in spring, 59.3\% of those at Entrance 3C and $64.4 \%$ of those at Entrance $1 \mathrm{C}$ also moved downward toward the flow refuge. In summer, the percent of upstream headed smolts moving down toward the refuge was 58\% at Entrance 3C and 71\% at Entrance 1C. We suspect that flow was so sluggish at Entrance 6C, that smolts did not require a flow refuge to escape upstream, however, the refuge was useful and more extensively used at Entrances $1 \mathrm{C}$ and 3C where water velocities were higher. The direction of travel data for the B1 sluiceway entrances clearly indicate that fish were not entrained at the time they were detected. Only about 50 to $65 \%$ of the sampled fish were moving in a downstream direction despite being detected very near or above the top of the chain gate controlling flow. DIDSON sampling at Entrance 3C often revealed predators moving around the piers and holding between piers and in the velocity refuges just above the sill at elevation $68 \mathrm{ft}$ above MSL and immediately upstream of the chain gate.

\subsection{Major Fish Passage Metrics}

As in previous study years (2000, 2001, 2002, and 2004), we observed a pretty close correspondence between the percent of fish and discharge passing through the three major dam structures, but the correspondence between fish and flow passage percentages broke down at finer scales such as sluiceway outlets versus turbines or spill bays.

\subsubsection{Project and Powerhouse FPE}

Project FPE estimates of $73.4 \%$ in spring and $80.7 \%$ in summer 2005 were made possible primarily by surface passage routes because there were no STSs deployed at B1. Spill efficiency and B2 FGE was about average for non-drought years for which full-Project data are available. Fish passage efficiency (FPE) must be viewed in the context of differences in structure and operations. The B1 sluiceway and B2CC passed a very large proportion of the estimated total project fish passage relative to the amount of water discharged through those surface routes (Figures 3.41 and 3.42). The contribution of surface routes to FPE made up for a lack of screens at B1 and for average spill efficiency in 2005. Project FPE was within 6\% of estimates in 2000 and 2002 and summer FPE was 2\% above 2000 levels and $7 \%$ above 2002 levels, two non-drought years. The FPE estimate in spring 2005 (73.4\%) was very close to the 2004 estimate (73.0\%) and in summer FPE was 11\% higher than in 2004. Surface passage was especially important in maintaining a relatively high (80.7\%) FPE estimate in late summer, when Project FPE often declines. Limited turbine discharge through B1 in summer resulted in most fish passing through the B1 sluiceway. The Project FPE estimate for spring also was about $80 \%$ when B1 passage was ignored. In 2005, B2 screen guidance was about average for that structure (about $45 \%$ in spring and $37 \%$ in summer). 
Project spill efficiency in spring (40\%) was about $4 \%$ below the average for the four non-drought years sampled, and at $44 \%$, it was about $2 \%$ above average in summer.

For just B2 and the spillway, FPE was over $80 \%$ in spring (the NOAA Fisheries mandated goal) and 82\% in summer. However, this high FPE estimate for part of the Project would not necessarily translate into a high Project FPE if one powerhouse was actually off-line for the passage season. Eliminating one powerhouse from the calculation must increase FPE since a portion of turbine passage is removed from the denominator. In 2005, all of B1's turbine passage was “unguided” (since no screens were installed) and spill passage makes up a more substantial proportion of the total. Changes in operations can have unforeseen consequences and issues of forebay approach, water quality, forebay predation, delay, and tailrace egress must be considered (Ploskey et al. 2003; 2005).

\subsubsection{Spill Efficiency and Effectiveness}

Estimates of spill efficiency in 2005 were similar to estimates for four non-drought years studied previously. In spring, spill efficiency was just $4 \%$ lower than the average efficiency for four non-drought years, and in summer, it was just 2\% higher. Percent spill, which in 2005 explained 34\% of the variation in spill efficiency in spring and 72\% in summer, also likely explains most of the difference in spillpassage efficiency among years, particularly the large differences between the drought year of 2001 (efficiency $=14 \%$ and $20 \%$ in spring and summer) and the average for non-drought years (efficiency = $44 \%$ and $42 \%$ in spring and summer).

As in 2004, the percent of fish passing the spillway (spillway efficiency) was similar to the proportion of water spilled each season (effectiveness $=0.98$ in spring and 0.86 in summer), and estimates in 2005 were within about $2 \%$ and 3\% of spring and summer estimates in 2004. The effectiveness in spring 2005 (0.98) was very close to the average of 5 years of spring estimates (1.05). For summer, the 2005 effectiveness estimate of 0.86 was about $21 \%$ lower than the five-year average of 1.1 , but was much closer to the average for the four non-drought years (0.92).

At close to 1:1, the effectiveness of the Bonneville spillway was 6.4 times less than the combined effectiveness of surface-passage routes (three B1 sluiceway outlets and the B2CC combined) in 2005 in spring, and it was 8.8 times less effective than surface routes in summer.

\subsubsection{Sluiceway Efficiency and Effectiveness}

As in 2004, the most outstanding metric in 2005 was the high effectiveness of surface-passage routes (Table 3.1 and Figure 3.23). Given the high effectiveness of surface passage routes relative to the spillway, it is obvious that provision of more surface passage routes would be desirable for increasing FPE, particularly if those routes are adjacent to turbines. While the removable spillway weir can provide a surface passage route and may be effective at passing fish, most of the fish passed there likely would have passed at the spillway anyway, and therefore an RSW probably would not increase Project FPE. The motivation for deploying an RSW would have to come from increased survival benefits rather than from increased spill-passage proportions or reduction in residence time, given that most juvenile salmonids first detected in the spillway forebay pass there and usually have short residence times ranging from 0.1 to 1.3 hours (Evans et al. 2001a, 2001b, 2003a).

The capacity of the B1 sluiceway was adequate in 2005 because B1 turbine operations were severely limited, as they were in 2004, but sluiceway flow would have to be increased substantially to provide 
$30 \%$ sluiceway efficiency for a fully loaded B1 powerhouse. In 2005, the B1 sluiceway passed about $4.9 \%$ of the B1 discharge in spring and $16.4 \%$ in summer, and these flow percentages passed $37.4 \%$ of B1 fish in spring, and 70.4\% of B1 fish in summer. Turbines at B1 were off for many hours in summer 2005 and left the sluiceway as the only available passage route, and this resulted in the very high B1 sluiceway efficiency in summer. With full B1 turbine operation, the percent of flow passing into the B1 sluiceway would be closer to 1\%, and this likely would be insufficient to provide high B1 sluiceway efficiency. Ferguson et al. (1998) recommended that a powerhouse surface-passage route should pass on the order of $5 \%$ to $10 \%$ of total powerhouse discharge. By that standard, the B1 sluiceway is clearly under capacity.

The high capacity of surface routes to pass juvenile salmonids in a relatively small discharge is well known (see the review by Ferguson et al. 1998) and would make cost effective the development of new surface-passage routes or the expansion of existing routes if spill could be reduced. Given the far greater effectiveness of surface passage routes over spill, it should be possible to reduce spill and maintain FPE by increasing the number of surface passage routes. Opportunities at Bonneville Dam include increasing the capacity of the B1 sluiceway so that more entrances can be opened and provision of removable spillway weirs. A doubling of discharge through additional surface passage routes from about 5\% to $10 \%$ of Project flow could make surface-passage efficiency comparable to 2004 spill efficiency using just 1/4 of the water spilled. This would allow for some training spill for spillway weirs. Adding surface passage also may reduce forebay delay because juvenile salmonids pass dams well by surface routes during daytime whereas many typically hold upstream from powerhouses and spillways until dark (Thorne and Johnson 1993).

\subsubsection{Effects of Percent Spill on Spill Efficiency and Project FPE}

The relationship between spill efficiency and percent spill differed in spring and summer 2005, and it appears that all of the difference in the relations can be attributed to a few days of spill efficiency estimates collected at the beginning of the spring season between April 19 and April 24 when spill was being held constant for 24-h periods (Figure 3.6). If data collected from those days are removed, the relationship (Figure 4.2) is much more like that depicted in Figure 3.26 for summer 2006 than the original relationship shown in Figure 3.24. For some unknown reason, spill efficiencies for periods of constant 24-h spill were lower than estimates for periods with high spill at night and low spill during the day. With the changes, percent spill explained about $68 \%$ of spill passage efficiency in spring, and this was much closer to the $72 \%$ explained in summer (Figure 3.26).

Linear relations of spill-passage efficiency in 2005 (Figure 3.26 and Figure 4.2) are consistent with linear relations observed in 2004 (Ploskey et al. 2005) and 2002 (Ploskey et al. 2003). In 2001, a drought and severely limited spill precluded a regression of efficiency on percent spill (Ploskey et al. 2002a). Another relationship consistent with that observed in 2002, 2004, and 2005 could be obtained from hydroacoustic data collected in 2000 (Figure 4.3), although Ploskey et al. (2002b) only regressed spill efficiency on spill rate and not on percent spill. 


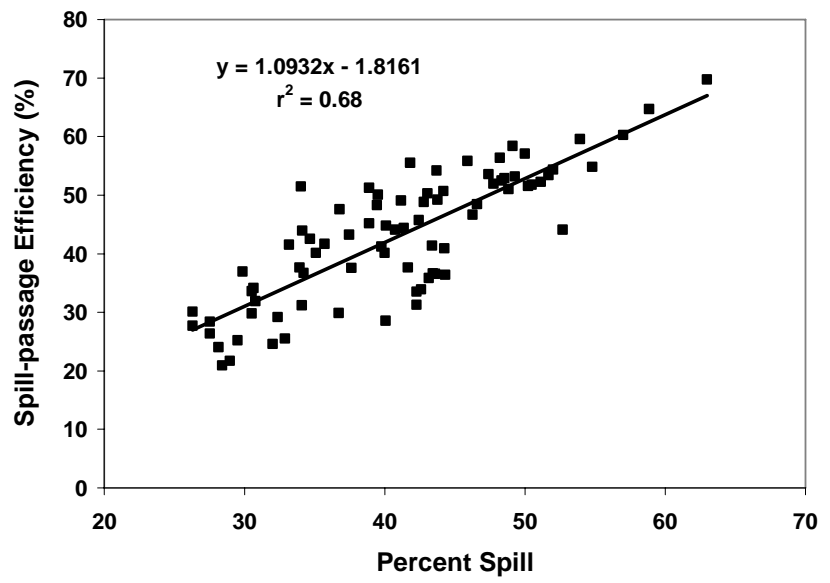

Figure 4.2. Revised Regression of Day and Night Estimates of Spill-Passage Efficiency on Percent Spill in Spring 2005
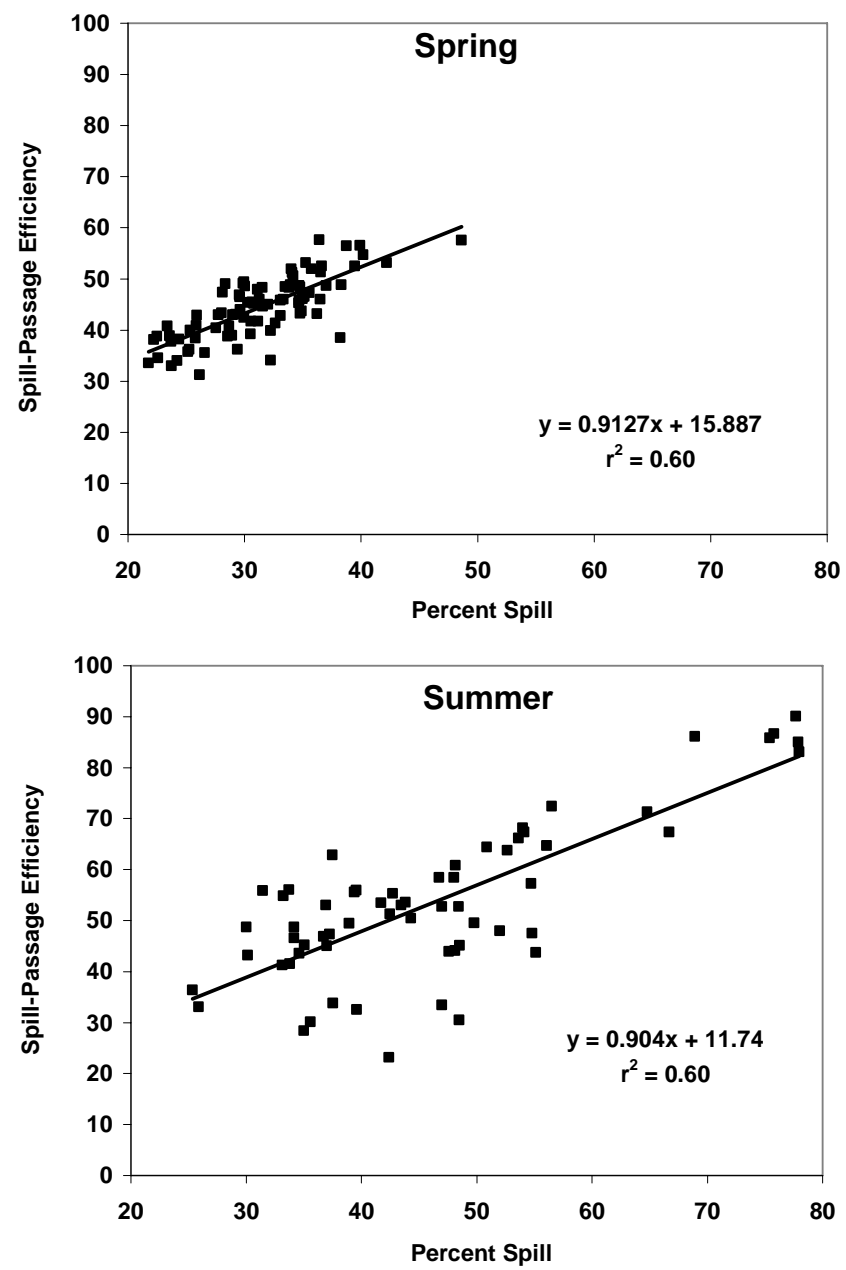

Figure 4.3. Regression of Day and Night Estimates of Spill-Passage Efficiency on Percent Spill in 2000 
Slightly curvilinear relations between Project FPE and percent spill in 2005 (Figures 3.27 and 3.28) only explained about $5 \%$ more variation than linear regressions, and this minor improvement in $\mathrm{r}^{2}$ was consistent with data patterns observed in 2002 and 2004 (Ploskey et al. 2003 and 2005). We thought that adjusting 2005 spill-passage data for reduced detectability with increasing discharge through individual spill bays might reduce the slight curvilinear tendencies, but the trends remain. Adjusted data indicate that increases in FPE were twice as high at low percent spill as they were at high percent spill. For example, a $15 \%$ increase in percent spill from $25 \%$ to $40 \%$ or from $30 \%$ to $45 \%$ bought a $20 \%$ increase in FPE, whereas increasing percent spill from 50\% to 65\% increased FPE by only $10 \%$.

We recommend correcting all previous hydroacoustic data for the effect of discharge on hydroacoustic detectability and re-analyzing all data to see whether the patterns persist as they did in 2005 data.

\subsubsection{Effect of Percent Spill on Percent Passage at B1 and B2}

The B2 powerhouse priority and percent spill had a strong effect on the percent of fish passing through B1 and B2 (Figure 3.29 and 3.30). From 25\% to 40\% spill, the percent of fish passing B1 declined 26\%, and the percent passing B2 increased 15\%. Further increases in percent spill above $40 \%$ had little effect on the percent passing B1, but it significantly decreased the number passing at B2. The decrease in percent fish passage at B2 when percent spill was increased above $40 \%$ shifted many fish from one nonturbine route to another, and increased SPE but provided only a slight increase in Project FPE, because $63 \%-64 \%$ of B2 fish would have passed by a non-turbine route (i.e., the B2CC or B2 Juvenile Bypass Facility).

\subsubsection{Effect of Spill on Project Sluiceway Efficiency}

An increase in Project sluiceway efficiency as percent spill increased from 50\% to 70\% of Project discharge in spring can be explained by the severe restriction of turbine discharge required to achieve those high spill percentages. The reduction in turbine discharge on nights of very high spill percentages greatly increased the percent of powerhouse flow going to surface routes, including the sluiceway at B1 and the B2CC at B2 and resulted in high sluiceway efficiency.

A weak regression trend of decreasing sluiceway-passage efficiency with increasing spill discharge (Figures 3.32 and 3.33) indicates how increasing spill discharge moved fish from one non-turbine route to another without necessarily increasing FPE. The regressions explained just $4 \%-5 \%$ of the variation in Project surface-passage efficiency because of a lot of variation in sluiceway efficiency estimates, but the negative trend was significant in both seasons.

\subsubsection{Effects of Spill Discharge on Spill Efficiency and Project FPE}

As observed in previous years (e.g., 2002 - Ploskey et al. 2003), relations suggest that percent spill is more important than the spill rate for achieving fish-passage benefits. First, relations between spillpassage efficiency and spill discharge usually exhibit a lot more variability than relations between spillpassage efficiency and percent spill. The best examples of the high variability can be seen in the wide range of spill-passage efficiency and FPE estimates at a single discharge level of 75,000 cfs, a common daytime spill level in 2005 for which many points are available (Figures 3.34 through 3.37). If we had as many points at other spill rates, we suspect that the similar variability in spill-passage efficiency would be evident. Second, the highest spill discharges usually are associated with the peak river flow for a year, and during normal to high-water years, percent spill may actually be lower at non-peak times when 
operators can control percent spill. Operators have no control over percent spill at very high river discharge because all available routes must be used to pass water, and percent spill will be around 33\%. The highest percent spill is achieved at night by reducing turbine discharge, but this is only possible when river flow is manageable.

\subsubsection{Comparison of Hydroacoustic and Radio Telemetry Estimates}

The purpose of our comparison of the passage estimates derived from hydroacoustics and radio telemetry is to better understand the strengths and weaknesses of each method, and to use this knowledge to develop more accurate passage estimates. These are very different methods of estimating fish passage metrics, and substantial differences in the estimates resulting from each are inevitable. Differences in estimates result from varying success at estimating passage among the various routes available, biases unique to each method, and the fact that the methods may sample very different populations depending upon the time of year and the composition of the run-at-large and the species composition of radio-tagged fish.

Hydroacoustics is a run-of-the-river sampling method, and radio telemetry samples only the fish that are tagged, in the proportions that they are tagged. The difference between the species composition of the out-migrating smolt population and the composition of the sample of smolts that are equipped with a transmitter is a possible source of error due to behavioral differences between species. In 2005, yearling Chinook salmon dominated the springtime species composition (46\%). Coho salmon were the second most abundant (26\%), followed by sub-yearling Chinook salmon (19\%), steelhead (7\%), and a relatively strong run of sockeye (2\%). The percentages in the spring run at large were quite different from the percentage of juvenile salmonids tagged with radio transmitters. In spring, 58\% of tagged fish were yearling Chinook salmon and $42 \%$ were steelhead (Table 4.1). In summer, the telemetry study tagged only sub-yearling Chinook salmon, which was much more representative of the run-at-large in summer.

Table 4.1. Percentage by Species of Total Fish Radio-Tagged (left) and of the Run-at Large as Sampled by the Juvenile Bypass System (right) in Spring 2005

\begin{tabular}{|lccc||}
\hline \multicolumn{1}{|c|}{ Species } & RT & & Run-at-Large \\
\hline Yearling Chinook & 58 & & 46 \\
Steelhead & 42 & 7 \\
Subyearling Chinook & 0 & 19 \\
Coho & 0 & 26 \\
Sockeye & 0 & 2 \\
\hline
\end{tabular}

There also may be detectability differences between telemetry and hydroacoustics. Detectability varies with location, because each location has unique structural and hydraulic characteristics. Hydroacoustic methods try to compensate for different sampling environments with detectability modeling but there are some situations, such as gap loss (a bias), where we cannot reliably do so (see below regarding B2 FGE). Telemetry antennas are assumed to detect tagged fish adequately in all locations and under all conditions, but we are unaware of any rigorous tests of this assumption, an issue that may be important at locations like the spillway during high discharge. 
Finally, there are likely effects of sample size upon the precision of radio telemetry estimates, particularly for little-used passage routes. For example, with spill and B2 generation given priority in 2005, telemetry estimates of B1 passage may be based on few fish, especially during periods of low B1 discharge, as was seen in summer.

The biggest differences in estimates by the two methods in 2005 were for B2 FGE (7.4\%) and B1 sluiceway effectiveness (8.8) in spring (Table 3.3) and for B2 FGE (14.1\%), B1 sluiceway efficiency (20.8\%), and B1 FPE (10.5\%) in summer. Some of these differences are similar to those from 2004 (Ploskey et al. 2005), and the consistency of the differences between the years may reflect a basic difference in the abilities of the two methods to sample these locations. Interestingly, estimates by the hydroacoustics and radio telemetry were closer in spring than they were in summer in 2005, whereas the opposite was true in 2004. The 2004 differences in spring trends may have resulted from differences in the species composition sampled, but that argument is not reasonable for explaining differences in summer 2005, when sub-yearling Chinook predominated in samples by both methods.

A more reasonable explanation for large differences in summer estimates of B1 FPE (10.5\%) and B1 sluiceway efficiency relative to B1 (20.5\%) by hydroacoustics and radio telemetry probably lies in the small sample size of tagged fish at B1 and contamination of hydroacoustic samples in late summer. In summer 2005, only 78 of 5,572 (1.4\%) subyearling Chinook salmon passed at B1, and these either passed into the sluiceway or turbines. False detection of some spent American shad in late summer would inflate hydroacoustic estimates of sluiceway passage, although most shad detections can be eliminated by high side aspect target strengths, relative to that of smolts. Nevertheless, in head or tail aspect relative to an acoustic beam, target strengths of adult American shad overlap those of subyearling Chinook salmon. Interestingly, both radio telemetry and hydroacoustics found the B2CC to be highly effective at passing fish and estimates of efficiency and effectiveness were $<4 \%$ each season in 2005. Radio telemetry sample sizes and hydroacoustic contamination by shad must not have been a significant problem at the B2CC.

The variation in the estimates of B1 sluiceway efficiency and effectiveness at B1 indicates that the abilities of the two methods to sample fish at the sluiceway or turbines are not equal. Hydroacoustic estimates of B1 sluiceway efficiency were $6.5 \%$ in spring and $4.7 \%$ in summer, while telemetry estimates were $2.0 \%$ and $0.8 \%$ for spring and summer, respectively. Summer estimates at B1, however, are largely biased by dam operations. During eight of the 30 days of the summer overlap between hydroacoustic and radio-telemetry study periods, the B1 turbines were not operated at all and there were 18 days in which less than $5 \%$ of project discharge went through the B1 turbines. Sluiceway discharge and passage continued, and, with B1 turbine passage impossible, FPE values were over $80 \%$, according to hydroacoustics and over $60 \%$ according to radio telemetry.

The most consistent differences in estimates made by hydroacoustic and radio telemetry over the 2004 and 2005 passage seasons was in estimates of FGE at B2. Hydroacoustic estimates were $7.4 \%$ higher in spring and $14.1 \%$ higher in summer 2005, and these differences were similar in magnitude to findings from previous years (Ploskey et al. 2002b and 2002c; 2003). The telemetry sample size was high at B2, and the consistency in the difference of the estimates between seasons may indicate that something other than species composition was causing the estimates to differ, since the species composition of the radio telemetry sample was only an issue in spring. It is possible, therefore, that these differences result from detectability issues. Hydroacoustics is unable to detect gap-loss fish - fish that are guided by the screens 
but do not enter the JBS because they go through the gaps along the tops and the sides of the STSs and then down into the turbines. We estimated gap loss between the tops of the screens and the intake ceilings to average about $12 \%$ in an unmodified unit and about $4 \%$ in a modified unit this spring. Although the potential has not been experimentally verified, the telemetry antennas may be able to detect gap-loss fish behind the STSs and may provide more valid stand-alone estimates of FGE at B2 than does standard hydroacoustic sampling.

At individual units, hydroacoustic estimates of FGE usually are higher than radio telemetry estimates, but there were exceptions at 25\% of the units in both seasons (e.g., Unit 11 and 13 in spring and Unit 17 and 18 in summer). It is of interest to note that both hydroacoustics and telemetry estimated low FGE at unit 18 during spring and summer. We estimated the passage at unit 18 to be the highest of all of the B2 turbines during spring and summer.

\subsection{Spatial Trends in Fish Passage}

\subsubsection{Horizontal Distribution}

The percent of discharge through major dam structures (B1, Spillway, and B2) was a good indicator of percent fish passage through those structures in 2005 (Figures 3.38 and 3.39), as it was in prior years (Table 4.2 -- Ploskey et al. 2002a, 2002b, 2003, and 2005). In 2004, Ploskey et al. (2005) reported a trend in the relation of percent fish passage and percent discharge at B1 and B2. They noted that percent passage consistently exceeded percent discharge at B1 and that the opposite usually was true at B2. The summer of 2004 was an exception for B2. In 2005, we found that the percent of fish passing at B1 exceeded percent discharge there by $4 \%$ in spring and by $3 \%$ in summer, while at B2, percent discharge was $4 \%$ higher than percent passage in spring and $4 \%$ lower than percent passage in summer (Table 4.2).

Table 4.2. Proportion of Fish Passed and Water Discharged by Structure and Season for each NonDrought Year with Full Project Passage Assessment

\begin{tabular}{|cccccccccc||}
\hline \hline \multirow{2}{*}{$\begin{array}{c}\text { Year: } \\
\text { Location }\end{array}$} & \multicolumn{2}{c}{$\mathbf{2 0 0 0}$} & \multicolumn{2}{c}{$\mathbf{2 0 0 2}$} & \multicolumn{2}{c}{$\mathbf{2 0 0 4}$} & \multicolumn{2}{c|}{$\mathbf{2 0 0 5}$} \\
\hline Proportion & Spring & Summer & Spring & Summer & Spring & Summer & Spring & Summer \\
\hline \hline B1 & Passage & 35 & 43 & 19 & 36 & 17 & 16 & 16 & 7 \\
& Discharge & 32 & 41 & 11 & 21 & 12 & 12 & 12 & 4 \\
Spillway & Passage & 44 & 49 & 52 & 43 & 40 & 33 & 40 & 44 \\
& Discharge & 33 & 48 & 49 & 44 & 42 & 39 & 40 & 52 \\
B2 & Passage & 21 & 7 & 29 & 21 & 43 & 51 & 44 & 49 \\
& Discharge & 36 & 11 & 40 & 35 & 47 & 49 & 48 & 45 \\
\hline \hline
\end{tabular}

The distribution of discharge among passage routes at B1 and B2 was not a good indicator of fish passage distributions at either powerhouse in spring nor summer. In spring, B1 sluiceways passed 37.37\% of all fish in just $4.9 \%$ of the B1 discharge and in summer they passed $70.9 \%$ of fish in $16.4 \%$ of B1 flow. The effectiveness of the sluiceways at B1 was almost twice that of the effectiveness of the B2CC in spring, but summer estimates were similar (Table 3.1). Sluiceway Outlet 1C passed the highest density of fish per unit of water at B1 in spring and summer (Figure 3.42). In comparison to the most effective turbine unit and spill bay, Sluiceway Outlet 1C passed 7 to 10 times higher densities of fish volume of water in both seasons. The proximity of Outlet $1 \mathrm{C}$ to the old navigation lock wall and of Outlet 6C to the pier between Units 6 and 7 may explain why these outlets were more effective than Outlet 3C in spring (Figure 3.42). In 2004, Ploskey et al. (2005) found that fish passage across entrances to the individual B1 sluiceways was skewered towards proximal guidance structures such as the old navigation lock wall 
adjacent to $1 \mathrm{C}$ and the pier between 6C and 7A. However, in summer 2005, effectiveness was highest at Outlet $1 \mathrm{C}$ and lowest at Outlet 6C. The latter finding does not necessarily mean that adjacent guidance structures did not enhance fish passage, especially for 1C, which had the highest passage for both seasons.

For comparison of sluiceways to each other and the B2CC, it is important to note that turbine generation at B1 in summer was minimal, and in fact there were days in summer when no turbines were operated and the sluiceway was the only passage route. The effectiveness of the sluice openings in attracting fish in the summer would likely be somewhat reduced in more normal operational years due to the increased flow through the turbines. Also, the tendency of summer migrants to travel deeper in the water column could also lead to greater turbine passage during a summer when turbine passage is available. In 2004, B1 sluice efficiency was slightly higher in summer than it was in spring, and this too was probably driven by greatly reduced discharge through B1 turbines in summer.

Fish passage across Outlet 1C, for both spring and summer, was skewed toward the old navigation wall while the sluice outlet at $6 \mathrm{C}$ showed more of a center line passage for spring and higher passage on the opposite side of the entrance from the pier between Unit 6 and Unit 7 in summer.

When strongly skewed, the lateral distribution of fish passage across B1 sluiceway outlets was highly skewed toward the side piers in 2006. This was observed at Outlet 1C in spring, and all B1 outlets (1C, 3C, and 6C) in summer, and it was similar to what was found in 1996 based on up-looking optical cameras mounted on the chain gate at sluiceway 5B (Ploskey et al. 1998). The lateral distribution was more uniform and slightly higher in the center of Outlets 3C and 6C in spring 2005, and this pattern was similar to that recorded by both hydroacoustics and underwater video cameras at Outlet 7C in 2002, when higher concentrations of fish passed over the middle portion of the entrance and lower proportions passed near the sides (Ploskey et al. 2003). Reasons for differences in lateral distributions are unknown, but might include differences in the velocity of approaching flow, the strength of lateral flow distributions along the powerhouse, and the distribution of predators.

The lateral distribution of discharge at the spillway was a reasonable indicator of the distribution of fish passage there. The proportion of passage to discharge at the spillway seemed to follow a general pattern of high passage/discharge on the southern end of the spillway including bays 16-18 and a decrease and steady trend line across bays 4-15.

As at B1, the distribution of flow at B2 was a poor predictor of fish-passage distributions because the B2CC passed $31.9 \%$ of the fish in $5.5 \%$ of B2 flow in spring and $43.5 \%$ of fish in $6.4 \%$ of flow in summer. The density of fish passage at the B2CC was 5.3 and 6.3 times higher than that of the turbine with the highest fish-passage density in spring and summer, respectively (Figure 3.42). The improvement in the balance of fish to flow at B2 in summer 2004 and 2005, relative to 2002, is quite likely due to the development of the B2CC prior to the 2004 season. Observations from previous years have shown that the horizontal distribution at B2 was skewed toward the south end of the powerhouse (Ploskey et al. 1998, 2002b and 2003). In 2004, fish passage was not skewed toward the southern end of the powerhouse (Ploskey et al. 2005). In 2005, Unit 18 passed more fish in spring than did any other turbine unit and passage in summer was not highly skewed toward the south end of B2. These results suggest, as do results from 2004 (Ploskey et al. 2005), that the B2CC is passing fish that in previous years would have passed at units near the south end of B2. 
Fluctuating levels of discharge among turbine units and spill bays contribute to the non-uniformity of passage among routes, but the preferential selection of surface routes creates large differences in fishpassage density among routes. Non-uniform horizontal distributions of fish passage across passage routes have been observed by numerous other studies conducted at Bonneville Dam from the early eighties to present (e.g., Uremovich et al. 1980; Willis and Uremovich 1981; Krcma et al. 1982; Holmberg et al. 1996; Hensleigh et al. 1999; Ploskey et al. 2002a and b; 2003). Non-uniform patterns of horizontal distribution across all passage routes make some sense when the discharge associated with that passage route is taken into account. Except for surface-passage routes, a rise or a fall in discharge at a particular route was coupled with a rise or a fall in passage. The proportion of passage to discharge varied from one passage route to another depending on horizontal location, the proximity of the route to the water's surface, and possibly the proximity to structure adjacent to a specific route. Examples of potentially important structure include the old navigation lock wall, the pier between Units 6 and 7, and the dam face at B2 and Cascades Island.

\subsubsection{Vertical Distributions}

The vertical distribution of fish at B1 in spring and summer indicated the presence of three distribution aggregates: near the intake ceilings, mid-depth, and near the intake floor (Figures 3.46 and 3.47). These distributions were nearly identical to those seen in 2004 and are similar to those from 2001. This year, from $44 \%$ to $50 \%$ of in-turbine fish detected at B1 were below Elevation $21 \mathrm{ft}$ above MSL, which is near the elevation of submerged traveling screens deployed before 2004. It is unlikely that screens, had they been installed, would have collected those deep fish. The vertical distribution of fish from the Prototype Surface Collector (PSC) test of 2000 (Ploskey et al. 2002a) was more surface-oriented than this year's inturbine distribution would suggest. The 2000 distribution data were collected from the upstream side of the PSC. Of course, fish that were missing near the ceiling of the turbine intake in 2004 and 2005 probably were missing because they already had been collected by sluiceway outlets near the water's surface (37\% in spring and 71\% in summer 2005). A descriptive model of passage is proposed: (1) most surface oriented smolts are collected by sluiceway outlets from the forebay, (2) remaining smolts in the upper water column are detected near the intake ceiling, and (3) smolts traveling deep had little potential for surface collection or interception by in-turbine screens. Fortunately, deep fish are more likely to pass near the hub of the turbine runner than fish near the intake ceiling, which tend to pass near the runner blade tip. The potential for blade strike and shear damage is lower near the hub than it is near the blade tip. Increasing the capacity of the B1 sluiceway has the potential to further reduce fish passage near the intake ceiling.

Vertical distributions of fish inside turbine intakes at B2 were uniform and not highly skewed toward intake ceilings (Figures 3.51 and 3.52), and average FGEs of $45.3 \%$ in spring and $35.4 \%$ in summer of 2005 resulted from distribution patterns. The FGE estimates of $47.6 \%$ in spring and $35.6 \%$ in summer 2004 were very similar to the 2005 estimates. The general trend of gradually decreasing frequency with increasing depth was also noted in 2004 (Ploskey et al. 2005).

The high effectiveness of the B2CC may be attributed to three factors: (1) the depth of the collector, which ranges from 19 to $24 \mathrm{ft}$ depending upon forebay elevation, (2) its horizontal location adjacent to the south forebay eddy where flow moving along the face of the powerhouse continually delivers fish near the forebay outlet, and (3) a fish capture velocity that extends well upstream of the sill. The vertical distribution of fish upstream of the B2CC was highly skewed toward the water's surface in both seasons (Figure 3.50). Nevertheless, $37 \%$ of spring fish and $47 \%$ of summer fish were $>9 \mathrm{ft}$ deep, and a shallow 
3- to 8-ft-deep outlet like the B1 sluiceway or The Dalles sluiceway outlets would not have been as effective as the B2CC for collecting deep fish.

\subsection{Temporal Trends in Fish Passage}

\subsubsection{Seasonal Trends}

\subsubsection{Project Passage Run Timing Smolt - Index and Hydroacoustics}

The correspondence between run timing estimates by hydroacoustics and the B2 Smolt Monitoring Facility (Figure 3.53) was reasonably good considering that hydroacoustic transducers sampled the run at large across the Project and the SMF only sampled fish guided by B2 screens. There was a substantial and well-defined peak in subyearling Chinook Salmon (based on the Smolt Monitoring Facility's data) from June 21 through July 4, most likely due to the 10 million plus sub-yearling Chinook salmon released from Priest Rapids and Ringold Springs Hatcheries from June 9-17 (Priest Rapids) and June 15-16 (Ringold Springs).

The effect of false detections of American shad on hydroacoustic passage estimates in summer 2005 likely was minimal due to a delay in shad run-timing. In 2004, large numbers of spent shad were observed throughout the last week or two of the summer possibly causing errors in hydroacoustic counts (Ploskey et al. 2005). Compared to 2004, the 2005 shad run was almost a week late. Figure 3.54 combines the timing of upstream passage of pre-spawned American Shad and a run-timing graph for juvenile salmonids. American Shad were likely to be present upstream of Bonneville Dam starting in late May. Summer fish counts were filtered based on echo and target strength (see Materials and Methods) in an attempt to exclude these much larger fish from our results but the spent adult American shad down migration is a very large one and large proportions of echograms can potentially be saturated by echoes from shad schools, especially at shallow depths. Our data show two passage peaks in summer, both of which precisely matched the timing of pulses of subyearling Chinook salmon detected by the B2 Smolt Monitoring Facility (Figure 3.53). Hydroacoustic peaks were associated with a peak in the numbers of unguided fish through turbines (Figure 3.55), which shad usually avoid, as well as an increase in sluiceway and B2CC efficiency (Figure 3.59) and effectiveness (Figure 3.60). Target-strength filtering of strong echoes from American shad is particularly effective for horizontally aimed beams like those used to sample all surface-passage routes in 2004 and 2005. The DIDSON that was used to sample a B1 sluiceway outlet in summer also detected few shad schools in late summer.

\subsubsection{Major Fish Passage Metrics}

Estimated Project FPE fluctuated considerably in both spring and summer. In spring, daily estimated Project FPE was frequently near $80 \%$ with two lower periods (one day below 60\%) from May 6-14 and from May 23-28. Figure 3.1, which gives species-specific run timing from the SMF, shows that subyearling smolts dominated the species composition during that period, and that it also was the start of the juvenile Sockeye Salmon passage. Sockeye salmon are thought to migrate deeper than others and might be poorly sampled by the B2 screens. Subyearling Chinook salmon also guide rather poorly, at least sometimes (see the early half of the subyearling Chinook salmon peak in summer, Figure 3.55). In summer, Project FPE estimates were mostly above 80\%, except for a few days at the beginning of summer and a few in the middle of summer. There were slight peaks in FPE (Figure 3.56) that coincided with peaks in subyearling Chinook salmon run-timing (Figure 3.1) and with peaks in sluiceway efficiency (Figure 3.59) and effectiveness (Figure 3.60). 
Estimated spill efficiency was quite variable in spring and summer, oscillating between $26 \%$ and just over $61 \%$ in spring and a low of $31 \%$ to a high of $53 \%$ in summer (Figure 3.57 ), but $60 \%-70 \%$ of that variation usually can be explained by percent spill (Figures 3.35, 4.2, and 4.3). The rise at the very end of the summer (after July 6) may have been minimally influenced by early, spent, adult shad down migrants (see below). Since spill effectiveness is simply spill efficiency divided by the proportion of total project discharge that goes through the spillway, it is reasonable that the two time histories should be related. In the case of 2005 hydroacoustic data, the seasonal trend in spill effectiveness (see Figure 3.58) is just as variable as spill efficiency (Figure 3.57).

In 2005, the B1 screens were not installed (and so all B1 fish except those passing the sluiceway were "unguided") the B1 sluiceway was a very successful surface-passage route that preserved Project FPE, especially in summer. There was a higher percentage of fish passing through the sluiceways during summer than in spring. Figure 3.59 shows that Project sluiceway efficiency (including both powerhouses and their respective surface-passage routes) was very sporadic in the spring and summer. Values varied by as much as $37 \%$ in spring from one day to the next. Sluiceway efficiency had three high peaks in spring of over $40 \%$ and summer had four peaks over $40 \%$. This is a very important trend, especially in late summer, when Project FPE typically drops off due to low screen guidance of subyearling fish. As noted previously, peaks in Project sluiceway efficiency coincide with peaks in run timing, so the surface passage routes had a very important role in facilitating fish passage especially in summer.

\subsubsection{Diel Trends}

\subsubsection{Passage Efficiency and Effectiveness Estimates}

Total Project FPE and spill efficiency indicated very strong diel patterning, with sustained highs during nighttime hours relative to generally consistent lower estimates during daytime hours in both spring and summer (Figure 3.62 and 3.63). Fish passage at the spillway was clearly higher at night that it was during the day (Figure 3.79). The higher nighttime efficiencies were evident even during six days of constant spill discharge, 24-h per day in spring (Figure 3.64). The diel pattern observed for spill efficiency and Project FPE in 2005 was consistent with observations in 2004 but was stronger and more consistent than in years before 2004. In 2000, Project FPE varied < 4\% over the diel cycle in spring and summer (Ploskey et al. 2002a). Spill efficiency in 2000 indicated an increase during nighttime hours in the summer, and little patterning in the spring. In the drought year of 2001, there was a slight increase in FPE from day to night in both seasons, as was the case with spill efficiency in the spring (Ploskey et al. 2002b). Diel trends in 2002 (Ploskey et al. 2003) most closely resembled those observed in 2004, possibly because of similar water availability and the absence of the PSC in those years.

A very significant finding was that increased spill efficiency and spillway passage was partly due to higher spill rates at night (Figure 3.78) and partly to a natural diel pattern independent of spill. There were six days in summer when spill was held constant for $24 \mathrm{~h}$ per day and in spite of constant spillway discharge, the percent of daily passage by spill doubled (Figure 3.64). This reconfirms a similar finding of higher spill efficiency in the drought year of 2001 when spill was constant throughout spring and summer (Ploskey et al. 2002c).

Spillway Effectiveness had no diel patterning in either season (Figure 3.53), reflecting the direct relationship of hourly passage to percent spill and spill discharge (Figure 3.59). As spill increased at night, spill passage followed the same pattern. The B1 sluiceway entrances and B2CC had higher increased effectiveness during the day (Figure 3.53) despite increased discharge during nighttime hours 
through surface routes (e.g., Figures 3.57 and 3.61). Greater sluiceway passage effectiveness during the day underscores the influence of the diel behavioral component of passage through surface routes.

Project discharge patterns had an overwhelming influence upon diel patterns of fish passage; some of these trends were atypical and would not be observed under conditions of normal or above-average discharge. Operators had a lot of control in 2005 because it was a year of slightly below-average river flow. In 2005, diel discharge patterns resulted in fish passage through turbines being higher during the day than at night because turbine operations were sharply curtailed at night to provide water for spill. Passage through turbines typically would be higher at night than during the day if discharge were constant. Unguided fish pass through turbine units, which typically have higher passage at night (Johnson and Giorgi 1999; Johnson and Carlson 2000). In addition, B1 FPE was higher at night than it was during the day in both seasons but particularly in summer (Figure 3.68), in spite of distinctly higher and sluiceway passage during the daytime (Figures 3.76 and 3.77). The same thing happened with B2 FPE in summer (Figure 3.70) when B2 turbine discharge was curtailed to provide water for nighttime spill, and the B2CC was left as a predominant passage route at night. The efficiency of the B2CC relative to B2 was much higher at night than during the day in summer (Figure 3.68), whereas B2CC efficiency relative to the Project and B2CC fish passage both were higher during the day than they were at night.

Diel trends in project FPE were more influenced by trends in spill passage and spill-passage efficiency, which were higher at night than during the day, than by diel trends in B2CC and B1 sluiceway efficiency, effectiveness, and passage, which were higher during the day than at night. As noted above, diel trends in Project FPE and spill efficiency and passage were similar. The B2CC and the B1 sluiceways were more efficient at passing fish during daylight hours than during night hours in both spring and summer (Figure 3.65). We assumed the influence of daytime passage efficiency through these surface routes would likely be reflected in the diel pattern of Project FPE, but it was not because reduced turbine usage at night raised FPE by shunting water and fish to the spillway and surface routes from turbines. During the early afternoon and into the evening when sluice efficiency is the greatest, it was equal to the amount of passage through the spillway, but at night, differences in spillway and sluiceway efficiency increased sharply to $45 \%$ which produced the highest Project FPE at night.

\subsubsection{Fish Passage}

\subsection{Total Passage}

Crepuscular peaks are typical in juvenile salmonid passage at hydropower projects in the Pacific Northwest, and 2005 was no exception. The general rule of thumb that 'fish follow flow' was observed in 2005 in terms of project-wide passage, as peaks in diel passage coincided with peaks in discharge and generally, as discharge decreased, fish passage also decreased. However, flow alone does not explain diel passage patterns; likely fish behavior such as holding during daytime until visual cues are lost may partly explain increased fish passage at twilight. The dissimilarity between guided and unguided diel passage patterns in 2005 was largely due to spillway passage, which obscured the effects of unguided nighttime passage through turbine units and daytime-dominated sluiceway passage.

\subsection{Powerhouse 1}

True diel patterns of fish passage can only be obtained when operational conditions remain unchanged throughout the diel cycle. This certainly was not the case at B1, where hourly patterns of fish passage reflected operational conditions instead of behavioral phenomena (Figure 3.76 and 3.77). In 2005, to accommodate desired spill patterns, most turbine units at B1 were shut down at night resulting in hourly 
distributions of turbine passage that were more the product of Project operations than fish behavior. Nighttime turbine discharge was about 1.7 times lower in spring and about 1.6 times lower in summer than daytime turbine discharge in order to accommodate high nighttime spill. Unlike 2004 when 67\% and $62 \%$ of fish passed through the turbine in spring and summer respectively (Ploskey et al. 2005), in $200560 \%$ of fish passed through the turbines in spring but only $24 \%$ of fish passed through the turbines in summer. The low summer turbine passage may be caused by the almost 6 hours at night of zero flow through the turbines. In spring, sluiceway passage comprised between $32 \%$ and $47 \%$ of total passage during daylight hours and between $25 \%$ and $57 \%$ during nighttime hours. In the summer, estimated B1 sluiceway passage accounted for between $58 \%$ and $75 \%$, and between $51 \%$ and $100 \%$ of total B1 passage during daylight and nighttime hours, respectively.

\subsection{Spill Passage}

As with turbine passage, patterns of diel passage at the spillway can only be revealed if discharge through the spillway remained constant through all hours of the day. This was not the case in most of the 2005 fish passage seasons when there was higher spillway discharge at night (Figure 3.78). Hourly spillway passage mostly reflects the effect of discharge on diel passage, based upon correlations of efficiency with percent spill and spill rate, so it is not surprising that spillway passage closely followed the pattern of hourly spillway discharge, with peaks occurring at dusk. A similar pattern in estimated spill passage was observed in 2002, when spill discharge was lower during the day than at night (Ploskey et al. 2003). In the low water year of 2001, when spillway discharge remained relatively constant through all hours of the day, increased passage at night was still evident, especially in spring (Ploskey et al. 2002b). The trends observed in 2001 (Ploskey et al. 2002b) support what others have reported regarding higher passage at night via deep-passage spillway routes (e.g., Thorne and Johnson 1993; Ploskey et al. 2001c), and indicate that the hourly passage trends observed at the spillway in 2005 likely have a large behavioral component along with the influence of spill operations. This was clear during the six days of constant spill in summer (Figure 3.64), when there was a strong diel trend under a constant spillway discharge regime.

\subsection{Powerhouse 2}

Discharge through B2 was not constant across the diel cycle, primarily due to decreases of flow through the turbine units at night of about $2 \%$ and $16 \%$ in spring and summer, respectively (Figures 3.79 and 3.80). Much like passage at B1 and the spillway, diel passage at B2 was largely driven by project operations and probably less so by fish behavior. However, a behavioral component is evident with total turbine passage in the summer; passage is shown to increase in the early evening hours just prior to the nighttime decrease in discharge (Figure 3.81), a trend that supports others' observations that nighttime passage at B2 is typically higher than daytime passage, given equal discharge (Ploskey et al. 1998).

Diel passage patterns at the B2CC probably were driven more by fish behavior than by Project operations since discharge through the B2CC varied $<4 \%$ across the diel cycle. Hourly flow through the B2CC remained relatively constant, although the proportion of B2 flow through the B2CC varied by as much as $16 \%$ because flow through B2 turbines was decreased at night to increase spill (see Figure 3.61). In spite of slightly increased flow and flow proportions at night, fish passage at the B2CC was higher during the day than it was at night (Figures 3.79 and 3.80). In spring, estimated B2CC passage remained fairly constant during the day with no high peaks or low valleys and generally declined slightly at night. In the summer, passage hit a peak at 0500 h before slowly declining through the morning hours and then passage started to increase to a maximum passage at $2100 \mathrm{~h}$ before decreasing to a low at $0300 \mathrm{~h}$. The constant daytime passage in the spring, and the early morning and early evening peak in passage in 
summer, suggests a difference in how spring and summer migrants find and pass the B2CC. Perhaps the smaller summer migrants are more susceptible to being entrained in the eddy located above the B2CC entrance, accumulating throughout the night and day and generally delaying their passage until early morning or early evening. The explanation for differences in daily passage patterns at the B2CC between spring and summer migrants is unknown, but the overall pattern of higher passage during daylight hours observed during both seasons in 2005 supports prior observations of fish passage through the old B2 iceand-trash sluiceway (e.g., Magne et al. 1986; Biosonics 1998; Ploskey et al. 2001a).

\subsection{B2 Guidance Efficiency}

There was no obvious diel pattern in B2 FGE estimates in spring and summer 2005, and variability in hourly estimates was high, especially in summer at night. As noted in Ferguson et al. (2004), estimates of FGE are inherently variable due to other factors such as species, rearing history, stock, fish condition, time of day, environmental conditions, and project operations. Spatial and temporal variability results from complex interactions between physical and biological factors such as the arrival of different stocks at a dam throughout the season.

\subsection{Fish Guidance Efficiencies of B2 Turbines}

In 2005, the most important factor affecting FGE at B2 apparently was related to gatewell modifications at Units 15 and 17 because the FGE of those units was higher than that of all other unmodified B2 units in spring and all but one unit (Unit 11) in summer. The FGE of Unit 11 was $5 \%$ and $8 \%$ higher in spring and summer than it was in those respective seasons in 2004 for unknown reasons, but these differences probably are not significant, given the variability in estimates. The adjacent B2CC was operational in both 2004 and 2005, but it was not operational in 2000 when Unit 11 FGE was just 21\% in spring and 7\% in summer, so we thought that B2 sluiceway operation may have affected Unit 11 FGE. However, FGE at Unit 11 was higher in 2001 and 2002 than it was in 2000, even though the sluiceway was closed in all three years (Table 4.3). Estimates for 2001 and 2002 were close to those obtained in 2004 and 2005 in spring and only slightly lower than the summer 2004 and 2005 estimates, so it appears that the low FGE in 2000 may be an outlier. Estimates of Unit 11 FGE in 1996 also were very low like those estimates for 2000, even though there were nearly equal numbers of sluiceway opened and closed treatments in 1996. The very low FGE at Unit 11 in some years appears to be unrelated to the operation of the adjacent sluiceway and caused by something else that has yet to be identified.

In most years sampled before 2005, FGE tended to be higher at interior units of B2 and lower at the end units, but that pattern was only partially observed in 2005 due to high FGE at Units 11 in spring and summer. The FGE at Unit 18 was lower than that at all other units in spring and summer 2005, and this was consistent with most previous estimates.

The trend of higher FGE at intakes between TIEs was more ambiguous in 2005 than in previous years. Modified Intake 15B was the only intake between TIEs, and although FGE there was higher than that of at all other sampled intakes except modified Intake 17A in spring, it is impossible to separate TIE effects from gatewell modification effects. In summer, the FGE at Intake 15B was higher than that estimated for all intakes except Intakes 11A and 17A. Oddly, the FGE of modified Intake 17A located behind a TIE was comparable to that of modified Intake 15B located between two TIEs in both seasons, although we would have expected a 10\% advantage for Intake 15B based upon its location between two TIEs (see Ploskey et al. 2005). 
Table 4.3. Unit 11 FGE Estimates in Years When the B2 Sluiceway Entrances were Closed and Opened. Numbers of opened and closed treatments in 1996 and 1998 were nearly equal.

\begin{tabular}{|llcl|}
\hline Year & $\begin{array}{c}\text { FGE (\%) } \\
\text { Spring }\end{array}$ & $\begin{array}{c}\text { FGE (\%) } \\
\text { Summer }\end{array}$ & B2 Sluiceway Status \\
\hline \hline 1996 & 16 & 10 & Open \& Closed \\
1998 & 46 & 35 & Open \& Closed \\
2000 & 21 & 7 & Closed \\
2001 & 43 & 30 & Closed \\
2002 & 43 & 38 & Closed \\
2004 & 43 & 41 & Opened \\
2005 & 48 & 49 & Opened \\
\hline \hline
\end{tabular}

\subsection{Smolt Approach and Fate at B1 Sluiceway Entrance 3C}

The distance associated with 90\% entrance efficiency for B1 Sluiceway Outlet 3C was about three times higher in the summer than it was in the spring, and reduced turbine flow in summer may be mostly responsible for observed differences. The average distance associated with the $90 \%$ entrance probability for four conditions was about $7 \mathrm{ft}$ in spring and about $21.5 \mathrm{ft}$ in summer. Differences in entrance efficiency were obvious in contour plots (Figures 3.88 and 3.89) and in line plots of mean and maximum entrance probabilities as a function of range upstream of the outlet (Figure 3.90). The frequency of sampling hours with $<20,000$ cfs of powerhouse flow or sluiceway-only flow was much higher in summer than it was in spring (Figure 2.15), and this would have greatly simplified the flow environment for approaching smolts in summer. Forebay circulation, including lateral flow along the face of the powerhouse on either side of the pier between Units 6 and 7, is greatly diminished when two or fewer turbines are operating. In addition, smaller subyearling fish may be less likely to explore widely than yearling fish, which are larger and have greater swimming capability. There were a few days in spring when thousands of yearling fish were observed holding upstream of the outlet; this was not observed during summer sampling when fish approach rate was more consistent and predictable. Days of widespread holding in spring were most pronounced when turbine discharge was low. On those days an ambush by local predators was sometimes the only event that seemed to break up holding of smolts, which were often spooked into the entrance and sometimes away from it. A simulated mechanical predator might be useful for reducing holding at surface passage routes like the B1 sluiceway outlets that lack adequate capture velocities.

The lack of fish capture velocity at the B1 sluiceway entrances is a shortcoming associated with the limited capacity of the existing channel. The three chain gates could only be opened down to Elevation $71.5 \mathrm{ft}$ above MSL or the channel would be flooded at above-average pool elevations. If the channel had greater capacity, gates could be opened down to Elevation $68 \mathrm{ft}$ above MSL, where the existing sill is located. Hydroacoustic data showed that a noticeable percentage of fish moving in an upstream direction over the chain gates at Entrances $1 \mathrm{C}$ and $3 \mathrm{C}$ also were moving downward in the water column. The chain gates at the B1 sluiceway entrances form a sharp crested weir at elevation $71.5 \mathrm{ft}$ above MSL and they pool a 3.5-ft deep volume of water between the top of the weir and the concrete sill at elevation $68 \mathrm{ft}$ above MSL. Flow passing over the weir creates a weak hydraulic roller that fish can use as a flow refuge. 
From a fish-capture standpoint, it would be much better to open gates to elevation $68 \mathrm{ft}$ above MSL and eliminate any flow refuge that smolts might use to avoid entrainment. Low approach velocities may be more of a hindrance for passing yearlings in spring than for passing subyearlings in summer. Ideally, surface outlets from forebays would have capture velocities that extend at least $2 \mathrm{~m}$ upstream of the flow control structure. At the B2CC in 2004, a capture velocity extending well upstream of the sill was instrumental in taking smolts that otherwise might have initially avoided that outlet. Providing surface flow outlets with an entrainment zone extending upstream of structure could reduce entrance rejection, decrease forebay residence time and risk of predation, and increase passage of schools of smolts (Ploskey et al., In Press). Flow into the B1 sluiceway entrances was less than one-tenth of flow into the B2CC. Flow was higher at Entrance 1C near the downstream end of the channel than it was into Entrance 3C or 6C, and hydroacoustic data indicated that Entrance 1C passed the most fish and the highest densities of fish each season.

Observations at B1, the B2CC, and The Dalles sluiceway outlets suggest that the initial process for capture of fish by entraining flows is the mechanism that disrupts schools and results in predominance of single-target detections at turbines and spill bays. Many of the tracking events were of schools of fish, whereas single fish usually are detected at turbine intakes and very near spill-gate openings. Schools of juvenile salmonids in the hydraulic zone of the sluiceway indicate that the sluiceway flow net is not disrupting natural migration behavior. Most fish approaching the B2CC entrance were oriented upstream into flow but were swept downstream because they were swimming slower than the surrounding flow. Most did not appear to struggle against the flow until they were in the entrainment zone and then it was too late. At The Dalles Dam, fish were able to swim up to the upstream edge of the sill and still swim away, although most approaching fish that ventured over the sill were entrained. A school sometimes would approach the sill but only the most downstream individuals in the school would be entrained. At $\mathrm{B} 1$, fish could move above the controlling gate and most could still escape. If fish have uncertainty about passing and the ability to avoid entrainment, school proximity to entraining flows likely would pick off the most downstream individuals first. The rate of increase in flow (acceleration) probably determines the abruptness of the transition to the entrainment zone and may determine whether fish are indecisive about entering. Providing surface passage routes without abrupt transitions to the entrainment zone could decrease forebay holding time and risk of predation.

Biologists must understand local flow, smolt, and predator dynamics on a diel basis to be able to maximize surface-collector performance for any location in a forebay. Forebay location of surface passage routes may be the primary concern to assure that smolts commonly move nearby, but it should not be the only concern. Based upon the DIDSON fish approach and entrance study in 2005, we recommend eliminating chain gates and the flow refuge they create.

We also recommend installing a vortex suppression shelf upstream of the sill at sill elevation (68 $\mathrm{ft}$ above MSL) to prevent vortices from capturing smolts to the turbine that otherwise would pass into the outlet (See Appendix $\mathrm{H}$ for movie clips of smolt movement, predators, and vortices). This horizontal shelf could be designed to hang from the top of the uppermost trash rack and therefore could be moved among intakes if desired. An alternative to vortex suppression devices would be to prioritize turbine operations so that units with open sluiceway entrances have lowest operational priority and do not run most of the time. However, the efficiency and effectiveness of a sluiceway entrance should be evaluated with associated turbines on and off to determine which approach is best. Attraction flow by a unit and sluiceway may be more important than eliminating vortices, and testing is the only way to know for 
certain. We also recommend on-and-off testing of constant lighting at sluiceway entrances at night because smolt schools held up more at night than they did during the day, and there was reduced predator activity and success during the day. Predators often spooked smolts into Sluiceway Outlet 3C, which made us wonder whether a mechanical scare-fish rigged to drag back and forth at specific times of day might facilitate entry into a sluiceway outlet. Electrifying the sill area periodically might be a useful way to eliminate predators holding over a sill and upstream of chain gates. Shocked predators would be swept downstream into the sluiceway and eliminated from the forebay. Of course eliminating chain gates or just the impounded water volume upstream of chain gates would eliminate the flow refuge that predators occasionally use. 


\subsection{Recommendations}

1. We recommend continued study and development of surface routes of passage to increase Project FPE. Probably the most important result of our 2005 hydroacoustic sampling and estimation is the efficacy of the surface passage routes at the two powerhouses to pass a great many fish in remarkably little water (Figures 3.42), especially during daylight (Figures 3.76, $3.77,3.79,3.80$ ). Surface routes passed one-fifth (Project Sluiceway Efficiency $=20.2 \%$ ) of the total passage in spring and about a quarter (Project Sluiceway Efficiency $=26.2 \%$ ) of the total run-at-large in summer in only about $5 \%$ of the total Project discharge. Development of surface passage at mainstem dams will only become more important with greater competition among uses of always limited and sometimes very scarce water resources.

2. In light of the very high passage estimates for the B1 sluiceway entrances and the very high effectiveness of the B1 sluiceway, engineers should explore ways to increase the capacity of the B1 sluiceway so that more entrances could be opened or the same number of entrances could be opened more. Toward that end and to further improve understanding of surface attraction and passage, further manipulation and sampling of B1 sluiceway opening configurations may be helpful. The specific entrances and their relation to the wing wall, the powerhouse ends, and each other may be important to maximize sluiceway passage.

3. If the B1 sluiceway channel capacity can be increased, we also recommend not using chain gates to control flow. The chain gates created a flow refuge immediately upstream of the controlling weir into which smolts could escape entrainment. A broad crested weir would eliminate the flow refuge immediately upstream of the chain gate, which, in 2005, facilitated smolt escape from higher velocity flow over the gate and provided a convenient refuge for predators. Eliminating chain gates also would increase approach velocities so that smolts are captured upstream of the sill controlling flow. In assessing B1 sluiceway discharge needs, we recommend following guidelines provided by Ferguson et al. (1998), who recommended 5\% to $10 \%$ of total powerhouse discharge. The B1 sluiceway passes far less that $5 \%$ of powerhouse discharge when the powerhouse is fully loaded.

4. Further DIDSON and other hydroacoustic studies should be conducted to help relate hydraulic patterns and fish entry into surface-passage routes. While it is true that success or failure of surface passage routes depends upon location within a forebay, it is also true that well positioned surface passage routes can be rejected by fish for unknown reasons. Those reasons must be identified and understood before successful transfer of surface passage designs can be routinely accomplished.

5. We also recommend installing a vortex suppression shelf upstream of the sill and at the sill elevation (68 ft above MSL) to prevent vortices from capturing smolts to the turbine that otherwise would pass into the entrance (See Appendix H for movie clips of smolt movement, predators, and vortices). This horizontal shelf could be designed to hang from the top of the uppermost trash rack, and therefore could be moved among intakes if desired. An alternative to vortex suppression devices would be to prioritize turbine operations so that units with open sluiceway entrances have the lowest operational priority and do not run most of the time. This would eliminate vortex formation upstream of sluiceway entrances when those units were off. However, the efficiency and effectiveness of a sluiceway entrance should be evaluated with associated turbines on and off to determine which approach is best. Attraction 
flow by a unit and sluiceway may be more important than eliminating vortices, and testing is the only way to know for certain.

6. We recommend on-and-off testing of constant lighting at sluiceway entrances because there was a definite tendency for schools of smolts to pass into the sluiceway during the day rather than at night, and there was reduced predator activity and success during the day.

7. We recommend additional study of FGE, particularly for the end units at Powerhouse 2. The B2CC has changed passage conditions and proportions at B2, perhaps for the long term. Unit 11 FGE was higher in 2004 and 2005 than in some prior years, perhaps improved by operation of the adjacent B2CC, but Unit 18 FGE remained consistently low. Total discharge and estimated fish passage, however, is highest at the ends of the powerhouse and lower in the interior because Units 11 and 18 are priority units (last off and first on).

8. Research should shift from assessing effects of spill percent and discharge to assessing effective spill patterns. The 2005 study provided a fourth year of data indicating that most of the benefits of spill occur when spill is $<45 \%$ of Project flow and that spilling $>45 \%$ of Project flow provides greatly diminished returns (Figure 3.27 and 3.28) per unit of spill. In 2005, this result remained strongly in evidence even though spillway passage estimates were adjusted to compensate for potential loss of detectability associated with increased spill discharge through individual bays. Spill is most efficient at night in part because smolts pass spill gates more readily when it is dark (Figure 3.64), regardless of discharge, so it is efficient to rely on spill more at night than during the daytime. In addition, surface passage routes are more efficient during the day than they are at night, so a removable spillway weir should be tested as a way to cost effectively increase spill passage during the daytime without relying on spill volume.

9. As in 2004, we recommend designing spill studies with randomized replication of experimental units to identify optimum spill and sluiceway operations for maximizing juvenile fish passage by time of day.

10. When spill data from 2000, 2001, 2002, and 2004 are re-analyzed to recalculate effectiveness measures and reassess spill effects based upon revised spill discharge estimates made available in 2005, we recommend adjusting hourly passage estimates to compensate for effects of spill-bay discharge rate on hydroacoustic detectability. 


\subsection{References}

Belcher, E.O., H.Q. Dinh, D.C. Lynn, T.J. Laughlin. 1999. "Beam forming and imaging with acoustic lenses in small, high-frequency sonars.” Proceeding of Oceans '99 Conference, September 13-16, .

BioSonics, Incorporated. 1998. Hydroacoustic Evaluation and Studies at Bonneville Dam, Spring/Summer 1997. Contract Report to the U.S. Army Corps of Engineers Portland District, Portland, Oregon.

Evans, S. D., J. M. Plumb, A. C. Braatz, K. S. Gates, N. S. Adams, and D. W. Rondorf. 2001a. Passage Behavior of Radio-Tagged Yearling Chinook Salmon and Steelhead at Bonneville Dam Associated with the Surface Bypass Program, 2000. Final report to the U.S. Army Corps of Engineers, Portland District.

Evans, S.D., N.S. Adams, and D.W. Rondorf. 2001b. Passage Behavior of Radio-Tagged Subyearling Chinook Salmon at Bonneville Dam Associated with the Surface Bypass Program, 2000. Final report to the U.S. Army Corps of Engineers, Portland District.

Evans, S.D, C.D. Smith, N.S. Adams, and D.W. Rondorf. 2001c. Passage Behavior of RadioTagged Yearling Chinook Salmon at Bonneville Dam, 2001. Final report to the U.S. Army Corps of Engineers, Portland District.

Evans, S.D, C.D. Smith, N.S. Adams, and D.W. Rondorf. 2001d. Passage Behavior of RadioTagged Subyearling Chinook Salmon at Bonneville Dam, 2001. Final report to the U.S. Army Corps of Engineers, Portland District.

Evans, S.D., L.S. Wright, C.D. Smith, R.E. Wardell, N.S. Adams, and D.W. Rondorf. 2003a. Passage Behavior of Radio-Tagged Yearling Chinook and Steelhead at Bonneville Dam, 2002. Final report to the U.S. Army Corps of Engineers, Portland District.

Evans, S.D., L.S. Wright, R.E. Wardell, N.S. Adams, and D.W. Rondorf. 2003b. Passage Behavior of Radio-Tagged Subyearling Chinook at Bonneville Dam, 2002. Final report to the U.S. Army Corps of Engineers, Portland District.

Everest, F.H. and D.W. Chapman. 1972. "Habitat selection and spatial interaction by juvenile chinook salmon and steelhead trout in two Idaho streams.” J. Fish. Res. Board. Can. 29:91100.

Ferguson, J.W., G.M. Matthews, R.L. McComas, R.F. Absolon, D.A. Brege, M.H. Gessel, and L.G. Gilbreath. 2004. Passage of Adult and Juvenile Salmon through Federal Columbia River Power System Dams. NOAA Technical Memorandum, Fish Ecology Division, Northwest Fisheries Science Center, National Marine Fisheries Service.

Ferguson, J.W., T.P. Poe, and T.J. Carlson. 1998. "Surface-Oriented Bypass Systems for Juvenile Salmonids on the Columbia River, USA.” Chapter 22 in Jungworth, E.M., Schmutz, S., and Weiss, S. (Eds.) Fish Migration and Fish Bypasses, pp. 281-299. Blackwell Publishing Fishing News Books, Blackwell Science Ltd Publisher, Oxford, UK. 
Gessel, M.H., B.H. Monk, and J.G. Williams. 1988. Evaluation of the Juvenile Fish Collection and Bypass Systems at Bonneville Dam 1987. Annual Report by the National Oceanic and Atmospheric Administration, National Marine Fisheries Service, Coastal Zone and Estuarine Studies Division to the U.S. Army Engineers Portland District, Portland, Oregon.

Gessel, M.H., J.G. Williams, D.A. Brege, and R.F. Krcma. 1991. “Juvenile Salmonid Guidance at the Bonneville Dam Second Powerhouse, Columbia River, 1983-1989.” North American Journal of Fisheries Management 11:400-412.

Hansel, H.C., R.S. Shively, J.E. Hensleigh, B.D. Liedtke, R.E. Wardell, R.H. Wertheimer, and T.P. Poe. 1999. Movement, Distribution, and Behavior of Radio-Tagged Juvenile Chinook Salmon and Steelhead in the Forebay of Bonneville Dam, 1998. Prepared for the U.S. Army Corps of Engineers, Portland District, by the U.S. Geological Survey, Biological Resources Division, Cook, Washington.

Hawkes, L.A., R.D. Martinson, R.F. Absolon, and S. Killins. 1991. Monitoring of Downstream Salmon and Steelhead at Federal Hydroelectric Facilities. Annual Report 1990 by the National Oceanic and Atmospheric Administration, National Marine Fisheries Service, ETSD, to the U.S. Department of Energy, Bonneville Power Administration, Portland, Oregon.

Hensleigh, J.E., R.S. Shively, H.C. Hansel, J.M. Hardiman, G.S. Holmberg, B.D. Liedtke, T.L. Martinelli, R.E. Wardell, R.H. Wertheimer, and T.P. Poe. 1999. Movement, Distribution, and Behavior of Radio-Tagged Juvenile Chinook Salmon and Steelhead in John Day, The Dalles, and Bonneville Dam Forebays, 1997. Final report to the U.S. Army Corps of Engineers, Portland District.

Holmberg, G.S., R.S. Shively, H.C. Hansel, T.L. Martinelli, M.B. Sheer, J.M. Hardiman, B.D. Liedtke, L.S. Blythe, and T.P. Poe. 1996. Movement, Distribution, and Behavior of RadioTagged Juvenile Chinook Salmon in John Day, The Dalles, and Bonneville Dam Forebays, 1996. Final report to the U.S. Army Corps of Engineers, Portland District.

Johnson, G.E. and A.E. Giorgi. 1999. Development of Surface Flow Bypasses at Bonneville Dam: A Synthesis of Data from 1995 to 1998 and a Draft M\&E Plan for 2000. Draft final report submitted October 8, 1999 to Portland District, U.S. Army Corps of Engineers, Portland, Oregon.

Johnson, G.E. and T.J. Carlson. 2000. Monitoring and Evaluation of the Prototype Surface Collector at Bonneville First Powerhouse in 2000: Synthesis of Information on PSC Performance. U.S. Army Corps of Engineers Draft Report prepared by BioAnalysts, Inc and Battelle.

Johnson, G., J. Hedgepeth, J. Skalski, and A. Giorgi. 2004. “A Markov chain analysis to determine fish entrainment zones.” Fisheries Research 69: 349-358.

Johnson GE, ME Hanks, F Khan, CB Cook, J Hedgepeth, RP Mueller, CL Rakowski, MC Richmond, SL Sargeant, JA Serkowski, and JR Skalski. 2005. Hydroacoustic Evaluation of Juvenile Salmonid Passage at The Dalles Dam in 200 . PNNL-15180, Pacific Northwest National Laboratory, Richland, Washington.

Karlin, S. 1968. A First Course in Stochastic Processes. Academic Press, New York. 
Kemeny, J.G. and J.L. Snell, 1960. Finite Markov Chains. D. Van Nostrand Company, Inc., Princeton, New Jersey.

Krcma, R.F., D. DeHart, M. Gessel, C. Long, and C. W. Sims. 1982. Evaluation of Submersible Traveling Screens, Passage of Juvenile Salmonids through the Ice-Trash Sluiceway, and Cycling of Gatewell-Orifice Operations at the Bonneville First Powerhouse, 1981. Final Report by the National Oceanic and Atmospheric Administration, National Marine Fisheries Service, Coastal Zone and Estuarine Studies Div. to the U.S. Army Engineer District, Portland, Oregon.

Love, R.H. 1977. "Target Strength of an Individual Fish at any Aspect.” Journal of the Acoustical Society of America, 62(6):1397-1403.

Magne, R.A., D.J. Rawding, and W.T. Nagy. 1986. Hydroacoustic Monitoring at the Bonneville Dam Second Powerhouse during 1986 Fish Guiding Efficiency Tests. Fishery Field Unit, U.S. Army Engineer District, Portland, Oregon.

Magne, R.A. 1987. Hydroacoustic Monitoring at the Bonneville Dam Project in 1987. Fishery Field Unit, U.S. Army Engineer District, Portland, Oregon.

Magne, R.A., R.J. Stansell, and W.T. Nagy. 1989. A Summary of Hydroacoustic Monitoring at the Bonneville Dam Second Powerhouse in 1988. Fishery Field Unit, U.S. Army Engineer District, Portland, Oregon.

Muir, W.D., A.E. Giorgi, W.S. Zaugg, and B.R. Beckman. 1989. An Assessment of the Relationship between Smolt Development and Fish Guidance Efficiency at Bonneville Dam. Annual Report by the National Marine Fisheries Service, Coastal Zone and Estuarine Studies Division, Northwest Fisheries Center, Seattle, Washington.

NMFS (National Marine Fisheries Service). 2000. Biological Opinion. Reinitiation of Consultation of the Federal Columbia River Power System, including the Juvenile Fish Transportation Program and 19 Bureau of Reclamation Projects in Columbia Basin.

Ploskey, G.R., P.N. Johnson, W.T. Nagy, M.G. Burczinski, and L.R. Lawrence. 1998. Hydroacoustic Evaluations of Smolt Passage at Bonneville Dam Including Surface Collection Simulations. USAE Waterway Experiment Station Technical Report EL-98-4 prepared for the U.S. Army Engineer District, Portland, Oregon.

Ploskey, G.R. and T.J. Carlson. 1999. Comparison of Hydroacoustic and Net Estimates of Fish Guidance Efficiency of an Extended Submersible Bar Screen at John Day Dam. North American Journal of Fisheries Management 19:1066-1079.

Ploskey, G.R., W.T. Nagy, L.R. Lawrence, D.S. Patterson, C.R. Schilt, P.N. Johnson, and J.R. Skalski. 2001a. Hydroacoustic Evaluation of Juvenile Salmonid Passage through Experimental Routes at Bonneville Dam in 1998. Technical Report ERDC/EL TR-01-2, U.S. Army Engineer Research and Development Center, Vicksburg, MS. 
Ploskey, G.R., W.T. Nagy, L.R. Lawrence, M.E. Hanks, C.R. Schilt, P.N. Johnson, G.E. Johnson, D.S. Patterson, and J.R. Skalski. 2001b. Hydroacoustic Evaluation of Juvenile Salmon Passage at The Dalles Dam: 1999. Technical Report ERDC/EL TR-01-11, U.S. Army Engineer Research and Development Center, Vicksburg, MS.

Ploskey, G., T. Poe, A. Giorgi, and G. Johnson. 2001c. Synthesis of Radio Telemetry, Hydroacoustic, and Survival Studies of Juvenile Salmon at The Dalles Dam (1982-2000). Final report Contract Number DACW57-00-D-0009, Task Order Case No. 3. Prepared for the U.S. Army Corps of Engineers, Portland, OR by Battelle Pacific Northwest Division and BioAnalysts, Inc.

Ploskey, G.R., C.R. Schilt, M.E. Hanks, J.R. Skalski, W.T. Nagy, P.N. Johnson, D.S. Patterson, J. Kim, and L. Lawrence. 2002a Hydroacoustic Evaluation of a Prototype Surface Collector and In-Turbine Screens at Bonneville Dam First Powerhouse in 2000. Technical Report ERDC/ELTR-02-15 of the U.S. Army Research and Development Center, Waterways Experiment Station, Vicksburg, Mississippi.

Ploskey, G.R., C.R. Schilt, M.E. Hanks, P.N. Johnson, J.R. Skalski, W.T. Nagy, P.N. Johnson, D.S. Patterson, J. Kim, and L. Lawrence. 2002b. Hydroacoustic Evaluation of Fish Passage through Bonneville Dam in 2000. Technical Report ERDC/ELTR-02-8 of the U.S. Army Engineer Research and Development Center, Waterways Experiment Station, Vicksburg, Mississippi.

Ploskey, G.R., C.R. Schilt, M.E. Hanks, P. N. Johnson, J. Kim, J.R. Skalski, D.S. Patterson, W.T. Nagy, and L.R. Lawrence. 2002c Hydroacoustic Evaluation of Fish-Passage Efficiency at Bonneville Dam in 2001. Final Report PNNL-14047. Pacific Northwest National Laboratory, Richland, WA.

Ploskey, G. R., C. R. Schilt, J. Kim, C.W. Escher, and J. R. Skalski. 2003. Hydroacoustic Evaluation of Fish Passage through Bonneville Dam in 2002. Technical Report by the Pacific Northwest National Laboratory, Richland, WA, for the U.S. Army Corps of Engineers, Portland District, Portland, OR.

Ploskey, G.R., M.A. Weiland, C.R. Schilt, J. Kim, P.N. Johnson, M.E. Hanks, D.S. Patterson, J.R. Skalski, and J.B. Hedgepeth. 2005. Hydroacoustic Evaluation of Fish Passage through Bonneville Dam in 2004. Technical Report PNNL-15249 by the Pacific Northwest National Laboratory, Richland, WA for the U.S. Army Corps of Engineers, Portland District, Portland, OR.

Ploskey, G.R., G.E. Johnson, M.A. Weiland, F. Khan, R.P. Mueller, J.A. Serkowski, C.L. Rakowski, J.B. Hedgepeth, J.R. Skalski, B.D. Ebberts, and B.A. Klatte. 2006. “Acoustic Camera Evaluation of Juvenile Salmonid Approach and Fate at Surface Flow Outlets of Two Hydropower Dams.” HydroVision 2006 Conference, Portland, Oregon. HCI Publications, Kansas City, Missouri.

Rakowski C.L., J.A. Serkowski, and M.C. Richmond. 2001a. Numerical Simulations of the Bonneville Powerhouse 2 Forebay Supporting Fish Guidance Efficiency Improvement Studies. Draft technical report, Pacific Northwest National Laboratory, P.O. Box 999, Richland, WA 99352 
Rakowski, C.L., J.A. Serkowski, M.C. Richmond, and K.P. Recknagle. 2001b. Development and Application of a 3D CFD Model for the Bonneville Project Powerhouse 1 and Powerhouse 2. PNNL-13593, Pacific Northwest National Laboratory, Richland, WA.

Stansell R.J., R.A. Magne, W.T. Nagy, and L.M. Beck. 1990. Hydroacoustic Monitoring of Downstream Migrant Juvenile Salmonids at Bonneville Dam, 1989. Fishery Field Unit, U.S. Army Engineer District, Portland, Oregon.

Taylor, H. and S. Karlin. 1998. An Introduction to Stochastic Modeling. Academic Press, San Diego, California.

Thorne, R.E. and E.S. Kuehl. 1989. Evaluation of Hydroacoustics Techniques for Assessment of Juvenile Fish Passage at Bonneville Powerhouse I. Final Report by BioSonics Inc., Seattle, WA, for the U.S. Army Engineer District, Portland, Oregon.

Thorne, R.E. and G.E. Johnson. 1993. “A Review of Hydroacoustic Studies for Estimation of Salmonid Downriver Migration Past Hydroelectric Facilities on the Columbia and Snake Rivers in the 1980s.” Reviews in Fisheries Science 1 (1) 27-56.

Uremovich, B.L., S.P. Cramer, C.F. Willis, and C.O. Junge. 1980. Passage of Juvenile Salmonids through the Ice-Trash Sluiceway and Squawfish Predation at Bonneville Dam, 1980. Oregon Department of Fish and Wildlife, Annual progress report prepared for the U.S. Army Engineer District, Portland, Oregon.

Willis, C.F. and B.L. Uremovich. 1981. Evaluation of the Ice and Trash Sluiceway at Bonneville Dam as a Bypass System for Juvenile Salmonids, 1981. Oregon Department of Fish and Wildlife Annual progress report prepared for the U.S. Army Engineer District, Portland, Oregon.

Wood, L.A., R.D. Martinson, R.J. Graves, D.R. Carroll, and S.D. Killins. 1994. Monitoring of Downstream Salmon and Steelhead at Federal Hydroelectric Facilities. Annual Report 1993 by the National Oceanic and Atmospheric Administration, National Marine Fisheries Service, ETSD to the U.S. Department of Energy, Bonneville Power Administration, Portland, Oregon. 
Hydroacoustic Evaluation of Fish Passage through Bonneville Dam in 2005 


\section{Appendix A}

\section{Transducer Calibrations and Receiver Gains}


Hydroacoustic Evaluation of Fish Passage through Bonneville Dam in 2005 


\section{Appendix A}

\section{Transducer Calibrations and Receiver Gains}

Appendix A.1. Calibration data and calculated receiver gains for single-beam and split-beam transducers deployed at Powerhouse 1 to provide equal detectability for on-axis targets ranging in acoustic size from -56 to $-36 \mathrm{~dB}$. Results for split-beam transducers are presented for the $x$ phase, $y$ phase, and the mean of $x$ and $y$ phases.

\begin{tabular}{|c|c|c|c|c|c|c|c|c|}
\hline $\begin{array}{l}\text { Echo- } \\
\text { sounder } \\
\text { Letter and } \\
\text { Channel } \\
\text { Number }\end{array}$ & $\begin{array}{l}\text { Trans- } \\
\text { ducer } \\
\text { Number } \\
\text { and Phase } \\
\text { (if split } \\
\text { beams) }\end{array}$ & $\begin{array}{c}\text { Difference in } \\
\text { Cable } \\
\text { Length } \\
\text { Between } \\
\text { Calibrated } \\
\text { Cable and } \\
\text { Installed } \\
\text { Cable (ft) }\end{array}$ & $\begin{array}{l}\text { Receiver } \\
\text { Gain } \\
\text { Adjusted for } \\
\text { Difference in } \\
\text { Cable } \\
\text { Length (dB) }\end{array}$ & $\begin{array}{l}\text { Source Level } \\
\text { Adjusted for } \\
\text { Difference in } \\
\text { Cable } \\
\text { Length (dB) }\end{array}$ & $\begin{array}{c}\text { Receiver } \\
\text { Sensitivity } \\
\text { Adjusted for } \\
\text { Difference in } \\
\text { Cable } \\
\text { Length (dB) }\end{array}$ & $\begin{array}{c}\text { Target } \\
\text { Strength } \\
\text { of } \\
\text { Smallest } \\
\text { On-axis } \\
\text { Target } \\
\text { (dB) }\end{array}$ & $\begin{array}{l}\text { Voltage of } \\
\text { Smallest } \\
\text { On-axis } \\
\text { Target } \\
\text { (dB) }\end{array}$ & $\begin{array}{c}\text { Voltage of } \\
\text { Smallest } \\
\text { On-axis } \\
\text { Target at } \\
20 \mathrm{~dB} \text { per } \\
\text { Volt (V) }\end{array}$ \\
\hline C-1 & 1 & 0 & 4.96 & 213.91 & -112.87 & -56 & 50 & 2.50 \\
\hline C-2 & 2 & 0 & 5.23 & 213.82 & -113.05 & -56 & 50 & 2.50 \\
\hline C-3 & 3 & 0 & 7.13 & 212.92 & -114.05 & -56 & 50 & 2.50 \\
\hline C-4 & 4 & 0 & 5.09 & 213.88 & -112.97 & -56 & 50 & 2.50 \\
\hline C-5 & 5 & 0 & 4.30 & 214.21 & -112.51 & -56 & 50 & 2.50 \\
\hline C-6 & 6 & 0 & 6.06 & 213.53 & -113.59 & -56 & 50 & 2.50 \\
\hline C-7 & 7 & 0 & 4.47 & 214.18 & -112.65 & -56 & 50 & 2.50 \\
\hline D-1 & 9 & 0 & 5.37 & 213.72 & -113.09 & -56 & 50 & 2.50 \\
\hline D-2 & 17 & 0 & 4.52 & 214.21 & -112.73 & -56 & 50 & 2.50 \\
\hline D-3 & 11 & 0 & 5.70 & 213.67 & -113.37 & -56 & 50 & 2.50 \\
\hline D-4 & 10 & 0 & 5.05 & 213.88 & -112.93 & -56 & 50 & 2.50 \\
\hline D-5 & 12 & 0 & 5.88 & 213.57 & -113.45 & -56 & 50 & 2.50 \\
\hline D-6 & 16 & 0 & 4.11 & 214.42 & -112.53 & -56 & 50 & 2.50 \\
\hline D-7 & 14 & 0 & 4.61 & 214.04 & -112.65 & -56 & 50 & 2.50 \\
\hline D-8 & 15 & 0 & 4.37 & 214.32 & -112.69 & -56 & 50 & 2.50 \\
\hline R-1 & $53(x)$ & 0 & 5.45 & 216.38 & -105.83 & -56 & 60 & 3.00 \\
\hline R-1 & $53(y)$ & 0 & 5.47 & 216.38 & -105.85 & -56 & 60 & 3.00 \\
\hline R-1 & 53 & 0 & 5.46 & 216.38 & -105.84 & -56 & 60 & 3.00 \\
\hline $\mathrm{R}-2$ & $51(\mathrm{x})$ & 0 & 5.18 & 216.81 & -105.99 & -56 & 60 & 3.00 \\
\hline $\mathrm{R}-2$ & $51(\mathrm{y})$ & 0 & 5.26 & 216.79 & -106.05 & -56 & 60 & 3.00 \\
\hline $\mathrm{R}-2$ & 51 & 0 & 5.22 & 216.80 & -106.02 & -56 & 60 & 3.00 \\
\hline
\end{tabular}


Appendix A.2. Calibration data and calculated receiver gains for split-beam transducers deployed at Powerhouse 1 Sluice way to provide equal detectability for on-axis targets ranging in acoustic size from -56 to $-36 \mathrm{~dB}$. Results for split-beam transducers are presented for the $x$ phase, $y$ phase, and the mean of $x$ and $y$ phases.

\begin{tabular}{|c|c|c|c|c|c|c|c|c|}
\hline $\begin{array}{l}\text { Echo- } \\
\text { sounder } \\
\text { Letter and } \\
\text { Channel } \\
\text { Number }\end{array}$ & $\begin{array}{l}\text { Trans- } \\
\text { ducer } \\
\text { Number } \\
\text { and Phase } \\
\text { (if split } \\
\text { beams) }\end{array}$ & $\begin{array}{c}\text { Difference in } \\
\text { Cable } \\
\text { Length } \\
\text { Between } \\
\text { Calibrated } \\
\text { Cable and } \\
\text { Installed } \\
\text { Cable (ft) }\end{array}$ & $\begin{array}{l}\text { Receiver } \\
\text { Gain } \\
\text { Adjusted for } \\
\text { Difference in } \\
\text { Cable } \\
\text { Length (dB) }\end{array}$ & $\begin{array}{c}\text { Source Level } \\
\text { Adjusted for } \\
\text { Difference in } \\
\text { Cable } \\
\text { Length (dB) }\end{array}$ & $\begin{array}{c}\text { Receiver } \\
\text { Sensitivity } \\
\text { Adjusted for } \\
\text { Difference in } \\
\text { Cable } \\
\text { Length (dB) }\end{array}$ & $\begin{array}{c}\text { Target } \\
\text { Strength } \\
\text { of } \\
\text { Smallest } \\
\text { On-axis } \\
\text { Target } \\
\text { (dB) }\end{array}$ & $\begin{array}{l}\text { Voltage of } \\
\text { Smallest } \\
\text { On-axis } \\
\text { Target } \\
\text { (dB) }\end{array}$ & $\begin{array}{c}\text { Voltage of } \\
\text { Smallest } \\
\text { On-axis } \\
\text { Target at } \\
20 \mathrm{~dB} \text { per } \\
\text { Volt (V) }\end{array}$ \\
\hline X-10 & $414(\mathrm{x})$ & 0 & 5.05 & 216.14 & -105.19 & -56 & 60 & 3.00 \\
\hline X-10 & $414(y)$ & 0 & 5.10 & 216.11 & -105.21 & -56 & 60 & 3.00 \\
\hline$X-10$ & 414 & 0 & 5.08 & 216.13 & -105.20 & -56 & 60 & 3.00 \\
\hline$X-11$ & $415(x)$ & 0 & 6.02 & 215.83 & -105.85 & -56 & 60 & 3.00 \\
\hline$X-11$ & $415(\mathrm{y})$ & 0 & 5.99 & 215.84 & -105.83 & -56 & 60 & 3.00 \\
\hline$X-11$ & 415 & 0 & 6.00 & 215.84 & -105.84 & -56 & 60 & 3.00 \\
\hline X-12 & $416(x)$ & 0 & 5.55 & 216.00 & -105.55 & -56 & 60 & 3.00 \\
\hline X-12 & $416(y)$ & 0 & 5.56 & 216.01 & -105.57 & -56 & 60 & 3.00 \\
\hline$X-12$ & 416 & 0 & 5.56 & 216.01 & -105.56 & -56 & 60 & 3.00 \\
\hline$X-13$ & $417(x)$ & 0 & 5.64 & 216.01 & -105.65 & -56 & 60 & 3.00 \\
\hline$X-13$ & $417(y)$ & 0 & 5.66 & 216.01 & -105.67 & -56 & 60 & 3.00 \\
\hline$X-13$ & 417 & 0 & 5.65 & 216.01 & -105.66 & -56 & 60 & 3.00 \\
\hline$X-20$ & $410(\mathrm{x})$ & 0 & 4.33 & 216.66 & -104.99 & -56 & 60 & 3.00 \\
\hline$X-20$ & $410(y)$ & 0 & 4.37 & 216.66 & -105.03 & -56 & 60 & 3.00 \\
\hline$X-20$ & 410 & 0 & 4.35 & 216.66 & -105.01 & -56 & 60 & 3.00 \\
\hline$X-21$ & $402(x)$ & 0 & 4.56 & 216.57 & -105.13 & -56 & 60 & 3.00 \\
\hline$X-21$ & $402(y)$ & 0 & 4.62 & 216.57 & -105.19 & -56 & 60 & 3.00 \\
\hline $\mathrm{X}-21$ & 402 & 0 & 4.59 & 216.57 & -105.16 & -56 & 60 & 3.00 \\
\hline
\end{tabular}


Appendix A.3. Calibration data and calculated receiver gains for single-beam and split-beam transducers deployed at the spillway to provide equal detectability for on-axis targets ranging in acoustic size from -56 to $-36 \mathrm{~dB}$. Results for split-beam transducers are presented for the $x$ phase, $y$ phase, and the mean of $x$ and $y$ phases.

\begin{tabular}{|c|c|c|c|c|c|c|c|c|}
\hline $\begin{array}{l}\text { Echo- } \\
\text { sounder } \\
\text { Letter and } \\
\text { Channel } \\
\text { Number }\end{array}$ & $\begin{array}{l}\text { Trans- } \\
\text { ducer } \\
\text { Number } \\
\text { and Phase } \\
\text { (if split } \\
\text { beams) }\end{array}$ & $\begin{array}{c}\text { Difference in } \\
\text { Cable } \\
\text { Length } \\
\text { Between } \\
\text { Calibrated } \\
\text { Cable and } \\
\text { Installed } \\
\text { Cable (ft) }\end{array}$ & $\begin{array}{l}\text { Receiver } \\
\text { Gain } \\
\text { Adjusted for } \\
\text { Difference in } \\
\text { Cable } \\
\text { Length (dB) }\end{array}$ & $\begin{array}{l}\text { Source Level } \\
\text { Adjusted for } \\
\text { Difference in } \\
\text { Cable } \\
\text { Length (dB) }\end{array}$ & $\begin{array}{c}\text { Receiver } \\
\text { Sensitivity } \\
\text { Adjusted for } \\
\text { Difference in } \\
\text { Cable } \\
\text { Length (dB) }\end{array}$ & $\begin{array}{c}\text { Target } \\
\text { Strength } \\
\text { of } \\
\text { Smallest } \\
\text { On-axis } \\
\text { Target } \\
\text { (dB) }\end{array}$ & $\begin{array}{l}\text { Voltage of } \\
\text { Smallest } \\
\text { On-axis } \\
\text { Target } \\
\text { (dB) }\end{array}$ & $\begin{array}{c}\text { Voltage of } \\
\text { Smallest } \\
\text { On-axis } \\
\text { Target at } \\
20 \mathrm{~dB} \text { per } \\
\text { Volt (V) }\end{array}$ \\
\hline M-0 & $404(\mathrm{x})$ & 0 & 5.47 & 213.58 & -113.05 & $\begin{array}{l}-56 \\
\end{array}$ & 50 & 2.50 \\
\hline M-0 & $404(\mathrm{y})$ & 0 & 5.41 & 213.60 & -113.01 & -56 & 50 & 2.50 \\
\hline M-0 & 404 & 0 & 5.44 & 213.59 & -113.03 & -56 & 50 & 2.50 \\
\hline M-1 & $412(x)$ & 0 & 8.41 & 212.28 & -114.69 & -56 & 50 & 2.50 \\
\hline M-1 & $412(y)$ & 0 & 8.39 & 212.32 & -114.71 & -56 & 50 & 2.50 \\
\hline M-1 & 412 & 0 & 8.40 & 212.30 & -114.70 & -56 & 50 & 2.50 \\
\hline O-0 & $113(x)$ & 0 & 4.73 & 211.04 & -109.77 & -56 & 50 & 2.50 \\
\hline O-0 & $113(\mathrm{y})$ & 0 & 4.64 & 211.09 & -109.73 & -56 & 50 & 2.50 \\
\hline $\mathrm{O}-0$ & 113 & 0 & 4.69 & 211.07 & -109.75 & -56 & 50 & 2.50 \\
\hline $\mathrm{P}-0$ & 49 & -300 & 9.69 & 208.89 & -112.58 & -56 & 50 & 2.50 \\
\hline P-1 & 50 & -200 & 10.99 & 208.14 & -113.13 & -56 & 50 & 2.50 \\
\hline P-2 & 51 & -50 & 9.49 & 208.76 & -112.25 & -56 & 50 & 2.50 \\
\hline P-3 & 53 & -50 & 7.04 & 210.07 & -111.11 & -56 & 50 & 2.50 \\
\hline P-4 & 54 & 200 & 4.28 & 211.21 & -109.49 & -56 & 50 & 2.50 \\
\hline Q-1 & 57 & 50 & 0.57 & 210.98 & -95.56 & -56 & 60 & 3.00 \\
\hline Q-2 & 42 & 200 & 1.86 & 210.79 & -96.65 & -56 & 60 & 3.00 \\
\hline Q-3 & 43 & 200 & 0.49 & 210.72 & -95.21 & -56 & 60 & 3.00 \\
\hline Q-4 & 44 & 50 & 1.13 & 210.66 & -95.80 & -56 & 60 & 3.00 \\
\hline Q-5 & 45 & -50 & 2.36 & 210.15 & -96.51 & -56 & 60 & 3.00 \\
\hline $\mathrm{F}-0$ & 46 & -300 & 8.73 & 209.77 & -102.50 & -56 & 60 & 3.00 \\
\hline F-1 & 47 & -200 & 8.68 & 209.43 & -102.11 & -56 & 60 & 3.00 \\
\hline F-2 & 48 & -50 & 5.88 & 210.63 & -100.51 & -56 & 60 & 3.00 \\
\hline F-3 & 55 & -50 & 8.10 & 209.73 & -101.83 & -56 & 60 & 3.00 \\
\hline F-4 & 56 & 300 & 5.72 & 210.54 & -100.26 & -56 & 60 & 3.00 \\
\hline
\end{tabular}


Appendix A.4. Calibration data and calculated receiver gains for single and split-beam transducers to provide equal detectability for on-axis targets ranging from -56 to $-36 \mathrm{~dB}$ in acoustic size at Powerhouse 2. Results for split-beam transducers are presented for the $x$ phase, $y$ phase, and the mean of $x$ and $y$ phases.

\begin{tabular}{|c|c|c|c|c|c|c|c|c|}
\hline $\begin{array}{l}\text { Echo- } \\
\text { sounder } \\
\text { Letter and } \\
\text { Channel } \\
\text { Number }\end{array}$ & $\begin{array}{l}\text { Trans- } \\
\text { ducer } \\
\text { Number } \\
\text { and Phase } \\
\text { (if split } \\
\text { beams) }\end{array}$ & $\begin{array}{c}\text { Difference in } \\
\text { Cable } \\
\text { Length } \\
\text { Between } \\
\text { Calibrated } \\
\text { Cable and } \\
\text { Installed } \\
\text { Cable (ft) }\end{array}$ & $\begin{array}{l}\text { Receiver } \\
\quad \text { Gain } \\
\text { Adjusted for } \\
\text { Difference in } \\
\text { Cable } \\
\text { Length (dB) }\end{array}$ & $\begin{array}{c}\text { Source Level } \\
\text { Adjusted for } \\
\text { Difference in } \\
\text { Cable } \\
\text { Length (dB) }\end{array}$ & $\begin{array}{c}\text { Receiver } \\
\text { Sensitivity } \\
\text { Adjusted for } \\
\text { Difference in } \\
\text { Cable } \\
\text { Length (dB) }\end{array}$ & $\begin{array}{c}\text { Target } \\
\text { Strength } \\
\text { of } \\
\text { Smallest } \\
\text { On-axis } \\
\text { Target } \\
\text { (dB) }\end{array}$ & $\begin{array}{l}\text { Voltage of } \\
\text { Smallest } \\
\text { On-axis } \\
\text { Target } \\
\text { (dB) }\end{array}$ & $\begin{array}{c}\text { Voltage of } \\
\text { Smallest } \\
\text { On-axis } \\
\text { Target at } \\
20 \mathrm{~dB} \text { per } \\
\text { Volt (V) }\end{array}$ \\
\hline$\overline{\mathrm{U}-0}$ & $403(x)$ & $\overline{0}$ & $\bar{~} 5.57$ & 216.08 & "-105.65 & ב-56 & 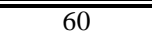 & 3.00 \\
\hline $\mathrm{U}-0$ & $403(y)$ & 0 & 5.60 & 216.13 & -105.73 & -56 & 60 & 3.00 \\
\hline U-0 & 403 & 0 & 5.59 & 216.11 & -105.69 & -56 & 60 & 3.00 \\
\hline U-1 & $405(\mathrm{x})$ & 0 & 5.56 & 216.25 & -105.81 & -56 & 60 & 3.00 \\
\hline U-1 & $405(y)$ & 0 & 5.54 & 216.27 & -105.81 & -56 & 60 & 3.00 \\
\hline U-1 & 405 & 0 & 5.55 & 216.26 & -105.81 & -56 & 60 & 3.00 \\
\hline $\mathrm{V}-0$ & $406(x)$ & 0 & 4.99 & 216.18 & -105.17 & -56 & 60 & 3.00 \\
\hline $\mathrm{V}-0$ & $406(y)$ & 0 & 5.01 & 216.20 & -105.21 & -56 & 60 & 3.00 \\
\hline V-0 & 406 & 0 & 5.00 & 216.19 & -105.19 & -56 & 60 & 3.00 \\
\hline V-1 & $407(\mathrm{x})$ & 0 & 5.04 & 216.15 & -105.19 & -56 & 60 & 3.00 \\
\hline V-1 & $407(y)$ & 0 & 5.02 & 216.15 & -105.17 & -56 & 60 & 3.00 \\
\hline V-1 & 407 & 0 & 5.03 & 216.15 & -105.18 & -56 & 60 & 3.00 \\
\hline $\mathrm{W}-0$ & $117(x)$ & 0 & 7.37 & 220.94 & -112.31 & -56 & 60 & 3.00 \\
\hline W-0 & $117(y)$ & 0 & 7.48 & 220.89 & -112.37 & -56 & 60 & 3.00 \\
\hline $\mathrm{W}-0$ & 117 & 0 & 7.43 & 220.92 & -112.34 & -56 & 60 & 3.00 \\
\hline W-1 & $54(\mathrm{x})$ & 0 & 6.07 & 221.22 & -111.29 & -56 & 60 & 3.00 \\
\hline W-1 & $54(\mathrm{y})$ & 0 & 6.07 & 221.20 & -111.27 & -56 & 60 & 3.00 \\
\hline W-1 & 54 & 0 & 6.07 & 221.21 & -111.28 & -56 & 60 & 3.00 \\
\hline E-1 & 119 & 0 & 4.37 & 214.34 & -112.71 & -56 & 50 & 2.50 \\
\hline E-2 & 120 & 0 & 4.98 & 214.03 & -113.01 & -56 & 50 & 2.50 \\
\hline E-5 & 123 & 0 & 4.59 & 214.30 & -112.89 & -56 & 50 & 2.50 \\
\hline E-6 & 124 & 0 & 4.52 & 214.33 & -112.85 & -56 & 50 & 2.50 \\
\hline G-3 & 36 & 0 & 5.28 & 214.13 & -113.41 & -56 & 50 & 2.50 \\
\hline G-4 & 37 & 0 & 5.02 & 214.09 & -113.11 & -56 & 50 & 2.50 \\
\hline G-5 & 38 & 0 & 6.48 & 213.05 & -113.53 & -56 & 50 & 2.50 \\
\hline G-6 & 39 & 0 & 5.58 & 213.53 & -113.11 & -56 & 50 & 2.50 \\
\hline G-7 & 40 & 0 & 6.00 & 213.23 & -113.23 & -56 & 50 & 2.50 \\
\hline G-8 & 41 & 0 & 8.32 & 212.05 & -114.37 & -56 & 50 & 2.50 \\
\hline $\mathrm{H}-1$ & 539 & 0 & 1.34 & 215.99 & -111.33 & -56 & 50 & 2.50 \\
\hline H-2 & 540 & 0 & 1.50 & 215.95 & -111.45 & -56 & 50 & 2.50 \\
\hline H-7 & 59 & 0 & 4.83 & 214.28 & -113.11 & -56 & 50 & 2.50 \\
\hline H-8 & 60 & 0 & 3.23 & 215.16 & -112.39 & -56 & 50 & 2.50 \\
\hline $\mathrm{I}-0$ & $400(\mathrm{x})$ & 0 & 7.26 & 217.11 & -108.37 & -56 & 60 & 3.00 \\
\hline $\mathrm{I}-0$ & $400(y)$ & 0 & 7.20 & 217.15 & -108.35 & -56 & 60 & 3.00 \\
\hline $\mathrm{I}-0$ & 400 & 0 & 7.23 & 217.13 & -108.36 & -56 & 60 & 3.00 \\
\hline I-1 & $401(x)$ & 0 & 7.47 & 217.04 & -108.51 & -56 & 60 & 3.00 \\
\hline I-1 & $401(y)$ & 0 & 7.45 & 217.06 & -108.51 & -56 & 60 & 3.00 \\
\hline $\mathrm{I}-1$ & 401 & 0 & 7.46 & 217.05 & -108.51 & -56 & 60 & 3.00 \\
\hline
\end{tabular}




\section{Appendix B}

\section{Detailed Transducer Locations and Aiming Angles}


Hydroacoustic Evaluation of Fish Passage through Bonneville Dam in 2005 


\section{Appendix B}

\section{Detailed Transducer Locations and Aiming Angles}

Appendix B.1. Transducer locations at Powerhouse 1 in 2005. Angle refers to the angle off the trashrack or extended- submerged-bar-screen (ESBS) plane. Abbreviations are as follows: $\mathrm{SB}=$ split-beam; $(\mathrm{D})$ = downstream; Rack = trash rack, where Rack 1 is the uppermost of six trash racks, and its top is at Elevation $69 \mathrm{ft} \mathrm{MSL.}$

\begin{tabular}{|c|c|c|c|c|c|c|c|c|c|}
\hline $\begin{array}{l}\text { System } \\
\text { Letter }\end{array}$ & Channel & $\begin{array}{l}\text { Trans- } \\
\text { ducer }\end{array}$ & $\begin{array}{l}\text { Beam } \\
\text { Angle }\end{array}$ & $\begin{array}{l}\text { Intake } \\
\text { or Bay }\end{array}$ & Structure & $\begin{array}{c}\text { Location of } \\
\text { Placement on Structure }\end{array}$ & $\begin{array}{l}\text { Elevation } \\
\quad(\mathrm{ft})\end{array}$ & Aim & $\begin{array}{c}\text { Angle } \\
\text { (Degrees) }\end{array}$ \\
\hline $\mathrm{C}$ & 1 & 1 & 6 & 1B & Rack 1 & $4.4 \mathrm{ft}$ below top; $11.0 \mathrm{ft} \mathrm{S}$ of $\mathrm{N}$ Side & 64.6 & Down & 32 \\
\hline $\mathrm{C}$ & 2 & 2 & 6 & $1 \mathrm{~A}$ & Rack 1 & $4.4 \mathrm{ft}$ below top; $8.8 \mathrm{ft} \mathrm{S}$ of N Side & 64.6 & Down & 32 \\
\hline $\mathrm{C}$ & 3 & 3 & 6 & $3 \mathrm{~A}$ & Rack 1 & $4.4 \mathrm{ft}$ below top; $11.0 \mathrm{ft} \mathrm{S}$ of $\mathrm{N}$ Side & 64.6 & Down & 32 \\
\hline $\mathrm{C}$ & 4 & 4 & 6 & 3B & Rack 1 & $4.4 \mathrm{ft}$ below top; $13.2 \mathrm{ft} \mathrm{S}$ of $\mathrm{N}$ Side & 64.6 & Down & 32 \\
\hline $\mathrm{C}$ & 5 & 5 & 6 & $3 \mathrm{C}$ & Rack 1 & $4.4 \mathrm{ft}$ below top; $13.2 \mathrm{ft} \mathrm{S}$ of $\mathrm{N}$ Side & 64.6 & Down & 32 \\
\hline $\mathrm{C}$ & 6 & 6 & 6 & $4 \mathrm{~A}$ & Rack 1 & $4.4 \mathrm{ft}$ below top; $8.8 \mathrm{ft} \mathrm{S}$ of $\mathrm{N}$ Side & 64.6 & Down & 32 \\
\hline $\mathrm{C}$ & 7 & 7 & 6 & $4 \mathrm{~B}$ & Rack 1 & $4.4 \mathrm{ft}$ below top; $11.0 \mathrm{ft} \mathrm{S}$ of $\mathrm{N}$ Side & 64.6 & Down & 32 \\
\hline $\mathrm{D}$ & 1 & 9 & 6 & $5 \mathrm{~A}$ & Rack 1 & $4.4 \mathrm{ft}$ below top; $13.2 \mathrm{ft} \mathrm{S}$ of N Side & 64.6 & Down & 32 \\
\hline $\mathrm{D}$ & 2 & 17 & 6 & $5 B$ & Rack 1 & $4.4 \mathrm{ft}$ below top; $11.0 \mathrm{ft} \mathrm{S}$ of $\mathrm{N}$ Side & 64.6 & Down & 32 \\
\hline $\mathrm{D}$ & 3 & 11 & 6 & $7 \mathrm{~A}$ & Rack 1 & $4.4 \mathrm{ft}$ below top; $8.8 \mathrm{ft} \mathrm{S}$ of $\mathrm{N}$ Side & 64.6 & Down & 32 \\
\hline $\mathrm{D}$ & 4 & 10 & 6 & 7C & Rack 1 & $4.4 \mathrm{ft}$ below top; $8.8 \mathrm{ft} \mathrm{S}$ of $\mathrm{N}$ Side & 64.6 & Down & 32 \\
\hline $\mathrm{D}$ & 5 & 12 & 6 & $8 \mathrm{C}$ & Rack 1 & $4.4 \mathrm{ft}$ below top; $13.2 \mathrm{ft} \mathrm{S}$ of N Side & 64.6 & Down & 32 \\
\hline $\mathrm{D}$ & 6 & 16 & 6 & $9 \mathrm{~B}$ & Rack 1 & $4.4 \mathrm{ft}$ below top; $8.8 \mathrm{ft} \mathrm{S}$ of $\mathrm{N}$ Side & 64.6 & Down & 32 \\
\hline $\mathrm{D}$ & 7 & 14 & 6 & 10B & Rack 1 & $4.4 \mathrm{ft}$ below top; $13.2 \mathrm{ft} \mathrm{S}$ of N Side & 64.6 & Down & 32 \\
\hline $\mathrm{D}$ & 8 & 15 & 6 & $10 \mathrm{C}$ & Rack 1 & $4.4 \mathrm{ft}$ below top; $11.0 \mathrm{ft} \mathrm{S}$ of N Side & 64.6 & Down & 32 \\
\hline $\mathrm{R}$ & 1 & 53 & SB 6 & $6 \mathrm{~B}$ & Rack 1 & $4.4 \mathrm{ft}$ below top; $8.8 \mathrm{ft} \mathrm{S}$ of N Side & 64.6 & Down & 32 \\
\hline $\mathrm{R}$ & 2 & 51 & SB 6 & $6 \mathrm{~A}$ & Rack 1 & $4.4 \mathrm{ft}$ below top; $11.0 \mathrm{ft} \mathrm{S}$ of $\mathrm{N}$ Side & 64.6 & Down & 32 \\
\hline $\mathrm{X}$ & 10 & 414 & SB 6 & Sluice 1C & Chain gate & 1-ft from North Side & & Side & \\
\hline $\mathrm{X}$ & 11 & 415 & SB 6 & Sluice $1 \mathrm{C}$ & Chain gate & 1-ft from South Side & & Side & \\
\hline $\mathrm{X}$ & 12 & 416 & SB 6 & Sluice 3C & Chain gate & 1-ft from North Side & & Side & \\
\hline $\mathrm{X}$ & 13 & 417 & SB 6 & Sluice 3C & Chain gate & 1-ft from South Side & & Side & \\
\hline $\mathrm{X}$ & 20 & 410 & SB 6 & Sluice 6C & Chain gate & 1-ft from North Side & & Side & \\
\hline $\mathrm{X}$ & 21 & 402 & SB 6 & Sluice 6C & Chain gate & 1-ft from South Side & & Side & \\
\hline
\end{tabular}


Appendix B.2. Transducer locations at the Spillway in 2005. Spillway transducer elevations depend upon gate position and are presented for a $3 \mathrm{ft}$ opening, the maximum observed in 2005. Angle is the angle of the center of the transducer beam off the spill-gate. Abbreviations are as follows: $S B=$ split-beam; $(U)=$ upstream.

\begin{tabular}{|c|c|c|c|c|c|c|c|c|c|}
\hline $\begin{array}{l}\text { System } \\
\text { Letter }\end{array}$ & Channel & $\begin{array}{l}\text { Trans- } \\
\text { ducer }\end{array}$ & $\begin{array}{l}\text { Beam } \\
\text { Angle }\end{array}$ & $\begin{array}{l}\text { Intake } \\
\text { or Bay }\end{array}$ & Structure & $\begin{array}{c}\text { Location of } \\
\text { Placement on Structure }\end{array}$ & $\begin{array}{l}\text { Elevation } \\
\quad(\mathrm{ft})\end{array}$ & Aim & $\begin{array}{c}\text { Angle } \\
\text { (Degrees) }\end{array}$ \\
\hline M & 0 & 404 & SB 10 & 5 & Spill Gate & $28 \mathrm{ft}$ below the top; $37.0 \mathrm{ft} \mathrm{S}$ of $\mathrm{N}$ side & 59.0 & Down & $9(\mathrm{U})$ \\
\hline M & 1 & 412 & SB 10 & 7 & Spill Gate & $28 \mathrm{ft}$ below the top; $28.5 \mathrm{ft} \mathrm{S}$ of $\mathrm{N}$ side & 59.0 & Down & $9(\mathrm{U})$ \\
\hline $\mathrm{O}$ & 0 & 113 & SB 10 & 17 & Spill Gate & $28 \mathrm{ft}$ below the top; $28.5 \mathrm{ft} \mathrm{S}$ of $\mathrm{N}$ side & 59.0 & Down & $9(\mathrm{U})$ \\
\hline $\mathrm{P}$ & 1 & 49 & 10 & 8 & Spill Gate & $28 \mathrm{ft}$ below the top; $17.1 \mathrm{ft} \mathrm{S}$ of $\mathrm{N}$ side & 59.0 & Down & $9(U)$ \\
\hline $\mathrm{P}$ & 2 & 50 & 10 & 10 & Spill Gate & $28 \mathrm{ft}$ below the top; $28.5 \mathrm{ft} \mathrm{S}$ of $\mathrm{N}$ side & 59.0 & Down & $9(U)$ \\
\hline $\mathrm{P}$ & 3 & 51 & 10 & 12 & Spill Gate & $28 \mathrm{ft}$ below the top; $37.0 \mathrm{ft} \mathrm{S}$ of $\mathrm{N}$ side & 59.0 & Down & $9(\mathrm{U})$ \\
\hline $\mathrm{P}$ & 4 & 53 & 10 & 14 & Spill Gate & $28 \mathrm{ft}$ below the top; $28.5 \mathrm{ft} \mathrm{S}$ of $\mathrm{N}$ side & 59.0 & Down & $9(\mathrm{U})$ \\
\hline $\mathrm{P}$ & 5 & 54 & 10 & 16 & Spill Gate & $28 \mathrm{ft}$ below the top; $37.0 \mathrm{ft} \mathrm{S}$ of $\mathrm{N}$ side & 59.0 & Down & $9(\mathrm{U})$ \\
\hline Q & 1 & 57 & 10 & 1 & Spill Gate & $28 \mathrm{ft}$ below the top; $28.5 \mathrm{ft} \mathrm{S}$ of $\mathrm{N}$ side & 59.0 & Down & $9(\mathrm{U})$ \\
\hline $\mathrm{Q}$ & 2 & 42 & 10 & 2 & Spill Gate & $28 \mathrm{ft}$ below the top; $37.0 \mathrm{ft} \mathrm{S}$ of $\mathrm{N}$ side & 59.0 & Down & $9(\mathrm{U})$ \\
\hline $\mathrm{Q}$ & 3 & 43 & 10 & 3 & Spill Gate & $28 \mathrm{ft}$ below the top; $17.1 \mathrm{ft} \mathrm{S}$ of $\mathrm{N}$ side & 59.0 & Down & $9(\mathrm{U})$ \\
\hline $\mathrm{Q}$ & 4 & 44 & 10 & 4 & Spill Gate & $28 \mathrm{ft}$ below the top; $28.5 \mathrm{ft} \mathrm{S}$ of $\mathrm{N}$ side & 59.0 & Down & $9(\mathrm{U})$ \\
\hline $\mathrm{Q}$ & 5 & 45 & 10 & 6 & Spill Gate & $28 \mathrm{ft}$ below the top; $37.0 \mathrm{ft} \mathrm{S}$ of $\mathrm{N}$ side & 59.0 & Down & $9(\mathrm{U})$ \\
\hline $\mathrm{F}$ & 1 & 46 & 10 & 9 & Spill Gate & $28 \mathrm{ft}$ below the top; $28.5 \mathrm{ft} \mathrm{S}$ of $\mathrm{N}$ side & 59.0 & Down & $9(\mathrm{U})$ \\
\hline $\mathrm{F}$ & 2 & 47 & 10 & 11 & Spill Gate & $28 \mathrm{ft}$ below the top; $17.1 \mathrm{ft} \mathrm{S}$ of $\mathrm{N}$ side & 59.0 & Down & $9(\mathrm{U})$ \\
\hline $\mathrm{F}$ & 3 & 48 & 10 & 13 & Spill Gate & $28 \mathrm{ft}$ below the top; $37.0 \mathrm{ft} \mathrm{S}$ of $\mathrm{N}$ side & 59.0 & Down & $9(\mathrm{U})$ \\
\hline $\mathrm{F}$ & 4 & 55 & 10 & 15 & Spill Gate & $28 \mathrm{ft}$ below the top; $17.1 \mathrm{ft} \mathrm{S}$ of $\mathrm{N}$ side & 59.0 & Down & $9(\mathrm{U})$ \\
\hline $\mathrm{F}$ & 5 & 56 & 10 & 18 & Spill Gate & $28 \mathrm{ft}$ below the top; $28.5 \mathrm{ft} \mathrm{S}$ of $\mathrm{N}$ side & 59.0 & Down & $9(\mathrm{U})$ \\
\hline
\end{tabular}


Appendix B.3. Transducer locations at Powerhouse 2 in 2005. Angle refers to the angle off the trashrack plane. Abbreviations are as follows: $S B=$ split-beam; $(D)=$ downstream; $(U)=$ upstream; Beam = a horizontal beam lowered into the trash-rack slot; Rack = trash rack, where Rack 1 is the uppermost of six trash racks, and its top is at Elevation $38 \mathrm{ft} \mathrm{MSL}$.

\begin{tabular}{|c|c|c|c|c|c|c|c|c|c|}
\hline $\begin{array}{l}\text { System } \\
\text { Letter }\end{array}$ & Channel & $\begin{array}{l}\text { Trans- } \\
\text { ducer }\end{array}$ & $\begin{array}{l}\text { Beam } \\
\text { Angle }\end{array}$ & $\begin{array}{l}\text { Intake } \\
\text { or Bay }\end{array}$ & Structure & $\begin{array}{l}\text { Location of } \\
\text { Placement on Structure }\end{array}$ & $\begin{array}{l}\text { Elevation } \\
\quad(\mathrm{ft})\end{array}$ & Aim & $\begin{array}{c}\text { Angle } \\
{ }^{\circ} \text { off } \\
\text { Vertical }\end{array}$ \\
\hline $\mathrm{U}$ & 0 & 403 & 6 & B2CC & Barge & $10.5^{\prime}$ below water's surface & & Side & 108 \\
\hline $\mathrm{U}$ & 1 & 405 & 6 & B2CC & Barge & $12.5^{\prime}$ below water's surface & & Side & 112 \\
\hline V & 0 & 406 & 6 & B2CC & Barge & $6.5^{\prime}$ below water's surface & & Side & 100 \\
\hline V & 1 & 407 & 6 & B2CC & Barge & 8.5' below water's surface & & Side & 104 \\
\hline W & 0 & 117 & 3 & B2CC & Barge & 2.5' below water's surface & & Side & 92 \\
\hline W & 1 & 54 & 3 & B2CC & Barge & 4.5' below water's surface & & Side & 96 \\
\hline E & 1 & 119 & 6 & $11 \mathrm{~A}$ & Rack 1 & $13^{\prime} \mathrm{S}$ of $\mathrm{N}$ side of rack & & Down & 16 \\
\hline E & 2 & 120 & 6 & $11 \mathrm{~A}$ & Rack 4 & 13 ' S of N side of rack & & Up & 16 \\
\hline E & 5 & 123 & 6 & 13B & Rack 1 & 8.17' S of N side of rack & & Down & 16 \\
\hline E & 6 & 124 & 6 & 13B & Rack 4 & 8.17' S of N side of rack & & Up & 16 \\
\hline G & 3 & 36 & 6 & $12 \mathrm{C}$ & Rack 1 & 8.17' S of N side of rack & 30.7 & Down & 16 \\
\hline G & 4 & 37 & 6 & $12 \mathrm{C}$ & Rack 4 & 8.17' S of N side of rack & 4.5 & Up & 16 \\
\hline G & 5 & 38 & 6 & $14 \mathrm{~B}$ & Rack 1 & $13^{\prime} \mathrm{S}$ of $\mathrm{N}$ side of rack & 30.7 & Down & 16 \\
\hline G & 6 & 39 & 6 & $14 \mathrm{~B}$ & Rack 4 & $13^{\prime} \mathrm{S}$ of $\mathrm{N}$ side of rack & 4.5 & Up & 16 \\
\hline G & 7 & 40 & 6 & $15 B$ & Rack 1 & $13^{\prime} \mathrm{S}$ of $\mathrm{N}$ side of rack & 30.7 & Down & 16 \\
\hline G & 8 & 41 & 6 & $15 B$ & Rack 4 & $13^{\prime} \mathrm{S}$ of $\mathrm{N}$ side of rack & 4.5 & Up & 16 \\
\hline $\mathrm{H}$ & 1 & 539 & 6 & $17 \mathrm{~A}$ & Rack 1 & 18.5' S of N Side of rack & 30.7 & Down & 16 \\
\hline $\mathrm{H}$ & 2 & 540 & 6 & $17 \mathrm{~A}$ & Rack 4 & 18.5' S of N Side of rack & 4.5 & Up & 16 \\
\hline $\mathrm{H}$ & 7 & 59 & 6 & 18B & Rack 1 & $13^{\prime} \mathrm{S}$ of $\mathrm{N}$ side of rack & 30.7 & Down & 16 \\
\hline $\mathrm{H}$ & 8 & 60 & 6 & 18B & Rack 4 & $13^{\prime} \mathrm{S}$ of $\mathrm{N}$ side of rack & 4.5 & Up & 16 \\
\hline I & 0 & 400 & 6 & $16 \mathrm{~B}$ & Rack 1 & 19.75' S of N Side of rack & 30.7 & Down & 16 \\
\hline I & 1 & 401 & 6 & $16 \mathrm{~B}$ & Rack 4 & 19.75 ' S of N Side of rack & 4.5 & Up & 16 \\
\hline
\end{tabular}


Hydroacoustic Evaluation of Fish Passage through Bonneville Dam in 2005 


\section{Appendix C}

\section{Autotracker Definitions and Settings}


Hydroacoustic Evaluation of Fish Passage through Bonneville Dam in 2005 


\section{Appendix C}

\section{Autotracker Definitions and Settings}

Appendix C.1. Definitions of autotracking software parameters used for processing hydroacoustic data from Bonneville Dam in 2005.

\begin{tabular}{|c|c|}
\hline Parameter & Definition \\
\hline BlockSize & Maximum number of ping of data to process as a sample \\
\hline MaxRange & Range $(\mathrm{cm})$ to end autotracking \\
\hline MinRange & Range $(\mathrm{cm})$ to begin autotracking \\
\hline StructureThreshold & $\begin{array}{l}\text { Fraction of possible echoes in a range bin that triggers assignment as } \\
\text { structure }\end{array}$ \\
\hline RangeNoise & Range $(\mathrm{cm})$ uncertainty in the position of an echo in range \\
\hline GateSize & $\begin{array}{l}\text { Maximum range about the predicted postion of the next echo in which an } \\
\text { encounter echo will be added to a fish track }\end{array}$ \\
\hline DKMax & $\begin{array}{l}\text { The max ping difference the autotracker will check to find the next ping in a } \\
\text { track segment }\end{array}$ \\
\hline Alpha & $\begin{array}{l}\text { Parameter used in an Alpha-Beta tracking formula; Beta was calculated } \\
\text { from Alpha as follows: Beta }=2(2-\text { Alpha })-4(1-\text { Alpha }) 0.5\end{array}$ \\
\hline LinkGate & Range $(\mathrm{cm})$ over which two colinear tracked segments will be linked \\
\hline LinkDKMax & $\begin{array}{l}\text { The maximum ping difference the autotracker will span to link segments into } \\
\text { a track }\end{array}$ \\
\hline $\begin{array}{l}\text { Maximum Echo or Target } \\
\text { Strength }\end{array}$ & $\begin{array}{l}\text { Largest acoustic size acceptible for autotracking. This may be based upon } \\
\text { echo strength }(\mathrm{dB}) \text { from single beams or target strength }(\mathrm{dB}) \text { from split } \\
\text { beams }\end{array}$ \\
\hline $\begin{array}{l}\text { Minimum Echo or Target } \\
\text { Strength }\end{array}$ & $\begin{array}{l}\text { Smallest acoustic size acceptible for tracking. Also known as the on-axis } \\
\text { strength of an echo. }\end{array}$ \\
\hline Noise & $\begin{array}{l}\text { The number of dilates and erodes used to identify noise regions (greater } \\
\text { than } 0)(-1 \text { means do not do noise for a channel) }\end{array}$ \\
\hline BottomStartRange & $\begin{array}{l}\text { The range (in centimeters) to begin the routine to identify the surface or } \\
\text { bottom range (should be between min and max range) (if bottom } \\
\text { identification is not needed, set value greater than max range) }\end{array}$ \\
\hline BottomCtThold & $\begin{array}{l}\text { The proportion of a range that must be occupied by echoes }>\text { than the } \\
\text { bottom amplitude threshold to be marked as bottom. }(0-1)\end{array}$ \\
\hline BottomAmplThold & $\begin{array}{l}\text { The minimum echo strength (in decibels) above which echoes will be tallied } \\
\text { as bottom or surface echoes }\end{array}$ \\
\hline OutputChannel & $\begin{array}{l}\text { An option to write out fish with a different channel number than the one } \\
\text { assigned at collection (set to }-1 \text { to keep original channel number) }\end{array}$ \\
\hline Location & The name of the Dam or other general location of data collection \\
\hline
\end{tabular}


Appendix C.2. Autotracking software setting used for Bonneville Dam data in 2005

\begin{tabular}{|c|c|c|c|c|c|c|c|c|c|c|c|c|c|c|c|c|c|c|}
\hline $\begin{array}{l}\text { System \& } \\
\text { Transducer } \\
\text { Number }\end{array}$ & $\begin{array}{l}\text { Block } \\
\text { Size }\end{array}$ & $\begin{array}{l}\text { Max } \\
\text { Range }\end{array}$ & $\begin{array}{l}\text { Mid } \\
\text { Range }\end{array}$ & $\begin{array}{l}\text { Structure } \\
\text { Threshold }\end{array}$ & $\begin{array}{l}\text { Range } \\
\text { Noise }\end{array}$ & $\begin{array}{l}\text { Gate } \\
\text { Size }\end{array}$ & DKMax & Alpha & LinkGate & $\begin{array}{l}\text { Link } \\
\text { DKMax }\end{array}$ & $\begin{array}{l}\text { Max } \\
\text { Echo } \\
\text { Strength }\end{array}$ & $\begin{array}{l}\text { Min } \\
\text { Echo } \\
\text { Strength }\end{array}$ & Noise & $\begin{array}{l}\text { Bottom } \\
\text { Start } \\
\text { Range }\end{array}$ & $\begin{array}{l}\text { Bottom } \\
\text { Ct } \\
\text { Threshold }\end{array}$ & $\begin{array}{l}\text { Bottom } \\
\text { Ampl } \\
\text { Thold }\end{array}$ & $\begin{array}{l}\text { Output } \\
\text { Channel }\end{array}$ & Location \\
\hline C01 & 1200 & 22 & 1 & 0.075 & 0.2 & 0.12 & 4 & 0.4 & 0.24 & 20 & -26 & -56 & 5 & 36 & 0.3 & -25.99 & -1 & Bonneville \\
\hline $\mathrm{CO2}$ & 1200 & 22 & 1 & 0.075 & 0.2 & 0.12 & 4 & 0.4 & 0.24 & 20 & -26 & -56 & 5 & 36 & 0.3 & -25.99 & -1 & Bonneville \\
\hline C03 & 1200 & 22 & 1 & 0.075 & 0.2 & 0.12 & 4 & 0.4 & 0.24 & 20 & -26 & -56 & 5 & 36 & 0.3 & -25.99 & -1 & Bonneville \\
\hline CO4 & 1200 & 22 & 1 & 0.075 & 0.2 & 0.12 & 4 & 0.4 & 0.24 & 20 & -26 & -56 & 5 & 36 & 0.3 & -25.99 & -1 & Bonneville \\
\hline C05 & 1200 & 22 & 1 & 0.075 & 0.2 & 0.12 & 4 & 0.4 & 0.24 & 20 & -26 & -56 & 5 & 36 & 0.3 & -25.99 & -1 & Bonneville \\
\hline C06 & 1200 & 22 & 1 & 0.075 & 0.2 & 0.12 & 4 & 0.4 & 0.24 & 20 & -26 & -56 & 5 & 36 & 0.3 & -25.99 & -1 & Bonneville \\
\hline $\mathrm{CO}$ & 1200 & 22 & 1 & 0.075 & 0.2 & 0.12 & 4 & 0.4 & 0.24 & 20 & -26 & -56 & 5 & 36 & 0.3 & -25.99 & -1 & Bonneville \\
\hline D01 & 1200 & 22 & 1 & 0.075 & 0.2 & 0.12 & 4 & 0.4 & 0.24 & 20 & -26 & -56 & 5 & 36 & 0.3 & -25.99 & -1 & Bonneville \\
\hline D02 & 1200 & 22 & 1 & 0.075 & 0.2 & 0.12 & 4 & 0.4 & 0.24 & 20 & -26 & -56 & 5 & 36 & 0.3 & -25.99 & -1 & Bonneville \\
\hline D03 & 1200 & 22 & 1 & 0.075 & 0.2 & 0.12 & 4 & 0.4 & 0.24 & 20 & -26 & -56 & 5 & 36 & 0.3 & -25.99 & -1 & Bonneville \\
\hline D04 & 1200 & 22 & 1 & 0.075 & 0.2 & 0.12 & 4 & 0.4 & 0.24 & 20 & -26 & -56 & 5 & 36 & 0.3 & -25.99 & -1 & Bonneville \\
\hline D05 & 1200 & 22 & 1 & 0.075 & 0.2 & 0.12 & 4 & 0.4 & 0.24 & 20 & -26 & -56 & 5 & 36 & 0.3 & -25.99 & -1 & Bonneville \\
\hline D06 & 1200 & 22 & 1 & 0.075 & 0.2 & 0.12 & 4 & 0.4 & 0.24 & 20 & -26 & -56 & 5 & 36 & 0.3 & -25.99 & -1 & Bonneville \\
\hline D07 & 1200 & 22 & 1 & 0.075 & 0.2 & 0.12 & 4 & 0.4 & 0.24 & 20 & -26 & -56 & 5 & 36 & 0.3 & -25.99 & -1 & Bonneville \\
\hline D08 & 1200 & 22 & 1 & 0.075 & 0.2 & 0.12 & 4 & 0.4 & 0.24 & 20 & -26 & -56 & 5 & 36 & 0.3 & -25.99 & -1 & Bonneville \\
\hline E01 & 1395 & 17 & 1 & 0.075 & 0.2 & 0.12 & 4 & 0.4 & 0.24 & 20 & -26 & -56 & 5 & 36 & 0.3 & -25.99 & -1 & Bonneville \\
\hline E02 & 1395 & 11.5 & 4 & 0.075 & 0.2 & 0.08 & 4 & 0.3 & 0.18 & 20 & -26 & -56 & 5 & 36 & 0.3 & -25.99 & -1 & Bonneville \\
\hline E05 & 1395 & 17 & 1 & 0.075 & 0.2 & 0.12 & 4 & 0.4 & 0.24 & 20 & -26 & -56 & 5 & 36 & 0.3 & -25.99 & -1 & Bonneville \\
\hline E06 & 1395 & 11.5 & 4 & 0.075 & 0.2 & 0.08 & 4 & 0.3 & 0.18 & 20 & -26 & -56 & 5 & 36 & 0.3 & -25.99 & -1 & Bonneville \\
\hline F01 & 1500 & 12 & 5 & 0.075 & 0.2 & 0.12 & 4 & 0.5 & 0.24 & 20 & -26 & -56 & 5 & 9.85 & 0.3 & -25.99 & -1 & Bonneville \\
\hline F02 & 1500 & 12 & 5 & 0.075 & 0.2 & 0.12 & 4 & 0.5 & 0.24 & 20 & -26 & -56 & 5 & 9.9 & 0.3 & -25.99 & -1 & Bonneville \\
\hline F03 & 1500 & 12 & 5 & 0.075 & 0.2 & 0.12 & 4 & 0.5 & 0.24 & 20 & -26 & -56 & 5 & 9.84 & 0.3 & -25.99 & -1 & Bonneville \\
\hline F04 & 1500 & 12 & 5 & 0.075 & 0.2 & 0.12 & 4 & 0.5 & 0.24 & 20 & -26 & -56 & 5 & 9.95 & 0.3 & -25.99 & -1 & Bonneville \\
\hline F05 & 1500 & 12 & 5 & 0.075 & 0.2 & 0.12 & 4 & 0.5 & 0.24 & 20 & -26 & -56 & 5 & 9.84 & 0.3 & -25.99 & -1 & Bonneville \\
\hline G03 & 1395 & 17 & 1 & 0.075 & 0.2 & 0.12 & 4 & 0.4 & 0.24 & 20 & -26 & -56 & 5 & 36 & 0.3 & -25.99 & -1 & Bonneville \\
\hline G04 & 1395 & 11.5 & 4 & 0.075 & 0.2 & 0.08 & 4 & 0.3 & 0.18 & 20 & -26 & -56 & 5 & 36 & 0.3 & -25.99 & -1 & Bonneville \\
\hline G05 & 1395 & 17 & 1 & 0.075 & 0.2 & 0.12 & 4 & 0.4 & 0.24 & 20 & -26 & -56 & 5 & 36 & 0.3 & -25.99 & -1 & Bonneville \\
\hline G06 & 1395 & 11.5 & 4 & 0.075 & 0.2 & 0.08 & 4 & 0.3 & 0.18 & 20 & -26 & -56 & 5 & 36 & 0.3 & -25.99 & -1 & Bonneville \\
\hline G07 & 1395 & 17 & 1 & 0.075 & 0.2 & 0.12 & 4 & 0.4 & 0.24 & 20 & -26 & -56 & 5 & 36 & 0.3 & -25.99 & -1 & Bonneville \\
\hline G08 & 1395 & 11.5 & 4 & 0.075 & 0.2 & 0.08 & 4 & 0.3 & 0.18 & 20 & -26 & -56 & 5 & 36 & 0.3 & -25.99 & -1 & Bonneville \\
\hline $\mathrm{HO1}$ & 1395 & 17 & 1 & 0.075 & 0.2 & 0.12 & 4 & 0.4 & 0.24 & 20 & -26 & -56 & 5 & 36 & 0.3 & -25.99 & -1 & Bonneville \\
\hline $\mathrm{HO2}$ & 1395 & 11.5 & 4 & 0.075 & 0.2 & 0.08 & 4 & 0.3 & 0.18 & 20 & -26 & -56 & 5 & 36 & 0.3 & -25.99 & -1 & Bonneville \\
\hline $\mathrm{H} 07$ & 1395 & 17 & 1 & 0.075 & 0.2 & 0.12 & 4 & 0.4 & 0.24 & 20 & -26 & -56 & 5 & 36 & 0.3 & -25.99 & -1 & Bonneville \\
\hline $\mathrm{H} 08$ & 1395 & 11.5 & 4 & 0.075 & 0.2 & 0.08 & 4 & 0.3 & 0.18 & 20 & -26 & -56 & 5 & 36 & 0.3 & -25.99 & -1 & Bonneville \\
\hline 100 & 1395 & 11.5 & 4 & 0.075 & 0.2 & 0.08 & 4 & 0.4 & 0.18 & 20 & -26 & -56 & 5 & 36 & 0.3 & -25.99 & -1 & Bonneville \\
\hline 101 & 1395 & 17 & 1 & 0.075 & 0.2 & 0.12 & 4 & 0.3 & 0.24 & 20 & -26 & -56 & 5 & 36 & 0.3 & -25.99 & -1 & Bonneville \\
\hline MOO & 1500 & 12 & 5 & 0.075 & 0.2 & 0.12 & 4 & 0.5 & 0.24 & 20 & -26 & -56 & 5 & 9.74 & 0.3 & -25.99 & -1 & Bonneville \\
\hline M01 & 1500 & 12 & 5 & 0.075 & 0.2 & 0.12 & 4 & 0.5 & 0.24 & 20 & -26 & -56 & 5 & 9.74 & 0.3 & -25.99 & -1 & Bonneville \\
\hline 000 & 1500 & 12 & 5 & 0.075 & 0.2 & 0.12 & 4 & 0.5 & 0.24 & 20 & -26 & -56 & 5 & 10.05 & 0.3 & -25.99 & -1 & Bonneville \\
\hline P01 & 1500 & 12 & 5 & 0.075 & 0.2 & 0.12 & 4 & 0.5 & 0.24 & 20 & -26 & -56 & 5 & 9.9 & 0.3 & -25.99 & -1 & Bonneville \\
\hline P02 & 1500 & 12 & 5 & 0.075 & 0.2 & 0.12 & 4 & 0.5 & 0.24 & 20 & -26 & -56 & 5 & 9.9 & 0.3 & -25.99 & -1 & Bonneville \\
\hline P03 & 1500 & 12 & 5 & 0.075 & 0.2 & 0.12 & 4 & 0.5 & 0.24 & 20 & -26 & -56 & 5 & 9.95 & 0.3 & -25.99 & -1 & Bonneville \\
\hline P04 & 1500 & 12 & 5 & 0.075 & 0.2 & 0.12 & 4 & 0.5 & 0.24 & 20 & -26 & -56 & 5 & 9.9 & 0.3 & -25.99 & -1 & Bonneville \\
\hline P05 & 1500 & 12 & 5 & 0.075 & 0.2 & 0.12 & 4 & 0.5 & 0.24 & 20 & -26 & -56 & 5 & 9.7 & 0.3 & -25.99 & -1 & Bonneville \\
\hline Q01 & 1500 & 12 & 5 & 0.075 & 0.2 & 0.12 & 4 & 0.5 & 0.24 & 20 & -26 & -56 & 5 & 9.9 & 0.3 & -25.99 & -1 & Bonneville \\
\hline Q02 & 1500 & 12 & 5 & 0.075 & 0.2 & 0.12 & 4 & 0.5 & 0.24 & 20 & -26 & -56 & 5 & 10 & 0.3 & -25.99 & -1 & Bonneville \\
\hline Q03 & 1500 & 12 & 5 & 0.075 & 0.2 & 0.12 & 4 & 0.5 & 0.24 & 20 & -26 & -56 & 5 & 9.9 & 0.3 & -25.99 & -1 & Bonneville \\
\hline Q04 & 1500 & 12 & 5 & 0.075 & 0.2 & 0.12 & 4 & 0.5 & 0.24 & 20 & -26 & -56 & 5 & 9.8 & 0.3 & -25.99 & -1 & Bonneville \\
\hline Q05 & 1500 & 12 & 5 & 0.075 & 0.2 & 0.12 & 4 & 0.5 & 0.24 & 20 & -26 & -56 & 5 & 9.74 & 0.3 & -25.99 & -1 & Bonneville \\
\hline R01 & 1200 & 22.5 & 1 & 0.075 & 0.2 & 0.12 & 4 & 0.4 & 0.24 & 20 & -26 & -56 & 5 & 36 & 0.3 & -25.99 & -1 & Bonneville \\
\hline R02 & 1200 & 22.5 & 1 & 0.075 & 0.2 & 0.12 & 4 & 0.4 & 0.24 & 20 & -26 & -56 & 5 & 36 & 0.3 & -25.99 & -1 & Bonneville \\
\hline Uoo & 500 & 12 & 1 & 1 & 0.2 & 0.035 & 4 & 0.4 & 0.12 & 20 & -26 & -56 & 6 & 10 & 0.3 & -25.99 & -1 & Bonneville \\
\hline U01 & 500 & 10 & 1 & 1 & 0.2 & 0.035 & 4 & 0.4 & 0.12 & 20 & -26 & -56 & 6 & 8 & 0.3 & -25.99 & -1 & Bonneville \\
\hline voo & 500 & 12 & 1 & 1 & 0.2 & 0.035 & 4 & 0.4 & 0.12 & 20 & -26 & -56 & 6 & 36 & 0.3 & -25.99 & -1 & Bonneville \\
\hline V01 & 500 & 12 & 1 & 1 & 0.2 & 0.035 & 4 & 0.4 & 0.12 & 20 & -26 & -56 & 6 & 36 & 0.3 & -25.99 & -1 & Bonneville \\
\hline Woo & 500 & 13 & 1 & 1 & 0.2 & 0.035 & 4 & 0.4 & 0.12 & 20 & -26 & -56 & 6 & 36 & 0.3 & -25.99 & -1 & Bonneville \\
\hline W01 & 500 & 13 & 1 & 1 & 0.2 & 0.035 & 4 & 0.4 & 0.12 & 20 & -26 & -56 & 6 & 36 & 0.3 & -25.99 & -1 & Bonneville \\
\hline $\mathrm{X} 10$ & 1500 & 6 & 1 & 0.075 & 0.2 & 0.035 & 4 & 0.4 & 0.12 & 20 & -26 & -56 & 5 & 36 & 0.3 & -25.99 & -1 & Bonneville \\
\hline X11 & 1500 & 6 & 1 & 0.075 & 0.2 & 0.035 & 4 & 0.4 & 0.12 & 20 & -26 & -56 & 5 & 36 & 0.3 & -25.99 & -1 & Bonneville \\
\hline $\mathrm{X} 12$ & 1500 & 6 & 1 & 0.075 & 0.2 & 0.035 & 4 & 0.4 & 0.12 & 20 & -26 & -56 & 5 & 36 & 0.3 & -25.99 & -1 & Bonneville \\
\hline X13 & 1500 & 6 & 1 & 0.075 & 0.2 & 0.035 & 4 & 0.4 & 0.12 & 20 & -26 & -56 & 5 & 36 & 0.3 & -25.99 & -1 & Bonneville \\
\hline$\times 20$ & 1500 & 6 & 1 & 0.075 & 0.2 & 0.035 & 4 & 0.4 & 0.12 & 20 & -26 & -56 & 5 & 36 & 0.3 & -25.99 & -1 & Bonneville \\
\hline$\times 21$ & 1500 & 6 & 1 & 0.075 & 0.2 & 0.035 & 4 & 0.4 & 0.12 & 20 & -26 & -56 & 5 & 36 & 0.3 & -25.99 & -1 & Bonneville \\
\hline
\end{tabular}




\section{Appendix D}

\section{Statistical Analysis System Code for Filtering Echo Traces Selected by Autotracking Software}


Hydroacoustic Evaluation of Fish Passage Through Bonneville Dam in 2005 


\section{Appendix D}

\section{Statistical Analysis System Code for Filtering Echo Traces Selected by Autotracking Software}

Appendix D.1. Definitions of variables for filtering echo traces selected by autotracking software in 2005.

\begin{tabular}{|c|c|}
\hline Parameter & Definition \\
\hline System & $\begin{array}{l}\text { Corresponds to an echosounder and associated transducers. Echosounder } \\
\text { channels and transducer locations are described in Appendix B. }\end{array}$ \\
\hline Mux_Channel & $\begin{array}{l}\text { Corresponds to a single transducer attached to one specific echosounder } \\
\text { channel. }\end{array}$ \\
\hline First_Ping & $\begin{array}{l}\text { The absolute ping number for the first echo in an a series of echoes forming an } \\
\text { echo trace. }\end{array}$ \\
\hline Last_Ping & $\begin{array}{l}\text { The absolute ping number for the last echo in an a series of echoes forming an } \\
\text { echo trace. Last_Ping / Group_Size is the total number of pings in an echo trace. }\end{array}$ \\
\hline Group_Size & $\begin{array}{l}\text { Describes the number transducers sampled simultaneously (1=slow multiplex; } \\
2=\text { fast multiplex) }\end{array}$ \\
\hline Mean_Target_Strength & $\begin{array}{l}\text { The average echo amplitude of a fish trace in } \mathrm{dB} \text {. This would be echo strength for } \\
\text { fish detected by single beam transducers. Maximum echo-strength thresholds } \\
\text { were set } 2.3 \mathrm{~dB} \text { lower than target-strength thresholds based upon empirical data } \\
\text { from the two types of distributions. }\end{array}$ \\
\hline Linearity1 & $\begin{array}{l}\text { The mean } \mathrm{cm} \text { deviation of echoes from a line fit through a series of echoes } \\
\text { forming a trace. }\end{array}$ \\
\hline Linearity2 & $\begin{array}{l}\text { The mean } \mathrm{cm} \text { deviation of echoes from a parabola fit through a series of echoes } \\
\text { forming a trace. }\end{array}$ \\
\hline Noise_Count_Average & $\begin{array}{l}\text { The number of noise echoes in a window around an echo trace. The window } \\
\text { began } 5 \text { pings before the first echo and ended } 5 \text { pings after the last echo in the } \\
\text { trace and was } \pm 0.5 \mathrm{~m} \text { in range. }\end{array}$ \\
\hline Slope & (last range- first range)/(last relative ping- first relative ping) \\
\hline First_Range & The ranges of the first echoes in an echo trace. \\
\hline Last_Range & The ranges of the last echoes in an echo trace. \\
\hline Echo_Count & Number of echoes in track \\
\hline Noise_Index & Noise Sum / Track echo count \\
\hline Noise_Count_Average & Noise Count / Track echo count \\
\hline Contrast & $\begin{array}{l}\text { the ratio of average fish echo amplitude to the average noise echo amplitude in } \\
\text { the same window }\end{array}$ \\
\hline Track_Type & 0 if normal, 1 if flat track near clutter \\
\hline Mean_Echo_Strength & Mean echostrength (not corrected for phase information) \\
\hline Mean_Pulse_Width & Duration of transmitted pulses \\
\hline
\end{tabular}


Appendix D.2. Statistical Analysis System code for filtering out echo traces that did not meet fish trace criteria in spring 2005. Minimum ranges for sampling, as described in the Materials and Methods section of the report, were implemented elsewhere in the data processing program.

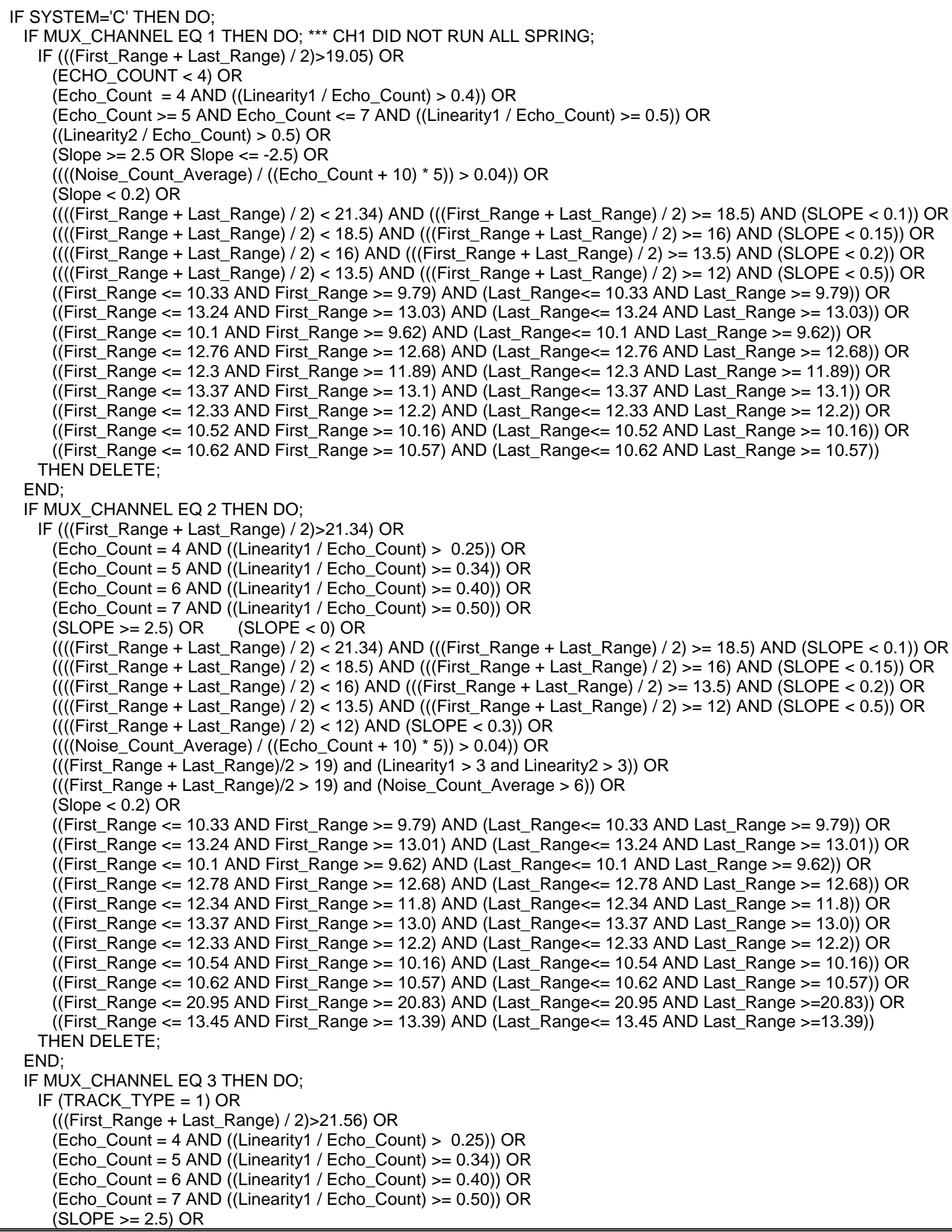


$(((($ First_Range + Last_Range $) / 2)<21.56)$ AND ((First_Range + Last_Range $) / 2)>=16)$ AND (SLOPE < 0.1)) OR $(((($ First_Range + Last_Range) $/ 2)<16)$ AND $((($ First_Range + Last_Range $) / 2)>=14.5)$ AND $($ SLOPE $<0.2))$ OR $(((($ First_Range + Last_Range $) / 2)<14.5)$ AND (((First_Range + Last_Range) / 2) $>=13)$ AND (SLOPE $<0.3))$ OR $(((($ First_Range + Last_Range $) / 2)<13)$ AND $((($ First_Range + Last_Range $) / 2)>=9)$ AND (SLOPE < 0.4) $)$ OR $(((($ First_Range + Last_Range) $/ 2)<9)$ AND (SLOPE < 0.3)) OR

$((($ Noise_Count_Average $) /(($ Echo_Count +10$) * 5))>0.04))$ OR

((First_Range $<=20.58$ AND First_Range $>=19.9)$ AND (Last_Range $<=20.58$ AND Last_Range $>=19.90)$ ) OR

((First_Range $<=19.55$ AND First_Range $>=19.43)$ AND (Last_Range $<=19.55$ AND Last_Range $>=19.43)$ ) OR

((First_Range $<=19.59$ AND First_Range $>=19.47$ ) AND (Last_Range $<=19.59$ AND Last_Range $>=19.47)$ ) OR

((First_Range $<=19.50$ AND First_Range $>=19.37$ ) AND (Last_Range $<=19.50$ AND Last_Range $>=19.37)$ ) OR

((First_Range $<=10.32$ AND First Range $>=10.01$ ) AND (Last_Range $<=10.32$ AND Last Range $>=10.01)$ ) OR

((First_Range $<=12.97$ AND First_Range $>=12.81)$ AND (Last_Range $<=12.97$ AND Last_Range $>=12.81)$ ) OR

((First_Range $<=20.29$ AND First_Range $>=20.06$ ) AND (Last_Range $<=20.29$ AND Last_Range $>=20.06)$ ) OR ((First_Range $<=13.39$ AND First_Range $>=13.01)$ AND (Last_Range $<=13.39$ AND Last_Range $>=13.01)$ ) OR ((First_Range $<=13.13$ AND First_Range $>=12.82$ ) AND (Last_Range $<=13.13$ AND Last_Range $>=12.82)$ ) OR ((First_Range $<=10.36$ AND First_Range $>=10.1$ ) AND (Last_Range $<=10.36$ AND Last_Range $>=10.1)$ ) OR ((First_Range $<=19.65$ AND First_Range $>=19.59)$ AND (Last_Range $<=19.65$ AND Last_Range $>=19.59)$ ) OR ((First_Range $<=12.82$ AND First_Range $>=12.60)$ AND (Last_Range $<=12.82$ AND Last_Range $>=12.60)$ ) OR ((First_Range $<=21.05$ AND First_Range $>=20.81$ ) AND (Last_Range $<=21.05$ AND Last_Range $>=20.81)$ ) OR ((First Range $<=12.47$ AND First Range $>=12.34$ ) AND (Last Range $<=12.47$ AND Last Range $>=12.34$ )) OR ((First_Range $<=19.93$ AND First_Range $>=19.52)$ AND (Last_Range $<=19.93$ AND Last_Range $>=19.52)$ ) OR ((First_Range $<=13.52$ AND First_Range $>=13.37$ ) AND (Last_Range $<=13.52$ AND Last Range $>=13.37)$ ) OR ((First_Range $<=12.31$ AND First_Range $>=12.09$ ) AND (Last_Range $<=12.31$ AND Last_Range $>=12.09)$ ) OR ((First_Range $<=10.2$ AND First Range $>=9.84$ ) AND (Last Range $<=10.2$ AND Last Range $>=9.84)$ ) OR

((First_Range $<=12.62$ AND First_Range $>=12.38)$ AND (Last_Range $<=12.62$ AND Last_Range $>=12.38)$ ) OR ((First_Range $<=10.14$ AND First_Range $>=9.82$ ) AND (Last_Range $<=10.14$ AND Last_Range $>=9.82)$ ) OR ((First_Range $<=20.71$ AND First_Range $>=20.57)$ AND (Last_Range $<=20.71$ AND Last_Range $>=20.57)$ ) OR $((($ First_Range + Last_Range $) / 2)>19)$ AND $($ SLOPE $<0.2))$

THEN DELETE;

END;

IF MUX_CHANNEL EQ 4 THEN DO;

IF (TRACK TYPE = 1) OR

(((First_Range + Last_Range) / 2)>21.40) OR

$($ Echo_Count $=4$ AND $(($ Linearity1 $/$ Echo_Count $)>0.25))$ OR

$($ Echo_Count $=5$ AND $(($ Linearity1 $/$ Echo_Count $)>=0.34))$ OR

$($ Echo_Count $=6$ AND $(($ Linearity $1 /$ Echo_Count $)>=0.40))$ OR

$($ Echo_Count $=7$ AND $(($ Linearity1 $/$ Echo_Count $)>=0.50))$ OR

(SLOPE >= 2.5) OR

$(((($ First_Range + Last_Range) / 2) < 20) AND (((First_Range + Last_Range) / 2) $>=13.5)$ AND (SLOPE < 0.25)) OR

$(((($ First_Range + Last_Range $) / 2)<13.5)$ AND $((($ First_Range + Last_Range $) / 2)>=11.8)$ AND $($ SLOPE $<6))$ OR

$(((($ First_Range + Last_Range $) / 2)<13.5)$ AND $((($ First_Range + Last_Range $) / 2)>=11.8)$ AND $($ LINEARITY1 $>5))$ OR

$(((($ First_Range + Last_Range $) / 2)<11.8)$ AND $((($ First_Range + Last_Range $) / 2)>=10)$ AND $($ SLOPE $<0.2))$ OR

$(((($ First_Range + Last_Range $) / 2)<10)$ AND $((($ First_Range + Last_Range $) / 2)>=7)$ AND $($ SLOPE $<0.25))$ OR

$(((($ First_Range + Last_Range) $/ 2)<7)$ AND $($ SLOPE $<0.3))$ OR

$((($ Noise_Count_Average $) /(($ Echo_Count +10$) * 5))>0.04))$ OR

((First_Range $<=20.45$ AND First_Range $>=20.35)$ AND (Last_Range $<=20.45$ AND Last_Range $>=20.35)$ ) OR

(First_Range $=20.95$ AND Last_Range $=20.95$ ) OR

(First_Range $=20.92$ AND Last_Range $=20.92$ ) OR

((First_Range $<=20.92$ AND First_Range $>=20.9)$ AND (Last_Range $<=20.92$ AND Last_Range $>=20.9)$ ) OR

$($ MEAN_ECHO_STRENGTH $>-3 \overline{7})$ OR (First_Range $=20.61$ AND Last_Range $=20.61$ ) OR

(First_Range $<=20.54$ AND First_Range $>=20.32$ ) AND (Last_Range $<=20.54$ AND Last_Range $>=20.32$ ) OR

(((First_Range+Last_Range)/2) $>=20.5$ AND Slope $<0.15)$ OR

(First_Range $<=20.38$ AND First_Range $>=20.0$ ) AND (Last_Range $<=20.38$ AND Last_Range $>=20.0$ ) OR $((($ First_Range+Last_Range $) / 2)>=20.3$ AND Slope $<0.5)$ OR

( Slope $<=0$ ) OR

(First_Range $<=19.91$ AND First_Range $>=19.66$ ) AND (Last_Range $<=19.91$ AND Last_Range $>=19.66$ ) OR

(First_Range $<=9.75$ AND First_Range $>=9.62$ ) AND (Last_Range $<=9.75$ AND Last_Range $>=9.62$ ) OR

(First_Range $<=10.04$ AND First_Range $>=9.74$ ) AND (Last_Range $<=10.04$ AND Last_Range $>=9.74$ ) OR

(First_Range $<=10.36$ AND First_Range $>=10.22$ ) AND (Last_Range $<=10.36$ AND Last_Range $>=10.22$ ) OR

(First_Range $<=17.79$ AND First_Range $>=17.74$ ) AND (Last_Range $<=17.79$ AND Last_Range $>=17.74$ ) OR

(First_Range $<=10.48$ AND First_Range $>=10.36$ ) AND (Last_Range $<=10.48$ AND Last_Range $>=10.46$ )

THEN DELETE;

END;

IF MUX_CHANNEL EQ 5 THEN DO;

IF (TRACK_TYPE = 1) OR

$((($ First_Range + Last Range $) / 2)>21.76)$ OR

(Echo_Count $=4$ AND $(($ Linearity $1 /$ Echo_Count $)>0.25))$ OR

(Echo_Count $=5$ AND $(($ Linearity $1 /$ Echo_Count $)>=0.34))$ OR

$($ Echo_Count $=6$ AND $(($ Linearity $1 /$ Echo_Count $)>=0.40))$ OR

$($ Echo_Count $=7$ AND $(($ Linearity $1 /$ Echo_Count $)>=0.50))$ OR 
(SLOPE >= 2.5) OR

$(((($ First_Range + Last_Range $) / 2)<20)$ AND $((($ First_Range + Last_Range $) / 2)>=15)$ AND $($ SLOPE $<0.1))$ OR $(((($ First_Range + Last_Range $) / 2)<15)$ AND $((($ First_Range + Last_Range $) / 2)>=12)$ AND $($ SLOPE $<0.3))$ OR $(((($ First_Range + Last_Range $) / 2)<12)$ AND $($ SLOPE $<0.4))$ OR $(((($ Noise_Count_Average $) /(($ Echo_Count +10$) * 5))>0.04))$ OR

$(($ First_Range $=\mathbf{2 0 . 6 7 )}$ AND (Last_Range=20.67)) OR

(First_Range $<=20.68$ AND First_Range $>=20.63$ ) AND (Last_Range $<=20.68$ AND Last_Range $>=20.63$ ) OR (Mean_Echo_Strength > -37) OR

(First_Range $<=20.42$ AND First_Range $>=20.39$ ) AND (Last_Range $<=20.42$ AND Last_Range $>=20.39$ ) OR $(($ First_Range $=20.46)$ AND (Last_Range $=20.46)$ ) OR

(First_Range $<=20.79$ AND First_Range $>=20.73$ ) AND (Last_Range $<=20.79$ AND Last_Range $>=20.73$ ) OR (Slope $<=0$ ) OR

$((($ First_Range+Last_Range $) / 2)>=20$ AND Slope $<0.1)$ OR

(First_Range $<=20.87$ AND First_Range $>=20.86$ ) AND (Last_Range $<=20.87$ AND Last_Range $>=20.86$ ) OR

((First_Range $<=20.58$ AND First_Range $>=20.35)$ AND (Last_Range $<=20.58$ AND Last_Range $>=20.35)$ ) AND Slope $<$ $0.5) \mathrm{OR}$

(((First_Range+Last_Range)/2) $>=20.6$ AND Slope $<0.3)$ OR

(First_Range $<=10 . \overline{1} 7$ AND First_Range $>=9.9$ ) AND (Last_Range $<=10.17$ AND Last_Range $>=9.9$ ) OR

(First_Range $<=20.65$ AND First_Range $>=20.28$ ) AND (Last_Range $<=20.65$ AND Last_Range $>=20.28$ ) OR

(First_Range $<=18.14$ AND First_Range $>=18.12$ ) AND (Last_Range $<=18.14$ AND Last_Range $>=18.12$ ) OR

(First_Range $<=20.26$ AND First_Range $>=19.97$ ) AND (Last_Range $<=20.26$ AND Last_Range $>=19.97$ ) OR

(First Range $<=15.24$ AND First Range $>=15.21$ ) AND (Last Range $<=15.24$ AND Last Range $>=15.21$ ) OR

(First_Range $<=17.83$ AND First_Range $>=17.79$ ) AND (Last_Range $<=17.83$ AND Last_Range $>=17.79$ ) OR

(First_Range $<=16.94$ AND First_Range $>=16.8$ ) AND (Last_Range $<=16.94$ AND Last_Range $>=16.8$ ) OR

(First_Range $<=17.35$ AND First_Range $>=17.26$ ) AND (Last_Range $<=17.35$ AND Last_Range $>=17.26$ ) OR

(First_Range $<=19.66$ AND First_Range $>=19.62$ ) AND (Last_Range $<=19.66$ AND Last_Range $>=19.62$ )

THEN DELETE;

END;

IF MUX_CHANNEL EQ 6 THEN DO;

IF (TRACK_TYPE = 1) OR

(((First_Range + Last_Range) / 2)>20.35) OR

(Echo_Count $=4$ AND $(($ Linearity1 $/$ Echo_Count $)>0.25))$ OR

$($ Echo_Count $=5$ AND $(($ Linearity1 $/$ Echo_Count $)>=0.34))$ OR

$($ Echo_Count $=6$ AND $(($ Linearity $1 /$ Echo_Count $)>=0.40))$ OR

$($ Echo_Count $=7$ AND $(($ Linearity1 $/$ Echo_Count $)>=0.50))$ OR

(SLOPE $>=2.5)$ OR

$((($ First_Range + Last_Range $) / 2)<20.35)$ AND ((First_Range + Last_Range $) / 2)>=15)$ AND $($ SLOPE $<0.15))$ OR

$(((($ First_Range + Last_Range $) / 2)<15)$ AND $((($ First_Range + Last_Range $) / 2)>=13.5)$ AND $($ SLOPE $<0.3))$ OR

$(((($ First_Range + Last_Range $) / 2)<13.5)$ AND $((($ First_Range + Last_Range $) / 2)>=12.3)$ AND $($ SLOPE $<0.7))$ OR

$(((($ First_Range + Last_Range $) / 2)<12$.3) AND (( First_Range + Last_Range $) / 2)>=7)$ AND $($ SLOPE $<0.25))$ OR

$(((($ First_Range + Last_Range $) / 2)<7)$ AND $($ SLOPE $<0.35))$ OR

$((($ Noise_Count_Average $) /(($ Echo_Count +10$) * 5))>0.04))$ OR

(First_Range $<=20.23$ AND First_Range $>=20.19$ ) AND (Last_Range $<=20.23$ AND Last_Range $>=20.19$ ) OR

(First_Range $<=17.76$ AND First_Range $>=17.58$ ) AND (Last_Range $<=17.76$ AND Last_Range $>=17.58$ ) OR $(((($ First_Range + Last_Range $) / \overline{2})>19)$ AND $($ SLOPE $<1.5))$ OR

$((($ First_Range + Last_Range $) / 2)<12)$ AND (((First_Range + Last_Range $) / 2)>=11)$ AND $($ SLOPE $<0.44))$ OR

(First_Range $<=13.97$ AND First_Range $>=13.91$ ) AND (Last_Range $<=13.97$ AND Last_Range $>=13.91$ ) OR

(First_Range $<=13.74$ AND First_Range $>=13.67$ ) AND (Last_Range $<=13.74$ AND Last_Range $>=13.67$ ) OR

(First_Range $<=10.89$ AND First_Range $>=10.8$ ) AND (Last_Range $<=10.89$ AND Last_Range $>=10.8$ )

THEN DELETE;

END;

IF MUX_CHANNEL EQ 7 THEN DO;

IF (TRACK_TYPE = 1) OR

$((($ First_Range + Last_Range $) / 2)>21.64)$ OR

$($ Echo_Count $=4$ AND $(($ Linearity1 $/$ Echo_Count $)>0.25))$ OR

(Echo_Count $=5$ AND $(($ Linearity $1 /$ Echo_Count $)>=0.34))$ OR

$($ Echo_Count $=6$ AND $(($ Linearity $1 /$ Echo_Count $)>=0.40))$ OR

$($ Echo_Count $=7$ AND $(($ Linearity $1 /$ Echo_Count $)>=0.50))$ OR

(SLOPE $>=2.5$ ) OR

$(((($ First_Range + Last_Range $) / 2)<21.64)$ AND ((First_Range + Last_Range $) / 2)>=15)$ AND $($ SLOPE $<0.15))$ OR

$(((($ First_Range + Last_Range $) / 2)<15)$ AND ((First_Range + Last_Range $) / 2)>=13.6)$ AND $($ SLOPE $<0.25))$ OR

$(((($ First_Range + Last_Range $) / 2)<13.6)$ AND $((($ First_Range + Last_Range $) / 2)>=13.4)$ AND $($ SLOPE $<0.25))$ OR

$(((($ First_Range + Last_Range $) / 2)<13.4)$ AND $((($ First_Range + Last_Range $) / 2)>=12.6)$ AND $($ SLOPE $<0.3))$ OR

$((($ First_Range + Last_Range $) / 2)<12.6)$ AND $((($ First_Range + Last_Range $) / 2)>=11.95)$ AND $($ SLOPE $<0.6))$ OR

$(((($ First_Range + Last_Range) $/ 2)<11.95)$ AND $((($ First_Range + Last_Range $) / 2)>=8)$ AND $($ SLOPE $<0.2))$ OR

$(((($ First_Range + Last_Range $) / 2)<8)$ AND $($ SLOPE $<0.3))$ OR

$(((($ Noise_Count_Average $) /(($ Echo_Count +10$) * 5))>0.04))$ OR

((First_Range $<=21.19$ AND First_Range $>=21.06$ ) AND (Last_Range $<=21.19$ AND Last_Range $>=21.06)$ ) OR

(((First_Range+Last_Range)/2) $>=20.9$ AND Slope $<=0.2)$ OR

((First_Range $<=20.61$ AND First_Range $>=20.55)$ AND (Last_Range $<=20.61$ AND Last_Range $>=20.55)$ ) OR 
((First_Range $<=10.55$ AND First_Range $>=10.14)$ AND (Last_Range $<=10.55$ AND Last_Range $>=10.14))$ OR ((First_Range $<=21.12$ AND First_Range $>=20.68)$ AND (Last_Range $<=21.12$ AND Last_Range $>=20.68)$ ) OR ((First_Range $<=10.84$ AND First_Range $>=10.65)$ AND (Last_Range $<=10.84$ AND Last_Range $>=10.65)$ ) OR ((First_Range $<=13.93$ AND First_Range $>=13.88$ ) AND (Last_Range $<=13.93$ AND Last_Range $>=13.88)$ ) OR ((First Range $<=19.27$ AND First Range $>=19.23$ ) AND (Last Range $<=19.27$ AND Last Range $>=19.23)$ ) OR ((First_Range $<=20.33$ AND First_Range $>=20.12$ ) AND (Last_Range $<=20.33$ AND Last_Range $>=20.12)$ ) OR ((First_Range $<=19.46$ AND First_Range $>=19.31$ ) AND (Last_Range $<=19.46$ AND Last_Range $>=19.31)$ ) OR ((First_Range $<=10.65$ AND First_Range $>=10.43$ ) AND (Last_Range $<=10.65$ AND Last_Range $>=10.43)$ ) OR ((First_Range $<=20.41$ AND First_Range $>=20.23$ ) AND (Last_Range $<=20.41$ AND Last_Range $>=20.23)$ ) OR ((First_Range $<=10.01$ AND First_Range $>=9.88$ ) AND (Last_Range $<=10.01$ AND Last_Range $>=9.88)$ ) OR ((First_Range $<=20.96$ AND First_Range $>=20.7$ ) AND (Last_Range $<=20.96$ AND Last_Range $>=20.7)$ ) OR ((First_Range $<=20.63$ AND First_Range $>=20.38$ ) AND (Last_Range $<=20.63$ AND Last_Range $>=20.38$ )) THEN DELETE; END;

END;

IF SYSTEM='D' THEN DO;

IF MUX_CHANNEL EQ 1 THEN DO;

IF (( (First_Range + Last_Range) / 2)>21.73) OR

(Echo_Count $=4$ AND $(($ Linearity $1 /$ Echo_Count $)>0.25))$ OR

$($ Echo_Count $=5$ AND $(($ Linearity $1 /$ Echo_Count $)>=0.34))$ OR

(Echo Count $=6$ AND $(($ Linearity $1 /$ Echo - Count $)>=0.40)$ ) OR

$($ Echo_Count $=7$ AND $(($ Linearity $1 /$ Echo_Count $)>=0.50))$ OR

$(((($ First_Range + Last_Range $) / 2)<21.73)$ AND $((($ First_Range + Last_Range $) / 2)>=15)$ AND (SLOPE $<0.15))$ OR

$(((($ First_Range + Last_Range $) / 2)<15)$ AND (((First_Range + Last_Range $) / 2)>=13.15)$ AND (SLOPE < 0.25)) OR

$(((($ First_Range + Last_Range $) / 2)<13.15)$ AND $((($ First_Range + Last_Range $) / 2)>=11.82)$ AND $($ SLOPE $<0.5))$ OR

$(((($ First_Range + Last_Range $) / 2)<11.82)$ AND $((($ First_Range + Last_Range $) / 2)>=10.36)$ AND $($ SLOPE $<0.25))$ OR

$(((($ First_Range + Last_Range $) / 2)<10.36)$ AND $((($ First_Range + Last_Range $) / 2)>=9.65)$ AND $($ SLOPE $<0.45))$ OR

$(((($ First_Range + Last_Range $) / 2)<9.65)$ AND $($ SLOPE $<0.2))$ OR

$((($ Noise_Count_Average $) /(($ Echo_Count +10$) * 5))>0.04))$ OR

((First_Range $<=21.15$ AND First_Range $>=20.97)$ AND (Last_Range $<=21.15$ AND Last_Range $>=20.97)$ ) OR

(((First_Range+Last_Range)/2) $>=20.9$ AND Slope $<=0.3)$ OR

((First_Range $<=21.02$ AND First_Range $>=20.89)$ AND (Last_Range $<=21.02$ AND Last_Range $>=20.89)$ ) OR

$((($ First_Range+Last_Range $) / 2)>=19.54$ AND Slope $<=0.2)$ OR

$((($ First_Range+Last_Range $) / 2)>=10.36$ AND Slope $<=0.4)$ OR

((First_Range $<=12.5$ AND First_Range $>=12.37$ ) AND (Last_Range $<=12.5$ AND Last_Range $>=12.37)$ ) OR

((First_Range $<=21.15$ AND First_Range $>=20.71$ ) AND (Last_Range $<=21.15$ AND Last_Range $>=20.71)$ ) OR

((First_Range $<=19.58$ AND First_Range $>=19.39)$ AND (Last_Range $<=19.58$ AND Last_Range $>=19.39)$ ) OR

((First_Range $<=13.62$ AND First_Range $>=13.43$ ) AND (Last_Range $<=13.62$ AND Last_Range $>=13.43)$ ) OR

((First_Range $<=12.73$ AND First_Range $>=12.65)$ AND (Last_Range $<=12.73$ AND Last_Range $>=12.65)$ )

THEN DELETE;

END;

IF MUX CHANNEL EQ 2 THEN DO;

IF (TRACK_TYPE=1) OR

((First_Range + Last Range) / 2)>21.25) OR

(Echo_Count $=4$ AND $(($ Linearity $1 /$ Echo_Count $)>0.25))$ OR

(Echo_Count $=5$ AND $(($ Linearity $1 /$ Echo_Count $)>=0.34))$ OR

$($ Echo_Count $=6$ AND $(($ Linearity $1 /$ Echo_Count $)>=0.40))$ OR

(Echo_Count $=7$ AND $(($ Linearity $1 /$ Echo_Count $)>=0.50))$ OR

(SLOPE >= 2.5) OR

$(\mathrm{SLOPE}<0.2)$ OR

$(((($ First_Range + Last_Range) $/ 2)<21.25)$ AND (((First_Range + Last_Range) $/ 2)>=19.75)$ AND (SLOPE $<0.15))$ OR

$(((($ First_Range + Last_Range $) / 2)<19.75)$ AND $((($ First_Range + Last_Range $) / 2)>=18.9)$ AND $($ SLOPE $<0.45))$ OR

$(((($ First_Range + Last_Range $) / 2)<12.76)$ AND $((($ First_Range + Last_Range $) / 2)>=11.64)$ AND $($ SLOPE $<0.45))$ OR

$(((($ First_Range + Last_Range $) / 2)<10.5)$ AND $((($ First_Range + Last_Range $) / 2)>=9.65)$ AND $($ SLOPE $<0.45))$ OR

$(((($ First_Range + Last_Range $) / 2)<6.5)$ AND $($ SLOPE $<0.3))$ OR

$(((($ Noise_Count_Average $) /(($ Echo_Count +10$) * 5))>0.04))$ OR

((First_Range $<=21.05$ AND First_Range $>=20.84)$ AND (Last_Range $<=21.05$ AND Last_Range $>=20.84)$ ) OR

(((First_Range+Last_Range)/2) $>=20.93$ AND Slope $<=0.35)$ OR

((First Range $<=19.81$ AND First Range $>=19.49)$ AND (Last Range $<=19.81$ AND Last Range $>=19.49)$ ) OR

((First_Range $<=20.73$ AND First_Range $>=20.53$ ) AND (Last_Range $<=20.73$ AND Last_Range $>=20.53)$ ) OR

((First Range $<=12.89$ AND First Range $>=12.79$ ) AND (Last_Range $<=12.89$ AND Last Range $>=12.79$ )) OR

((First_Range $<=20.17$ AND First_Range $>=20.07$ ) AND (Last_Range $<=20.17$ AND Last_Range $>=20.07)$ ) OR

((First_Range $<=20.41$ AND First_Range $>=20.22$ ) AND (Last_Range $<=20.41$ AND Last_Range $>=20.22)$ ) OR

((First_Range $<=19.56$ AND First_Range $>=19.31$ ) AND (Last_Range $<=19.56$ AND Last_Range $>=19.31)$ ) OR

((First_Range $<=20.9$ AND First_Range $>=20.76$ ) AND (Last_Range $<=20.9$ AND Last_Range $>=20.76)$ ) OR

((First_Range $<=7.06$ AND First_Range $>=6.95$ ) AND (Last_Range $<=7.06$ AND Last_Range $>=6.95)$ ) OR

((First_Range $<=15.63$ AND First_Range $>=15.56)$ AND (Last_Range $<=15.63$ AND Last_Range $>=15.56)$ ) OR

$((($ First_Range+Last_Range $) / 2)>=19$ AND Noise_Count_Average $>3$ )

THEN DËLETE; 
END;

IF MUX_CHANNEL EQ 3 THEN DO;

IF (TRACK TYPE=1) OR

(((First_Range + Last_Range) / 2)>21.66) OR

(Echo Count $=4$ AND $(($ Linearity $1 /$ Echo Count $)>0.25))$ OR

$($ Echo_Count $=5$ AND $(($ Linearity1 $/$ Echo_Count $)>=0.34))$ OR

(Echo Count $=6$ AND $(($ Linearity $1 /$ Echo_Count $)>=0.40)$ ) OR

(Echo_Count $=7$ AND $(($ Linearity1 $/$ Echo_Count $)>=0.50)$ ) OR

(LINEARITY1>3.2 AND LINEARITY2>3.2 AND NOISE_COUNT_AVERAGE>3) OR

(SLOPE $>=2$ ) OR

(SLOPE < 0.15) OR

$(((($ First_Range + Last_Range) / 2) < 21.66) AND (((First_Range + Last_Range) / 2) >= 18) AND (SLOPE < 0.1)) OR

$(((($ First Range + Last Range $) / 2)<18)$ AND (((First Range + Last Range $) / 2)>=15)$ AND (SLOPE $<0.15))$ OR

$(((($ First_Range + Last_Range $) / 2)<15)$ AND (((First_Range + Last_Range) $/ 2)>=13.40)$ AND (SLOPE $<0.2))$ OR

$(((($ First_Range + Last_Range $) / 2)<13.40)$ AND $((($ First_Range + Last_Range $) / 2)>=11.57)$ AND $($ SLOPE $<0.7))$ OR

$(((($ First_Range + Last_Range $) / 2)<10.45)$ AND (((First_Range + Last_Range $) / 2)>=9.65)$ AND $($ SLOPE $<0.7))$ OR

$(((($ First_Range + Last_Range $) / 2)<6.5)$ AND $($ SLOPE $<0.3))$ OR

$(((($ Noise_Count_Average $) /(($ Echo_Count +10$) * 5))>0.04))$ OR

((First_Range $<=19.91$ AND First_Range $>=19.34)$ AND (Last_Range $<=19.91$ AND Last_Range $>=19.34)$ ) OR ((First_Range $<=20.84$ AND First_Range $>=20.68$ ) AND (Last_Range $<=20.84$ AND Last_Range $>=20.68$ )) OR ((First_Range $<=13.78$ AND First_Range $>=13.36$ ) AND (Last_Range $<=13.78$ AND Last_Range $>=13.36)$ ) OR ((First Range $<=19.74$ AND First Range $>=19.68)$ AND (Last Range $<=19.74$ AND Last Range $>=19.68)$ ) OR ((First_Range $<=13.88$ AND First_Range $>=13.84$ ) AND (Last_Range $<=13.88$ AND Last_Range $>=13.84)$ ) OR ((First Range $<=14.42$ AND First Range $>=14.39$ ) AND (Last Range $<=14.42$ AND Last Range $>=14.39$ )) OR ((First_Range $<=10.58$ AND First_Range $>=10.54)$ AND (Last_Range $<=10.58$ AND Last_Range $>=10.54)$ ) OR ((First_Range $<=20.92$ AND First_Range $>=20.87$ ) AND (Last_Range $<=20.92$ AND Last_Range $>=20.87$ )) OR ((First_Range $<=20.45$ AND First_Range $>=20.2)$ AND (Last_Range $<=20.45$ AND Last_Range $>=20.2)$ ) OR ((First_Range $<=20.3$ AND First_Range $>=20.0$ ) AND (Last_Range $<=20.3$ AND Last_Range $>=20.0)$ ) OR

(((First_Range+Last_Range)/2) $>=19$ AND Noise_Count_Average $>2.8)$ OR

((First Range $<=14.48$ AND First Range $>=14 . \overline{36}$ ) AND (Last Range $<=14.48$ AND Last Range $>=14.36)$ ) OR ((First_Range $<=19.62$ AND First_Range $>=19.30)$ AND (Last_Range $<=19.62$ AND Last_Range $>=19.30)$ ) OR ((First_Range $<=18.37$ AND First_Range $>=18.34$ ) AND (Last_Range $<=18.37$ AND Last_Range $>=18.34)$ ) OR ((First_Range $<=18.73$ AND First_Range $>=18.47$ ) AND (Last_Range $<=18.73$ AND Last_Range $>=18.47)$ ) OR ((First_Range $<=17.95$ AND First_Range $>=17.77)$ AND (Last_Range $<=17.95$ AND Last_Range $>=17.77)$ ) THEN DELETE;

END;

IF MUX_CHANNEL EQ 4 THEN DO;

IF (TRACK_TYPE $=1$ AND SLOPE $<0.7)$ OR

(((First_Range + Last_Range) / 2) >21.38) OR

$($ Echo_Count $=4$ AND $(($ Linearity1 $/$ Echo_Count $)>0.25))$ OR

(Echo Count $=5$ AND ((Linearity1 $/$ Echo Count $)>=0.34)$ ) OR

$($ Echo_Count $=6$ AND $(($ Linearity $1 /$ Echo_Count $)>=0.40))$ OR

(Echo Count $=7$ AND $(($ Linearity $1 /$ Echo Count $)>=0.50)$ OR

(LINEARITY1>3.2 AND LINEARITY2>3.2 AND NOISE_COUNT_AVERAGE>3) OR

(LINEARITY1>5.5 AND LINEARITY2>5.5 AND SLOPE<0.7) OR

(SLOPE >= 2) OR

$(\mathrm{SLOPE}<0.15)$ OR

$(((($ First_Range + Last_Range) / 2) < 21.38) AND (((First_Range + Last_Range) / 2) $>=18)$ AND (SLOPE <0.1)) OR

$(((($ First_Range + Last_Range $) / 2)<18)$ AND $((($ First_Range + Last_Range $) / 2)>=15)$ AND $(\mathrm{SLOPE}<0.15))$ OR

$(((($ First_Range + Last_Range $) / 2)<15)$ AND $((($ First_Range + Last_Range $) / 2)>=12.9)$ AND $($ SLOPE $<0.2))$ OR

$(((($ First_Range + Last_Range $) / 2)<12.9)$ AND $((($ First_Range + Last_Range $) / 2)>=12.56)$ AND $($ SLOPE $<0.5))$ OR

$(((($ First_Range + Last_Range $) / 2)<12.3)$ AND $((($ First_Range + Last_Range $) / 2)>=12.2)$ AND $($ SLOPE $<0.5))$ OR

$(((($ First_Range + Last_Range $) / 2)<11.8)$ AND $((($ First_Range + Last_Range $) / 2)>=11.5)$ AND $($ SLOPE $<0.5))$ OR

$(((($ First_Range + Last_Range $) / 2)<10.15)$ AND $((($ First_Range + Last_Range $) / 2)>=9.5)$ AND $($ SLOPE < 0.5) $)$ OR

$(((($ First_Range + Last_Range $) / 2)<6.5)$ AND $($ SLOPE $<0.3))$ OR

$(((($ Noise_Count_Average $) /(($ Echo_Count +10$) * 5))>0.04))$ OR

((First_Range $<=12.41$ AND First_Range $>=12.38)$ AND (Last_Range $<=12.41$ AND Last_Range $>=12.38)$ ) OR ((First_Range $<=10.43$ AND First_Range $>=10.04)$ AND (Last_Range $<=10.43$ AND Last_Range $>=10.04)$ ) OR ((First_Range $<=20.45$ AND First_Range $>=20.20$ ) AND (Last_Range $<=20.45$ AND Last_Range $>=20.20)$ ) OR ((First Range $<=12.12$ AND First Range $>=12.08)$ AND (Last Range $<=12.12$ AND Last Range $>=12.08)$ ) OR ((First_Range $<=10.26$ AND First_Range $>=10.20)$ AND (Last_Range $<=10.26$ AND Last_Range $>=10.20)$ ) OR ((First Range $<=20.77$ AND First Range $>=20.57$ ) AND (Last Range $<=20.77$ AND Last Range $>=20.57$ )) OR ((First_Range $<=10.49$ AND First_Range $>=10.42$ ) AND (Last_Range $<=10.49$ AND Last_Range $>=10.42)$ ) OR ((First_Range $<=20.64$ AND First_Range $>=20.32$ ) AND (Last_Range $<=20.64$ AND Last_Range $>=20.32)$ ) OR ((First_Range $<=16.16$ AND First_Range $>=16.13)$ AND (Last_Range $<=16.16$ AND Last_Range $>=16.13)$ ) OR ((First_Range $<=19.02$ AND First_Range $>=18.91)$ AND (Last_Range $<=19.02$ AND Last_Range $>=18.91)$ ) OR ((First_Range $<=9.4$ AND First_Range $>=9.37$ ) AND (Last_Range $<=9.4$ AND Last_Range $>=9.37)$ ) OR

((First_Range $<=20.16$ AND First_Range $>=20.07$ ) AND (Last_Range $<=20.16$ AND Last_Range $>=20.07)$ ) OR

((First_Range $<=20.16$ AND First_Range $>=9.95)$ AND (Last_Range $<=10.16$ AND Last_Range $>=9.95)$ ) THEN DELETE; 
END;

IF MUX_CHANNEL EQ 5 THEN DO;

IF (TRACK TYPE=1) OR

$((($ First_Range + Last_Range $) / 2)>22.11)$ OR

(Echo Count $=4$ AND $(($ Linearity $1 /$ Echo Count $)>0.25))$ OR

$($ Echo_Count $=5$ AND $(($ Linearity1 $/$ Echo_Count $)>=0.34))$ OR

(Echo Count $=6$ AND $(($ Linearity $1 /$ Echo_Count $)>=0.40))$ OR

(Echo_Count $=7$ AND $(($ Linearity1 $/$ Echo_Count $)>=0.50)$ ) OR

(LINEARITY1>3.5 AND LINEARITY2>3.5 AND NOISE_INDEX>6.5 AND SLOPE<0.85) OR

(LINEARITY1>4.5 AND LINEARITY2>3.5 AND NOISE_COUNT_AVERAGE>3.5) OR

(SLOPE $>=2$ ) OR

$(\mathrm{SLOPE}<0.15)$ OR

$((($ First_Range + Last_Range $) / 2)<22.11)$ AND $((($ First_Range + Last_Range $) / 2)>=19.85)$ AND $($ SLOPE $<0.1))$ OR

$(((($ First_Range + Last_Range $) / 2)<19.85)$ AND (((First_Range + Last_Range $) / 2)>=19.5)$ AND $($ SLOPE $<0.5))$ OR

$(((($ First_Range + Last_Range $) / 2)<19.5)$ AND $((($ First_Range + Last_Range $) / 2)>=12.7)$ AND $($ SLOPE $<0.15))$ OR

$(((($ First_Range + Last_Range $) / 2)<12.7)$ AND $((($ First_Range + Last_Range $) / 2)>=11.9)$ AND (SLOPE < 0.5)) OR

$(((($ First_Range + Last_Range $) / 2)<8.61)$ AND $((($ First_Range + Last_Range $) / 2)>=8.16)$ AND $($ SLOPE $<0.5))$ OR

$(((($ First_Range + Last_Range $) / 2)<6.5)$ AND $($ SLOPE $<0.3))$ OR

$((($ Noise_Count_Average $) /(($ Echo_Count +10$) * 5))>0.04))$ OR

((First Range $<=20.9$ AND First Range $>=20.87$ ) AND (Last Range $<=20.9$ AND Last Range $>=20.87$ )) OR

((First_Range $<=12.92$ AND First_Range $>=12.43$ ) AND (Last_Range $<=12.92$ AND Last_Range $>=12.43)$ ) OR

((First Range $<=20.95$ AND First Range $>=20.36$ ) AND (Last Range $<=20.95$ AND Last Range $>=20.36)$ ) OR

((First_Range $<=13.26$ AND First_Range $>=13.04$ ) AND (Last_Range $<=13.26$ AND Last_Range $>=13.04)$ ) OR

((First Range $<=20.61$ AND First Range $>=20.39$ ) AND (Last Range $<=20.61$ AND Last Range $>=20.39$ )) OR

((First_Range $<=10.67$ AND First_Range $>=10.57$ ) AND (Last_Range $<=10.67$ AND Last_Range $>=10.57)$ ) OR

((First Range $<=13.04$ AND First Range $>=12.72$ ) AND (Last Range $<=13.04$ AND Last Range $>=12.72)$ ) OR

((First_Range $<=19.64$ AND First_Range $>=19.40$ ) AND (Last_Range $<=19.64$ AND Last_Range $>=19.40)$ ) OR

((First_Range $<=9.63$ AND First_Range $>=9.56$ ) AND (Last_Range $<=9.63$ AND Last_Range $>=9.56)$ ) OR

((First_Range $<=10.35$ AND First_Range $>=10.32)$ AND (Last_Range $<=10.35$ AND Last_Range $>=10.32)$ ) OR

((First_Range $<=19.49$ AND First_Range $>=19.23$ ) AND (Last_Range $<=19.49$ AND Last_Range $>=19.23)$ ) OR

((First_Range $<=20.54$ AND First_Range $>=20.46)$ AND (Last_Range $<=20.54$ AND Last_Range $>=20.46)$ ) OR

$((($ First Range + Last Range $) / 2)>19)$ AND ((Noise Count Average $>2))$ OR

((First_Range $<=10.19$ AND First_Range $>=10.16)$ AND (Last_Range $<=10.19$ AND Last_Range $>=10.16)$ ) OR

((First_Range $<=10$ AND First_Range $>=9.97$ ) AND (Last_Range $<=10$ AND Last_Range $>=9.97)$ ) OR

$((($ First_Range + Last_Range) / 2) $>20)$ AND ((Slope < .4)) OR

((First_Range $<=6.91$ AND First_Range $>=6.84$ ) AND (Last_Range $<=6.91$ AND Last_Range $>=6.84)$ ) OR

((First_Range $<=9.91$ AND First_Range $>=9.68$ ) AND (Last_Range $<=9.91$ AND Last_Range $>=9.68)$ ) OR

((First_Range $<=20.16$ AND First_Range $>=20.06$ ) AND (Last_Range $<=20.16$ AND Last_Range $>=20.06)$ )

THEN DELETE;

END;

IF MUX CHANNEL EQ 6 THEN DO;

IF (TRACK_TYPE=1) OR

(((First Range + Last Range) / 2)>21.59) OR

(Echo_Count $=4$ AND $(($ Linearity1 $/$ Echo_Count $)>0.25))$ OR

(Echo Count $=5$ AND $(($ Linearity $1 /$ Echo_Count $)>=0.34))$ OR

$($ Echo_Count $=6$ AND $(($ Linearity1 $/$ Echo_Count $)>=0.40))$ OR

(Echo Count $=7$ AND ((Linearity1 $/$ Echo Count $)>=0.50)$ OR

(LINEARITY1>4.5 AND LINEARITY2>3.5 AND SLOPE<0.5) OR

(SLOPE $>=2.5)$ OR

$(((($ First_Range + Last_Range) / 2) < 21.59) AND (((First_Range + Last_Range) / 2) >= 15) AND (SLOPE < 0.1)) OR

$(((($ First_Range + Last_Range $) / 2)<15)$ AND $((($ First_Range + Last_Range $) / 2)>=13.16)$ AND $($ SLOPE $<0.15))$ OR

$(((($ First_Range + Last_Range $) / 2)<13.16)$ AND (((First_Range + Last_Range $) / 2)>=11.55)$ AND $($ SLOPE $<0.8))$ OR

$(((($ First_Range + Last_Range $) / 2)<10.25)$ AND $((($ First_Range + Last_Range $) / 2)>=9.5)$ AND $($ SLOPE $<0.7))$ OR

$(((($ First_Range + Last_Range $) / 2)<9.5)$ AND $((($ First_Range + Last_Range $) / 2)>=3)$ AND $($ SLOPE $<0.2))$ OR

$(((($ First_Range + Last_Range $) / 2)<3)$ AND $($ SLOPE $<0.3))$ OR

$(((($ Noise_Count_Average $) /(($ Echo_Count +10$) * 5))>0.04))$ OR

((First_Range $<=10.77$ AND First_Range $>=10.61)$ AND (Last_Range $<=10.77$ AND Last_Range $>=10.61)$ ) OR $(((($ First_Range + Last_Range $) / 2)>=20.5)$ AND (SLOPE $<0.2))$ OR

((First_Range $<=10.61$ AND First_Range $>=10.35)$ AND (Last_Range $<=10.61$ AND Last_Range $>=10.35)$ ) OR ((First_Range $<=20.51$ AND First_Range $>=20.28)$ AND (Last_Range $<=20.51$ AND Last_Range $>=20.28)$ ) OR (slope $<0.01$ ) OR

((First Range $<=21.35$ AND First Range $>=21.32$ ) AND (Last Range $<=21.35$ AND Last Range $>=21.32)$ ) OR

((First_Range $<=10.26$ AND First_Range $>=10.24)$ AND (Last_Range $<=10.26$ AND Last_Range $>=10.24)$ ) OR

((First_Range $<=13.26$ AND First_Range $>=13.23$ ) AND (Last_Range $<=13.26$ AND Last_Range $>=13.23)$ ) OR

((First_Range $<=13.62$ AND First_Range $>=13.59)$ AND (Last_Range $<=13.62$ AND Last_Range $>=13.59)$ ) OR

((First_Range $<=10.39$ AND First_Range $>=10.32$ ) AND (Last_Range $<=10.39$ AND Last_Range $>=10.32)$ )

THEN DELETE; END;

END; 


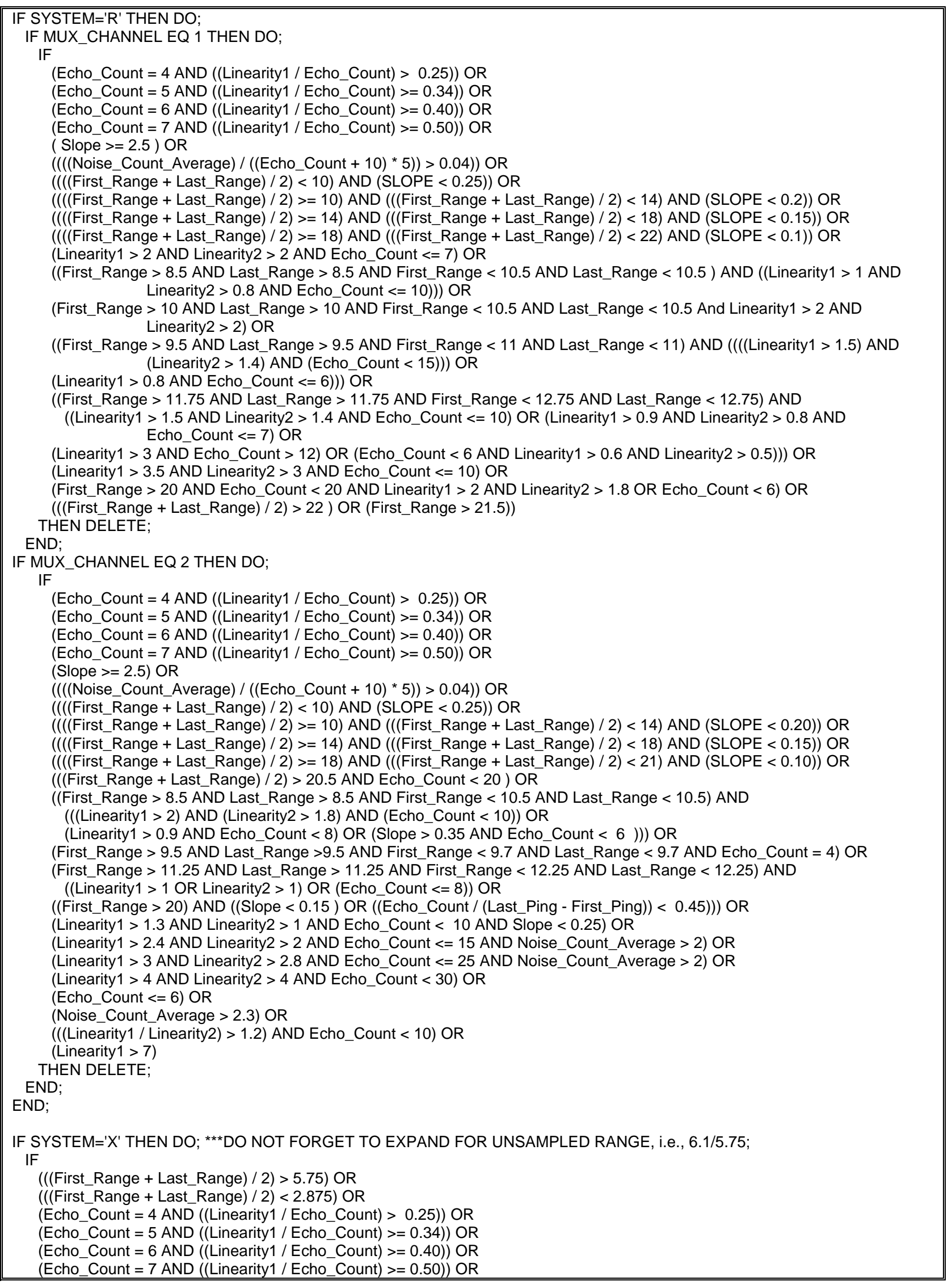




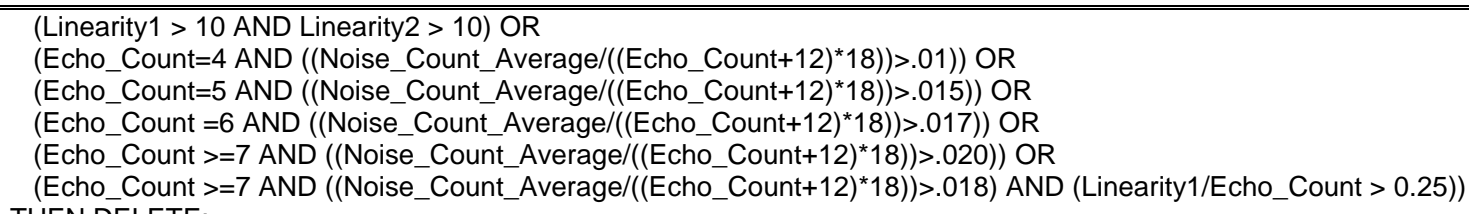

IF KCFS GE 6.3 AND KCFS LT 9.1 THEN DO:

IF (((Last_Ping + 1 - First_Ping) / Group_Size $)>100)$ OR (mean_pulse_width $>300$ ) OR

(LINEARITY1 < 0.5 AND LINEARITY2 < 0.5 AND SLOPE < 0.1 AND ABS(FIRST_RANGE - LAST_RANGE) < 0.05) OR $(($ FIRST RANGE $=$ LAST RANGE AND SLOPE $<=0)$ AND (FIRST RANGE + LASST RANGE) $/ 2<=10.20)$ OR $(($ FIRST_RANGE + LAST_RANGE)/2 > 11.00) OR

((FIRST RANGE + LAST RANGE)/2 > 9.5 AND (FIRST RANGE + LAST RANGE)/2 $<=9.7$ AND MUX CHANNEL=2) OR ((FIRST_RANGE + LAST_RANGE)/2 > 9.75 AND (FIRST̄_RANGE + LAST̄_RANGE)/2 < $=9.95$ AND MUX_CHANNEL=2) OR ((FIRST_RANGE + LAST_RANGE)/2 > 10.3 AND (FIRST_RANGE + LAST_RANGE)/2 $<=10.4$ AND MUX_CHANNEL $=2)$ OR $((F I R S T+R A N G E+$ LAST_RANGE)/2 > $=9.85$ AND (FIRST'_RANGE + LAST̄_RANGE)/2 <= 10.25 AND MŪX_CHANNEL=5) OR

((FIRST_RANGE + LAST_RANGE)/2 >=9.75 AND (FIRST_RANGE + LAST_RANGE)/2 <= 9.80 AND MUX_CHANNEL=5) OR

((FIRST_RANGE + LAST_RANGE)/2 > 9.75 AND (FIRST_RANGE + LAST_RANGE)/2 $<=11.00$ AND SLOPE $<-0.5)$ OR $(($ FIRST_RANGE + LAST_RANGE)/2 $>9.25$ AND (FIRST_RANGE + LAST_RANGE) $/ 2<=9.75$ AND SLOPE $<0.2)$ OR 
((FIRST RANGE + LAST RANGE)/2 > 7.00 AND (FIRST_RANGE + LAST RANGE)/2 <= 9.25 AND SLOPE < 0.5) OR ((FIRST_RANGE + LAST_RANGE)/2 > 6.00 AND (FIRST_RANGE + LAST_RANGE)/2<= 7.00 AND SLOPE $<0.6)$ OR ((FIRST_RANGE + LAST RANGE)/2 $<=6.00$ AND SLOPE $<=0.6)$ OR

(SLOPE $>4.5$ OR SLOPE $<-4.5)$ OR

(Linearity2 > 4) OR

((Linearity1 / Echo_Count >= 0.45) AND (Linearity2 > 2.5) AND ECHO_COUNT < 25 AND SLOPE < 2 AND (FIRST_RANGE + LASTT_RANGE) $/ 2<10.00$ ) OR

$(($ Echo_Count $=4$ OR Echo_Count $=5)$ AND $(($ Linearity1 $/$ Echo_Count $)>=0.4))$ OR

$(($ Echo_Count $=6$ OR Echo_Count $=7)$ AND $(($ Linearity1 $/$ Echo_Count $)>=0.6)$ AND $($ FIRST_RANGE + LAST_RANGE)/2 < 10.00) OR

((Linearity2 / Echo Count) $>0.6)$ OR

$((($ Noise_Count_Average $) /(($ Echo_Count +10$) * 5))>0.045)$

THEN DELETE;

END;

IF KCFS GE 9.1 THEN DO;

IF ((Last_Ping + 1 - First_Ping) / Group_Size $)>100)$ OR

(mean_pulse_width $>300$ ) OR

$(\mathrm{SLOPE}>4 . \overline{5} \mathrm{OR}$ SLOPE $<-4.5)$ OR

((FIRST RANGE + LAST RANGE)/2 > 11.50) OR

((FIRST_RANGE + LAST_RANGE)/2 > 9.75 AND (FIRST_RANGE + LAST_RANGE) $/ 2<=11.50$ AND SLOPE $<-0.5)$ OR ((FIRST_RANGE + LAST_RANGE)/2 > 10.55 AND (FIRST̄RANGE + LAST̄_RANGE)/2 < $=10.85$ AND MUX_CHANNEL=2 AND SLOPE $<1)$ OR

((FIRST RANGE + LAST RANGE) $/ 2>9.10$ AND (FIRST RANGE + LAST RANGE) $/ 2<=9.75$ AND SLOPE < 0.7) OR ((FIRST_RANGE + LAST_RANGE)/2 > 6.00 AND (FIRST_RANGE + LAST_RANGE)/2<=9.10 AND SLOPE < 0.8) OR ((FIRST_RANGE + LAST_RANGE)/2 $<=6.00$ AND SLOPE $<=1)$ OR

$(($ ECHO_COUNT < 7) AND $($ ABS $($ LAST_RANGE-FIRST_RANGE) $>0.75))$ OR

((SLOPE $>1)$ AND (LINEARITY1 >3) AND (LINEARITY2 >3)) OR

((Linearity1 / Echo_Count >= 0.32) AND (Linearity2 > 2) AND ECHO_COUNT < 15 AND SLOPE < 1.5) OR

(Linearity2 > 4) OR

(Echo_Count $=4$ AND $(($ Linearity1 $/$ Echo_Count $)>0.25))$ OR

(Echo_Count $=5$ AND $(($ Linearity $1 /$ Echo_Count $)>=0.34))$ OR

$(($ Echo_Count $=6$ OR Echo_Count $=7)$ AND $(($ Linearity1 $/$ Echo_Count $)>=0.5))$ OR

((Linearity2 / Echo_Count) $>0.6)$ OR

$((($ Noise_Count_Average $) /(($ Echo_Count +10$) * 5))>0.045)$

THEN DELETE;

END;

END;

*** Ready for 2005;

IF SYSTEM = 'M' THEN DO; **Split beam downlooking Xder at Spillway SB5 \& SB7;

IF KCFS LT 3.3 THEN DO;

IF (((Last_Ping +1 - First_Ping) / Group_Size $)>100)$ OR

(mean pulse width $>300$ ) OR

((FIRST_RAN̄GE + LAST_RANGE)/2 > 10.00) OR

((FIRST_RANGE + LAST_RANGE)/2 $>9.10$ AND (FIRST_RANGE + LAST RANGE) $/ 2<=9.50$ AND SLOPE $<0.1)$ OR $(($ FIRST_RANGE + LAST_RANGE)/2 > 8.00 AND (FIRST_RANGE + LAST_RANGE)/2<=9.10 AND SLOPE $<0.2)$ OR ((FIRST_RANGE + LAST_RANGE)/2 $<=8.00$ AND SLOPE $<=0.8)$ OR

((Linearity2 > 4) AND (ECHO_COUNT < 30)) OR

(Echo_Count $=4$ AND $(($ Linearity $1 /$ Echo_Count $)>0.25))$ OR

$($ Echo_Count $=5$ AND $(($ Linearity1 $/$ Echo_Count $)>=0.34))$ OR

$($ Echo_Count $=6$ AND $(($ Linearity $1 /$ Echo_Count $)>=0.40))$ OR

$($ Echo_Count $=7$ AND $(($ Linearity1 $/$ Echo_Count $)>=0.50))$ OR

((Linearity2 / Echo_Count) $>0.6)$ OR

((Linearity1 / Echo_Count) $>0.5)$ OR

$($ NOISE_INDEX $>\overline{10})$ OR

$((($ Noise_Count_Average $) /(($ Echo_Count +10$) * 5))>0.045)$

THEN DELETE;

END;

IF KCFS GE 3.3 AND KCFS LT 6.3 THEN DO;

IF ((Last_Ping +1 - First_Ping) / Group_Size $)>100)$ OR

(mean_pulse_width >300) OR

((FIRST_RANGE + LAST_RANGE)/2 > 10.50) OR

((FIRST_RANGE + LAST_RANGE)/2 > 9.75 AND (FIRST_RANGE + LAST_RANGE)/2 $<=10.50$ AND SLOPE $<-1)$ OR $(($ FIRST_RANGE + LAST_RANGE)/2 > 9.20 AND (FIRST_RANGE + LAST_RANGE)/2 < $=9.75$ AND (SLOPE $<0.1$ OR SLOPE > 2)) OR

((FIRST_RANGE + LAST_RANGE)/2 $>7.00$ AND (FIRST_RANGE + LAST_RANGE)/2 $<=9.20$ AND SLOPE $<0.2)$ OR ((FIRST_RANGE + LAST_RANGE)/2 > 6.00 AND (FIRST_RANGE + LAST_RANGE)/2<= 7.00 AND SLOPE $<0.3)$ OR $(($ FIRST_RANGE + LAST_RANGE $) / 2<=6.00$ AND SLOPE $<=0.5)$ OR 


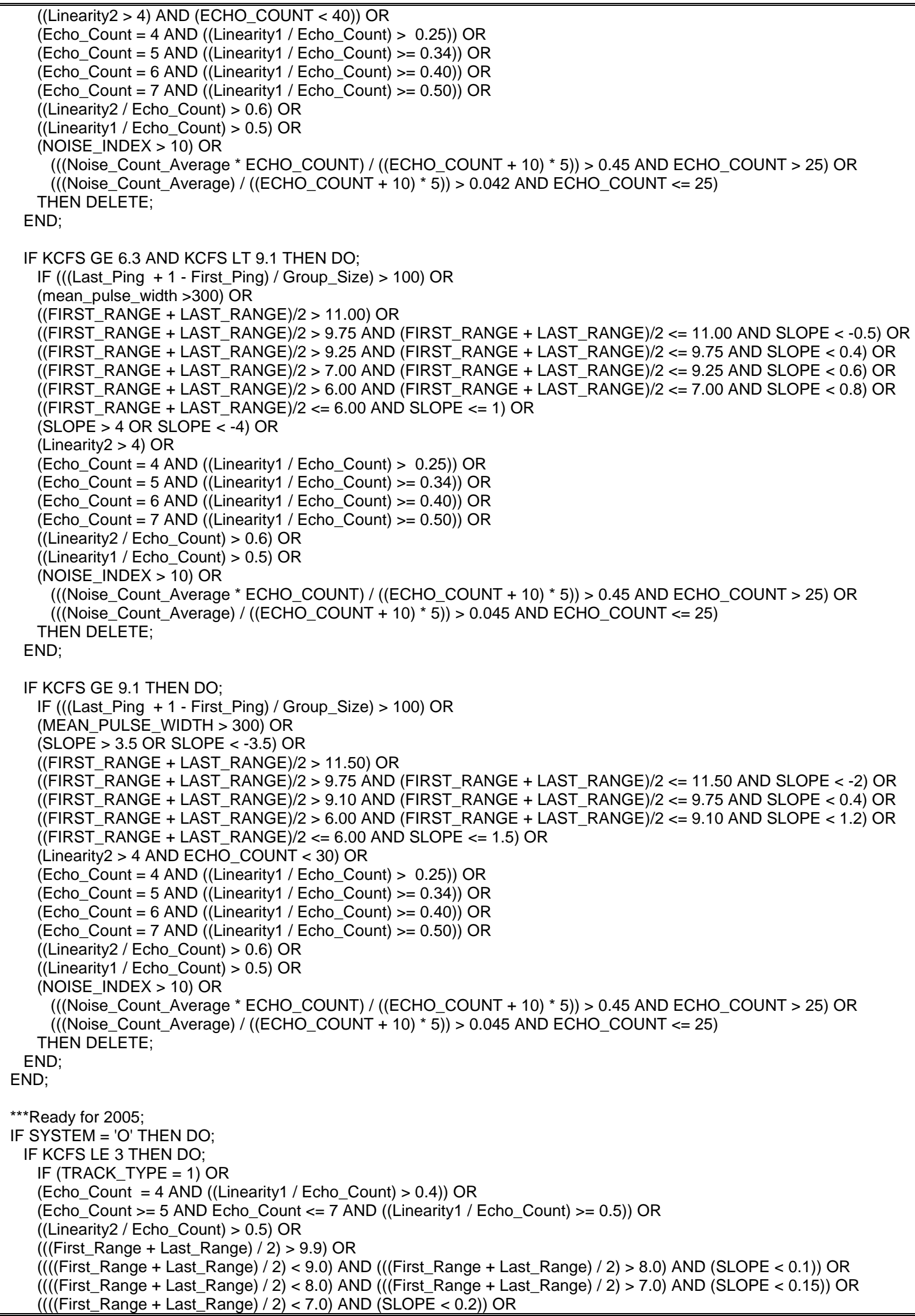


$(((($ Noise_Count_Average $) /(($ Echo_Count + 10 $)$ * 5) $)>0.04))$ THEN DELETE;

END;

IF KCFS GT 3 AND KCFS LE 4 THEN DO;

IF (TRACK_TYPE = 1) OR

$($ Echo_Count $=4$ AND $(($ Linearity1 $/$ Echo_Count $)>0.4))$ OR

(Echo_Count $>=5$ AND Echo_Count $<=7$ AND ((Linearity1 / Echo_Count) $>=0.5)$ ) OR

$(($ Linearity2 / Echo_Count) $>0.5)$ OR (((First_Range + Last_Range $) / 2)>10.1)$ OR

$(((($ First_Range + Last_Range $) / 2)>9.5)$ AND $($ SLOPE $<-0.2))$ OR

$(((($ First_Range + Last_Range) / 2) $<=9.5)$ AND ((First_Range + Last_Range $) / 2)>=9.25)$ AND $($ SLOPE $<0.5))$ OR

$(((($ First_Range + Last_Range $) / 2)<9.0)$ AND $((($ First_Range + Last_Range $) / 2)>8.0)$ AND $($ SLOPE $<0.1))$ OR

$(((($ First_Range + Last_Range $) / 2)<8.0)$ AND $((($ First_Range + Last_Range $) / 2)>7.0)$ AND $($ SLOPE $<0.15))$ OR

$(((($ First_Range + Last_Range $) / 2)<7.0)$ AND $($ SLOPE $<0.2))$ OR

$((($ Noise_Count_Average $) /(($ Echo_Count +10$) * 5))>0.04))$ OR

(NOISE_COUNT_AVERAGE > 2.5) OR

(LINEARITY1 $>2$ AND LINEARITY2 $>2$ AND NOISE_COUNT_AVERAGE > 2) OR

(LINEARITY1 > 2.4 AND LINEARITY2 > 2.4)

THEN DELETE;

END;

IF KCFS GT 4 AND KCFS LE 5 THEN DO;

IF (TRACK_TYPE = 1) OR

$($ Echo_Count $=4$ AND $(($ Linearity1 $/$ Echo_Count $)>0.4))$ OR

(Echo_Count $>=5$ AND Echo_Count $<=7$ AND ((Linearity1 / Echo_Count) $>=0.5)$ ) OR

$(($ Linearity2 / Echo_Count) $>0.5)$ OR

$((($ First_Range + Last_Range $) / 2)>10.05)$ OR

$(((($ First_Range + Last_Range) / 2) < 9.3) AND ((First_Range + Last_Range $) / 2)>8.0)$ AND $($ SLOPE < 0.1)) OR

$(((($ First_Range + Last_Range $) / 2)<8.0)$ AND $((($ First_Range + Last_Range $) / 2)>7.0)$ AND $($ SLOPE $<0.15))$ OR

$((($ First_Range + Last_Range) $/ 2)<7.0)$ AND $($ SLOPE $<0.2))$ OR

$(((($ Noise_Count_Averäge $) /(($ Echo_Count +10$) * 5))>0.04))$ OR

$((($ First_Range + Last_Range $) / 2)>9.5)$ AND $($ SLOPE $<-0.2))$ OR

(LINEARITY1 > 2.4 AND LINEARITY2 > 2.4 AND ECHO_COUNT < 20) OR

$(((($ First_Range + Last_Range) / 2) $<=9.0)$ AND $((($ First_Range + Last_Range $) / 2)>=8.5)$ AND $($ SLOPE $<=0.5)$ AND THEN DELETE; $($ ECHO_COUNT $<=8)$ )

END;

IF KCFS GT 5 AND KCFS LE 6 THEN DO;

IF (TRACK_TYPE = 1) OR

(Echo_Count $=4$ AND $(($ Linearity1 $/$ Echo_Count $)>0.4))$ OR

(Echo_Count $>=5$ AND Echo_Count $<=7$ AND ((Linearity1 / Echo_Count) $>=0.5))$ OR

$(($ Linearity2 / Echo_Count $)>0.5)$ OR

$((($ First_Range + Lâst_Range $) / 2)>10.2)$ OR

$((($ First_Range + Last_Range $) / 2)>9.3)$ AND $($ SLOPE $<-0.2))$ OR

$(((($ First_Range + Last_Range $) / 2)<9.3)$ AND (((First_Range + Last_Range $) / 2)>8.3)$ AND $($ SLOPE $<0.15))$ OR

$((($ First_Range + Last_Range $) / 2)<8.3)$ AND $((($ First_Range + Last_Range $) / 2)>7.3)$ AND $($ SLOPE $<0.15))$ OR

$(((($ First_Range + Last_Range $) / 2)<7.3)$ AND $($ SLOPE $<0.2))$ OR

$((($ Noise_Count_Average $) /(($ Echo_Count +10$) * 5))>0.04))$ OR

(LINEARITY1 > 2.4 AND LINEARITY2 > 2.4 AND ECHO_COUNT < 12)

THEN DELETE;

END;

IF KCFS GT 6 AND KCFS LE 7 THEN DO;

IF (TRACK_TYPE = 1) OR

(Echo_Count $=4$ AND $(($ Linearity1 $/$ Echo_Count $)>0.4))$ OR

(Echo_Count $>=5$ AND Echo_Count $<=7$ AND ((Linearity1 / Echo_Count) $>=0.5)$ ) OR

((Linearity2 / Echo_Count) $>0.5)$ OR

$((($ First_Range + Last_Range $) / 2)>10.5)$ OR

$((($ First_Range + Last_Range $) / 2)>=9.4)$ AND SLOPE $<-0.15)$ OR

$(((($ First_Range + Last_Range) / 2) $<9.4)$ AND (((First_Range + Last_Range $) / 2)>8.4)$ AND $($ SLOPE < 0.1) $)$ OR

$(((($ First_Range + Last_Range $) / 2)<8.4)$ AND $((($ First_Range + Last_Range $) / 2)>7.4)$ AND $($ SLOPE $<0.15))$ OR

$((($ First_Range + Last_Range $) / 2)<7.4)$ AND $($ SLOPE $<0.2))$ OR

$((($ Noise_Count_Average $) /(($ Echo_Count +10$) * 5))>0.04)$ OR

(LINEARITY1 > 2.4 AND LINEARITY2 $>2.4$ AND ECHO_COUNT $<12$ ) OR

(LINEARITY1 > 2.4 AND LINEARITY2 > 2.4 AND ECHO_COUNT > 11 AND SLOPE $<0.4$ ) OR

$(((($ First_Range + Last_Range) / 2) $<7.1)$ AND $((($ First_Range + Last_Range $) / 2)>6.5)$ AND $($ SLOPE < 0.5) $)$ THEN DELETE;

END; 


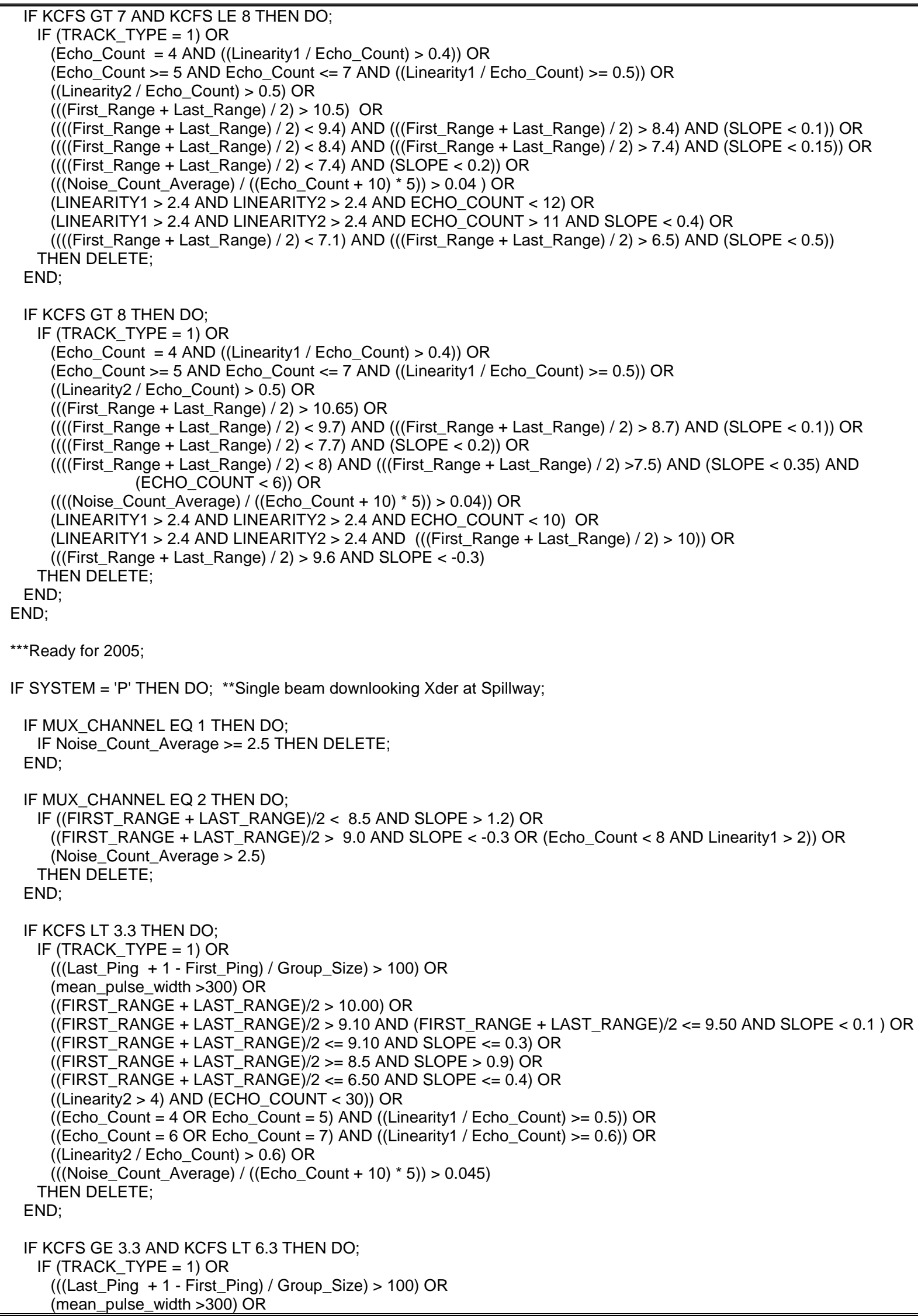




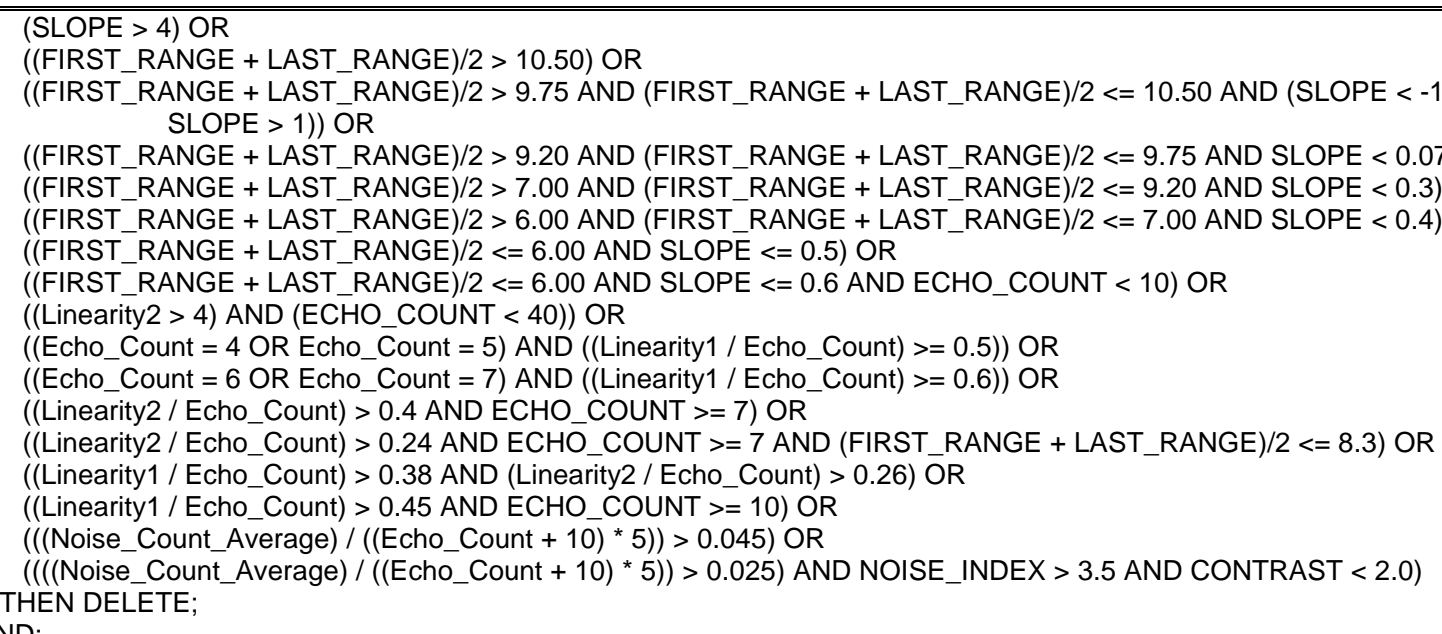
END;

IF KCFS GE 6.3 AND KCFS LT 9.1 THEN DO;

IF ((Last_Ping + 1 - First_Ping) / Group_Size $)>100)$ OR

(mean pulse width $>300$ ) OR

(LINEARITY1 < 0.5 AND LINEARITY2 < 0.5 AND SLOPE < 0.1 AND ABS(FIRST_RANGE - LAST_RANGE) < 0.05) OR $((F I R S T$ RANGE $=$ LAST_RANGE AND SLOPE $<=0)$ AND (FIRST_RANGE + LAST_RANGE)/2 $<=10.20)$ OR

((FIRST_RANGE + LAST_RANGE)/2 > 9.90 AND (FIRST_RANGE + LAST_RANGE)/2<10.15 AND MUX_CHANNEL=1) OR

$(($ FIRST_RANGE + LAST_RANGE)/2 > 11.00) OR

((FIRST_RANGE + LAST_RANGE)/2 > 9.75 AND (FIRST_RANGE + LAST_RANGE) $/ 2<=11.00$ AND SLOPE $<-1$ ) OR ((FIRST_RANGE + LAST_RANGE)/2 > 9.25 AND (FIRST_RANGE + LAST_RANGE)/2<= 9.75 AND SLOPE < 0.1) OR ((FIRST_RANGE + LAST_RANGE)/2 $>7.00$ AND (FIRST_RANGE + LAST_RANGE) $/ 2<=9.25$ AND SLOPE $<0.3$ ) OR ((FIRST_RANGE + LAST_RANGE)/2 > 6.00 AND (FIRST_RANGE + LAST_RANGE)/2<= 7.00 AND SLOPE $<0.4)$ OR ((FIRST_RANGE + LAST_RANGE)/2 $<=6.00$ AND SLOPE $<=0.6)$ OR (SLOPE > 4.5 OR SLOPE $<-4.5$ ) OR

(linearity $1>3.5$ and linearity2 $>3$ and slope $<1$ ) OR

(Linearity2 > 4 AND ECHO_COUNT < 20) OR

((Linearity1 / Echo_Count $>=0.45)$ AND (Linearity2 > 2.5) AND ECHO_COUNT $<25$ AND SLOPE < 1 AND (FIRST_RANGE + LAST_RANGE) $/ 2<10.00)$ OR

$(($ Echo_Count $=4$ OR Echo_Count $=5$ OR Echo_Count $=6)$ AND $(($ Linearity1 $/$ Echo_Count $)>=0.4)$ AND SLOPE $<1)$ OR $(($ Echo_Count $=7)$ AND $(($ Linearity1 $/$ Echo_Count $)>=0.6)$ AND (FIRST_RANGE + LAST_RANGE)/2 $<10.00)$ OR

((Linearity2 / Echo_Count) $>0.6)$ OR

$((($ Noise_Count_Average $) /(($ Echo_Count +10$) * 5))>0.045)$

THEN DELETE; END;

IF KCFS GE 9.1 THEN DO;

IF ((Last_Ping + 1 - First_Ping) / Group_Size $)>100)$ OR

(mean_pulse_width $>30 \overline{0}$ ) OR

(SLOPE > 5 OR SLOPE < -5) OR

((FIRST_RANGE + LAST_RANGE)/2 > 8.95 AND (FIRST_RANGE + LAST_RANGE)/2 < 9.05 AND MUX_CHANNEL=1) OR $(($ FIRST_RANGE + LAST_RANGE)/2 > $=10.00$ AND (FIRST_RANGE + LASTT_RANGE)/2 <= 10.15 AND MUX_CHANNEL=1) OR

((FIRST_RANGE + LAST_RANGE)/2 >= 11.05 AND (FIRST_RANGE + LAST_RANGE)/2 < 11.15 AND MUX_CHANNEL=1) OR

((FIRST_RANGE + LAST_RANGE)/2 > 11.50) OR

((FIRST_RANGE + LAST_RANGE)/2 > 10.00 AND SLOPE $>2)$ OR

((FIRST_RANGE + LAST_RANGE)/2 > 9.75 AND (FIRST_RANGE + LAST_RANGE)/2 <= 11.50 AND SLOPE $<-0.5)$ OR

((FIRST_RANGE + LAST_RANGE)/2 > 9.10 AND (FIRST_RANGE + LAST_RANGE)/2 <= 9.75 AND SLOPE <0.3) OR

((FIRST_RANGE + LAST_RANGE)/2 > 6.00 AND (FIRST_RANGE + LAST_RANGE)/2 < $=9.10$ AND SLOPE $<0.6)$ OR

((FIRST_RANGE + LAST_RANGE)/2 $<=6.00$ AND SLOPE $<=0.9)$ OR

((Linearity1 / Echo_Count $>=0.45$ ) AND (Linearity2 > 2.5) AND ECHO_COUNT < 15 AND SLOPE $<1.5$ AND

(Linearity2 $>4$ ) OR (FIRST_RANGE + LAST_RANGE)/2 < 10.50) OR

$(($ Echo_Count $=4$ OR Echo_Count $=5)$ AND $(($ Linearity $1 /$ Echo_Count $)>=0.4))$ OR

$(($ Echo_Count $=6$ OR Echo_Count $=7)$ AND $(($ Linearity $1 /$ Echo_Count $)>=0.5))$ OR

((Linearity2 / Echo_Count) $>0.6)$ OR

(NOISE_INDEX $>6$.0 AND NOISE_COUNT_AVERAGE $>1.5)$ OR

$(($ Noise_Count_Average / $(($ Echo_Count $+\overline{10}) * 5))>=0.035)$

THEN DELETE; 
END;

END;

${ }^{* * \star}$ Ready for 2005 ;

IF SYSTEM = 'Q' THEN DO; **Single beam downlooking Xder at Spillway;

IF KCFS LT 3.3 THEN DO;

IF ((Last_Ping + 1 - First_Ping) / Group_Size $)>100)$ OR

(mean_pulse_width $>300$ ) OR

((FIRST_RANGE + LAST_RANGE)/2 > 10.00) OR

((FIRST_RANGE + LAST_RANGE)/2 $>9.10$ AND (FIRST_RANGE + LAST_RANGE)/2 $<=9.50$ AND SLOPE $<0.1)$ OR

$(($ FIRST_RANGE + LAST_RANGE)/2 <= 9.10 AND SLOPE $<=0.3)$ OR

((Linearity2 > 4) AND (ECHO_COUNT < 30)) OR

((Linearity1 > 5.5) AND (Linearity2 > 5.5) AND (ECHO_COUNT > 30)) OR

$(($ Echo_Count $=4$ OR Echo_Count $=5)$ AND $(($ Linearity1 $/$ Echo_Count $)>=0.5))$ OR

$(($ Echo_Count $=6$ OR Echo_Count $=7)$ AND $(($ Linearity1 $/$ Echo_Count $)>=0.6))$ OR

((Linearity2 / Echo_Count) $>0.6)$ OR

$((($ Noise_Count_Average $) /(($ Echo_Count +10$) * 5))>0.045)$

THEN DELETE;

END;

IF KCFS GE 3.3 AND KCFS LT 6.3 THEN DO;

IF (TRACK_TYPE = 1) OR

$((($ Last_Ping +1 - First_Ping) / Group_Size $)>100)$ OR

(mean_pulse_width $>300$ ) OR

((FIRSTRRANGE + LASTRRANGE)/2 > 10.50) OR

((FIRST_RANGE + LAST_RANGE)/2 > 9.75 AND (FIRST_RANGE + LAST_RANGE)/2<= 10.50 AND SLOPE $<-1)$ OR

$(($ FIRST_RANGE + LAST_RANGE)/2 $>9.20$ AND (FIRST_RANGE + LAST_RANGE)/2 < $=9.75$ AND (SLOPE $<0.5$ OR SLOPE > 2)) OR

$(($ FIRST_RANGE + LAST_RANGE)/2 $>7.00$ AND (FIRST_RANGE + LAST_RANGE)/2 $<=9.20$ AND (SLOPE $<0.65$ OR $(($ Echo_Count $=4$ OR Echo_Count $=5)$ AND $(($ Linearity1 $/$ Echo_Count $)>=0.25))))$ OR

$(($ FIRST_RANGE + LAST_RANGE)/2 $>6.00$ AND (FIRST_RANGE + LAST_RANGE)/2 $<=7.00$ AND SLOPE $<0.4)$ OR ((FIRST_RANGE + LAST_RANGE)/2 $<=6.00$ AND SLOPE $<=0.35)$ OR

((FIRST_RANGE + LAST_RANGE)/2 $<=6.00$ AND SLOPE $<=0.6$ AND ECHO_COUNT $<10$ ) OR

(SLOPE > 3) OR

((Linearity2 > 4) AND (ECHO_COUNT < 40)) OR

$(($ Echo_Count $=4$ OR Echo_Count $=5)$ AND $(($ Linearity1 $/$ Echo_Count $)>=0.4))$ OR

$(($ Echo_Count $=6$ OR Echo_Count $=7)$ AND $(($ Linearity $1 /$ Echo_Count $)>=0.5))$ OR

((Linearity2 / Echo_Count) >0.4 AND ECHO_COUNT >= 7) OR

$(($ Linearity1 > 3.5) AND (Linearity2 > 3.5) AND ((Noise_Count_Average > 2.4) OR (NOISE_INDEX > 5.0))) OR

$(($ Noise_Count_Average $/(($ Echo_Count +10$) * 5))>0.033)$ OR

$((($ Noise_Count_Average $) /(($ Echo_Count +10$) * 5))>0.025)$ AND NOISE_INDEX $>3.5$ AND CONTRAST $<2.0)$

THEN DELETE;

END;

IF KCFS GE 6.3 AND KCFS LT 9.1 THEN DO;

IF ((Last_Ping + 1 - First_Ping) / Group_Size $)>100)$ OR

(mean_pulse_width $>30 \overline{0}$ ) OR

(LINEARITY1 < 0.5 AND LINEARITY2 < 0.5 AND SLOPE < 0.1 AND ABS(FIRST_RANGE - LAST_RANGE) $<0.05)$ OR

((FIRST_RANGE = LAST_RANGE AND SLOPE <=0) AND (FIRST_RANGE + LAST_RANGE)/2<=10.20) OR

((FIRST_RANGE + LAST_RANGE)/2 > 11.00) OR

((FIRST_RANGE + LAST_RANGE)/2 > 9.75 AND (FIRST_RANGE + LAST_RANGE)/2 <= 11.00 AND SLOPE < -1) OR

((FIRST_RANGE + LAST_RANGE)/2 > 9.25 AND (FIRST_RANGE + LAST_RANGE)/2<= 9.75 AND SLOPE < 0.1) OR ((FIRST_RANGE + LAST_RANGE)/2 > 7.00 AND (FIRST_RANGE + LAST_RANGE)/2<=9.25 AND SLOPE < 0.7) OR $(($ FIRST_RANGE + LAST_RANGE)/2 $>6.00$ AND (FIRST_RANGE + LAST_RANGE)/2 $<=7.00$ AND SLOPE $<0.8)$ OR ((FIRST_RANGE + LAST_RANGE)/2 $<=6.00$ AND SLOPE $<=0.9)$ OR

(SLOPE > 4.5 OR SLOPE <-4.5) OR

((MUX_CHANNEL=1) AND (FIRST_RANGE + LAST_RANGE)/2 > 7.4 AND (FIRST_RANGE + LAST_RANGE)/2<=8.00) OR

(Linearity2 $>4$ AND ECHO COUNT $<20$ ) OR

((Linearity1 / Echo_Count $>=0.45)$ AND (Linearity2 > 2.5) AND ECHO_COUNT $<25$ AND SLOPE $<1$ AND (FIRST_RANGE + LAST_RANGE) $/ 2<10.00)$ OR

$(($ Echo_Count $=4$ OR Echo_Count $=5$ OR Echo_Count $=6)$ AND $(($ Linearity $1 /$ Echo_Count $)>=0.4))$ OR

$(($ Echo_Count $=7)$ AND $(($ Linearity1 $/$ Echo_Count $)>=0.5)$ AND (FIRST_RANGE + LAST_RANGE)/2 < 10.00) OR

((Linearity2 / Echo_Count) $>0.6)$ OR

$((($ Noise_Count_Average $) /(($ Echo_Count +10$) * 5))>0.045)$

THEN DELETE;

END;

IF KCFS GE 9.1 THEN DO; 


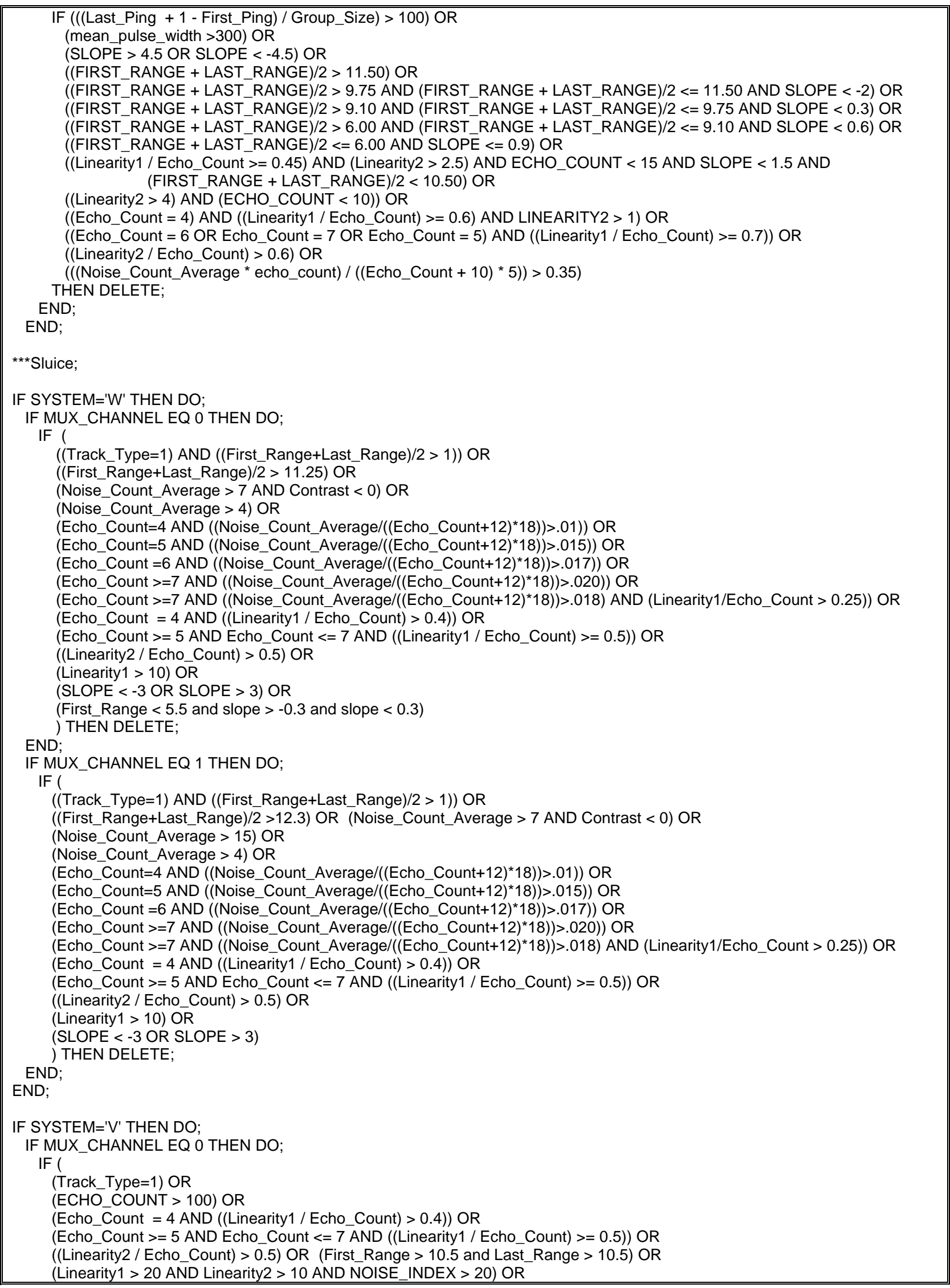


(SLOPE < -3 OR SLOPE > 3) OR

(Echo_Count $=4$ AND $(($ Noise_Count_Average/((Echo_Count+12)*18) $)>.01))$ OR

$\left(\right.$ Echo_Count $=5$ AND $\left.\left.\left.\left((\text { Noise_Count_Average/((Echo_Count+12 })^{\star} 18\right)\right)>.015\right)\right)$ OR

$\left(\right.$ Echo_Count $=6$ AND $\left.\left.\left.\left((\text { Noise_Count_Average/((Echo_Count }+12)^{\star} 18\right)\right)>.017\right)\right)$ OR

(Echo Count $>=7$ AND $(($ Noise Count Average/((Echo Count +12$) \star 18))>.020))$ OR

$($ Echo_Count $>=7$ AND $(($ Noise_Count_Average/((Echo_Count +12$) * 18))>.018)$ AND (Linearity1/Echo_Count $>0.25))$ OR

(Linearity1 $<0.5$ AND Linearity $2<0.5$ AND Slope $=0$ ) OR

(First_Range $>10$ AND Last_Range $>10$ AND (Slope > -0.15 AND Slope < 0.15) AND (( Noise_Count_Average) / $\left.\left.\left.\left((\text { Echo_Count }+10)^{\star} 6\right)\right)>0.045\right)\right)$ OR

(First_Range $>10.7$ AND Last_Range $>10.7)$ OR

((First_Range + Last_Range)/2 > 9 AND (Slope > -0.1 AND Slope < 0.1) AND (((Noise_Count_Average) / ((Echo_Count + 10)*6)) $>0.045)$ ) OR

(First_Range $>2$ AND First_Range $<2.5$ AND Last_Range $>2$ AND Last_Range $<2.5$ AND Slope $>-0.1$ AND Slope $<0.1$ ) OR

(First_Range $>5.4$ AND First_Range $<5.7$ AND Last_Range $>5.4$ AND Last_Range $<5.7$ AND Slope $>-0.1$ AND Slope $<$ $0.1)$ OR

(First_Range $>6.4$ AND First_Range $<7.2$ AND Last_Range $>6.4$ AND Last_Range $<7.2$ AND Slope $>-0.2$ AND Slope $<$ $0.2)$ OR

(First_Range $>7$ AND First_Range $<7.4$ AND Last_Range $>7$ AND Last_Range $<7.4$ AND Slope $>-0.1$ AND Slope $<0.1$ ) OR

(First_Range $>8$ AND First_Range $<8.2$ AND Last_Range $>8$ AND Last_Range $<8.2$ AND Slope $>-0.1$ AND Slope $<0.1$ ) OR

(ECHO_COUNT < 5 AND ECHO_COUNT / ((LAST_PING / GROUP_SIZE + 1) - FIRST_Ping / GROUP_SIZE) < 0.8) OR

(ECHO_COUNT >=5 AND ECHO_COUNT <=6 AND ECHO_COUNT / ((LAST_PING / GROUP_SIZE + 1) - FIRST_Ping / GROUP_SIZE) $<0 . \overline{7})$ OR

$(($ First_Range + Last_Range $) / 2<=4$ AND $($ Slope $<0.15)$ AND $($ ECHO_COUNT $>60))$

) THEN DELETE;

END;

IF MUX_CHANNEL EQ 1 THEN DO;

IF (

((Track_Type=1) AND ((First_Range+Last_Range)/2 > 1)) OR

(First Range $>10.3$ and Last Range $>10 . \overline{3}$ ) OR

(Noise_Count_Average $>7$ AND Contrast $<0$ ) OR

(Noise_Count_Average $>4$ ) OR

(Echo_Count=4 AND $(($ Noise_Count_Average/((Echo_Count+12)*18))>.01)) OR

(Echo_Count=5 AND $(($ Noise_Count_Average/((Echo_Count+12)*18) $)>.015))$ OR

$($ Echo_Count $=6$ AND $(($ Noise_Count_Average/((Echo_Count+12)*18) $)>.017))$ OR

(Echo_Count $>=7$ AND $(($ Noise_Count_Average/((Echo_Count+12)*18)) $>.020))$ OR

(Echo_Count $>=7$ AND $(($ Noise_Count_Average/(Echo_Count+12)*18) $)>.018)$ AND (Linearity1/Echo_Count $>0.25))$ OR

$($ Echo_Count $=4$ AND $(($ Linearity1 $/$ Echo_Count $)>0 . \overline{4}))$ OR

(Echo_Count $>=5$ AND Echo_Count $<=7$ AND ((Linearity1 $/$ Echo_Count) $>=0.5)$ ) OR

$(($ Linearity2 / Echo_Count) $>\overline{0.5})$ OR

(Linearity1 > 10) OR

(SLOPE < -3 OR SLOPE > 3) OR

(First_Range $>10$ AND Last_Range $>10$ AND (Slope $>-0.15$ AND Slope $<0.15)$ AND (((Noise_Count_Average) $/$

) THEN DELETE; $\left.\left.\left.\left((\text { Echo_Count }+10)^{\star} 6\right)\right)>0.045\right)\right)$

END;

END;

IF SYSTEM='U' THEN DO;

IF MUX_CHANNEL EQ 0 THEN DO;

reg $=0.6892 *$ fb_el-41.973;

IF (

((First_Range+Last_Range)/2 >=(reg-1) AND Track_Type=1) OR

((First_Range+Last_Range)/2 > $>($ reg-0.1)) OR

$(($ First_Range+Last_Range)/2 > (reg - 1)) AND (Slope $>-0.2$ and Slope $<0.2))$ OR

(Echo_Count=4 AND (First_Range+Last_Range)/2 >=reg-0.6) OR

(Noise_Count_Average $>$ 6.5 AND Contrast $<0$ ) OR

(Noise Count Average $>15$ ) OR

(Noise_Count_Average $>7.5$ AND Slope $>2.5$ ) OR

(Noise Count Average > 7.5 AND Slope $<-2.5$ ) OR

(Echo_Count=4 AND $(($ Noise_Count_Average/((Echo_Count+12)*18))>.01)) OR

$\left(\right.$ Echo_Count $=5$ AND $\left.\left.\left.\left((\text { Noise_Count_Average/(Echo_Count+12 })^{\star} 18\right)\right)>.015\right)\right)$ OR

$\left(\right.$ Echo_Count $=6$ AND $\left.\left.\left.\left((\text { Noise_Count_Average/((Echo_Count+12 })^{\star} 18\right)\right)>.017\right)\right)$ OR

(Echo_Count $>=7$ AND $(($ Noise

(Echo_Count >=7 AND $(($ Noise_Count_Average/((Echo_Count+12)*18) $)>.018)$ AND (Linearity1/Echo_Count $>0.25))$ OR

$($ Echo_Count $=4$ AND $(($ Linearity1 $/$ Echo_Count $)>0.4))$ OR

(Echo_Count $>=5$ AND Echo_Count $<=7$ AND ((Linearity1 / Echo_Count) $>=0.5))$ OR

$(($ Linearity2 / Echo_Count $)>0.5)$ 


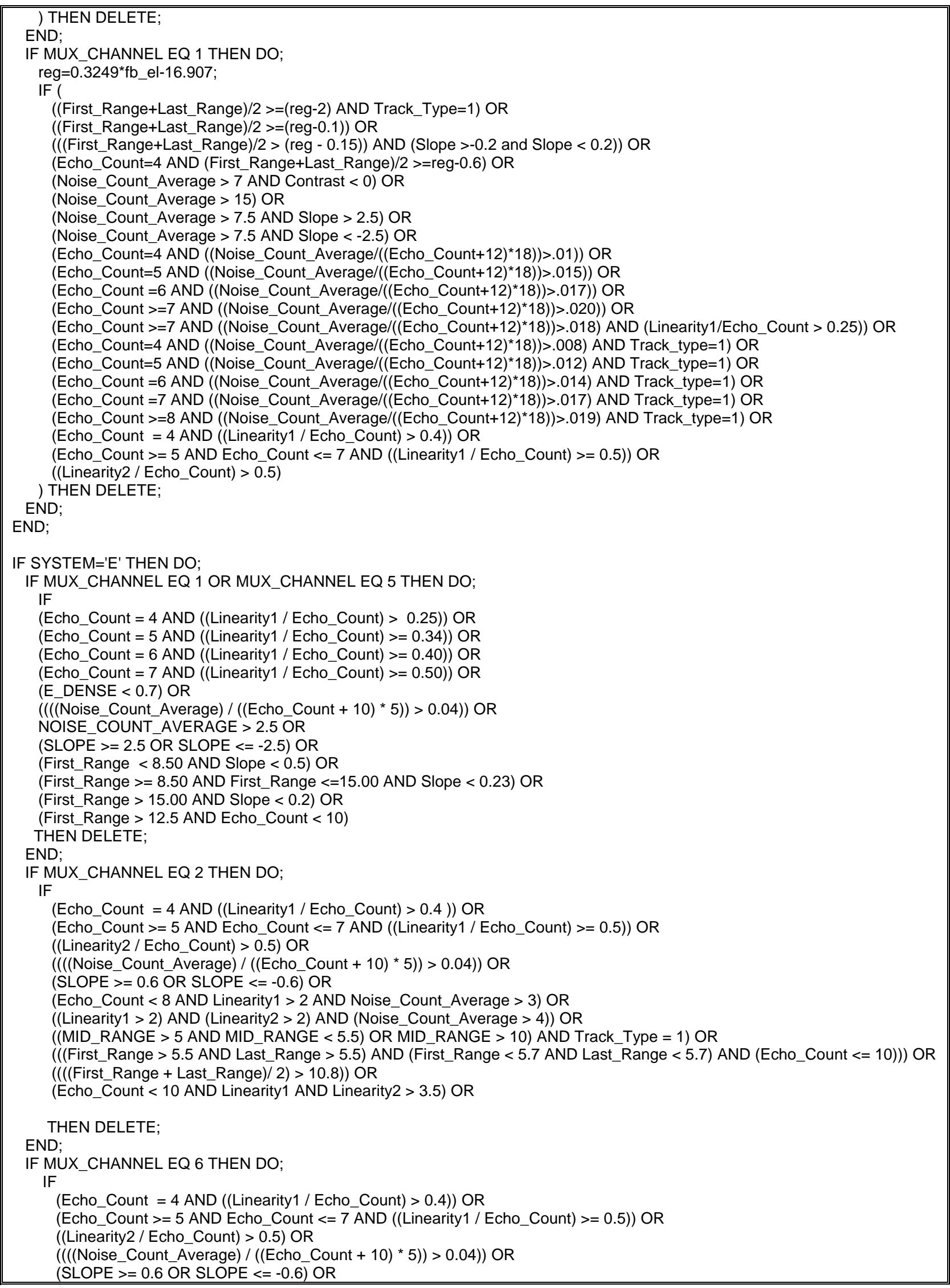




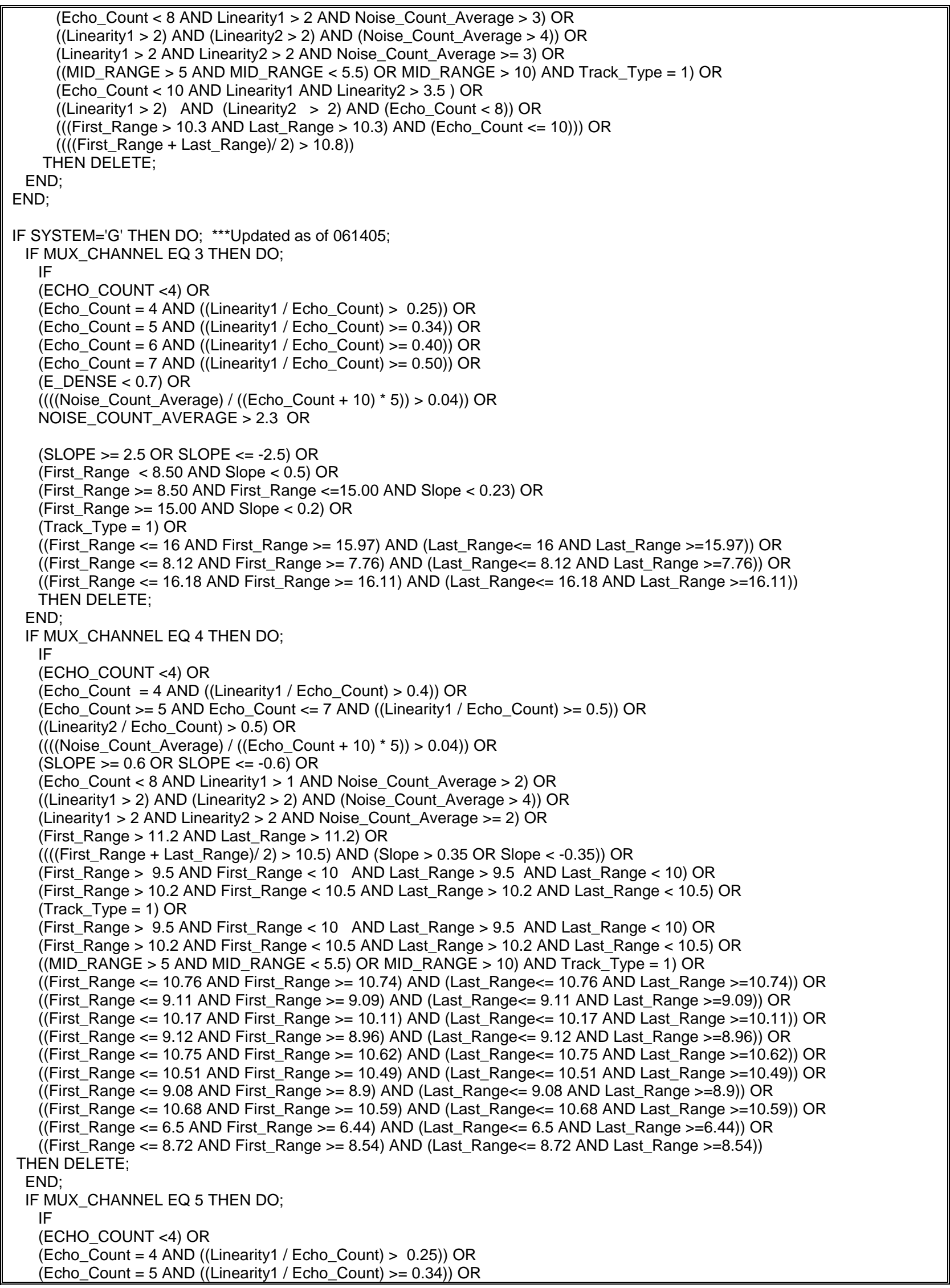


(Echo Count $=6$ AND ((Linearity1 $/$ Echo Count $)>=0.40))$ OR

(Echo_Count $=7$ AND $(($ Linearity1 $/$ Echo_Count $)>=0.50))$ OR

(E DENSE < 0.7) OR

(Linearity1 $>2$ OR Linearity2 > 2) OR

$(((($ Noise_Count_Average $) /(($ Echo_Count +10$) * 5))>0.04))$ OR

NOISE_COUNT_AVERAGE $>2.3$ OR

(SLOPE $>=2.5$ OR SLOPE $<=-2.5$ ) OR

(First_Range $<8.50$ AND Slope $<0.5$ ) OR

(First_Range $>=8.50$ AND First_Range $<=15.00$ AND Slope $<0.23$ ) OR

(First_Range $>=15.00$ AND Slope $<0.2$ ) OR

(Track_Type $=1$ )

THEN DELETE;

END;

IF MUX_CHANNEL EQ 6 THEN DO;

IF

$($ ECHO_COUNT $<4)$ OR

$($ Echo_Count $=4$ AND $(($ Linearity1 $/$ Echo_Count $)>0.4))$ OR

(Echo_Count $>=5$ AND Echo_Count $<=7$ AND ((Linearity1 / Echo_Count $)>=0.5))$ OR

((Linearity2 / Echo_Count) $>0.5)$ OR

$((($ Noise_Count_Average $) /(($ Echo_Count +10$) * 5))>0.04))$ OR

(SLOPE $>=0.6$ OR SLOPE $<=-0.6)$ OR

(Echo_Count $<8$ AND Linearity1 $>2$ AND Noise_Count_Average $>3$ ) OR

$(($ Linearity1 $>2)$ AND (Linearity2 > 2) AND (Noise Count Average > 4)) OR

(Linearity1 $>2$ AND Linearity2 $>2$ AND Noise_Count_Average $>=3$ ) OR

(First_Range $>11.2$ AND Last_Range $>11.2$ ) OR

$(((($ First_Range + Last_Range $) / 2)>10.5)$ AND (Slope $>0.35$ OR Slope $<-0.35))$ OR

(First_Range $>$ 8.7 AND First_Range $<9$ AND Last_Range $>8.7$ AND Last_Range $<$ ) OR

((MID_RANGE > 5 AND MID_RANGE < 5.5) OR MID_RANGE > 10) AND Track_Type = 1) OR

((First_Range $<=10.7$ AND First_Range $>=10.67$ ) AND (Last_Range $<=10.7$ AND Last_Range $>=10.67)$ ) OR

((First_Range $<=9.87$ AND First_Range $>=9.87$ ) AND (Last_Range $<=9.87$ AND Last_Range $>=9.87)$ ) OR

((First_Range $<=11.09$ AND First_Range $>=11.06)$ AND (Last_Range $<=11.09$ AND Last_Range $>=11.06)$ )

THEN DELETE;

END;

IF MUX_CHANNEL EQ 7 THEN DO;

IF

$($ ECHO_COUNT <4) OR

(Echo_Count $=4$ AND $(($ Linearity $1 /$ Echo_Count $)>0.25))$ OR

(Echo_Count $=5$ AND ((Linearity1 $/$ Echo_Count) $>=0.34))$ OR

(Echo_Count $=6$ AND $(($ Linearity1 $/$ Echo_Count $)>=0.40))$ OR

$($ Echo_Count $=7$ AND $(($ Linearity1 $/$ Echo_Count $)>=0.50))$ OR

$($ E_DENSE < 0.7) OR

(Linearity1 > 2 OR Linearity2 > 2) OR

$((($ Noise_Count_Average $) /(($ Echo_Count +10$) * 5))>0.04))$ OR

NOISE COUNT_AVERAGE $>2.3$ OR

(SLOPE $>=2.5$ OR SLOPE $<=-2.5$ ) OR

(First_Range $<8.50$ AND Slope $<0.5$ ) OR

(First_Range $>=8.50$ AND First_Range $<=15.00$ AND Slope $<0.23$ ) OR

(First_Range $>=15.00$ AND Slope $<0.2$ ) OR

(Track_Type $=1$ ) OR

((First_Range $<=16.23$ AND First_Range $>=16.17)$ AND (Last_Range $<=16.23$ AND Last_Range $>=16.17)$ ) OR

((First_Range $<=10.91$ AND First_Range $>=10.71$ ) AND (Last_Range $<=10.91$ AND Last_Range $>=10.71)$ ) OR

((First_Range $<=16.17$ AND First_Range $>=16.08$ ) AND (Last_Range $<=16.17$ AND Last_Range $>=16.08)$ ) OR

((First_Range $<=16.01$ AND First_Range $>=15.94)$ AND (Last_Range $<=16.01$ AND Last_Range $>=15.94)$ )

THEN DELETE;

END;

IF MUX_CHANNEL EQ 8 THEN DO;

IF

(ECHO_COUNT <4) OR

(Echo Count $=4$ AND ((Linearity1 $/$ Echo Count $)>0.4)$ ) OR

(Echo_Count $>=5$ AND Echo_Count $<=7$ AND ((Linearity1 / Echo_Count) $>=0.5)$ ) OR

((Linearity2 / Echo_Count) $>0.5)$ OR

$(((($ Noise_Count_Average $) /(($ Echo_Count +10$) * 5))>0.04))$ OR

(SLOPE $>=0.6$ OR SLOPE $<=-0.6)$ OR

(Echo_Count $<8$ AND Linearity $1>2$ AND Noise_Count_Average $>3$ ) OR

$(($ Linearity1 $>$ 2) AND (Linearity2 $>$ 2) AND (Noise_Count_Average > 4)) OR

(First_Range $>$ 11.2 AND Last_Range $>11.2$ ) OR

$((($ First_Range + Last_Range $) / 2)>10.5)$ AND (Slope $>0.35$ OR Slope $<-0.35))$ OR

((MID_RANGE > 5 AND MID_RANGE < 5.5) OR MID_RANGE > 10) AND Track_Type = 1) OR

((First_Range $<=10.94$ AND First_Range $>=10.87)$ AND (Last_Range $<=10.94$ AND Last_Range $>=10.87)$ ) OR 


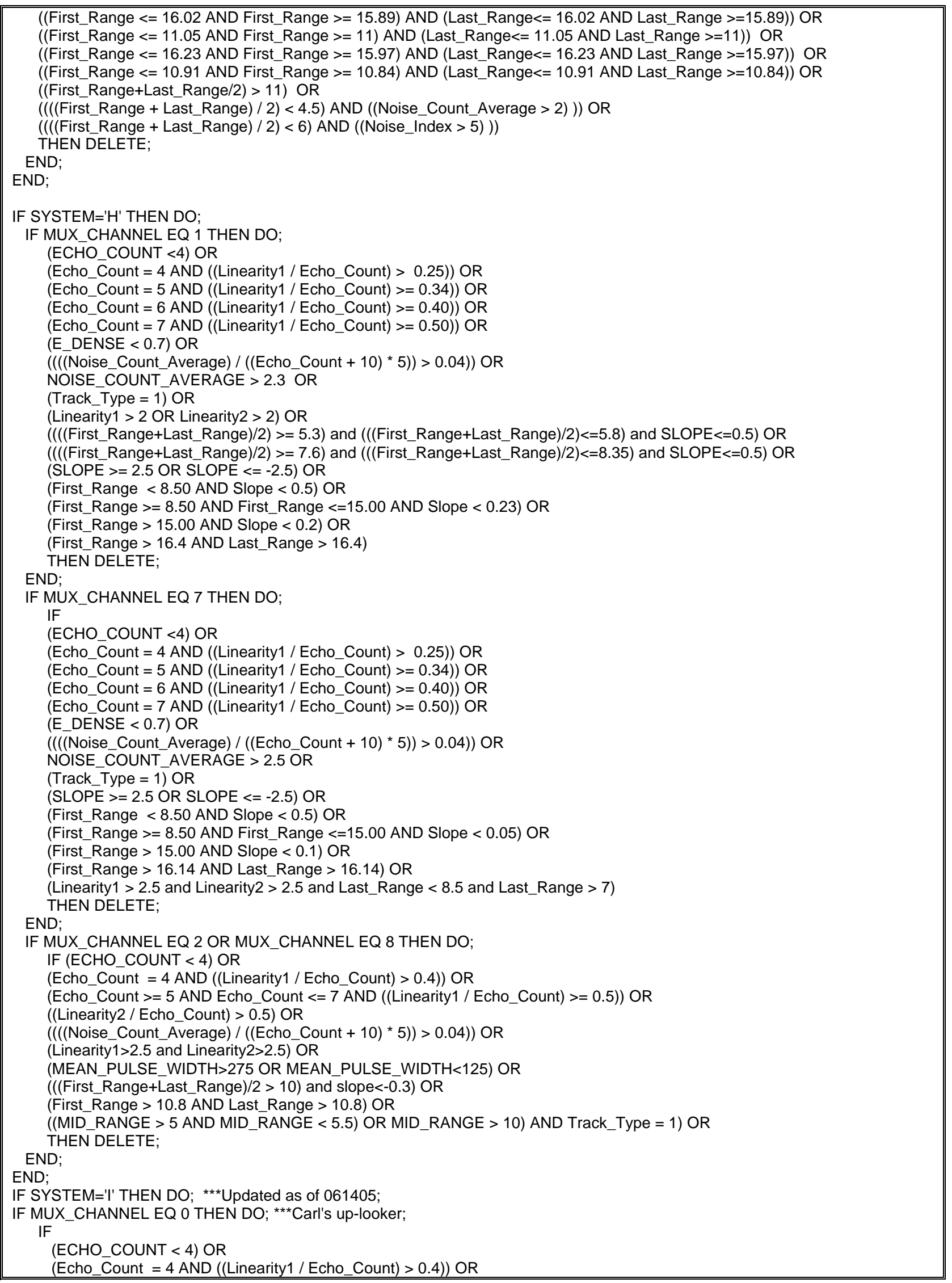




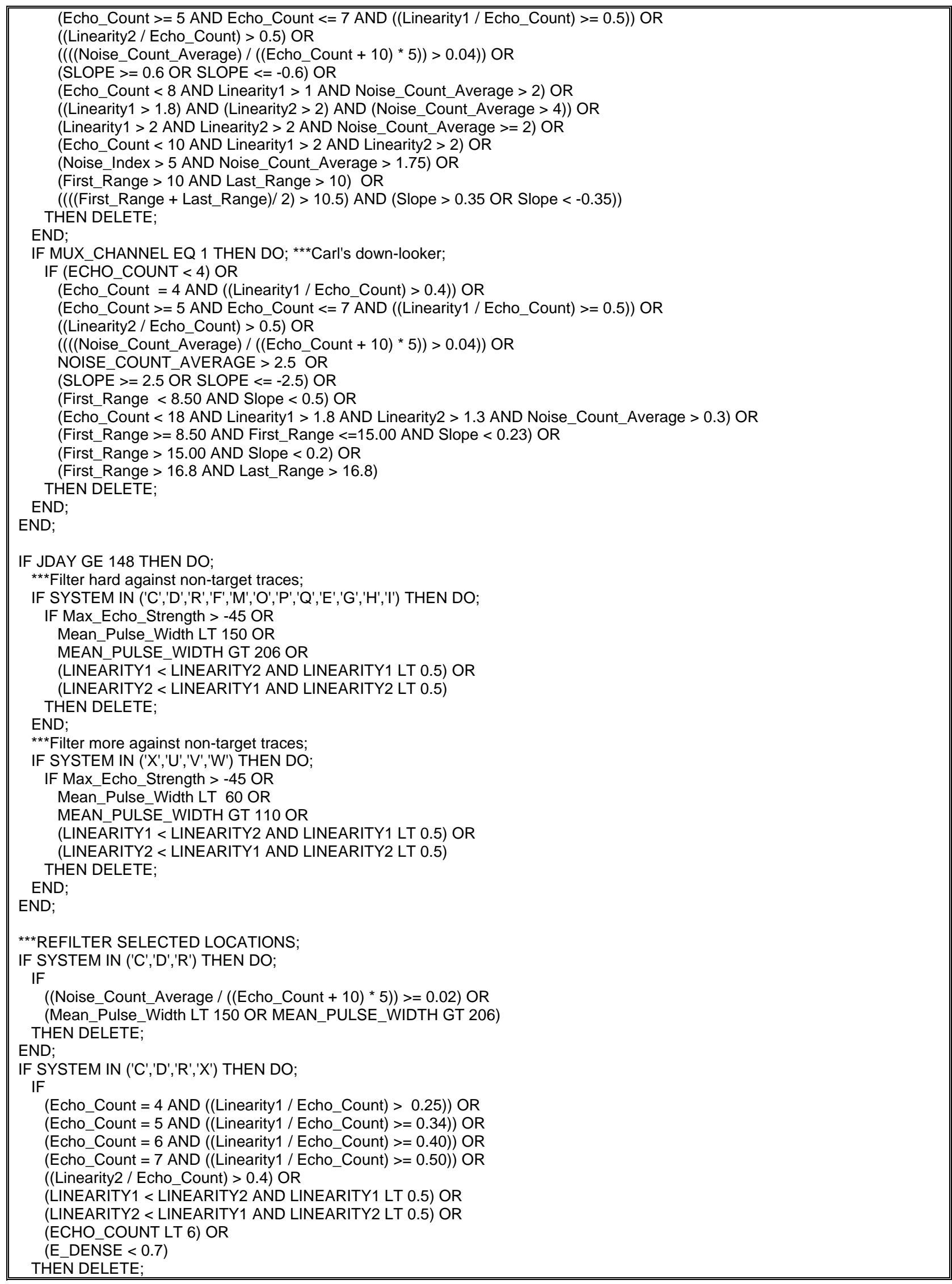




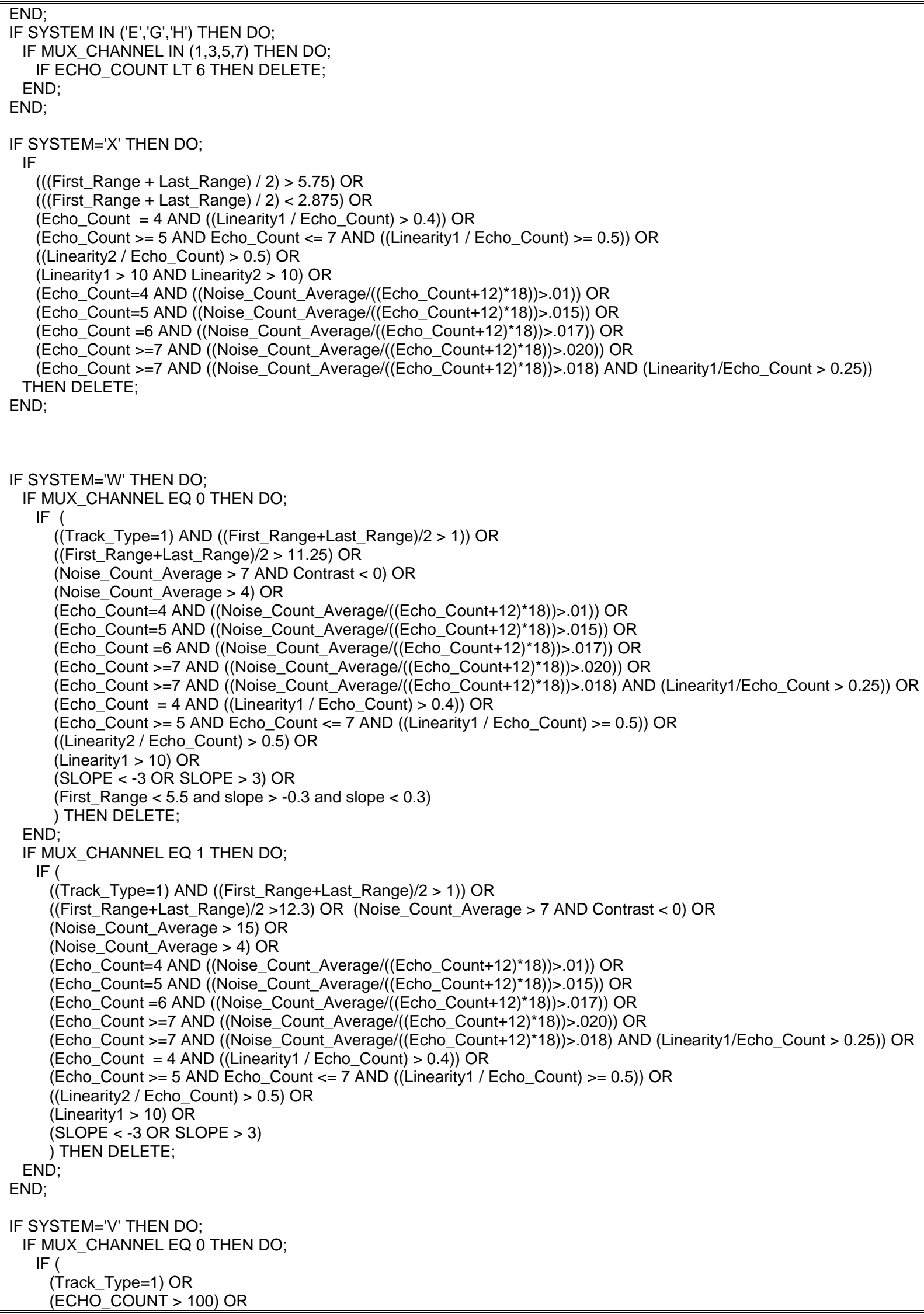


(Echo_Count $=4$ AND ((Linearity1 / Echo_Count) $>0.4))$ OR

(Echo_Count $>=5$ AND Echo_Count $<=7$ AND ((Linearity1 / Echo_Count) $>=0.5)$ ) OR

((Linearity2 / Echo_Count) $>0.5$ ) OR (First_Range $>10.5$ and Last_Range $>10.5$ ) OR

(Linearity1 $>20$ AND Linearity2 $>10$ AND NOISE_INDEX $>20$ ) OR

(SLOPE < -3 OR SLOPE > 3) OR

(Echo_Count=4 AND $(($ Noise_Count_Average/((Echo_Count+12)*18) $)>.01))$ OR

(Echo Count $=5$ AND $\left.\left.\left.\left((\text { Noise Count Average/((Echo_Count+12 })^{\star} 18\right)\right)>.015\right)\right)$ OR

$\left(\right.$ Echo_Count $=6$ AND $\left.\left.\left.\left((\text { Noise_Count_Average/((Echo_Count+12) })^{\star 18}\right)\right)>.017\right)\right)$ OR

(Echo_Count $>=7$ AND $(($ Noise_Count_Average/((Echo_Count+12)*18) $)>.020))$ OR

(Echo_Count $>=7$ AND $\left.\left.\left((\text { Noise_Count_Average/((Echo_Count+12) })^{\star} 18\right)\right)>.018\right)$ AND $($ Linearity1/Echo_Count $\left.>0.25)\right)$ OR (Linearity1 $<0.5$ AND Linearity $2<0.5$ AND Slope $=0$ ) OR

(First_Range > 10 AND Last_Range > 10 AND (Slope > -0.15 AND Slope < 0.15) AND (((Noise_Count_Average) / $(($ Echo_Count + 10)*6) $)>0.045))$ OR

(First_Range $>$ 10.7 AND Last_Range $>10.7$ ) OR

$(($ First_Range + Last_Range) $/ \overline{2}>9$ AND (Slope $>-0.1$ AND Slope $<0.1)$ AND $((($ Noise_Count_Average) $/(($ Echo_Count + 10)*6)) $>0.045)$ ) OR

(First_Range $>2$ AND First_Range $<2.5$ AND Last_Range $>2$ AND Last_Range $<2.5$ AND Slope $>-0.1$ AND Slope $<0.1$ ) OR

(First_Range $>5.4$ AND First_Range $<5.7$ AND Last_Range $>5.4$ AND Last_Range $<5.7$ AND Slope $>-0.1$ AND Slope $<$ $0.1) \mathrm{OR}$

(First_Range $>6.4$ AND First_Range $<7.2$ AND Last_Range $>6.4$ AND Last_Range $<7.2$ AND Slope $>-0.2$ AND Slope $<$ $0.2) \mathrm{OR}$

(First_Range $>7$ AND First_Range $<7.4$ AND Last_Range $>7$ AND Last_Range $<7.4$ AND Slope $>-0.1$ AND Slope $<0.1$ ) OR

(First_Range $>8$ AND First_Range $<8.2$ AND Last_Range $>8$ AND Last_Range $<8.2$ AND Slope $>-0.1$ AND Slope $<0.1$ ) OR

(ECHO_COUNT < 5 AND ECHO_COUNT / ((LAST_PING / GROUP_SIZE + 1) - FIRST_Ping / GROUP_SIZE) < 0.8) OR

(ECHO_COUNT >=5 AND ECHO COUNT <=6 AND ECHO COUNT / ((LAST_PING / GROUP_SIZE + 1) - FIRST Ping / GROUP_SIZE) $<0 . \overline{7})$ OR

$(($ First_Range + Last_Range)/2 <= 4 AND $($ Slope $<0.15)$ AND $($ ECHO_COUNT $>60))$

) THEN DELETE;

END;

IF MUX_CHANNEL EQ 1 THEN DO;

IF (

((Track_Type $=1)$ AND ((First_Range+Last_Range)/2 > 1)) OR

(First_Range $>10.3$ and Last_Range $>10.3$ ) OR

(Noise_Count_Average $>7$ AND Contrast $<0$ ) OR

(Noise_Count_Average $>4$ ) OR

(Echo_Count=4 AND $(($ Noise_Count_Average/((Echo_Count+12)*18) $)>.01))$ OR

$($ Echo_Count $=5$ AND $(($ Noise_Count_Average/((Echo_Count +12$) * 18))>.015))$ OR

(Echo_Count $=6$ AND $\left(\left(\right.\right.$ Noise Count Average $\left.\left.\left.\left./(\text { Echo_Count }+12)^{\star} 18\right)\right)>.017\right)\right)$ OR

(Echo_Count $>=7$ AND $\left.\left.\left.\left((\text { Noise_Count_Average/((Echo_Count }+12)^{\star} 18\right)\right)>.020\right)\right)$ OR

(Echo_Count $>=7$ AND $\left.\left.\left((\text { Noise_Count_Average/(Echo_Count+12) })^{\star} 18\right)\right)>.018\right)$ AND (Linearity1/Echo_Count $\left.\left.>0.25\right)\right)$ OR

(Echo_Count $=4$ AND $(($ Linearity1 $/$ Echo_Count $)>0.4))$ OR

(Echo_Count $>=5$ AND Echo_Count $<=7$ AND ((Linearity1 / Echo_Count) $>=0.5)$ ) OR

((Linearity2 / Echo_Count) $>0.5)$ OR

(Linearity1 > 10) OR

(SLOPE <-3 OR SLOPE > 3) OR

(First_Range $>10$ AND Last_Range $>10$ AND (Slope $>-0.15$ AND Slope $<0.15)$ AND ((Noise_Count_Average) $/$

) THEN DELETE;

$\left.\left.\left.\left((\text { Echo_Count }+10)^{\star} 6\right)\right)>0.045\right)\right)$

END;

END;

IF SYSTEM='U' THEN DO;

IF MUX_CHANNEL EQ 0 THEN DO;

reg $=0.6892 *$ fb_el-41.973;

IF (

((First_Range+Last_Range)/2 >=(reg-1) AND Track_Type=1) OR

((First_Range+Last_Range)/2 $>=($ reg-0.1)) OR

$(($ First_Range+Last_Range)/2 > (reg - 1)) AND (Slope >-0.2 and Slope <0.2)) OR

(Echo Count $=4$ AND (First Range+Last Range) $/ 2>=$ reg-0.6) OR

(Noise_Count_Average $>6.5$ AND Contrast $<0$ ) OR

(Noise Count Average $>15$ ) OR

(Noise_Count_Average > 7.5 AND Slope $>2.5$ ) OR

(Noise Count Average > 7.5 AND Slope $<-2.5$ ) OR

$($ Echo_Count $=4$ AND $(($ Noise_Count_Average/((Echo_Count+12)*18) $)>.01))$ OR

$\left(\right.$ Echo_Count $=5$ AND $\left.\left.\left.\left((\text { Noise_Count_Average/((Echo_Count }+12)^{\star} 18\right)\right)>.015\right)\right)$ OR

$($ Echo_Count $=6$ AND $(($ Noise_Count_Average/ $(($ Echo_Count +12$) * 18))>.017))$ OR

(Echo_Count $>=7$ AND $(($ Noise_Count_Average/((Echo_Count +12$) \star 18))>.020))$ OR 


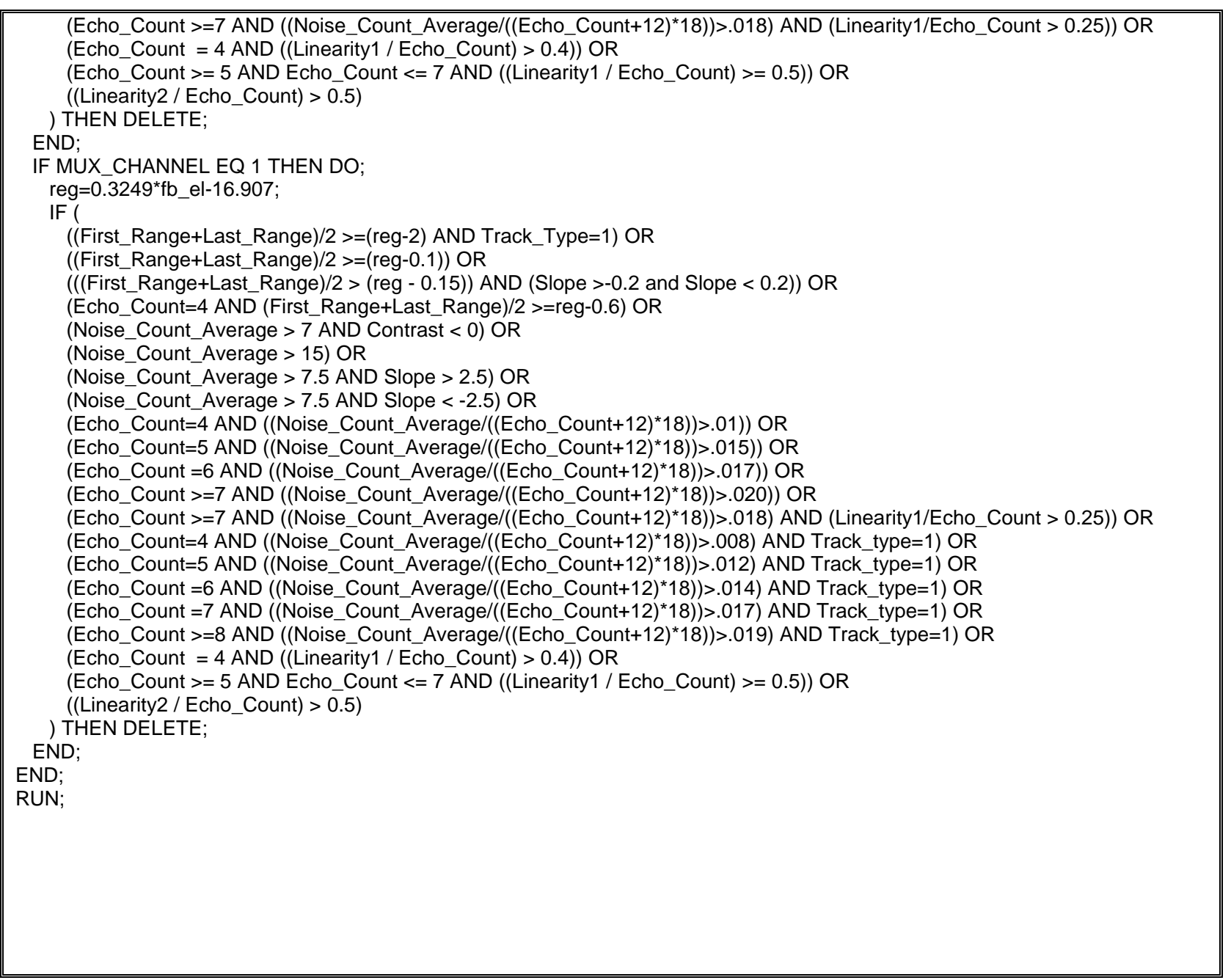


Appendix D.3. Statistical Analysis System (SAS) code for tighter filtering out echo traces that did not meet fish trace criteria in spring 2005. Minimum ranges for sampling guided, unguided, and spilled fish, which are presented in legends of Figures 2.1-2.3, 2.5, and 2.6 were implemented elsewhere in the processing program

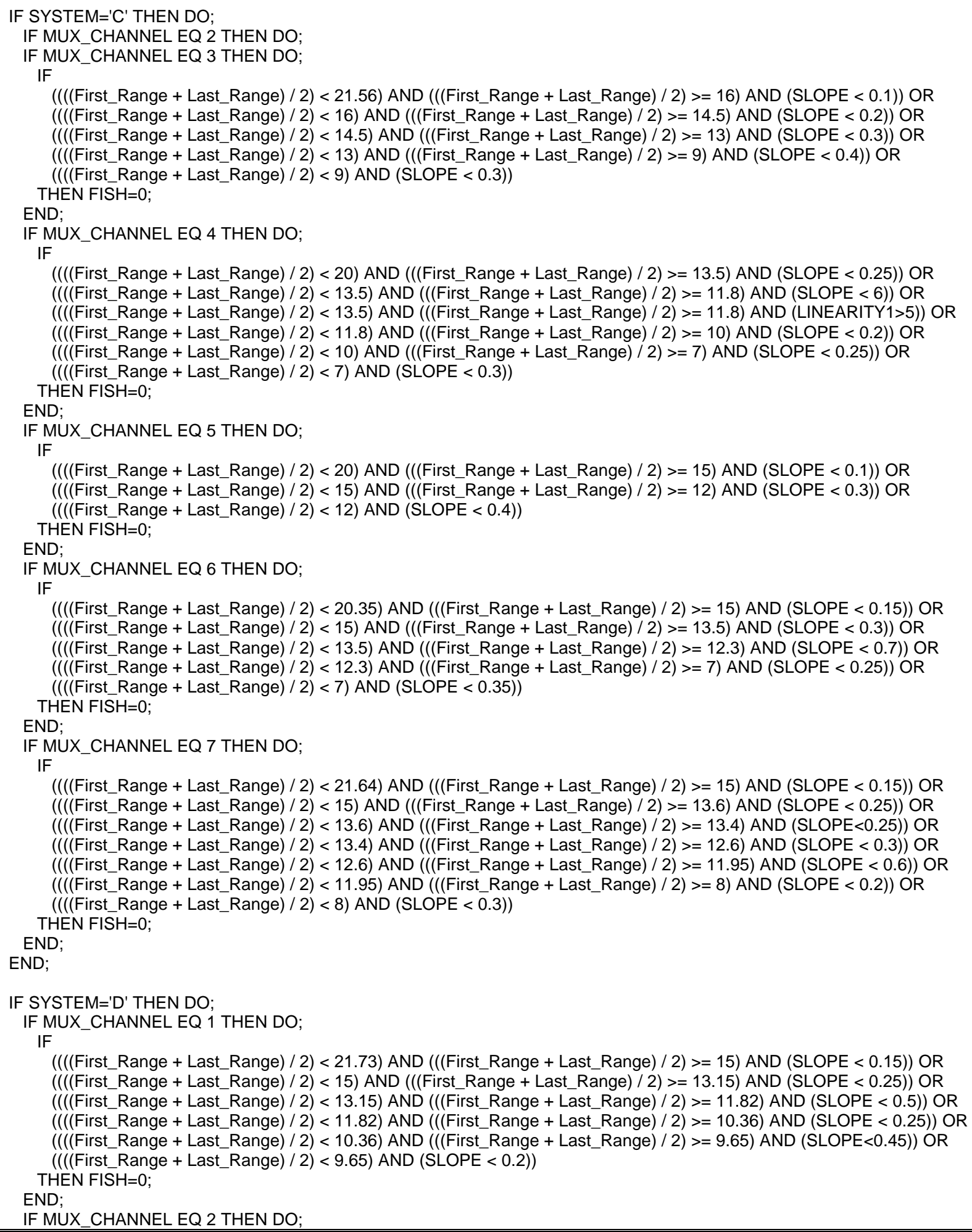




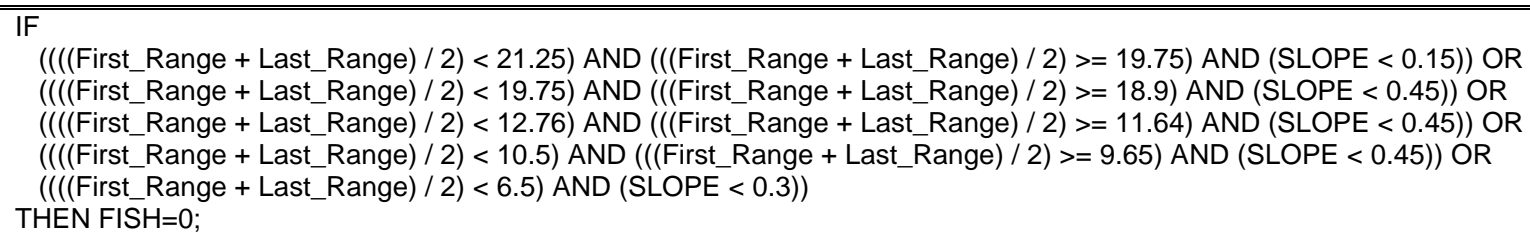




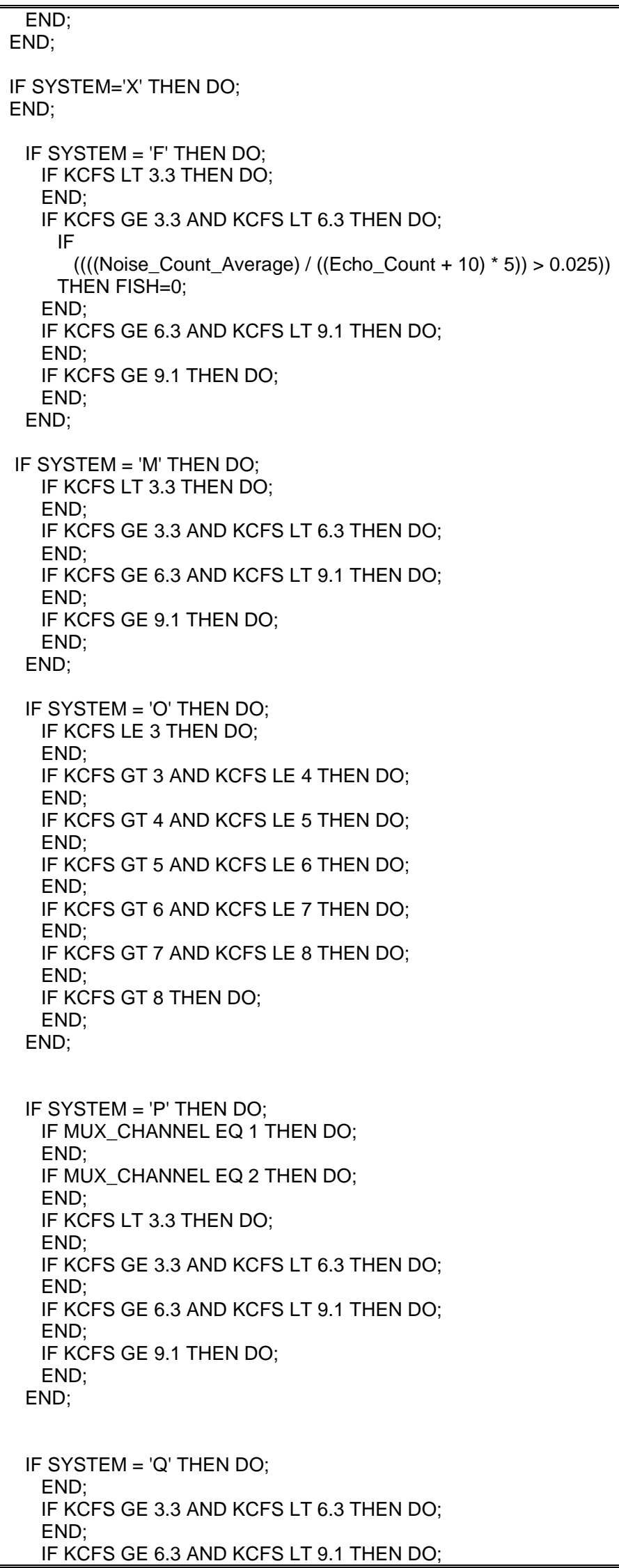




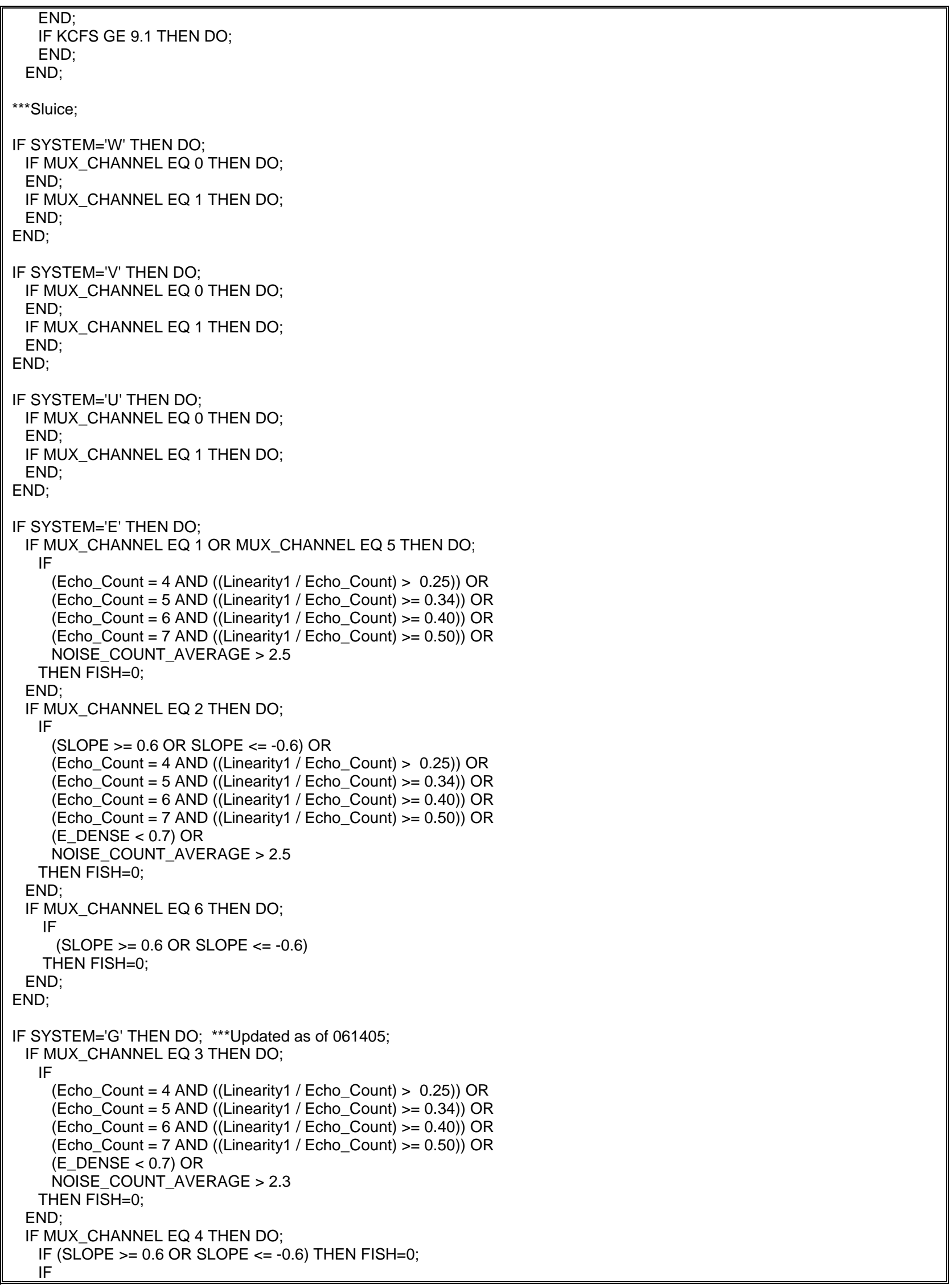




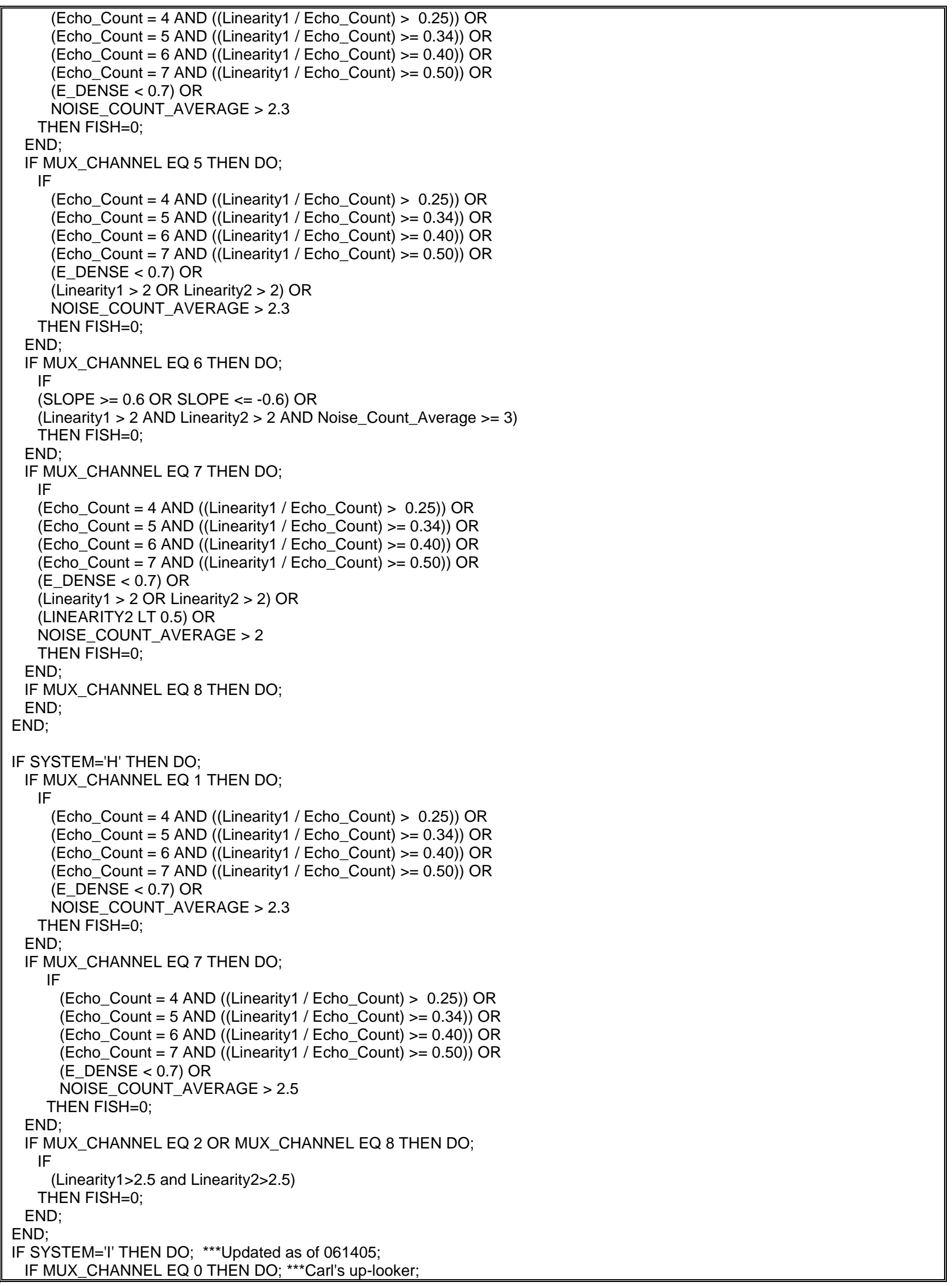




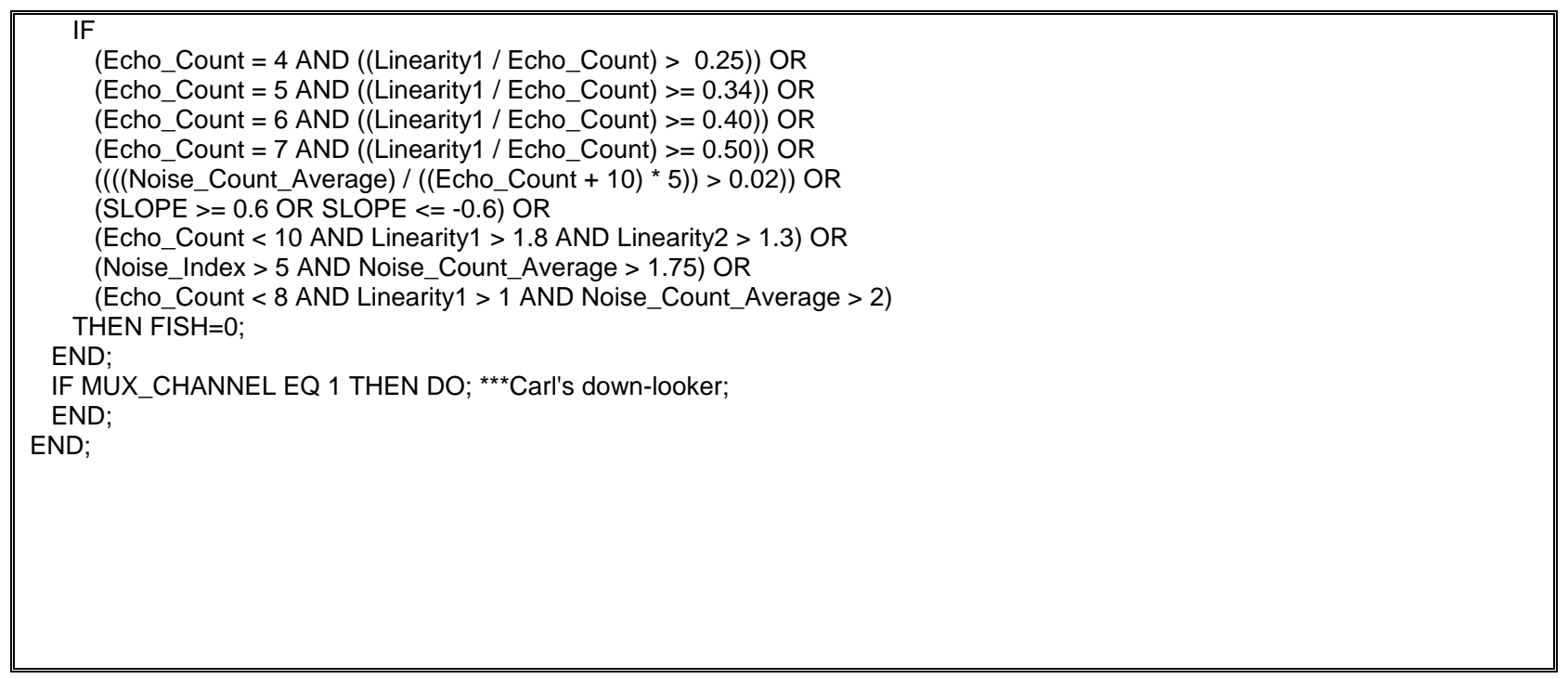


Appendix D.4. Statistical Analysis System (SAS) code for filtering out echo traces that did not meet fish trace criteria in summer 2005. Minimum ranges for sampling guided, unguided, and spilled fish, which are presented in legends of Figures 2.1-2.3, 2.5, and 2.6 were implemented elsewhere in the processing program.

IF SYSTEM='C' THEN DO;

IF MUX_CHANNEL EQ 1 THEN DO;

IF (((First_Range + Last_Range) / 2)>19.05) OR

(Echo_Count $=4$ AND $(($ Linearity1 / Echo_Count $)>0.4))$ OR

(Echo_Count $>=5$ AND Echo_Count $<=7$ AND ((Linearity1 $/$ Echo_Count $)>=0.5)$ ) OR

((Linearity2 / Echo_Count) $>0.5)$ OR

(Slope $>=2.5$ OR Slope $<=-2.5)$ OR

$((($ Noise_Count_Average $) /(($ Echo_Count +10$) * 5))>0.04))$ OR

(Slope $<\overline{0} .2)$ OR

$(((($ First_Range + Last_Range) / 2) < 21.34) AND (((First_Range + Last_Range) / 2) $>=18.5)$ AND (SLOPE < 0.1)) OR

$(((($ First_Range + Last_Range $) / 2)<18.5)$ AND (((First_Range + Last_Range) / 2) $>=16)$ AND $($ SLOPE $<0.15))$ OR

$(((($ First_Range + Last_Range) $/ 2)<16)$ AND (((First_Range + Last_Range) / 2) $>=13.5)$ AND (SLOPE $<0.2))$ OR

$((($ First_Range + Last_Range $) / 2)<13.5)$ AND ((First_Range + Last_Range $) / 2)>=12)$ AND $($ SLOPE $<0.5))$ OR

((First_Range $<=10.33$ AND First_Range $>=9.79$ ) AND (Last_Range $<=10.33$ AND Last_Range $>=9.79)$ ) OR

((First_Range $<=13.24$ AND First_Range $>=13.03$ ) AND (Last_Range $<=13.24$ AND Last_Range $>=13.03)$ ) OR

((First_Range $<=10.1$ AND First Range $>=9.62$ ) AND (Last_Range $<=10.1$ AND Last Range $>=9.62)$ ) OR

((First_Range $<=12.76$ AND First_Range $>=12.68$ ) AND (Last_Range $<=12.76$ AND Last_Range $>=12.68)$ ) OR

((First_Range $<=12.3$ AND First_Range $>=11.89$ ) AND (Last_Range $<=12.3$ AND Last_Range $>=11.89)$ ) OR

((First_Range $<=13.37$ AND First_Range $>=13.1$ ) AND (Last_Range $<=13.37$ AND Last_Range $>=13.1)$ ) OR

((First_Range $<=12.33$ AND First_Range $>=12.2$ ) AND (Last_Range $<=12.33$ AND Last_Range $>=12.2)$ ) OR

((First_Range $<=10.52$ AND First_Range $>=10.16)$ AND (Last_Range $<=10.52$ AND Last_Range $>=10.16)$ ) OR

((First_Range $<=10.62$ AND First_Range $>=10.57$ ) AND (Last_Range $<=10.62$ AND Last_Range $>=10.57)$ )

THEN DELETE;

END;

IF MUX_CHANNEL EQ 2 THEN DO;

IF ((First_Range + Last_Range) / 2)>21.34) OR

(Echo_C̄ount $=4$ AND $(($ Linearity1 / Echo_Count $)>0.4))$ OR

(Echo_Count $>=5$ AND Echo_Count $<=7$ AND ((Linearity1 / Echo_Count) $>=0.5)$ ) OR

((Linearity2 / Echo_Count) $>0.5)$ OR

$(\mathrm{SLOPE}>=2.5) \mathrm{OR} \quad(\mathrm{SLOPE}<0) \mathrm{OR}$

$(((($ First_Range + Last_Range $) / 2)<21.34)$ AND (((First_Range + Last_Range) / 2) $>=18.5)$ AND (SLOPE $<0.1))$ OR

$(((($ First_Range + Last_Range $) / 2)<18.5)$ AND $((($ First_Range + Last_Range $) / 2)>=16)$ AND $($ SLOPE $<0.15))$ OR

$(((($ First_Range + Last_Range $) / 2)<16)$ AND $((($ First_Range + Last_Range $) / 2)>=13.5)$ AND (SLOPE $<0.2))$ OR

$(((($ First_Range + Last_Range $) / 2)<13.5)$ AND $((($ First_Range + Last_Range $) / 2)>=12)$ AND $($ SLOPE $<0.5))$ OR

$((($ First Range + Last Range $) / 2)<12)$ AND $($ SLOPE $<0.3))$ OR

$((($ Noise_Count_Average $) /(($ Echo_Count +10$) * 5))>0.04))$ OR

$((($ First_Range + Last_Range $) / 2>19)$ and (Linearity1 $>3$ and Linearity2 $>3))$ OR

$((($ First_Range + Last_Range $) / 2>19)$ and (Noise_Count_Average $>6))$ OR

(Slope $<0.2$ ) OR

((First_Range $<=10.33$ AND First_Range $>=9.79)$ AND (Last_Range $<=10.33$ AND Last_Range $>=9.79)$ ) OR

((First_Range $<=13.24$ AND First_Range $>=13.01$ ) AND (Last_Range $<=13.24$ AND Last_Range $>=13.01)$ ) OR

((First_Range $<=10.1$ AND First_Range $>=9.62)$ AND (Last_Range $<=10.1$ AND Last_Range $>=9.62)$ ) OR

((First_Range $<=12.78$ AND First_Range $>=12.68$ ) AND (Last_Range $<=12.78$ AND Last_Range $>=12.68)$ ) OR

((First_Range $<=12.34$ AND First_Range $>=11.8)$ AND (Last_Range $<=12.34$ AND Last_Range $>=11.8)$ ) OR

((First_Range $<=13.37$ AND First_Range $>=13.0)$ AND (Last_Range $<=13.37$ AND Last_Range $>=13.0)$ ) OR

((First_Range $<=12.33$ AND First_Range $>=12.2$ ) AND (Last_Range $<=12.33$ AND Last_Range $>=12.2)$ ) OR

((First_Range $<=10.54$ AND First_Range $>=10.16)$ AND (Last_Range $<=10.54$ AND Last_Range $>=10.16)$ ) OR

((First_Range $<=10.62$ AND First_Range $>=10.57$ ) AND (Last_Range $<=10.62$ AND Last_Range $>=10.57)$ ) OR

((First_Range $<=20.95$ AND First_Range $>=20.83$ ) AND (Last_Range $<=20.95$ AND Last_Range $>=20.83)$ ) OR

((First_Range $<=13.45$ AND First_Range $>=13.39)$ AND (Last_Range $<=13.45$ AND Last_Range $>=13.39)$ )

THEN DELETE;

END;

IF MUX_CHANNEL EQ 3 THEN DO;

IF (TRACK_TYPE $=1$ ) OR

$((($ First_Range + Last_Range) / 2) $>21.56)$ OR

(Echo_Count $=4$ AND ((Linearity1 / Echo_Count) $>0.4))$ OR

(Echo_Count $>=5$ AND Echo_Count $<=7$ AND ((Linearity1 / Echo_Count) $>=0.5)$ ) OR

((Linearity2 / Echo_Count) $>0.5)$ OR

(SLOPE >= 2.5) OR

$(((($ First_Range + Last_Range $) / 2)<21.56)$ AND $((($ First_Range + Last_Range $) / 2)>=16)$ AND $($ SLOPE $<0.1))$ OR

$(((($ First_Range + Last_Range $) / 2)<16)$ AND $((($ First_Range + Last_Range $) / 2)>=14.5)$ AND $($ SLOPE $<0.2))$ OR

$((($ First_Range + Last_Range $) / 2)<14.5)$ AND $((($ First_Range + Last_Range $) / 2)>=13)$ AND $($ SLOPE $<0.3))$ OR 
$(((($ First_Range + Last_Range $) / 2)<13)$ AND (((First_Range + Last_Range) / 2) >= 9) AND (SLOPE < 0.4)) OR $(((($ First_Range + Last_Range $) / 2)<9)$ AND $($ SLOPE $<0.3))$ OR $((($ Noise_Count_Average $) /(($ Echo_Count +10$) * 5))>0.04))$ OR

((First_Range $<=20.58$ AND First_Range $>=19.9$ ) AND (Last_Range $<=20.58$ AND Last_Range $>=19.90)$ ) OR ((First Range $<=19.55$ AND First Range $>=19.43$ ) AND (Last Range $<=19.55$ AND Last ((First_Range $<=19.59$ AND First_Range $>=19.47$ ) AND (Last_Range $<=19.59$ AND Last_Range $>=19.47)$ ) OR ((First_Range $<=19.50$ AND First Range $>=19.37$ ) AND (Last Range $<=19.50$ AND Last Range $>=19.37)$ ) OR ((First_Range $<=10.32$ AND First_Range $>=10.01$ ) AND (Last_Range $<=10.32$ AND Last_Range $>=10.01)$ ) OR ((First_Range $<=12.97$ AND First_Range $>=12.81$ ) AND (Last_Range $<=12.97$ AND Last_Range $>=12.81)$ ) OR ((First_Range $<=20.29$ AND First_Range $>=20.06)$ AND (Last_Range $<=20.29$ AND Last_Range $>=20.06)$ ) OR ((First_Range $<=13.39$ AND First Range $>=13.01)$ AND (Last_Range $<=13.39$ AND Last Range $>=13.01)$ ) OR ((First_Range $<=13.13$ AND First_Range $>=12.82$ ) AND (Last_Range $<=13.13$ AND Last_Range $>=12.82)$ ) OR ((First_Range $<=10.36$ AND First_Range $>=10.1$ ) AND (Last_Range $<=10.36$ AND Last_Range $>=10.1)$ ) OR ((First_Range $<=19.65$ AND First_Range $>=19.59)$ AND (Last_Range $<=19.65$ AND Last_Range $>=19.59)$ ) OR ((First_Range $<=12.82$ AND First_Range $>=12.60)$ AND (Last_Range $<=12.82$ AND Last_Range $>=12.60)$ ) OR ((First_Range $<=21.05$ AND First_Range $>=20.81$ ) AND (Last_Range $<=21.05$ AND Last_Range $>=20.81)$ ) OR ((First_Range $<=12.47$ AND First_Range $>=12.34$ ) AND (Last_Range $<=12.47$ AND Last_Range $>=12.34)$ ) OR ((First_Range $<=19.93$ AND First_Range $>=19.52)$ AND (Last_Range $<=19.93$ AND Last_Range $>=19.52)$ ) OR ((First_Range $<=13.52$ AND First_Range $>=13.37$ ) AND (Last_Range $<=13.52$ AND Last_Range $>=13.37)$ ) OR ((First_Range $<=12.31$ AND First_Range $>=12.09$ ) AND (Last_Range $<=12.31$ AND Last_Range $>=12.09)$ ) OR ((First_Range $<=10.2$ AND First_Range $>=9.84$ ) AND (Last_Range $<=10.2$ AND Last_Range $>=9.84)$ ) OR ((First_Range $<=12.62$ AND First_Range $>=12.38$ ) AND (Last_Range $<=12.62$ AND Last_Range $>=12.38)$ ) OR ((First_Range $<=10.14$ AND First_Range $>=9.82$ ) AND (Last_Range $<=10.14$ AND Last_Range $>=9.82)$ ) OR ((First_Range $<=20.71$ AND First_Range $>=20.57$ ) AND (Last_Range $<=20.71$ AND Last_Range $>=20.57)$ ) OR $((($ First_Range + Last_Range $) / 2)>19)$ AND $($ SLOPE $<0.2))$

THEN DELETE;

END;

IF MUX_CHANNEL EQ 4 THEN DO;

IF (TRACK_TYPE = 1) OR

(((First_Range + Last_Range) / 2) $>21.40)$ OR

(Echo_Count $=4$ AND $(($ Linearity1 $/$ Echo_Count $)>0.4))$ OR

(Echo_Count $>=5$ AND Echo_Count $<=7$ AND ((Linearity1 / Echo_Count) $>=0.5)$ ) OR

((Linearity2 / Echo_Count) $>0.5)$ OR

(SLOPE $>=2.5)$ OR

$(((($ First_Range + Last_Range $) / 2)<20)$ AND $((($ First_Range + Last_Range $) / 2)>=13.5)$ AND $($ SLOPE $<0.25))$ OR

$(((($ First_Range + Last_Range $) / 2)<13.5)$ AND $((($ First_Range + Last_Range $) / 2)>=11.8)$ AND $($ SLOPE $<6))$ OR

$(((($ First_Range + Last_Range $) / 2)<13.5)$ AND $((($ First_Range + Last_Range $) / 2)>=11.8)$ AND (LINEARITY1 $>5))$ OR

$(((($ First_Range + Last_Range) $/ 2)<11.8)$ AND ((First_Range + Last_Range) $/ 2)>=10)$ AND (SLOPE $<0.2))$ OR

$(((($ First_Range + Last_Range $) / 2)<10)$ AND $((($ First_Range + Last_Range $) / 2)>=7)$ AND (SLOPE $<0.25))$ OR

$(((($ First_Range + Last_Range $) / 2)<7)$ AND $($ SLOPE $<0.3))$ OR

$((($ Noise Count Average $) /(($ Echo Count +10$) * 5))>0.04))$ OR

((First_Range $<=20.45$ AND First_Range $>=20.35)$ AND (Last_Range $<=20.45$ AND Last_Range $>=20.35)$ ) OR

(First_Range $=20.95$ AND Last_Range $=20.95$ ) OR

(First_Range $=20.92$ AND Last_Range $=20.92$ ) OR

((First_Range $<=20.92$ AND First_Range $>=20.9$ ) AND (Last_Range $<=20.92$ AND Last_Range $>=20.9$ )) OR

$($ MEAN̄ECHO_STRENGTH $>-3 \overline{7}$ ) OR (First_Range $=20.61$ AND Last_Range $=20.61)$ OR

(First_Range $<=20.54$ AND First_Range $>=20.32$ ) AND (Last_Range $<=20.54$ AND Last_Range $>=20.32$ ) OR

$((($ First_Range+Last_Range $) / 2)>=20.5$ AND Slope $<0.15)$ OR

(First_Range $<=20.38$ AND First_Range $>=20.0$ ) AND (Last_Range $<=20.38$ AND Last_Range $>=20.0$ ) OR

$((($ First_Range+Last_Range $) / 2)>=20.3$ AND Slope $<0.5)$ OR

( Slope $<=0$ ) OR

(First_Range $<=19.91$ AND First_Range $>=19.66$ ) AND (Last_Range $<=19.91$ AND Last_Range $>=19.66$ ) OR

(First_Range $<=9.75$ AND First_Range $>=9.62$ ) AND (Last_Range $<=9.75$ AND Last_Range $>=9.62$ ) OR

(First_Range $<=10.04$ AND First_Range $>=9.74$ ) AND (Last_Range $<=10.04$ AND Last_Range $>=9.74$ ) OR

(First_Range $<=10.36$ AND First_Range $>=10.22$ ) AND (Last_Range $<=10.36$ AND Last_Range $>=10.22$ ) OR

(First_Range $<=17.79$ AND First_Range $>=17.74$ ) AND (Last_Range $<=17.79$ AND Last_Range $>=17.74$ ) OR

(First_Range $<=10.48$ AND First_Range $>=10.36$ ) AND (Last_Range $<=10.48$ AND Last_Range $>=10.46$ ) THEN DELETE;

END;

IF MUX CHANNEL EQ 5 THEN DO;

IF (TRACK_TYPE = 1) OR

(((First_Range + Last_Range) / 2) $>21.76)$ OR

$($ Echo_Count $=4$ AND $(($ Linearity1 $/$ Echo_Count $)>0.4))$ OR

(Echo_Count $>=5$ AND Echo_Count $<=7$ AND ((Linearity1 / Echo_Count) $>=0.5)$ ) OR

((Linearity2 / Echo_Count) $>0.5)$ OR

(SLOPE $>=2.5$ ) OR

$(((($ First_Range + Last_Range $) / 2)<20)$ AND $((($ First_Range + Last_Range $) / 2)>=15)$ AND $($ SLOPE $<0.1))$ OR

$((($ First_Range + Last_Range $) / 2)<15)$ AND $((($ First_Range + Last_Range $) / 2)>=12)$ AND $($ SLOPE $<0.3))$ OR

$(((($ First_Range + Last_Range $) / 2)<12)$ AND $($ SLOPE $<0.4))$ OR

$(((($ Noise_Count_Average $) /(($ Echo_Count +10$) * 5))>0.04))$ OR 
((First_Range $=20.67)$ AND (Last_Range=20.67)) OR

(First_Range $<=20.68$ AND First_Range $>=20.63$ ) AND (Last_Range $<=20.68$ AND Last_Range $>=20.63$ ) OR (Mean Echo Strength > -37) OR

(First_Range $<=20.42$ AND First_Range $>=20.39$ ) AND (Last_Range $<=20.42$ AND Last_Range $>=20.39$ ) OR ((First Range $=20.46)$ AND (Last_Range $=20.46)$ ) OR

(First_Range $<=20.79$ AND First_Range $>=20.73$ ) AND (Last_Range $<=20.79$ AND Last_Range $>=20.73$ ) OR (Slope $<=0$ ) OR

$((($ First_Range+Last_Range $) / 2)>=20$ AND Slope $<0.1)$ OR

(First_Range $<=20.87$ AND First_Range $>=20.86$ ) AND (Last_Range $<=20.87$ AND Last_Range $>=20.86$ ) OR

$((($ First_Range $<=20.58$ AND First_Range $>=20.35)$ AND (Last_Range $<=20.58$ AND Last_Range $>=20.35))$ AND Slope $<$ $0.5) \mathrm{OR}$

((First_Range+Last_Range)/2) $>=20.6$ AND Slope $<0.3)$ OR

(First_Range $<=10 . \overline{1} 7$ AND First_Range $>=9.9$ ) AND (Last_Range $<=10.17$ AND Last_Range $>=9.9$ ) OR

(First_Range $<=20.65$ AND First_Range $>=20.28$ ) AND (Last_Range $<=20.65$ AND Last_Range $>=20.28$ ) OR

(First_Range $<=18.14$ AND First_Range $>=18.12$ ) AND (Last_Range $<=18.14$ AND Last_Range $>=18.12$ ) OR

(First_Range $<=20.26$ AND First_Range $>=19.97$ ) AND (Last_Range $<=20.26$ AND Last_Range $>=19.97$ ) OR

(First_Range $<=15.24$ AND First_Range $>=15.21$ ) AND (Last_Range $<=15.24$ AND Last_Range $>=15.21$ ) OR

(First_Range $<=17.83$ AND First_Range $>=17.79$ ) AND (Last_Range $<=17.83$ AND Last_Range $>=17.79$ ) OR

(First_Range $<=16.94$ AND First_Range $>=16.8$ ) AND (Last_Range $<=16.94$ AND Last_Range $>=16.8$ ) OR

(First_Range $<=17.35$ AND First_Range $>=17.26$ ) AND (Last_Range $<=17.35$ AND Last_Range $>=17.26$ ) OR

(First_Range $<=19.66$ AND First_Range $>=19.62$ ) AND (Last_Range $<=19.66$ AND Last_Range $>=19.62$ )

THEN DELETE;

END;

IF MUX CHANNEL EQ 6 THEN DO;

IF (TRACK_TYPE = 1) OR

(((First_Range + Last_Range) / 2)>20.35) OR

(Echo_Count $=4$ AND $(($ Linearity1 $/$ Echo_Count $)>0.4))$ OR

(Echo_Count $>=5$ AND Echo_Count $<=7$ AND $(($ Linearity1 $/$ Echo_Count $)>=0.5))$ OR

((Linearity2 / Echo_Count) $>0.5)$ OR

(SLOPE $>=2.5)$ OR

$(((($ First_Range + Last_Range $) / 2)<20.35)$ AND (((First_Range + Last_Range) / 2) $>=15)$ AND (SLOPE < 0.15)) OR

$(((($ First_Range + Last_Range $) / 2)<15)$ AND $((($ First_Range + Last_Range $) / 2)>=13.5)$ AND $($ SLOPE $<0.3))$ OR

$(((($ First_Range + Last_Range $) / 2)<13.5)$ AND $((($ First_Range + Last_Range $) / 2)>=12.3)$ AND $($ SLOPE $<0.7))$ OR

$(((($ First_Range + Last_Range $) / 2)<12.3)$ AND $((($ First_Range + Last_Range $) / 2)>=7)$ AND $($ SLOPE $<0.25))$ OR

$(((($ First_Range + Last_Range) $/ 2)<7)$ AND (SLOPE $<0.35))$ OR

$((($ Noise_Count_Average $) /(($ Echo_Count +10$) * 5))>0.04))$ OR

(First_Range $<=20.23$ AND First_Range $>=20.19$ ) AND (Last_Range $<=20.23$ AND Last_Range $>=20.19$ ) OR

(First_Range $<=17.76$ AND First_Range $>=17.58$ ) AND (Last_Range $<=17.76$ AND Last_Range $>=17.58$ ) OR $(((($ First_Range + Last_Range) $/ 2)>19)$ AND (SLOPE $<1.5))$ OR

$(((($ First_Range + Last_Range $) / 2)<12)$ AND $((($ First_Range + Last_Range $) / 2)>=11)$ AND $($ SLOPE $<0.44))$ OR

(First Range $<=13.97$ AND First Range $>=13.91$ ) AND (Last Range $<=13.97$ AND Last Range $>=13.91$ ) OR

(First_Range $<=13.74$ AND First_Range $>=13.67$ ) AND (Last_Range $<=13.74$ AND Last_Range $>=13.67$ ) OR

(First_Range $<=10.89$ AND First_Range $>=10.8$ ) AND (Last_Range $<=10.89$ AND Last_Range $>=10.8$ )

THEN DELETE;

END;

IF MUX_CHANNEL EQ 7 THEN DO;

IF (TRACK_TYPE = 1) OR

(((First_Range + Last_Range) / 2) $>21.64)$ OR

(Echo_Count $=4$ AND $(($ Linearity1 $/$ Echo_Count $)>0.4))$ OR

(Echo_Count $>=5$ AND Echo_Count $<=7$ AND ((Linearity1 / Echo_Count) $>=0.5)$ ) OR

((Linearity2 / Echo_Count) $>0.5)$ OR

(SLOPE $>=2.5)$ OR

$(((($ First_Range + Last_Range $) / 2)<21.64)$ AND $((($ First_Range + Last_Range $) / 2)>=15)$ AND $($ SLOPE $<0.15))$ OR $(((($ First_Range + Last_Range $) / 2)<15)$ AND $((($ First_Range + Last_Range $) / 2)>=13.6)$ AND $(\mathrm{SLOPE}<0.25))$ OR

$(((($ First_Range + Last_Range $) / 2)<13.6)$ AND $((($ First_Range + Last_Range $) / 2)>=13.4)$ AND $($ SLOPE $<0.25))$ OR $(((($ First_Range + Last_Range $) / 2)<13.4)$ AND $((($ First_Range + Last_Range $) / 2)>=12.6)$ AND $(\mathrm{SLOPE}<0.3))$ OR

$(((($ First_Range + Last_Range $) / 2)<12.6)$ AND (( First_Range + Last_Range $) / 2)>=11.95)$ AND $($ SLOPE $<0.6))$ OR $(((($ First_Range + Last_Range) $/ 2)<11.95)$ AND (((First_Range + Last_Range $) / 2)>=8)$ AND (SLOPE $<0.2))$ OR

$(((($ First_Range + Last_Range $) / 2)<8)$ AND (SLOPE $<0.3))$ OR

$((($ Noise Count Average $) /(($ Echo Count +10$) * 5))>0.04))$ OR

((First_Range $<=21.19$ AND First_Range $>=21.06)$ AND (Last_Range $<=21.19$ AND Last_Range $>=21.06)$ ) OR ((First Range+Last Range $/ 2)>=20.9$ AND Slope $<=0.2)$ OR

((First_Range $<=20.61$ AND First_Range $>=20.55)$ AND (Last_Range $<=20.61$ AND Last_Range $>=20.55)$ ) OR ((First_Range $<=10.55$ AND First_Range $>=10.14$ ) AND (Last_Range $<=10.55$ AND Last_Range $>=10.14)$ ) OR ((First_Range $<=21.12$ AND First_Range $>=20.68)$ AND (Last_Range $<=21.12$ AND Last_Range $>=20.68)$ ) OR ((First_Range $<=10.84$ AND First_Range $>=10.65)$ AND (Last_Range $<=10.84$ AND Last_Range $>=10.65)$ ) OR ((First_Range $<=13.93$ AND First_Range $>=13.88$ ) AND (Last_Range $<=13.93$ AND Last_Range $>=13.88)$ ) OR ((First_Range $<=19.27$ AND First_Range $>=19.23$ ) AND (Last_Range $<=19.27$ AND Last_Range $>=19.23)$ ) OR ((First_Range $<=20.33$ AND First_Range $>=20.12$ ) AND (Last_Range $<=20.33$ AND Last_Range $>=20.12)$ ) OR $(($ First_Range $<=19.46$ AND First_Range $>=19.31)$ AND (Last_Range $<=19.46$ AND Last_Range $>=19.31)$ ) OR 
((First_Range $<=10.65$ AND First_Range $>=10.43)$ AND (Last_Range $<=10.65$ AND Last_Range $>=10.43)$ ) OR

((First_Range $<=20.41$ AND First_Range $>=20.23$ ) AND (Last_Range $<=20.41$ AND Last_Range $>=20.23$ ) $)$ OR

((First_Range $<=10.01$ AND First_Range $>=9.88$ ) AND (Last_Range $<=10.01$ AND Last_Range $>=9.88)$ ) OR

((First_Range $<=20.96$ AND First_Range $>=20.7$ ) AND (Last_Range $<=20.96$ AND Last_Range $>=20.7)$ ) OR

((First_Range $<=20.63$ AND First_Range $>=20.38$ ) AND (Last_Range $<=20.63$ AND Last_Range $>=20.38$ ) THEN DELETE; END;

END;

IF SYSTEM='D' THEN DO;

IF MUX CHANNEL EQ 1 THEN DO;

IF ((First_Range + Last_Range) / 2)>21.73) OR

(Echo_Count $=4$ AND $(($ Linearity1 $/$ Echo_Count $)>0.4))$ OR

(Echo_Count $>=5$ AND Echo_Count $<=7$ AND ((Linearity1 / Echo_Count) $>=0.5)$ ) OR

((Linearity2 / Echo_Count) $>0.5)$ OR

$(((($ First_Range + Last_Range $) / 2)<21.73)$ AND ((First_Range + Last_Range $) / 2)>=15)$ AND (SLOPE $<0.15))$ OR

$(((($ First_Range + Last_Range $) / 2)<15)$ AND $((($ First_Range + Last_Range $) / 2)>=13.15)$ AND $($ SLOPE $<0.25))$ OR

$(((($ First_Range + Last_Range $) / 2)<13.15)$ AND $((($ First_Range + Last_Range $) / 2)>=11.82)$ AND $($ SLOPE $<0.5))$ OR

$(((($ First_Range + Last_Range $) / 2)<11.82)$ AND $((($ First_Range + Last_Range $) / 2)>=10.36)$ AND $($ SLOPE $<0.25))$ OR

$(((($ First_Range + Last_Range $) / 2)<10.36)$ AND $((($ First_Range + Last_Range $) / 2)>=9.65)$ AND $($ SLOPE $<0.45))$ OR

$(((($ First_Range + Last_Range $) / 2)<9.65)$ AND $($ SLOPE $<0.2))$ OR

$((($ Noise_Count Average $) /(($ Echo Count +10$) * 5))>0.04))$ OR

((First_Range $<=21.15$ AND First_Range $>=20.97)$ AND (Last_Range $<=21.15$ AND Last_Range $>=20.97)$ ) OR

((First Range+Last Range)/2) $>=20.9$ AND Slope $<=0.3)$ OR

((First_Range $<=21.02$ AND First_Range $>=20.89$ ) AND (Last_Range $<=21.02$ AND Last_Range $>=20.89$ ) $)$ OR

((First_Range+Last_Range)/2) $>=19.54$ AND Slope $<=0.2)$ OR

$((($ First_Range+Last_Range $) / 2)>=10.36$ AND Slope $<=0.4)$ OR

((First_Range $<=12.5$ AND First_Range $>=12.37$ ) AND (Last_Range $<=12.5$ AND Last_Range $>=12.37)$ ) OR

((First_Range $<=21.15$ AND First_Range $>=20.71$ ) AND (Last_Range $<=21.15$ AND Last_Range $>=20.71)$ ) OR

((First_Range $<=19.58$ AND First_Range $>=19.39)$ AND (Last_Range $<=19.58$ AND Last_Range $>=19.39)$ ) OR

((First_Range $<=13.62$ AND First_Range $>=13.43$ ) AND (Last_Range $<=13.62$ AND Last_Range $>=13.43)$ ) OR

((First_Range $<=12.73$ AND First_Range $>=12.65$ ) AND (Last_Range $<=12.73$ AND Last_Range $>=12.65)$ )

THEN DELETE;

END;

IF MUX_CHANNEL EQ 2 THEN DO;

IF (TRACK_TYPE=1) OR

(((First Range + Last Range) / 2)>21.25) OR

(Echo_Count $=4$ AND $(($ Linearity1 / Echo_Count $)>0.4))$ OR

(Echo_Count $>=5$ AND Echo_Count $<=7$ AND $(($ Linearity1 $/$ Echo_Count $)>=0.5))$ OR

((Linearity2 / Echo_Count) $>0.5)$ OR

(SLOPE $>=2.5)$ OR

$(\mathrm{SLOPE}<0.2) \mathrm{OR}$

$(((($ First Range + Last Range $) / 2)<21.25)$ AND $((($ First Range + Last Range $) / 2)>=19.75)$ AND (SLOPE < 0.15)) OR

$(((($ First_Range + Last_Range $) / 2)<19.75)$ AND $((($ First_Range + Last_Range $) / 2)>=18.9)$ AND $($ SLOPE $<0.45))$ OR

$(((($ First_Range + Last_Range $) / 2)<12.76)$ AND $((($ First_Range + Last_Range $) / 2)>=11.64)$ AND $($ SLOPE $<0.45))$ OR

$(((($ First_Range + Last_Range) $/ 2)<10.5)$ AND ((First_Range + Last_Range) / 2) $>=9.65)$ AND (SLOPE $<0.45))$ OR

$(((($ First_Range + Last_Range $) / 2)<6.5)$ AND $($ SLOPE $<0.3))$ OR

$(((($ Noise_Count_Average $) /(($ Echo_Count +10$) * 5))>0.04))$ OR

((First_Range $<=21.05$ AND First_Range $>=20.84)$ AND (Last_Range $<=21.05$ AND Last_Range $>=20.84)$ ) OR

(((First_Range+Last_Range)/2) $>=-20.93$ AND Slope $<=0.35)$ OR

((First_Range $<=19.81$ AND First_Range $>=19.49)$ AND (Last_Range $<=19.81$ AND Last_Range $>=19.49)$ ) OR

((First_Range $<=20.73$ AND First_Range $>=20.53$ ) AND (Last_Range $<=20.73$ AND Last_Range $>=20.53$ ) OR

((First_Range $<=12.89$ AND First_Range $>=12.79$ ) AND (Last_Range $<=12.89$ AND Last_Range $>=12.79)$ ) OR

((First_Range $<=20.17$ AND First_Range $>=20.07$ ) AND (Last_Range $<=20.17$ AND Last_Range $>=20.07)$ ) OR

((First_Range $<=20.41$ AND First_Range $>=20.22$ ) AND (Last_Range $<=20.41$ AND Last_Range $>=20.22)$ ) OR

((First_Range $<=19.56$ AND First_Range $>=19.31$ ) AND (Last_Range $<=19.56$ AND Last_Range $>=19.31)$ ) OR

((First_Range $<=20.9$ AND First_Range $>=20.76$ ) AND (Last_Range $<=20.9$ AND Last_Range $>=20.76$ ) ) OR

((First_Range $<=7.06$ AND First_Range $>=6.95)$ AND (Last_Range $<=7.06$ AND Last_Range $>=6.95)$ ) OR

((First_Range $<=15.63$ AND First_Range $>=15.56)$ AND (Last_Range $<=15.63$ AND Last_Range $>=15.56)$ ) OR

$((($ First_Range+Last_Range $) / 2)>=19$ AND Noise_Count_Average $>3$ )

THEN DELLETE;

END;

IF MUX_CHANNEL EQ 3 THEN DO;

IF (TRACK_TYPE=1) OR

(((First_Range + Last_Range) / 2)>21.66) OR

(Echo_Count $=4$ AND $(($ Linearity1 $/$ Echo_Count $)>0.4))$ OR

(Echo_Count $>=5$ AND Echo_Count $<=7$ AND ((Linearity1 / Echo_Count) $>=0.5)$ ) OR

((Linearity2 / Echo Count) $>0.5$ ) OR

(LINEARITY1>3.2 AND LINEARITY2>3.2 AND NOISE_COUNT_AVERAGE>3) OR

(SLOPE >= 2) OR 
(SLOPE < 0.15) OR

$(((($ First_Range + Last_Range $) / 2)<21.66)$ AND ((First_Range + Last_Range $) / 2)>=18)$ AND (SLOPE $<0.1))$ OR $(((($ First_Range + Last_Range $) / 2)<18)$ AND $((($ First_Range + Last_Range $) / 2)>=15)$ AND $($ SLOPE $<0.15))$ OR $(((($ First_Range + Last_Range $) / 2)<15)$ AND $((($ First_Range + Last_Range $) / 2)>=13.40)$ AND $($ SLOPE $<0.2))$ OR $(((($ First_Range + Last_Range $) / 2)<13.40)$ AND (((First_Range + Last_Range) $/ 2)>=11.57)$ AND (SLOPE $<0.7))$ OR $(((($ First_Range + Last_Range $) / 2)<10.45)$ AND ((First_Range + Last_Range $) / 2)>=9.65)$ AND $($ SLOPE $<0.7))$ OR $(((($ First_Range + Last_Range $) / 2)<6.5)$ AND (SLOPE < 0.3)) OR

$(((($ Noise_Count_Average $) /(($ Echo_Count +10$) * 5))>0.04))$ OR

((First_Range $<=19.91$ AND First_Range $>=19.34)$ AND (Last_Range $<=19.91$ AND Last Range $>=19.34)$ ) OR ((First_Range $<=20.84$ AND First_Range $>=20.68$ ) AND (Last_Range $<=20.84$ AND Last_Range $>=20.68)$ ) OR ((First Range $<=13.78$ AND First Range $>=13.36$ ) AND (Last Range $<=13.78$ AND Last Range $>=13.36$ ) OR ((First_Range $<=19.74$ AND First_Range $>=19.68$ ) AND (Last_Range $<=19.74$ AND Last_Range $>=19.68)$ ) OR ((First_Range $<=13.88$ AND First_Range $>=13.84$ ) AND (Last_Range $<=13.88$ AND Last_Range $>=13.84)$ ) OR ((First_Range $<=14.42$ AND First_Range $>=14.39$ ) AND (Last_Range $<=14.42$ AND Last_Range $>=14.39$ ) $)$ OR ((First_Range $<=10.58$ AND First_Range $>=10.54)$ AND (Last_Range $<=10.58$ AND Last_Range $>=10.54)$ ) OR ((First_Range $<=20.92$ AND First_Range $>=20.87$ ) AND (Last_Range $<=20.92$ AND Last_Range $>=20.87$ ) OR ((First_Range $<=20.45$ AND First_Range $>=20.2$ ) AND (Last_Range $<=20.45$ AND Last_Range $>=20.2)$ ) OR ((First_Range $<=20.3$ AND First_Range $>=20.0$ ) AND (Last_Range $<=20.3$ AND Last_Range $>=20.0)$ ) OR (( (First_Range+Last_Range)/2) $>=19$ AND Noise_Count_Average $>2.8)$ OR

((First_Range $<=14.48$ AND First_Range $>=14.36)$ AND (Last_Range $<=14.48$ AND Last_Range $>=14.36)$ ) OR ((First_Range $<=19.62$ AND First_Range $>=19.30)$ AND (Last_Range $<=19.62$ AND Last_Range $>=19.30)$ ) OR ((First_Range $<=18.37$ AND First_Range $>=18.34$ ) AND (Last_Range $<=18.37$ AND Last_Range $>=18.34)$ ) OR ((First_Range $<=18.73$ AND First_Range $>=18.47$ ) AND (Last_Range $<=18.73$ AND Last_Range $>=18.47)$ ) OR ((First_Range $<=17.95$ AND First_Range $>=17.77)$ AND (Last_Range $<=17.95$ AND Last_Range $>=17.77)$ ) THEN DELETE; END;

IF MUX_CHANNEL EQ 4 THEN DO;

IF (TRACK_TYPE=1 AND SLOPE<0.7) OR

(((First_Range + Last_Range) / 2)>21.38) OR

(Echo_Count $=4$ AND $(($ Linearity1 $/$ Echo_Count $)>0.4))$ OR

(Echo_Count $>=5$ AND Echo_Count $<=7$ AND ((Linearity1 / Echo_Count) $>=0.5)$ ) OR

((Linearity2 / Echo Count) $>0.5$ ) OR

(LINEARITY1>3.2 AND LINEARITY2>3.2 AND NOISE_COUNT_AVERAGE>3) OR

(LINEARITY1>5.5 AND LINEARITY2>5.5 AND SLOPE<0.7) OR

(SLOPE >= 2) OR

(SLOPE < 0.15) OR

$(((($ First_Range + Last_Range) / 2) < 21.38) AND (((First_Range + Last_Range) / 2) >= 18) AND (SLOPE < 0.1)) OR

$(((($ First_Range + Last_Range $) / 2)<18)$ AND $((($ First_Range + Last_Range $) / 2)>=15)$ AND $($ SLOPE $<0.15))$ OR

$(((($ First_Range + Last_Range $) / 2)<15)$ AND (((First_Range + Last_Range $) / 2)>=12.9)$ AND $($ SLOPE $<0.2))$ OR

$(((($ First_Range + Last_Range $) / 2)<12.9)$ AND $((($ First_Range + Last_Range $) / 2)>=12.56)$ AND $(\mathrm{SLOPE}<0.5))$ OR

$(((($ First_Range + Last_Range $) / 2)<12.3)$ AND $((($ First_Range + Last_Range $) / 2)>=12.2)$ AND $($ SLOPE $<0.5))$ OR

$(((($ First_Range + Last_Range $) / 2)<11.8)$ AND $((($ First_Range + Last_Range $) / 2)>=11.5)$ AND $($ SLOPE $<0.5))$ OR

$(((($ First_Range + Last_Range $) / 2)<10.15)$ AND $((($ First_Range + Last_Range $) / 2)>=9.5)$ AND $($ SLOPE $<0.5))$ OR

$(((($ First_Range + Last_Range $) / 2)<6.5)$ AND (SLOPE < 0.3)) OR

$((($ Noise_Count_Average $) /(($ Echo_Count +10$) * 5))>0.04))$ OR

((First_Range $<=12.41$ AND First_Range $>=12.38$ ) AND (Last_Range $<=12.41$ AND Last_Range $>=12.38)$ ) OR

((First_Range $<=10.43$ AND First_Range $>=10.04$ ) AND (Last_Range $<=10.43$ AND Last_Range $>=10.04)$ ) OR

((First_Range $<=20.45$ AND First_Range $>=20.20)$ AND (Last_Range $<=20.45$ AND Last_Range $>=20.20)$ ) OR

((First_Range $<=12.12$ AND First_Range $>=12.08$ ) AND (Last_Range $<=12.12$ AND Last_Range $>=12.08)$ ) OR

((First_Range $<=10.26$ AND First_Range $>=10.20$ ) AND (Last_Range $<=10.26$ AND Last_Range $>=10.20)$ ) OR

((First_Range $<=20.77$ AND First_Range $>=20.57$ ) AND (Last_Range $<=20.77$ AND Last_Range $>=20.57)$ ) OR

((First_Range $<=10.49$ AND First_Range $>=10.42$ ) AND (Last_Range $<=10.49$ AND Last_Range $>=10.42)$ ) OR

((First_Range $<=20.64$ AND First_Range $>=20.32$ ) AND (Last_Range $<=20.64$ AND Last_Range $>=20.32)$ ) OR

((First_Range $<=16.16$ AND First_Range $>=16.13)$ AND (Last_Range $<=16.16$ AND Last_Range $>=16.13)$ ) OR

((First_Range $<=19.02$ AND First_Range $>=18.91)$ AND (Last_Range $<=19.02$ AND Last_Range $>=18.91)$ ) OR

((First_Range $<=9.4$ AND First_Range $>=9.37$ ) AND (Last_Range $<=9.4$ AND Last_Range $>=9.37)$ ) OR

((First_Range $<=20.16$ AND First_Range $>=20.07$ ) AND (Last_Range $<=20.16$ AND Last_Range $>=20.07)$ ) OR

((First_Range $<=20.16$ AND First_Range $>=9.95)$ AND (Last_Range $<=10.16$ AND Last_Range $>=9.95)$ ) THEN DELETE;

END;

IF MUX_CHANNEL EQ 5 THEN DO;

IF (TRACK TYPE=1) OR

$((($ First_Range + Last_Range $) / 2)>22.11)$ OR

(Echo_Count $=4$ AND $(($ Linearity1 $/$ Echo_Count $)>0.4))$ OR

(Echo_Count $>=5$ AND Echo_Count $<=7$ AND ((Linearity1 / Echo_Count) $>=0.5)$ ) OR

((Linearity2 / Echo Count) $>0.5$ ) OR

(LINEARITY1>3.5 AND LINEARITY2>3.5 AND NOISE_INDEX>6.5 AND SLOPE<0.85) OR

(LINEARITY1>4.5 AND LINEARITY2>3.5 AND NOISE_COUNT_AVERAGE>3.5) OR

(SLOPE $>=2$ ) OR

(SLOPE < 0.15) OR 
$(((($ First_Range + Last_Range $) / 2)<22.11)$ AND ((First_Range + Last_Range) / 2) $>=19.85)$ AND (SLOPE < 0.1) ) OR $(((($ First_Range + Last_Range $) / 2)<19.85)$ AND $((($ First_Range + Last_Range $) / 2)>=19.5)$ AND $($ SLOPE $<0.5))$ OR $(((($ First_Range + Last_Range $) / 2)<19.5)$ AND $((($ First_Range + Last_Range $) / 2)>=12.7)$ AND $($ SLOPE $<0.15))$ OR $(((($ First_Range + Last_Range $) / 2)<12.7)$ AND $((($ First_Range + Last_Range $) / 2)>=11.9)$ AND $($ SLOPE $<0.5))$ OR $(((($ First_Range + Last_Range $) / 2)<8.61)$ AND $((($ First_Range + Last_Range $) / 2)>=8.16)$ AND $($ SLOPE $<0.5))$ OR $(((($ First_Range + Last_Range $) / 2)<6.5)$ AND $($ SLOPE $<0.3))$ OR

$((($ Noise Count Average $) /(($ Echo Count +10$) * 5))>0.04))$ OR

((First_Range $<=20.9$ AND First_Range $>=20.87$ ) AND (Last_Range $<=20.9$ AND Last_Range $>=20.87)$ ) OR

((First_Range $<=12.92$ AND First_Range $>=12.43$ ) AND (Last_Range $<=12.92$ AND Last_Range $>=12.43)$ ) OR

((First_Range $<=20.95$ AND First_Range $>=20.36)$ AND (Last_Range $<=20.95$ AND Last_Range $>=20.36)$ ) OR

((First Range $<=13.26$ AND First Range $>=13.04$ ) AND (Last Range $<=13.26$ AND Last Range $>=13.04)$ ) OR

((First_Range $<=20.61$ AND First_Range $>=20.39)$ AND (Last_Range $<=20.61$ AND Last_Range $>=20.39)$ ) OR

((First_Range $<=10.67$ AND First_Range $>=10.57$ ) AND (Last_Range $<=10.67$ AND Last_Range $>=10.57)$ ) OR

((First_Range $<=13.04$ AND First_Range $>=12.72$ ) AND (Last_Range $<=13.04$ AND Last_Range $>=12.72)$ ) OR

((First_Range $<=19.64$ AND First_Range $>=19.40$ ) AND (Last_Range $<=19.64$ AND Last_Range $>=19.40)$ ) OR

((First_Range $<=9.63$ AND First_Range $>=9.56$ ) AND (Last_Range $<=9.63$ AND Last_Range $>=9.56)$ ) OR

((First_Range $<=10.35$ AND First_Range $>=10.32$ ) AND (Last_Range $<=10.35$ AND Last_Range $>=10.32)$ ) OR

((First_Range $<=19.49$ AND First_Range $>=19.23$ ) AND (Last_Range $<=19.49$ AND Last_Range $>=19.23)$ ) OR

((First_Range $<=20.54$ AND First_Range $>=20.46)$ AND (Last_Range $<=20.54$ AND Last_Range $>=20.46)$ ) OR

$((($ First_Range + Last_Range $) / 2)>19)$ AND $(($ Noise_Count_Average $>2))$ OR

((First_Range $<=10 . \overline{19}$ AND First_Range $>=10.16)$ AND (Last_Range $<=10.19$ AND Last_Range $>=10.16))$ OR

((First_Range $<=10$ AND First_Range $>=9.97)$ AND (Last_Range $<=10$ AND Last_Range $>=9.97)$ ) OR

$((($ First_Range + Last_Range) $/$ 2) $>$ 20) AND ((Slope $<.4))$ OR

((First Range $<=6.91$ AND First Range $>=6.84$ ) AND (Last Range $<=6.91$ AND Last Range $>=6.84$ )) OR

((First_Range $<=9.91$ AND First_Range $>=9.68$ ) AND (Last_Range $<=9.91$ AND Last_Range $>=9.68)$ ) OR

((First_Range $<=20.16$ AND First_Range $>=20.06)$ AND (Last_Range $<=20.16$ AND Last_Range $>=20.06)$ ) THEN DELETE;

END;

IF MUX_CHANNEL EQ 6 THEN DO;

IF (TRACK_TYPE=1) OR

(((First_Range + Last_Range) / 2)>21.59) OR

(Echo_Count $=4$ AND $(($ Linearity1 $/$ Echo_Count $)>0.4))$ OR

(Echo_Count $>=5$ AND Echo_Count $<=7$ AND ((Linearity1 / Echo_Count) $>=0.5)$ ) OR

((Linearity2 / Echo_Count) $>0.5$ ) OR

(LINEARITY1>4.5 AND LINEARITY2>3.5 AND SLOPE<0.5) OR

(SLOPE $>=2.5)$ OR

$(((($ First_Range + Last_Range) / 2) < 21.59) AND (((First_Range + Last_Range) / 2) $>=15)$ AND (SLOPE < 0.1)) OR

$(((($ First_Range + Last_Range $) / 2)<15)$ AND ((First_Range + Last_Range $) / 2)>=13.16)$ AND (SLOPE $<0.15))$ OR

$(((($ First_Range + Last_Range $) / 2)<13.16)$ AND (((First_Range + Last_Range $) / 2)>=11.55)$ AND $($ SLOPE $<0.8))$ OR

$(((($ First_Range + Last_Range $) / 2)<10.25)$ AND $((($ First_Range + Last_Range $) / 2)>=9.5)$ AND $($ SLOPE $<0.7))$ OR

$(((($ First_Range + Last_Range $) / 2)<9.5)$ AND $((($ First_Range + Last_Range $) / 2)>=3)$ AND $($ SLOPE $<0.2))$ OR

$(((($ First_Range + Last_Range $) / 2)<3)$ AND $($ SLOPE $<0.3))$ OR

$(((($ Noise Count Average $) /(($ Echo Count +10$) * 5))>0.04))$ OR

((First_Range $<=10.77$ AND First_Range $>=10.61)$ AND (Last_Range $<=10.77$ AND Last_Range $>=10.61)$ ) OR

$((($ First_Range + Last_Range $) / 2)>=20.5)$ AND (SLOPE $<0 . \overline{2}))$ OR

((First_Range $<=10.6 \overline{1}$ AND First_Range $>=10.35)$ AND (Last_Range $<=10.61$ AND Last_Range $>=10.35)$ ) OR

((First_Range $<=20.51$ AND First_Range $>=20.28)$ AND (Last_Range $<=20.51$ AND Last_Range $>=20.28)$ ) OR

(slope $<0.01)$ OR

((First_Range $<=21.35$ AND First_Range $>=21.32$ ) AND (Last_Range $<=21.35$ AND Last_Range $>=21.32)$ ) OR

((First_Range $<=10.26$ AND First_Range $>=10.24)$ AND (Last_Range $<=10.26$ AND Last_Range $>=10.24)$ ) OR

((First_Range $<=13.26$ AND First_Range $>=13.23$ ) AND (Last_Range $<=13.26$ AND Last_Range $>=13.23)$ ) OR

((First_Range $<=13.62$ AND First_Range $>=13.59)$ AND (Last_Range $<=13.62$ AND Last_Range $>=13.59)$ ) OR

((First_Range $<=10.39$ AND First_Range $>=10.32$ ) AND (Last_Range $<=10.39$ AND Last_Range $>=10.32)$ )

THEN DELETE;

END;

END;

IF SYSTEM='R' THEN DO;

IF MUX_CHANNEL EQ 1 THEN DO;

IF $(($ Echo Count $=4$ AND $(($ Linearity $1 /$ Echo Count $)>0.4))$ OR

(Echo_Count $>=5$ AND Echo_Count $<=7$ AND ((Linearity1 / Echo_Count) $>=0.5)$ ) OR

((Linearity2 / Echo_Count) $>0.5)$ OR

( Slope $>=2.5)$ OR

$(((($ Noise_Count_Average $) /(($ Echo_Count +10$) * 5))>0.04))$ OR

$(((($ First_Range + Last_Range) / 2) $<10)$ AND (SLOPE < 0.25)) OR

$(((($ First_Range + Last_Range $) / 2)>=10)$ AND $((($ First_Range + Last_Range $) / 2)<14)$ AND $($ SLOPE $<0.2))$ OR

$(((($ First_Range + Last_Range) $/ 2)>=14)$ AND $((($ First_Range + Last_Range $) / 2)<18)$ AND $($ SLOPE $<0.15))$ OR

$((($ First_Range + Last_Range $) / 2)>=18)$ AND $((($ First_Range + Last_Range $) / 2)<22)$ AND $($ SLOPE $<0.1))$ OR

(Linearity1 $>2$ AND Linearity2 $>2$ AND Echo_Count $<=7$ ) OR

((First_Range > 8.5 AND Last_Range $>8.5$ AND First_Range $<10.5$ AND Last_Range $<10.5)$ AND ((Linearity $1>1$ AND 


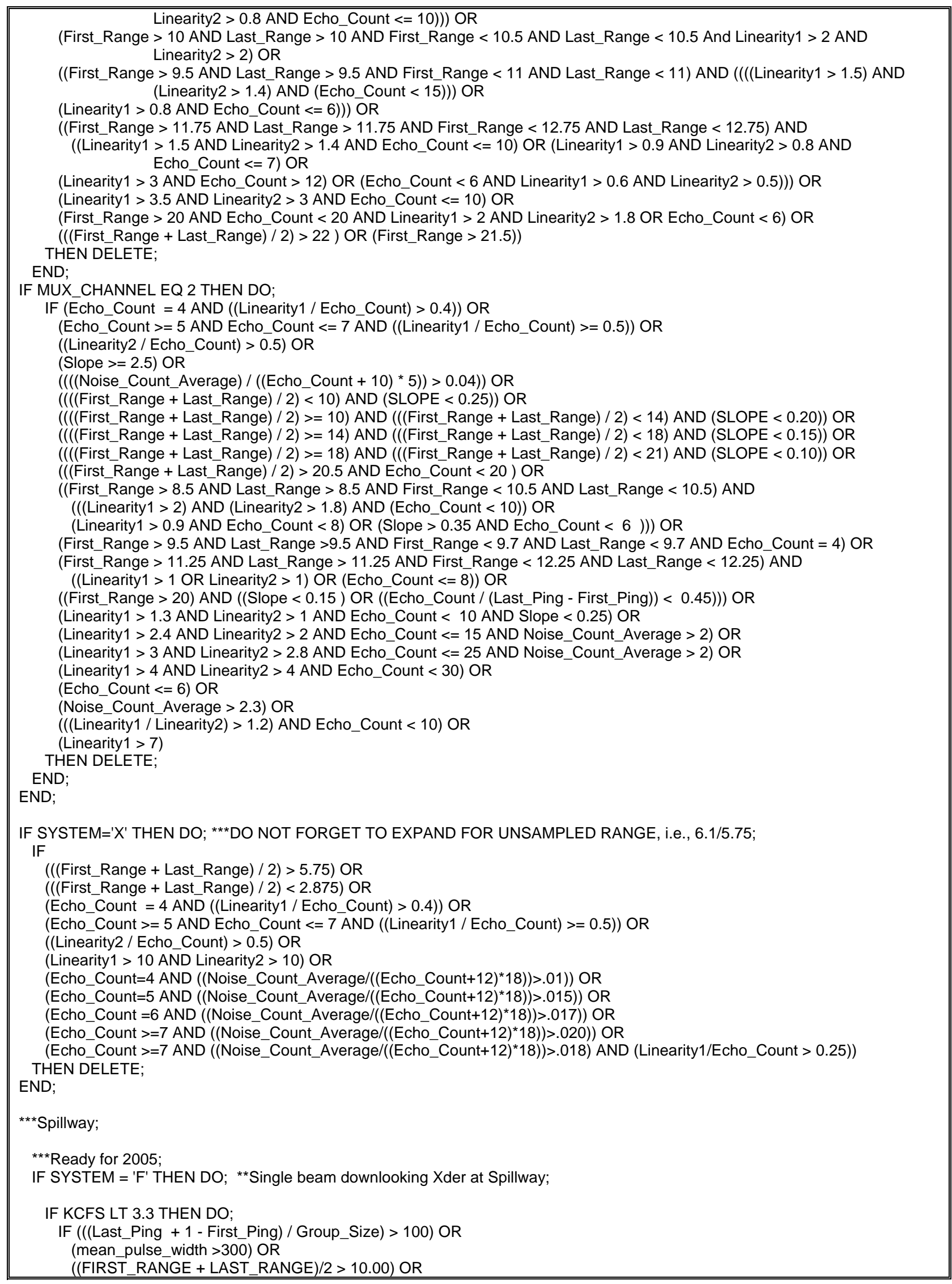


((FIRST_RANGE + LAST_RANGE)/2 <= 9.50 AND (FIRST_RANGE + LAST_RANGE)/2 > 9.10 AND SLOPE < 0.1 ) OR ((FIRST_RANGE + LAST_RANGE)/2 <= 9.10 AND (FIRST_RANGE + LAST_RANGE)/2 > 8.00 AND SLOPE $<=0.3)$ OR ((FIRST_RANGE + LAST_RANGE)/2 $<=8.00$ AND (FIRST_RANGE + LAST_RANGE)/2 $>6.00$ AND SLOPE $<=0.35)$ OR $(($ FIRST_RANGE + LAST_RANGE)/2 $<=6.00$ AND SLOPE $<=0.45)$ OR ((Linearity2 > 4) AND $($ ECHO_COUNT < 30)) OR

$(($ Echo_Count $=4$ OR Echo_Count $=5)$ AND $(($ Linearity1 $/$ Echo_Count $)>=0.5))$ OR

$(($ Echo_Count $=6$ OR Echo_Count $=7)$ AND $(($ Linearity1 $/$ Echo_Count $)>=0.6))$ OR

((Linearity2 / Echo_Count) $>0.6)$ OR

((Linearity2 / Echo_Count) > 0.24 AND ECHO_COUNT >= 7 AND (FIRST_RANGE + LAST_RANGE)/2 <= 8.3) OR $((($ Noise_Count_Average $) /(($ Echo_Count +10$) * 5))>0.045)$ END; THEN DELETE;

IF KCFS GE 3.3 AND KCFS LT 6.3 THEN DO;

IF (TRACK_TYPE = 1) OR

(((Last_Ping + 1 - First_Ping) / Group_Size $)>100)$ OR

(mean_pulse_width >300) OR

((FIRST_RANGEE + LAST_RANGE)/2 > 10.2) OR

((FIRST_RANGE + LAST_RANGE)/2 > 10.00 AND (SLOPE $<-0.6$ OR SLOPE $>0.4))$ OR

((FIRST_RANGE + LAST_RANGE)/2 > 9.75 AND (FIRST_RANGE + LAST_RANGE)/2 <= 10.50 AND SLOPE < -1) OR

((FIRST_RANGE + LAST_RANGE)/2 > 9.65 AND (FIRST_RANGE + LAST_RANGE)/2 <= 9.85 AND MUX_CHANNEL=2) OR

$(($ FIRST_RANGE + LAST_RANGE)/2 > 9.20 AND (FIRST_RANGE + LAST_RANGE)/2 <= 9.75 AND (SLOPE < 0.1 OR SLOPE > 2)) OR

$(($ FIRST_RANGE + LAST_RANGE)/2 $>7.00$ AND (FIRST_RANGE + LAST_RANGE)/2 <= 9.20 AND SLOPE $<0.4)$ OR ((FIRST_RANGE + LAST_RANGE)/2 $>6.00$ AND (FIRST_RANGE + LAST_RANGE) $/ 2<=7.00$ AND SLOPE $<0.5)$ OR ((FIRST_RANGE + LAST_RANGE)/2 > 5.00 AND (FIRST_RANGE + LAST_RANGE)/2<=6.00 AND SLOPE <= 1.5 ) OR $\left(\left(E C H O \_C O U N T<=6\right)\right.$ AND $($ ABS $\left.(L A S T+R A N G E-F I R S T+R A N G E)>0.7)\right)$ OR

((Linearity2 > 4) AND (ECHO_COUNT < 40$))$ OR

((SLOPE>1) AND (LINEARITY1 >3) AND (LINEARITY2 >3)) OR

$(($ Echo_Count $=4$ OR Echo_Count $=5)$ AND $(($ Linearity1 $/$ Echo_Count $)>=0.4))$ OR

$(($ Echo_Count $=6$ OR Echo_Count $=7)$ AND $(($ Linearity $1 /$ Echo_Count $)>=0.5))$ OR

((Linearity2 / Echo_Count) $>0.4$ AND ECHO_COUNT $>=7)$ OR

$(((($ Noise_Count_Average $) /(($ Echo_Count $+\overline{10}) * 5))>0.025))$

THEN DELETE;

END;

IF KCFS GE 6.3 AND KCFS LT 9.1 THEN DO;

IF ((Last_Ping +1 - First_Ping $) /$ Group_Size $)>100)$ OR

(mean_pulse_width >300) OR

(LINEARITY1 < 0.5 AND LINEARITY2 < 0.5 AND SLOPE < 0.1 AND ABS(FIRST_RANGE - LAST_RANGE) $<0.05)$ OR

$((F I R S T$ RANGE = LAST_RANGE AND SLOPE <= 0) AND (FIRST_RANGE + LASST_RANGE)/2 <= 10.20) OR

((FIRST_RANGE + LAST_RANGE)/2 $>11.00)$ OR

((FIRST_RANGE + LAST_RANGE)/2 > 9.5 AND (FIRST_RANGE + LAST_RANGE)/2 <= 9.7 AND MUX_CHANNEL=2) OR

((FIRST_RANGE + LAST_RANGE)/2 > 9.75 AND (FIRST_RANGE + LAST̄_RANGE)/2 < 9.95 AND MUX_CHANNEL=2) OR ((FIRST_RANGE + LAST_RANGE)/2 > 10.3 AND (FIRST_RANGE + LAST_RANGE)/2 <= 10.4 AND MUX_CHANNEL=2) OR ((FIRST_RANGE + LAST_RANGE)/2 >= 9.85 AND (FIRST_RANGE + LAST̄_RANGE)/2 <= 10.25 AND MUTXCHANNEL=5) OR

$((F I R S T+R A N G E+L A S T+R A N G E) / 2>=9.75$ AND (FIRST_RANGE + LAST_RANGE)/2<=9.80 AND MUX_CHANNEL=5) OR

((FIRST_RANGE + LAST_RANGE)/2 > 9.75 AND (FIRST_RANGE + LAST_RANGE)/2<= 11.00 AND SLOPE < -0.5) OR ((FIRST_RANGE + LAST_RANGE)/2 $>9.25$ AND (FIRST_RANGE + LAST_RANGE)/2 $<=9.75$ AND SLOPE $<0.2)$ OR ((FIRST_RANGE + LAST_RANGE)/2 $>7.00$ AND (FIRST_RANGE + LAST_RANGE) $/ 2<=9.25$ AND SLOPE $<0.5)$ OR $(($ FIRST_RANGE + LAST_RANGE)/2 $>6.00$ AND (FIRST_RANGE + LAST_RANGE)/2<= 7.00 AND SLOPE $<0.6)$ OR ((FIRST_RANGE + LAST_RANGE)/2 <= 6.00 AND SLOPE $<=0.6)$ OR

$($ SLOPE $>$ 4.5 OR SLOPE $<-4.5)$ OR

(Linearity2 > 4) OR

((Linearity1 / Echo_Count >= 0.45) AND (Linearity2 > 2.5) AND ECHO_COUNT < 25 AND SLOPE < 2 AND (FIRST_RANGE + LASTT_RANGE) $/ 2<10.00)$ OR

$(($ Echo_Count $=4$ OR Echo_Count $=5)$ AND $(($ Linearity $1 /$ Echo_Count $)>=0.4))$ OR

$(($ Echo_Count $=6$ OR Echo_Count $=7)$ AND $(($ Linearity $1 /$ Echo_Count $)>=0.6)$ AND $($ FIRST_RANGE + LAST_RANGE $) / 2<$ 10.00) OR

((Linearity2 / Echo_Count) > 0.6) OR

$((($ Noise_Count_Average $) /(($ Echo_Count +10$) * 5))>0.045)$

THEN DELETE;

END;

IF KCFS GE 9.1 THEN DO;

IF ((Last_Ping + 1 - First_Ping) / Group_Size $)>100)$ OR

(mean_pulse_width >300) OR 
(SLOPE > 4.5 OR SLOPE <-4.5) OR
((FIRST_RANGE + LAST_RANGE)/2 > 11.50) OR
((FIRST_RANGE + LAST_RANGE)/2 > 9.75 AND (FIRST_RANGE + LAST_RANGE)/2<= 11.50 AND SLOPE <-0.5) OR ((FIRST_RANGE + LAST_RANGE)/2 > 9.75 AND (FIRST_RANGE + LAST_RANGE)/2<=11.50 AND SLOPE $<-0.5)$ OR
((FIRST_RANGE + LAST_RANGE)/2 $>10.55$ AND (FIRST_RANGE + LAST_RANGE)/2<= 10.85 AND MUX_CHANNEL=2 AND SLOPE $<1$ ) OR

((FIRST_RANGE + LAST_RANGE)/2 > 9.10 AND (FIRST_RANGE + LAST_RANGE)/2<= 9.75 AND SLOPE <0.7) OR ((FIRST_RANGE + LAST_RANGE)/2 $>6.00$ AND (FIRST_RANGE + LAST_RANGE)/2<= 9.10 AND SLOPE $<0.8)$ OR $(($ FIRST_RANGE + LAST_RANGE)/2 $<=6.00$ AND SLOPE $<=1)$ OR

$(($ ECHO COUNT < 7) AND (ABS(LAST RANGE-FIRST RANGE) $>0.75))$ OR

((SLOPE $>1)$ AND (LINEARITY1 >3) AND (LINEARITY2 $>3)$ ) OR

((Linearity1 / Echo_Count >= 0.32) AND (Linearity2 > 2) AND ECHO_COUNT < 15 AND SLOPE < 1.5) OR

(Linearity2 > 4) OR

$($ Echo_Count $=4$ AND $(($ Linearity $1 /$ Echo_Count $)>0.25))$ OR

(Echo_Count $=5$ AND $(($ Linearity $1 /$ Echo_Count $)>=0.34))$ OR

$(($ Echo_Count $=6$ OR Echo_Count $=7)$ AND $(($ Linearity $1 /$ Echo_Count $)>=0.5))$ OR

((Linearity2 / Echo_Count) > 0.6) OR

$((($ Noise_Count_Average $) /(($ Echo_Count +10$) * 5))>0.045)$

THEN DELETE;

END;

END;

***Ready for 2005;

IF SYSTEM = 'M' THEN DO; **Split beam downlooking Xder at Spillway SB5 \& SB7;

IF KCFS LT 3.3 THEN DO;

IF ((Last_Ping + 1 - First_Ping) / Group_Size $)>100)$ OR

(mean_pulse_width >300) OR

((FIRST_RANGE + LAST_RANGE)/2 > 10.00) OR

((FIRST_RANGE + LAST_RANGE)/2 > 9.10 AND (FIRST_RANGE + LAST_RANGE)/2 $<=9.50$ AND SLOPE $<0.1)$ OR ((FIRST_RANGE + LAST_RANGE)/2 $>8.00$ AND (FIRST_RANGE + LAST_RANGE)/2 $<=9.10$ AND SLOPE $<0.2)$ OR ((FIRST_RANGE + LAST_RANGE)/2 <= 8.00 AND SLOPE $<=0.8)$ OR

((Linearity2 > 4) AND (ECHO_COUNT < 30)) OR

(Echo_Count $=4$ AND $(($ Linearity1 $/$ Echo_Count $)>0.25))$ OR

$($ Echo_Count $=5$ AND $(($ Linearity $1 /$ Echo_Count $)>=0.34))$ OR

(Echo_Count $=6$ AND $(($ Linearity1 $/$ Echo_Count $)>=0.40))$ OR

$($ Echo_Count $=7$ AND $(($ Linearity1 $/$ Echo_Count $)>=0.50))$ OR

((Linearity2 / Echo_Count) $>0.6)$ OR

((Linearity1 / Echo_Count) $>0.5)$ OR

(NOISE_INDEX $>$ 10) OR

$((($ Noise_Count_Average $) /(($ Echo_Count +10$) * 5))>0.045)$

THEN DELETE;

END;

IF KCFS GE 3.3 AND KCFS LT 6.3 THEN DO;

IF ((Last_Ping + 1 - First_Ping) / Group_Size $)>100)$ OR

(mean_pulse width >300) OR

((FIRST_RANGE + LAST_RANGE)/2 > 10.50) OR

((FIRST_RANGE + LAST_RANGE)/2 > 9.75 AND (FIRST_RANGE + LAST_RANGE)/2 <= 10.50 AND SLOPE < -1) OR $(($ FIRST_RANGE + LAST_RANGE)/2 > 9.20 AND (FIRST_RANGE + LAST_RANGE)/2 < 9.75 AND (SLOPE < 0.1 OR SLOPE > 2)) OR

$(($ FIRST_RANGE + LAST_RANGE)/2 $>7.00$ AND (FIRST_RANGE + LAST_RANGE)/2 $<=9.20$ AND SLOPE $<0.2)$ OR ((FIRST_RANGE + LAST_RANGE)/2 $>6.00$ AND (FIRST_RANGE + LAST_RANGE)/2<=7.00 AND SLOPE $<0.3)$ OR $(($ FIRST_RANGE + LAST_RANGE)/2 $<=6.00$ AND SLOPE $<=0.5)$ OR

((Linearity2 > 4) AND (ECHO_COUNT < 40)) OR

$($ Echo_Count $=4$ AND $(($ Linearity1 $/$ Echo_Count $)>0.25))$ OR

$($ Echo_Count $=5$ AND $(($ Linearity $1 /$ Echo_Count $)>=0.34))$ OR

(Echo_Count $=6$ AND $(($ Linearity $1 /$ Echo_Count $)>=0.40))$ OR

$($ Echo_Count $=7$ AND $(($ Linearity $1 /$ Echo_Count $)>=0.50))$ OR

((Linearity2 / Echo_Count) $>0.6)$ OR

((Linearity1 / Echo_Count) $>0.5)$ OR

(NOISE_INDEX $>\overline{10}$ ) OR

$\left(\left((\right.\right.$ Noise_Count_Average * ECHO_COUNT $) /\left(\left(\right.\right.$ ECHO_COUNT + 10) $\left.\left.{ }^{*} 5\right)\right)>0.45$ AND ECHO_COUNT > 25) OR

$((($ Noise_Count_Average $) /(($ ECHO_COUNT +10$) * 5))>0.042$ AND ECHO_COUNT $<=25)$ THEN DELETE; END;

IF KCFS GE 6.3 AND KCFS LT 9.1 THEN DO;

IF (((Last_Ping + 1 - First_Ping) / Group_Size $)>100)$ OR

(mean pulse width >300) OR

$(($ FIRST_RAN̄GE + LAST_RANGE)/2 > 11.00) OR

((FIRST_RANGE + LAST_RANGE)/2 > 9.75 AND (FIRST_RANGE + LAST_RANGE)/2 <= 11.00 AND SLOPE $<-0.5)$ OR 
((FIRST RANGE + LAST RANGE)/2 > 9.25 AND (FIRST_RANGE + LAST RANGE)/2 <= 9.75 AND SLOPE < 0.4) OR ((FIRST_RANGE + LAST_RANGE) $/ 2>7.00$ AND (FIRST_RANGE + LAST_RANGE) $/ 2<=9.25$ AND SLOPE $<0.6)$ OR ((FIRST_RANGE + LAST_RANGE)/2 > 6.00 AND (FIRST_RANGE + LAST_RANGE)/2<= 7.00 AND SLOPE <0.8) OR ((FIRST_RANGE + LAST_RANGE)/2 $<=6.00$ AND SLOPE $<=1)$ OR

$($ SLOPE $>4$ OR SLOPE $<-4)$ OR

(Linearity2 > 4) OR

(Echo Count $=4$ AND ((Linearity1 / Echo Count $)>0.25))$ OR

(Echo_Count $=5$ AND $(($ Linearity $1 /$ Echo_Count $)>=0.34))$ OR

$($ Echo_Count $=6$ AND $(($ Linearity $1 /$ Echo_Count $)>=0.40))$ OR

$($ Echo_Count $=7$ AND $(($ Linearity $1 /$ Echo_Count $)>=0.50))$ OR

((Linearity2 / Echo_Count) $>0.6)$ OR

((Linearity1 / Echo_Count) $>0.5)$ OR

(NOISE INDEX $>10$ ) OR

$((($ Noise_Count_Average * ECHO_COUNT $) /(($ ECHO_COUNT + 10) * 5) $)>0.45$ AND ECHO_COUNT > 25) OR

$\left(\left((\right.\right.$ Noise_Count_Average $\left.) /\left(\left(E C H O \_C O U N T+10\right) * 5\right)\right)>0.045$ AND ECHO_COUNT $\left.<=25\right)$ THEN DELETE; END;

IF KCFS GE 9.1 THEN DO;

IF ((Last_Ping + 1 - First_Ping) / Group_Size $)>100)$ OR

(MEAN_PULSE_WIDTH $>300$ ) OR

(SLOPE > 3.5 OR SLOPE <-3.5) OR

$(($ FIRST_RANGE + LAST_RANGE)/2 > 11.50) OR

((FIRST_RANGE + LAST RANGE)/2 > 9.75 AND (FIRST RANGE + LAST RANGE)/2 $<=11.50$ AND SLOPE $<-2$ ) OR ((FIRST_RANGE + LAST_RANGE) $/ 2>9.10$ AND (FIRST_RANGE + LAST_RANGE) $/ 2<=9.75$ AND SLOPE < 0.4) OR ((FIRST_RANGE + LAST_RANGE)/2 > 6.00 AND (FIRST_RANGE + LAST_RANGE)/2< $<9.10$ AND SLOPE $<1.2)$ OR $(($ FIRST_RANGE + LAST_RANGE)/2 $<=6.00$ AND SLOPE $<=1.5)$ OR

(Linearity2 > 4 AND ECHO COUNT < 30) OR

(Echo_Count $=4$ AND $(($ Linearity $1 /$ Echo_Count $)>0.25))$ OR

(Echo_Count $=5$ AND $(($ Linearity $1 /$ Echo_Count $)>=0.34))$ OR

$($ Echo_Count $=6$ AND $(($ Linearity1 $/$ Echo_Count $)>=0.40))$ OR

(Echo_Count $=7$ AND $(($ Linearity $1 /$ Echo_Count $)>=0.50))$ OR

((Linearity2 / Echo_Count) $>0.6)$ OR

((Linearity1 / Echo_Count) > 0.5) OR

(NOISE_INDEX > 10) OR

$((($ Noise_Count_Average * ECHO_COUNT) $/(($ ECHO_COUNT + 10) *5) $)>0.45$ AND ECHO_COUNT > 25) OR

$((($ Noise_Count_Average $) /(($ ECHO_COUNT +10$) * 5))>0.045$ AND ECHO_COUNT $<=25)$ THEN DELETE;

END;

***Ready for 2005;

IF SYSTEM = 'O' THEN DO;

IF KCFS LE 3 THEN DO;

IF (TRACK_TYPE $=1)$ OR

(Echo_Count $=4$ AND $(($ Linearity1 $/$ Echo_Count $)>0.4))$ OR

(Echo_Count $>=5$ AND Echo_Count $<=7$ AND ((Linearity1 / Echo_Count) $>=0.5)$ ) OR

((Linearity2 / Echo_Count) $>0.5)$ OR

$((($ First_Range + Last_Range $) / 2)>9.9)$ OR

$(((($ First_Range + Last_Range) $/ 2)<9.0)$ AND $((($ First_Range + Last_Range $) / 2)>8.0)$ AND $($ SLOPE < 0.1)) OR

$((($ First_Range + Last_Range $) / 2)<8.0)$ AND $((($ First_Range + Last_Range $) / 2)>7.0)$ AND $($ SLOPE $<0.15))$ OR

$(((($ First_Range + Last_Range $) / 2)<7.0)$ AND (SLOPE < 0.2)) OR

$((($ Noise_Count_Average $) /(($ Echo_Count +10$) * 5))>0.04))$

THEN DELETE;

END;

IF KCFS GT 3 AND KCFS LE 4 THEN DO;

IF (TRACK_TYPE = 1) OR

(Echo_Count $=4$ AND $(($ Linearity $1 /$ Echo_Count $)>0.4))$ OR

(Echo Count $>=5$ AND Echo Count $<=7$ AND ((Linearity1 / Echo Count) $>=0.5)$ ) OR

$(($ Linearity2 / Echo_Count) $>0.5)$ OR (((First_Range + Last_Range $) / 2)>10.1)$ OR

$(((($ First_Range + Last_Range $) / 2)>9.5)$ AND $($ SLOPE $<-0.2))$ OR

$(((($ First_Range + Last_Range $) / 2)<=9.5)$ AND $((($ First_Range + Last_Range $) / 2)>=9.25)$ AND (SLOPE $<0.5))$ OR

$(((($ First_Range + Last_Range $) / 2)<9.0)$ AND $((($ First_Range + Last_Range $) / 2)>8.0)$ AND $($ SLOPE $<0.1))$ OR

$(((($ First_Range + Last_Range $) / 2)<8.0)$ AND $((($ First_Range + Last_Range $) / 2)>7.0)$ AND $($ SLOPE < 0.15) $)$ OR

$(((($ First_Range + Last_Range $) / 2)<7.0)$ AND $($ SLOPE $<0.2))$ OR

$(((($ Noise_Count_Averäge $) /(($ Echo_Count +10$) * 5))>0.04))$ OR

(NOISE_COUNT̄AVERAGE > 2.5) OR

(LINEARITY1 $>2$ AND LINEARITY2 $>2$ AND NOISE_COUNT_AVERAGE > 2) OR

(LINEARITY1 > 2.4 AND LINEARITY2 > 2.4) 
THEN DELETE;

END;

IF KCFS GT 4 AND KCFS LE 5 THEN DO;

IF (TRACK TYPE = 1) OR

(Echo_Count $=4$ AND $(($ Linearity1 $/$ Echo_Count $)>0.4))$ OR

(Echo_Count $>=5$ AND Echo_Count $<=7$ AND ((Linearity1 $/$ Echo_Count) $>=0.5)$ ) OR

((Linearity2 / Echo_Count) $>0.5)$ OR

$((($ First_Range + Last_Range $) / 2)>10.05)$ OR

$(((($ First_Range + Last_Range $) / 2)<9.3)$ AND $((($ First_Range + Last_Range $) / 2)>8.0)$ AND $($ SLOPE $<0.1))$ OR

$(((($ First_Range + Last_Range $) / 2)<8.0)$ AND $((($ First_Range + Last_Range $) / 2)>7.0)$ AND $($ SLOPE $<0.15))$ OR

$(((($ First_Range + Last_Range $) / 2)<7.0)$ AND $($ SLOPE $<0.2))$ OR

$(((($ Noise_Count_Average $) /(($ Echo_Count +10$) * 5))>0.04))$ OR

$(((($ First_Range + Last_Range) / 2) $>$ - 9.5) AND (SLOPE < -0.2)) OR

(LINEARITY1 > 2.4 AND LINEARITY2 > 2.4 AND ECHO_COUNT < 20) OR

$((($ First_Range + Last_Range) / 2) $<=9.0)$ AND (((First_Range + Last_Range) / 2) $>=8.5)$ AND (SLOPE <=0.5) AND THEN DELETE; (ECHO_COUNT <= 8))

END;

IF KCFS GT 5 AND KCFS LE 6 THEN DO;

IF (TRACK TYPE = 1) OR

$($ Echo_Count $=4$ AND $(($ Linearity1 $/$ Echo_Count $)>0.4))$ OR

(Echo_Count $>=5$ AND Echo_Count $<=7$ AND ((Linearity1 $/$ Echo_Count) $>=0.5))$ OR

((Linearity2 / Echo_Count) $>0.5)$ OR

$((($ First_Range + Last_Range $) / 2)>10.2) O R$

$((($ First_Range + Last_Range $) / 2)>9.3)$ AND (SLOPE $<-0.2))$ OR

$(((($ First_Range + Last_Range $) / 2)<9.3)$ AND $((($ First_Range + Last_Range $) / 2)>8.3)$ AND $($ SLOPE $<0.15))$ OR

$(((($ First_Range + Last_Range $) / 2)<8.3)$ AND $((($ First_Range + Last_Range $) / 2)>7.3)$ AND $($ SLOPE $<0.15))$ OR

$((($ First_Range + Last_Range $) / 2)<7.3)$ AND $($ SLOPE $<0.2))$ OR

$(((($ Noise_Count_Averäge $) /(($ Echo_Count +10$) * 5))>0.04))$ OR

$($ LINEARITY1 > 2.4 AND LINEARITY2 > 2.4 AND ECHO_COUNT < 12)

THEN DELETE;

END;

IF KCFS GT 6 AND KCFS LE 7 THEN DO;

IF (TRACK_TYPE = 1) OR

$($ Echo_Count $=4$ AND $(($ Linearity1 $/$ Echo_Count $)>0.4))$ OR

(Echo_Count $>=5$ AND Echo_Count $<=7$ AND ((Linearity1 / Echo_Count) $>=0.5)$ ) OR

((Linearity2 / Echo_Count) $>0.5$ ) OR

$((($ First Range + Last Range $) / 2)>10.5)$ OR

$((($ First_Range + Last_Range $) / 2)>=9.4)$ AND SLOPE $<-0.15)$ OR

$(((($ First_Range + Last_Range $) / 2)<9.4)$ AND (((First_Range + Last_Range $) / 2)>8.4)$ AND $($ SLOPE $<0.1))$ OR

$(((($ First_Range + Last_Range $) / 2)<8.4)$ AND $((($ First_Range + Last_Range $) / 2)>7.4)$ AND $($ SLOPE < 0.15)) OR

$((($ First_Range + Last_Range $) / 2)<7.4)$ AND $($ SLOPE $<0.2))$ OR

$((($ Noise_Count_Average $) /(($ Echo_Count +10$) * 5))>0.04)$ OR

(LINEARITY1 > 2.4 AND LINEARITY2 > 2.4 AND ECHO COUNT < 12) OR

(LINEARITY1 > 2.4 AND LINEARITY2 > 2.4 AND ECHO_COUNT > 11 AND SLOPE < 0.4) OR

$(((($ First_Range + Last_Range) / 2) $<7.1)$ AND $((($ First_Range + Last_Range $) / 2)>6.5)$ AND $($ SLOPE $<0.5))$

THEN DELETE;

END;

IF KCFS GT 7 AND KCFS LE 8 THEN DO;

IF (TRACK_TYPE = 1) OR

$($ Echo_Count $=4$ AND $(($ Linearity1 $/$ Echo_Count $)>0.4))$ OR

(Echo_Count $>=5$ AND Echo_Count $<=7$ AND ((Linearity1 / Echo_Count) $>=0.5)$ ) OR

((Linearity2 / Echo_Count) $>0.5)$ OR

$((($ First_Range + Last_Range $) / 2)>10.5)$ OR

$(((($ First_Range + Last_Range) / 2) < 9.4) AND ((First_Range + Last_Range $) / 2)>8.4)$ AND $($ SLOPE < 0.1) $)$ OR

$(((($ First_Range + Last_Range $) / 2)<8.4)$ AND $((($ First_Range + Last_Range $) / 2)>7.4)$ AND $($ SLOPE < 0.15)) OR

$(((($ First_Range + Last_Range $) / 2)<7.4)$ AND $($ SLOPE $<0.2))$ OR

$((($ Noise_Count_Average $) /(($ Echo_Count +10$) * 5))>0.04)$ OR

(LINEARITY1 > 2.4 AND LINEARITY2 > 2.4 AND ECHO_COUNT < 12) OR

(LINEARITY1 > 2.4 AND LINEARITY2 > 2.4 AND ECHO_COUNT > 11 AND SLOPE $<0.4)$ OR

$(((($ First_Range + Last_Range $) / 2)<7.1)$ AND $((($ First_Range + Last_Range $) / 2)>6.5)$ AND $($ SLOPE < 0.5) $)$ THEN DELETE;

END;

IF KCFS GT 8 THEN DO;

IF (TRACK_TYPE = 1) OR 


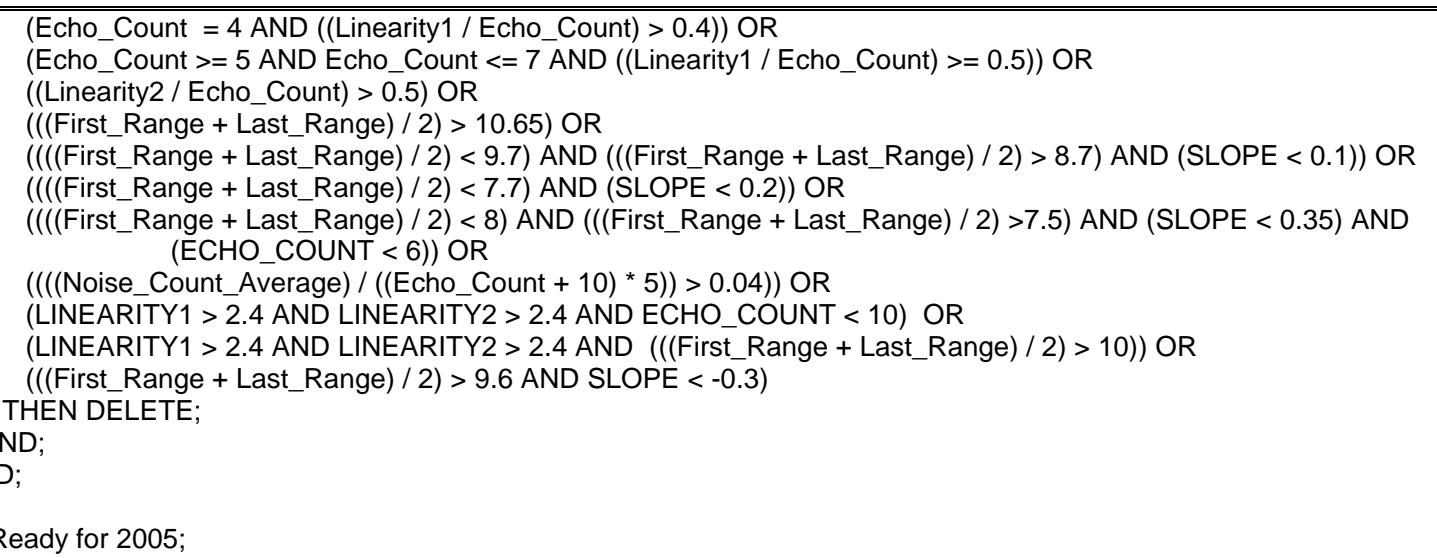

IF SYSTEM = 'P' THEN DO; **Single beam downlooking Xder at Spillway;

IF MUX_CHANNEL EQ 1 THEN DO;

IF Noise_Count_Average $>=2.5$ THEN DELETE; END;

IF MUX_CHANNEL EQ 2 THEN DO;

IF ((FIRST_RANGE + LAST_RANGE) $/ 2<8.5$ AND SLOPE $>1.2)$ OR

$(($ FIRST_RANGE + LAST_RANGE)/2 > 9.0 AND SLOPE $<-0.3$ OR (Echo_Count $<8$ AND Linearity1 $>2))$ OR

(Noise_Count_Average $>2.5$ )

THEN DELETE;

END;

IF KCFS LT 3.3 THEN DO;

IF (TRACK_TYPE = 1) OR

$((($ Last_Ping +1 - First_Ping) / Group_Size $)>100)$ OR

(mean_pulse_width >300) OR

((FIRST_RANGE + LAST_RANGE)/2 > 10.00) OR

$(($ FIRST_RANGE + LAST_RANGE)/2 > 9.10 AND (FIRST_RANGE + LAST_RANGE)/2 < $=9.50$ AND SLOPE $<0.1)$ OR

((FIRST_RANGE + LAST_RANGE)/2 $<=9.10$ AND SLOPE $<=0.3)$ OR

((FIRST_RANGE + LAST_RANGE) $/ 2>=8.5$ AND SLOPE $>0.9)$ OR

((FIRST_RANGE + LAST_RANGE)/2 $<=6.50$ AND SLOPE $<=0.4)$ OR

((Linearity2 > 4) AND (ECHO COUNT < 30)) OR

$(($ Echo_Count $=4$ OR Echo_Count $=5)$ AND $(($ Linearity1 $/$ Echo_Count $)>=0.5))$ OR

$(($ Echo_Count $=6$ OR Echo_Count $=7)$ AND $(($ Linearity1 $/$ Echo_Count $)>=0.6))$ OR

((Linearity2 / Echo_Count) $>0.6)$ OR

$((($ Noise Count Average $) /(($ Echo_Count +10$) * 5))>0.045)$

THEN DELETE;

END;

IF KCFS GE 3.3 AND KCFS LT 6.3 THEN DO;

IF (TRACK_TYPE = 1) OR

(((Last_Ping + 1 - First_Ping) / Group_Size $)>100)$ OR

(mean_pulse_width >300) OR

(SLOPE > 4) OR

((FIRST_RANGE + LAST_RANGE)/2 > 10.50) OR

((FIRST_RANGE + LAST_RANGE)/2 > 9.75 AND (FIRST_RANGE + LAST RANGE)/2 <= 10.50 AND (SLOPE $<-1$ OR SLOPE > 1)) OR

$(($ FIRST_RANGE + LAST_RANGE)/2 > 9.20 AND (FIRST_RANGE + LAST_RANGE)/2<= 9.75 AND SLOPE $<0.07)$ OR ((FIRST_RANGE + LAST_RANGE)/2 $>7.00$ AND (FIRST_RANGE + LAST_RANGE)/2 $<=9.20$ AND SLOPE $<0.3)$ OR

((FIRST_RANGE + LAST_RANGE)/2 > 6.00 AND (FIRST_RANGE + LAST_RANGE)/2 $<=7.00$ AND SLOPE $<0.4)$ OR ((FIRST_RANGE + LAST_RANGE) $/ 2<=6.00$ AND SLOPE $<=0.5)$ OR

$(($ FIRST_RANGE + LAST_RANGE)/2 $<=6.00$ AND SLOPE $<=0.6$ AND ECHO_COUNT $<10)$ OR ((Linearity2 > 4) AND (ECHO COUNT < 40)) OR

$(($ Echo_Count $=4$ OR Echo_Count $=5)$ AND $(($ Linearity1 $/$ Echo_Count $)>=0.5))$ OR

$(($ Echo_Count $=6$ OR Echo_Count $=7)$ AND $(($ Linearity1 $/$ Echo_Count $)>=0.6))$ OR

((Linearity2 / Echo_Count) $>0.4$ AND ECHO_COUNT >= 7) OR

((Linearity2 / Echo_Count) $>0.24$ AND ECHO_COUNT >= 7 AND (FIRST_RANGE + LAST_RANGE)/2 <= 8.3) OR

((Linearity1 / Echo_Count) $>0.38$ AND (Linearity2 / Echo_Count) $>0.26)$ OR

((Linearity1 / Echo_Count) $>0.45$ AND ECHO_COUNT $>=10)$ OR

$((($ Noise_Count_Average $) /(($ Echo_Count +10$) * 5))>0.045)$ OR

$((($ Noise_Count_Average $) /(($ Echo_Count +10$) * 5))>0.025)$ AND NOISE_INDEX $>3.5$ AND CONTRAST $<2.0)$ 


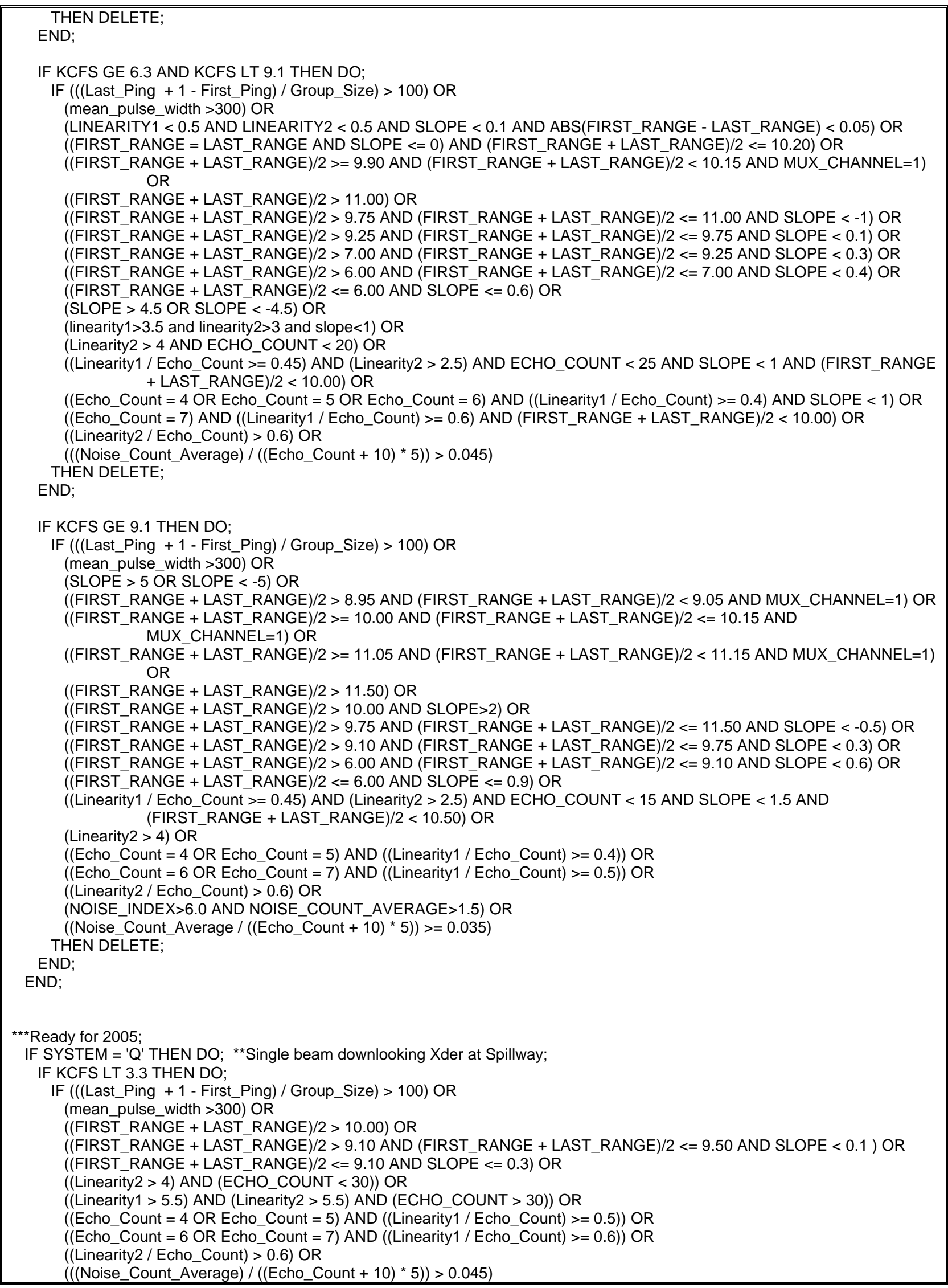


THEN DELETE;

END;

IF KCFS GE 3.3 AND KCFS LT 6.3 THEN DO;

IF (TRACK TYPE = 1) OR

$((($ Last_Ping +1 - First_Ping) / Group_Size $)>100)$ OR

(mean_pulse width $>300$ ) OR

((FIRST_RAN̄GE + LAST_RANGE)/2 > 10.50) OR

((FIRST RANGE + LAST RANGE)/2 > 9.75 AND (FIRST RANGE + LAST RANGE)/2 <= 10.50 AND SLOPE $<-1)$ OR

((FIRST_RANGE + LAST_RANGE)/2 > 9.20 AND (FIRST_RANGE + LAST_RANGE)/2<= 9.75 AND (SLOPE < 0.5 OR SLOPE > 2)) OR

((FIRST_RANGE + LAST_RANGE)/2 > 7.00 AND (FIRST_RANGE + LAST_RANGE)/2 <= 9.20 AND (SLOPE < 0.65 OR $(($ Echo_Count $=4$ OR Echo_Count $=5)$ AND $(($ Linearity1 $/$ Echo_Count $)>=0.25))))$ OR

((FIRST_RANGE + LAST_RANGE)/2 > 6.00 AND (FIRST_RANGE + LAST_RANGE)/2 <= 7.00 AND SLOPE $<0.4)$ OR ((FIRST_RANGE + LAST_RANGE)/2 $<=6.00$ AND SLOPE $<=0.35)$ OR

$((F I R S T+R A N G E+$ LAST_RANGE) $/ 2<=6.00$ AND SLOPE $<=0.6$ AND ECHO_COUNT $<10)$ OR

(SLOPE > 3) OR

((Linearity2 > 4) AND (ECHO_COUNT < 40)) OR

$(($ Echo_Count $=4$ OR Echo_Count $=5)$ AND $(($ Linearity1 $/$ Echo_Count $)>=0.4))$ OR

$(($ Echo_Count $=6$ OR Echo_Count $=7)$ AND $(($ Linearity1 $/$ Echo_Count $)>=0.5))$ OR

((Linearity2 / Echo_Count) $>0.4$ AND ECHO_COUNT >= 7) OR

$(($ Linearity1 > 3.5) AND (Linearity2 > 3.5) AND ((Noise_Count_Average > 2.4) OR (NOISE_INDEX > 5.0))) OR

$(($ Noise_Count_Average / $(($ Echo_Count +10$) * 5))>0.033)$ OR

$(((($ Noise_Count_Average $) /(($ Echo_Count +10$) * 5))>0.025)$ AND NOISE_INDEX $>3.5$ AND CONTRAST $<2.0)$

THEN DELETE; END;

IF KCFS GE 6.3 AND KCFS LT 9.1 THEN DO;

IF (((Last_Ping + 1 - First_Ping) / Group_Size $)>100)$ OR

(mean pulse width $>300$ ) OR

(LINEARITY1 < 0.5 AND LINEARITY2 < 0.5 AND SLOPE < 0.1 AND ABS(FIRST_RANGE - LAST_RANGE) $<0.05)$ OR

$(($ FIRST_RANGE $=$ LAST_RANGE AND SLOPE $<=0)$ AND (FIRST_RANGE + LASTT_RANGE) $/ 2<=10.20)$ OR

$(($ FIRST_RANGE + LAST_RANGE)/2 > 11.00) OR

((FIRST_RANGE + LAST_RANGE)/2 > 9.75 AND (FIRST_RANGE + LAST_RANGE)/2 <= 11.00 AND SLOPE < -1) OR ((FIRST_RANGE + LAST_RANGE)/2 > 9.25 AND (FIRST_RANGE + LAST_RANGE)/2<= 9.75 AND SLOPE < 0.1) OR $(($ FIRST_RANGE + LAST_RANGE)/2 $>7.00$ AND (FIRST_RANGE + LAST_RANGE)/2<=9.25 AND SLOPE < 0.7) OR ((FIRST_RANGE + LAST_RANGE)/2 > 6.00 AND (FIRST_RANGE + LAST_RANGE)/2 < $=7.00$ AND SLOPE < 0.8) OR ((FIRST_RANGE + LAST_RANGE)/2 $<=6.00$ AND SLOPE $<=0.9)$ OR

(SLOPE > 4.5 OR SLOPE <-4.5) OR

((MUX_CHANNEL=1) AND (FIRST_RANGE + LAST_RANGE)/2 > 7.4 AND (FIRST_RANGE + LAST_RANGE)/2 <= 8.00) OR

(Linearity2 > 4 AND ECHO_COUNT $<20$ ) OR

((Linearity1 / Echo_Count $>=0.45)$ AND (Linearity2 > 2.5) AND ECHO_COUNT $<25$ AND SLOPE $<1$ AND (FIRST_RANGE + LAST_RANGE) $/ 2<10.00)$ OR

$(($ Echo_Count $=4$ OR Echo_Count $=5$ OR Echo_Count $=6)$ AND $(($ Linearity $1 /$ Echo_Count $)>=0.4))$ OR

$(($ Echo_Count $=7)$ AND $(($ Linearity1 $/$ Echo_Count $)>=0.5)$ AND (FIRST_RANGE + LAST_RANGE)/2 < 10.00) OR

((Linearity2 / Echo Count) > 0.6) OR

$((($ Noise_Count_Average $) /(($ Echo_Count +10$) * 5))>0.045)$

THEN DELETE;

END;

IF KCFS GE 9.1 THEN DO;

IF ((Last_Ping + 1 - First_Ping) / Group_Size $)>100)$ OR

(mean_pulse_width >300) OR

(SLOPE > 4.5 OR SLOPE <-4.5) OR

((FIRST RANGE + LAST RANGE)/2 > 11.50) OR

((FIRST_RANGE + LAST_RANGE)/2 > 9.75 AND (FIRST_RANGE + LAST_RANGE)/2<= 11.50 AND SLOPE < -2) OR $(($ FIRST_RANGE + LAST_RANGE)/2 > 9.10 AND (FIRST_RANGE + LAST_RANGE)/2<= 9.75 AND SLOPE $<0.3)$ OR

((FIRST_RANGE + LAST_RANGE)/2 > 6.00 AND (FIRST_RANGE + LAST_RANGE)/2 < $=9.10$ AND SLOPE <0.6) OR $(($ FIRST RANGE + LAST RANGE) $/ 2<=6.00$ AND SLOPE $<=0.9)$ OR

((Linearity1 / Echo_Count $>=0.45$ ) AND (Linearity2 > 2.5) AND ECHO_COUNT < 15 AND SLOPE $<1.5$ AND (FIRST RANGE + LAST RANGE)/2<10.50) OR

((Linearity2 > 4) AND $($ ECHO_COUNT < 10)) OR

$(($ Echo_Count $=4)$ AND $(($ Linearity1 $/$ Echo Count $)>=0.6)$ AND LINEARITY2 > 1) OR

$(($ Echo_Count $=6$ OR Echo_Count $=7$ OR Echo_Count $=5)$ AND $(($ Linearity1 $/$ Echo_Count $)>=0.7))$ OR

((Linearity2 / Echo Count) > 0.6) OR

$((($ Noise_Count_Average * echo_count) $/(($ Echo_Count + 10) * 5) $)>0.35)$

THEN DELETE;

END; 


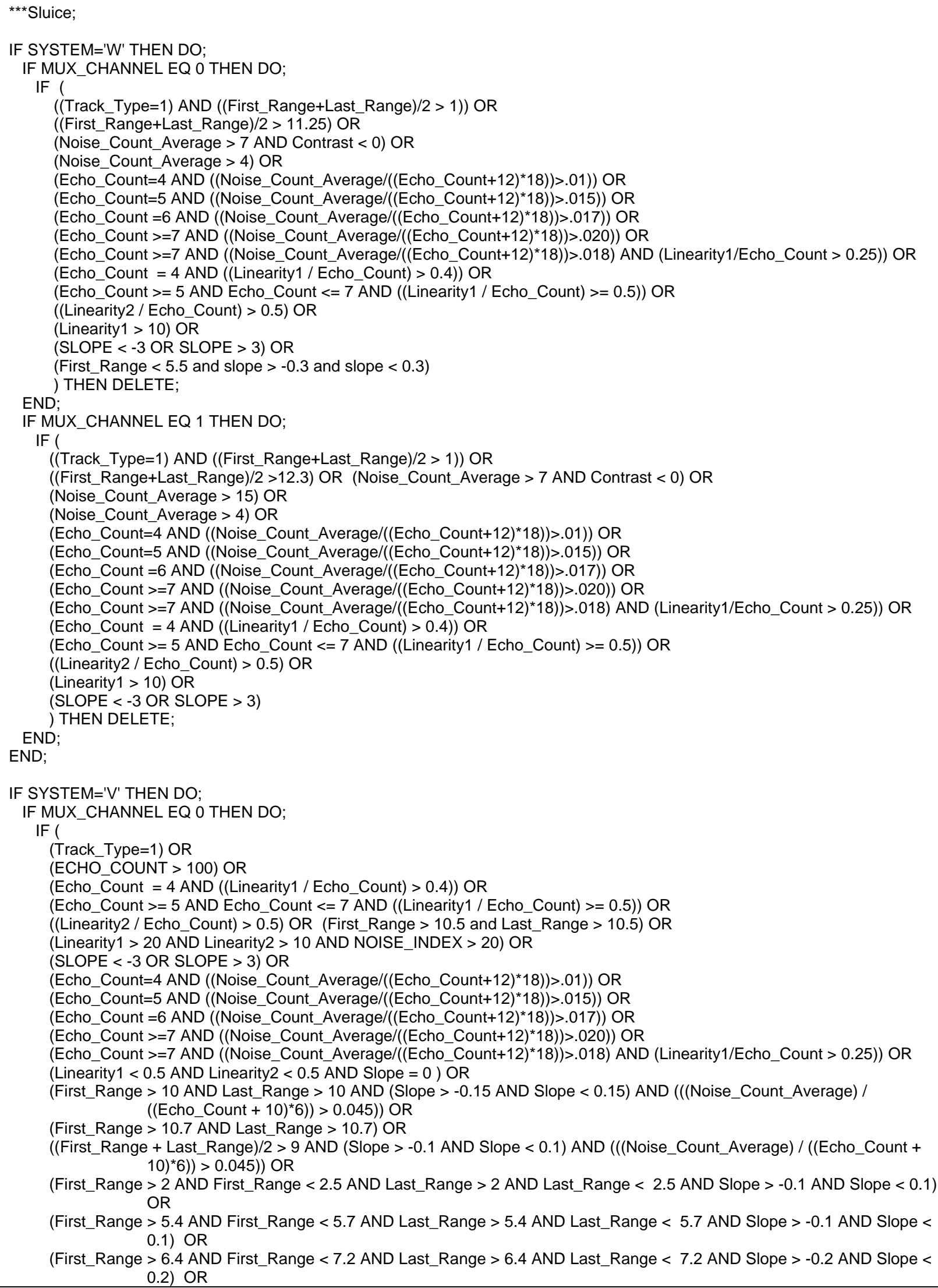

(First_Range > 5.4 AND First_Range $<5.7$ AND Last_Range $>5.4$ AND Last_Range $<5.7$ AND Slope $>-0.1$ AND Slope $<$ $0.1)$ OR

(First_Range > 6.4 AND First_Range $<7.2$ AND Last_Range $>6.4$ AND Last_Range $<7.2$ AND Slope $>-0.2$ AND Slope $<$ $0.2) \mathrm{OR}$ 
(First_Range > 7 AND First_Range $<7.4$ AND Last_Range $>7$ AND Last_Range $<7.4$ AND Slope > -0.1 AND Slope < 0.1) OR

(First_Range $>8$ AND First_Range $<8.2$ AND Last_Range $>8$ AND Last_Range $<8.2$ AND Slope $>-0.1$ AND Slope $<0.1$ ) OR

(ECHO COUNT < 5 AND ECHO COUNT / (LAST PING / GROUP SIZE + 1) - FIRST Ping / GROUP SIZE) < 0.8) OR

(ECHO_COUNT >=5 AND ECHO_COUNT <=6 AND ECHO_COUNT / ((LAST_PING / ḠROUP_SIZE + 1) - FIRST_Ping / GROUP_SIZE) $<0 . \overline{7}$ ) OR

$\left((\right.$ First_Range + Last_Range $) / 2<=4$ AND $($ Slope $<0.15)$ AND $\left.\left(E C H O \_C O U N T>60\right)\right)$

) THEN DELETE;

END;

IF MUX_CHANNEL EQ 1 THEN DO;

IF (

((Track_Type=1) AND ((First_Range+Last_Range)/2 > 1)) OR

(First_Range $>10.3$ and Last_Range $>10 . \overline{3}$ ) OR

(Noise_Count_Average $>7$ AÑ Contrast $<0$ ) OR

(Noise_Count_Average $>4$ ) OR

(Echo_Count=4 AND $(($ Noise_Count_Average/((Echo_Count+12)*18))>.01)) OR

$\left(\right.$ Echo_Count $=5$ AND $\left.\left.\left.\left((\text { Noise_Count_Average/((Echo_Count+12 })^{\star} 18\right)\right)>.015\right)\right)$ OR

$($ Echo_Count $=6$ AND $(($ Noise_Count_Average/((Echo_Count +12$) * 18))>.017))$ OR

(Echo_Count $>=7$ AND $(($ Noise_Count_Average/((Echo_Count +12$) * 18))>.020))$ OR

(Echo_Count $>=7$ AND $(($ Noise_Count_Average/((Echo_Count+12)*18) $)>.018)$ AND (Linearity1/Echo_Count $>0.25))$ OR

(Echo_Count $=4$ AND ((Linearity1 / Echo_Count) $>0.4))$ OR

(Echo_Count $>=5$ AND Echo_Count $<=7$ AND ((Linearity1 / Echo_Count) $>=0.5)$ ) OR

((Linearity2 / Echo Count) $>0.5)$ OR

(Linearity1 > 10) OR

(SLOPE < -3 OR SLOPE > 3) OR

(First_Range > 10 AND Last_Range > 10 AND (Slope > -0.15 AND Slope < 0.15) AND (((Noise_Count_Average) /

) THEN DELETE; $\left.\left.\left.\left((\text { Echo Count }+10)^{\star} 6\right)\right)>0.045\right)\right)$

END;

IF SYSTEM='U' THEN DO;

IF MUX_CHANNEL EQ 0 THEN DO;

reg $=0.6892 * \mathrm{fb} \_\mathrm{el}-41.973$;

IF (

((First_Range+Last_Range)/2 >=(reg-1) AND Track_Type=1) OR

((First_Range+Last_Range)/2 $>=($ reg-0.1)) OR

$((($ First_Range+Last_Range)/2 $>$ (reg - 1)) AND (Slope $>-0.2$ and Slope $<0.2))$ OR

(Echo_Count $=4$ AND (First_Range+Last_Range)/2 >=reg-0.6) OR

(Noise_Count_Average $>6.5$ AND Contrast $<0$ ) OR

(Noise_Count_Average $>15$ ) OR

(Noise Count Average $>7.5$ AND Slope $>2.5$ ) OR

(Noise_Count_Average > 7.5 AND Slope $<-2.5$ ) OR

(Echo_Count=4 AND $(($ Noise_Count_Average/((Echo_Count+12)*18) $)>.01))$ OR

(Echo_Count=5 AND $(($ Noise_Count_Average/((Echo_Count+12)*18) $)>.015))$ OR

$($ Echo_Count $=6$ AND $(($ Noise_Count_Average $/(($ Echo_Count +12$) \star 18))>.017))$ OR

(Echo_Count $>=7$ AND $(($ Noise_Count_Average/ $(($ Echo_Count +12$) \star 18))>.020))$ OR

(Echo_Count $>=7$ AND $(($ Noise_Count_Average/((Echo_Count +12$) \star 18))>.018)$ AND $($ Linearity1/Echo_Count $>0.25))$ OR

(Echo_Count $=4$ AND $(($ Linearity1 $/$ Echo_Count $)>0.4))$ OR

(Echo_Count $>=5$ AND Echo_Count $<=7$ AND ((Linearity1 / Echo_Count) $>=0.5)$ ) OR

((Linearity2 / Echo_Count) $>0.5$ )

) THEN DELETE;

END;

IF MUX_CHANNEL EQ 1 THEN DO;

reg $=0.3249 *$ fb_el-16.907;

IF (

((First_Range+Last_Range)/2 >=(reg-2) AND Track_Type=1) OR

((First_Range+Last_Range)/2 >=(reg-0.1)) OR

$((($ First_Range+Last_Range)/2 $>$ (reg - 0.15)) AND (Slope $>-0.2$ and Slope < 0.2)) OR

(Echo_Count=4 AND (First_Range+Last_Range)/2 >=reg-0.6) OR

(Noise Count Average $>7$ AND Contrast $<0$ ) OR

(Noise_Count_Average $>15$ ) OR

(Noise_Count_Average $>7.5$ AND Slope $>2.5$ ) OR

(Noise_Count_Average $>7.5$ AND Slope $<-2.5$ ) OR

(Echo_Count=4 AND $(($ Noise_Count_Average/((Echo_Count+12)*18) $)>.01))$ OR

(Echo_Count=5 AND $(($ Noise_Count_Average/((Echo_Count+12)*18))>.015)) OR

$($ Echo_Count $=6$ AND $(($ Noise_Count_Average $/(($ Echo_Count +12$) * 18))>.017))$ OR

(Echo_Count $>=7$ AND $\left.\left.\left.\left((\text { Noise_Count_Average/((Echo_Count }+12)^{\star} 18\right)\right)>.020\right)\right)$ OR

(Echo_Count $>=7$ AND $(($ Noise_Count_Average/((Echo_Count+12)*18)) $>.018)$ AND $($ Linearity1/Echo_Count $>0.25))$ OR 


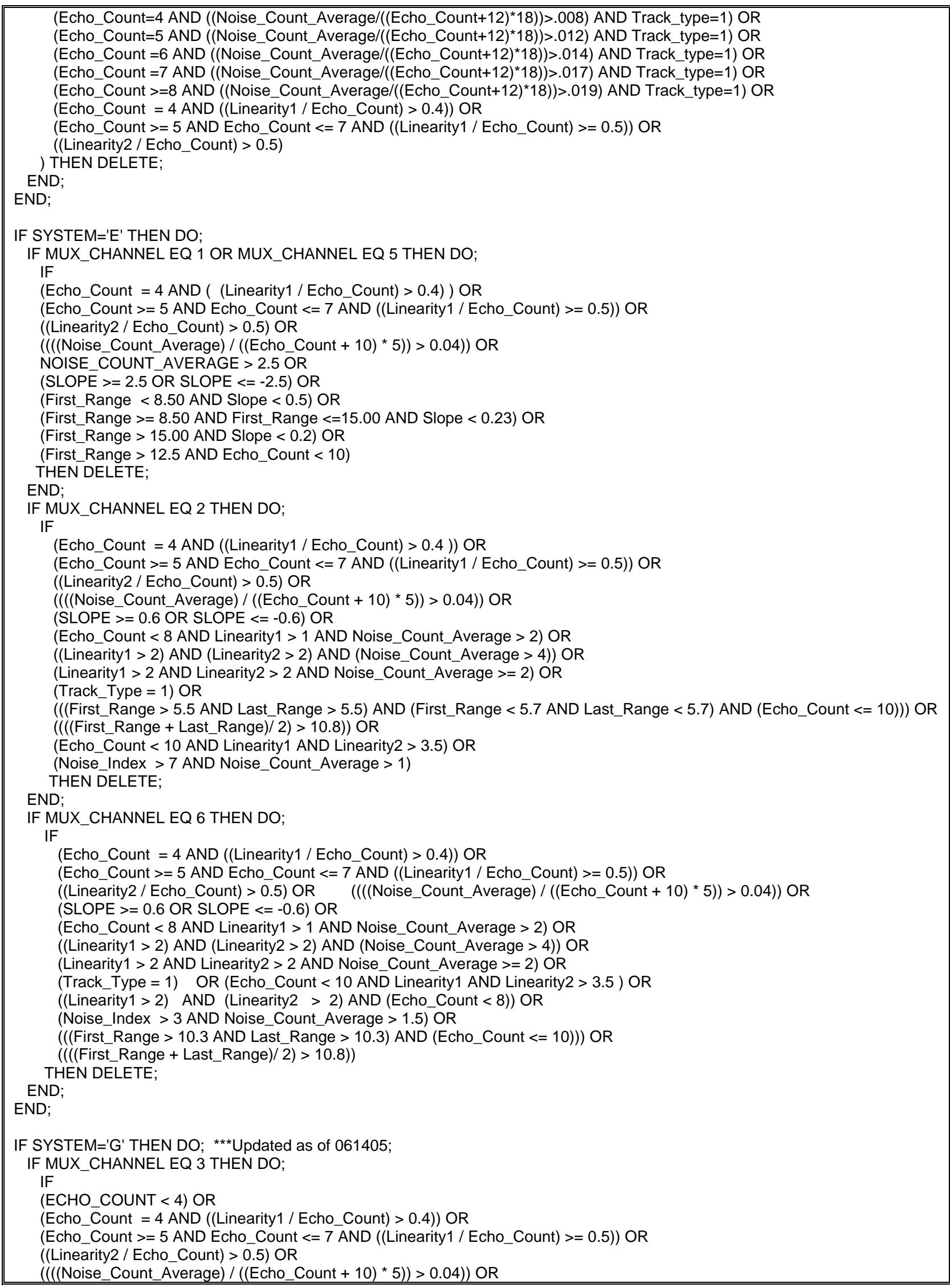


NOISE_COUNT_AVERAGE > 2.5 OR

(SLOPE $>=2.5$ OR SLOPE $<=-2.5$ ) OR

(First_Range $<8.50$ AND Slope $<0.5$ ) OR

(First_Range $>=8.50$ AND First_Range $<=15.00$ AND Slope $<0.23$ ) OR

(First_Range $>=15.00$ AND Slope $<0.2$ ) OR

(Track_Type $=1)$ OR

((First_Range $<=16$ AND First_Range $>=15.97)$ AND (Last_Range $<=16$ AND Last_Range $>=15.97)$ ) OR

((First_Range $<=8.12$ AND First_Range $>=7.76$ ) AND (Last_Range $<=8.12$ AND Last Range $>=7.76$ )) OR

((First_Range $<=16.18$ AND First_Range $>=16.11)$ AND (Last_Range $<=16.18$ AND Last_Range $>=16.11)$ ) THEN DELETE;

END;

IF MUX_CHANNEL EQ 4 THEN DO;

IF

$($ ECHO_COUNT $<4)$ OR

(Echo_Count $=4$ AND $(($ Linearity1 $/$ Echo_Count $)>0.4))$ OR

(Echo_Count $>=5$ AND Echo_Count $<=7$ AND ((Linearity1 / Echo_Count) $>=0.5))$ OR

((Linearity2 / Echo_Count) $>0.5)$ OR

$((($ Noise_Count_Average $) /(($ Echo_Count +10$) * 5))>0.04))$ OR

(SLOPE $>=0.6$ OR SLOPE $<=-0.6)$ OR

(Echo_Count $<8$ AND Linearity1 $>1$ AND Noise_Count_Average $>2$ ) OR

$(($ Linearity1 $>2)$ AND (Linearity2 $>2$ ) AND (Noise_Count_Average $>4)$ ) OR

(Linearity1 $>2$ AND Linearity2 $>2$ AND Noise_Count_Average $>=2$ ) OR

(First_Range $>11.2$ AND Last_Range $>11.2$ ) OR

$((($ First_Range + Last_Range $) / 2)>10.5)$ AND (Slope $>0.35$ OR Slope $<-0.35))$ OR

(First_Range $>9.5$ AND First_Range $<10$ AND Last_Range $>9.5$ AND Last_Range $<10$ ) OR

(First_Range $>10.2$ AND First_Range $<10.5$ AND Last_Range $>10.2$ AND Last_Range $<10.5$ ) OR

(Track Type = 1) OR

(First_Range $>$ 9.5 AND First_Range $<10$ AND Last_Range $>9.5$ AND Last_Range $<10$ ) OR

(First_Range $>10.2$ AND First_Range $<10.5$ AND Last_Range $>10.2$ AND Last_Range $<10.5$ ) OR

(Track_Type = 1) OR

((First_Range $<=10.76$ AND First_Range $>=10.74$ ) AND (Last_Range $<=10.76$ AND Last_Range $>=10.74)$ ) OR

((First_Range $<=9.11$ AND First_Range $>=9.09$ ) AND (Last_Range $<=9.11$ AND Last_Range $>=9.09)$ ) OR

((First_Range $<=10.17$ AND First_Range $>=10.11$ ) AND (Last_Range $<=10.17$ AND Last_Range $>=10.11)$ ) OR

((First_Range $<=9.12$ AND First_Range $>=8.96$ ) AND (Last_Range $<=9.12$ AND Last_Range $>=8.96)$ ) OR

((First_Range $<=10.75$ AND First_Range $>=10.62$ ) AND (Last_Range $<=10.75$ AND Last_Range $>=10.62)$ ) OR

((First_Range $<=10.51$ AND First_Range $>=10.49)$ AND (Last_Range $<=10.51$ AND Last_Range $>=10.49)$ ) OR

((First_Range $<=9.08$ AND First_Range $>=8.9$ ) AND (Last_Range $<=9.08$ AND Last_Range $>=8.9)$ ) OR

((First_Range $<=10.68$ AND First_Range $>=10.59$ ) AND (Last_Range $<=10.68$ AND Last_Range $>=10.59)$ ) OR

((First_Range $<=6.5$ AND First_Range $>=6.44$ ) AND (Last_Range $<=6.5$ AND Last_Range $>=6.44)$ ) OR

$(($ First_Range $<=8.72$ AND First_Range $>=8.54)$ AND (Last_Range $<=8.72$ AND Last_Range $>=8.54)$ )

THEN DELETE;

END;

IF MUX_CHANNEL EQ 5 THEN DO;

IF

(ECHO_COUNT < 4) OR

(Echo_Count $=4$ AND ((Linearity1 / Echo_Count) $>0.4))$ OR

(Echo_Count $>=5$ AND Echo_Count $<=7$ AND ((Linearity1 / Echo_Count) $>=0.5)$ ) OR

((Linearity2 / Echo_Count) $>0.5)$ OR

$(((($ Noise_Count_Average $) /(($ Echo_Count +10$) * 5))>0.04))$ OR

NOISE_COUNT_AVERAGE $>2.5$ OR

(SLOPE $>=2.5$ OR SLOPE $<=-2.5$ ) OR

(First_Range $<8.50$ AND Slope $<0.5$ ) OR

(First_Range $>=8.50$ AND First_Range $<=15.00$ AND Slope $<0.23$ ) OR

(First_Range $>=15.00$ AND Slope $<0.2$ ) OR

(Track_Type $=1)$

THEN DELETE;

END;

IF MUX_CHANNEL EQ 6 THEN DO;

IF

(ECHO COUNT <4) OR

(Echo_Count $=4$ AND $(($ Linearity1 $/$ Echo_Count $)>0.4))$ OR

(Echo_Count $>=5$ AND Echo_Count $<=7$ AND ((Linearity1 / Echo_Count) $>=0.5)$ ) OR

((Linearity2 / Echo_Count) $>0.5)$ OR

$((($ Noise_Count_Average $) /(($ Echo_Count +10$) * 5))>0.04))$ OR

(SLOPE $>=0.6$ OR SLOPE $<=-0.6)$ OR

(Echo_Count $<8$ AND Linearity $1>1$ AND Noise_Count_Average $>2$ ) OR

$(($ Linearity1 $>2)$ AND (Linearity2 $>2$ ) AND (Noise_Count_Average $>4)$ ) OR

(Linearity1 $>2$ AND Linearity2 $>2$ AND Noise_Count_Average $>=2$ ) OR 


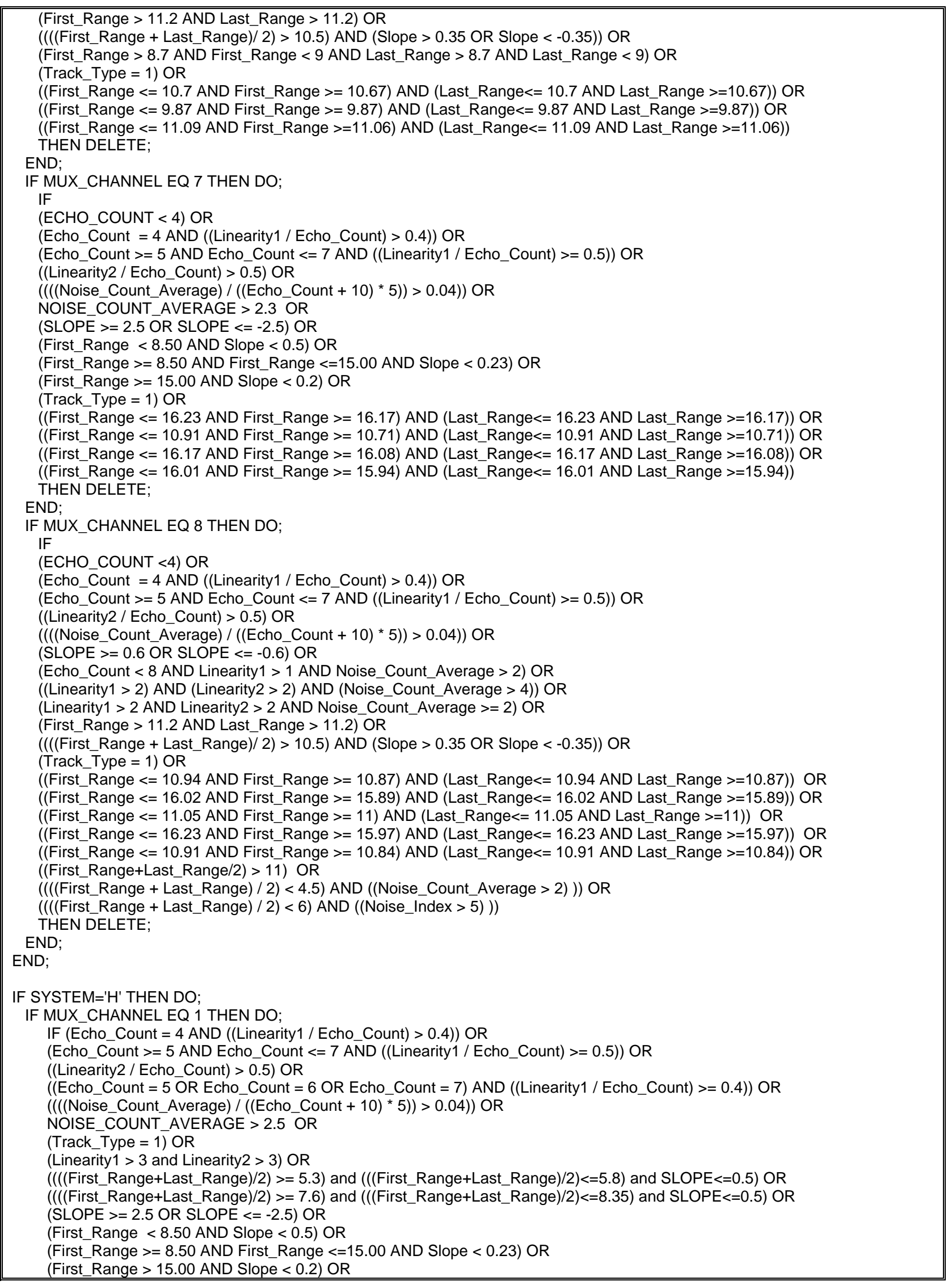




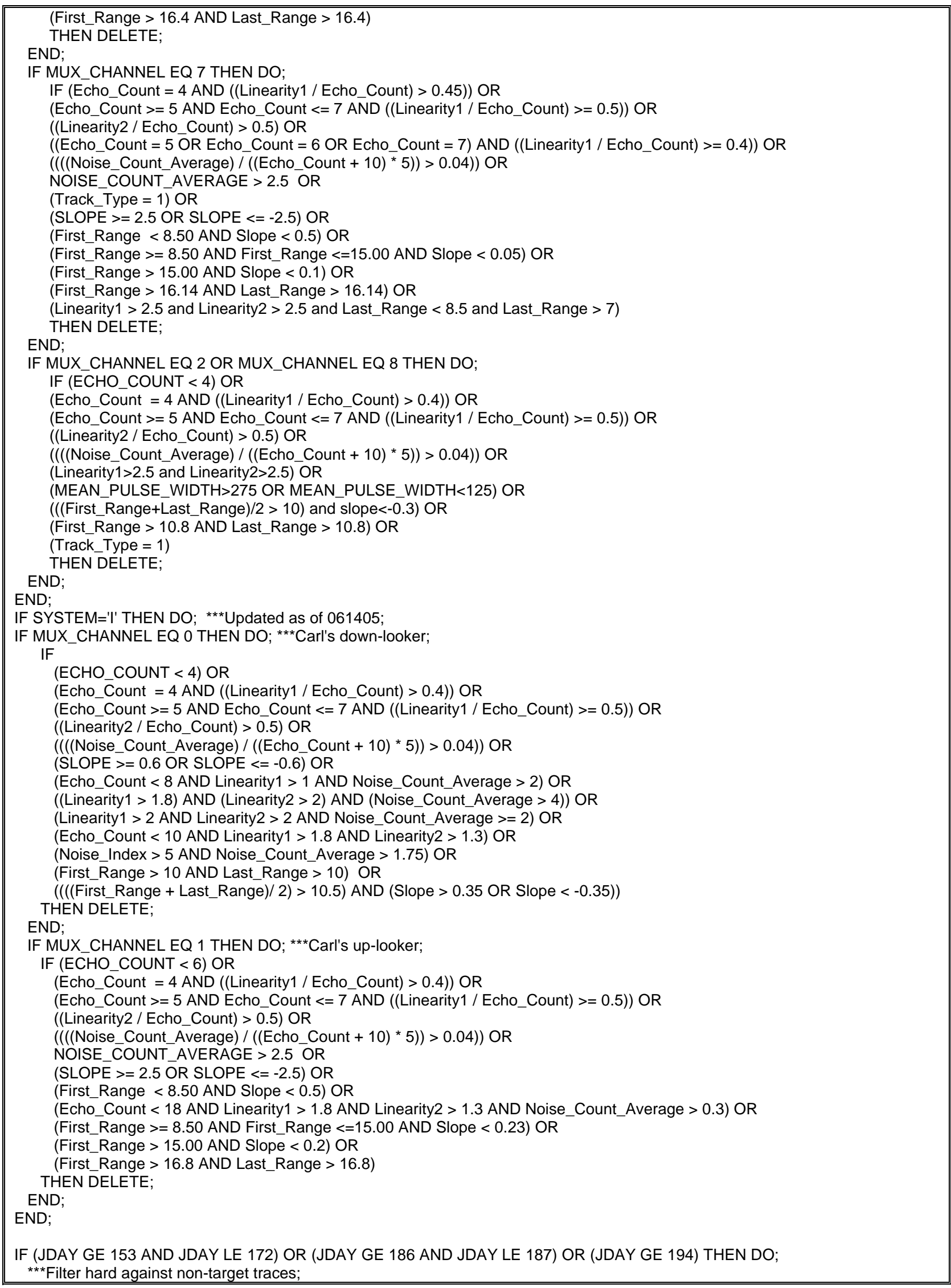




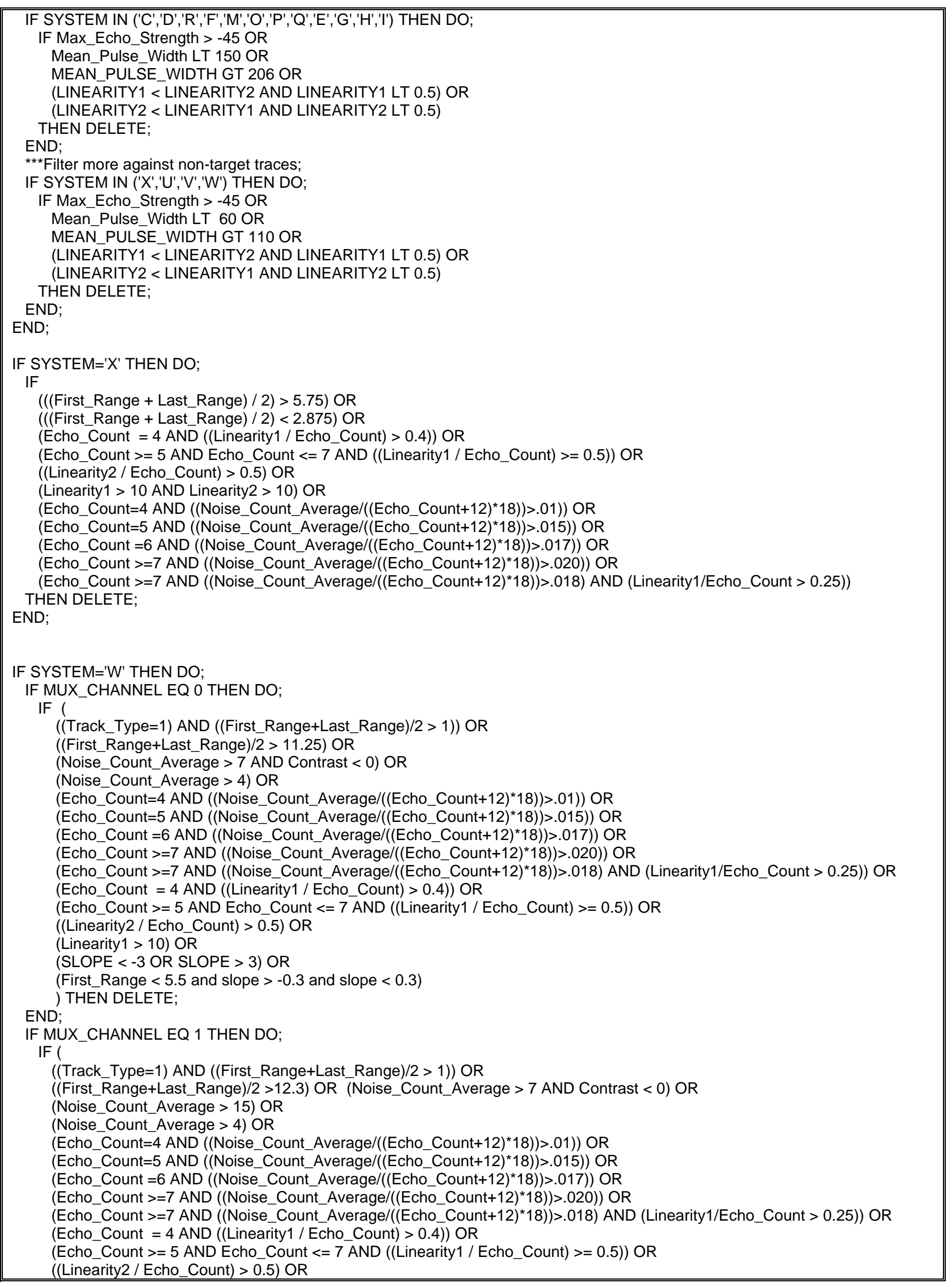




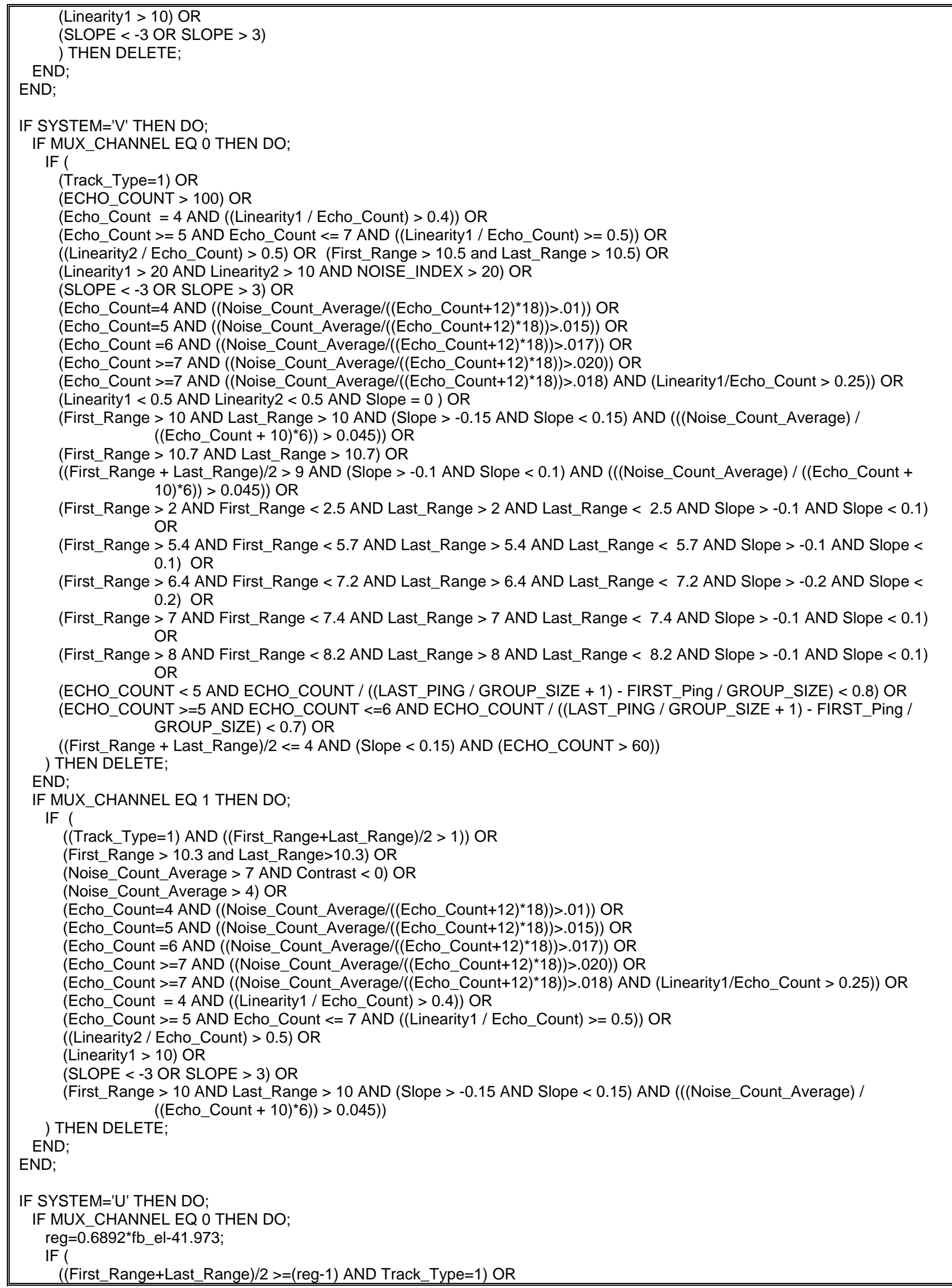




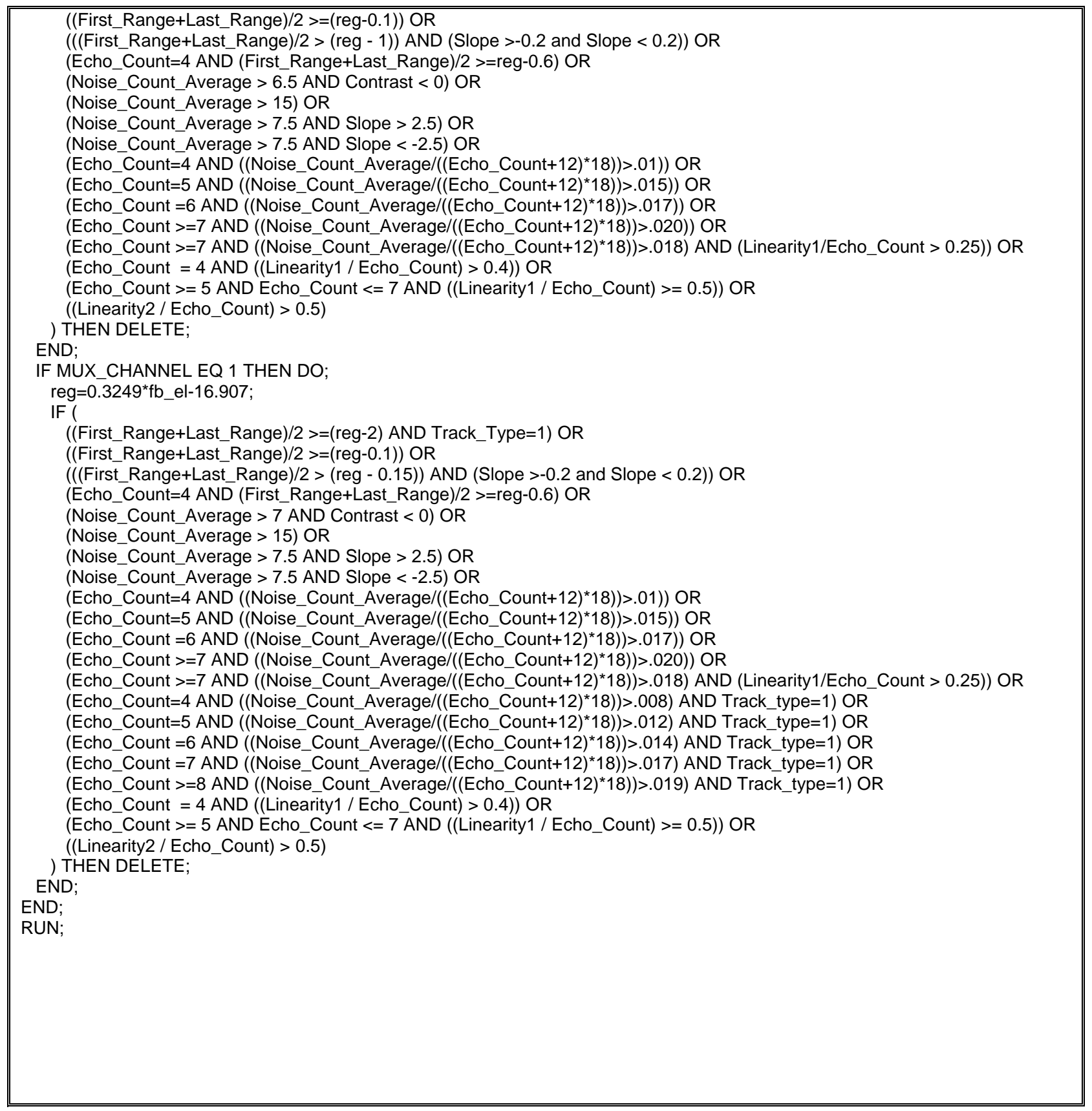


Appendix D.5. Statistical Analysis System (SAS) code for tighter filtering out echo traces that did not meet fish trace criteria in summer 2005. Minimum ranges for sampling guided, unguided, and spilled fish, which are presented in legends of Figures 2.1-2.3, 2.5, and 2.6 were implemented elsewhere in the processing program.

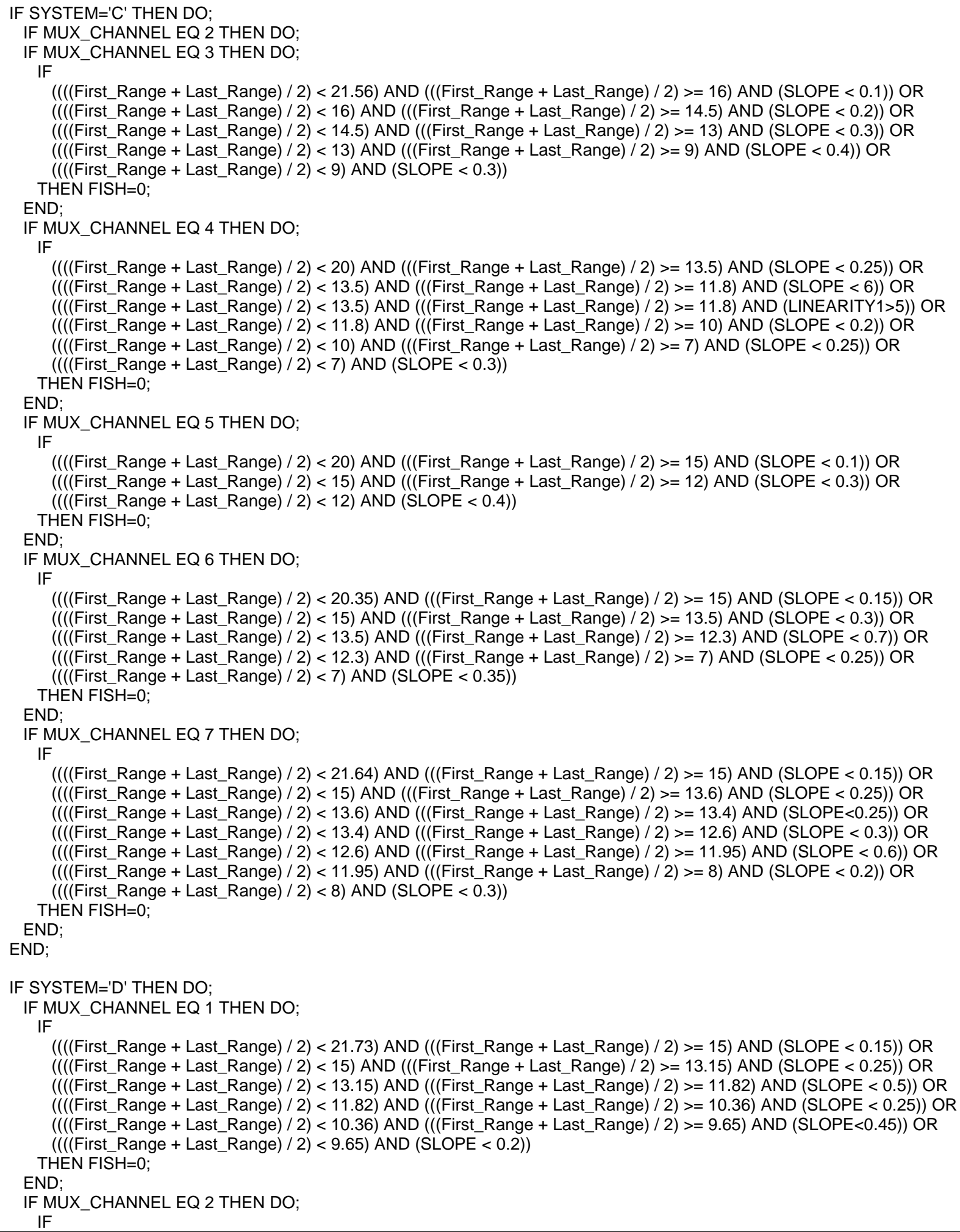




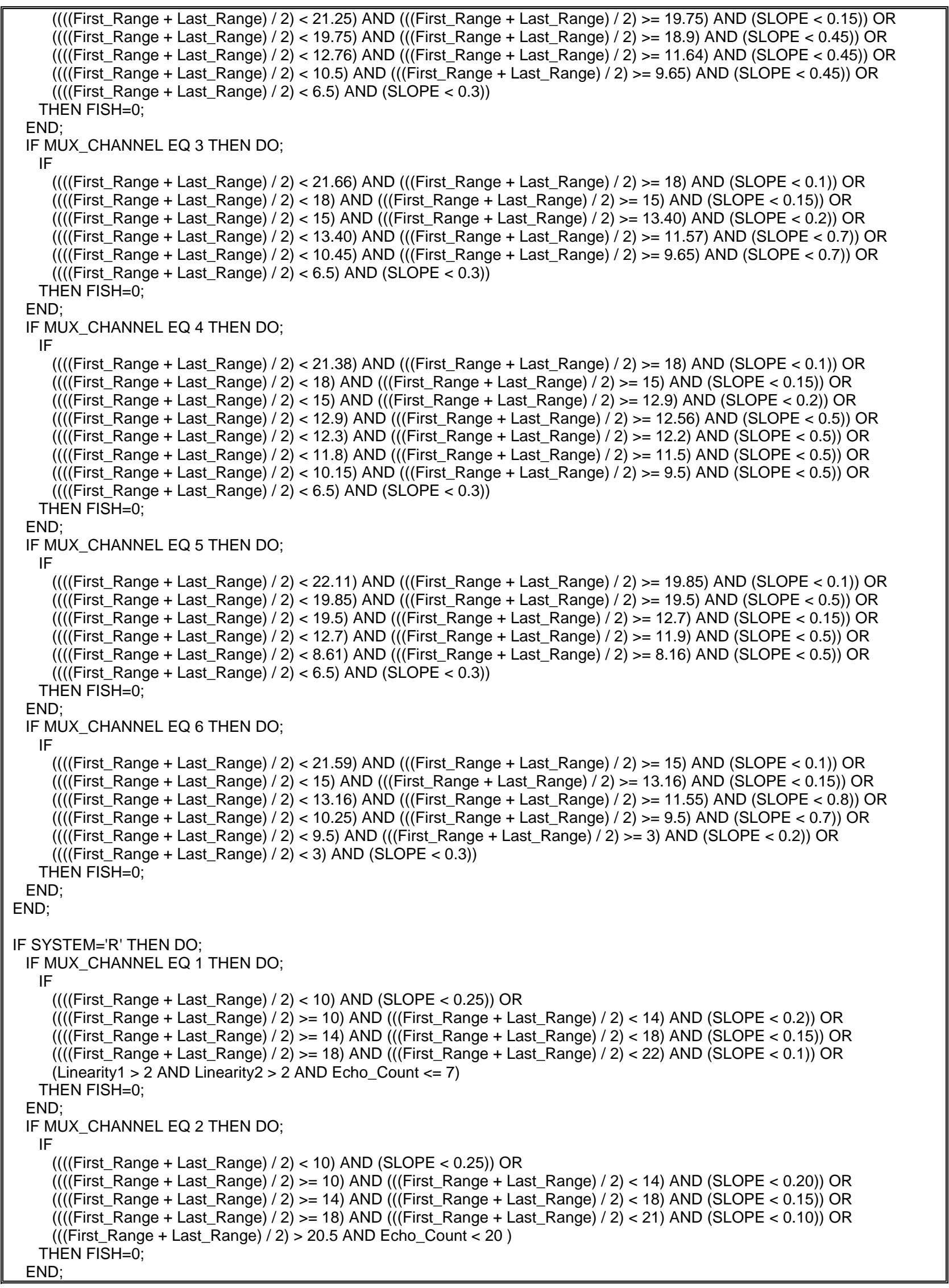




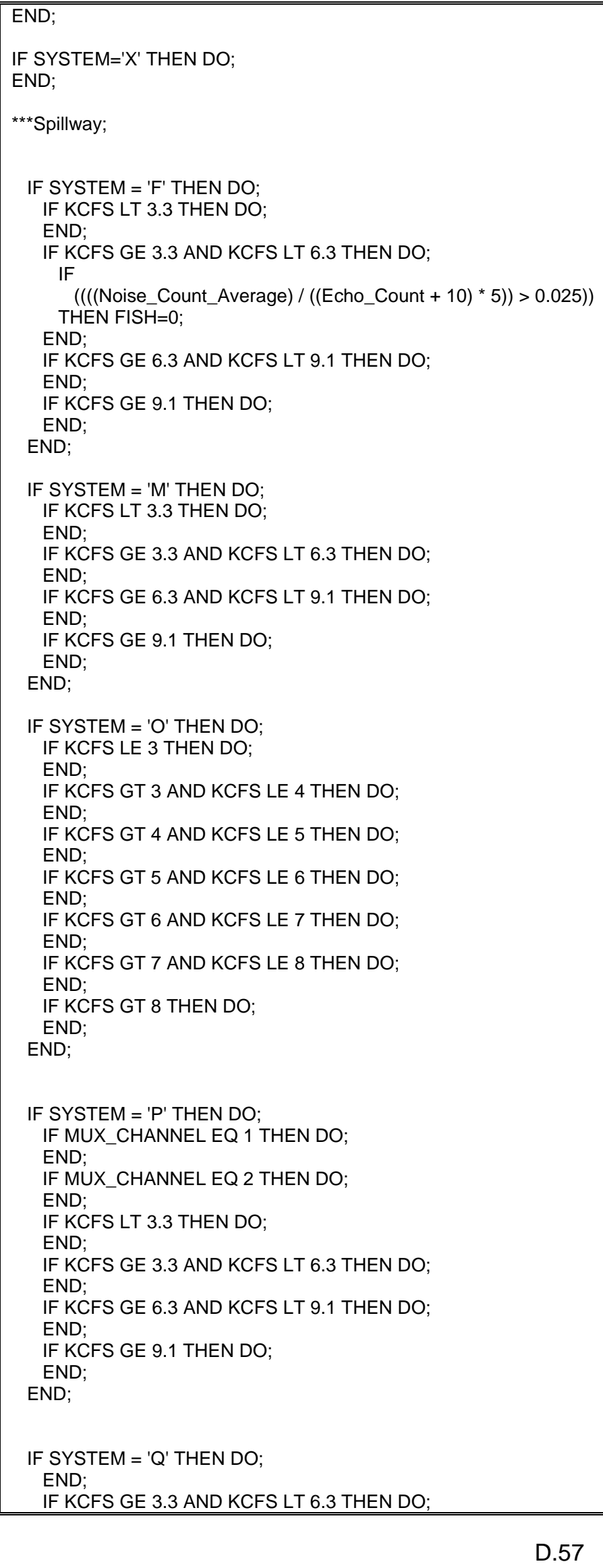




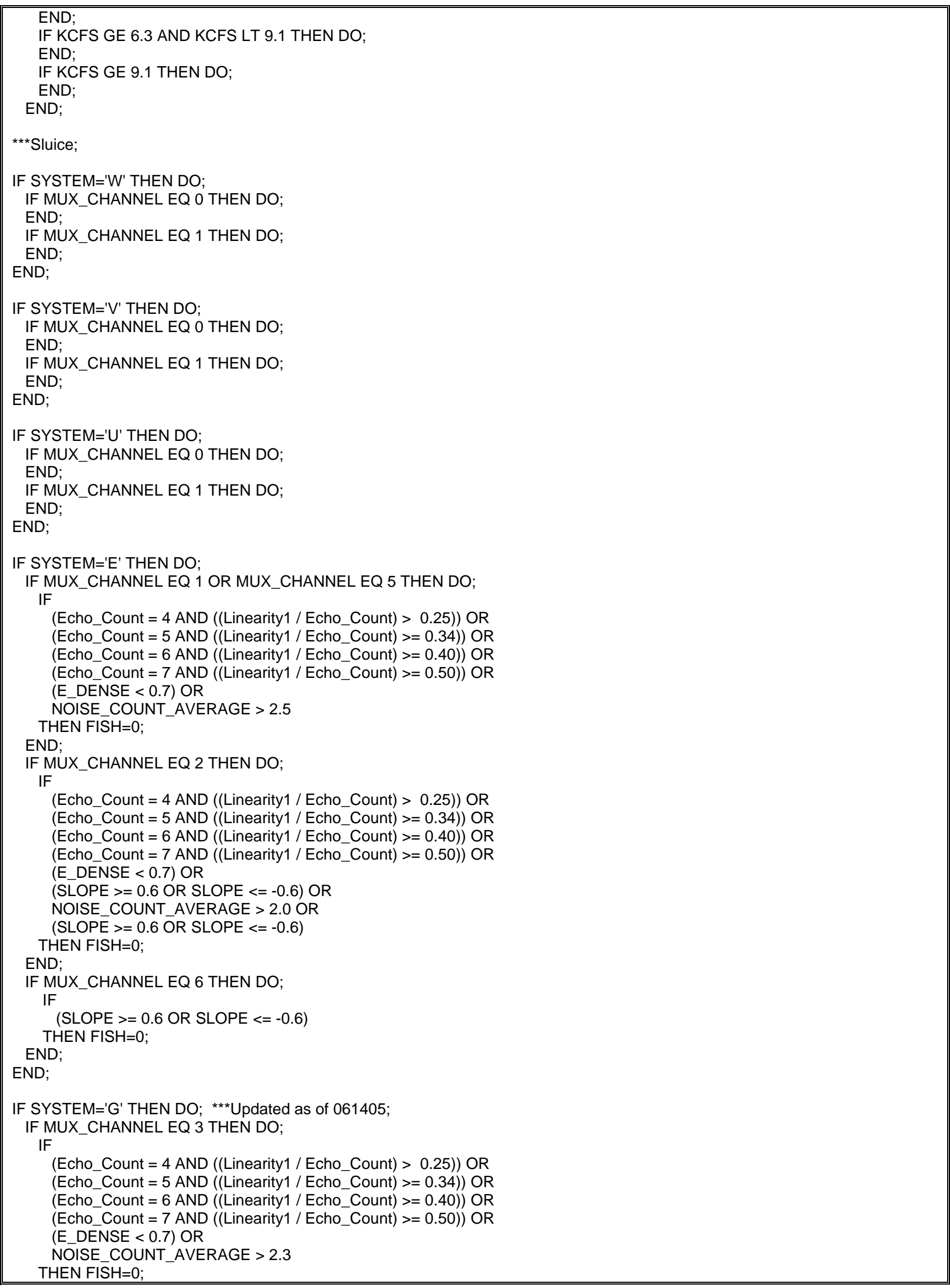




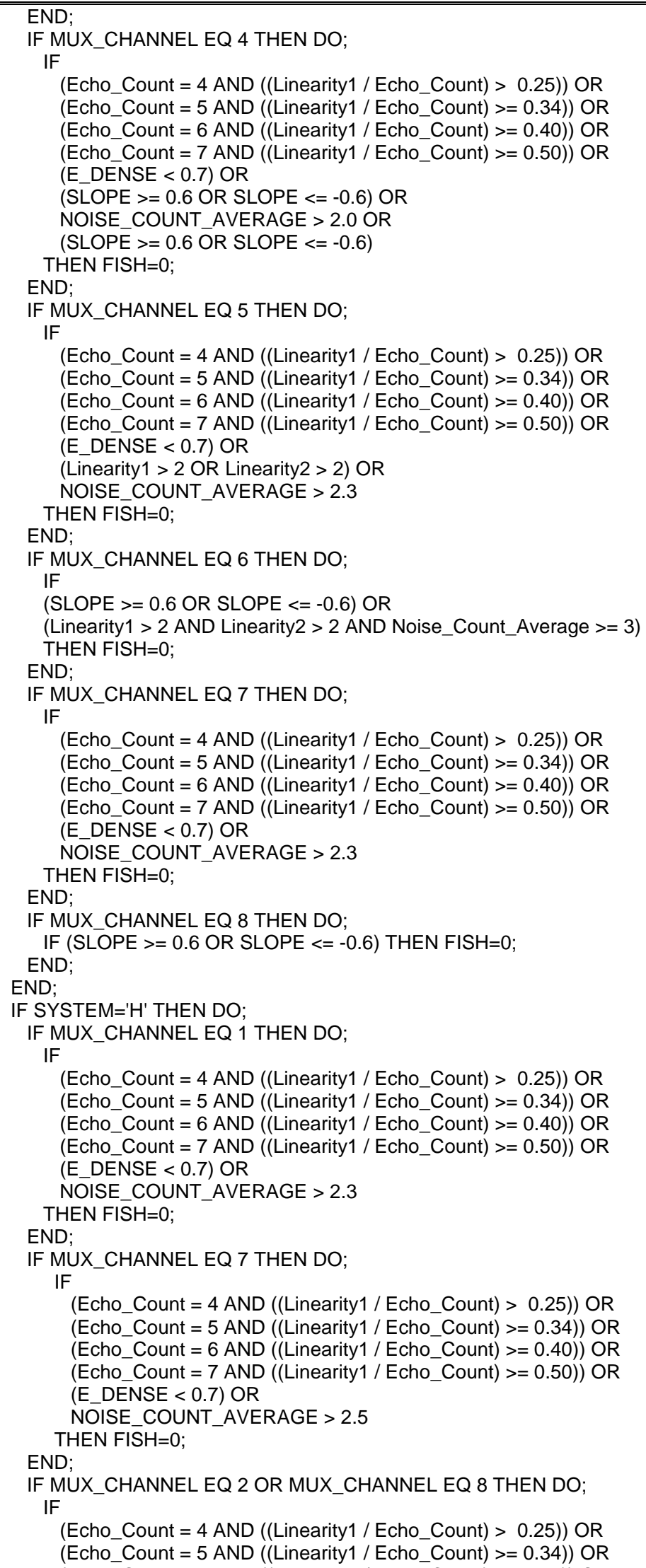




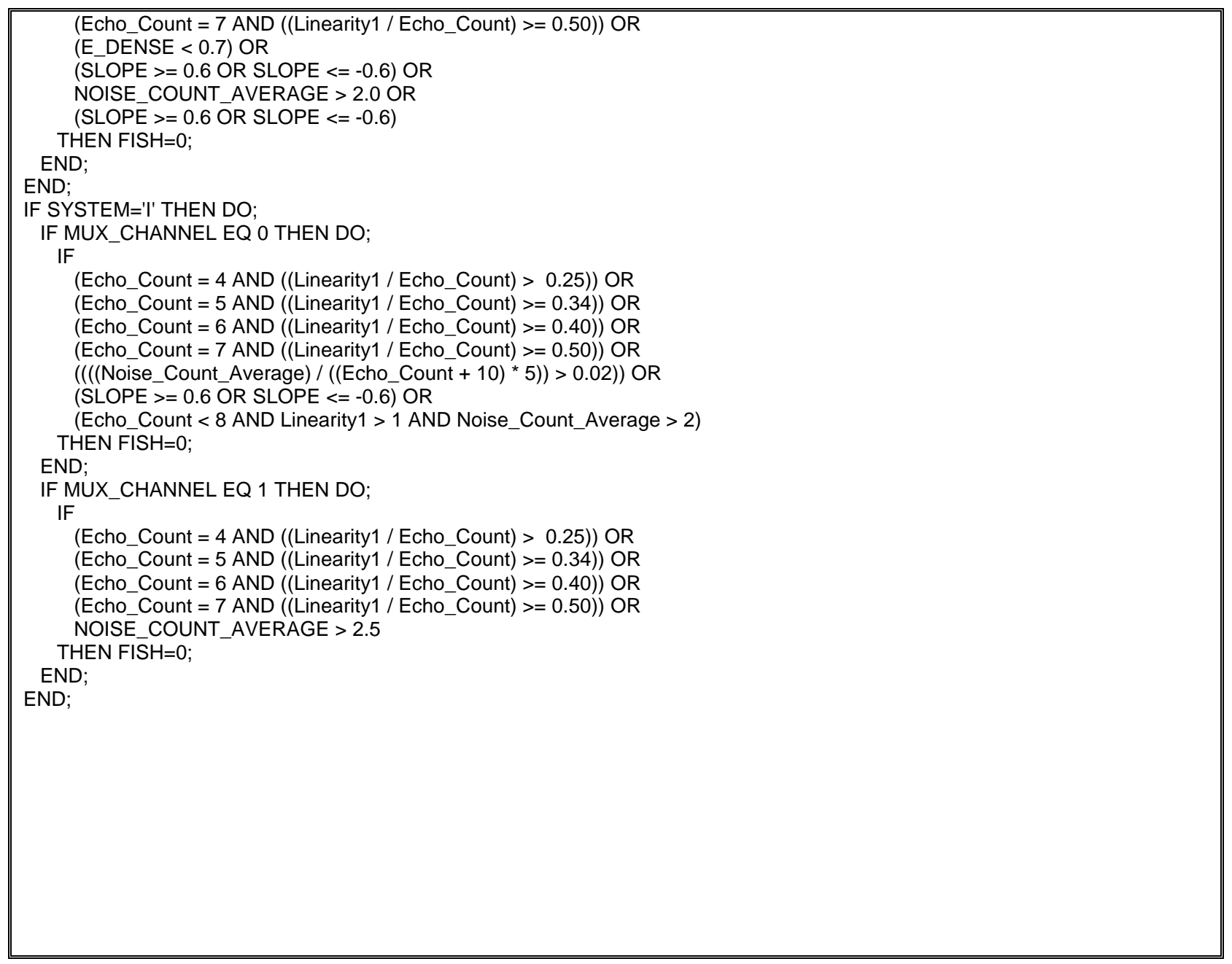




\section{Appendix E}

\section{Tables of Hourly Fish Passage, Flow, and Forebay Elevation Estimates}

(on accompanying CD) 
Hydroacoustic Evaluation of Fish Passage through Bonneville Dam in 2005 


\section{Appendix E}

\section{Tables of Hourly Fish Passage, Flow, and Forebay Elevation Estimates}

Appendix E.1. List of Appendix CSV Files on the Accompanying CD*

\begin{tabular}{ll}
\hline Table & Description \\
\hline Appendix E-3 & Hourly estimates of fish passage for spring 2005. \\
Appendix E-4 & Hourly estimates of fish passage for summer 2005. \\
Appendix E-5 & Hourly estimates of fish-passage variances for spring 2005. \\
Appendix E-6 & Hourly estimates of fish-passage variances for summer 2005. \\
Appendix E-7 & $\begin{array}{l}\text { Hourly estimates of turbine-unit and spill-bay specific discharge and average } \\
\text { forebay water surface elevation for spring 2005. } \\
\text { Hourly estimates of turbine-unit and spill-bay specific discharge and average } \\
\text { forebay water surface elevation for summer 2005. }\end{array}$ \\
\hline \hline
\end{tabular}

*A CD with Tables E3 through E8 accompanies the final report. 
Appendix E.2. Definitions of Variables in Headings of Appendix E Tables on the Accompanying CD. Turbines 2 and 10 were off all spring and summer.

\begin{tabular}{|c|c|c|c|}
\hline Variable & Definition & Variable & Definition \\
\hline Begins with $S_{-}$ & \multicolumn{3}{|c|}{ Hourly sum of spatially and temporally expanded estimates of fish passage } \\
\hline Begins with $\mathrm{V}_{-}$ & \multicolumn{3}{|c|}{ Hourly sum of temporally expanded variances } \\
\hline Begins with TU_ & \multicolumn{3}{|c|}{ Turbine } \\
\hline Begins with $\mathrm{SB}_{-}$ & \multicolumn{3}{|l|}{ Spill bay } \\
\hline Ends with CFS & \multicolumn{3}{|l|}{ Cubic ft / s } \\
\hline Contains SL1CS & Sluice Entrance 2C south half & Contains SB4 & Spillway bay 4 \\
\hline Contains SL1CN & Sluice Entrance 2C north half & Contains SB3 & Spillway bay 3 \\
\hline Contains SL3CS & Sluice Entrance 4C south half & Contains SB2 & Spillway bay 2 \\
\hline Contains SL3CN & Sluice Entrance 4C north half & Contains SB1 & Spillway bay 1 \\
\hline Contains SL6CS & Sluice Entrance 6C south half & Contains B2CC1 & B2 Corner Collector 1 \\
\hline Contains SL6CN & Sluice Entrance 6C north half & Contains B2CC2 & B2 Corner Collector 2 \\
\hline Contains I1AD & Intake 1A Downlooker & Contains B2CC3 & B2 Corner Collector 3 \\
\hline Contains I1BD & Intake 1B Downlooker & Contains B2CC4 & B2 Corner Collector 4 \\
\hline Contains I3AD & Intake 3A Downlooker & Contains B2CC5 & B2 Corner Collector 5 \\
\hline Contains I3BD & Intake 3B Downlooker & Contains B2CC6 & B2 Corner Collector 6 \\
\hline Contains I3CD & Intake 3C Downlooker & Contains I11AG & Intake 11A Guided \\
\hline Contains I4AD & Intake 4A Downlooker & Contains I11AU & Intake 11A Unguided \\
\hline Contains I4BD & Intake 4B Downlooker & Contains I11CG & Intake 11C Guided \\
\hline Contains I5AD & Intake 5A Downlooker & Contains I11CU & Intake 11C Unguided \\
\hline Contains I5BD & Intake 5B Downlooker & Contains I12AG & Intake 12A Guided \\
\hline Contains I6AD & Intake 6A Downlooker & Contains I12AU & Intake 12A Unguided \\
\hline Contains I6BD & Intake 6B Downlooker & Contains I12CG & Intake 12C Guided \\
\hline Contains I7AD & Intake 7A Downlooker & Contains I12CU & Intake 12C Unguided \\
\hline Contains I7CD & Intake 7C Downlooker & Contains I13BG & Intake 13B Guided \\
\hline Contains I8CD & Intake 8C Downlooker & Contains I13BU & Intake 13B Unguided \\
\hline Contains I9BD & Intake 9B Downlooker & Contains I14BG & Intake 14B Guided \\
\hline Contains SB18 & Spillway bay 18 & Contains I14BU & Intake 14B Unguided \\
\hline Contains SB17 & Spillway bay 17 & Contains I15BG & Intake 15B Guided \\
\hline Contains SB16 & Spillway bay 16 & Contains I15BU & Intake 15B Unguided \\
\hline Contains SB15 & Spillway bay 15 & Contains I16BG & Intake 16B Guided \\
\hline Contains SB14 & Spillway bay 14 & Contains I16BU & Intake 16B Unguided \\
\hline Contains SB13 & Spillway bay 13 & Contains I17AG & Intake 17A Guided \\
\hline Contains SB12 & Spillway bay 12 & Contains I17AU & Intake 17A Unguided \\
\hline Contains SB11 & Spillway bay 11 & Contains I17BG & Intake 17B Guided \\
\hline Contains SB10 & Spillway bay 10 & Contains I17BU & Intake 17B Unguided \\
\hline Contains SB9 & Spillway bay 9 & Contains I17CG & Intake 17C Guided \\
\hline Contains SB8 & Spillway bay 8 & Contains I17CU & Intake 17C Unguided \\
\hline Contains SB7 & Spillway bay 7 & Contains I18BG & Intake 18B Guided \\
\hline Contains SB6 & Spillway bay 6 & Contains I18BU & Intake 18B Unguided \\
\hline Contains SB5 & Spillway bay 5 & FB_EL & Forebay Elevation \\
\hline
\end{tabular}




\section{Appendix F}

Inputs for Detectability Modeling and Resulting Polynomial Coefficients for Estimating Effective Beam Angle-Based Upon Range from a Transducer 
Hydroacoustic Evaluation of Fish Passage through Bonneville Dam in 2005 


\section{Appendix F}

\section{Inputs for Detectability Modeling and Resulting Polynomial Coefficients for Estimating Effective Beam Angle-Based Upon Range from a Transducer}

Appendix F.1. Deployment-specific values input into a stochastic detectability model for estimating effective beam angle as a function of range from a transducer. Constants were as follows: Target Strength threshold $=-56 \mathrm{~dB}$; Maximum ping gap $=4$; Minimum echo count $=4$ echoes in 5 pings; Tilt $=0$ (we used beam coordinates for fish plunge and speed). B2CC transducers were numbered from 1 to 6 , corresponding to the order of deployment below the water's surface (top to bottom). Spill bay detectability was modeled for discharge $<3,000$ cfs and from 3,000 to 12,000 cfs by 1,000 cfs increments.

\begin{tabular}{|c|c|c|c|c|c|c|c|c|}
\hline Deployment & $\begin{array}{c}\text { Aiming } \\
\text { Direction }\end{array}$ & $\begin{array}{l}\text { Min. } \\
\text { Range } \\
\text { (m) }\end{array}$ & $\begin{array}{l}\text { Max. } \\
\text { Range } \\
\text { (m) }\end{array}$ & $\begin{array}{c}-3 \mathrm{~dB} \\
\text { Beam } \\
\text { Angle } \\
\text { (degrees) }\end{array}$ & $\begin{array}{c}\text { Pulse } \\
\text { Repetition } \\
\text { Rate } \\
\text { (pings/s) }\end{array}$ & $\begin{array}{l}\text { Mean Target } \\
\text { Strength } \\
\text { (dB } \| 1 \mu \mathrm{Pa})\end{array}$ & $\begin{array}{c}\text { TS } \\
\text { Standard } \\
\text { Deviation } \\
\text { (dB) }\end{array}$ & $\begin{array}{c}\text { Ping-to-ping } \\
\text { TS } \\
\text { Correlation }\end{array}$ \\
\hline \multicolumn{9}{|c|}{ Spring } \\
\hline B1 Sluice 1C & Lateral & 1 & 6 & 6 & 25 & -40.1 & 4.64 & 0.02225 \\
\hline B1 Sluice 3C & Lateral & 1 & 6 & 6 & 25 & -40.4 & 4.61 & 0.03247 \\
\hline B1 Sluice 6C & Lateral & 1 & 6 & 6 & 25 & -40.6 & 4.73 & 0.0443 \\
\hline B2CC 1 \& 2 & Lateral & 1 & 12 & 3 & 33 & -44.4 & 3.39 & 0.05043 \\
\hline B2CC $3,4,5,6$ & Lateral & 1 & 11 & 6 & 33 & -44.4 & 3.39 & 0.05043 \\
\hline B1 Turbine & Down & 1 & 20 & 6 & 20 & -45.8 & 3.36 & 0.25435 \\
\hline B2 Turbines & Down & 1 & 18 & 6 & 23 & -47.6 & 2.44 & 0.00000 \\
\hline B2 Turbines & Up & 1 & 11 & 6 & 23 & -47.2 & 2.87 & 0.00563 \\
\hline \multirow[t]{2}{*}{ Spill bay } & Down & 1 & 11 & 10 & 25 & -45.8 & 3.64 & 0.11097 \\
\hline & & & & Summer & & & & \\
\hline B1 Sluice 1C & Lateral & 1 & 6 & 6 & 25 & -46.3 & 3.58 & 0.00000 \\
\hline B1 Sluice 3C & Lateral & 1 & 6 & 6 & 25 & -46.3 & 3.57 & 0.00000 \\
\hline B1 Sluice 6C & Lateral & 1 & 6 & 6 & 25 & -46.9 & 3.37 & 0.00777 \\
\hline $\mathrm{B} 2 \mathrm{CC} 1 \& 2$ & Lateral & 1 & 12 & 3 & 33 & -47.7 & 2.99 & 0.00529 \\
\hline $\mathrm{B} 2 \mathrm{CC} 3,4,5,6$ & Lateral & 1 & 11 & 6 & 33 & -47.7 & 2.99 & 0.00529 \\
\hline B1 Turbine & Down & 1 & 22 & 6 & 20 & -49.6 & 2.38 & 0.25689 \\
\hline B2 Turbines & Down & 1 & 18 & 6 & 23 & -49.2 & 2.31 & 0.04074 \\
\hline B2 Turbines & Up & 1 & 11 & 6 & 23 & -49.1 & 2.60 & 0.01007 \\
\hline Spill bay & Down & 1 & 11 & 10 & 25 & -48.3 & 3.29 & 0.07763 \\
\hline
\end{tabular}


Appendix F.2. Target plunge in degrees off of a plane perpendicular to the range axis of the hydroacoustic beam by deployment, spill discharge treatment, and range from the transducer. Negative values indicate movement away from the transducer and positive values indicate movement toward the transducer.

\begin{tabular}{|c|c|c|c|c|c|c|c|c|c|c|c|c|c|c|c|c|c|c|c|c|c|}
\hline \multirow[b]{2}{*}{ Deployment } & \multirow[b]{2}{*}{ Treatment } & \multirow[b]{2}{*}{1} & \multirow[b]{2}{*}{2} & \multirow[b]{2}{*}{3} & \multirow[b]{2}{*}{4} & \multirow[b]{2}{*}{5} & \multirow[b]{2}{*}{6} & \multirow[b]{2}{*}{7} & \multirow[b]{2}{*}{8} & \multicolumn{3}{|c|}{ Range (m) } & \multirow[b]{2}{*}{12} & \multirow[b]{2}{*}{13} & \multirow[b]{2}{*}{14} & \multirow[b]{2}{*}{15} & \multirow[b]{2}{*}{16} & \multirow[b]{2}{*}{17} & \multirow[b]{2}{*}{18} & & \\
\hline & & & & & & & & & & 9 & 10 & 11 & & & & & & & & 19 & 20 \\
\hline & & & & & & & & & & קpring & & & & & & & & & & & \\
\hline B1 SL1C & ALL & -18.6 & -18.6 & -18.6 & -20.0 & -6.9 & -6.9 & -6.9 & & & & & & & & & & & & & \\
\hline B1 SL3C & ALL & -24.7 & -24.7 & -24.7 & -16.2 & -16.8 & -16.8 & -16.8 & & & & & & & & & & & & & \\
\hline B1 SL6C & ALL & -35.6 & -35.6 & -35.6 & -28.3 & -4.6 & -4.6 & -4.6 & & & & & & & & & & & & & \\
\hline B2CC 1 \& 2 & ALL & -66.9 & -66.9 & -66.9 & -66.9 & -60.0 & -50.1 & -44.3 & -28.5 & -14.8 & -14.8 & -14.8 & -14.8 & & & & & & & & \\
\hline $\mathrm{B} 2 \mathrm{CC} 3,4,5,6$ & ALL & -60.5 & -60.5 & -60.5 & -58.7 & -55.5 & -49.6 & -35.9 & -25.8 & -14.5 & 4.1 & 4.1 & & & & & & & & & \\
\hline B1 Turbine & ALL & -48.8 & -48.8 & -48.8 & -48.8 & -48.8 & -45.5 & -49.5 & -51.4 & -42.3 & -37.3 & -43.2 & -43.4 & -41.0 & -35.7 & -33.1 & -29.9 & -29.9 & -29.9 & -29.9 & -29.9 \\
\hline B2 Turbine Down & ALL & -46.3 & -46.3 & -46.3 & -46.3 & -46.3 & -41.1 & -34.5 & -29.0 & -32.0 & -28.2 & -21.2 & -19.0 & -18.8 & -17.4 & -17.4 & -17.4 & -17.4 & -17.4 & & \\
\hline B2 Turbine Up & ALL & 23.0 & 23.0 & 23.0 & 23.0 & 23.0 & 8.0 & 9.1 & 9.1 & 9.1 & 9.1 & 9.1 & 9.1 & & & & & & & & \\
\hline Spill Bays & $<3$ & -26.1 & -43.0 & -54.9 & -61.8 & -63.7 & -60.6 & -52.5 & -39.5 & -21.4 & & & & & & & & & & & \\
\hline Spill Bays & $>3 \&<4$ & -26.1 & -43.0 & -54.9 & -61.8 & -69.0 & -62.0 & -53.9 & -36.9 & -24.2 & & & & & & & & & & & \\
\hline Spill Bays & $>4 \&<5$ & -26.1 & -43.0 & -54.9 & -61.8 & -63.0 & -61.4 & -53.2 & -30.0 & -24.0 & & & & & & & & & & & \\
\hline Spill Bays & $>5 \&<6$ & -26.1 & -43.0 & -54.9 & -61.8 & -64.3 & -59.0 & -55.4 & -30.9 & -19.8 & 2.8 & & & & & & & & & & \\
\hline Spill Bays & $>6 \&<7$ & -26.1 & -43.0 & -54.9 & -61.8 & -65.0 & -57.6 & -59.5 & -35.2 & -21.8 & 0.4 & & & & & & & & & & \\
\hline Spill Bays & $>7 \&<8$ & -26.1 & -43.0 & -54.9 & -61.8 & -61.1 & -53.5 & -60.4 & -38.6 & -26.8 & 7.1 & & & & & & & & & & \\
\hline Spill Bays & $>8 \&<9$ & -26.1 & -43.0 & -54.9 & -61.8 & -64.2 & -53.9 & -59.4 & -38.0 & -29.4 & 0.9 & & & & & & & & & & \\
\hline Spill Bays & $>9 \&<10$ & -26.1 & -43.0 & -54.9 & -61.8 & -63.7 & -60.6 & -52.5 & -39.5 & -21.4 & 1.6 & & & & & & & & & & \\
\hline Spill Bays & $>10 \&<11$ & -26.1 & -43.0 & -54.9 & -61.8 & -63.7 & -60.6 & -52.5 & -39.5 & -21.4 & 1.6 & 29.6 & & & & & & & & & \\
\hline Spill Bays & $>11 \&<12$ & -26.1 & -43.0 & -54.9 & -61.8 & -63.7 & -60.6 & -52.5 & -39.5 & -21.4 & 1.6 & 29.6 & & & & & & & & & \\
\hline & & & & & & & & & & jummer & & & & & & & & & & & \\
\hline B1 SL1C & ALL & -18.6 & -18.6 & -18.6 & -20.0 & -6.9 & -6.9 & -6.9 & & & & & & & & & & & & & \\
\hline B1 SL3C & ALL & -24.7 & -24.7 & -24.7 & -16.2 & -16.8 & -16.8 & -16.8 & & & & & & & & & & & & & \\
\hline B1 SL6C & ALL & -35.6 & -35.6 & -35.6 & -28.3 & -4.6 & -4.6 & -4.6 & & & & & & & & & & & & & \\
\hline B2CC 1 \& 2 & ALL & -66.9 & -66.9 & -66.9 & -66.9 & -60.0 & -50.1 & -44.3 & -28.5 & -14.8 & -14.8 & -14.8 & -14.8 & & & & & & & & \\
\hline B2CC 3, 4, 5, 6 & ALL & -60.5 & -60.5 & -60.5 & -58.7 & -55.5 & -49.6 & -35.9 & -25.8 & -14.5 & 4.1 & 4.1 & & & & & & & & & \\
\hline B1 Turbine & ALL & -48.8 & -48.8 & -48.8 & -48.8 & -48.8 & -45.5 & -49.5 & -51.4 & -42.3 & -37.3 & -43.2 & -43.4 & -41.0 & -35.7 & -33.1 & -29.9 & -29.9 & -29.9 & -29.9 & -29.9 \\
\hline B2 Turbine Down & ALL & -46.3 & -46.3 & -46.3 & -46.3 & -46.3 & -41.1 & -34.5 & -29.0 & -32.0 & -28.2 & -21.2 & -19.0 & -18.8 & -17.4 & -17.4 & -17.4 & -17.4 & -17.4 & & \\
\hline B2 Turbine Up & ALL & 23.0 & 23.0 & 23.0 & 23.0 & 23.0 & 8.0 & 9.1 & 9.1 & 9.1 & 9.1 & 9.1 & 9.1 & & & & & & & & \\
\hline Spill Bays & $<3$ & -18.3 & -33.0 & -47.8 & -63.5 & -67.8 & -62.8 & -50.9 & -34.4 & -15.4 & & & & & & & & & & & \\
\hline Spill Bays & $>3 \&<4$ & -18.3 & -33.0 & -47.8 & -63.5 & -70.6 & -60.9 & -58.1 & -29.5 & -9.9 & & & & & & & & & & & \\
\hline Spill Bays & $>4 \&<5$ & -18.3 & -33.0 & -47.8 & -63.5 & -67.6 & -65.7 & -51.8 & -25.1 & -9.9 & & & & & & & & & & & \\
\hline Spill Bays & $>5 \&<6$ & -18.3 & -33.0 & -47.8 & -63.5 & -70.1 & -18.3 & -52.5 & -28.9 & -10.7 & & & & & & & & & & & \\
\hline Spill Bays & $>6 \&<7$ & -18.3 & -33.0 & -47.8 & -63.5 & -75.5 & -67.2 & -33.0 & -34.4 & -20.7 & 1.5 & & & & & & & & & & \\
\hline Spill Bays & $>7 \&<8$ & -18.3 & -33.0 & -47.8 & -63.5 & -62.2 & -58.1 & -49.4 & -29.9 & -8.1 & 5.0 & & & & & & & & & & \\
\hline Spill Bays & $>8 \&<9$ & -18.3 & -33.0 & -47.8 & -63.5 & -64.2 & -57.9 & -49.2 & -35.0 & -14.3 & 3.5 & & & & & & & & & & \\
\hline Spill Bays & $>9 \&<10$ & -18.3 & -33.0 & -47.8 & -63.5 & -65.3 & -59.2 & -56.8 & -34.4 & -15.4 & -2.4 & & & & & & & & & & \\
\hline Spill Bays & $>10 \&<11$ & -18.3 & -33.0 & -47.8 & -63.5 & -67.8 & -62.8 & -47.3 & -33.0 & -23.8 & 11.6 & 20.7 & & & & & & & & & \\
\hline Spill Bays & $>11 \&<12$ & -18.3 & -33.0 & -47.8 & -63.5 & -67.8 & -62.8 & -50.9 & -34.4 & -15.4 & 3.7 & 20.7 & & & & & & & & & \\
\hline
\end{tabular}


Appendix F.3. Target speed ( $\mathrm{m} /$ second) by deployment, spill bay discharge treatment (cfs $\times 1,000$ ), and range from each transducer.

\begin{tabular}{|c|c|c|c|c|c|c|c|c|c|c|c|c|c|c|c|c|c|c|c|c|c|}
\hline \multirow[b]{2}{*}{ Deployment } & \multirow[b]{2}{*}{ Treatment } & \multirow[b]{2}{*}{1} & \multirow[b]{2}{*}{2} & \multirow[b]{2}{*}{3} & \multirow[b]{2}{*}{4} & \multirow[b]{2}{*}{5} & \multirow[b]{2}{*}{6} & \multirow[b]{2}{*}{7} & \multirow[b]{2}{*}{8} & \multicolumn{3}{|c|}{ Range (m) } & \multirow[b]{2}{*}{12} & \multirow[b]{2}{*}{13} & \multirow[b]{2}{*}{14} & \multirow[b]{2}{*}{15} & \multirow[b]{2}{*}{16} & \multirow[b]{2}{*}{17} & \multirow[b]{2}{*}{18} & & \\
\hline & & & & & & & & & & 9 & 10 & 11 & & & & & & & & 19 & 20 \\
\hline & & & & & & & & & & pring & & & & & & & & & & & \\
\hline B1 SL1C & ALL & 0.87 & 0.87 & 0.87 & 1.00 & 1.69 & 1.69 & 1.69 & & & & & & & & & & & & & \\
\hline B1 SL3C & ALL & 0.52 & 0.52 & 0.52 & 0.70 & 1.30 & 1.30 & 1.30 & & & & & & & & & & & & & \\
\hline B1 SL6C & ALL & 0.34 & 0.34 & 0.34 & 0.48 & 0.89 & 0.89 & 0.89 & & & & & & & & & & & & & \\
\hline $\mathrm{B} 2 \mathrm{CC} 1$ \& 2 & ALL & 0.44 & 0.53 & 0.70 & 1.02 & 1.49 & 1.82 & 2.14 & 2.36 & 2.30 & 2.66 & 3.07 & 3.07 & & & & & & & & \\
\hline $\mathrm{B} 2 \mathrm{CC} 3,4,5,6$ & ALL & 0.61 & 0.72 & 0.91 & 1.26 & 1.94 & 2.38 & 2.92 & 3.74 & 4.32 & 4.19 & 4.19 & & & & & & & & & \\
\hline B1 Turbine & ALL & 0.75 & 0.75 & 0.75 & 0.75 & 0.75 & 0.82 & 0.82 & 0.79 & 0.85 & 0.82 & 0.82 & 0.77 & 0.76 & 0.82 & 0.83 & 0.89 & 0.83 & 0.81 & 0.80 & 0.80 \\
\hline B2 Turbine Down & ALL & 1.40 & 1.40 & 1.40 & 1.40 & 1.40 & 1.58 & 1.69 & 1.45 & 1.30 & 1.33 & 1.41 & 1.39 & 1.33 & 1.38 & 1.69 & 1.69 & 1.69 & 1.69 & & \\
\hline B2 Turbine Up & ALL & 0.91 & 0.91 & 0.91 & 0.91 & 0.91 & 1.32 & 1.10 & 1.00 & 1.42 & 1.15 & & & & & & & & & & \\
\hline Spill Bays & $<3$ & 0.50 & 0.50 & 0.50 & 0.70 & 1.03 & 1.28 & 1.45 & 1.57 & 1.93 & & & & & & & & & & & \\
\hline Spill Bays & $>3 \&<4$ & 0.50 & 0.50 & 0.50 & 0.75 & 0.91 & 1.28 & 1.32 & 1.63 & 1.79 & & & & & & & & & & & \\
\hline Spill Bays & $>4 \&<5$ & 0.50 & 0.50 & 0.50 & 0.77 & 0.98 & 1.51 & 1.62 & 1.99 & 2.51 & & & & & & & & & & & \\
\hline Spill Bays & $>5 \&<6$ & 0.50 & 0.50 & 0.50 & 0.79 & 1.15 & 1.74 & 1.92 & 2.35 & 2.86 & & & & & & & & & & & \\
\hline Spill Bays & $>6 \&<7$ & 0.50 & 0.50 & 0.50 & 0.94 & 1.33 & 2.01 & 2.12 & 2.68 & 3.21 & 3.60 & & & & & & & & & & \\
\hline Spill Bays & $>7 \&<8$ & 0.50 & 0.50 & 0.71 & 1.17 & 1.54 & 2.28 & 2.38 & 2.95 & 3.51 & 3.87 & & & & & & & & & & \\
\hline Spill Bays & $>8 \&<9$ & 0.50 & 0.75 & 1.05 & 1.47 & 1.57 & 2.46 & 2.56 & 3.22 & 3.73 & 4.06 & & & & & & & & & & \\
\hline Spill Bays & $>9 \&<10$ & 0.62 & 1.00 & 1.39 & 1.78 & 2.17 & 2.56 & 2.94 & 3.33 & 3.72 & 4.11 & & & & & & & & & & \\
\hline Spill Bays & $>10 \&<11$ & 0.88 & 1.27 & 1.65 & 2.04 & 2.43 & 2.82 & 3.21 & 3.59 & 3.98 & 4.37 & 4.76 & & & & & & & & & \\
\hline Spill Bays & $>11 \&<12$ & 1.14 & 1.53 & 1.91 & 2.30 & 2.69 & 3.08 & 3.47 & 3.85 & 4.24 & 4.63 & 5.02 & & & & & & & & & \\
\hline & & & & & & & & & & ummer & & & & & & & & & & & \\
\hline B1 SL1C & ALL & 0.87 & 0.87 & 0.87 & 1.00 & 1.69 & 1.69 & 1.69 & & & & & & & & & & & & & \\
\hline B1 SL3C & ALL & 0.52 & 0.52 & 0.52 & 0.70 & 1.30 & 1.30 & 1.30 & & & & & & & & & & & & & \\
\hline B1 SL6C & ALL & 0.34 & 0.34 & 0.34 & 0.48 & 0.89 & 0.89 & 0.89 & & & & & & & & & & & & & \\
\hline $\mathrm{B} 2 \mathrm{CC} 1$ \& 2 & ALL & 0.44 & 0.53 & 0.70 & 1.02 & 1.49 & 1.82 & 2.14 & 2.36 & 2.30 & 2.66 & 3.07 & 3.07 & & & & & & & & \\
\hline B2CC $3,4,5,6$ & ALL & 0.61 & 0.72 & 0.91 & 1.26 & 1.94 & 2.38 & 2.92 & 3.74 & 4.32 & 4.19 & 4.19 & & & & & & & & & \\
\hline B1 Turbine & ALL & 0.75 & 0.75 & 0.75 & 0.75 & 0.75 & 0.82 & 0.82 & 0.79 & 0.85 & 0.82 & 0.82 & 0.77 & 0.76 & 0.82 & 0.83 & 0.89 & 0.83 & 0.81 & 0.80 & 0.80 \\
\hline B2 Turbine Down & ALL & 1.40 & 1.40 & 1.40 & 1.40 & 1.40 & 1.58 & 1.69 & 1.45 & 1.30 & 1.33 & 1.41 & 1.39 & 1.33 & 1.38 & 1.69 & 1.69 & 1.69 & 1.69 & & \\
\hline B2 Turbine Up & ALL & 0.91 & 0.91 & 0.91 & 0.91 & 0.91 & 1.32 & 1.10 & 1.00 & 1.42 & 1.15 & & & & & & & & & & \\
\hline Spill Bays & $<3$ & 0.50 & 0.50 & 0.50 & 0.50 & 0.50 & 0.73 & 1.12 & 1.51 & 1.89 & & & & & & & & & & & \\
\hline Spill Bays & $>3 \&<4$ & 0.50 & 0.50 & 0.50 & 0.50 & 0.60 & 0.99 & 1.38 & 1.77 & 2.16 & & & & & & & & & & & \\
\hline Spill Bays & $>4 \&<5$ & 0.50 & 0.50 & 0.50 & 0.67 & 0.86 & 1.25 & 1.64 & 2.03 & 2.42 & & & & & & & & & & & \\
\hline Spill Bays & $>5 \&<6$ & 0.50 & 0.50 & 0.56 & 0.74 & 1.13 & 1.51 & 1.90 & 2.29 & 2.68 & & & & & & & & & & & \\
\hline Spill Bays & $>6 \&<7$ & 0.50 & 0.50 & 0.61 & 1.00 & 1.39 & 1.77 & 2.16 & 2.55 & 2.94 & 3.33 & & & & & & & & & & \\
\hline Spill Bays & $>7 \&<8$ & 0.50 & 0.50 & 0.87 & 1.26 & 1.65 & 2.03 & 2.42 & 2.81 & 3.20 & 3.59 & & & & & & & & & & \\
\hline Spill Bays & $>8 \&<9$ & 0.50 & 0.74 & 1.13 & 1.52 & 1.91 & 2.30 & 2.68 & 3.07 & 3.46 & 3.85 & & & & & & & & & & \\
\hline Spill Bays & $>9 \&<10$ & 0.62 & 1.00 & 1.39 & 1.78 & 2.17 & 2.56 & 2.94 & 3.33 & 3.72 & 4.11 & & & & & & & & & & \\
\hline Spill Bays & $>10 \&<11$ & 0.88 & 1.27 & 1.65 & 2.04 & 2.43 & 2.82 & 3.21 & 3.59 & 3.98 & 4.37 & 4.76 & & & & & & & & & \\
\hline Spill Bays & $>11 \&<12$ & 1.14 & 1.53 & 1.91 & 2.30 & 2.69 & 3.08 & 3.47 & 3.85 & 4.24 & 4.63 & 5.02 & & & & & & & & & \\
\hline
\end{tabular}


Appendix F.4. Beam pattern factors, expressed as the decibel drop in sound pressure level as a function of the half angle off of the acoustic axis by deployment and by discharge treatment (cfs $x$ $1,000)$ for the spill bay deployment.

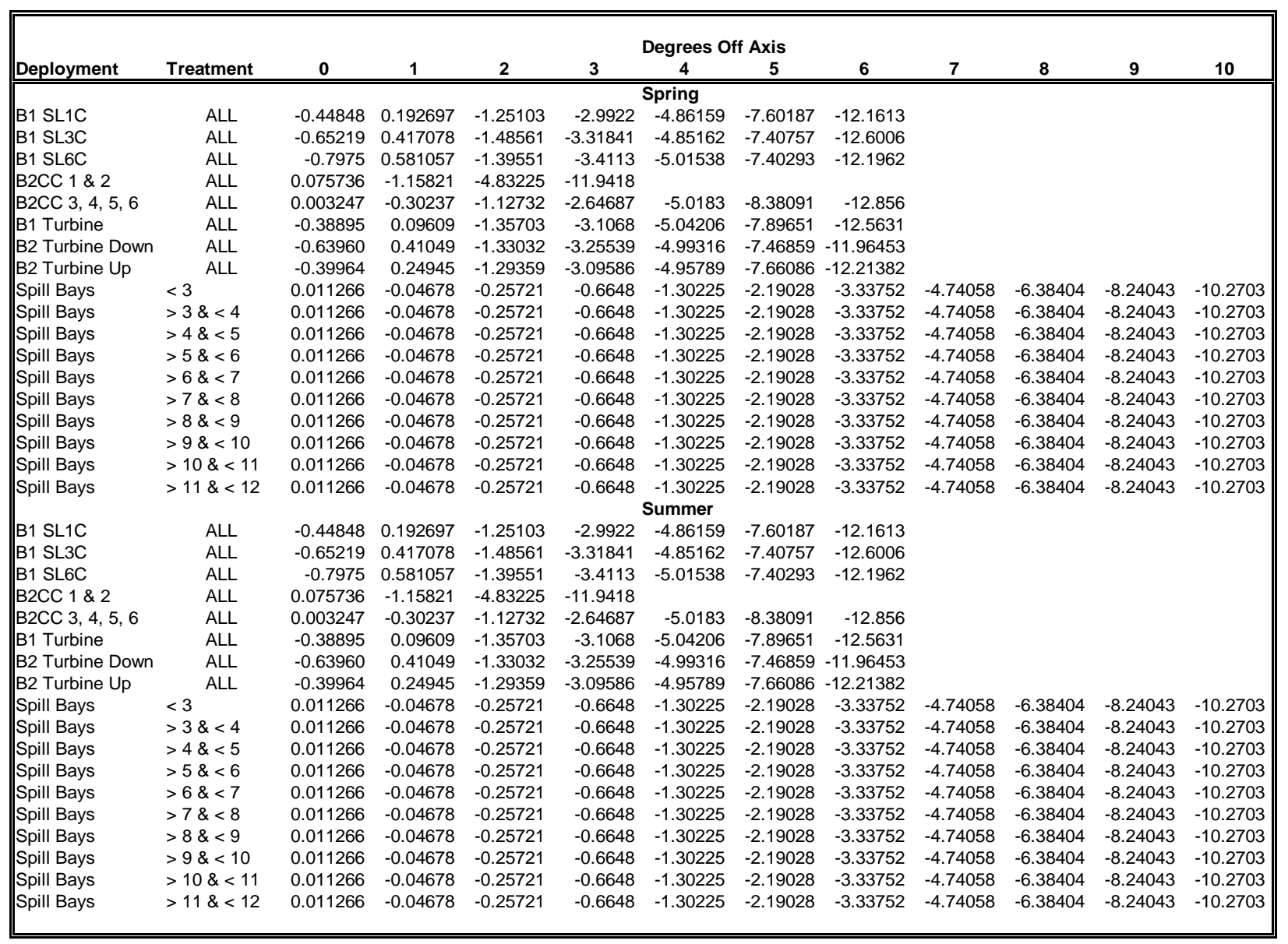


Appendix F.5. Coefficients of equations describing effective beam angle (EBA) as a function of range from a transducer by deployment and treatment. Spill discharge treatments are in cfs $x$ 1,000. The form of the equation for calculating EBA is: EBA $=C 5+C 4 * M I D \_R+$ C3*MID_R2 + C2*MID_R3 + COEF1*MID_R4, where MID_R is mid range in $\mathrm{m}$.

\begin{tabular}{|c|c|c|c|c|c|c|}
\hline Deployment & Treatment & $\mathrm{C} 1$ & $\mathrm{C} 2$ & C3 & $\mathrm{C} 4$ & $\mathrm{C} 5$ \\
\hline B1 SL1C & ALL & 0.012727 & -0.208636 & 1.123333 & -2.139589 & 9.237143 \\
\hline B1 SL3C & ALL & 0.014545 & -0.257727 & 1.595001 & -4.044159 & 12.257145 \\
\hline B1 SL6C & ALL & 0.012879 & -0.234949 & 1.511666 & -4.070503 & 12.907142 \\
\hline B2CC 1 \& 2 & ALL & 0.000252 & -0.007640 & 0.094227 & -0.603918 & 4.831086 \\
\hline B2CC 3, 4, 5, 6 & ALL & 0.001367 & -0.035274 & 0.329309 & -1.482838 & 9.715757 \\
\hline B1 Turbine & ALL & -0.000042 & 0.002441 & -0.051198 & 0.503024 & 5.367409 \\
\hline B2 Turbine Down & ALL & -0.000405 & 0.018442 & -0.304148 & 2.222797 & -0.441217 \\
\hline B2 Turbine Up & ALL & -0.000819 & 0.029009 & -0.372154 & 2.160442 & 1.053586 \\
\hline Spill Bays & $<3$ & 0.004394 & -0.112902 & 1.010245 & -3.789126 & 17.989697 \\
\hline Spill Bays & $>3 \&<4$ & 0.000542 & -0.024864 & 0.338397 & -1.811650 & 16.242120 \\
\hline Spill Bays & $>4 \&<5$ & 0.003263 & -0.087976 & 0.824487 & -3.333363 & 17.736665 \\
\hline Spill Bays & $>5 \&<6$ & 0.003339 & -0.089965 & 0.855297 & -3.571399 & 18.115455 \\
\hline Spill Bays & $>6 \&<7$ & 0.002465 & -0.069184 & 0.688444 & -3.026271 & 17.323637 \\
\hline Spill Bays & $>7 \&<8$ & 0.002611 & -0.075416 & 0.767972 & -3.404608 & 17.549091 \\
\hline Spill Bays & $>8 \&<9$ & 0.002774 & -0.071344 & 0.637658 & -2.453075 & 15.404547 \\
\hline Spill Bays & $>9 \&<10$ & 0.003112 & -0.076201 & 0.632553 & -2.119955 & 14.155456 \\
\hline Spill Bays & $>10 \&<11$ & 0.000638 & -0.009913 & 0.020597 & 0.136906 & 11.152122 \\
\hline Spill Bays & $>11 \&<12$ & -0.001489 & 0.046766 & -0.514024 & 2.238935 & 8.080301 \\
\hline B1 SL1C & ALL & 0.008674 & -0.113510 & 0.356251 & 0.405575 & 3.422859 \\
\hline B1 SL3C & ALL & 0.005720 & -0.087904 & 0.454583 & -0.977507 & 6.897142 \\
\hline B1 SL6C & ALL & 0.003902 & -0.076035 & 0.537917 & -1.712861 & 8.287144 \\
\hline B2CC 1 \& 2 & ALL & -0.000170 & 0.004865 & -0.033110 & -0.120499 & 3.413081 \\
\hline B2CC 3, 4, 5, 6 & ALL & 0.000924 & -0.018576 & 0.139275 & -0.728499 & 7.229394 \\
\hline B1 Turbine & ALL & -0.000062 & 0.003702 & -0.080687 & 0.797274 & 2.488151 \\
\hline B2 Turbine Down & ALL & -0.000393 & 0.017580 & -0.285979 & 2.086837 & -1.082255 \\
\hline B2 Turbine Up & ALL & -0.000860 & 0.029064 & -0.359855 & 2.061177 & 0.069192 \\
\hline Spill Bays & $<3$ & 0.001439 & -0.027716 & 0.140018 & -0.179313 & 11.556970 \\
\hline Spill Bays & $>3 \&<4$ & 0.001917 & -0.039981 & 0.275577 & -0.894646 & 12.511818 \\
\hline Spill Bays & $>4 \&<5$ & 0.001812 & -0.040583 & 0.315484 & -1.169697 & 12.635152 \\
\hline Spill Bays & $>5 \&<6$ & 0.000871 & -0.020324 & 0.186168 & -0.997483 & 12.796363 \\
\hline Spill Bays & $>6 \&<7$ & 0.000860 & -0.025367 & 0.274128 & -1.433583 & 13.183332 \\
\hline Spill Bays & $>7 \&<8$ & 0.001795 & -0.049328 & 0.473916 & -1.998901 & 13.140001 \\
\hline Spill Bays & $>8 \&<9$ & 0.000437 & -0.012832 & 0.126941 & -0.605245 & 10.955454 \\
\hline Spill Bays & $>9 \&<10$ & -0.001212 & 0.033201 & -0.329977 & 1.305913 & 7.775151 \\
\hline Spill Bays & $>10 \&<11$ & 0.000082 & 0.013807 & -0.299674 & 1.800237 & 6.123030 \\
\hline Spill Bays & $>11 \&<12$ & -0.001929 & 0.064110 & -0.754272 & 3.597871 & 3.251212 \\
\hline
\end{tabular}


Hydroacoustic Evaluation of Fish Passage through Bonneville Dam in 2005 


\section{Appendix G}

\section{Analysis of Variance and Least-Square Means for FGE Estimates among B2 Turbine Intakes}


Hydroacoustic Evaluation of Fish Passage through Bonneville Dam in 2005 


\section{Appendix G}

\section{Analysis of Variance and Least-Square Means for FGE Estimates among B2 Turbine Intakes}

Appendix G.1. Analysis of variance and tests for differences in least square means in FGE among B2 turbine units in spring 2005.

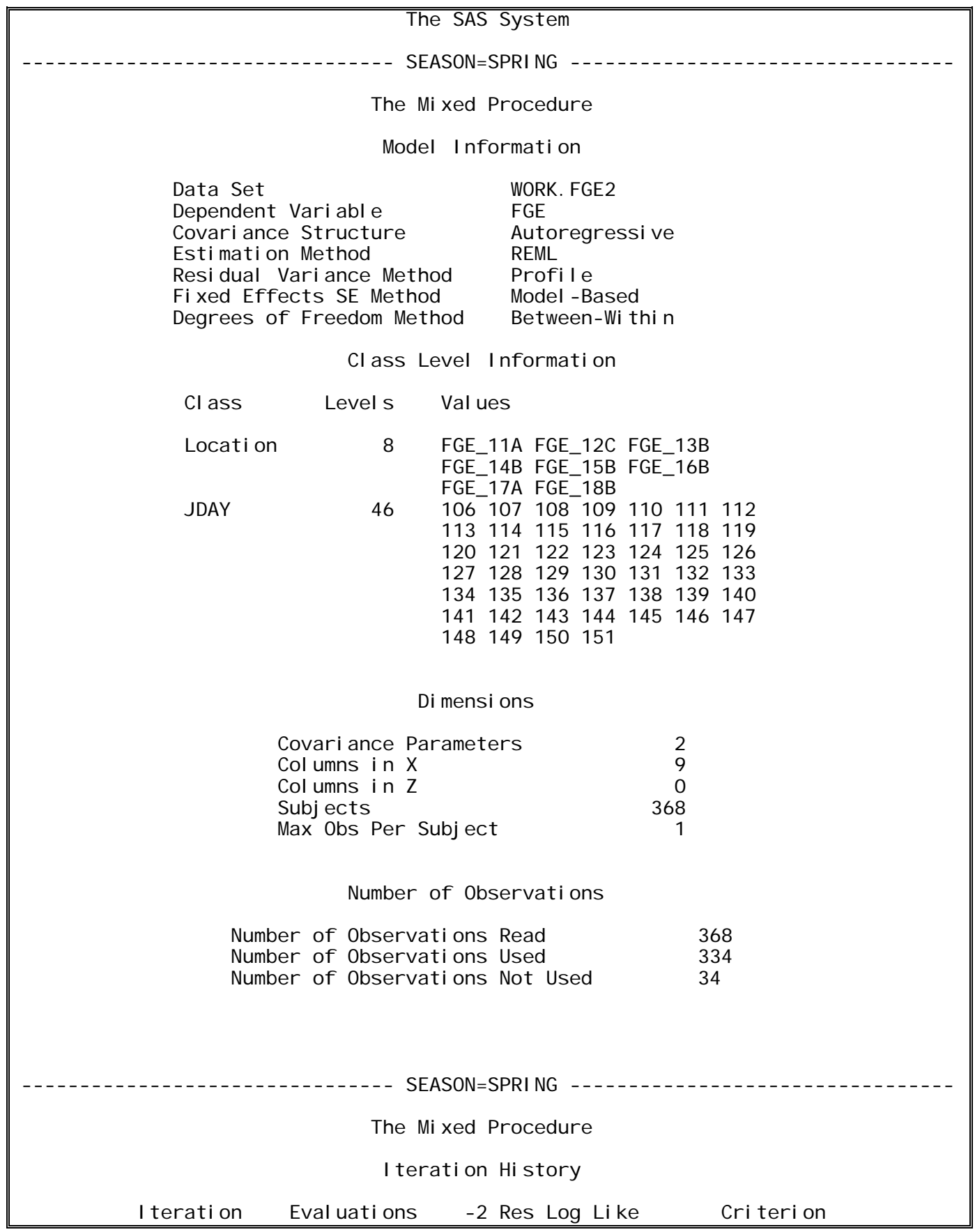




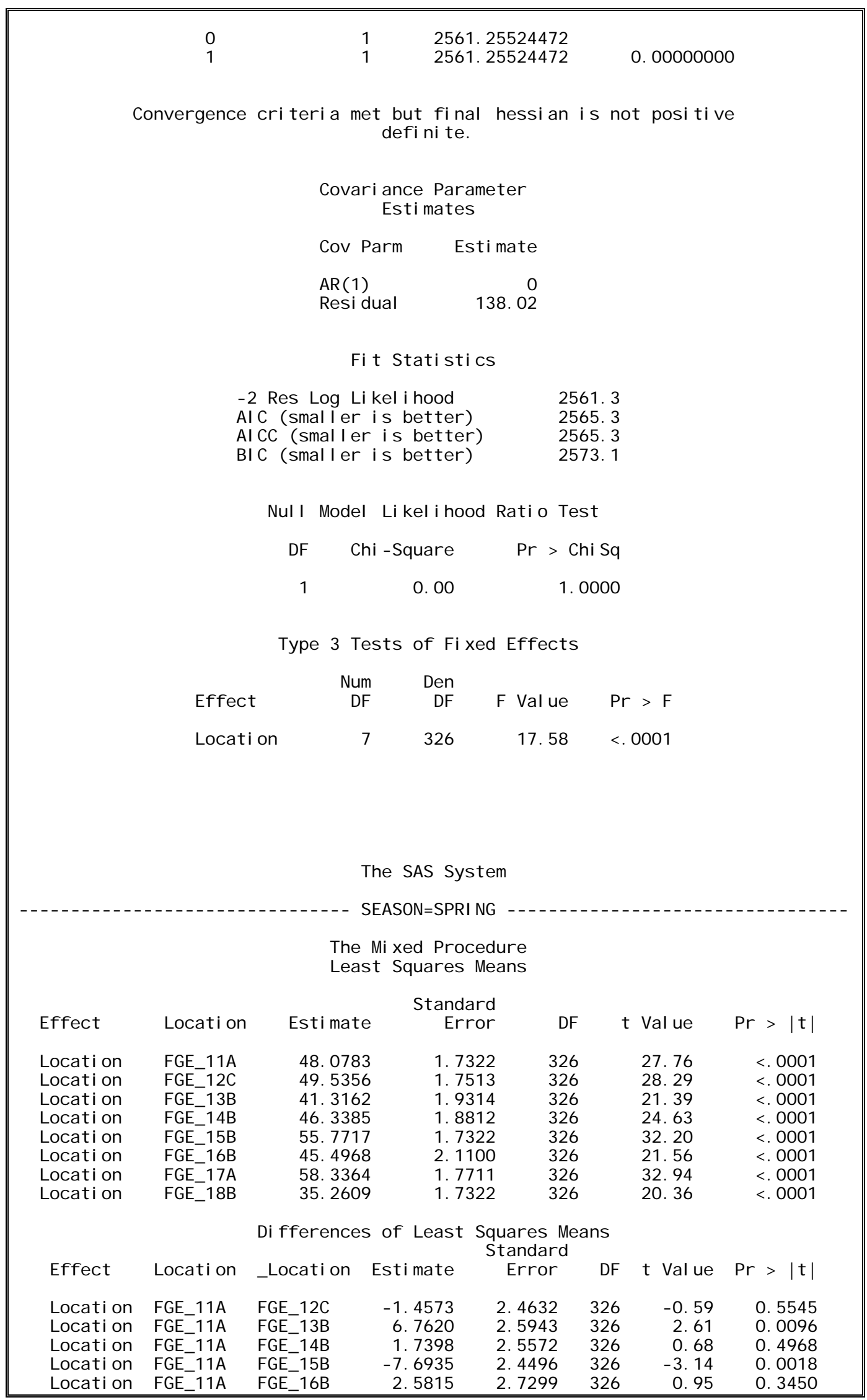


Hydroacoustic Evaluation of Fish Passage through Bonneville Dam in 2005

\begin{tabular}{|c|c|c|c|c|c|c|c|}
\hline $\begin{array}{l}\text { Location } \\
\text { Location } \\
\text { Location } \\
\text { Location } \\
\text { Location } \\
\text { Location } \\
\text { Location } \\
\text { Location } \\
\text { Location } \\
\text { Location } \\
\text { Location } \\
\text { Location } \\
\text { Location } \\
\text { Location } \\
\text { Location } \\
\text { Location } \\
\text { Location } \\
\text { Location } \\
\text { Location } \\
\text { Location }\end{array}$ & $\begin{array}{l}\text { FGE } 11 \mathrm{~A} \\
F G E-11 \mathrm{~A} \\
F G E-12 C \\
F G E-12 C \\
F G E-12 C \\
F G E-12 C \\
F G E-12 C \\
F G E-12 C \\
F G E-13 B \\
F G E-13 B \\
F G E-13 B \\
F G E-13 B \\
F G E-13 B \\
F G E-14 B \\
F G E-14 B \\
F G E-14 B \\
F G E-14 B \\
F G E-15 B \\
F G E-15 B \\
F G E-15 B\end{array}$ & 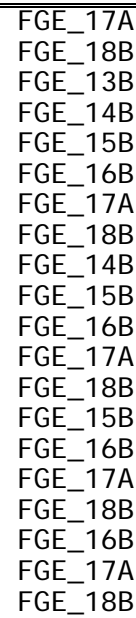 & $\begin{array}{r}10.2581 \\
12.8174 \\
8.2193 \\
3.1971 \\
-6.2362 \\
4.0388 \\
-8.8008 \\
14.2747 \\
-5.0222 \\
-14.4555 \\
-4.1806 \\
-17.0201 \\
6.0553 \\
-9.4333 \\
0.8417 \\
-11.9979 \\
11.0776 \\
10.2750 \\
-2.5646 \\
20.5109\end{array}$ & $\begin{array}{l}2.4773 \\
2.4496 \\
2.6071 \\
2.5702 \\
2.4632 \\
2.7421 \\
2.4907 \\
2.4632 \\
2.6961 \\
2.5943 \\
2.8605 \\
2.6205 \\
2.5943 \\
2.5572 \\
2.8268 \\
2.5837 \\
2.5572 \\
2.7299 \\
2.4773 \\
2.4496\end{array}$ & $\begin{array}{l}326 \\
326 \\
326 \\
326 \\
326 \\
326 \\
326 \\
326 \\
326 \\
326 \\
326 \\
326 \\
326 \\
326 \\
326 \\
326 \\
326 \\
326 \\
326 \\
326\end{array}$ & $\begin{array}{r}-4.14 \\
5.23 \\
3.15 \\
1.24 \\
-2.53 \\
1.47 \\
-3.53 \\
5.80 \\
-1.86 \\
-5.57 \\
-1.46 \\
-6.50 \\
2.33 \\
-3.69 \\
0.30 \\
-4.64 \\
4.33 \\
3.76 \\
-1.04 \\
8.37\end{array}$ & 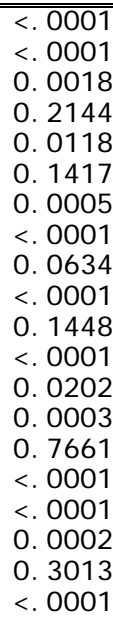 \\
\hline
\end{tabular}


Appendix G.2. Analysis of variance and tests for differences in least square means in FGE among B2 turbine units in summer 2005.

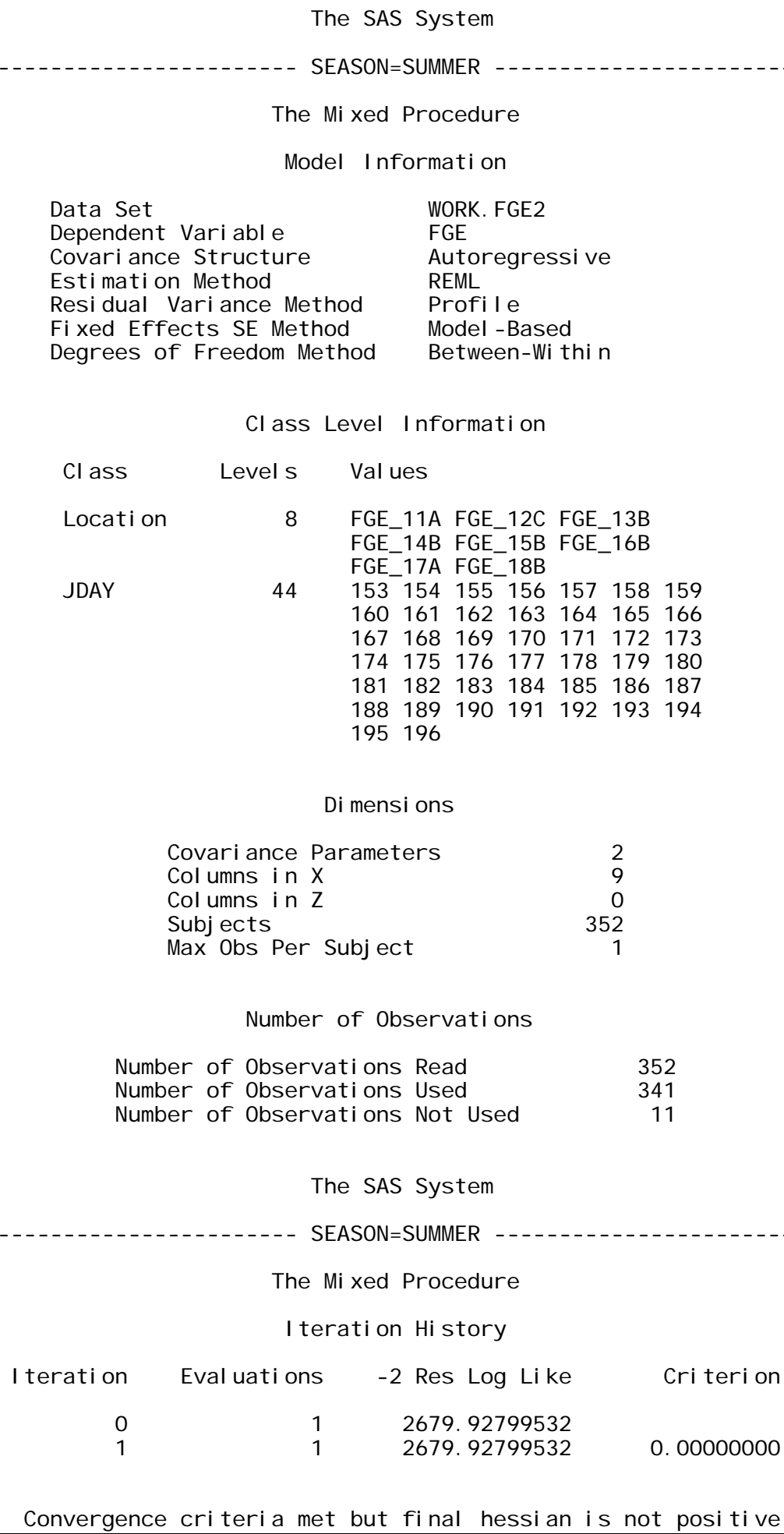




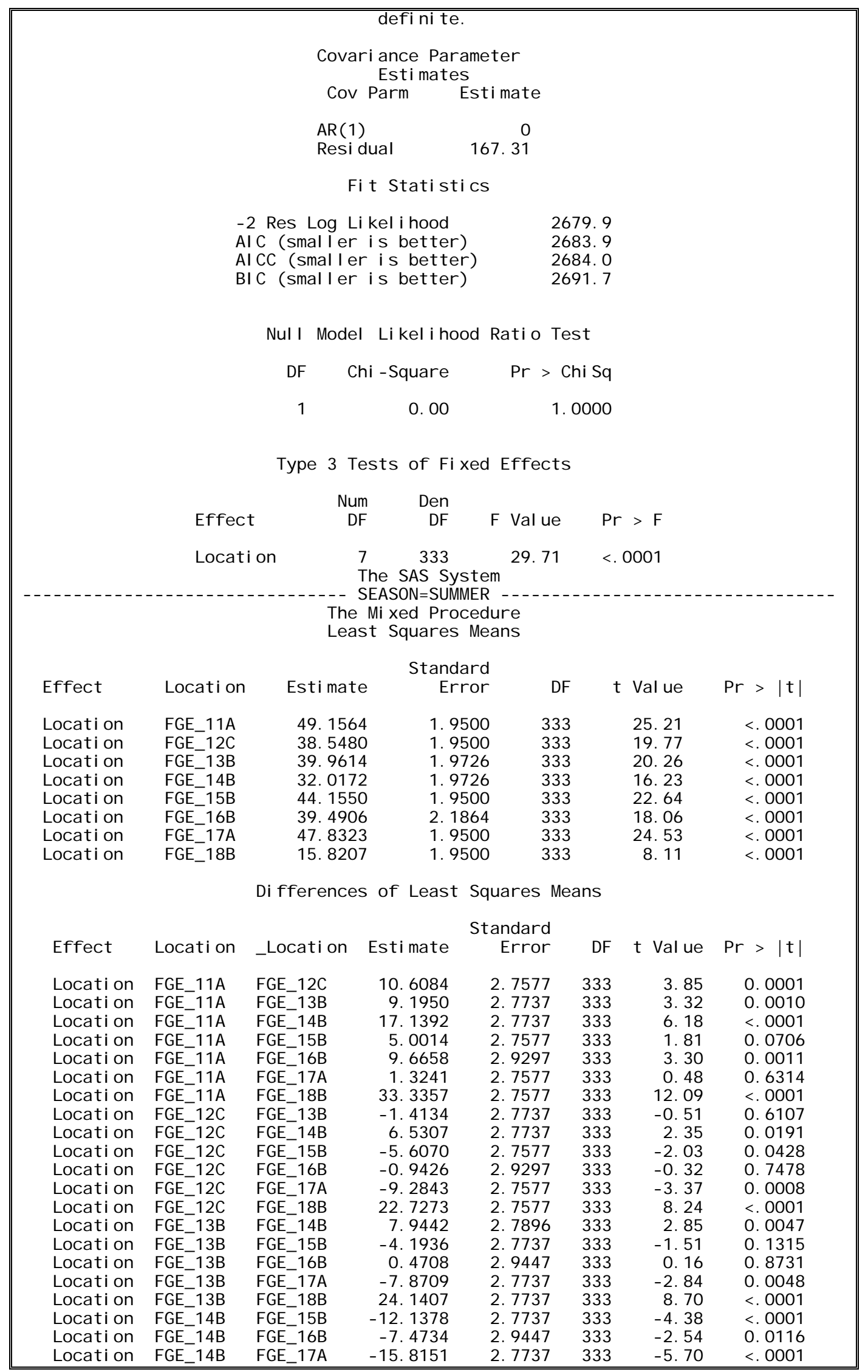


Hydroacoustic Evaluation of Fish Passage through Bonneville Dam in 2005

\begin{tabular}{|c|c|c|c|c|c|c|c|}
\hline $\begin{array}{l}\text { Location } \\
\text { Location } \\
\text { Location } \\
\text { Location } \\
\text { Location } \\
\text { Location } \\
\text { Location }\end{array}$ & $\begin{array}{l}F G E-14 B \\
F G E-15 B \\
F G E-15 B \\
F G E-15 B \\
F G E-16 B \\
F G E-16 B \\
F G E-17 A\end{array}$ & $\begin{array}{l}F G E-18 B \\
F G E-16 B \\
F G E-17 A \\
F G E-18 B \\
F G E-17 A \\
F G E-18 B \\
F G E-18 B\end{array}$ & $\begin{array}{r}16.1965 \\
4.6644 \\
-3.6773 \\
28.3343 \\
-8.3417 \\
23.6699 \\
32.0116\end{array}$ & $\begin{array}{l}2.7737 \\
2.9297 \\
2.7577 \\
2.7577 \\
2.9297 \\
2.9297 \\
2.7577\end{array}$ & $\begin{array}{l}333 \\
333 \\
333 \\
333 \\
333 \\
333 \\
333\end{array}$ & $\begin{array}{r}5.84 \\
1.59 \\
-1.33 \\
10.27 \\
-2.85 \\
8.08 \\
11.61\end{array}$ & $\begin{array}{l}<.0001 \\
0.1123 \\
0.1833 \\
<.0001 \\
0.00047 \\
<.0001 \\
<.00001\end{array}$ \\
\hline
\end{tabular}




\section{Appendix $\mathrm{H}$}

\section{DIDSON Movie Files of Smolts Approaching Sluiceway Outlet 3C in 2005 \\ (on accompanying CD)}


Hydroacoustic Evaluation of Fish Passage through Bonneville Dam in 2005 


\section{Appendix $\mathrm{H}$}

\section{DIDSON Movie Files of Smolts Approaching Sluiceway Outlet 3C in 2005 \\ (on accompanying $\mathrm{CD}$ )}

Figure H.1.Diagram of six DIDSON views from a location near the center of a barge upstream of Sluiceway Outlet $3 \mathrm{C}$. Each pie-shaped view was about $30^{\circ}$ wide and $12^{\circ}$ deep, and successive views were sampled sequentially for 10 minutes each. Movie descriptions include view numbers for reference.

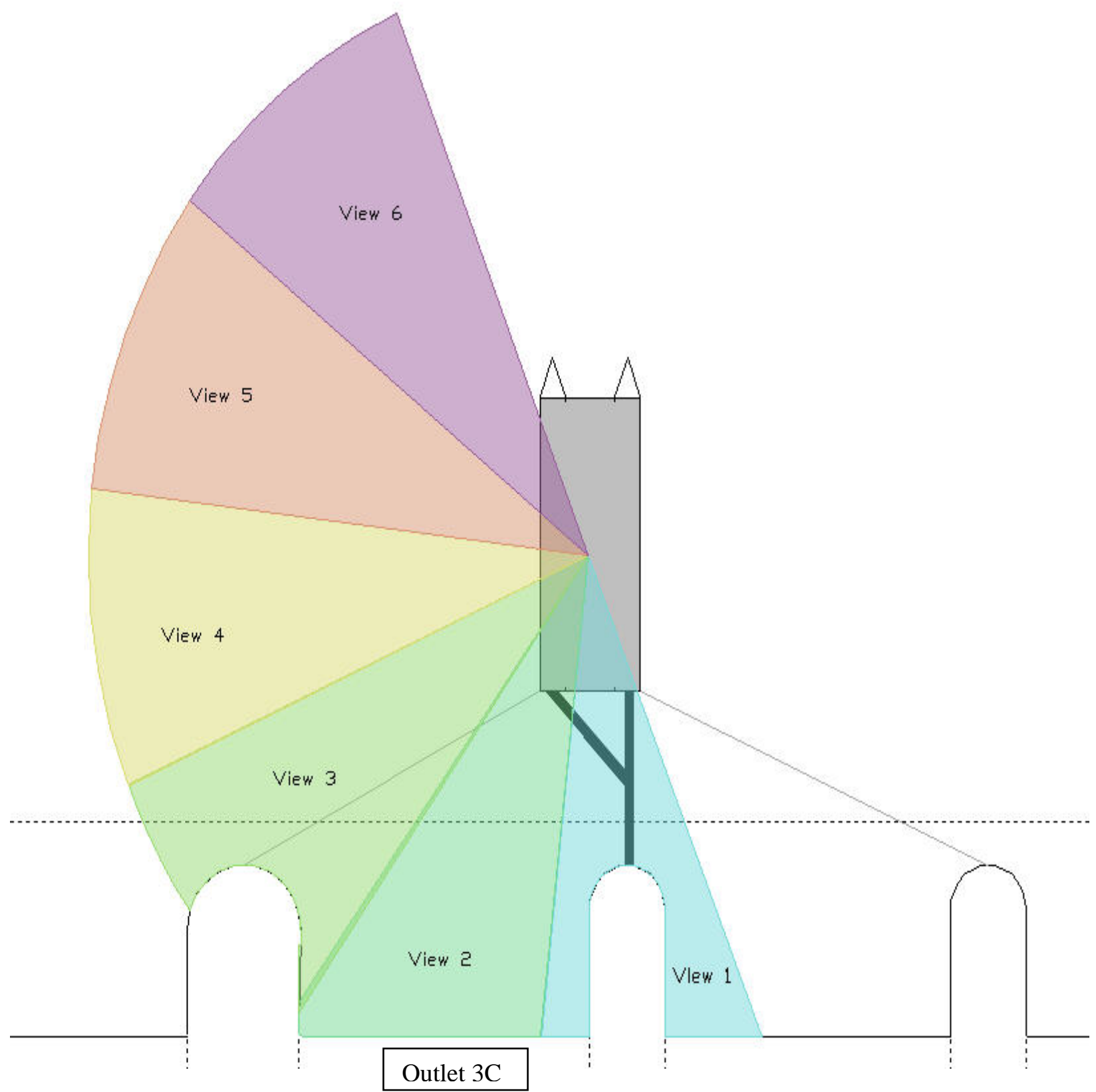


Figure H.2.DIDSON image from plan view 2 (see Appendix H.1) for orientation for movie files. Numbers indicate range from the DIDSON in meters $(\mathrm{m})$.

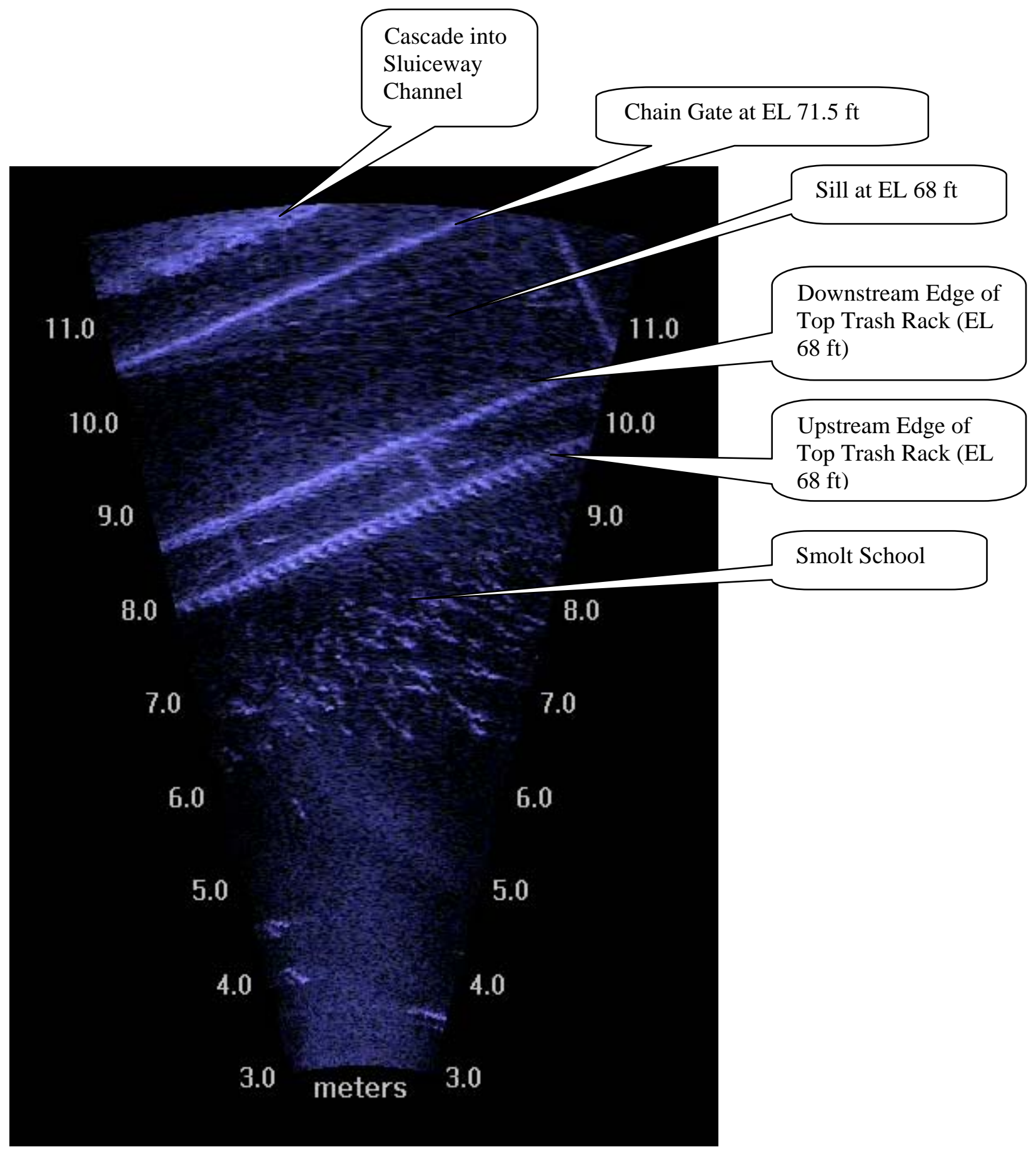


Table H.1. Index and descriptions of CODECs and DIDSON movie files on the attached CD

\begin{tabular}{|c|c|}
\hline File Name & Description \\
\hline Appendix HOO TSCC.exe & TechSmith Screen-Capture CODEC to run some movies \\
\hline Appendix H01 Movie.avi & $\begin{array}{l}\text { View } 2 \text { showing large schools pouring into the outlet over the top trash rack, } \\
\text { sill, and chain gate during daylight at } 0630 \text { hours on May } 26,2006 \text {. Some } \\
\text { large fish are visible including a possible predator over the sill near the end of } \\
\text { the clip. Note tight schooling typical of daytime smolt behavior and relatively } \\
\text { steady movement downstream into the outlet. }\end{array}$ \\
\hline Appendix H02 Movie.avi & $\begin{array}{l}\text { View } 2 \text { showing relatively few smolts holding and some passing over the sill } \\
\text { at night. Smolts clearly can escape entrainment even from above the chain } \\
\text { gate or sill. Visible smolt are not tightly schooling at night. }\end{array}$ \\
\hline Appendix H03 Movie.avi & $\begin{array}{l}\text { View } 3 \text { and then View } 4 \text { showing few smolts moving into the sluiceway outlet } \\
\text { at night but a lot of smolts holding in the forebay. Holding in the forebay and } \\
\text { continuous attacks by predators on non-schooling or very loosely schooled } \\
\text { aggegrations were typical from dusk to dawn. Sluiceway passage was low. }\end{array}$ \\
\hline Appendix H04 Movie.avi & $\begin{array}{l}\text { View } 3 \text { and then } 2 \text { showing smolts holding in the forebay upstream of the } \\
\text { outlet and very low passage into the sluiceway outlet at night. Right after the } \\
\text { view change, a large fish (perhaps a salmonid) fell back into the sluiceway. } \\
\text { Predators that hunted near the sill and opening rarely passed into the } \\
\text { sluiceway. }\end{array}$ \\
\hline Appendix H05 Movie.avi & $\begin{array}{l}\text { View } 4 \text { and then View } 3 \text { showing more nighttime holding, behavior, and } \\
\text { predation. Directive movements of smolts backing downstream toward the } \\
\text { sluiceway outlet was not observed at night. }\end{array}$ \\
\hline Appendix H06 Movie.avi & $\begin{array}{l}\text { View } 5 \text { at night showing more non-schooling holding behavior upstream of } \\
\text { Sluiceway Ontrance } 3 \mathrm{C} \text { and predators in the vicinity }\end{array}$ \\
\hline Appendix H07 Movie.avi & $\begin{array}{l}\text { View } 3 \text { showing more nighttime holding of smolts upstream of Sluiceway } \\
\text { Outlet 3C }\end{array}$ \\
\hline Appendix H08 Movie.avi & $\begin{array}{l}\text { View } 3 \text { at night showing a predator coming off of the sill, attacking smolts and } \\
\text { returning to the sill with another predator }\end{array}$ \\
\hline Appendix H09 Movie.avi & $\begin{array}{l}\text { Small vortex entrains a few smolt into the turbine from the entrance to the } \\
\text { sluiceway (View } 2 \text { during the day) }\end{array}$ \\
\hline Appendix H10 Movie.avi & $\begin{array}{l}\text { View } 2 \text { during the daytime showing a small vortex entraining 5-6 smolts into } \\
\text { the turbine from just upstream of the top of the trash rack at Sluiceway Outlet } \\
3 \mathrm{C}\end{array}$ \\
\hline Appendix H11 Movie.avi & $\begin{array}{l}\text { View } 2 \text { during the daytime showing a large vortex devastating a large school } \\
\text { of smolt backing downstream toward Sluiceway Outlet 3C }\end{array}$ \\
\hline Appendix H12 Movie.avi & $\begin{array}{l}\text { View } 2 \text { during the day showing another large vortex entraining smolts } \\
\text { heading for Sluiceway Outlet } 3 \mathrm{C} \text { into Turbine Intake } 3 \mathrm{C}\end{array}$ \\
\hline Appendix H13 Movie.avi & $\begin{array}{l}\text { View } 2 \text { during daylight showing a vortex entraining a large fish into Turbine } \\
\text { Intake 3C }\end{array}$ \\
\hline Appendix H14 Movie.avi & $\begin{array}{l}\text { View } 2 \text { during daytime showing tight schooling behavior and movement of } \\
\text { smolts into Sluiceway Outlet 3C }\end{array}$ \\
\hline Appendix H15 Movie.avi & $\begin{array}{l}\text { View } 2 \text { during daytime showing tight schooling behavior, sluiceway passage, } \\
\text { and a predator spooking smolts into the outlet }\end{array}$ \\
\hline
\end{tabular}


Hydroacoustic Evaluation of Fish Passage through Bonneville Dam in 2005 